UNIVERSIDAD POLITÉCNICA DE VALENCIA

FACULTAD DE BELLAS ARTES DE SAN CARLOS

DEPARTAMENTO DE COMUNICACIÓN

AUDIOVISUAL, DOCUMENTACIÓN E

HISTORIA DEL ARTE

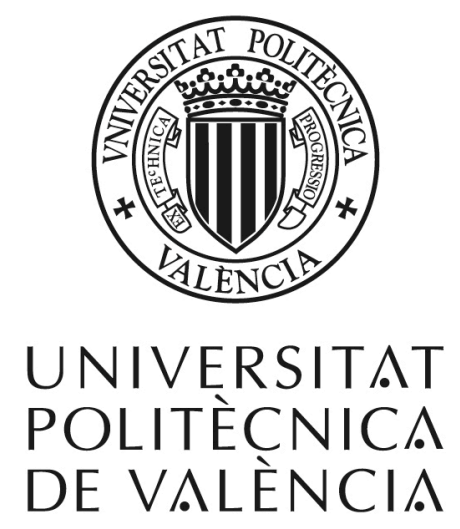

\title{
MÉTODOS EXACTOS Y HEURÍSTICOS DE AFINACIÓN. APLICACIÓN A LA TROMPETA
}

TESIS DOCTORAL

Presentada por José Ibáñez Barrachina Dirigida por el Dr. D. Vicente Liern Carrión Valencia, 2008 
VICENTE LIERN CARRIÓn, profesor titular de Universidad del Departamento de Matemáticas para la Economía y la Empresa de la Universidad de Valencia,

\section{CERTIFICA:}

Que la tesis, Métodos exactos y heurísticos de afinación. Aplicación a la trompeta, presentado por D. José Ibáñez Barrachina, ha sido realizado bajo su dirección.

Y para que así conste, en cumplimiento de la legislación vigente, firma este certificado.

Valencia, a 14 de febrero de 2008.

Fdo: Vicente Liern Carrión 
A Finin y Pepe, mis padres 


\section{Agradecimientos}

La realización de este trabajo no hubiera sido posible sin la colaboración del departamento de Comunicación Audiovisual, Documentación e Historia del Arte. Mención especial merece el Dr. Vicente Liern Carrión, director de esta memoria, su labor como tutor ha sido encomiable, y su loable generosidad he hecho que dedicara muchas horas de su tiempo personal para ayudarme en aquellos momentos difíciles, por ello merece un enorme agradecimiento, sin su ayuda este trabajo no habría visto nunca la luz. Por último mi más sincero agradecimiento a Maria Isabel por estar a mi lado en los buenos y malos momentos. 


\section{Introducción}

Capítulo 1. Historia de la trompeta

1.1 Antecesores de la trompeta

1.2 De la trompeta natural a la cromática

1.3 La boquilla

1.4 Diferentes modelos actuales

1.5 Evolución del repertorio para trompeta

1.6 Sordinas

1.7 La trompeta en el Jazz

1.8 La fabricación industrial

\section{PARTE I: Afinación clásica}

Capítulo 2. Sistemas de afinación

2.1 Conceptos previos

2.2 Medición de la sensación de altura

2.2.1 Intervalos. Aritmética

2.2.2 Definiciones

2.3 Afinaciones

2.3.1 Sistema de Pitágoras

2.3.2 Afinación justa: Sistema de Zarlino

2.3.3 Ventajas e inconvenientes de las afinaciones

2.3.4 Comentarios

2.4 Temperamentos regulares cíclicos 
2.4.1 Temperamento igual (de 12 notas)

2.4.2 Sistema de Holder

2.4.3 Ventajas y desventajas de los temperamentos

regulares cíclicos

2.5 Temperamentos irregulares

2.6 Un número adecuado de divisiones por octava

2.7 Comparación de los sistemas de afinación

2.8 Fracciones continuas y cantidad de notas por octava

2.8.1 Fracciones continuas

2.8.2 Fracciones continuas y temperamentos mesotónicos

2.9 Sensibilidad de percepción

Capítulo 3. Afinación práctica: el intérprete y el compositor.

3.1 Aspectos técnicos

3.1.1 Mediciones con el programa informático Audacity ${ }^{\circledR}$.

3.1.2 Mediciones con afinadores cromáticos.

3.1.3 Trompetas empleadas.

3.2 Afinación estática

3.2.1 Experimento 1. Notas seriadas.

3.2.2 Clasificación de las notas largas por la posición en la que se interpretan

3.2.3 Experimento 2. Notas no seriadas.

\subsection{Afinación Dinámica}

3.3.1 Experimento 3.

a) Resultados globales.

b) Relación sistema de afinación-trompeta empleada.

\subsubsection{Experimento 4.}

a) Resultados globales.

b) Relación sistema de afinación-trompeta empleada. 
3.4 Las matemáticas como fuente de inspiración del compositor

3.4.1 Introducción a la música contemporánea

3.4.2 Aportaciones de Kepler

3.5 Composición de la obra Esferas

3.5.1 Cálculos de Kepler

3.5.2 Esferas

3.5.2.1 Análisis de la obra

3.5.2.2 Partitura de Esferas

PARTE II: Afinación Fuzzy.

Capítulo 4. Sistemas de afinación borrosos. Compatibilidad.

4.1 Introducción a la lógica borrosa.

4.2 Los conjuntos borrosos

4.2.1 Niveles de satisfacción o tolerancia.

4.3 Números borrosos

4.3.1 Intervalos de confianza. Operaciones elementales

4.3.2 Números borrosos. Operaciones con números borrosos triangulares

4.4 Sistemas borrosos de afinación

4.4.1 Aportaciones de Garbuzov

4.4.2 Notas como conjuntos borrosos

4.4.3 Compatibilidad entre dos notas musicales

4.4.4 Compatibilidad entre sistemas de afinación

4.5 Sistemas temperado, pitagórico, de Zarlino y de Hölder.

Compatibilidad

Capítulo 5. Los sistemas de afinación en la práctica musical.

5.1 Test de percepción

5.2 Análisis de compatibilidad

5.2.1 Fragmento de Haydn

5.2.2 Fragmento de Béla Bartók 


\section{Conclusiones.}

Futuras investigaciones.

\section{Referencias bibliográficas.}

Apéndice.

A.1 Resultados para las notas largas.

A.2 Resultados para los fragmentos.

A.3 Resultados del test de psicoacústica. 


\section{INTRODUCCIÓN}

Nuestros intereses en Métodos exactos y heurísticos de afinación. Aplicación a la trompeta han respondido a tres tipos de objetivos: la investigación, propiamente dicha, en la que se ha perseguido el máximo rigor en la utilización del método científico, la aplicabilidad por otros músicos o estudiosos de la acústica, de los resultados obtenidos y del diseño de las experiencias y, por último, la utilidad pedagógica del estudio.

En cuanto a la investigación hemos intentado que tanto los aspectos teóricos como los prácticos estuviesen bien fundamentados y el planteamiento y desarrollo de las prácticas fuesen rigurosos. En este sentido, los resultados que se presentan responden a resultados estadísticos obtenidos a partir de varias repeticiones de las experiencias. Sin embargo, desde el punto de vista de la investigación histórica, creemos necesario aclarar que entre los objetivos de este trabajo no está el estudio de la evolución histórica de los sistemas de afinación. Así, aunque al introducirlos se da una breve descripción histórica que sirve para situarlos en el contexto histórico-científico, no se pretende que ésta sea exhaustiva, ni mucho menos hacer aportaciones científicas en esta área de conocimiento.

En cuanto a la aplicabilidad a la que hacíamos referencia, los sistemas de afinación y los experimentos se han descrito de manera que quien lo desee pueda repetir experiencias similares para este u otro instrumento. Además, nos hemos impuesto la condición de que el instrumental empleado para el desarrollo de esta memoria estuviese al alcance de cualquier instrumentista. Por esta razón, todos los 
cálculos, desarrollos matemáticos, estadísticas y gráficos están realizados con el programa EXCEL $^{\circledR}$, del que disponen la inmensa mayoría de usuarios de ordenadores para las plataformas Windows, Linux y Macintosh. Los análisis de la afinación se han realizado con los afinadores cromáticos SEIKO ${ }^{\circledR}$ ST 747-100 y $\mathrm{KORG}^{\circledR}$ CA-70 que son de una gama media, de precio muy asequible, y con el programa gratuito AUDACITY ${ }^{\circledR 1}$ que también funciona en las plataformas Windows, Linux y Macintosh.

En cuanto a los aspectos didácticos, además de la condición de docente del autor, no debemos olvidar que gran parte de los resultados obtenidos en este trabajo pueden ser utilizados, dándoles un enfoque adecuado, en las aulas de música. Creemos que como bien dice P. Puig Adam², “...la didáctica no concibe ya la clase como una sala de conferencias; ya la palabra maestro se va pareciendo cada vez más a la de maestro de taller y cada vez menos a la de conferenciante". De hecho, negar al alumno la posibilidad de analizar su propio instrumento musical con medios actuales, sería negar una parte importante del momento artístico-cultural que les rodea y, en definitiva, se estaría perjudicando el proceso de formación.

\section{Análisis de la tesis}

El trabajo consta en cinco capítulos a los que se añaden unas conclusiones, las referencias bibliográficas y un apéndice. En el primer capítulo se presenta una visión general de la trompeta, instrumento al que se ha destinado, esencialmente, el estudio. El resto de la memoria está estructurado en dos partes. La primera trata de los sistemas de afinación clásicos y la segunda de sistemas de afinación que permiten manejar la incertidumbre o imprecisión en los sonidos. La secuencia lógica que se sigue en los dos capítulos que forman cada una de estas partes es la misma: en el primer capítulo se recogen los resultados teóricos y en el segundo se desarrollan aplicaciones prácticas. Por último, se presentan dos secciones que recogen las conclusiones y bibliografía y un apéndice final en el que se resume mediante tablas, gráficos y resultados de tests gran parte de los resultados de las prácticas de afinación que se han llevado a cabo.

En el primer capítulo, Historia de la trompeta, hemos planteado cuál es la situación actual de la trompeta y las propiedades del sonido que serán motivo de estudio en esta memoria. Para ello, se presenta una breve descripción de la evolución histórica de la trompeta y su acústica, se resumen los resultados de acústica que se utilizarán en capítulos posteriores, de manera que estos queden determinados de forma precisa, con una notación unificada y de manera que el trabajo sea más cohesionado.

\footnotetext{
${ }^{1}$ Este programa puede obtenerse en la página web http://audacity.sourceforge.net/.

${ }^{2}$ P. Puig Adam, "La Matemática y su enseñanza actual" (1960) en (Liern 1994b).
} 
En el segundo capítulo, Sistemas de afinación, se introducen, en términos "músico-matemáticos" los sistemas de afinación de Pitágoras, de Zarlino, de Holder y el temperamento igual de 12 notas. El estudio trata por separado las afinaciones y los temperamentos y se han planteado las ventajas e inconvenientes de cada uno de ellos. Para compararlos, se ha hecho un estudio exhaustivo de las distancias, en cents, que hay entre las notas musicales de estos sistemas. Estas distancias se han estructurado en tablas y en gráficos obtenidos con EXCEL ${ }^{\circledR}$ de manera que resulten manejables. Además, hemos aportado algunos argumentos matemáticos a uno de los problemas que se han planteado los musicólogos de todos los tiempos: ¿cuál es el número óptimo de divisiones en una octava?

En el tercer capítulo, Afinación práctica y Esferas, hemos realizado algunas experiencias para contrastar la teoría expuesta en los capítulos anteriores. Se ha dividido en dos partes. La primera de ellas se dedica a lo que hemos llamado afinación estática. En concreto se ha estudiado la afinación de escalas cromáticas y de notas largas no seriadas. La segunda parte se dedica a la afinación dinámica, es decir la afinación en la práctica musical. Para ello hemos analizado un fragmento del Concierto en Mi bemol Mayor, Hob. Vlle, N. 1 para trompeta y orquesta de Franz Joseph Haydn (1732-1809) y un fragmento del Adagio de Música para cuerda, percusión y celesta (1937) de Béla Bartók (1881-1945). Por supuesto, la elección de estas obras ha estado motivada por la gran diferencia de estilos, que permite un análisis en dos escenarios muy dispares.

Una parte importante del tercer capítulo es la presentación de Esferas. Esta obra está compuesta como ejercicio práctico de los sistemas de afinación y para ello se han utilizado los cálculos que Kepler describe en su obra Harmonices Mundi (1619) para obtener la música que "debería constituir la amonía universal". Los siete pentagramas (compases) que obtiene Kepler sirven de base para la creación de una obra de música contemporánea para un quinteto de metales formado por pícolo, trompeta, trompa, trombón y tuba.

La segunda parte de la tesis está formada por dos capítulos que, basándose en la lógica borrosa permiten trasladar al ámbito de la práctica cotidiana de los músicos los resultados teóricos que han sido expuestos en los capítulos precedentes.

En el cuarto capítulo, Utilidad de la lógica fuzzy en los sistemas de afinación y psicoacústica musical, hemos flexibilizado concepto de nota musical, de manera que las frecuencias teóricas y las que se obtienen en la práctica no se conviertan en dos realidades diferente. A partir del concepto borroso de nota musical se establece la idea de grados de compatibilidad entre sistemas de afinación y se dan métodos para calcular cuál es el grado de compatibilidad entre los sistemas de afinación estudiados en el segundo capítulo. 
El capítulo cinco, Los sistemas de afinación en la práctica musical, aún va más allá en la necesidad de que el trabajo que presentamos tenga utilidad práctica. Si bien en el capítulo cuarto se analiza la compatibilidad entre los sistemas de afinación teóricos, ahora centramos el interés en analizar la compatibilidad de los sistemas de afinación con los que han sido estudiados los fragmentos de Haydn y Béla Bartók en el capítulo 3.

En el quinto capítulo, se describe un test que pretende medir el grado de percepción de las notas, los intervalos y las escalas para los diferentes sistemas de afinación. El estudio se ha realizado con 75 encuestas a estudiantes y profesores de música del Conservatorio Profesional de Música de Murcia. Además, los resultados de este estudio se comparan con otros existentes en la literatura.

La parte principal del trabajo concluye con los capítulos dedicados a las conclusiones generales, nuevas perspectivas y la bibliografía. Además, de las conclusiones parciales que se han ido anotando en cada capítulo, creemos interesante recoger de forma resumida las conclusiones generales que pueden servir tanto para dar una idea general de la memoria como para ofrecer a cualquier instrumentista la posibilidad de analizar cómo se ajustan, en su conjunto, a su práctica cotidiana.

En cuanto a las nuevas perspectivas se recoge, en un listado, aquellos problemas que no han sido tratados y que, sin embargo, creemos que resultan interesantes para investigaciones posteriores. Sin duda, el campo en el que resulta necesario intensificar la investigación es los sistemas de afinación borrosos con los que estamos convencidos de que se conseguirá englobar la evolución de la música actual, en la que los medios tecnológicos juegan un papel muy importante, con los estudios teóricos clásicos.

La bibliografía, por las características del tema que se ha tratado, pertenece a diferentes áreas del conocimiento: Historia de la Música, Historia de las Matemáticas, Acústica, Análisis Matemático y Matemáticas con Conjuntos Borrosos. Las referencias no pretenden ser un listado exhaustivo de Música, Acústica y Matemáticas, aunque a través de ellas se puede obtener una relación muy actualizada. Hemos utilizado además dos direcciones web de Bailache y Monzo. Somos conscientes del peligro de utilizar Internet, puesto que no tiene controles de calidad. No obstante, el rigor de los trabajos del profesor Bailache ${ }^{2}$ y J. L. Monzo ${ }^{3}$ están fuera de toda duda.

\footnotetext{
${ }^{2}$ Bailache es profesor de la Universite de Nantes y ha trabajado en el IRCAM.

${ }^{3}$ J. L. Monzo, entre otras muchas actividades, es el organizador de un Congreso Anual sobre la Justa Entonación
} 
El apéndice consta de dos partes. En la primera de ellas se resumen los resultados de las prácticas realizadas en los capítulos tercero y quinto, sirve además para guiar a cualquiera que pueda estar interesado en repetir estas experiencias u otras similares. Se muestra cómo hemos recogido los resultados, cómo los hemos agrupado, etc. Al separarlo del resto de la memoria se evita engrosar los mencionados capítulos con una cantidad excesiva de datos numéricos. Además, aparece una copia de las fichas originales que han servido para realizar el test de psicoacústica descrito en el capítulo quinto.

En la segunda parte del apéndice presentamos un DVD que contiene los archivos sonoros de las grabaciones utilizados en las prácticas y la interpretación de la obra "Esferas" realizada en la VIII Conferencia de Decanos y Directores de Matemáticas en la Universidad Politécnica de Valencia (noviembre 2006). 
"Si bien es algo excepcional que un cientifico posea una cultura musical sólida, es aún más excepcional dar con un músico cuya cultura científica también lo sea"

Pierre Boulez (2003)

\section{CAPÍTULO 1: Historia de la trompeta}

Para tener una visión general y más completa de las posibilidades técnicas de la trompeta actual, creemos necesario abordar con anterioridad un extenso repaso a cómo ha ido evolucionando este instrumento a lo largo de la historia. Hoy en día no concebimos una trompeta que no sea cromática, es decir, que pueda realizar todas las notas al igual que un instrumento como el piano (más adelante entraremos si además es capaz de producir algunas otras notas), pero durante siglos este instrumento ha sufrido innumerables cambios.

Hasta el S. XIX con la invención de los sistemas de válvulas y pistones, la trompeta siempre había sido natural, sólo podía emitir los sonidos armónicos de su fundamental; pero aún con estas limitaciones existían diferentes tipos de trompetas según el lugar en que nos encontráramos o los materiales de que se disponía para fabricarlas. Así, desde los pueblos más antiguos se han utilizado como trompetas las defensas de los elefantes o las conchas marinas.

\subsection{Antecesores de la trompeta}

La trompeta siempre ha sido un instrumento relevante, estando presente en los eventos más importantes, en las guerras, en las celebraciones e incluso en las escrituras bíblicas. 
Siete sacerdotes irán delante del Arca tocando las siete trompetas que sirven en el Jubileo. El día séptimo darán siete vueltas y cuando suenen las trompetas todo el pueblo subirá al ataque, dando su grito de guerra. En ese momento se derrumbarán los muros de la ciudad y cada uno entrará por lo más directo.

Josué, El libro de Josué 6, 1-27

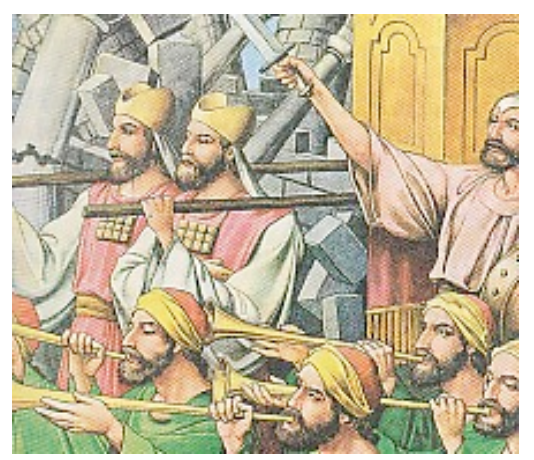

Fig. 1.1 Trompetas de Jericó

Fuente: M. Wade Matthews (2004)

Además, los trompetistas gozaron durante mucho tiempo del reconocimiento general y de una posición social de privilegio con respecto a los demás músicos

En la antigüedad y en la edad media ocupaban los timbaleros y los trompeteros (con exclusión de los demás instrumentos de metal) un rango social de singular consideración. En tiempos de Constantino se colocaban más alto que los mismos tribunos en la escala de dignidades, y más tarde, bajo el emperador Segismundo, se establecía una rigurosa división entre ellos y los demás músicos; formaban la servidumbre en la corte, y en el ejercito constituian asimismo un grupo aparte. En dicha época guardaban los trompeteros secretos relativos a su noble arte, cuya defensa les era confirmada por medio de un privilegio imperial otorgado en 1426. La estima de que gozaban estos músicos era tal aún en la época de Bach, que todavía podian celebrarse Paukerkonzerte (conciertos de timbaleros y trompeteros) durante el siglo XVIII.

H. Scherchen (1997) 
Históricamente todos los pueblos antiguos conocieron la trompeta: los romanos, los israelitas, los griegos, los etruscos, los germanos, los celtas... Todas estas trompetas poseían la característica de producir únicamente la serie armónica de su nota fundamental.

En el interior de la tumba del faraón egipcio Tutankamón se encontraron dos trompetas de plata y bronce rectas, con unas dimensiones de 58 y 49,4 centímetros, respectivamente, que actualmente se encuentran en el Museo de El Cairo.

La primera forma conocida de la trompeta es la tuba romana (Fig. 1.2), que tenía una longitud aproximada de 120 centímetros, de tubo cónico de 10 a 28 milímetros de diámetro.

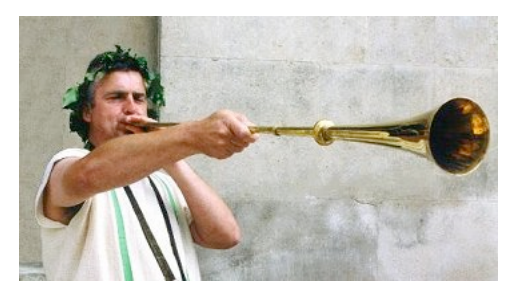

Fig. 1.2 Tuba romana

Junto con la tuba, los romanos utilizaron también la buccina, el cornu y el litus. Cada una de estas trompetas tenía un uso diferente. La tuba se utilizaba en infantería y el litus en caballería. La música de la legión romana se componía de tuba, cornu y buccina. La tuba sonaba para el ataque, el cornu para indicar el movimiento de los estandartes y la buccina estaba reservada al comandante en jefe. La tuba era un instrumento igualmente religioso utilizado para el culto público.

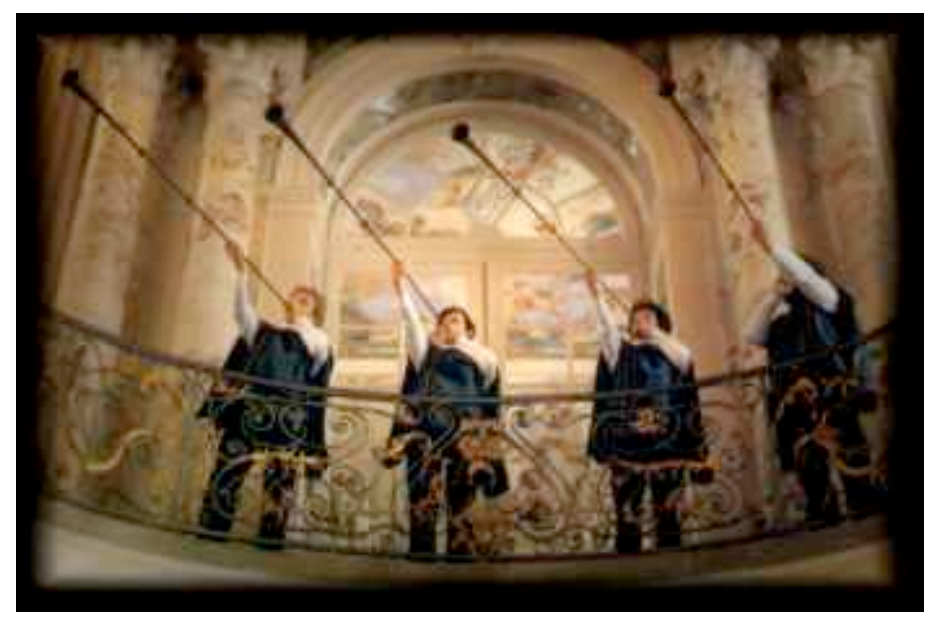

Fig. 1.3 Intérpretes de buccina 


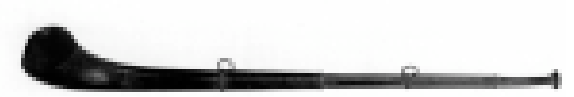

Fig. 1.4 litus

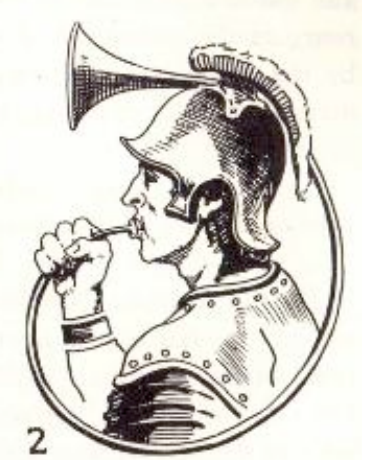

Fig. 1.5 Intérprete de cornu

Fuente: F. Bonanni (1964)

Las primeras trompetas carecían de boquilla y pabellón y estaban destinadas a proyectar la voz humana. Estas trompetas megáfono eran utilizadas durante ciertos ritos religiosos y mágicos, la circuncisión, ritos célebres o la puesta del sol. Eran utilizadas sólo por los hombres, de manera que estaban asociadas al sexo masculino, contrariamente a ciertos tipos de tambores que eran utilizados exclusivamente por las mujeres.

Se encontraron trompetas de este género en los pueblos arcaicos de Nueva Guinea y en el Noroeste de Brasil, así como en Australia, donde eran llamadas didjeridoo.

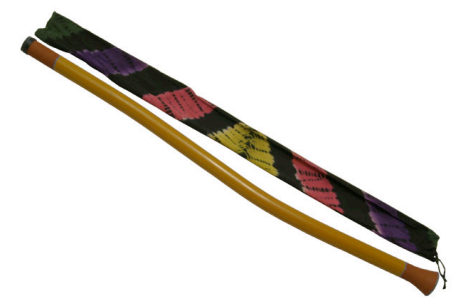

Fig. 1.6 Didjeridoo

Fuente: M. Wade Matthews (2004)

La karnyx era una larga trompeta celtica hecha de bronce. Se tocaba sobre la vertical del cuerpo por encima de la cabeza del instrumentista, de forma que su sonido se proyectaba desde tres metros por encima del suel. Fue muy conocida en Europa aproximadamente entre los años 200 a.C. a 200 d.C. Para los celtas la 
karnyx tenía un uso militar, incluso los ejemplares más recientes tenían un extraordinario pabellón en forma de cabeza de dragón. Alrededor de 1816 se encontró en el Nordeste de Escocia un ejemplar que ha sido reconstruido.

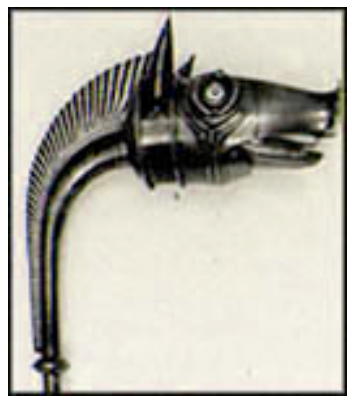

Fig. 1.7 Detalle de karnyx

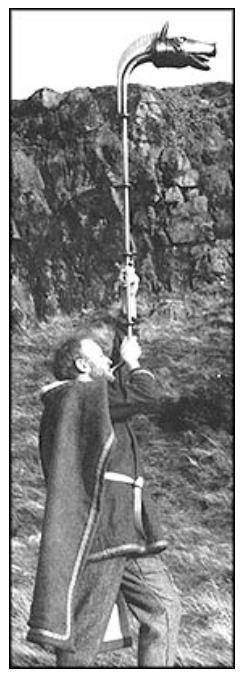

Fig. 1.8 karnyx ${ }^{1}$

Fuente: M. Wade Matthews (2004)

En la Grecia clásica nos encontramos con un instrumento semejante a una trompeta, el salpinx. Contaba con un delgado tubo recto de bronce y una boquilla ósea. Tradicionalmente, este instrumento ha sido asociado con la guerra.
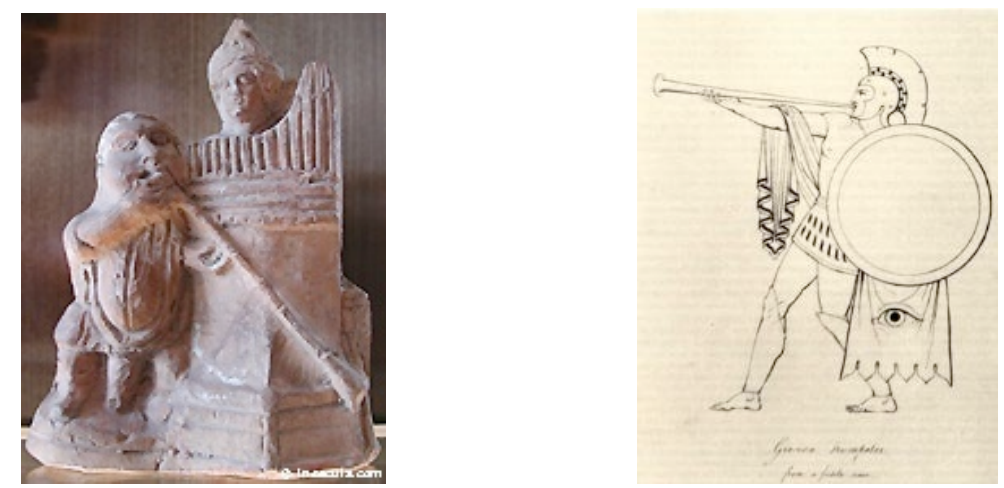

Fig. 1.9 Intérpretes de salpinx ${ }^{2}$

El uso de la trompeta no siempre fue el de hacer música sola o en conjunto. En Israel, se utilizaba para reunir a toda la asamblea. En Egipto, estaba

\footnotetext{
${ }^{1}$ Fuente: http://en.citizendium.org/wiki/ancient.celtic.music

${ }^{2}$ Fuente: www.tapsbugler.com/historyofthebugle/historyofthebugle2.html
} 
presente en los misterios celebrados en honor a Osiris y era tocada por los soldados. En Grecia (salpinx), tenía un uso exclusivamente militar, aunque también se trataba de una disciplina olímpica. En Etruria, según Virgilio, las trompetas proclamaban la voluntad de los dioses ó incluso el fin de una era.

El olifante, de origen bizantino, deriva tal como su nombre indica de las defensas del elefante. Este instrumento está relacionado con las trompas de marfil medieval, en las cuales se soplaba por un extremo. Finamente tallada fue apreciada por las clases pudientes como señal de posesión de tierras, o por las iglesias, como relicario más que como instrumento musical.

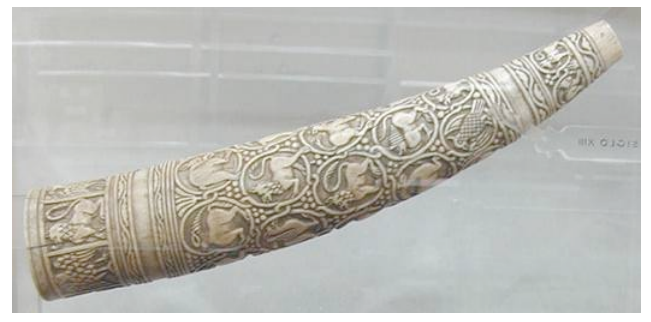

Fig. 1.10 olifante

Fuente: Fundación Lázaro Galdiano ${ }^{3}$

El busines era una especie de trompeta grande de importación Sarracena, con un tubo cilíndrico recto y el pabellón dilatado.

Al igual que en la trompa, la trompeta stopf y la trompeta sordina también emplean la introducción de la mano en el pabellón para modificar su sonoridad, timbre, etc. En la primera, se bajaban un semitono todos los armónicos naturales por la introducción de la mano en el pabellón del instrumento. Y por el mismo medio se modificaba la sonoridad en la segunda

El corneto era un instrumento construido en madera y recubierto de piel. $\mathrm{Su}$ embocadura es en forma de copa y presenta orificios para los dedos. La variedad aguda y curvada, más común que la recta, estan afinadas en sol o en la (actualmente se fabrican cornetos en sol, la y do). Se utilizó entre 1550 y 1650 en combinación con trombones, como apoyo de la música coral en la TURMMUSIK (música desde la torre) y en conjuntos de viento y mixtos. A pesar de sus características constructivas, este instrumento tiene un timbre muy similar al de la trompeta actual.

\footnotetext{
${ }^{3}$ www.flg.es/fotos/2000/2577.jpg
} 


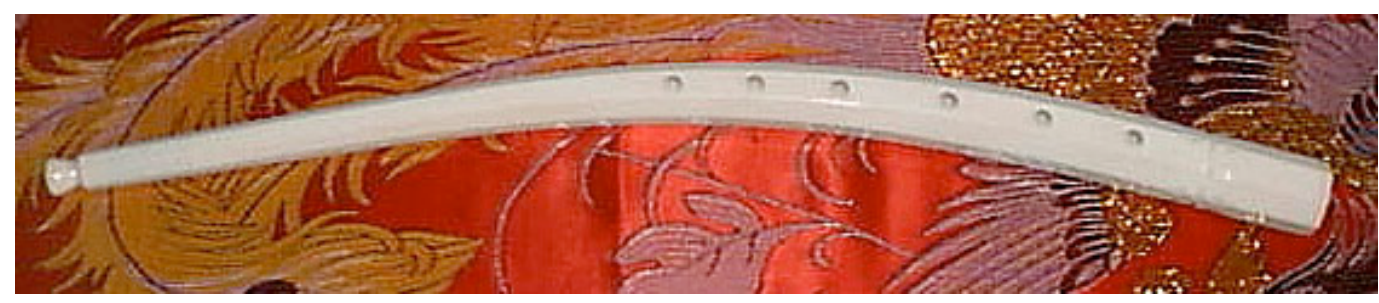

Fig. 1.11 Corneto

Fuente: E. Mende (1978)

La trompeta curvada pesa relativamente poco. Su extraordinaria belleza la convierte en una pieza de decoración.

Una de las trompetas más importantes del periodo barroco, el clarino, tambien recibió los nombres de clarion y clairon. El vocablo clarino se refiere al registro más agudo de la trompeta y se remonta al S. XII, cuando designaba las largas trompetas rectas; posteriormente se aplicó, al parecer, a instrumentos más cortos de tubo estrecho. Tambien, clarín o clarino (a veces "claret"), designaba a la voz más aguda de los conjuntos de trompetas y la palabra figura ocasionalmente con este significado en la obra de J. S. Bach.

El anafil es un instrumento de viento de la época medieval. En la clasificación Hornbostel-Sachs, aerófono de embocadura (aerófono tipo trompeta). Documentado desde la dominación islámica de la península ibérica, se trata de una trompeta recta natural, con un tubo de metro y medio de largo aproximadamente.Llamado también "náfil moresc", conservó este nombre a causa del uso generalizado que hicieron los moros andalusinos para ejecutar las partes agudas de las fanfarrias y los toques militares. Fue introducido en Europa por los ejércitos sarracenos y cristianos de las cruzadas. Su equivalente moderno es el "náfir", que en Magreb se hace sonar desde los minaretes hasta el mes de Ramadán. Se fabrica con cobre y en dos secciones, el pabellón, que tiene forma de copa y la embocadura, que es cónica.

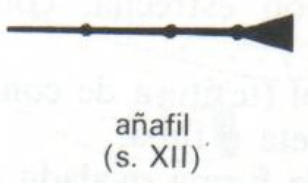

Fig. 1.12 Añafil

Fuente: L. Andrés y V. Alberola (2008)

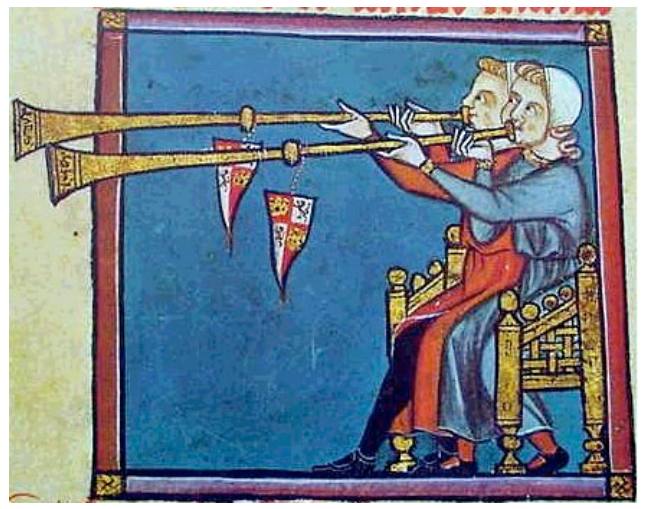

Fig. 1.13 Interpretes de Añafil Fuente: Museo de la Música de Urueña ${ }^{4}$

\footnotetext{
${ }^{4}$ Colección Luis Delgado
} 
El serpenton es un antiguo instrumento musical de viento, originalmente el bajo de la familia de la trompeta. Su nombre procede de su forma, un tubo largo y sinuoso, con una curvatura extra, teniendo forma de "S". El serpentón lo inventó en torno a 1590 un clérigo francés, Edmé Guillaume. Empleado especialmente para acompañar a los coros en las iglesias, cayó en desuso después de la revolución francesa. El cuerpo era de madera y cubierto con piel o lienzo con una boquilla construida normalmente de marfil o hueso. Este instrumento se considera como el antepasado más claro de los instrumentos de metal graves como la tuba o el bombardino.

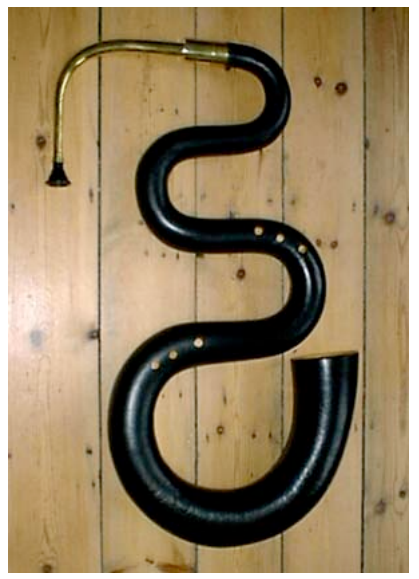

Fig. 1.14 Serpenton

Fuente: M. Wade Matthews (2004)

La Basse-Trompete es una especie de serpenton patentado en 1810; este instrumento no debe confundirse con la Trompete Basse (trompeta baja).

La Trompeta en reb fue utilizada en el s. XVII durante la época Barroca. Construida por Johann Leonard Ehe.

La Trompeta en fa era utilizada para las primeras voces de Bach y durante casi toda la época Barroca. Existe otra trompeta en fa pero que sonaba una octava por debajo que fue utilizada por compositores como Richard Strauss (Till Eulenspiegel) o Richard Wagner (Tanhauser).

La trompeta alto en sol fue utilizada a finales del Barroco. Construida por Johann Wilhelm Haas (1649-1723) en Nuremberg. En su pabellón llevaba grabada una inscripción con el lugar de su fabricación y otra con la marca de la fábrica Haas, que era una liebre en plena carrera. 


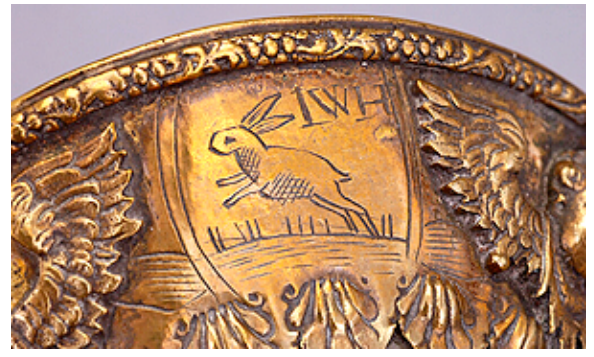

Fig. 1.15 Inscripción en la campana de las trompetas Haas Fuente: University of Dakota, Nacional Music Museum

La trompeta alto en re la construyó M. J. Carl Codish en Nuremberg. El pabellón de la trompeta estaba decorado con cabezas de ángeles en relieve sobre el metal cincelado.

La trompeta de caballería era utilizada para los toques de ordenanza de las tropas montadas. En algunas naciones, como en la nuestra, forman verdaderas bandas, que ejecutan toques a varias voces. Fueron construidas en el S. XVIII.

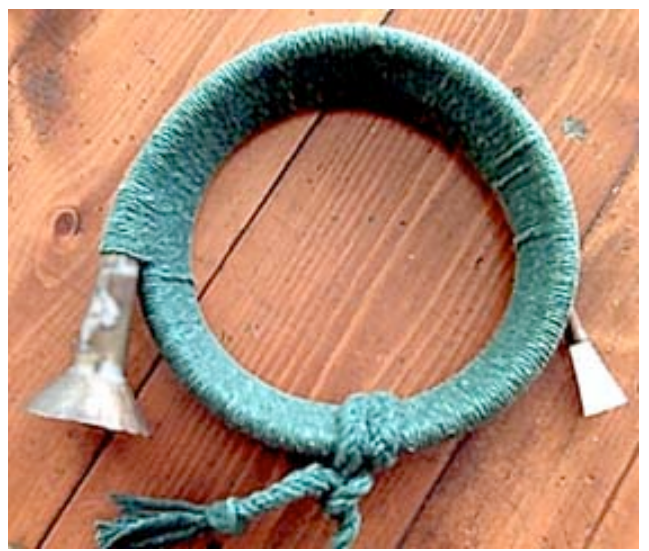

Fig. 1.16 Clarino

Fuente: A. Baines (1974)

La trompeta natural se utilizó durante todo el periodo Barroco y la primera mitad del Siglo XIX, aunque tuvo su mayor auge durante el periodo comprendido entre 1600 y 1700, denominado "Edad de oro de la trompeta".Esta trompeta está formada por dos tubos, el pabellón, dos elementos curvados entre las partes rectas y cinco piezas que se utilizan como unión entre éstas. La parte ensanchada del pabellón está rematada por una corona y también lleva un pomo ornamental 


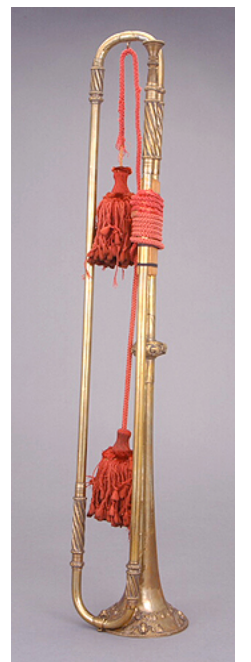

Fig. 1.17 Trompeta natural en Re de Johann Wilhelm Haas.

Fuente: A. Baines (1974)

Los elementos que componían las trompetas naturales no estaban soldados, simplemente se introducían unos dentro de otros con resina, siendo las fugas de aire reducidas con cera de abeja.

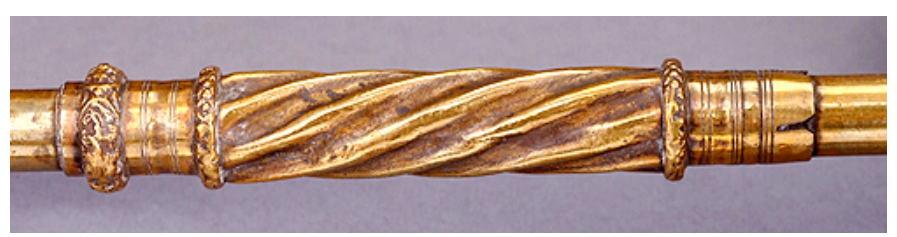

Fig. 1.18 Pomo de la trompeta natural

Fuente: A. Baines (1974)

En cuanto a las dimensiones, no resulta sencillo determinar unas medidas estándar. Por ejemplo, la trompeta natural o trompeta barroca tenía una longitud según Edward H. Tarr (1977) de 224 centímetros, mientras que para Anthony Baines (1974) su longitud era de 8 pies ó $239 \mathrm{cms}$. Pero incluso en las trompetas actuales tampoco existe un criterio unánime, ya que para Tarr la trompeta cromática en si bemol mide $130 \mathrm{cms}$, mientras que para Baines mide $131 \mathrm{cms}$; por otra parte, las medidas de la pequeña trompeta piccolo en si bemol, afinada una octava más alta, oscilan de los $65 \mathrm{cms}$ que dice Tarr a los 62 de Baines. 


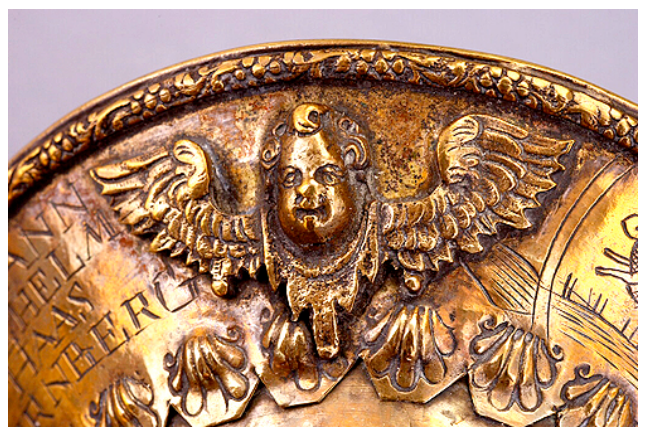

Fig. 1.19 Detalle de la campana

Fuente: A. Baines (1974)

Varios eran los constructores de trompetas naturales, siendo los más conocidos Johann Wilhelm Haas y Johann Leonhard Ehe en Nuremberg. El modelo de este último es el empleado en la actualidad como modelo por los constructores de réplicas de la época. Esta trompeta era empleada en el papel de "principal", para apoyar las cadencias armónicas y los pasajes fuertes.

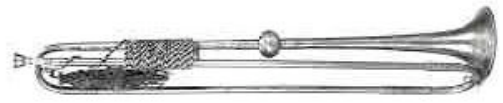

Fig. 1.20 Trompeta natural (Ehe)

Fuente: E. Mende (1978)

Sobre la trompeta natural el intérprete puede, modificando la tensión de sus labios, producir una serie de notas que están "impuestas por naturaleza" (de ahí su nombre "natural"). La nota más grave, llamada fundamental, es la producida por medio de la mínima tensión de los labios. La nota fundamental de la trompeta natural de la época barroca, afinada en do, se llama do ${ }_{1}$ y se representa de la siguiente manera:

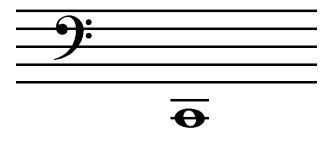

$\mathrm{do}_{1}$

La nota siguiente que se produce sobre una trompeta natural es el $\mathrm{do}_{2}$, situada en la octava superior a la precedente (fundamental).

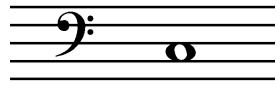

$\mathrm{do}_{2}$ 
Estas dos notas forman la primera octava de la serie de parciales. La segunda octava de esta serie se produce entre el $\mathrm{do}_{2}$ y el do $\mathrm{do}_{3}$ :

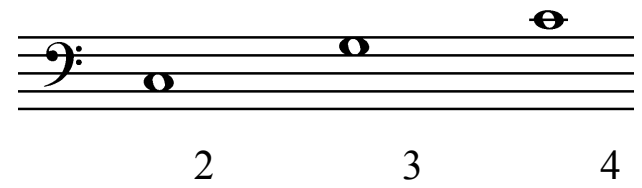

En la tercera octava de parciales aparecen los mismos que en la segunda y se añaden dos más $\left(\mathrm{mi}_{3}\right.$ y sib 3$)$ :

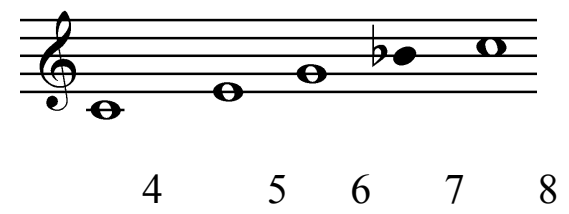

El parcial 7 (si bemol) se representa en negrita porque no se encuentra a medio camino entre los dos parciales que le rodean como ocurre en los anteriores sino que está un poco bajo 5 .

En estas tres primeras octavas se producen, a medida que vamos subiendo, los siguientes intervalos:

$\begin{array}{ll}\text { Entre el do } \mathrm{de} \mathrm{el} \mathrm{do}_{2} & \text { Octava } \\ \text { Entre el do } \mathrm{y} \mathrm{el} \mathrm{sol}_{2} & \text { Quinta } \\ \text { Entre el sol } \mathrm{y} \mathrm{el} \mathrm{do}_{3} & \text { Cuarta } \\ \text { Entre el do } \mathrm{y} \mathrm{el} \mathrm{mi}_{3} & \text { Tercera mayor } \\ \text { Entre el mi } \mathrm{m} \mathrm{el} \mathrm{sol}_{3} & \text { Tercera menor }\end{array}$

Los parciales de la cuarta octava constituyen una especie de escala. En esta octava se encuentran las mismas notas que en la octava anterior y además se intercalan otras notas que nos dan la siguiente escala

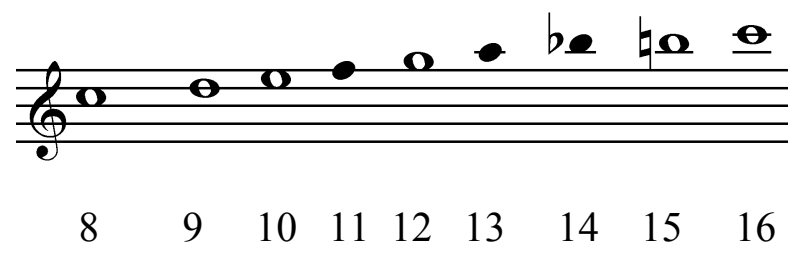

\footnotetext{
${ }^{5}$ En el capítulo 2 se explica que esto es así porque se está comparando con el sistema temperado de 12 notas que es un temperamento y no una afinación.
} 
Como en la octava anterior, los intervalos van reduciéndose. La distancia do $_{4}-\mathrm{re}_{4}$ representa el tono grande $6 / 8$, mientras que la distancia $\mathrm{re}_{4}-\mathrm{mi}_{4}$ representa el tono pequeño ${ }^{7} 10 / 9$.

La tercera do $_{4}-\mathrm{mi}_{4}$ es un poco más corta que la afinación temperada en uso actualmente, pero era perfecta en la época barroca donde se practicaban diversas afinaciones desiguales.

El parcial 14 está bajo, y el 11 y el 13 son extraños a la escala temperada comparada con las teclas blancas del piano.

El parcial 11 se sitúa a medio camino entre el fa $\mathrm{y}_{4}$ el fa ${ }_{4}^{\#}$, y el 13 más cerca del sol ${ }_{4}^{\#}$ que del la 4 .

En la época barroca, los trompetistas tocaban esta cuarta octava de la serie de parciales corrigiendo los defectos de afinación. Para ello modificaban la tensión de sus labios, técnica que era conocida como corrección labial.

La quinta octava de parciales no se utilizaba entera debido a su dificultad, ya que se encuentra en el registro más agudo.

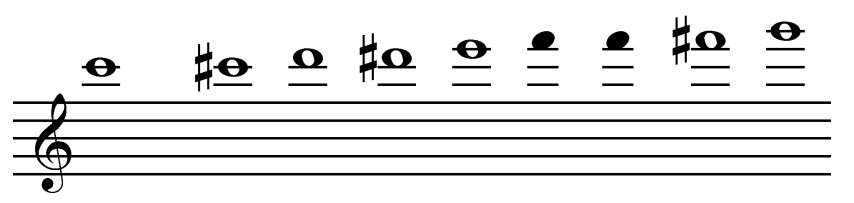

\section{$\begin{array}{lllllllll}16 & 17 & 18 & 19 & 20 & 21 & 22 & 23 & 24\end{array}$}

Según Edward H. Tarr, el parcial 24 fue escrito en dos conciertos, uno de Michael Haydn (1737-1806) y otro de Georg V. Reutter (1708-1772). Ambos fueron compuestos hacia 1760 para el instrumentista austriaco J. B. Resenberg, al que Leopold Mozart (1719-1787) calificó como "Excelente trompetista, que es particularmente ilustre por sus notas agudas".

Johann Sebastian Bach (1685-1750) fue quien escribió las partes más difíciles para trompeta, aunque no las más agudas. Pide a menudo los parciales 16 y 18 utilizando trompetas afinadas en re (Oratorio de Navidad, Magnificat...) y trompeta en $\mathrm{fa}^{8}$ para el $2^{\circ}$ Concierto de Brandenburgo (1721).

J. S. Bach contaba con un magnífico trompetista al cual escribía sus partes más complejas, Gottfried Reiche (1667-1734), (Fig.1.21), que estuvo a su servicio durante 11 años en la Orquesta Municipal de Leipzig.

\footnotetext{
${ }^{6}$ El concepto de tono grande aparece en la justa entonación.

${ }^{7}$ El concepto de tono pequeño aparece en la justa entonación.

${ }^{8} \mathrm{La}$ trompeta en re emite las mismas notas que la que está afinada en do pero suena un tono más alto, de la misma manera la trompeta en fa suena una cuarta más aguda que la de do.
} 


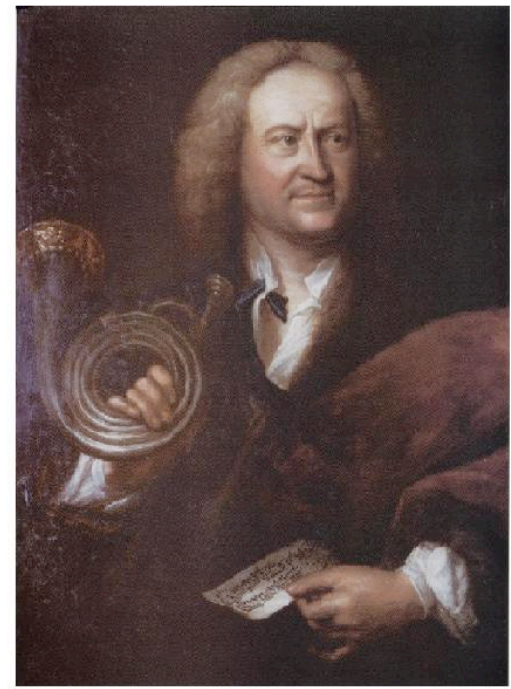

Fig. 1.21 Gottfried Reiche Fuente: E. Mende (1978)

El primer compositor que prestó atención a la trompeta y la introdujo en la música de concierto fue el italiano Claudio Monteverdi (1567-1643). En su ópera Orfeo (1607), Monteverdi utilizó el conjunto tradicional de las cortes (5 trompetas), pero únicamente en la "Toccata" (especie de fanfarria que se oía tres veces antes de levantarse el telón y que era utilizada para avisar el comienzo de la función). En 1584, una "Toccata" de trompetas había sido improvisada para la Obertura del Teatro Olímpico de Palladio en Vicenza y puesto que Monteverdi era conocido como "un ciudadano que presta atención a los detalles", fue con este espíritu con el que compuso la "Toccata" de Orfeo, en lugar de dejarla improvisar, como era corriente en la época. La "Toccata" era un fragmento puramente funcional y no música de concierto.

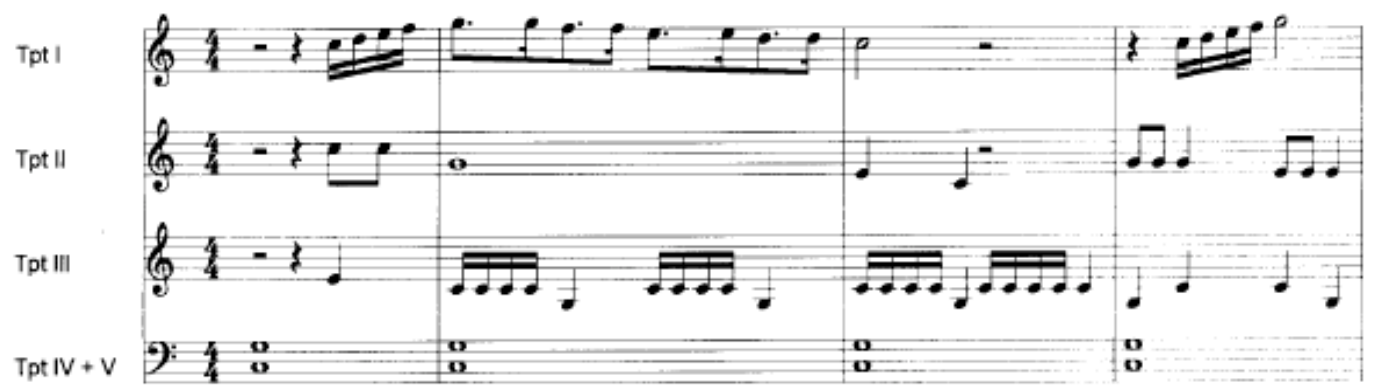

Fig. 1.22 Fragmento de la Toccata de Monteverdi

Por otra parte, la "Toccata" de Monteverdi comportaba algunas innovaciones con respecto a las fanfarrias improvisadas hasta entonces, pues aparte de estar escrita, en ella resaltaba la brillantez de la trompeta. 
Además, Monteverdi fue el primero en añadir a la "Toccata" la colaboración de otros instrumentos: cuerdas, dos flautas de pico y un gran número de instrumentos de bajo continuo. Sin embargo para que las trompetas no cubrieran con su sonoridad al resto del conjunto, pidió que éstas fueran tocadas con sordina. La sordina era de madera, tomaba la forma de un cimborio, y era atravesada en toda su longitud por un agujero cilíndrico. Cuando se introducía la sordina en el pabellón de la trompeta, se reducía la salida de columna de aire y se obtenía una transposición (ya sea de medio tono e incluso de un tono ascendente).

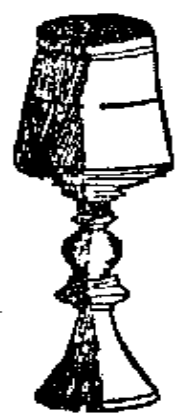

Fig. 1.23 Sordina

Fuente: B. Sluchin y R. Caussé (1991)

A pesar de que en Orfeo las trompetas tocaban al mismo tiempo que los otros instrumentos, no se puede decir que fuera Monteverdi el primero que utilizó la trompeta en esta época, ni siquiera que la utilizara como instrumento solista o como parte de la orquesta. El honor de dar a la trompeta carácter solista al mismo nivel que los demás instrumentos, correspondió a compositores que a la vez eran trompetistas, como Fantini o Bendinelli.

Girolano Fantini (c. 1600- c. 1675) fue a partir de 1630 trompetista de la Corte del Gran Duque de Toscana Fernando II. Las 8 sonatas para Trompeta y Órgano y las numerosas Danzas para Trompeta y Bajo Continuo, que editó en 1638 en su método titulado "Modo per imparare a sonare la tromba", son los ejemplos conocidos de música italiana de concierto en que se hacia intervenir a la trompeta.

Cesare Bendinelli (c. 1542-1617)fue un trompetista italiano afincado en Viena desde 1567 y primer trompetista de la Corte de Munich desde 1580. La importancia histórica de Bendinelli reside en su labor recopiladora de los métodos de ejecución trompetística de la época, materializada en "Tutta l'arte della trombetta" (1614), donde se contienen las primeras piezas fechadas (1584-8) para el registro del clarino. Las trompetas, agrupadas en coros de cinco y en ocasiones acompañadas con timbales, interpretaban las voces de cada coro según el registro. Cada voz tenía asignado un nombre en función de la altura que interpretaba: clarino, para la más aguda; sonata, alto e basso y vulgano, para las intermedias; y 
basso, para la más grave. Por otra parte, Bendinelli afirmaba ser el primero en aplicar sílabas linguales a la trompeta.

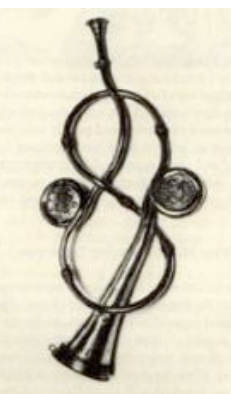

Fig. 1.24 Trompeta utilizada por Bendinelli

Hacia 1635, Fantini participó, en compañía de Girolano Frescobaldi (organista de la Iglesia de San. Pedro de Roma) en una celebración histórica presidida por el Cardenal Borghese. Trompetistas franceses que habían asistido a este concierto (el primero de la música moderna que reunía a estos dos instrumentos) consideraron que Fantini, si bien era capaz de producir las parciales notas intermedias, éstas eran impuras y en desorden. No es preciso concederle demasiada importancia a esta crítica, pues, como veremos, la trompeta se contentó durante mucho tiempo en Francia con su rol heroico tradicional. Fantini pasó a ser considerado maestro del arte de obtener notas por corrección labial; de hecho, varias de sus sonatas comportan pasajes que se sitúan fuera de los parciales.

Para designar el período o estilo de la música europea que se extendía aproximadamente entre los años 1600 y 1750, se acuñó el término Barroco, siendo especialmente utilizado en el s. XX para distinguir un período de la historia de la música.

Alessandro Stradella (1644-1682) fue uno de los principales compositores italianos de su época y uno de los más versátiles. Compuso dos de las más bellas sinfonías para trompeta, cuerdas y continuo que se conocen, siendo el acompañamiento instrumental realizado por un corno di caccia. La escritura y textura de una de sus Sonate di viole hacen de ésta el primer concerto grosso conocido.

Arcangelo Corelli (1653-1713) fue el primer compositor que cimentó su fama como autor de música exclusivamente instrumental. Compuso una Sonata para Trompeta.

Alessandro Melani (1639-1703) fue un compositor italiano y maestro de capilla en Orvieto, Ferrara, Catedral de Pistoia (Italia), Sta. Maria Maggiore y S. Luigi dei Francesi (Roma), siendo en este lugar donde llegó a ser el compositor más relevante de música sacra y predecesor de Alessandro Scarlatti. Entre sus 
numerosas composiciones realizó algunas cantatas donde la trompeta interpretaba la voz solista.

Alessandro Scarlatti (1660-1725) fue un compositor italiano apreciado sobre todo por sus concertos grossi y música para cuerdas. Al mismo tiempo fue uno de los compositores más prolíficos de Italia para nuestro instrumento, realizando al menos treinta y seis obras para una, dos y cuatro trompetas.

Giuseppe Torelli (1658-1709) compuso unas 150 obras instrumentales y contribuyó de manera significativa al desarrollo del concerto solista. Sus primeras colecciones impresas (1686-1688) son de música de camara, pero ya demuestran un paso hacia la escritura de concierto y la forma Ritornello. Estas características son más pronunciadas en sus numerosas piezas para trompeta y cuerdas, la mayor parte de ellas escritas para San Petronio, antes de 1696.

La importancia de Domenico Gabrielli (1651-1690) reside principalmente en su virtuosismo como violonchelista y posteriormente, como compositor. Además de piezas de cámara, compuso dos sonatas (con orquesta) para trompeta (su otro instrumento favorito); en sus obras vocales también combinó a menudo la trompeta con el violonchelo, en modo concertante o en obbligato ${ }^{9}$.

Henry Purcell (1659 - Westminster, 21 de noviembre de 1695) fue uno de los compositores más grandes del período barroco, a la vez que uno de los más sobresalientes entre todos los compositores ingleses. Con Purcell, la trompeta tuvo el mismo papel que tenía en la ópera italiana y fue tratada en consecuencia. Algunas de las arias y sinfonías que este compositor dedica a la trompeta y que se encuentran en Theyorksshire Fest. Song (1689), Dioclesian (1690), The Fair Queen (1692), L'Ode a Santa Cecilia (1692), Te Deum and Jubilate (1694), The Indian Queen (1695) y Trumpet Voluntary, compiten con el número de páginas más sublimes de la literatura de nuestro instrumento.

Los trompetistas tenían que tocar con seguridad y exactitud las difíciles partituras escritas para ellos, por lo que hoy en día se especula con la posibilidad de que estos instrumentistas utilizaran la técnica de corrección labial, considerando la partición y división del tubo mediante agujeros que se podían tapar con los dedos.

La técnica conocida como corrección labial consistía en colocar los labios con los dedos de las manos en la boquilla según la nota que se tenia que ejecutar, por tanto exigía unos tiempos de espera cuando el intérprete cambiaba la nota, puesto que éste debía volver a corregir la posición de los labios con los dedos para emitir la siguiente nota.

\footnotetext{
${ }^{9}$ término usado en la música concertante para indicar una parte independiente y esencial, pero secundaria a la melodía principal
} 
Es muy importante la inclusión de la trompeta en cantatas, oratorios y misas. Sobradamente conocidos son los pasajes de El Mesias de G. F. Haendel (donde en el fragmento The Trumpet Shall Sound la trompeta toca a solo junto con la voz), el Oratorio de Navidad, la Misa en Sim o la Cantata $N^{o} 51$ de J. S. Bach.

Leopold Mozart (1719-1787) fue compositor, violinista y teórico alemán. Realiza entre otras muchas composiciones, algunas piezas instrumentales donde aparecen elementos populares, prueba de ello es su famoso concierto en ReM.

Los conciertos en ReM de Franz Xaver Richter (1709-1789), Johann Melchior Molter (1696-1765), Giuseppe Tartini (1692-1770), George Philip Telemann (1681-1767) y Michael Haydn (1737-1806), se interpretaban con una trompeta en Re, hasta que J. S. Bach incluye en su $2^{\circ}$ concierto de Brandeburgo la trompeta en Fa. Johann Samuel Endler (1694-1762) escribe también para una pequeña trompeta en $\mathrm{Fa}$ agudo en una suite para clarino, con 2 trompas, cuerdas y bajo continuo.

Los trompetistas del período Barroco se encontraron con partituras de difícil ejecución y con un instrumento de características técnicas que resultaban poco adecuadas para interpretar esta música junto a la cuerda. Para ello, estos músicos tuvieron que superar las dificultades que presentanba el instrumento, afinando los parciales imprecisos y tocando más piano cuando no eran solistas.

Existía un número reducido de trompetistas en este período que fue más lejos que los demás, llegando a dominar el registro agudo conocido como clarino. Eran conocidos como "cantibiles" o "cantábiles" y gozaban de gran agilidad en el picado, sobre todo en los pasajes rápidos.

Los músicos del Renacimiento y Barroco perseguían imitar a la voz humana. En este sentido, eran los instrumentistas de viento los preferidos, puesto que por medio del aire y cantando a través del instrumento se acercaban más a la voz.

Al principio del Barroco, Fantini pidió que la trompeta hiciese un adorno vocal un tanto complejo: messa voce. Se trataba de tocar una longa creciéndola hasta la mitad de su valor y diminuyéndola hasta el final del mismo. Este adorno es semejante al que hoy conocemos como sonido filado.

El golpe de lengua que efectuaban todos los vientos en el Barroco era desigual, quedando los pasajes reducidos a grupos de dos notas, que tanto ligados como picados se interpretaban así: 


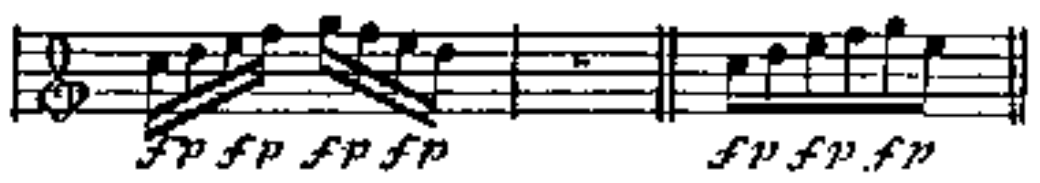

Fig. 1.25 Ejemplo de picado

Fuente: L. Andrés y V. Alberola (2008)

Los instrumentistas tenían que aprenderse muy bien la dicción, para interpretar lo que se exigía en la partitura. El picado en los arpegiados era corto pero más igualado. Las ligaduras eran muy estrictas y concernían principalmente, a los motivos descendentes.

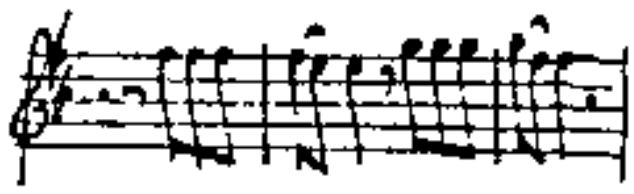

Fig. 1.26 Ejemplo de ligadura

Fuente: L. Andrés y V. Alberola (2008)

Fue al final del Barroco, principios del clasicismo, cuando se empezó a ligar grupos de notas de cierta importancia.

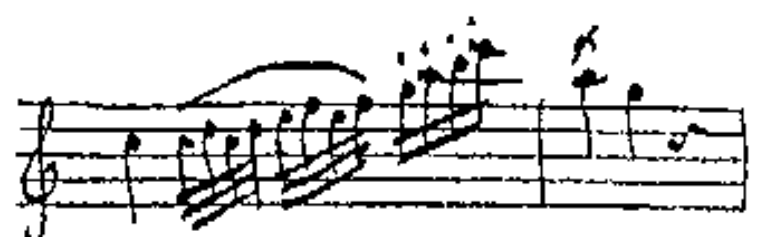

Fig. 1.27 Ejemplo de ligadura en L. Mozart

Fuente: L. Andrés y V. Alberola (2008)

Girolano Fantini utilizaba en sus composiciones el trillo, ornamento en forma de trémolo vocal utilizado particularmente en la música italiana de principios del s. XVII. El groppo es un grupo de ornamentos adjunto a una nota de anticipación o una nota cambiata ${ }^{10}$. Posteriormente se conoció el trino, comenzándose por la nota superior.

La forma concierto cambia, pasando de dos movimientos (Leopold Mozart o Michael Haydn) a tres (Franz Xaver Richter, Johann Melchoir Molter o Johann Sebastian Bach). Esta forma desembocará en el concierto clásico de tres

\footnotetext{
${ }^{10}$ término introducido en el s. XVII para designar una nota de paso acentuada, pero que ha llegado a significar una nota de adorno no acentuada desde la que se salta una tercera menor descendente
} 
movimientos, adquiriendo la estructura de la sonata clásica (Mozart, Haydn, Beethoven).

En el $2^{\circ}$ concierto de Brandemburgo de J. S. Bach se necesita un enorme dominio de la trompeta y un gran conocimiento de la música barroca, para poder interpretar los delicados pasajes que el compositor ha escrito en la partitura. El trompetista ha de ser muy escrupuloso en la afinación y sonoridad (sobre todo de los pasajes agudos) para no destacar del resto de solistas y de la orquesta.

Las dificultades que entrañan el Concierto $\mathrm{N}^{\circ} 1$ en ReM y el Concierto $\mathrm{N}^{\mathrm{o}}$ 2 en DoM de Michael Haydn son semejantes a las del $2^{\circ}$ concierto de Brandemburgo, pero con la singularidad de que el trompetista es el único solista, ya que son increíblemente agudos para interpretarse con una trompeta natural. Michael Haydn exige el fa $\mathrm{a}_{5}$ en su concierto $\mathrm{N}^{\mathrm{o}} 2$ y el la $\mathrm{a}_{5}$ en el concierto $\mathrm{N}^{\mathrm{o}} 1$, nota que supone el techo de lo escrito hasta el momento y que durante muchos años no se ha igualado; en la actualidad, sólo los solistas de jazz y algunos virtuosos los superan en sus improvisaciones o en las cadencias de ciertos conciertos, demostrando así sus habilidades.

Franz Xaver Richter se acerca bastante, en cuanto a los pasajes agudos se refiere, a los dos compositores anteriormente mencionados, llegando a escribir en su Concierto en Re Mayor un $\mathrm{Sol}_{5}$.

En el 1er movimiento del Concierto en ReM de Giuseppe Tartini nos encontramos con pasajes donde la digitación impera por su dificultad, esto nos lleva a pensar que la dificultad sería aun mayor sin la ayuda de los pistones que hoy en día se utilizan.

Para interpretar el Concierto en ReM de George Philippe Telemann, el trompetista debe estar dotado de una técnica impecable y de una considerable resistencia, puesto que su primer movimiento consta de frases muy largas y sin apenas descanso entre ellas, las cuales era imposible interpretar con la antigua técnica de la corrección labial.

Debido a la evolución de la trompeta piccolo sib/la (instrumento con el cual se interpretan los conciertos mencionados) y su semejanza con la tesitura del oboe o de la voz de soprano, hoy en día nos encontramos con adaptaciones, como el Concierto en Dom de Alessandro Marcello, el Concierto en Dom de Domenico Cimarosa o el Aria de La Reina de la Noche de la opera La Flauta Mágica de W. A. Mozart los cuales resultan de fácil adaptación por la tesitura pero entrañan una dificultad técnica enorme.

Actualmente es posible encontrar todo el repertorio anterior a 1750 trascrito para la trompeta piccolo en $\mathrm{Sib} / \mathrm{La}$, además la trompeta barroca es 
posible estudiarla a gran nivel en la mayoría de los conservatorios de Suiza, los países escandinavos, Alemania, Holanda, Inglaterra, Italia y Francia.

Las trompetas barrocas que se construyen hoy en día son réplicas de modelos antiguos, Rainer Egger construye actualmente sus trompetas basándose en los modelos de Hainlein (1632), J. L. Ehe II (c. 1700), W. W. Haas (c. 1750) y A. Wolf (c. 1800).

En 1795 Johann Ernst Altenburg (1734-1801) publicó su método Versuch einer Anleintung zur heroisch-musikalischen Trompeter- und Pauker-Kunst (ensayo e introducción a heroicos músicos trompetistas y timbaleros), que sirvió como guía de aprendizaje a los trompetistas de esa generación para interpretar la trompeta natural.

La trompeta natural representa durante el periodo barroco los ideales del estilo barroco, el poder, la heroicidad, la nobleza. Cuando se producen los cambios sociales y políticos a finales del S. XVIII también cambian los gustos por la música y por los instrumentos, a esto también contribuyen los cambios técnicos que Theobald Boehm (1794-1881) aplica en Munich a los instrumentos de madera, que a partir de ese momento ya pueden hacer sonar todas las notas de la escala cromática. Por el contrario, la trompeta queda anclada en el pasado y cae en desuso. La trompeta representa lo antiguo, lo anterior y los compositores dejan de utilizarla, además éstos tienen ahora otros instrumentos con mayores posibilidades técnicas que aprovechan.

A partir de aquí surge el interés por dotar a la trompeta de mecanismos que le permitan tocar de la misma manera que el resto de instrumentos sin las limitaciones técnicas que tenía, de aquí surgen las ideas que desembocaron en la actual trompeta. El primer intento o al menos el más efectivo y conocido fue el realizado por Anton Weidinger que construyó una trompeta de llaves con la cual era posible realizar la escala cromática.

El saxhorn fue inventado por Antoine-Joseph (conocido como Adolphe) Sax (6 de Noviembre de 1814- 4 de Febrero de 1894). Sax fue un inventor de instrumentos belga, famoso por la invención del saxofón entre otros instrumentos.

La familia de los saxhorns está formada por instrumentos de metal con válvulas, fue denominada así por su inventor Adolphe Sax que dió forma a estos instrumentos y su trabajo sirvió de base a los constructores de instrumentos para su fabricación. Los saxhorn son instrumentos de metal de forma cónica y con una boquilla más profunda que la de la trompeta, su sonido sería el resultante de fundir una trompa con una trompeta. El moderno tenor horn (alto horn en Estados Unidos de América), el horn barítono y el flugelhorn son las variantes más conocidas que son utilizadas habitualmente en las bandas de metales (Brass Bands). 

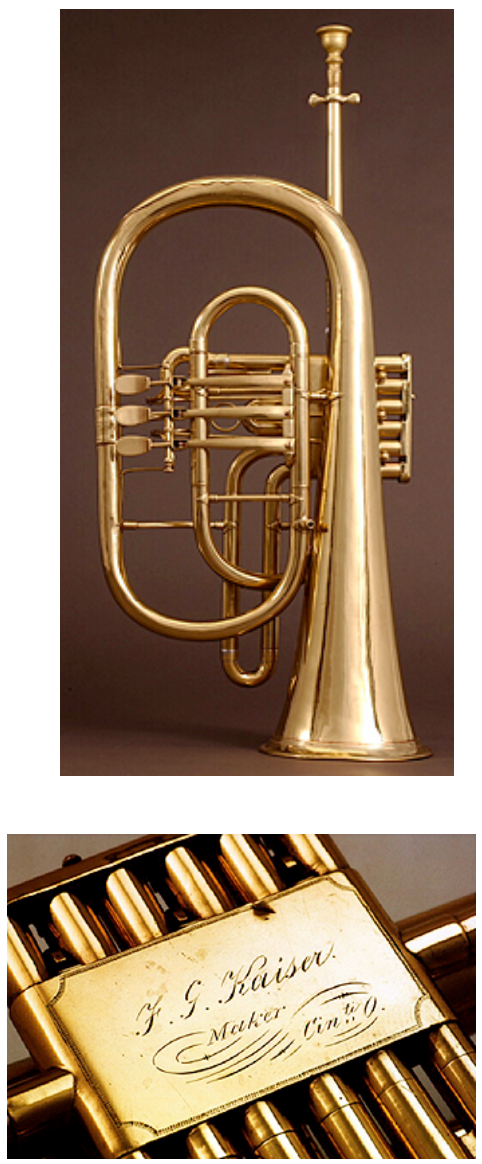

Fig. 1.28 Alto horn en F de Franz G. Kaiser, Cincinnati, Ohio, ca. 1858

Fuente: University of Dakota, Nacional Music Museum

Desarrollados durante la década de los 30 en el siglo XIX, la familia de los saxhorn fue patentada en parís en 1945. Al igual que los saxofones su diseño hace que puedan estar afinados tanto en Sib como en Mib. Durante la década de los 50 (1850) Sax continuó experimentando con los saxhorns con válvulas, llegando a ampliar la familia hasta diez modelos de diferentes tamaños.

Los saxhorn fueron popularizados por el distinguido Distin Quintet, que realizaron giras por toda Europa durante el S. XIX. Todo este movimiento tanto de los músicos, constructores de instrumentos o editoriales significó un fuerte empuje en Gran Bretaña donde acogieron estos instrumentos como suyos.

Los saxhorn fueron los instrumentos más comunes en las bandas militares de la guerra civil americana. Actualmente aunque estan en desuso muchos de ellos todavía existen composiciones originales para estos peculiares instrumentos, Desire Dondeyne's escribió en 1983 la obra "Tubissimo" para tuba baja o saxhorn y piano. 


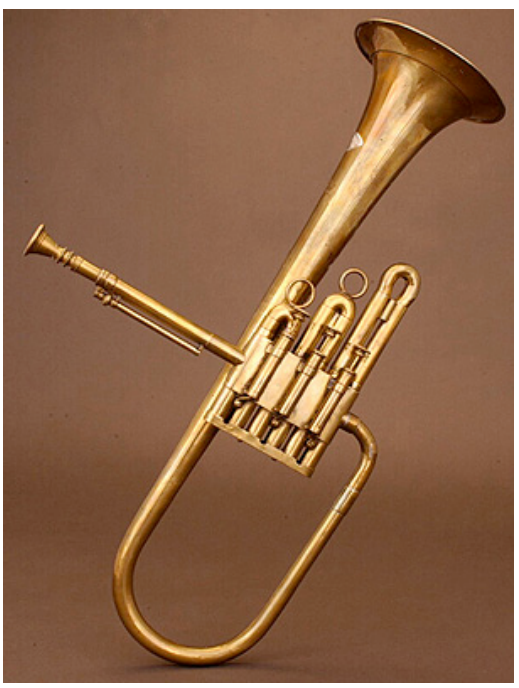

Fig. 1.29 Saxhorn soprano en Mib de Isaac Fiske,Worcester, Massachusetts, ca. 1850

Fuente: University of Dakota, Nacional Music Museum

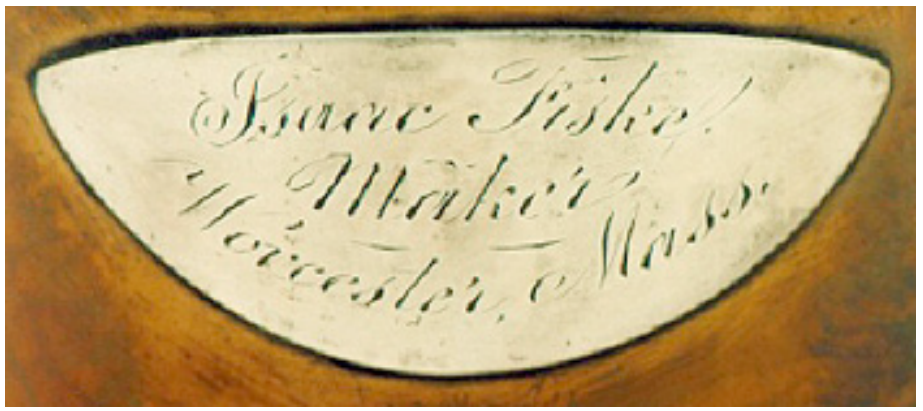

Fig. 1.30 Detalle de la marca en la campana

El bugle es un instrumento con un tubo acústico encorvado de metal, casi siempre de latón, de perforación cónica y de sección amplia, acabada en un pabellón. En el S. XVIII, aún como instrumento natural, fue usado por los cazadores y los militares para transmitir señales. La incorporación a principios del S. XIX de llaves y después de pistones, le permitieron hacer una escala cromática completa y actuar de solista en las primeras bandas de metales. Actualmente los utilizados en Gran Bretaña están afinados en sib y los del resto del continente europeo en do. En Estados Unidos el bugle de origen británico es conocido como cavalry bugle, siendo el bugle ordinario un instrumento con un pistón, parecido (en cuanto a su forma se refiere) a la trompeta. 


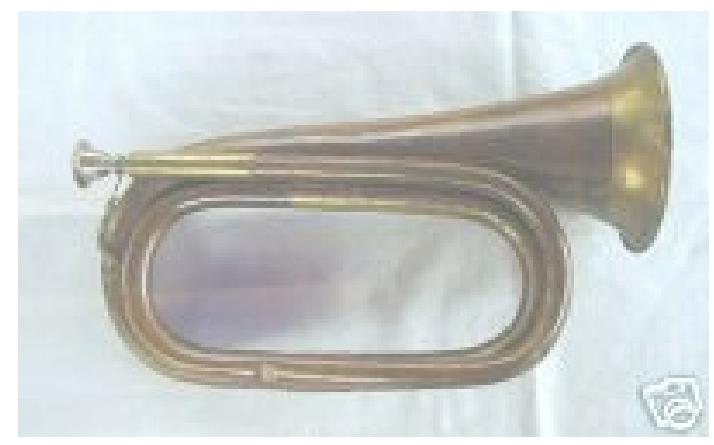

Fig. 1.31 Bugle

El bugle de llaves es un instrumento de viento-metal de amplio tubo cónico, con orificios controlados por llaves similares a las de los instrumentos de viento-madera. Se invento en 1810.

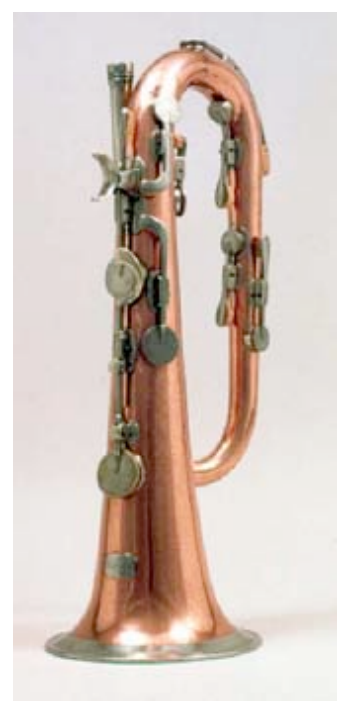

Fig. 1.32 Bugle de llaves Richard Willis England ca. 1920 Fuente: University of Dakota, Nacional Music Museum

Este bugle de nueve llaves fue uno de los primeros instrumentos utilizados, de esta clase, en los Estados Unidos de América, fue construido por Richard Willis (ca. 1795-1830) y su hijo Richard S. Willis. Richard Willis padre fue el primer profesor de música a tiempo completo, bandmaster y compositor de la Academia Militar de West Point, New York, en los Estados Unidos de América. Fue el primer solista de bugle de llaves en América alrededor de 1816. 
Muchos constructores probaron fortuna a la hora de fabricar bugles de llaves, la marca Metzler \& Co. realizó su primer bugle en 1833, a partir de 1839 cambió los bugles por otros instrumentos de viento y percusión. Adolphe Sax, famoso por inventar el saxofón, construyó un bugle de llaves, de los pocos que se conservan en Bélgica, en la ciudad belga de Menin, al sur de Brujas. George W. Shaw de Thompson, Connecticut, fue reconocido por la patente de un bugle de llaves en agosto de 1845. De acuerdo con esta patente, el material con que estaba construido permitía la elaboración de un producto extremadamente ligero en cuanto al peso se refiere, sin perder la calidad de sonido. Este instrumento estaba construido en cinco partes y no en dos como era habitual. Shaw exhibió su tortoise-shell bugle en Philadelphia (1846 y 1848) y en New York (1853). Elbridge G. Wright construyó en 1854 en Boston trece bugles de llaves de los cuales solo se conservan dos.

La marca Klemm \& Brother, que se estableció en Philadelphia en 1819, importaba bugles en sib y en do de una tienda de Neurkirchen (Markneukirchen) George \& August Klemm. A partir de mediados del S. XIX comenzaron a fabricarlos en Philadelphia especialmente desde la llegada a la empresa de un trabajador llamado William F. Seefeld, quien posteriormente abrió su propia tienda. De esta manera, los bugles eran construidos y vendidos indistintamente en las dos tiendas, Markneukirchen o Philadelphia.

El flugelhorn es un instrumento de metal con válvulas afinado en Sib, con la misma extensión que el fliscorno. Su tubo es cónico, con amplio pabellón y tamaño similar al del bugle de llaves. Es un instrumento presente en la mayoría de las bandas del continente europeo pero es raro en las británicas y norteamericanas.

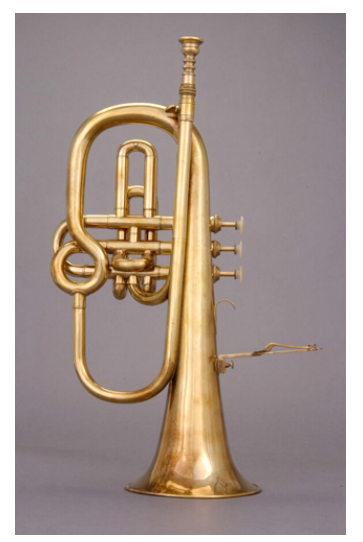

Fig. 1.33 Flugelhorn en Sib de louis Müller, Lyon, ca. 1840 Fuente: University of Dakota, Nacional Music Museum

El cornopean es un instrumento híbrido entre la trompeta y la corneta, tuvo cierta aceptación a mediados del S. XIX. Compartió lugar con los bugles de 
llaves pero su precisión era mayor al ir dotado del mecanismo de válvulas de Stölzel.

Los cornopean fabricados en Francia tenían dos pistones mientras que los fabricados en Inglaterra tenían tres. En Francia Guichard junto con Halary y Marcel Auguste Raoux constituían el estilo francés mientras que Richard Garret y Metzler \& Co. el estilo inglés.
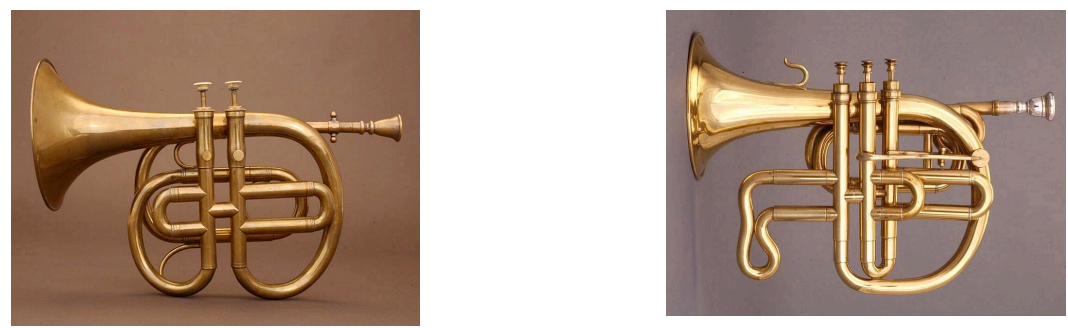

Fig. 1.34 Cornopean de Guichard y Halary\& Co. Fig. 1.35 Cornopean de Metzler Fuente: University of Dakota, Nacional Music Museum

La trompeta bastarda o trompeta española, era utilizada para conciertos de palacio y solemnidades públicas. Su sonoridad estaba entre la trompeta de sonido grave y el "clarino", de sonido agudo, por ello fue llamada bastarda. En los órganos de la península ibérica se incluían algunos registros que eran conocidos como trompetas o trompetería, los más habituales en España son los tubos horizontales que sobresalen por encima de la cabeza del interprete, en el resto de Europa algunos de los tubos (verticales) eran conocidos con nombres de trompetas, trompeta bastarda, trompeta de batalla, trompeta real, trompeta recordata, bass trumpet o cornopean. Estas "trompetas" las podemos ver actualmente en iglesias y catedrales de todo el mundo.

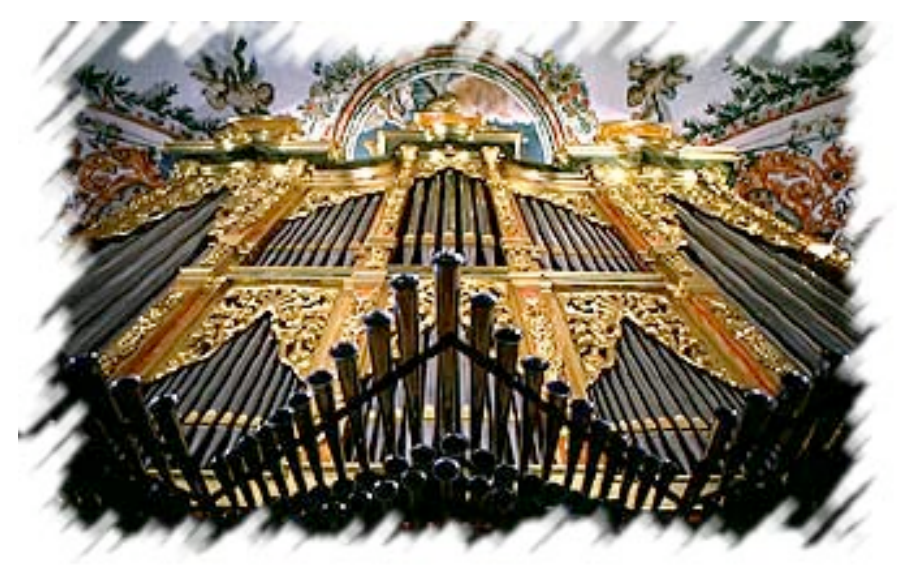

Fig. 1.36 Organo de la Iglesia de los Venerables de Sevilla 


\subsection{De la trompeta natural a la cromática}

A la trompeta natural se le aplican tonillos o piezas de recambio, llaves como a los instrumentos de madera y múltiples artificios que desembocan en los actuales pistones. Las piezas de recambio o tonillos se utilizaron hasta mediados del siglo XIX, su uso consistía en cambiarlos en función de la tonalidad. Sin duda, el tener que cambiarlos manualmente hacía que los cambios fuesen muy lentos y esto constituía un serio inconveniente.

Hacia 1750 Anton J. Hampel (1711-1771), cuernista de Dresde, observó que introduciendo la mano en el pabellón el sonido bajaba hasta un tono la nota emitida. Esta propiedad fue incorporada posteriormente (en 1777) de manera mecánica por los fabricantes M. Vöggel de Kalsruhe y J. Stein fabricante de Augsburg respectivamente. Construyeron varios modelos dando diferentes formas al pabellón que permitían llegar más fácil con la mano y mejorar la técnica anterior, este instrumento fue bautizado como "inventiontrompete".

La primera trompeta de llaves se construyó en Dresde alrededor de 1770. En los primeros prototipos el timbre característico de la trompeta desaparecía casi por completo; tras experimentar varios constructores con ella, fue Anton Weidinger (constructor y virtuoso de la trompeta) quien consiguió mayores logros con una de 3 llaves. Aunque estas trompetas tenían habitualmente 5 llaves, se han conservado algunos modelos con 4 o 6 . Tuvo aceptación en la década de $1790 \mathrm{y}$ comienzos del S. XIX como instrumento solista.

Hubo otros intentos por parte de Ferdinand Kölbel y Ernest Kellner, entre otros, de dotar a la trompeta de agujeros y llaves mediante los cuales se podían obtener todas las notas de la escala cromática sin embargo, fue Anton Weidinger (1767-1852), gran virtuoso de la trompeta de llaves, quien construye una trompeta con al menos tres llaves con el fin de poder elevar los parciales un semitono, un tono y un tono y medio. Franz Joseph Haydn (1732-1809) amigo de Weidinger escribe para éste y su trompeta de llaves en 1796, su célebre concierto para trompeta en Mi bemol Mayor, el cual todavía hoy es uno de los referentes del repertorio de los solistas de trompeta.

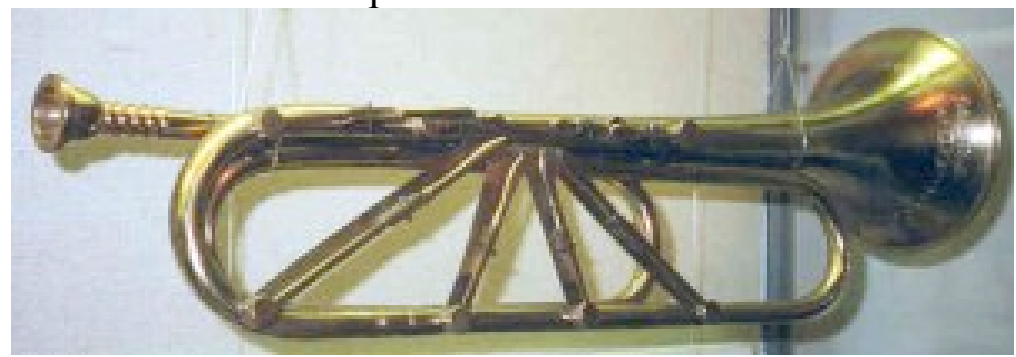

Fig. 1.37 Trompeta de llaves

Fuente: E. Mende (1978) 
En los tres años siguientes otros dos compositores, Leopold Kozeluch y Joseph Weigl, escribieron sendas obras para Weidinger. En Diciembre de 1802 presenta su trompeta de llaves en Leipzig incluyendo estas obras, las críticas fueron entusiastas por la evolución del instrumento.

Un poco más tarde Johann Nepomuk Hummel (1778-1837) escribió para Weidinger el otro gran concierto del repertorio clásico, su concierto en Mi mayor. Para ello Weidinger construyó otra trompeta de llaves pero ésta afinada en mi, esta nueva trompeta no tuvo el éxito de la anterior y el concierto, que fue estrenado el día de año nuevo de 1804, tuvo que interpretarse medio tono bajo (en Mib Mayor) para poder utilizar la misma trompeta que habia utilizado en el concierto de Franz Joseph Haydn. Weidinger tuvo que añadir una cuarta llave que resultaba indispensable para el registro grave que exigía el nuevo concierto.

Del trombón de varas surge la trompeta de varas. El primer ejemplar de esta trompeta se remonta hasta mediados del s. XVII, donde todo el cuerpo se deslizaba hacia delante y hacia atrás sobre un tubo sencillo que llevaba la boquilla.

A finales del S. XVIII se inventó en Inglaterra una trompeta de varas. Tenia una vara corta que se corría hacia detrás bajo el mentón del trompetista y que retornaba a su posición normal por la acción de un resorte.

Durante el S. XIX en Inglaterra se populariza la trompeta de varas o de corredera cuya invención se le atribuye a John Hyde y llevada a la práctica por un constructor llamado Woodham.

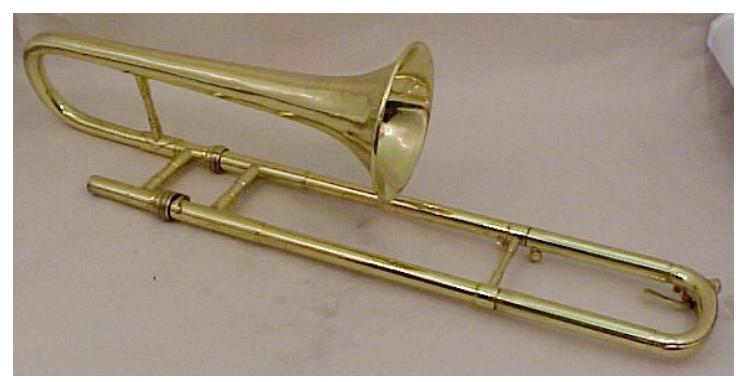

Fig. 1.38 Trompeta de varas, C. G. Conn. 1921

Uno de los máximos defensores de la trompeta de varas fue Thomas Harper padre (1786-1853) y su hijo, también llamado Thomas Harper (18161898). Harper padre sucedió a Hyde en las principales orquestas de Londres y en festivales de toda Inglaterra y éste fue sucedido por su hijo Thomas Jr. que no se retiró hasta 1885. Harper padre fue fiel a la trompeta de varas, la perfeccionó en 1833 con la colaboración de un fabricante londinense (Köhler) y publicó hacia 1835 un célebre método para trompeta de varas. En Francia, Adolph Sax contruye 
una trompeta de varas según los principios ingleses y François Georges Auguste Dauverné (1799-1874), maestro de Jean Baptiste Arban (1825-1889), realizó un perfeccionamiento del modelo Hyde colocando la vara abajo y delante, de manera que se pudiera manejar como la de un trombón.

La trumpet flat era una trompeta afinada en do que poseía una doble vara con varias posiciones. Con ella podía tocarse en tonalidad menor. Fue utilizada por Purcell (1659-1695) en su composición fúnebre para la Reina Maria (1694).

La corneta fue construida en Alemania hacia 1825. En sus inicios solo permitía toques muy rudimentarios, pero los pistones hicieron inmediatamente de ella un instrumento de una ligereza melódica y de una facilidad de ejecución sin precedentes que aseguraron su éxito. Los modelos actuales derivan principalmente de los tipos creados por Hallary y otros constructores en París.

Gustave Auguste Besson (1820-75) fundó, primero en París (1838) y luego en Londres (1851), unas factorías de instrumentos musicales. En 1856 inventa el sistema de prototipos que permite por primera vez estandarizar todos los elementos que constituyen un instrumento. Una de las mejoras más importantes de esta firma es la perforación recta en el año 1854 y, en 1855 la calibración en una pieza y un "prototipo" de sistema de mandriles que aseguraba la duplicación exacta de los instrumentos. En el año 1885 aparece en catálogo la primera trompeta piccolo en sol, una trompeta baja en do, (para obras de Wagner) y la trompeta en sib de tubo largo (la primera trompeta moderna en sib).

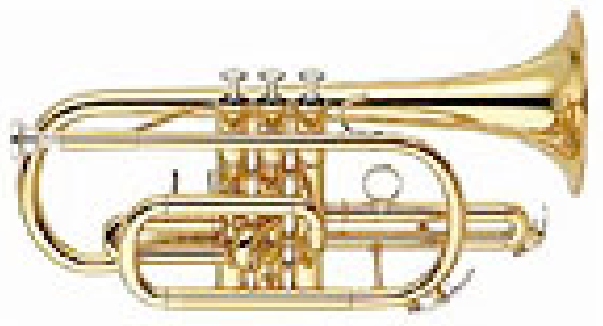

Fig. 1.39 Corneta

Con la invención del pistón, hacia 1815, el arte de la trompeta sufre una transformación radical, el sistema de pistones combinaba las ventajas de los sistemas anteriores sin presentar sus inconvenientes. Los problemas de la inventiontrompete y de la trompeta de llaves eran la desigualdad en la sonoridad. En la inventiontrompete, existian diferencias en el timbre entre los sonidos abiertos y los cerrados (bouché) y en la trompeta de llaves entre las notas al aire y las que se obtenían utilizando las llaves. En la trompeta de pistones (Fig.1.40) se eliminan estos problemas, es una trompeta totalmente cromática y su sonoridad es siempre uniforme. 
Durante el S. XIX se publicaron varios métodos para la corneta que todavía hoy son utilizados en los conservatorios como parte de la bibliografía y que son esenciales en la educación musical histórica y técnica de los trompetistas como el Méthode pour la trompette (1857) de F. G. A. Dauverné, Méthode complètte pour la trompette d'hamonie (c. 1836) de Kresser, Metodo d'instruzione per tromba a machina (1853) de Raniero Cacciamani (1818-1885) o el Método completo de corneta y saxhorn de Jean Baptiste Arban (1825-1889)

Actualmente las trompetas más utilizadas para el repertorio orquestal, jazzístico y popular suelen ser la trompeta en sib y la trompeta en do. La primera mide 1'475 metros y la segunda 1'314 metros.

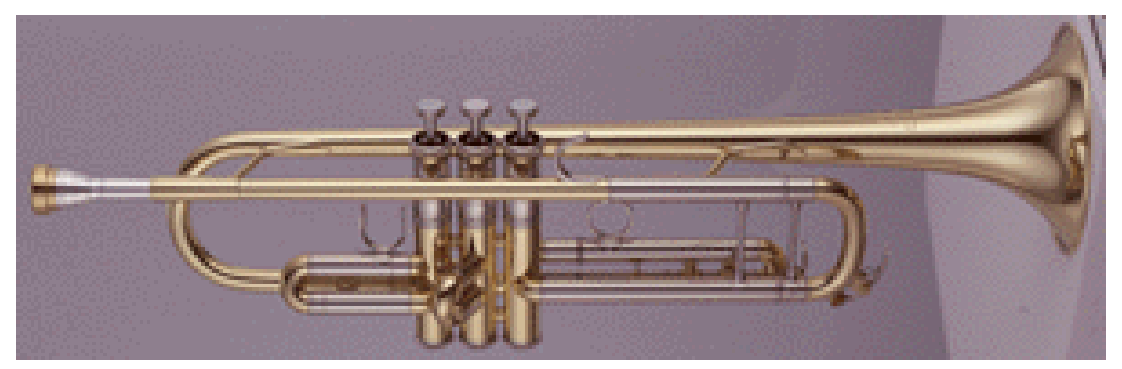

Fig.1.40 Trompeta moderna

En la trompeta de llaves al accionar el mecanismo se recorta la longitud del tubo, en la trompeta de pistones (como en la de varas), es al contrario, se aumenta la longitud del tubo. Además, el pistón cuenta con una ventaja respecto a la trompeta de varas, al accionarse (véase Fig. 1.41 y 1.42) siempre suena igual, mientras que al mover la vara con la mano ésta no siempre se situa en el mismo lugar.

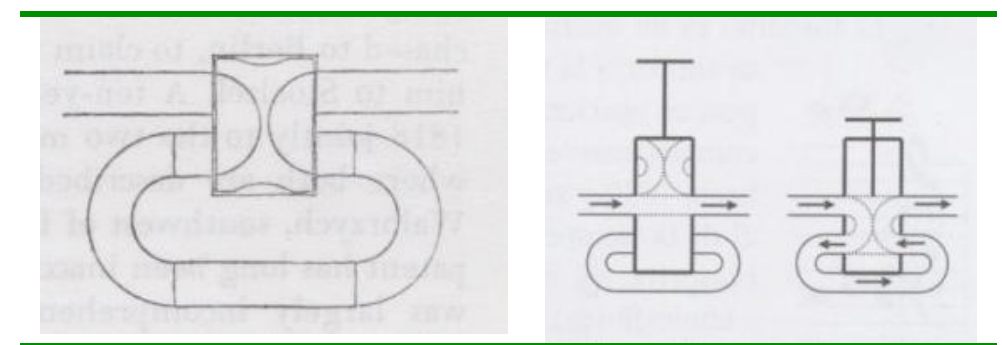

Fig. 1.41 Cilindro

Fig. 1.42 Pistón

Fuente: A. Carse (2002)

Junto a los pistones encontramos unos tubos adicionales por los que pasa el aire al accionar el pistón y que alargan el tubo. En la trompeta moderna el segundo pistón baja la afinación medio tono, el primer pistón un tono y el tercero tono y medio, además la combinación de estos hace posible la ejecución de la escala cromática. 
Al igual que las trompetas naturales de la época, las trompetas de pistones fueron construidas en fa con tonos de recambio que permitían tocar en mi, mi bemol, re, do, si, si bemol y a veces en la grave.

A la técnica tradicional (picado, ligado, seguridad en el ataque, etc.) se añade ahora un nuevo elemento que es esencial, la habilidad digital. Los trompetistas del barroco debían coordinar lengua y labios mientras que ahora estas habilidades se combinan con el movimiento de los dedos de la mano derecha.

La novedad del sistema crea una viva oposición, sobre todo por parte de los trompetistas de cierta edad, que se oponen a cambiar su forma de tocar. Sin embargo, la trompeta de pistones se impone rápidamente en la música militar y muy poco a poco en la música sinfónica.

Fue en 1815 cuando el trompista Gottfried Heinrich Stölzel (1690-1749), toca en Berlín una trompa provista de pistones construida por Griessling \& Schlott aunque no fue hasta 1820 cuando Stölzel junto con Friedrich Blühmel sacan a la luz la primera trompeta de pistones. Poco después surgieron discrepancias entre ellos sobre la paternidad de la idea original, continuando cada uno su camino en solitario. Así Schuster, fabricante de Karlsruhe, construye para Blühmel un modelo nuevo que será conocido como pistones Schuster.

Muchas son las tentativas de proveer a la trompeta de mecanismos que le permitieran emitir todos los sonidos de la escala cromática, uno de los que permanecieron en el tiempo fue el que Joseph Riedl presentó en Viena en 1832. Inventó un mecanismo de cilindros giratorios (véase Fig. 1.41) que son conocidos como cilindros todavía hoy en muchos países. La otra tentativa que prosperó fue la del francés François Perinet que en 1839 creó un pistón redondo al que denominó pistón Perinet y que es el más utilizado hoy en día en todo el mundo.

Estos dos sistemas conviven en la actualidad, y aunque el pistón (Perinet) es el más utilizado en la mayoría de paises, lo cierto es que en algunos países centroeuropeos (Alemania y Austria, por ejemplo), el cilindro es mayoritario. Por esta razón es habitual interpretar la música de los compositores de esta zona con los instrumentos de cilindros y el resto con las de pistones, de esta manera Ludwig Van Beethoven (1770-1827), Franz Joseph Haydn (1732-1809) y Wolfgang Amadeus Mozart (1756-1791) son muchas veces interpretados con cilindros y la música de Manuel de Falla (1876-1946), Igor Stravinsky (1882-1971), Béla Bartók (1881-1945), Giuseppe Verdi (1813-1901) o Luciano Berio (nacido en 1925), entre otros, se utilizan instrumentos de pistones.

La adición de los pistones permite a la trompeta además de producir toda la serie de parciales de su nota fundamental transportar ésta, de forma que suena 
toda la escala cromática. Al accionar los pistones la afinación baja un tono, medio tono o un tono y medio dependiendo de si accionamos el primero, el segundo o el tercer pistón respectivamente. Además podemos obtener el resto de notas mediante la combinación de todos los pistones.

Las primeras trompetas de pistones que se utilizaron en la orquesta estaban afinadas en fa, una cuarta más alta que la trompeta natural en do.

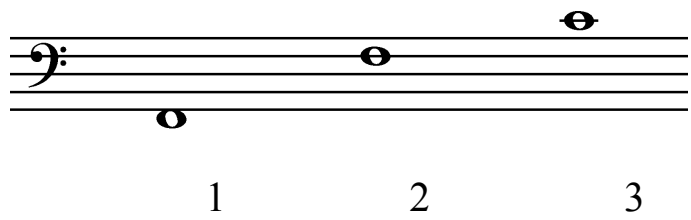

Richard Wagner (1813-1883), Anton Bruckner (1824-1896), Gustav Mahler (1860-1911) y Richard Strauss (1864-1949) escribieron la mayor parte de sus partituras para la trompeta de pistones en fa. A partir de la segunda mitad del siglo XIX empieza a tomar importancia la corneta en si bemol y poco después la trompeta en si bemol. De la misma manera se empieza a utilizar poco después la trompeta en do. Estos instrumentos tienen la mitad de longitud de sus equivalentes trompetas naturales barrocas, su fundamental se encuentra una octava más alta.

Trompeta Natural

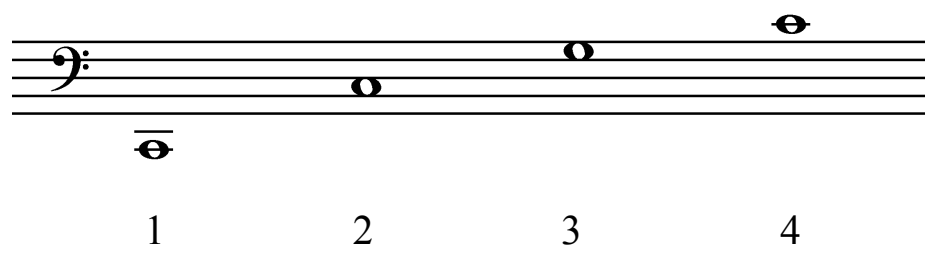

Trompeta de pistones

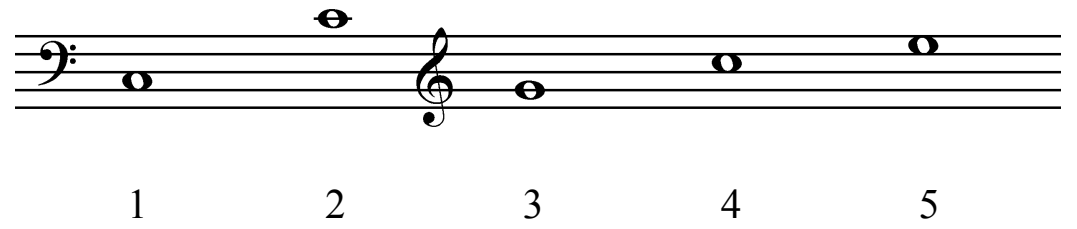

Serie armónica de una trompeta en do

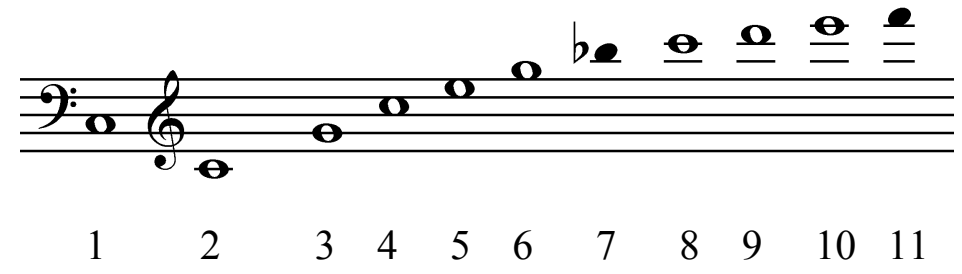


La trompeta en si bemol tendría la misma serie armónica pero sonaría un tono más baja.

La serie de parciales siguiente corresponde a una trompeta en do desde su nota fundamental, además, podemos observar los armónicos resultantes con las siete combinaciones mediante las cuales se obtienen todos los sonidos que componen la escala cromática.

Primera posición, al aire sin pisar ningún pistón

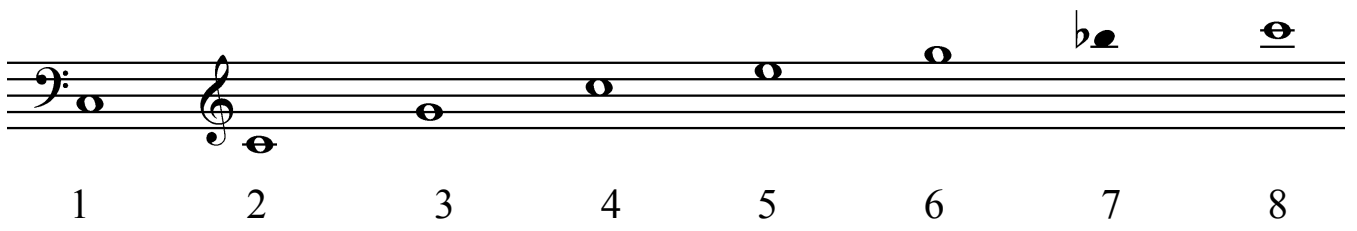

Segunda posición, pisando el segundo pistón

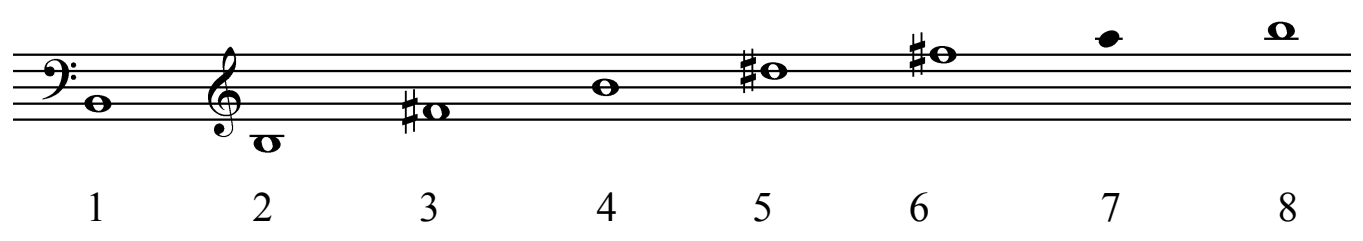

Tercera posición, pisando el primer pistón

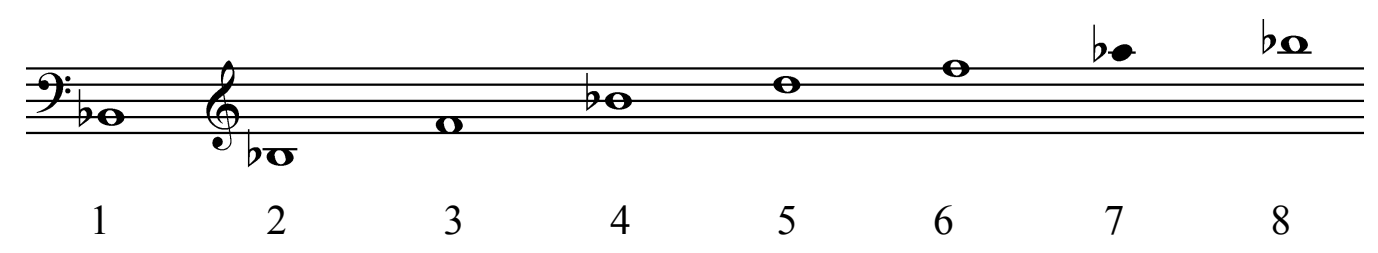

Cuarta posición, pisando el primer y el segundo pistón simultáneamente

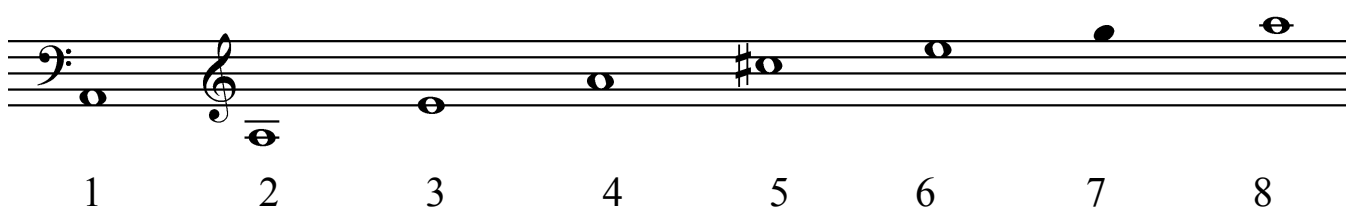

Quinta posición, pisando el segundo y el tercer pistón simultáneamente

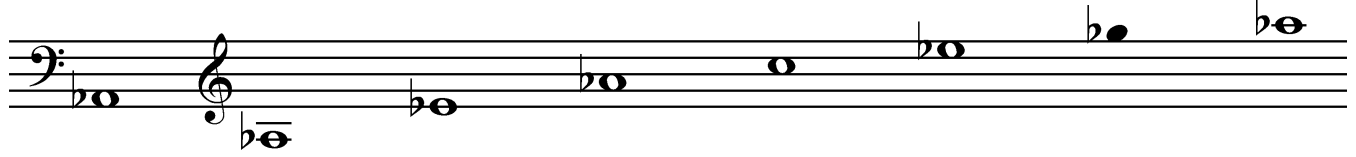




\begin{tabular}{cccccccc}
\hline 1 & 2 & 3 & 4 & 5 & 6 & 7 & 8
\end{tabular}

Sexta posicion, pisando el primer y el tercer pistón simultaneamente

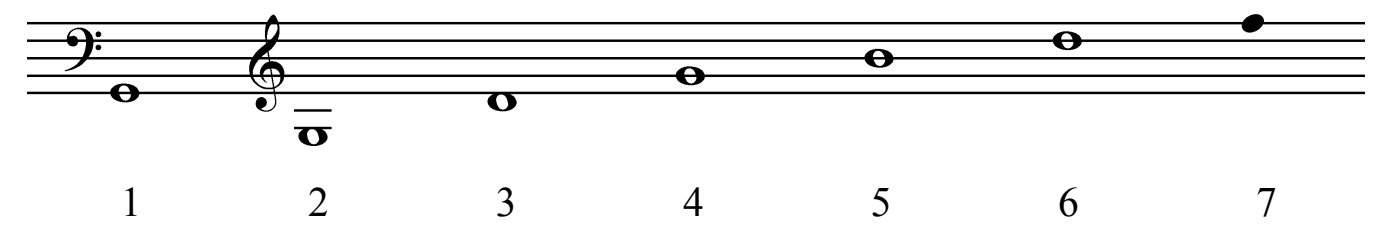

Séptima posición pisando los tres pistones simultáneamente

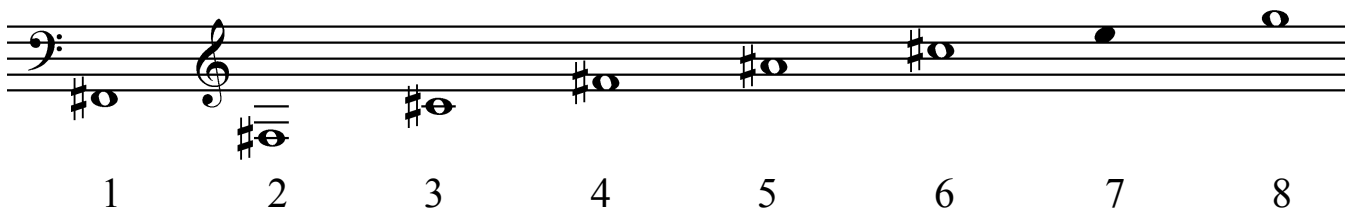

Al mismo tiempo que los pistones aparecieron las válvulas de los pistones, y de forma gradual se fueron añadiendo otros accesorios, como la válvula de afinación o bomba general, la llave para expulsar el agua (inventada hacia 1850) o las anillas para sujetar la trompeta y mover las válvulas de los pistones.

\subsection{La boquilla}

La trompeta es un instrumento que pertenece a la familia de viento-metal; es la más pequeña de toda la familia (fliscorno, trompa, trombón, bombardino y tuba) y se divide, básicamente, en dos piezas: boquilla y trompeta.

La boquilla esta formada por: borde, vaciado, granillo y cola. Esta pieza esta en contacto con los labios del trompetista por el borde y con la trompeta por la cola.

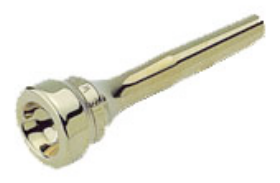

Fig. 1.43 boquilla

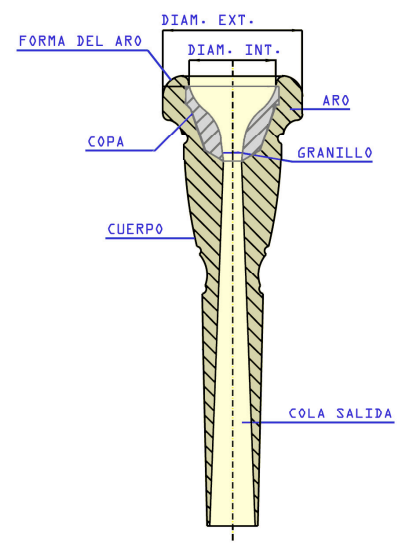

Fig. 1.44 Estructura de una boquilla 
La trompeta consta de: tudel, bomba general, pistones, bombas de los respectivos pistones, codo, pabellón o campana, anillas y desagüe.

- El tudel es el tubo principal de la trompeta, en un extremo del cual se coloca la boquilla y el otro extremo enlaza con la bomba general.

- La bomba general enlaza en un extremo con el tudel y por el otro entra en la cavidad del tercer pistón.

- Los pistones los nombraremos siempre mirando la trompeta desde la boquilla hacia el pabellón o campana, siendo entonces: 1 er pistón, $2^{\circ}$ pistón y 3er pistón.

- Los pistones están colocados dentro de unas cavidades que se conectan entre sí por medio de unas bombas a las que llamaremos (según el pistón a la que estén conectadas): bomba del ler pistón, bomba del $2^{\circ}$ pistón y bomba del 3er pistón.

- El tubo principal sale de la cavidad del 1er pistón y realiza una curvatura que se llama codo de la trompeta.

- Finalmente el tubo principal se ensancha progresivamente y termina en lo que llamaremos pabellón o campana.

Las partes que se llaman anillas y desagüe sirven:

- La anilla del tudel está colocada sobre el tudel, casi a la altura del 3er pistón y sirve para sujetar el instrumento.

- La anilla de la bomba del 3er pistón sirve para corregir la afinación de las notas que por la naturaleza del instrumento o por nuestra ejecución están desafinadas, sin parar por ello, la interpretación musical.

- La anilla de la bomba del 1er pistón realiza la misma función que la anterior.

- El desagüe sirve para extraer la saliva del instrumento, esta colocada en la parte inferior de la bomba general. Algunas trompetas tienen otro desagüe en la parte inferior de la bomba del 3er pistón.

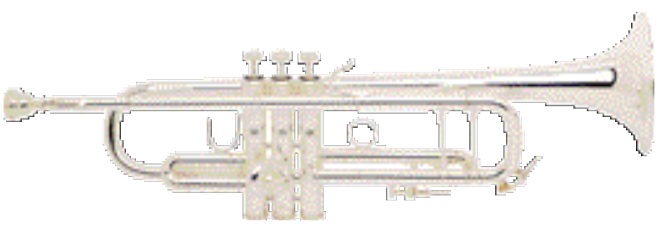

Fig. 1.45 Trompeta en sib

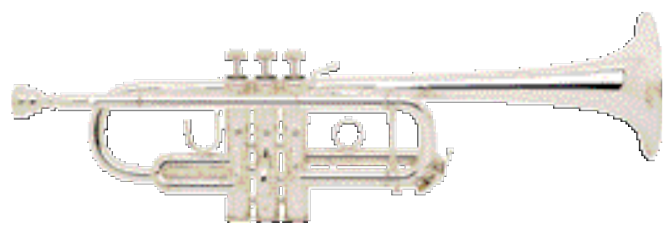

Fig. 1.46 Trompeta en do

\subsection{Diferentes modelos actuales}


La trompeta en Mib/Re se emplea con mayor asiduidad para interpretar las obras del repertorio Clásico. Sus medidas son: 1'105 metros la trompeta en mi bemol y 1'171 metros la trompeta en re.

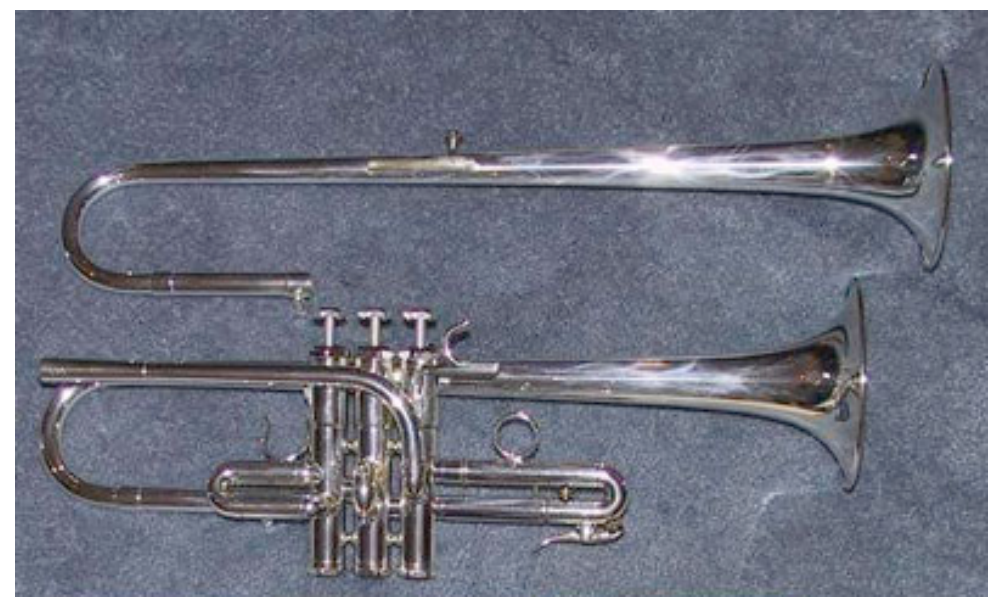

Fig. 1.47 Trompeta en mib y campana de re

Fuente: Elaboración propia

La trompeta en sib/la agudo o piccolo se suele utilizar principalmente en la música Barroca, no obstante compositores actuales como Julien François Zbinden o Iván Jevtic realizan magníficas páginas musicales para esta pequeña trompeta. Su longitud es de 0'737 metros.

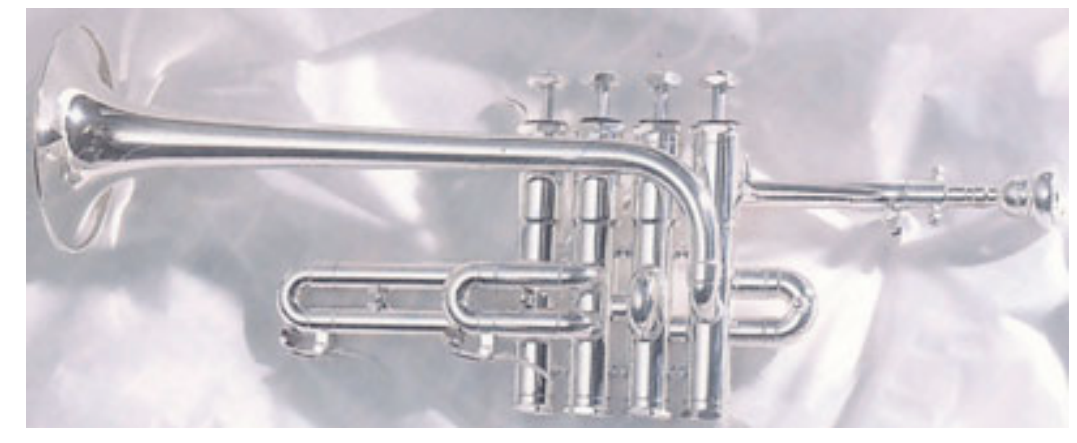

Fig. 1.48 Piccolo en sib/la agudo Fuente: Elaboración propia 


\section{5 Evolución del repertorio para trompeta}

Al introducirse la trompeta en la orquesta, su papel fue de mero acompañante, se situaba al lado de los timbales realizando la función de soporte armónico (dominante y tónica) el cual podría ser realizado con cualquiera de las trompetas naturales existentes.

\section{Bcelhowen: Simjonja 6}

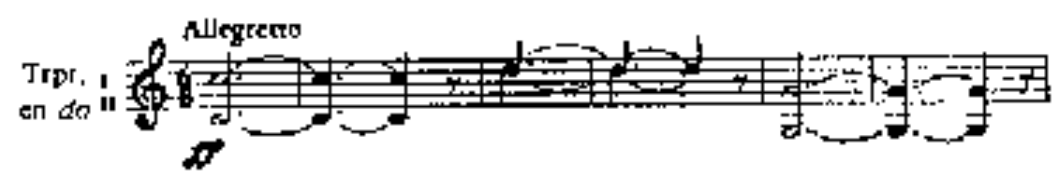

Fig. 1.49 Sinfonia No 6 L. V. Beethoven

Fuente: L. Andrés y V. Alberola (2008)

Un caso muy diferente ocurre en Leonora II y Leonora III de L. V. Beethoven, donde la trompeta aparece a modo de fanfarria anunciando la entrada del emperador, en este momento pierde el papel de acompañante y retoma el de protagonista.

Las notas largas a distancia de octava, los pasajes rítmicos y los floreos simples y dobles con una o dos notas, son típicas de las partes para trompeta. De la misma manera se escriben frases a solo de corta duración o temas construidos sobre la serie armónica, para que las trompetas pudiesen tocar parte de la melodía a tutti.

Inetjioven: Sinfaria 5

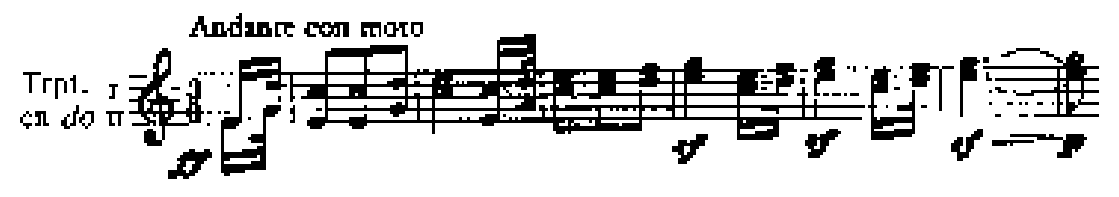

Fig. 1.50 Sinfonia $\mathrm{N}^{\mathrm{o}} 5 \mathrm{~L}$. V. Beethoven

Fuente: L. Andrés y V. Alberola (2008) 
Como observamos en el siguiente ejemplo, las trompetas no solamente tenían pasajes fuertes.

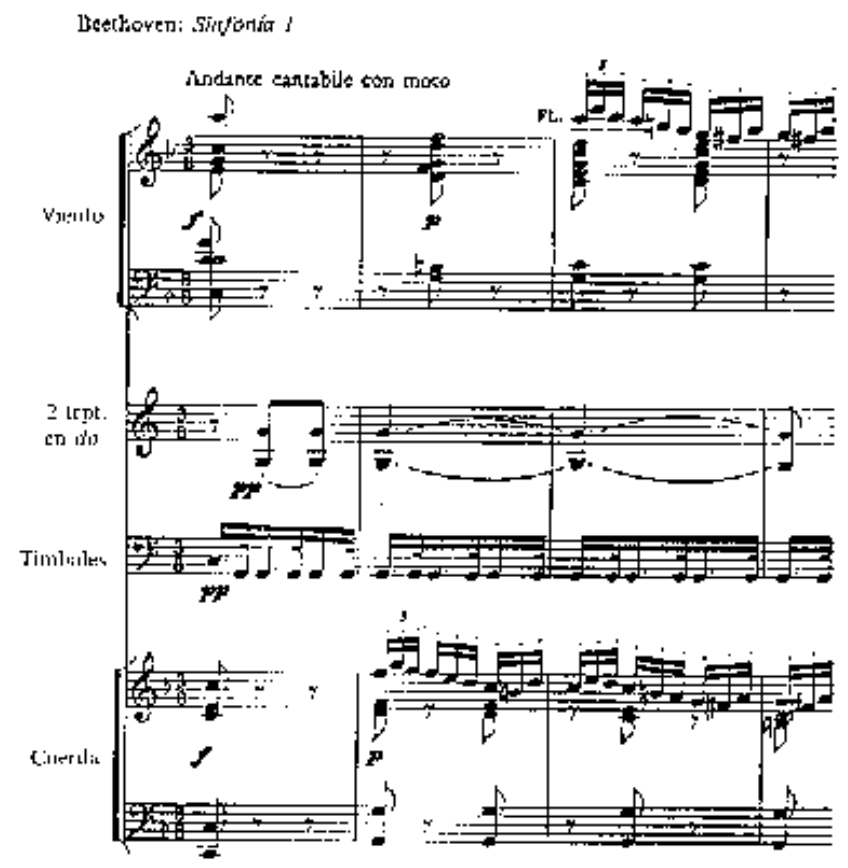

Fig. 1.51 Sinfonia $\mathrm{N}^{\mathrm{o}} 1 \mathrm{~L}$. V. Beethoven

Fuente: L. Andrés y V. Alberola (2008)

Beethoven trata a este instrumento como en la época Barroca y a excepción de esto, no aporta ningún avance en la evolución de este instrumento. W. A. Mozart utiliza la trompeta igual que Beethoven.

La forma sonata sustituirá la base estructural de casi toda música instrumental de este periodo, llevándola al concierto, a la literatura solista y a muchas piezas de cámara.

Todas estas formas no están estructuradas sobre la sonata antigua o suite, sino sobre el nuevo tipo sonata. Esto es fácilmente observable en los conciertos para trompeta de Franz Joseph Haydn y Johann Nepomuk Hummel:

\section{Allegro-Andante-Allegro}

Los conciertos realizados por Haydn y Hummel pueden ser denominados como concierto solista, donde éste tiene mayor relevancia que la orquesta. El concierto para solista es una forma sonata con doble introducción donde el solista 
resalta sus cualidades técnicas y musicales. Es fundamental que se establezca un diálogo entre el solista y la orquesta, alternando la presentación de temas y frases que configuran la obra. El primer tiempo del concierto suele terminar en esta época con una fermata por parte del instrumento solista que el intérprete improvisaba ya que el compositor no la escribia.

Los ejemplos más antiguos de este tipo de conciertos (llamado en el Barroco concerto grosso) los hallamos en las llamadas Sinfonie a piu Instrumenti de Alessandro Stradella (1642-82), seguidos por los concerti grossi de Arcangelo Corelli (1653-1713). Corelli usó en sus obras de este tipo una estructura en cinco movimientos, esquema modificado por Francesco Geminiani (1687-1762), quien adoptó la estructura en cuatro movimientos propia de la sonata de iglesia. Finalmente, Antonio Vivaldi adoptaría el esquema en tres movimientos: allegro-adagio-allegro, que fue el que finalmente acabó prevaleciendo en los conciertos propiamente dichos.

En el periodo clásico se intentaba buscar una sonoridad sutil, alegre y muy atractiva. Se trataba de tocar con gusto y de forma matizada.

Podemos destacar el comentario que realizó Leopold Mozart sobre el trompetista Michael Rosenberger (Hoftrompeter de Salzburgo):

Es un trompetista excelente y de gran reputación, sobre todo en el registro agudo, a causa de su rara pureza en el sonido, la velocidad en los rasgos y la calidad de su trinado.

La trompeta tuvo una función muy diferente en la época clásica. Después de haber sido uno de los instrumentos preferidos por los compositores en el periodo barroco, ahora se fundía con la orquesta en el tutti.

Solo en ocasiones una breve fanfarria (concluyendo un movimiento rápido o una sinfonía) recordaba el papel que la trompeta desempeñaba en las cortes, manteniendo su papel heroico únicamente para coronar un crescendo.

Los trompetistas tuvieron que adaptarse a la variedad de trompetas que aparecieron, cada una de ellas con diferentes fundamentales. De esta manera aparecen trompetas en $\mathrm{Fa}$ e incluso en Sol (con toda una serie de cuerpos de recambio) que permiten obtener otras tonalidades con mayor facilidad.

La técnica del clarino no se perdió en ésta época, puesto que compositores como Spenger compuso varios conciertos para trompeta aguda. J. Frohlich tambien siguió escribiendo para el registro clarino y en su Método para Trompeta llega a alcanzar los parciales 20 y 24. 
Sin embargo la técnica del clarino cae en desuso, la música para trompeta habia pasado de moda y el gusto musical de los oyentes evoluciona hacia otras sonoridades que producen los instrumentos modernos. Poco a poco los clarinistas iban siendo aislados. Las trompetas, conforme a la moda o espíritu clásico, eran utilizadas para reforzar el tutti y marcar el ritmo en todos los movimientos de la obras salvo en uno, donde la primera trompeta desarrolla una cantinela expresiva.

Uno de los problemas con que se encontraría Weidinger en el momento de ejecutar los conciertos de Franz Joseph Haydn y de Johann Nepomuk Hummel sería la diferencia de timbre y color en cada una de las notas al presionar las llaves. Ésta imperfección era causa de que el tubo de la trompeta se acortaba presionando las llaves y no como hoy en día, que el tubo se alarga cada vez que se presiona un pistón.

Un rasgo muy característico de las partes de trompeta del clasicismo son los grandes intervalos que encontramos en la segunda voz, como ocurre en la $7^{a}$ sinfonía (1er movimiento) de Ludwing van beethoven.

Félix Weingartner (1863-1942), célebre director de orquesta, creía descubrir en el estilo de Beethoven unos deseos de progreso todavía por venir, refiriéndose a las tentativas que se habían realizado para colocar pistones a la trompeta, y que Wagner, sin embargo, sí que quiso aprovechar.

Los pasajes con grandes saltos son muy característicos en las partes de trompeta en la obra de Beethoven. Éste uso extremadamente extraño de los parciales corresponde justamente y en muchas ocasiones, al carácter de Beethoven. Hans von Vulgo corrigió de ésta forma un pasaje para trompetas que se encuentra en la sinfonía heroica (1er movimiento, compases 655 a 663).

Es difícil precisar cuando los instrumentos de pistones fueron introducidos en Italia. Según Hector Berlioz, numerosas orquestas italianas utilizaban la trompeta de llaves hasta casi 1840. Existen partituras de trompeta cromática en la opera Italiana desde l'Elixir d'Amour (1832), y Lucrece Borgia (1833) de Gaetano Donizetti, o Beatrice de Tende (1834) de Vincenzo Bellini. Tal vez, las partes de trompeta cromática de Nabucco (1842) y de Lombards (1843) de Giuseppe Verdi, fueron todavía tocadas con trompeta de llaves.

Wagner y Bruckner rompieron con la típica tradición de los compositores de utilizar solamente dos trompetas en la orquesta y ampliaron éste número a tres, incluso Wagner, realizó composiciones donde reunía hasta doce trompetas en escena. Además, estos dos compositores exigieron a la trompeta otras cualidades como la amplitud del registro y la resistencia. 
Como organista, Bruckner parecía a menudo olvidar $\left(5^{a} y 7^{a}\right.$ sinfonías $)$ que los metales no son registros de órgano, por lo que compuso sin pensar si los intérpretes llegarían a resistir dignamente hasta el final de sus sinfonías. En lo concerniente al registro pide en su Te deum (1883-1884) y en su $8^{a}$ sinfonía

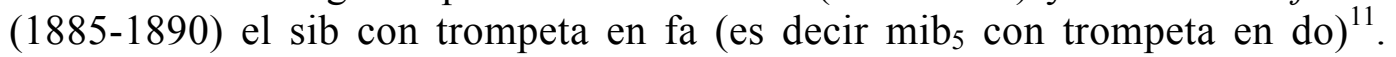
También fueron estos compositores los primeros en utilizar la trompeta para largas melodias y para ser tocadas con la dinámica piano $(p)$. Una melodia expuesta piano por la trompeta produce, sobre todo en el registro agudo, un efecto suave, vigoroso y concediéndole una nobleza y solemnidad que ningún otro instrumento podría alcanzar.

A las dificultades técnicas implicadas en las obras de Wagner y Bruckner, en referencia a la altura de los sonidos y de la expresión, se añadieron las que comportaba la transposición. Según Richard Strauss, el método Wagneriano de notación de las partes de trompeta, consistía en utilizar todos los acordes a fin de poder notar la parte de trompeta en Do Mayor. Si la transposición no es demasiado difícil en la música diatónica, se hace más embarazoso cuando se complican las alteraciones de la clave y cuando hay modulaciones. En la formación actual de los trompetistas se precisa de mucho tiempo para enseñar el principio de la transposición a partir de todos los acordes existentes y su estudio se hace imprescindible en cualquier conservatorio o escuela de música.

Héctor Berlioz, en el curso de su viaje a Alemania (1843) no desaprovechó la ocasión para señalar la superioridad de los trompetistas de orquesta alemanes, observación que también compartía Wagner. Parece ser que los trompetistas franceses de ésta época eran más virtuosos. Esto era debido a la pronunciada preferencia de estos músicos por la corneta, instrumento mucho más flexible y ágil que las trompetas existentes en ese periodo.

Como ya sabemos, Richard Strauss (1864-1949) esperaba mucho de los trompetistas de Orquesta y las exigencias de Gustav Mahler (1860-1911) no eran menores, salvo en el plano de la transposición, ya que este compositor se contentaba con trompetas en $\mathrm{si}^{\mathrm{b}}$ y fa. Desde entonces, tanto los compositores como los trompetistas de orquesta utilizan salvo excepciones las trompetas en $\mathrm{si}^{\mathrm{b}}$ $\mathrm{y}$ do.

Strauss y Mahler eran exigentes, pero lo fueron todavía más los compositores del Siglo XX. Es necesario citar al menos a los tres compositores mas significativos de la nueva escuela de Viena:

- Arnold Schoenberg (Viena, 13 de Noviembre de 1874 - Los Angeles, 13 de Julio de 1951).

\footnotetext{
${ }^{11}$ En ésta $8^{a}$ sinfonía pide dos trompetas $p p$ en el 1er movimiento de la $8^{a}$ sinfonía (1885), con un repique simple y repetido, mientras que el resto de la orquesta toca $f$. El compositor indicó que las trompetas estaban allí para anunciar la muerte.
} 
- Anton von Webern, alumno de Schoenberg (Nuremberg, 3 de Diciembre de 1883 - Nuremberg 1945).

- Alban Berg (Viena, 9 de Noviembre de 1885 - Viena, 24 de Diciembre de 1935)

En la nueva escuela de Viena se produjeron numerosos avances para la música (como se puede ver en el Capítulo 3), de la misma manera el uso que se le dio a la trompeta fue innovador. La trompeta es utilizada como elemento tímbrico y se explota este recurso con el uso de los registros extremos, agudo y grave, con dinámicas extremas, desde $p p$ hasta $f f$.

Contrariamente a numerosos instrumentistas de antes de la $2^{\mathrm{a}}$ Guerra Mundial, el trompetista de orquesta actual ya no puede contentarse con la trompeta en sib. No solamente las exigencias siempre mayores, sino también el redescubrimiento de las obras Barrocas para trompeta y los efectos especiales reclamados por la música desde Igor Stravinsky (1882-1971) implica que se construyan y utilicen trompetas en tonos todavía más elevados. Además de las mencionadas trompetas en sib y do nos encontramos con:

- la trompeta en Mib es habitualmente utilizada, tanto para el solista: Concierto en Mib Mayor de Franz Joseph Haydn (1732 -1809), Concierto en Mi Mayor de Johann Nepomuk Hummel (1778 -1837) y Concierto en Mib Mayor de Johann Baptist George Neruda (ca. 1707-1780), como para ciertos pasajes agudos y arriesgados en la orquesta.

- la trompeta sib/la agudo o trompeta piccolo, es muy utilizada en la orquesta para pasajes de gran dificultad y precisión por Igor Stravinsky en la Consagración de la Primavera (1913) y por Maurice Ravel (1875 -1937) en su Bolero. Además es utilizada en la actualidad como sustituto de la trompeta natural en fa y re barrocas.

La literatura para trompeta del S. XX se ve enriquecida constantemente por composiciones en las que podemos comprobar y constatar un proceso evolutivo estético y técnico.

Los intérpretes y constructores, aunaron esfuerzos para darle al instrumento la proyección artística de que goza en la actualidad y que hace de ésta uno de los más importantes instrumentos solistas en todo tipo de agrupaciones.

Hacia el año 1939 Paul Hindemith (1895 -1963) compositor alemán, compone una Sonata para trompeta de gran dificultad interpretativa por su peculiar estilo de escritura, donde coloca la trompeta en un primer plano muy brillante en todas sus proporciones sonoras, como demuestra claramente el último movimiento. Esta obra requiere una gran resistencia del intérprete. 
En 1947 Arthur Honegger (1892 -1955) compone Intrada para trompeta en do. Aunque su duración es corta (4 minutos) resulta una de las obras mas duras que se han escrito, contiene matices extremos desde fortísimo a pianisimo, utilizando un registro muy amplio.

Una de las obras más conocidas que los trompetistas actuales deben abordar es el Concierto para trompeta en do y orquesta (1946) de Henri Tomasi (1901-1971). Este concierto se ha convertido en la base del repertorio actual. La utilización de sordinas para modificar el timbre es una constante en toda la obra, empleando tanto la sordina straight como la cup. En el segundo tiempo se observan influencias del jazz con un pasaje en el que el autor anota en la partitura comme una improvisation. Tomasi también compuso Triptique para trompeta y piano y Variations gregorianes sur un salve regina para trompeta y organo.

André Jolivet (1905-1974) compone en 1948 su Concertino para trompeta y piano. Su preocupación era renovar y ampliar el lenguaje musical. Es uno de los primeros en utilizar el flatter y el glissando. Combina muy bien los efectos sonoros de la trompeta como demuestra en su Segundo concierto para trompeta (1954), donde realiza un empleo extraordinario de la sordina wa-wa, harmon y straight.

Alexander Arutunian (nacido en 1920) escribe en 1950 Concierto para trompeta en sib. Esta obra ha llegado a ser una de las composiciones más representativas y características del repertorio para trompeta del siglo XX. Hay que destacar la utilización de intervalos de segunda aumentada y de elementos procedentes de la música popular armenia. El concierto esta estructurado a modo de forma sonata con dos temas contrastantes. La cadencia final ha sido revisada y ampliada por Timofey Aleksandovich Dockshitzer (1921-2005), trompetista ucraniano para quien fue compuesto este concierto.

Otras obras de este época, pertenecientes junto a Tomasi y Jolivet al modernismo francés, las encontramos en los compositores Jean Hubeau (19171992) Sonata para Trompeta (1943), Alfred Desenclos (1912-1971) con su Incatation, Threne et Danse (1953) y Charles Chaynes con su Concierto para Trompeta y orquesta (1956).

De los compositores que han escrito para trompeta sola destacaremos a:

- Hans Werner Henze (nacido en 1926) autor de Sonatine para trompeta sola (1976), de gran dificultad técnica, de gran resistencia y dominio del doble y triple golpe de lengua.

- Ketil Hvoslef (nacido en 1939) autor de Tromba solo para trompeta en do (1990), el cual requiere un gran dominio en el picado simple y una gran resistencia. 
- Stanley Friedman autor de Solus (1975), obra en que se practican glissandos de medio tono por medio de las bombas del primer y tercer pistón, cuartos de tono, notas ejecutadas sin la bomba del segundo pistón, gritos...

- Frank Campo (New York, 1927) autor de Times (1983), obra dedicada a Thomas Stevens (trompeta solista de la Orquesta Filarmónica de Los Angeles desde 1972 hasta 1999),

- Robert Henderson (nacido en 1948) compuso en 1967 la obra Variations Movements, Henderson utiliza en el quinto movimiento de esta obra hasta tres pentagramas a la vez para una sola línea melódica, ver figura 1.59.

- Allen Vizzutti (nacido en 1952) autor de Cascades (1981) que contiene gran cantidad de intervalos de séptima, novena y décima.

De la misma manera en la obra de Pierre Boulez (nacido en 1925) Explosante fixe y Sequenza $X$ de Luciano Berio (1925-2003), la escritura vanguardista está presente de una manera muy clara. En Berio una flecha sobre una nota (fig. 1.52) nos indica que el trompetísta debe de tocar dentro del piano de cola. Boulez escribe una sucesión de notas (fig. 1.53) para indicar la aceleración progresiva y gradual de éstas, en lugar de anotar un acellerando. Berio busca un efecto sonoro combinando el movimiento de los pistones con diferentes clases de emisión (fig. 1.54), una nota con tremolo (VT), otra con flatter (FL) y finalmente la misma nota quiere que siga interpretándose con un doble picado muy rápido (DL), esto crea una sonoridad completamente indeterminada y provoca una aleatoriedad en el pasaje dependiendo de la ejecución del interprete.

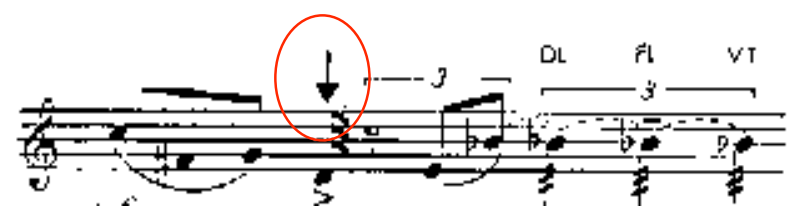

Fig. 1.52 Flecha

Fuente: L. Berio (1984), Sequenza X, Universal Edition, Milan.

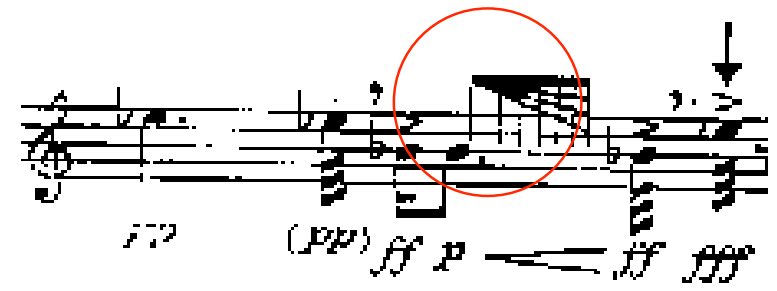

Fuente: L. Berio (1984), Sequenza X, Universal Edition, Milan. 


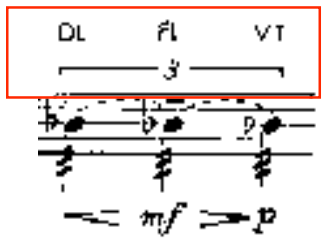

Fig. 1.54 tremolo

Fuente: L. Berio (1984), Sequenza X, Universal Edition, Milan.

Una de las características más usuales en la escritura contemporánea es la inclusión de las notas pedales en la música de concierto. Las notas pedales se encuentran fuera del registro de la trompeta moderna. Actualmente, debido a los grandes avances técnicos que se han producido durante el S. XX es posible realizar notas por debajo del registro más grave que permite la trompeta. Estas notas que surgieron como una ayuda para mejorar la embocadura o para relajarla en momentos de cansancio se han incluido en la música de concierto. Para ello no hay más que observar y analizar a Frank Campo en Times, donde apreciamos la primera octava de pedales, Stanley Friedman en Solus que llega a la segunda octava de pedales o Folke Rabe (nacido en 1935) en Shazam donde no sólo escribe hasta la triple octava de pedales sino que también lo hace en el extremo agudo completando de esta manera en el mismo concierto cinco octavas.

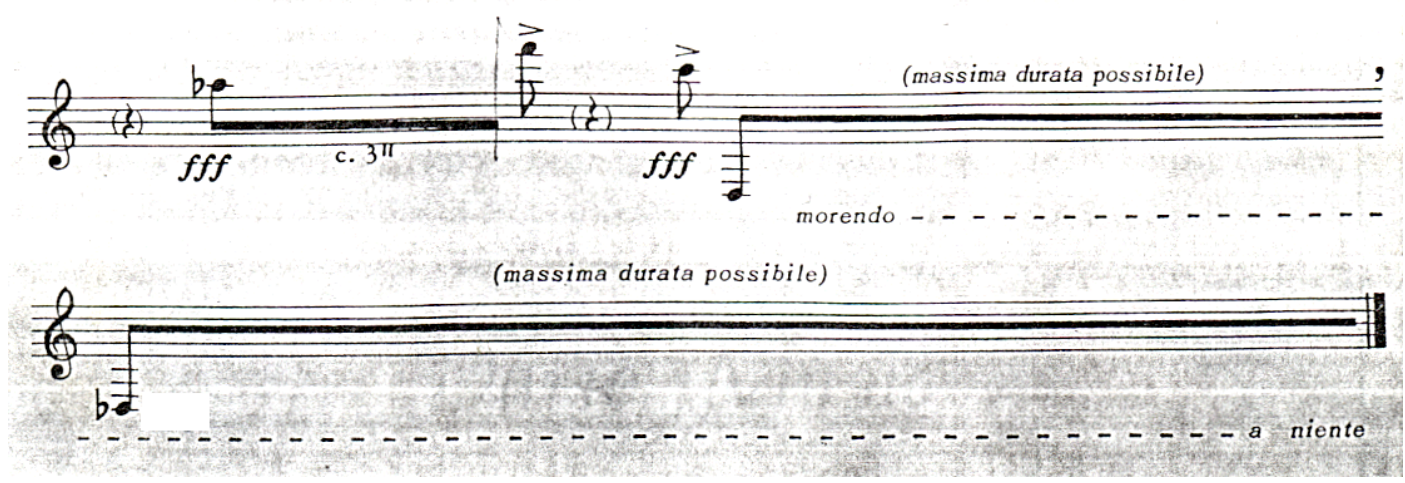

Fig. 1. 55 Fragmento con notas pedales

Fuente: F. Campo (1979), Times, Dario Music, New York.

Destacaremos notaciones sobre notas largas en segundos (Times de Campo), efectos sonoros (como Miles Davis con el Half Valve), bajando a medias los pistones o tapando el pabellón con un sombrero (hat) que utiliza Campo en Times, o como Friedman en Solus realizando Glissandos por cuartos de tono (por medio de las bombas). Tocar aleatoriamente algunos sonidos creciéndolos progresivamente y cantando al mismo tiempo las vocales que le indica, o como en su cuarto tiempo, donde quitando la bomba del segundo pistón, hay que intentar afinar lo que hay escrito, que está medio tono bajo del tono real. 
Robert Henderson centra sus Variation Movements en la acentuación $\left(2^{\circ} \mathrm{y}\right.$ $3 \mathrm{r}$ movimiento) y la lectura musical primero en un pentagrama, luego en dos y finalmente en tres pentagramas, alternativamente.

Hans Werner Henze en su segundo tiempo de Sonatine, buscando un efecto sonoro diferente emplea la sordina harmon colocándola y sacándola del pabellón al mismo tiempo que toca.

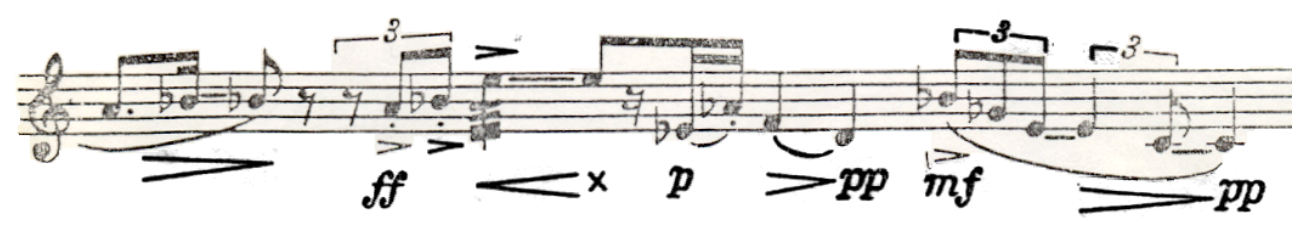

N.B. Wherever a crescendo reaches sign $*$, the imute is half off.

Fig. 1.56 Fragmento $2^{\circ}$ tpo. Henze

Fuente: H. W. Henze (1976), Sonatina, Dunster Music, Cambridge.

La interpretación de las notas que tienen los segundos escritos ( “) son de difícil ejecución y ajuste, puesto que es necesario mantenerse muy concentrado para tratar de hacerlas y medirlas lo más correctamente posible (teniendo en cuenta que el valor será aproximado, puesto que no dispondremos de un cronómetro para tal efecto). También hemos de hablar de la dificultad que tiene el ritmo, combinando con los saltos de intervalos y de picado.
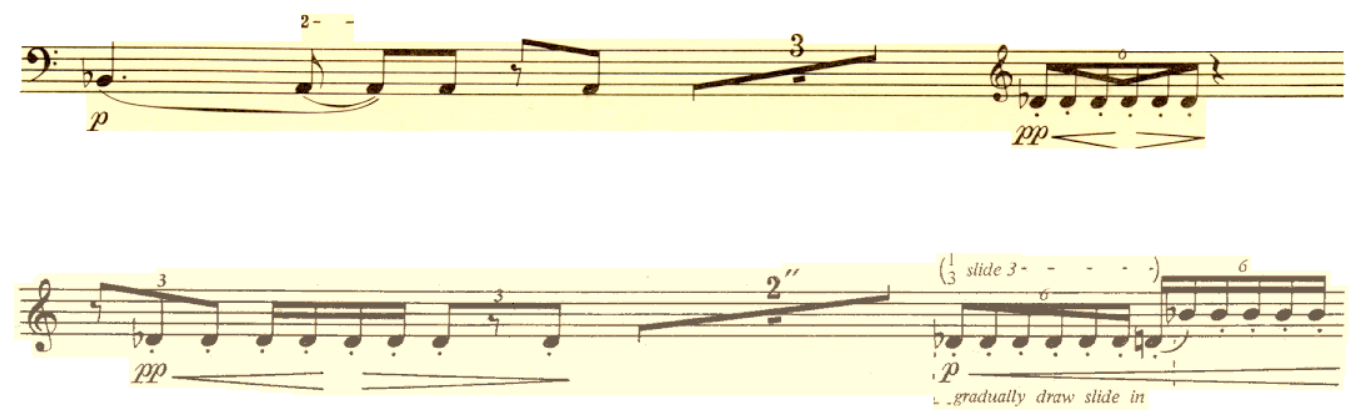

Fig. 1.57 Fragmento de Solus

Fuente: S. Friedman (1975), Solus, The brass press, Nashville.

En la interpretación de notas pedales en Times de Frank Campo y sobre todo en Shazam de Folke Rabe por la triple pedal, cuidaremos ante todo la afinación de éstas y su calidad sonora, ya que la dificultad de obtenerlas es solamente técnica y su resultado dependerá del tiempo que empleemos en su estudio. Al igual que el pasaje de Shazam donde el trompetista ha de controlar y dominar bien el registro agudo para llegar a tocar el Sol $5 \mathrm{y} \mathrm{Sol}_{5}^{\mathrm{b}}$. 


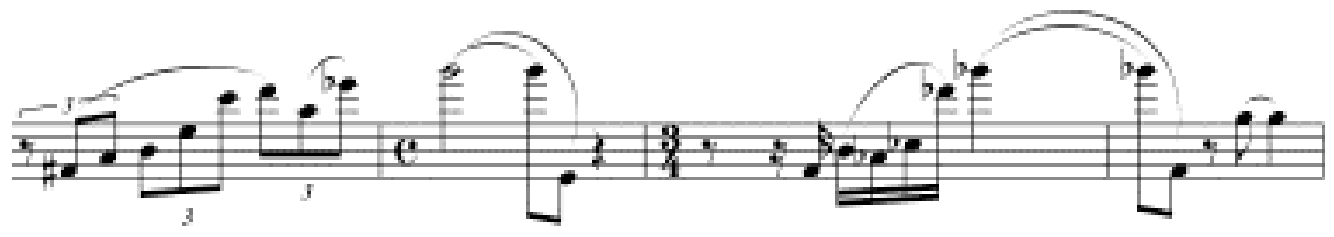

Fig. 1.58 Fragmento de Shazam

Fuente: F. Rabe (1984), Shazam, Edition Reimers AB, Stockholm.

La interpretación técnica de los tres pentagramas que Robert Henderson escribe en su quinto movimiento de Variation Movements, no es difícil, la dificultad estriba en leer al mismo tiempo que se tocan los tres pentagramas y en la interpretación interválica. También ocurre lo mismo (distancias interválicas grandes) en el segundo movimiento donde hay que añadir la acentuación dificultosa.

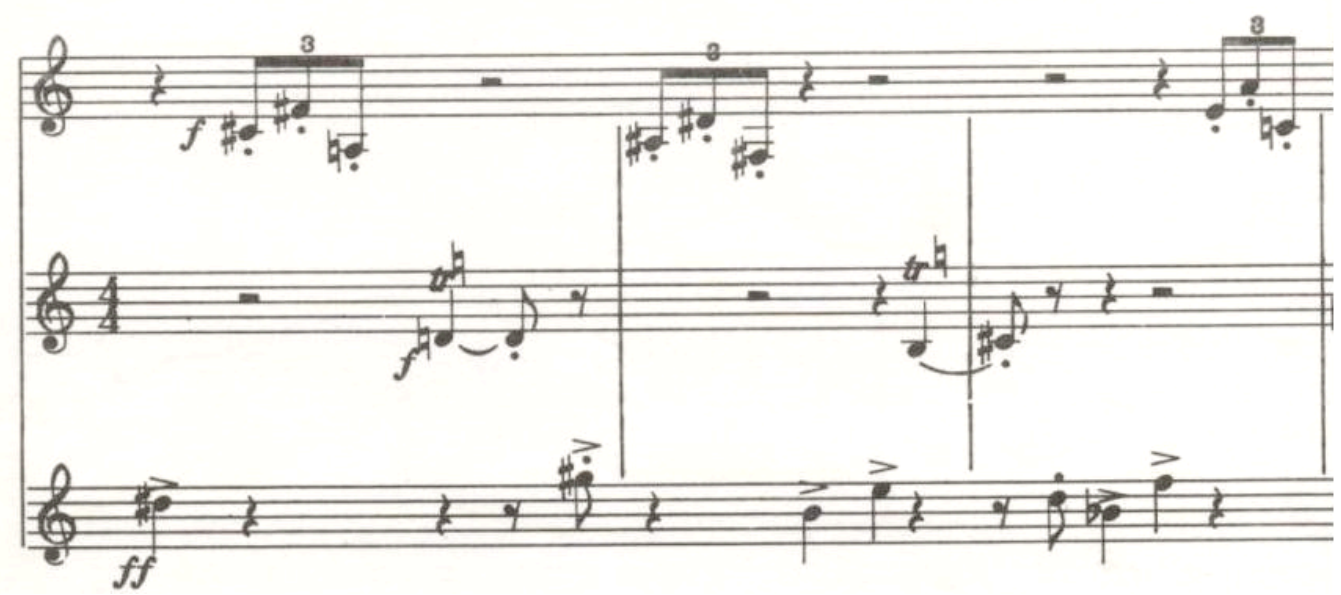

Fig. 1.59 Fragmento de Movements Variations

Fuente: R. Henderson (1967), Movements Variations, Western International Music INC, Los Angeles.

La problemática que presenta Stanley Friedman en Solus es la afinación de las notas en glissando sacando las bombas hasta donde esté afinado, los diminuendos hasta que no se escuche nada $(>\mathbf{N})$. Cuando extraemos la bomba en el cuarto movimiento, es muy arriesgada la interpretación debido a la afinación de las notas que hemos de reproducir con esa posición, puesto que la nota real en esa posición suena medio tono alto a lo que hay escrito. 


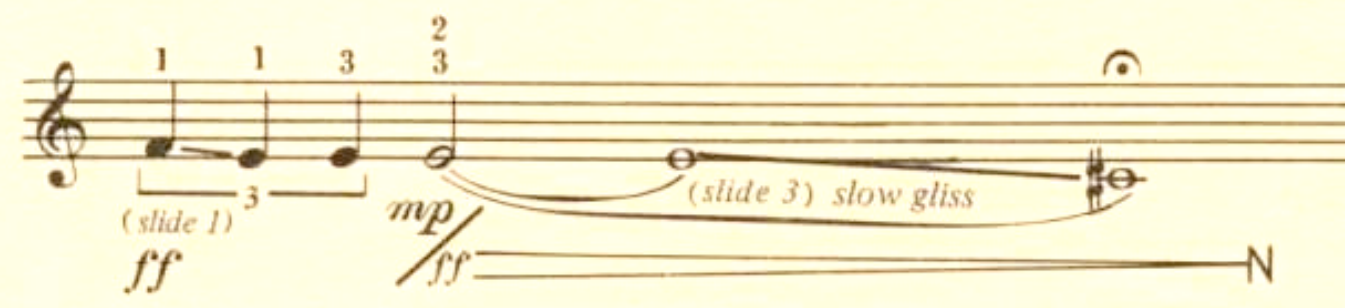

Fig. 1.60 Fragmento de Solus

Fuente: S. Friedman (1975), Solus, The brass press, Nashville.

Cuando interpretamos la Secuenza $X$ de Berio la dificultad de pronunciar trémolo, flatter y picado (rápido), después de realizar un buen trabajo técnico se supera con relativa facilidad; hemos de estar atentos y concentrados cuando nos giramos violentamente hacia el piano y luego hacia la partitura sin oscilar el sonido ni hacer con él un brusco movimiento o un cambio en la posición de la boquilla para continuar tocando mientras que las cuerdas del piano sigan con su resonancia (efecto buscado).

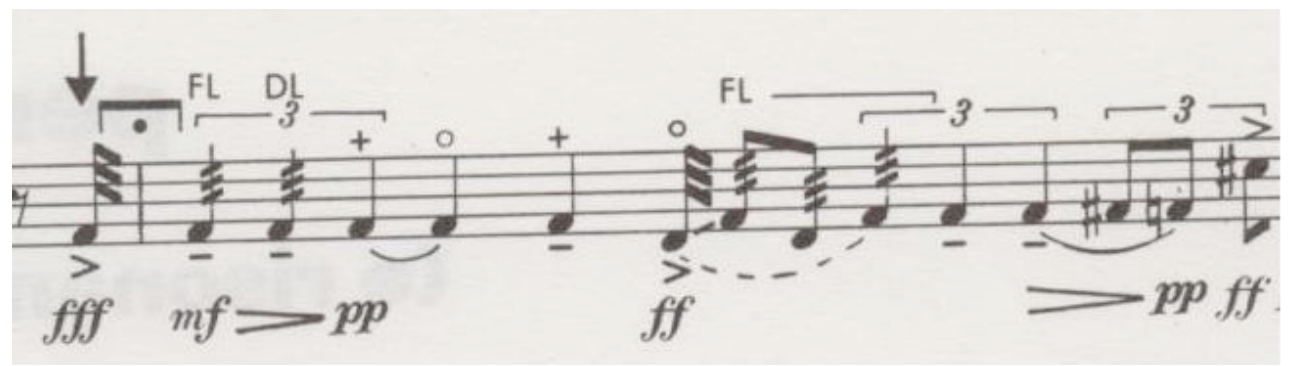

Fig. 1.61 Fragmento de Sequenza $X$

Fuente: L. Berio (1984), Sequenza X, Universal Edition, Milan.

El trabajo de Tromba Solo de Ketil Hvoslef en muy interesante para igualar el picado en todos los registros; trabajar la potencia en el aire y la resistencia. Al igual que (en menor dificultad) observamos en Cascades de Allen Vizzutti, donde es muy característica la escritura de grandes intervalos picados contrastando con fragmentos de gran rapidez de digitación (ligados), los primeros marcados por una interpretación ágil y majestuosa, y los segundos de manera rápida y elegante.

Los intervalos de los que hablamos en diferentes conciertos, no se parecen en nada a los que se empleaban en épocas anteriores: cuartas aumentadas, segundas aumentadas, séptimas mayores y novenas que estaban prohibidas, ahora son de huso común en la mayoría de estos conciertos. Además estos intervalos no se presentan reducidos, (como en el Clasicismo) sino ampliados por encima de la octava (décimas, undécimas,...). 


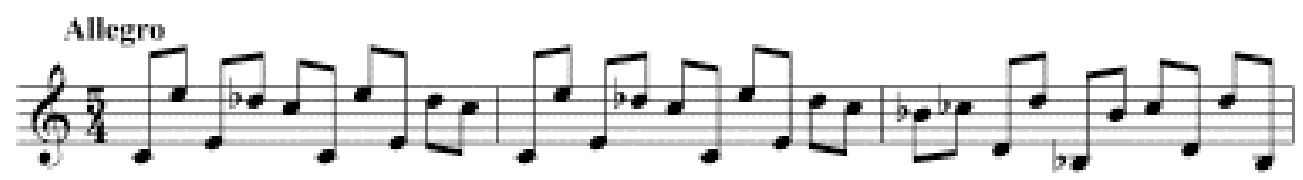

Fig. 1.62 Fragmento de Cascades

Fuente: A. Vizzutti (1981), Cascades, The brass press, Nashville.

Un avance en la grafía musical es la medida en segundos, donde no se ciñe el compositor a valores exactos sino a lo que él quiere en cada momento.

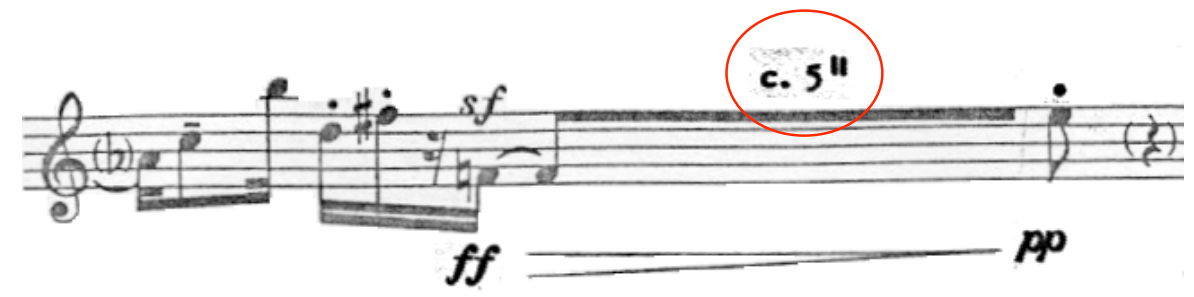

Fig. 1.63 notación en segundos

Fuente: F. Campo (1979), Times, Dario Music, New York.

Muchos de los efectos que en este tema estamos citando han sido innovados por la música de Jazz y aplicados con posterioridad a la música culta. Así pasa en el tercer movimiento del concierto de Robert Henderson donde el compositor, por medio de la acentuación, simula un ritmo jazzístico.

Fast and marked

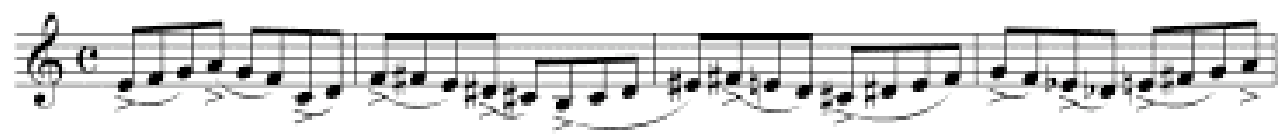

Fig. 1.64 Fragmento $2^{\circ}$ tpo. Henderson

Fuente: R. Henderson (1967), Movements Variations, Western International Music INC, Los Angeles.

Igualmente en Cascades que cada vez que el trompetista marca un pasaje ágil de digitación, parece más propiamente una improvisación del tema que se ha dado. De la misma manera el concierto de Bernard Alois Zimmermann (1918-1970) Nobody Knows The Troble I See, que parte de un spiritual y marca unos glissandos de gran dificultad interpretativa. 

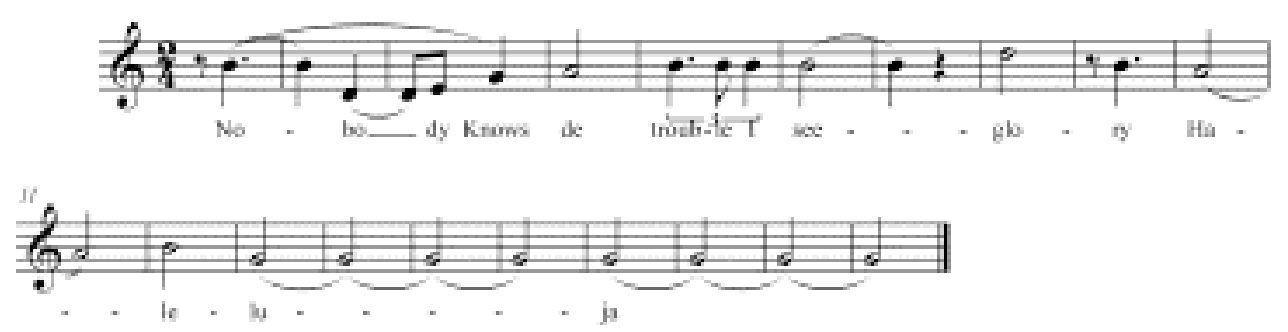

Fig. 1.65 Fragmento del espiritual

Fuente: B. A. Zimmermann (1954), Nobody knows the trouble I see, B. Schoott's Söhne, Mainz.

En cada época ha habido un instrumento representativo:

- en el barroco predominó el clarino

- en el clasicismo fue dominante la actuación de la trompeta de llaves

- en el romántico fue la época dorada de la corneta

- en el contemporáneo los compositores escriben para trompeta en Do, Sib, Mib, piccolo, fiscorno, corneta, etc.

Actualmente algunos compositores, utilizan diferentes trompetas dentro de una misma obra. En el $2^{\circ}$ concierto de Ivan Jévtic, se toca con trompeta en do y piccolo, en Semana santa en Cuzco de Henri Tomasi también se utiliza trompeta grande y pequeña (do y piccolo). En Toot Suite (1982) de Claude Bolling (nacido en 1930) es donde mayor número de trompetas se utiliza, el intérprete debe usar, en este orden: trompeta en do, trompeta en mi bemol, corneta, piccolo, fliscorno y otra vez piccolo. Estos cambios resultan de gran dificultad para la interpretación.

Durante el S. XX encontramos a la trompeta no solo como integrante de la orquesta o como solista sino que aparece en agrupaciones camerísticas, como solista junto al órgano, en el jazz, acompañada de instrumentos de percusión, etc.

\subsection{Sordinas}

El empleo de elementos que modifiquen el sonido natural de la trompeta viene utilizandose desde que Monteverdi escribiera su opera Orfeo. En ella Monteverdi utiliza un cimborio de madera para apagar el penetrante sonido de la trompeta. 


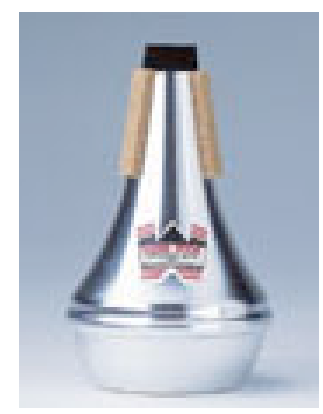

Fig. 1. 66 Sordina Straight

Fuente: M. Wade Matthews (2004)

Su uso no es solo el de apagar el sonido sino el de encontrar diferentes timbres con los que interpretar algunos pasajes. Henri Tomasi en el segundo tiempo de su Concierto utiliza la sordina cup para empezar, esta sordina aporta una sonoridad oscura e íntima, a continuación cambia de sordina y utiliza la straight o sordina recta que resulta de una sonoridad más chillona y metálica para llegar al clímax con el pabellón al aire donde la trompeta improvisa con doble forte y su sonido penetrante. Para terminar invierte la utilización de las sordinas, primero straight y después cup como si el sonido fuera decayendo.

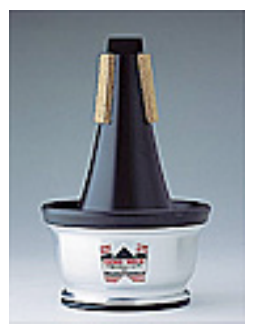

Fig. 1.67 Sordina cup

Fuente: B. Sluchin y R. Caussé (1991)

Su utilización en la música de concierto es habitual pero quien primero utilizó la sordina como elemento para modificar el sonido fueron los músicos de Jazz. Intérpretes como Miles Davis popularizaron la sordina harmon con un sonido metálico y aterciopelado que disimula las impurezas de un sonido sin sordina.

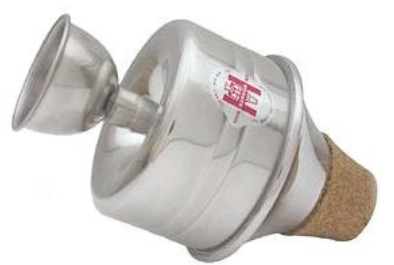

Fig. 1.68 Sordina Harmon o Wa-Wa

Fuente: B. Sluchin y R. Caussé (1991) 
La sordina harmon o wa-wa recibe dos nombres diferentes porque es capaz de producir sonoridades diferentes, por una parte si dejamos la campanilla de la sordina en su lugar y colocamos la mano sobre ella podemos producir el efecto wa-wa, si sacamos hasta la mitad la campana obtendremos otra sonoridad más metálica pero sin wa-wa, y por último al sacar la campanilla obtendremos una sonoridad más dulce y aterciopelada, cuando esta sordina se utiliza desprovista de la campanilla se le denomina harmon.

Muy utilizada por los músicos de big-band encontramos la sordina plunger, esta sordina ofrece un sonido parecido al de la wa-wa pero menos estridente, más oscuro y al colocarse en la mano y no en el pabellón de la trompeta resulta más cómoda de utilizar. Durante el S.XX se han fabricado con multitud de materiales e incluso algunos efectos como el que se obtiene con esta sordina se pueden imitar con elementos tan impensables o variados como una botella de plástico o una tapa de cartón.

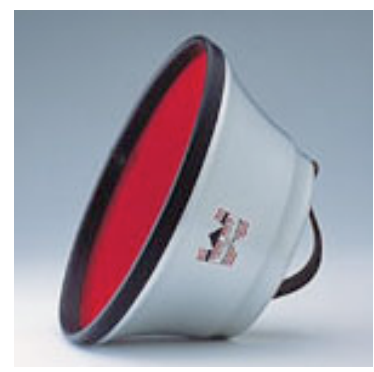

Fig. 1.69 Sordina Plunger

Fuente: B. Sluchin y R. Caussé (1991)

Debido a la gran sonoridad que produce una trompeta y de las desventajas que esto supone en las comunidades de vecinos los fabricantes han lanzado modelos de estudio que reducen considerablemente la sonoridad hasta casi no escucharse nada, la fábrica Yamaha ofrece un modelo llamado Silent Brass para todos los instrumentos de metal que conectado a unos auriculares nos permite estudiar sin ser oídos, regular el volumen que deseamos escuchar e incluso el eco que tendríamos en diferentes salas de concierto.

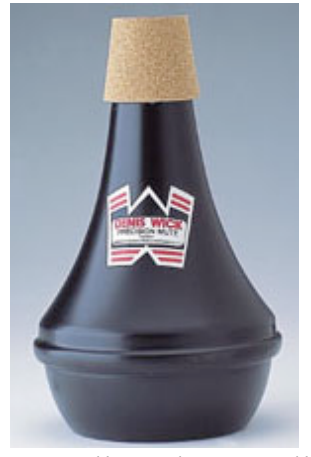

Fig. 1.70 Sordina de estudio

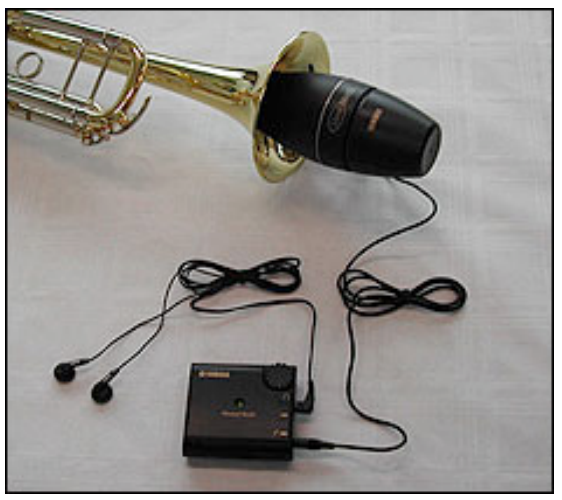

Fig. 1.71 Silent Brass 
Las sordinas se construyen en diversos materiales, la mayoría son de aleaciones de metal pero también podemos encontrar modelos hechos con otros materiales como la madera o la cera de abeja. La utilización de estos materiales cambia sutilmente la sonoridad siendo a gusto del intérprete la elección de una sordina de éste u otro material. La elección del tipo de sordina, straight, cup, wawa... viene predeterminada por el compositor.

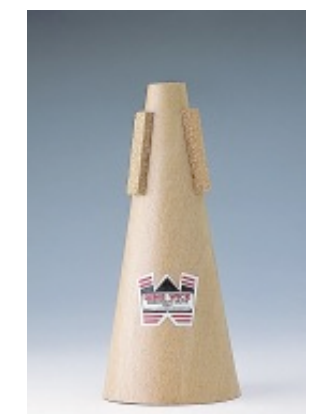

Fig. 1. 72 Sordina de madera

Fuente: B. Sluchin y R. Caussé (1991)

\subsection{La trompeta en el Jazz}

Durante el S. XX se produjeron varios cambios como consecuencia de la aparición de la trompeta en el Jazz. Ha sido considerada como el "rey en los instrumentos de Jazz" (Berendt 1986). En primer lugar Louis Armstrong (19011971) pasó de utilizar la corneta, instrumento con el que inició su andadura musical de la mano de Joe "King" Oliver (1885-1938), a la trompeta. Así se dio el primer paso a la masiva utilización de ésta en detrimento de la corneta que cayó en desuso y que actualmente solo se utiliza en las brass bands y para la interpretación del repertorio romántico.

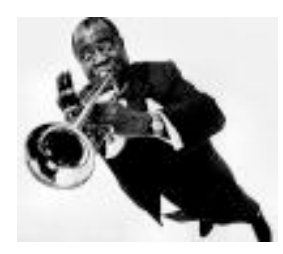

Fig. 1.73 Louis Armstrong

Fuente: M. Wade Matthews (2004)

Tras Armstrong aparecieron Bix Beiderbecke, Chet Baker o Fats navarro todos ellos alcanzando una gran fama pero sin aportar novedades reseñables al funcionamiento o evolución de la trompeta. 
Posteriormente, las novedades que los jazzistas introducían en sus interpretaciones han sido adaptadas a la música "clásica" o seria. Miles Davis (1926-1991) ha sido quien ha innovado más y estos efectos, sonoridades etc. se han trasladado a la música de concierto. Un efecto muy utilizado es el empleo del "half valve" que consiste en interpretar una nota con el pistón bajado solo hasta la mitad con lo que se consigue una sonoridad sorda diferente a la habitual. Además Davies fue el primero en dotar a la trompeta de una nueva sonoridad a través de un micrófono mediante el cual y tras ser modificado por los técnicos de sonido se obtenían sonoridades nuevas.

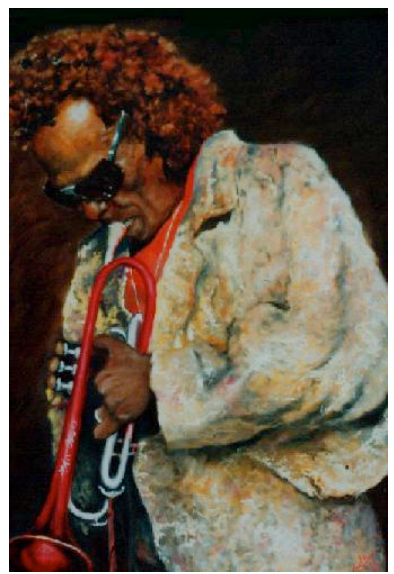

Fig. 1.74 Miles Davis

Dizzy Gillespie (1917- 1993) Ha tocado con los más grandes músicos del Jazz como Charlie Parker, Ella Fitgerald, Coleman Hawkins o Duke Ellington, autor de "A night in Tunisia" fue el impulsor del be bop, su trompeta con la campana hacia arriba y su cara hinchada al tocar se hicieron famosas. Formó la United Nations Big Band escogiendo a los mejores intérpretes sin importarle su nacionalidad. En esta formación tocaban Arturo Sandoval, Paquito d'Rivera, Claudio Roditi estre otros.

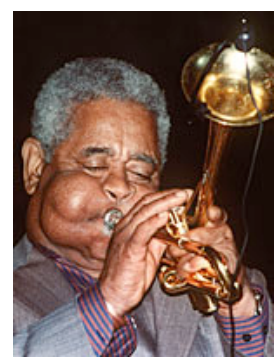

Fig. 1.75 Dizzy Gillespie

Fuente: M. Wade Matthews (2004)

Cat Anderson (1916-1981), formó parte de la big band de Duke Ellington, su papel era el de agudista, fue el primero en llegar al extremo agudo, superando 
la barrera del do $\mathrm{d}_{6}$ llegando en ocasiones hasta el sol 6 algo inaudito hasta entonces y que hoy en día realizan tan solo unos pocos.

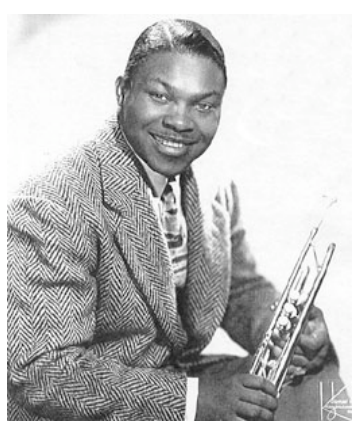

Fig. 1.76 Cat Anderson

Arturo Sandoval (nacido en 1949) su estilo de música afro-cubana o latin jazz le ha llevado a ser uno de los mejores trompetistas de su tiempo. Este cubano de la mano de Dizzy Gillespie primero como agudista y después como solista se ha hecho un hueco en el mercado discográfico mundial.

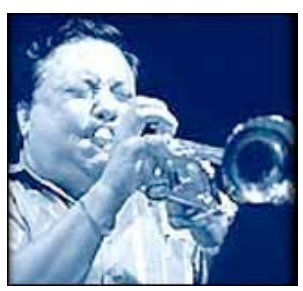

Fig. 1.77 Arturo Sandoval

Wynton Marsalis (nacido en 1961) Es el único trompetista que compagina el jazz y la música clásica con éxito. Ha grabado repertorio clásico, barroco, romántico y del S. XX. Además es autor de varios ballets como "At the Octoron balls" o "A fiddler's tale". Hizo su debut como profesional con Art Blakey's and the Jazz Messengers y ha vendido cerca de cinco millones de discos tanto clásicos como de jazz habiendo ganado con ellos 8 premios Grammy. En 1997 ganó el Pulitzer Prize en música, siendo el primer músico de Jazz en hacerlo.

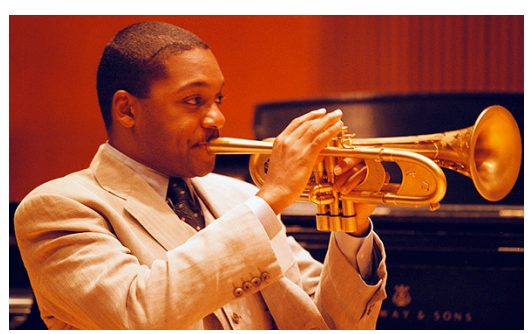

Fig. 1.78 Wynton Marsalis 
No sería justo terminar este apartado sin nombrar a trompetistas de la talla de Clark Terry, Cootie Williams, Maynard Ferguson, Clifford Brown, Woody Shaw o Freddie Hubbard quienes brillaron con luz propia en tiempos pretéritos y todavía hoy se recuerdan sus interpretaciones.

Todas las novedades surgidas de los solistas de Jazz han sido introducidas poco a poco en la música de concierto. Incluso algo tan aceptado como los cuartos de tono que propulsó el compositor checo Alois Haba fue el Jazz quien lo aceptó de inmediato pasando después a la música de concierto tras ver el éxito con que los jazzistas lo incluían en sus improvisaciones.

\subsection{La fabricación industrial}

A partir de la segunda mitad del siglo XIX, como consecuencia de la revolución industrial, se fundaron en Francia, Inglaterra, Alemania y Estados Unidos las primeras fábricas en serie de instrumentos musicales. Es difícil establecer el momento exacto en el que los artesanos pasaron a la fabricación en serie ya que fue paulatina y en algunos de los casos hoy día todavía trabajan de forma artesanal.

En 1842 Adolphe Sax funda su fábrica de Paris, hacia 1850 Henri Distin funda la suya en Inglaterra, en 1856 Gustave Auguste Besson (1820-1875) inventa el sistema de prototipos que permite por primera vez estandarizar todos los elementos que constituyen un instrumento. En 1859 la John F. Stratton Co. fue fundada en Nueva Cork, Stratton fue el primero en buscar en Europa mano de obra barata. Rápidamente la mayor parte de instrumentos empezaron a fabricarse alrededor de Markneukirchen y Leipzig y posteriormente vendidos en Estados Unidos con su nombre. Actualmente Besson pertenece a The Music Group.

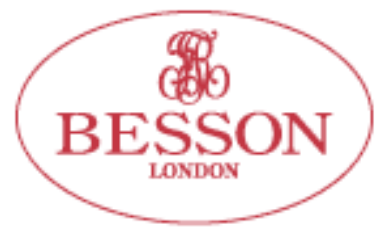

Since 1837

Fig. 1.79 Logotipo de Besson

En 1865 William Henry Hawkes fundó en Londres la sociedad Hawkes \& Son, en 1868 absorbió a la sociedad Henri Distin y en 1930 tras la fusión con Boosey \& Co. nace la actual Boosey \& Hawkes ${ }^{\circledR}$. En 1948 absorbieron a Besson. Con la fusión de ambas empresas constituyeron un imperio que lideraba el sector de editorial y se convirtió en una de las empresas más potentes en la fabricación de instrumentos. En 2003 la división de instrumentos fue vendida y ahora se dedican exclusivamente a la edición de partituras. 


\section{BOOSEY $\circlearrowleft$ HAWKES}

Fig. 1.80 Logotipo de Boosey \& Hawkes

Antes de 1867 la fabricación industrial ya había llegado a ThibouvilleLamy, esta fábrica mantuvo la hegemonía de 1880 a 1925 en la fabricación francesa. En 1875 Charles Gerard Conn (1844-1931), funda su fábrica en Elkhart-Indiana (USA), construyó la primera corneta americana. En 1985 la empresa fue vendida a United Musical Instruments (UMI) siendo su actual presidente Bernhard Muskantor. Conn ${ }^{\circledR}$ fue pionera en la fabricación americana. De hecho desde entonces la mayor parte de los instrumentos de metal americanos de todas las marcas se fabrican en Elkhart.

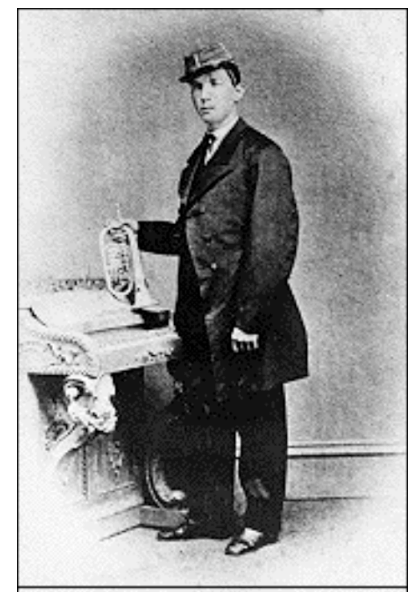

Fig. 1.81 Charles Gerard Conn

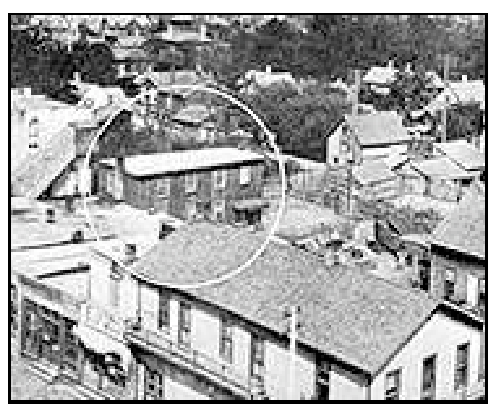

Fig. 1.82 Fábrica de Conn en 1875

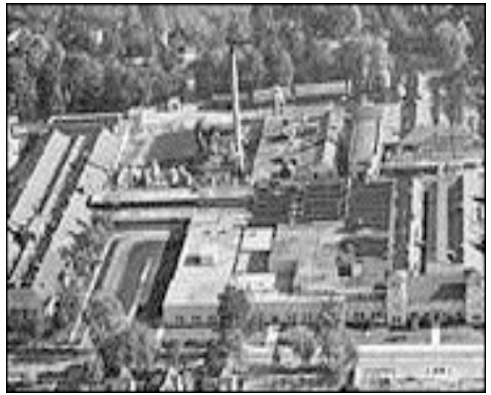

Fig. 1.83 Fábrica de Conn en 1950 
Fuera de Europa y América destaca una fábrica japonesa, Nipon Gakki Company Limited, que comenzó su producción de instrumentos musicales en 1887 y que posteriormente se transformó en la actual Yamaha ${ }^{\circledR}$ Corporation.

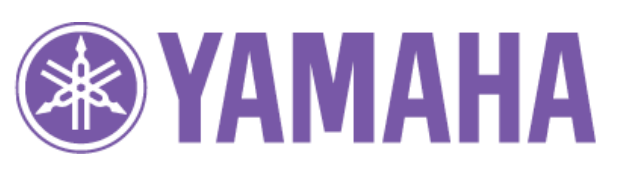

Fig. 1.84 Logotipo de la marca Yamaha

Thomas King $^{\circledR}$, afamado trombonista de la Lyceum Theatre Orchestra de Cleveland, encargó en 1893 a Henderson N. White el diseño de un trombón que fue llamado "the King trombone", posteriormente llegó la producción de trompetas. Cuando White murió en 1940, su esposa Edna White se hizo cargo de la empresa que en 1966 se fusionó con The Seeburg Corporation y formó la compañía King Musical Instruments. Desde 1985 King $^{\circledR}$ continúa en el mercado bajo el nombre de UMI.

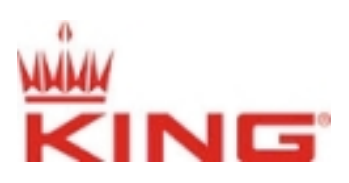

Fig. 1.85 Logotipo de King

Una de las marcas francesas más antiguas, Curtois ${ }^{\circledR}$, conocida a través de Antoine Curtois (1770-1855), no debe su nombre a éste sino a la tradición familiar que se remonta a 1789. En 1917 la compañía fue vendida a Emmanuel Gaudet (1860-1933) y todavía la conserva su nieto Jacques Gaudet (*1948).

\section{Antoine Conrtory}

Fig. 1.86 Logotipo de Courtois

A principios de 1900 Henri Selmer ${ }^{\circledR}$ abrió una tienda en París de boquillas y cañas para clarinete hechas a mano, pero no fue hasta los años 30 cuando la demanda le hizo empezar la fabricación de trompetas.

\section{Selmet}

Fig. 1.87 Logotipo de Selmer 
La historia de la compañía Blessing ${ }^{\circledR}$ comenzó en 1906 cuando su fundador Emil Karl Blessing creó la fábrica de Elkhart. Para la XXIII Olimpiada celebrada en Los Angeles (USA) construyeron 100 trompetas para la ceremonia de inauguración. Actualmente preside la empresa Randy Johnson.

\section{Blessing}

Fig. 1.88 Logotipo de Blessing

Emil Karl Blessing nació en 1880 en Oppelsbohm, un pequeño pueblo cerca de Stuttgart, Alemania. Emigró a América a los 15 años. Su trabajo como constructor de herramientas le llevó a fabricar en un garaje de Elkhart, Indiana en 1906 pistones para instrumentos de metal, la producción de trompetas y cornetas no se hizo esperar.

Con el tiempo sus hijos Emil Karl Jr. y Fred se hicieron cargo de la compañía. En 1940 trasladaron su factoría a su actual ubicación en West Beardsley Avenue en Elkhart.

Tras la muerte de Emil Karl en 1954, la tradición comenzada con él continúa con sus sucesores, y así fueron parando por la dirección de la empresa Emil Karl Jr., Virginia (hija de éste) y Merle Johnson (marido de virginia). Actualmente desde 1996 es presidente de Blessing Randy Johnson, nieto de Emil Karl.

Con motivo de los XXIII Juegos olímpicos celebrados en Los Angeles en 1984, Blessing construyó 100 trompetas heraldo de fanfarria para la ceremonia de inauguración.

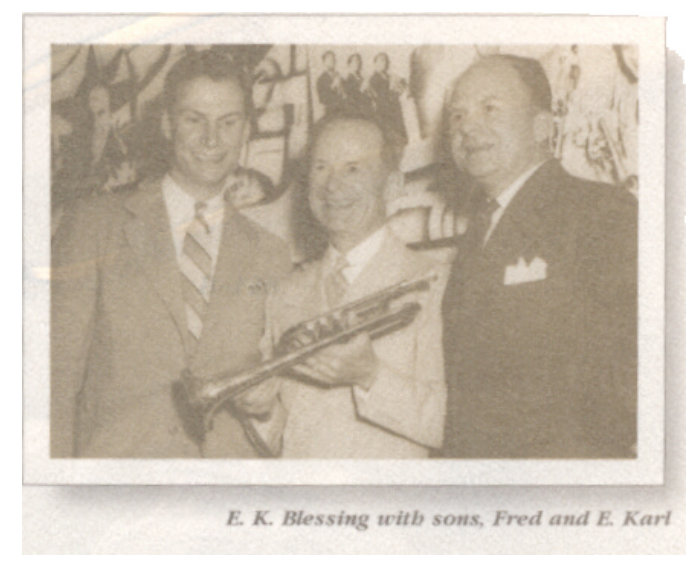

Fig. 1.89 Familia Blessing 
En 1927 Domenick Calicchio ${ }^{\circledR}$ fundó su propia compañía en Nueva York, aunque la primera fábrica estuvo ubicada en California siendo posteriormente trasladada a su ubicación actual en Tulsa-Oklahoma. Emigrante de origen italiano, Calicchio llegó a Estados Unidos en 1923 y empezó a trabajar en la fábrica de boquillas que Rudy Muck tenía en Nueva York. Su lema era "debo hacer cada trompeta mejor que la anterior". Sus actuales propietarios son John Duda y Bart Dalton.

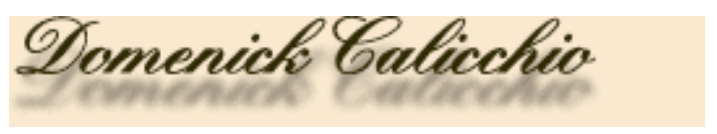

Fig. 1.90 Logotipo de Calicchio

Una de las marcas más utilizadas en la actualidad es la Vincent Bach ${ }^{\circledR}$ (1890-1976). Bach, vienés de nacimiento emigró a Estados Unidos para tocar la corneta como solista. Después de la $1^{\text {a }}$ Guerra Mundial empezó la producción de boquillas en Nueva York y en 1924 terminó su primera trompeta. En 1961 Vicent Bach $^{\circledR}$ Corporation fue adquirida por Selmer ${ }^{\circledR}$ y cuatro años después en 1965 comenzó su producción en Elkhart.

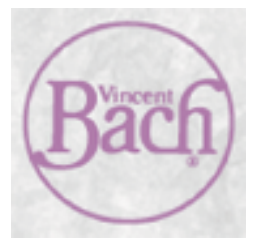

Fig. 1.91 Logotipo de V. Bach

Elder Benge ${ }^{\circledR}$ trompetista de la Orquesta Sinfónica de Chicago, vendió su primera trompeta hecha a mano a un compañero de su orquesta. A partir de 1952 la demanda de trompetas fue tan grande que Benge tuvo que dejar su actividad musical como integrante de la orquesta para poner todas sus energías en la producción de trompetas.

\section{BENGE}

Fig. 1.92 Logotipo de Benge

Un caso parecido ocurrió con Renold Otto Schilke (1910-1982) puesto que también fue miembro de la orquesta Sinfónica de Chicago en calidad de trompeta solista de 1939 a 1941. Schilke había estudiado metalurgia y música en la Universidad de Northwertern en Evanston y en la Universidad de Chicago. Su buen hacer en la construcción casi artesanal de sus instrumentos llamó la atención de las grandes marcas y en 1966 Yamaha ${ }^{\circledR}$ Corporation le contrató como asesor 
para participar en los diseños de sus instrumentos de metal, colaboración que duró hasta la muerte de Schilke en 1982. El 31 de octubre de 2002 Schilke ${ }^{\circledR}$ Musical Products Inc., fue vendida a Andrew Naumann, un constructor de trompetas naturales.

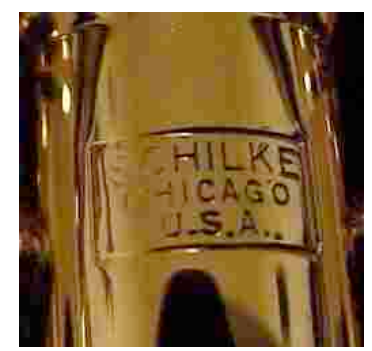

Fig. 1.93 Logotipo de Schilke

G. Leblanc Corporation fundada en 1946, es un holding que agrupa a una serie de marcas como Holton o Noblet (famosa por la construcción de clarinetes) todas ellas auténticos referentes en la fabricación de instrumentos musicales. Holton pasó a formar parte del grupo Leblanc en 1964, la fabricación de trompas por parte de F. Farkas así como su éxito, dio paso a la construcción de trompetas. Numerosos trompetistas tocan con trompetas Holton-Leblanc, el más representativo sin duda es Arturo Sandoval.

\section{Hotron@ Leblanc}

Fig. 1.94 Logotipos de Holton y Leblanc

La creación de nuevas fábricas continúa, en los años 80 vieron la luz empresas que fabrican trompetas como Stomvi ${ }^{\circledR}$ (Mislata-España), Monette ${ }^{\circledR}$ (1983) o Edwards ${ }^{\circledR}$ (1989), aunque esta última sacó a la luz su primer modelo de trompeta en 1994.

En la ciudad de Mislata, anexa ya a Valencia, se encuentra Stomvi ${ }^{\circledR}$, la única fábrica de trompetas española. La tradición musical en la familia Honorato no es nueva; ya el abuelo, Tomás Honorato, realizó su servicio militar como corneta de la Banda Real, además, su hijo fue clarinetista y se instaló en Mislata con sus tres hijos. Fue Vicente, el más joven de los hermanos, el que creó en 1979 la casa "Honorato" que se dedicaba al mundo de las joyas. Tres años más tarde empieza a construir piezas con las que logra montar su primera trompeta en 1985 (una historia muy similar a las que sucedían en los siglos XVI y XVII en Nuremberg, donde las casas de instrumentos se formaban a partir de los orfebres y joyeros de la época). Durante estos veinte años Stomvi ha realizado muy diferentes modelos de trompetas y en la actualidad también fabrican trombones. Las trompetas Stomvi son las únicas a las que se les aplica un baño de plata y oro. 


\section{Otomir}

Fig. 1.95 Logotipo de Stomvi

La Edwards Instrument Company fue fundada en 1989 y se dedicaba a la construcción de trombones. En 1994 empiezan a construir trompetas, tarea que le encargan a Andrew Naumann. En 1998 sale a la luz el primer modelo de trompeta Edwards en Sib y Do.

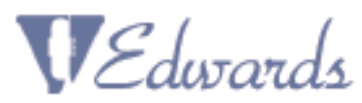

Fig. 1.96 Logotipo de Edwards

David Monette hizo sus primeras boquillas inspirado en su propia experiencia como trompetista. Después de probar muchas de las marcas más populares encontró una práctica inconsistente y una mala afinación. Era el momento de dar un paso adelante en la construcción y en le diseño de trompetas para lograr un sonido más rico en armónicos, más resonancia, y sonido más consistente con un menor esfuerzo.

Después de construir sus primeras trompetas en 1983, Monette concluyó que la una manera de terminar su proyecto de una trompeta revolucionaria era rediseñar la boquilla. Inspirado en el trabajo de Arthur Benade, Doctor en acústica, realizó cuanto necesitaba para lograr su objetivo. Construyeron una boquilla para cada trompeta dependiendo de su afinación, una boquilla para la trompeta en sib, otra para la trompeta en do..., de esta manera el instrumento poseía una resonancia mayor, una gran libertad y flexibilidad en la ejecución musical.

Las primeras boquillas Monette aparecieron en el mercado en 1985, inmediatamente los grandes trompetistas hicieron uso de ellas. Uno de sus más fervientes usuarios es el grandísimo jazzista Wynton Marsalis.

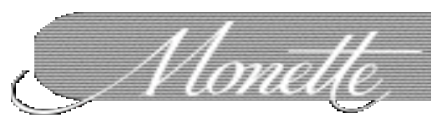

Fig. 1.97 Logotipo de Monette

Se echa en falta los nombres de algunas fábricas alemanas y austriacas de pequeño tamaño y gran especialización, conforme a su tradición. En muchos de los casos estas pequeñas empresas producen pabellones y mecanismos que venden 
a las grandes empresas donde son ensamblados a los tubos y se venden bajo el nombre de las grandes marcas.

La marca Júpiter comienza su andadura en 1930 cuando KHS Internacional, abre una empresa de instrumentos dedicada al mercado estudiantil (no profesional) en Taipei, Taiwán. Las siglas KHS provienen de "Kung Hsue She" que significan compañía que ayuda a las escuelas y la cultura. Esta simple definición representa las señas de identidad de Júpiter. En 1980, empieza a producir toda la gama de instrumentos de viento y percusión. Actualmente posee factorías en cuatro países aunque la principal se encuentra en Austin, Texas, en los Estados Unidos de America.

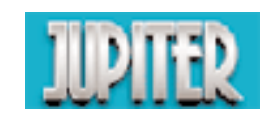

Fig. 1.98 Logotipo de Jupiter

Weril es una empresa $100 \%$ brasileña, siendo actualmente una de las cinco lideres en el segmento de instrumentos de viento. Fue inaugurada en 1909. Además Weril edita una revista con su nombre que es única en su género.

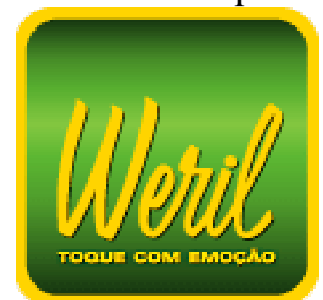

Fig. 1.99 Logotipo de Weril

Amati es una compañía checa que fabrica instrumentos de viento y accesorios. El inicio de su producción se remonta al S. XVIII aunque hasta 1945 no adoptó su actual nombre. Durante 180 años trabajaron de manera artesanal en una pequeña fábrica pero la fuerte demanda en la producción de instrumentos les llevó en poco tiempo a convertirse en la tercera empresa a nivel europeo. Su empresa filial V. F. Cerveny se dedica por completo a la fabricación de los instrumentos de cilindros. Amati Denak company posee 4 factorías empleando a 720 personas. Su cuartel general lo tienen en Kraslice, República Checa, en una fábrica con 470 empleados.

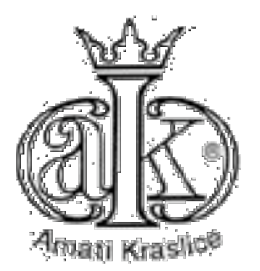

Fig. 1.100 Logotipo de Amati 

"La escala sonora constituye el fundamento físico del arte musical,
la escala está formada por los sonidos de la serie armónica
colocados según el orden diatónico en una sucesión diferente de la
que ofrece la naturaleza"
I. Stravinsky (1986)

\section{CAPÍTULO 2: Sistemas de afinación}

Cada una de las maneras de elegir los sonidos que utiliza la música constituye un sistema de afinación. Precisando más, como en nuestro estudio sólo tenemos en cuenta el tono de los sonidos, es decir, la frecuencia de su armónico fundamental, podemos identificar un sonido o nota musical con esta frecuencia. En este contexto, un sistema de afinación es cualquier subconjunto de $\mathrm{R}^{+}$que contiene todas las frecuencias que se utilizan en la música Por lo tanto, se trata de elegir en el conjunto de las frecuencias de todos los sonidos aquéllos que sirven para hacer música y descartar el resto. Los sonidos admitidos por el sistema de afinación se denominarán sonidos afinados o notas musicales.

Al menos desde el siglo VI a. C., los criterios de afinación constituyen métodos matemáticos que permiten seleccionar una cantidad reducida de notas que utilizará la música y, como se verá más adelante, el problema se puede reducir a elegir puntos en el intervalo [1, 2] véanse Girbau (1985), Liern (1994a).

Por supuesto, hay muchas maneras de elegir las notas musicales (Goldáraz, 1992) y de hecho ni siquiera existe una clasificación unánime de las formas de afinar. No obstante, la clasificación más extendida es la que resumimos a continuación (Fernández de la Gándara, Lorente, 1998; Goldáraz, 1992) y que se refiere a la música occidental.

Los sistemas de afinación se dividen en afinaciones, cuando todos los números que aparecen multiplicando a una nota patrón (diapasón) son racionales y temperamentos cuando aparece algún número irracional. Por tanto, el término afinación se contrapone al de temperamento puesto que en las primeras los 
intervalos son justos ${ }^{1}$ mientras que en los segundos aparecen intervalos "templados" o aproximados. En éstos se ha variado ligeramente la afinación de algunos intervalos, en especial las quintas, para conseguir determinadas ventajas armónicas; terceras aceptables (temperamentos mesotónicos) o eliminación de la quinta del lobo (temperamentos irregulares e igual). Atendiendo a la disposición de las quintas, los sistemas de afinación pueden clasificarse en

Sistemas cíclicos: Presentan una disposición de las quintas de forma que no hay ninguna impracticable, sean o no iguales.

Sistemas regulares: Son aquellos sistemas en los que todas las quintas (o todas menos una) tienen el mismo tamaño.

Los temperamentos, a su vez, pueden dividirse en:

Temperamento igual: la octava se divide en 12 partes o semitonos iguales de razón $\sqrt[12]{2}$. Las quintas quedan ligeramente bajas y las terceras mayores muy altas.

Temperamentos irregulares: Sistemas en los que más de una quinta es diferente de las demás.

Temperamentos mesotónicos. En sentido estricto, "de tonos medios" entre el mayor $9 / 8$ y el menor 10/9.

Los temperamentos irregulares suelen partir de sistemas regulares que, al modificarlos, presentan algún tipo de ventaja. Para conseguir su objetivo, eliminar la quinta del lobo, no hay unas reglas generales, por tanto es difícil agruparlos en categorías. No obstante, en Goldáraz (1992) se da la siguiente clasificación :

Temperamentos del siglo XVI (y principios del XVII). Pueden ser cíclicos o no, pero suelen responder a dos tipos de prácticas: modificar la afinación pitagórica para acercarse a la justa entonación o distribuir la comma pitagórica.

Temperamentos irregulares del siglo XVIII. Parten de un temperamento mesotónico y su objetivo es cerrar el círculo de quintas (de forma irregular) para conseguir consonancias más justas en las tonalidades más usuales ("naturales") y más desviadas en las menos usuales ("traspuestas") 2 .

Buenos temperamentos. El término bien temperado (o buen temperamento) no hace referencia a un temperamento en particular. El calificativo de

\footnotetext{
${ }^{1}$ Un intervalo formado por dos sonidos $\mathrm{f}_{1}, \mathrm{f}_{2}$ es justo si $\mathrm{f}_{2}$ es uno de los armónicos que aparece en la serie armónica de $\mathrm{f}_{1}$, es decir $\mathrm{f}_{1}=\mathrm{p} / \mathrm{q} \mathrm{f}_{2}$ con $\mathrm{p}$ y q números naturales no nulos.

2 "De esta forma el oyente recibe diferentes impresiones de los intervalos de acuerdo a sus diferencias y el compositor saca partido de tales diferencias, tal como quería Rameau en 1726. Cada tonalidad tiene una cualidad diferente; el cambio de tonalidad no constituye únicamente un cambio de altura como en el temperamento igual, sino un cambio de sonoridad destinado a explotar los diferentes “afectos” emocionales propios del Barroco.” (Goldáraz, 1992).
} 
"bueno" significa que permite la modulación a todas las tonalidades, es decir que es un temperamento circular, sin quinta del lobo.

Una vez introducido, aunque sea grosso modo, el concepto de afinación, cabe preguntarse si éste puede ser todavía un tema de interés para alguien que no se dedique al estudio de la Historia. La aparición de artículos en revistas de física o matemáticas sobre temas de música podrían dar una contestación a esta pregunta, ver por ejemplo Osserman (1993), Haluska (2000) y Schell (2002). Sin embargo, las necesidades de músicos y musicólogos proporcionan un respuesta mucho más convincente. Éstos han establecido dos campos de actuación: la búsqueda de nuevas afinaciones que aumenten las posibilidades en la creación musical y la recuperación de la fidelidad a las partituras antiguas. En este último sentido, M. Bernal ${ }^{3}$ asegura que:

"Uno de los principales problemas que se presentan en la praxis de la música antigua para tecla es la elección del temperamento adecuado. Entre 1500 y 1800, a medida que avanza y se amplía la teoría armónica, se buscan nuevas maneras de afinar los instrumentos de tecla. En cada momento el temperamento es un compromiso entre la afinación ideal y su realización práctica, a causa de la restricción que supone que las teclas negras tengan la doble función de sostenido y bemol [...]. Acertar con el temperamento adecuado será importante para expresar mejor el espiritu de la música de un momento dado",

entendiendo por adecuado aquel temperamento para el que fue concebida. De hecho, incluso la expresión "buen temperamento", empleada al menos a partir de la obra Clave bien temperado (Das Wohltemperierte Klavier I, 1721) de J. S. Bach, resulta imprecisa, puesto que como bien aclara J. J. Goldáraz buen temperamento no designa una única forma de afinar y continúa siendo un tema de discusión conocer si se trataba realmente del sistema de afinación de 12 notas por octava o se tratataba de otro temperamento de los que en la época se utilizaban en Alemania ${ }^{4}$.

\subsection{Conceptos previos}

El sonido puede definirse como "la sensación sonora que se produce en el sentido del oído por el movimiento vibratorio de los cuerpos, transmitido por un medio elástico como es el aire" (Calvo-Manzano, 1991). Se demuestra (Kinsler et al., 1995) que, de hecho, un cuerpo no puede producir sonido más que cuando

\footnotetext{
${ }^{3}$ Bernal (1999).

${ }^{4}$ Goldáraz (1992).
} 
vibra. Los sonidos se distinguen entre sí por tres cualidades esenciales ${ }^{5}$ : la altura, la intensidad y el timbre.

La altura es la cualidad que permite distinguir un sonido grave de otro agudo. Depende principalmente de la frecuencia de las vibraciones de la fuente sonora, así, los sonidos agudos se deben a movimientos vibratorios de frecuencia elevada y los sonidos graves a vibraciones de frecuencias bajas. No obstante, el oído humano no reacciona ante todas las frecuencias de los movimientos vibratorios, sino que sólo transforma en sonido una pequeña parte de ellas, aquellos cuyas frecuencias están comprendidas entre $16 \mathrm{~Hz}$ y $20000 \mathrm{~Hz}^{6}$. La característica subjetiva de la altura es lo que se denomina Tono.

La intensidad es la cualidad que permite distinguir un sonido fuerte de otro débil. La intensidad está ligada a la amplitud de las vibraciones sonoras. Como ocurre con la altura, el oído humano no podrá percibir un sonido cuya amplitud sea inferior a cierto valor mínimo y a la intensidad mínima correspondiente se le denomina "umbral de audibilidad". Si se hace aumentar mucho la amplitud de las vibraciones, la audición provoca sensación dolorosa. A la intensidad máxima correspondiente al límite soportable para el oído se le llama "umbral de dolor" (ver Fig. 2.1).

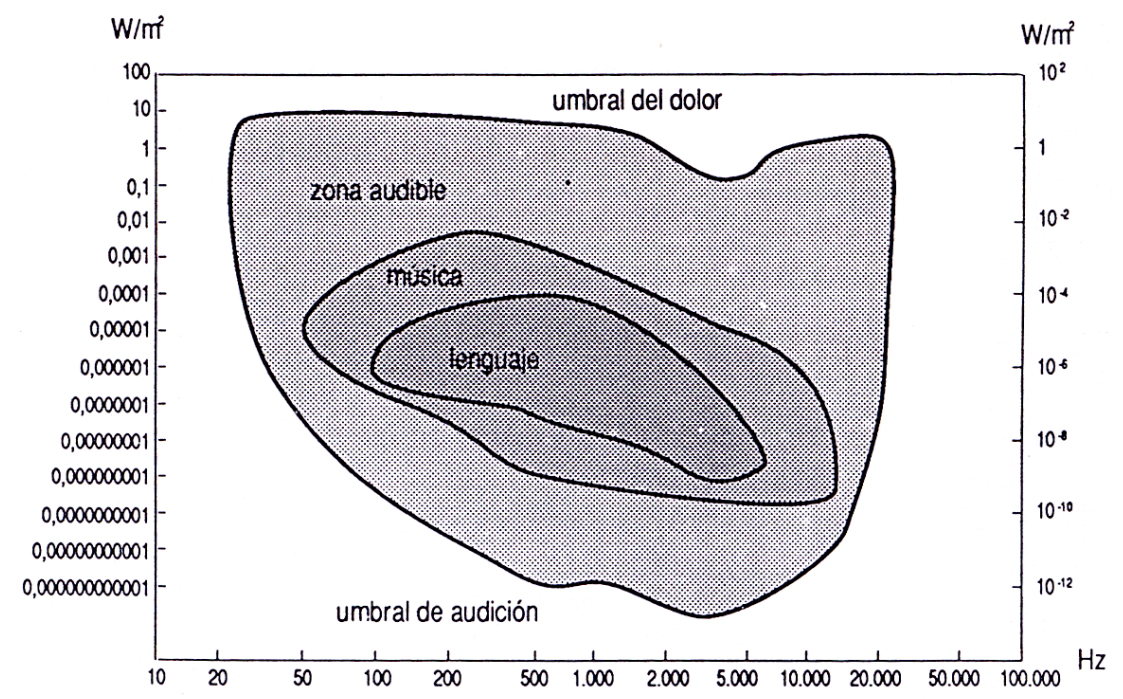

Fig. 2. 1 Área auditiva normal.

Fuente: Calvo-Manzano (1991)

\footnotetext{
${ }^{5}$ Hay otras cualidades como la duración, el volumen, el brillo, etc. que tienen menos importancia en nuestro estudio (Olazabal, 1954).

${ }^{6}$ Estos límites son bastante imprecisos, variando de persona a persona, sobre todo el superior. De hecho, muchos autores fijan el nivel máximo de audición en $16000 \mathrm{~Hz}$. (Larousse, 1992). Sin embargo, estas cifras no van a tener ninguna utilidad en este Trabajo de Investigación porque la Música no suele sobrepasar los $12000 \mathrm{~Hz}$.
} 
El timbre es la cualidad que permite distinguir dos sonidos que provienen de cuerpos sonoros diferentes. Si el sonido es musical está generado por un movimiento vibratorio periódico, es decir por superposición de sonidos simples armónicos, el timbre depende de las intensidades relativas de los diferentes sonidos simples que lo componen.

Hasta aquí hemos utilizado la palabra sonido para designar cualquier manifestación sonora independientemente de su naturaleza o de la sensación producida. Sin embargo, es necesario establecer una clasificación en dos grandes grupos que, tradicionalmente en Acústica Musical, se denominan sonidos y ruidos.

En este sentido restringido, un sonido es "toda sensasión agradable producida por movimientos vibratorios de altura definida y pocedencia fácil de establecer" (Calvo-Manzano, 1991). Esta definición, que responde de manera fiel a la idea que los músicos tienen del sonido músical, puede establecerse de forma más objetiva si tenemos en cuenta la siguiente Ley de Fourier (Matras, 1977):

"Toda onda periódica de frecuencia $\boldsymbol{f}$ puede ser descompuesta en una cantidad infinita de ondas sinusoidales de frecuencias

$$
f, \quad 2 x \boldsymbol{f}, \quad 3 \times f, \quad \ldots "
$$

Así, podemos decir que sonidos son todos aquellos complejos sonoros que obedecen a la Ley de Fourier. Sin embargo, somos conscientes de que así estaríamos excluyendo algunas manifestaciones sonoras que aceptamos como sonido tales como los producidos por los instrumentos placófonos y membranófonos cuyos sonidos no se ajustan a la Ley de Fourier.

Se tiene por tanto que, cuando la onda es periódica, el espectro de frecuencias que aparece sólo comporta un número reducido de valores, mientras que si no lo fuera el espectro sería continuo (véase Fig. 2.2).

Un ruido es la mezcla compleja de sonidos de frecuencias diferentes, las cuales producen frecuentemente una sensación desagradable. Desde el punto de vista físico, un ruido es un sonido de gran complejidad resultante de la superposición de ondas no armónicas.

Hecha esta pimera clasificación, resulta evidente que el objeto de nuestro estudio será los sonidos musicales, es decir que dentro de todo el espectro sonoro vamos a seleccionar los sonidos más sencillos, los que se obtienen como superposición de ondas periódicas simples y en los que, además, no aparece cualquier frecuencia, sino que, como afirma la Ley de Fourier, sólo están los múltiplos naturales de una frecuencia dada. 


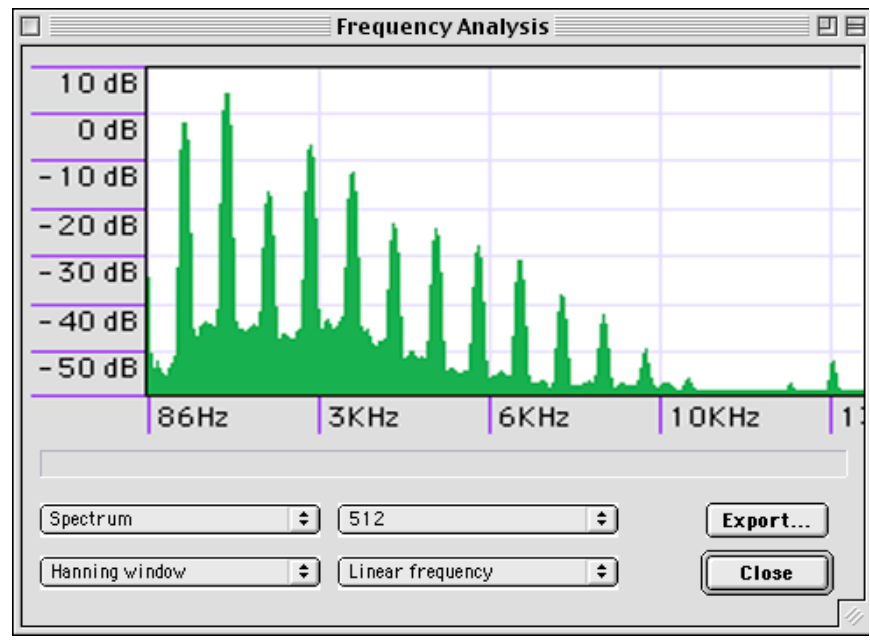

Fig. 2.2. Espectro de frecuencias de una nota musical interpretada por una trompeta, obtenido con el programa Audacity ${ }^{\circledR}$.

En esta Memoria de Doctorado vamos a analizar la afinación, por tanto de entre las cualidades de los sonidos que acabamos de citar sólo estamos interesados en la altura, dejando para investigaciones posteriores el estudio de las cualidades restantes.

\subsection{Medición de la sensación de altura}

Como hemos dicho cuando introducíamos el concepto de altura de un sonido, la manera de percibir esta cualidad es lo que se conoce como tono. $\mathrm{Si}$ suponemos un sonido simple de frecuencia $\mathrm{f}$, determinar su altura es evidente puesto que conocemos su frecuencia. Sin embargo, si nuestro interés es medir la sensación de altura la situación ya no es tan sencilla. Para ello, necesitamos tener en cuenta la Ley de Weber-Fechner (Matras, 1977), que asegura que, en la zona central del campo de audibilidad,

"la sensación sonora de intensidad es sensiblemente igual al logaritmo de la energía que produce la excitación”.

Si escribimos esta ley con una fórmula, la expresión es la siguiente (CalvoManzano, 1991):

$$
\mathrm{S}=10 \times \log _{10}\left(\frac{I}{I_{0}}\right) \mathrm{dB} .
$$


Veamos en un ejemplo la utilidad de esta fórmula

Ejemplo 2.1: Una trompeta al interpretar una nota produce una sensación $S_{o}$ de 60 $\mathrm{dB}$. ¿Qué sensación producirán dos trompetas interpretando la misma nota?

Sabemos que con una trompeta la sensación es

$$
60=10 \times \log _{10}\left(\frac{I}{I_{0}}\right),
$$

por tanto, para dos trompetas se tendrá

$$
\begin{aligned}
& \mathrm{S}=10 \times \log _{10}\left(\frac{2 I}{I_{0}}\right)=10 \times \log _{10}\left(2 \times \frac{I}{I_{0}}\right)=10 \times \log _{10}(2)+10 \times \log _{10}\left(\frac{I}{I_{0}}\right) \approx \\
& \approx 3+60=63 \mathrm{~dB} .
\end{aligned}
$$

Un hecho que en muchas ocasiones se pasa por alto, es que la Ley de Weber-Fechner es aplicable la zona central del campo de audibilidad pero no a cualquier frecuencia. Sirva para ilustrar este hecho el siguiente gráfico (Fig.2.3) de Calvo-Manzano (1991) en el que se muestran las líneas de isofonía. Los físicos Fletcher y Munson dedujeron experimentalmente en 1933 las líneas de igual nivel auditivo.

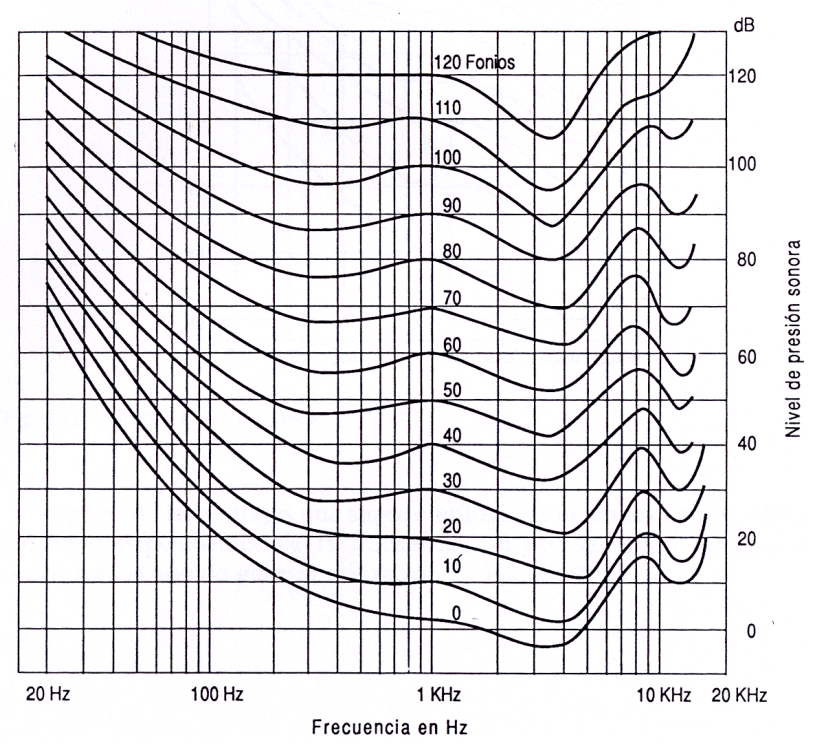

Fig. 2. 3 Líneas de isofonía.

Fuente: Calvo-Manzano (1991)

Por ejemplo, el valor umbral para frecuencias de $60 \mathrm{~Hz}$ es de $60 \mathrm{~dB}$, y a medida que la frecuencia aumenta el oído muestra una mayor sensibilidad. La banda que comprende frecuencias entre 3000 y $4000 \mathrm{~Hz}$ es, normalmente la de mayor sensibilidad. 
La Ley de Weber-Fechner, también puede aplicarse a la sensación de altura (Matras, 1977) y permite medir la sensación sonora que produce la diferencia de alturas de la forma siguiente. Si consideramos dos sonidos provocados por dos ondas simples de frecuencias $\mathrm{f}_{1}, \mathrm{f}_{2}$, la diferencia de altura se puede medir como

$$
\mathrm{S}=h \times \log _{10}\left(\frac{\mathrm{f}_{1}}{\mathrm{f}_{2}}\right),
$$

donde $h$ es una constante cuyo valor determinará que esta diferencia se exprese en unas unidades o en otras.

Como veremos a continuación, para nosotros resultará más cómodo trabajar con logaritmos en base 2, en lugar de logaritmos decimales, por tanto la expresión será la siguiente:

$$
\mathrm{S}=k \times \log _{2}\left(\frac{\mathrm{f}_{1}}{\mathrm{f}_{2}}\right),
$$

Si hacemos $k=1000$ la diferencia de alturas se expresa en savarts, es decir

$$
\mathrm{S}=1000 \times \log _{2}\left(\frac{\mathrm{f}_{1}}{\mathrm{f}_{2}}\right) \text { savarts. }
$$

El savart, que divide la octava en aproximadamente 301 partes, fue propuesto por F.Savart (1791 - 1841). Como esta unidad resultaba demasiado grande para comparar afinaciones, H. H. Ellis (1859-1939) introdujo el cent que divide la octava en 1200 partes.

Para obtener la fórmula anterior expresada en cents basta con sustituir el valor $k=1200$, es decir

$$
S=1200 \times \log _{2}\left(\frac{f_{1}}{f_{2}}\right) \text { cents. }
$$

Una vez fijadas las unidades que utilizaremos en este trabajo, vamos a introducir el concepto de intervalo y su aritmética, sobre los que, de forma explícita o implícita, versará todo el contenido de nuestra investigación.

\subsubsection{Intervalos. Aritmética}

Dados dos sonidos de frecuencias $\mathrm{f}_{1}$ y $\mathrm{f}_{2}$ no nulas, llamamos intervalo ${ }^{8}$ al cociente entre estas frecuencias, es decir $f_{1} / f_{2}$

\footnotetext{
${ }^{7}$ Como $\log _{2}(a)=\log _{10}(a) / \log _{10}(2)$, se tiene que $\mathrm{h} \times \log _{10}\left(\mathrm{f}_{1} / \mathrm{f}_{2}\right)=\mathrm{h} \times \log _{10}(2) \times \log _{2}\left(\mathrm{f}_{1} / \mathrm{f}_{2}\right)$.

Si llamamos $\mathrm{k}=\mathrm{hx} \log _{10}(2)$, ya tenemos la expresión de $\mathrm{S}$ en logaritmos binarios.
} 
Como acabamos de comprobar, la percepción del intervalo puede describirse mediante logaritmos, y esto determina la aritmética de los mismos:

Consideramos tres frecuencias $\mathrm{f}_{1}, \mathrm{f}_{2}$ y $\mathrm{f}_{3}$ no nulas ordenadas de mayor a menor (de agudo a grave).

a) Suma de intervalos: Para sumar los intervalos $\mathrm{f}_{1} / \mathrm{f}_{2}$ y $\mathrm{f}_{2} / \mathrm{f}_{3}$ hacemos

$$
\frac{f_{1}}{f_{2}} \operatorname{mas} \frac{f_{2}}{f_{3}}=\frac{f_{1}}{f_{2}} \times \frac{f_{2}}{f_{3}}=\frac{f_{1} \times f_{2}}{f_{2} \times f_{3}}=\frac{f_{1}}{f_{3}} .
$$
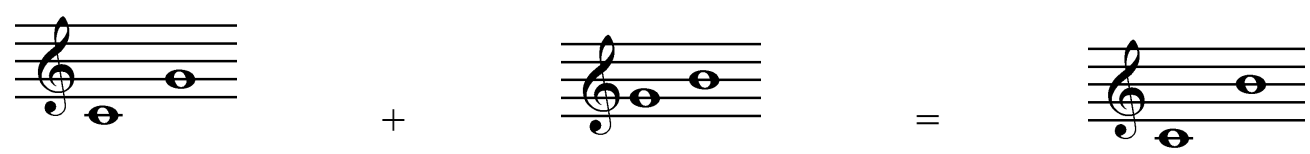

Comprobación: El nombre de suma recobra todo el sentido cuando trabajamos con sensación de altura en lugar de con el intervalo directamente. A continuación comprobamos que la sensación producida por el intervalo $\mathrm{f}_{1} / \mathrm{f}_{2}$ más la sensación de $\mathrm{f}_{2} / \mathrm{f}_{3}$ proporciona la misma sensación que $\mathrm{f}_{1} / \mathrm{f}_{3}$

$$
\begin{gathered}
1200 \times \log _{2}\left(\frac{f_{1}}{f_{2}}\right)+1200 \times \log _{2}\left(\frac{f_{2}}{f_{3}}\right)=1200 \times\left(\log _{2}\left(\frac{f_{1}}{f_{2}}\right)+\log _{2}\left(\frac{f_{2}}{f_{3}}\right)\right)= \\
=1200 \times\left(\log _{2}\left(\frac{f_{1}}{f_{2}} \times \frac{f_{2}}{f_{3}}\right)\right)=1200 \times\left(\log _{2}\left(\frac{f_{1}}{f_{3}}\right)\right) .
\end{gathered}
$$

b) Resta de intervalos: Para restar los intervalos $\mathrm{f}_{1} / \mathrm{f}_{3}$ y $\mathrm{f}_{2} / \mathrm{f}_{3}$ hacemos

$$
\frac{f_{1}}{f_{3}} \operatorname{menos} \frac{f_{2}}{f_{3}}=\frac{f_{1}}{f_{3}}: \frac{f_{2}}{f_{3}}=\frac{f_{1} \times f_{3}}{f_{2} \times f_{3}}=\frac{f_{1}}{f_{2}} \text {. }
$$
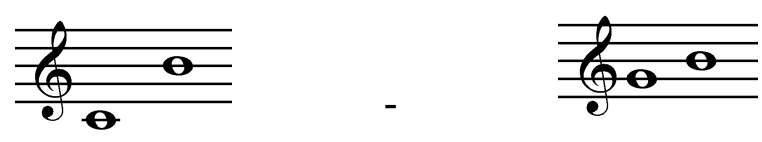

$=$

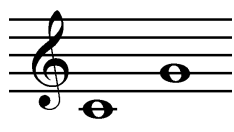

Comprobación: $\mathrm{Si}$ a la sensación producida por $\mathrm{f}_{1} / \mathrm{f}_{3}$ le restamos la producida por $\mathrm{f}_{2} / \mathrm{f}_{3}$, se obtiene la misma sensación que con $\mathrm{f}_{1} / \mathrm{f}_{2}$.

\footnotetext{
${ }^{8}$ Creemos importante advertir de la polisemia de la palabra intervalo. La acepción más habitual en este trabajo será “el cociente entre dos frecuencias". Sin embargo, también se utiliza en sentido matemático de la forma siguiente:

El intervalo $[a, b]$ es "el conjunto de todos los números reales entre a y b (incluidos a y b)".
} 


$$
\begin{aligned}
1200 \times \log _{2}\left(\frac{f_{1}}{f_{3}}\right) & -1200 \times \log _{2}\left(\frac{f_{2}}{f_{3}}\right)=1200 \times\left(\log _{2}\left(\frac{f_{1}}{f_{3}}\right)-\log _{2}\left(\frac{f_{2}}{f_{3}}\right)\right)= \\
= & 1200 \times\left(\log _{2}\left(\frac{f_{1}}{f_{3}}: \frac{f_{2}}{f_{3}}\right)\right)=1200 \times\left(\log _{2}\left(\frac{f_{1}}{f_{2}}\right)\right) .
\end{aligned}
$$

c) Suma de $n$ intervalos iguales: Para sumar $\mathrm{n}$ veces el intervalo $\mathrm{f}_{1} / \mathrm{f}_{2}$ hacemos:

$$
\frac{\mathrm{f}_{1}}{\mathrm{f}_{2}} \operatorname{mas} \frac{\mathrm{f}_{1}}{\mathrm{f}_{2}} \operatorname{mas} \ldots \text { mas } \frac{\mathrm{f}_{1}}{\mathrm{f}_{2}}=\left(\frac{\mathrm{f}_{1}}{\mathrm{f}_{2}}\right)^{n} \text {. }
$$
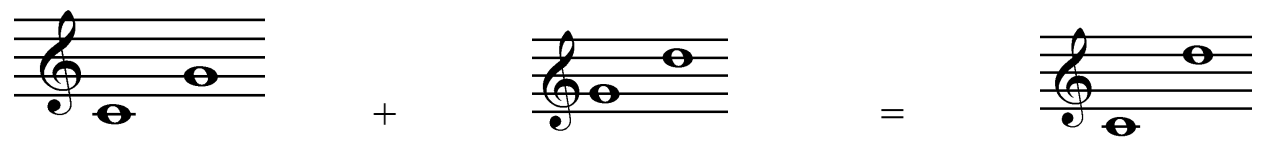

Comprobación: Al sumar $\mathrm{n}$ veces el intervalo $\mathrm{f}_{1} / \mathrm{f}_{2}$ obtenemos la sensación de $\left(\mathrm{f}_{1} / \mathrm{f}_{2}\right)^{\mathrm{n}}$ :

$$
\begin{gathered}
1200 \times \log _{2}\left(\frac{f_{1}}{f_{2}}\right)+1200 \times \log _{2}\left(\frac{f_{1}}{f_{2}}\right)+\ldots 1200 \times \log _{2}\left(\frac{f_{1}}{f_{2}}\right) \\
=1200 \times\left(\log _{2}\left(\frac{f_{1}}{f_{2}}\right)+\ldots+\log _{2}\left(\frac{f_{1}}{f_{2}}\right)\right)= \\
=1200 \times\left(\log _{2}\left(\frac{f_{1}}{f_{2}} \times \ldots \times \frac{f_{1}}{f_{2}}\right)\right)=1200 \times \log _{2}\left(\left(\frac{f_{1}}{f_{2}}\right)^{n}\right)
\end{gathered}
$$

d) Ampliación de intervalos: La ampliación de intervalos se hace sumando una o más octavas.

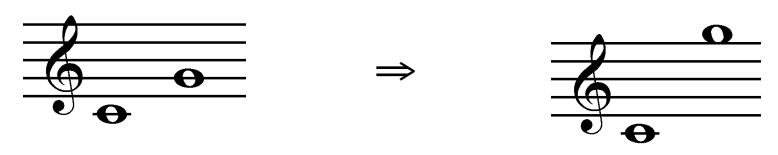

e) Reducción de intervalos: La reducción de intervalos se hace restando una o más octavas.
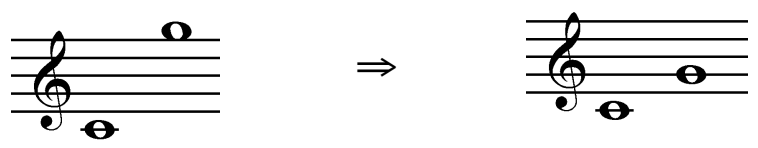
f) Inversión de intervalos: La inversión de un intervalo $\mathrm{f}_{1} / \mathrm{f}_{2}$ se hace aumentando el sonido $\mathrm{f}_{2}$ hasta que sea más agudo que $\mathrm{f}_{1}$, o bien reduciendo $f_{1}$ hasta que sea más grave que $f_{2}$.

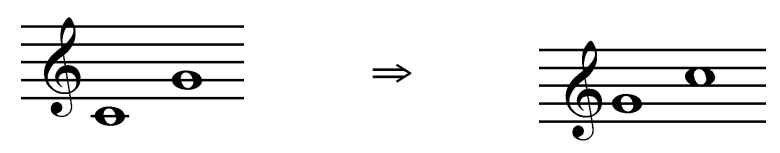

Entre todos los intervalos, el único que aparece en todos los sistemas de afinación es la octava. Ésta nos permite definir en el conjunto de todas las frecuencias una equivalencia ${ }^{9}$ entre sonidos que están a una octava de diferencia.

\subsubsection{Definiciones}

Como nuestra intención en este capítulo es mostrar las propiedades matemáticas que determinan las maneras de afinar, necesitamos establecer algunos conceptos de la forma más general posible, de manera que sean válidos para cualquier sistema de afinación ${ }^{10}$ :

\section{La octava}

En todos los sistemas de afinación aparece el concepto de octava. Un sonido de frecuencia $f_{1}$ se dice que es una octava más grave que otro $f_{2}$ si $f_{2}=2 \times f_{1}$. Hasta tal punto es intuitiva esta idea, que se usa de forma natural aunque no se tenga formación musical. Piénsese, por ejemplo, cuando cantan juntos un hombre y una mujer. El hombre suele cantar una octava más grave y sin embargo cualquiera reconoce que están interpretando las mismas notas.

Con esto, en lugar de estudiar todo el intervalo de frecuencias audibles, podemos reducir el estudio al intervalo [1,2[. Para ello, fijamos una nota patrón $f_{0}$, en la actualidad $f_{0}$ es el $\mathrm{La}_{4}$ de $440 \mathrm{~Hz}$. Dada una frecuencia $\mathrm{f}$, para trasladarla a $[1,2[$ seguimos los pasos siguientes:

\footnotetext{
${ }^{9}$ Para ser rigurosos, desde el punto de vista matemático, deberíamos decir una relación binaria de equivalencia, pero dados los objetivos de este Trabajo nos parece innecesario recargar la nomenclatura.

${ }^{10}$ Liern (1994a)
} 
1. Al fijar $\mathrm{La}_{4}=440 \mathrm{~Hz}$, el intervalo de frecuencias audibles queda dividido en intervalos de octava ${ }^{11}$ que, normalmente, empiezan con la nota Do de diferentes octavas, es decir,

$$
\left[f_{0}, 2 f_{0}\left[,\left[2 f_{0}, 2^{2} f_{0}\left[,\left[2^{2} f_{0}, 2^{3} f_{0}\left[, \ldots,\left[2^{n} f_{0}, 2^{n+1} f_{0}[\right.\right.\right.\right.\right.\right.\right.
$$

2. Comprobamos a que octava pertenece $f$. Por ejemplo, supongamos que $f$ está en $\left[2^{2} f_{0}, 2^{3} f_{0}[\right.$.

3. Dividimos la frecuencia $f$ por el Do correspondiente a su octava, es decir

$$
F=\frac{f}{2^{2} f_{0}} .
$$

Esto permite que podamos hacer todo el estudio dentro de los límites de una octava y para trasladarlo (transposición) a otra octava bastará con multiplicar por una potencia de 2 adecuada.

Por otro lado, como al trasladar las notas de frecuencia $f, 2 f, 4 f, \ldots, 2^{\mathrm{n}} f$ al intervalo [1,2[ obtendríamos $F$, decimos que $F$ es el representante de toda esta familia de notas

NOTA: La frecuencia del $\mathrm{La}_{4}$ ha sufrido múltiples modificaciones a lo largo de la historia. Su evolución desde el Renacimiento ha sido la siguiente:

$446 \mathrm{~Hz}$ : Renacimiento (instrumentos de viento de madera).

$415 \mathrm{~Hz}$ : instrumentos de viento de madera, afinados con los órganos parisinos (siglo XVII y XVIII).

$380 \mathrm{~Hz}$ : pequeño diapasón de lengüeta inglés de 1720

$480 \mathrm{~Hz}$ : órganos alemanes que tocaba Bach (principios del s. XVIII).

422,5 Hz: diapasón asociado con Georg Friedrich Händel (1740).

409 Hz: diapasón inglés (1780).

$400 \mathrm{~Hz}$ : diapasón (fines del s. XVIII).

$450 \mathrm{~Hz}$ : diapasón (fines del s. XVIII).

423,2 Hz: diapasón del teatro de ópera de Dresde (1815).

$435 \mathrm{~Hz}$ : diapasón (1826).

$451 \mathrm{~Hz}$ : diapasón de La Scala de Milán.

430,54 Hz: afinación "filosófica" o "científica".

$452 \mathrm{~Hz}$ : "tono sinfónico" (mediados del siglo XIX).

$435 \mathrm{~Hz}$ : "tono francés" comisión estatal de músicos y científicos franceses (16 de febrero de 1859).

11 En definitiva no se trata más que de una matematización del sistema franco-belga de notación musical. 
$435 \mathrm{~Hz}$ : "tono internacional" o "diapasón normal": Congreso de Viena (Conferencia Internacional sobre el Tono, 1887). El bandoneón actual.

$444 \mathrm{~Hz}$ : afinación de cámara (fines del s. XIX).

440 Hz: Reino Unido y Estados Unidos: (principios del siglo XX).

$440 \mathrm{~Hz}$ : Conferencia Internacional (1939).

440 Hz: Organización Internacional de Estandarización (1955).

440 Hz: Organización Internacional de Estandarización ISO 16 (1975).

\section{Distancia entre sonidos}

En música, la distancia entre sonidos recibe el nombre de intervalo ${ }^{12}$. Para determinar qué distancia es la adecuada debemos tener en cuenta que la percepción del sonido no es lineal, como podemos comprobar en el siguiente ejemplo.

Ejemplo 2.2. Sabemos que un sonido de frecuencia $880 \mathrm{~Hz}$. Es una octava más alto que otro de frecuencia $440 \mathrm{~Hz}$. Y a su vez éste es una octava más alto que un tercero de $220 \mathrm{~Hz}$. Si la percepción fuese lineal, la diferencia entre estos sonidos sería diferente: $880-440=440$ y $440-220=220$. Sin embargo, en la práctica sabemos que el oído en ambos casos percibe la misma distancia: una octava.

Este hecho ha sido muy estudiado por los investigadores de psicoacústica, y se recoge en la Ley de Weber-Fechner que asegura que la sensación sonora provocada por un sonido es función lineal del logaritmo de la excitación. Así, dados dos sonidos de frecuencias $f_{1}$ y $f_{2}$, la sensación sonora de que produce la diferencia de alturas es

donde h una constante positiva.

$$
d\left(f_{1}, f_{2}\right)=h\left|\log _{10}\left(\frac{f_{1}}{f_{2}}\right)\right|
$$

En el ejemplo anterior

$$
d\left(f_{1}, f_{2}\right)=h\left|\log _{10}\left(\frac{880}{440}\right)\right|=h \log _{10}(2)
$$

y así queda reflejada la sensación que produce la octava.

Las unidades más habituales para expresar esta distancia son el savart, $\sigma$, que se obtiene haciendo $\mathrm{h}=10^{3} \mathrm{y}$ el cent, $c$, que se obtiene con

$$
h=\frac{1200}{\log _{10} 2}=\frac{1200}{0.301030} \approx 3986,313714
$$

\footnotetext{
12 Si los sonidos son sucesivos se dice que es un intervalo melódico y si son simultáneos se dice que el intervalo es armónico
} 
Por comodidad de cálculo, nosotros trabajaremos con $\log _{2}$ en lugar de logaritmos decimales, $\mathrm{y}$ con $\mathrm{h}=1$. Entonces, podemos definir la distancia entre dos sonidos como

$$
d\left(f_{1}, f_{2}\right)=\left|\log _{2}\left(\frac{f_{1}}{f_{2}}\right)\right|
$$

Basta con multiplicar por 1200 para obtener la distancia en cents.

Si continuamos con el Ejemplo 2.2, se tiene

$$
\begin{aligned}
& d(440,220)=\left|\log _{2}\left(\frac{440}{220}\right)\right|=\log _{2}(2)=1 \\
& d(880,440)=\left|\log _{2}\left(\frac{880}{440}\right)\right|=\log _{2}(2)=1
\end{aligned}
$$

y para que esta distancia se exprese en cents multiplicamos por 1200, es decir 1 x $1200=1200$ cents en ambos casos.

\section{Siete notas}

Al menos desde el primer milenio antes de Cristo, los caldeos relacionaron muy estrechamente la música con la astrología y las matemáticas. De hecho, el destino de los hombres y la armonía del Universo se explicaba usando especulaciones matemáticas a las que atribuían multitud de propiedades. Parece ser que esto dio lugar a que numerosos fenómenos cósmicos fuesen representados por la comparación entre las longitudes de cuerdas tirantes. De este modo aparecieron cuatro relaciones asociadas con las cuatro estaciones del año que por su importancia, tomaron nombres propios:

$$
\text { 1/1 (unísono) 2/1 (octava) 3/2 (quinta) 4/3 (cuarta) }
$$

Entre los números cuyas propiedades eran especialmente útiles en la predicción de sucesos destacaban el 4 y el 7. De hecho, probablemente la antigua escala caldea era de siete notas.

En occidente, a partir de los caldeos y sobre todo los pitagóricos (siglo VI. a. C.) se ha considerado que las notas fundamentales eran 7 y que el resto eran alteraciones de esas notas. A las alteraciones se les llama sostenidos (\#) si aumentan la frecuencia y bemoles (b) si la disminuyen. Pero no precisaremos más en la definición de las alteraciones porque, como se verá más adelante, dependiendo del sistema de afinación significarán una cosa u otra. 


\section{Tonos y semitonos}

Se trata de intervalos que en la práctica se emplean más que los dados en (2). Dadas dos notas $f_{1}, f_{2}$ se tienen las siguientes relaciones:

Tono, (T): Decimos que $f_{2}$ es un tono más alta que $f_{1}$ si se puede obtener a partir de $f_{1}$ subiendo dos quintas y bajando una octava.

Semitono cromático, $(\mathrm{Sc})$ : Decimos que $f_{2}$ es un semitono cromático más alto que $f_{1}$ si se puede obtener a partir de $f_{1}$ subiendo siete quintas y bajando cuatro octavas.

Semitono diatónico, $(S d)$ : Decimos que $f_{2}$ es un semitono diatónico más alto $f_{1}$ si se puede obtener a partir de $f_{1}$ subiendo cinco quintas $\mathrm{y}$ bajando cuatro octavas.

Como se verá más adelante, hay sistemas de afinación en los que aparecen varios tipos de quinta, por tanto, la distancia o medida entre tonos y semitonos dependerá del sistema. Algunas de estas afinaciones verifican

$$
\mathrm{T}=\mathrm{Sc}+\mathrm{Sd} \text {, }
$$

e incluso $\mathrm{Sc}=\mathrm{Sd}$. Sin embargo, en general, no tienen por qué darse estas condiciones.

Acabamos esta sección enumerando las hipótesis con las que, salvo que se advierta de lo contrario, se utilizan en todo el trabajo.

1. Las notas se identifican con la frecuencia de su armónico fundamental.

2. Supondremos que la sensación de altura no depende ${ }^{13}$ de la intensidad ni del timbre.

3. Las unidades empleadas son los Hz. (para las frecuencias) y los cents (para la sensación de altura).

4. La precisión mínima con la que se trabaja es de \pm 5 cents.

\subsection{Afinaciones}

Desde la Antigua Mesopotamia (milenios IV y III a. de C.) el hombre se plantea con qué criterio la música admite unos sonidos y rechaza otros. Las teorías más arcaicas justificaron esta elección con razonamientos meramente religiosos o estéticos, consiguiendo con ello que durante muchos siglos la afinación fuese considerada una criba "caprichosa".

\footnotetext{
13 Esta restricción no supone ninguna pérdida de generalidad porque todo el estudio se realiza en la zona del campo de audibilidad en la que, como se ha dicho, es una hipótesis asumible.
} 
En el primer milenio antes de Cristo, los caldeos utilizaron la relación música-astrología-matemáticas para que los estudiosos de las estrellas explicasen el destino de los hombres y la armonía del Universo entrelazando la especulación matemática con los simbolismos. Esto dio lugar a que numerosos fenómenos cósmicos fuesen representados por la comparación entre las longitudes de cuerdas tirantes. De este modo aparecieron cuatro relaciones que, por su importancia, tomaron nombres propios ${ }^{14}$ : el unísono, la octava, la quinta y la cuarta ${ }^{15}$.

Se sabe que para los caldeos, el estudio de las propiedades de los números resultó fundamental en la predicción de sucesos, y en este sentido destacaron fundamentalmente el 4 y el 7, siendo este último, probablemente, el número de notas de la antigua escala caldea. En este contexto surge la primera afinación occidental que ha llegado hasta nuestros días: la afinación pitagórica.

\subsubsection{Sistema de Pitágoras}

Pitágoras nació en Samos hacia 570 a.C. y murió en Metaponte en 480 a.C. En su biografía es difícil separar los datos históricos de la leyenda originada a partir de abundante literatura apócrifa. Era hijo del comerciante Mnesarco, y muy probablemente acompañó a su padre en algunos de sus viajes. Su formación se ha dicho que fue muy completa a cargo de Hermodamas y Ferécides en Lesbos y de Tales y Anaximandro en Mileto. A pesar de que se ha discutido mucho acerca de los viajes de Pitágoras, lo cierto es que sólo a partir del contacto con diferentes países podría darse una explicación racional a algunas de sus doctrinas.

Hacia el año 512 a.C. fundó una escuela que tuvo gran influencia en el Sur de Italia y Grecia. A ella acudían jóvenes, ancianos, hombres y mujeres que formaron una asociación científica, filosófica, política y religiosa dedicada esencialmente al estudio de las matemáticas, la astronomía, la música, la fisiología y la medicina.

En el Harmonikon Enchidrion (alrededor del 100 a.C.) de Nicómaco se relata como Pitágoras descubrió las proporciones matemáticas de la música ${ }^{16}$ :

"Cierta vez, mientras calculaba (Pitágoras) si sería posible idear algún tipo de ayuda instrumental para los oídos que fuera firme e inequivoca... se produjo una milagrosa casualidad. Al pasar cerca de una fragua, escuchó cómo los martillos golpeaban el hierro contra el yunque, produciendo los sonidos que son más

\footnotetext{
14 En Historia General de la Música de A. Robertson y D. Stevens, ed. alpuerto (1988), se justifica cómo relacionaban estas cuatro fracciones con las estaciones del año.

${ }^{15}$ Liern (1994a)

${ }^{16}$ Neubauer (1992)
} 
armoniosos; si se combinan entre sí, excepto un par. Entre ellos, pudo reconocer la consonancia de la octava, la quinta y la cuarta. Pero notó que el intervalo entre la cuarta y la quinta era disonante en si mismo, pero era complementario a la mayor de estas dos consonancias. Contento, pues parecía que sus deseos habian sido satisfechos por un dios, corrió hacia el interior de la fragua y encontró tras realizar varios experimentos, que la diferencia de sonido era consistente con el peso de los martillos, pero no con la fuerza de los golpes, ni con las formas de los martillos, ni con la alteración del hierro al ser forjado. Tras tomar nota de los pesos de los martillos y de su momento de inclinación, que era idéntico, se marchó a su casa."

Aunque realmente no resulta creíble la manera de descubrir los intervalos consonantes (Goldáraz, 1992), lo cierto es que (quizás) Pitágoras, después de una serie de experimentos, con un monocordio (instrumento de una sola cuerda) comprobó que al dividir la cuerda por la mitad, al dividirla en tres partes iguales y al dividirla en cuatro partes cuando se hacía sonar estas porciones de cuerda con la cuerda original se obtenían intervalos consonantes. De hecho, para los pitagóricos estos son los únicos la octava, la quinta y la cuarta (que se corresponden respectivamente con las divisiones anteriores) son, junto con el unísono los únicos intervalos consonantes (ver Fig. 2.4)

Esta manera de relacionar los intervalos musicales con los números se puede resumir admitiendo que la afinación pitagórica consiste en aumentar y disminuir quintas ${ }^{17}$, puesto que el unísono y la octava no van a afectar a la afinación.

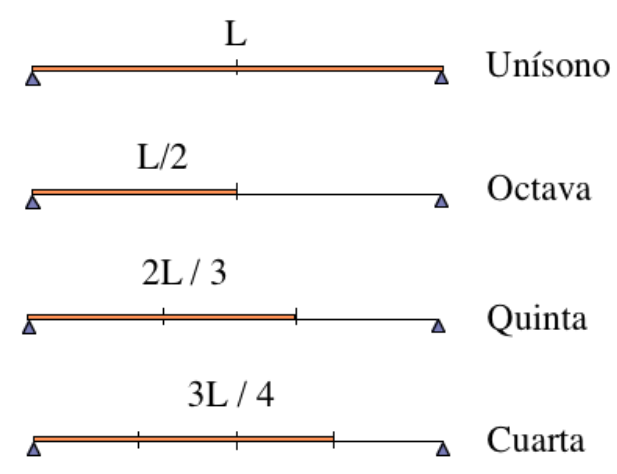

Fig. 2.4. Intervalos pitagóricos consonantes

Para obtener las notas restantes de la afinación de Pitágoras sumamos quintas sucesivamente y después restamos las octavas necesarias. Por ejemplo,

\footnotetext{
${ }^{17}$ Nótese que disminuir una quinta es lo mismo que aumentar una cuarta y disminuir una octava.
} 

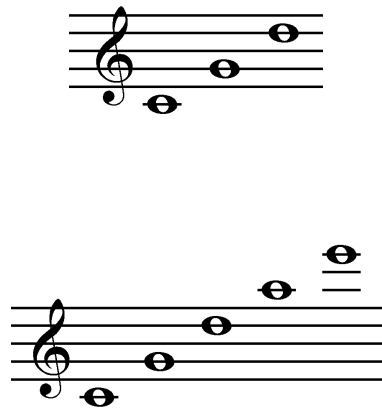

Restando una octava

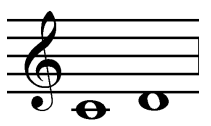

Restando dos octavas

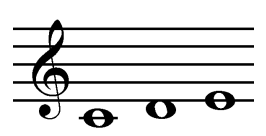

A partir del método expuesto en Liern (1994b, 1994c) podemos establecer una forma práctica de obtener las notas afinadas en el sistema pitagórico:

Paso 1: Numeramos las notas de la forma siguiente:

$$
0=\mathrm{Do}, 1=\mathrm{Re}, 2=\mathrm{Mi}, 3=\mathrm{Fa}, 4=\mathrm{Sol}, 5=\mathrm{La}, 6=\mathrm{Si}
$$

Paso 2: Escribimos filas de 7 números: 0, 1, 2, 3, 4, 5, 6. Marcamos el 3 y a partir de él contamos 5 lugares (contando también el 3), es decir, marcamos el número 0 . Si seguimos contando cinco lugares y marcando, al repetir este proceso obtenemos las siete notas naturales.

$$
\begin{array}{lllllllll}
0 & 1 & 2 & 3 & 4 & 5 & 6 \\
0 & 1 & 2 & 3 & 4 & 5 & 6 & \\
0 & 11 & 2 & 3 & 4 & 5 & 6 & \text { Naturales } \\
0 & 1 & 2 & 3 & 4 & 5 & 6
\end{array}
$$

Paso 3: Añadimos más filas arriba y debajo de las anteriores y repetimos el proceso. Las siete notas marcadas por debajo de las anteriores tendrán 1 sostenido, por debajo de éstas estarán las notas con 2 sostenidos y así indefinidamente. Si por el contrario contamos hacia arriba de las notas naturales obtenemos las notas con 1 bemol, con 2 bemoles, etc. 


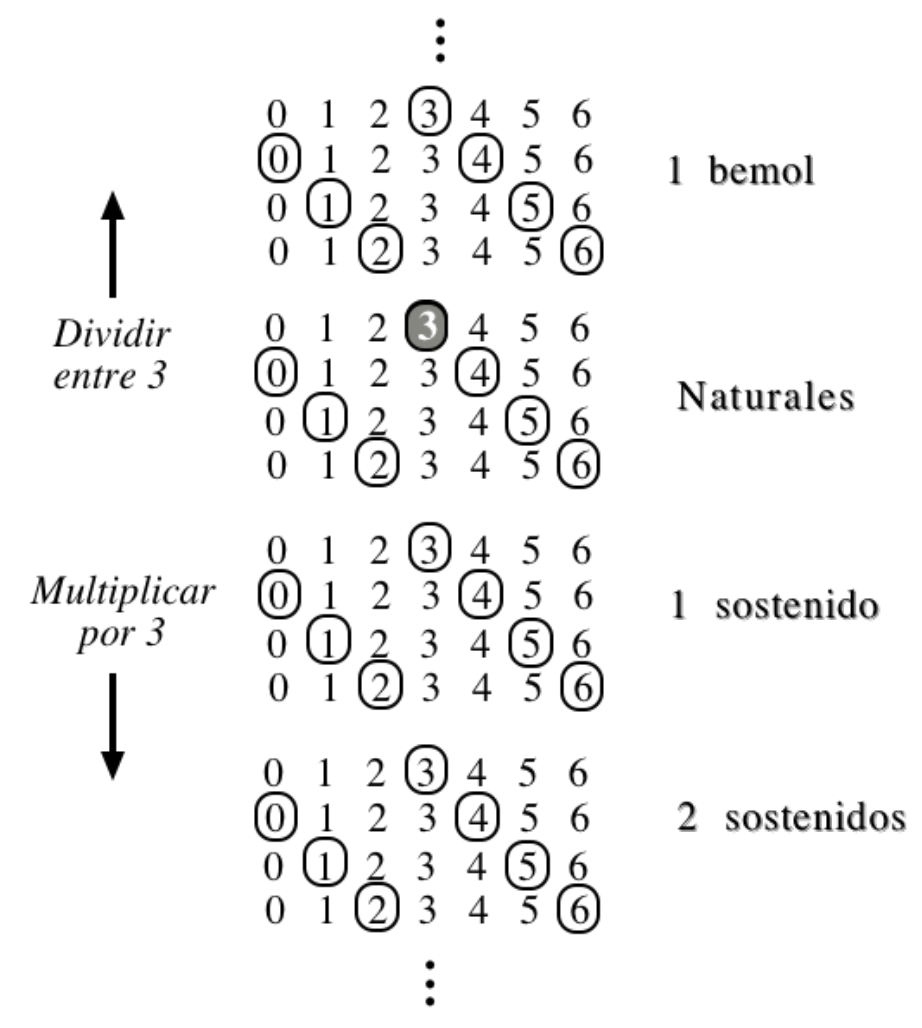

La forma de interpretar el método es la siguiente:

Para pasar de una nota marcada a la siguiente se multiplica por 3 su frecuencia si está por debajo y se divide entre 3 si está por encima. Si en lugar de ser la siguiente marcada es la que se ha marcado en segundo lugar se multiplica (o divide) por $3^{2}$, etc. Veámoslo en un ejemplo:

Ejemplo 2. 3 : ¿Por cuánto habrá que multiplicar o dividir la frecuencia del Mi para obtener un $\mathrm{Do}^{\#}$ ? ¿Y si se quiere obtener un $\mathrm{Si}^{\mathrm{b}}$ ?

a) Entre Mi y Do ${ }^{\#}$ hay 3 notas marcadas y como es hacia abajo en la tabla, debemos multiplicar por $3^{3}$. Es decir,

$$
\mathrm{Do}^{\#}=3^{3} \times \mathrm{Mi}=27 \times \mathrm{Mi}
$$

Para que esté dentro de la misma octava no hay más que restarle 4 octavas, es decir dividir entre $2^{4}=16$ :

$$
\mathrm{Do}^{\#}=\frac{3^{3}}{2^{4}} \times \mathrm{Mi}=\frac{27}{16} \times \mathrm{Mi}
$$


b) Entre Mi y $\mathrm{Si}^{\mathrm{b}}$ hay 6 notas marcadas y como es hacia arriba en la tabla, debemos dividir entre $3^{6}$. Es decir,

$$
\mathrm{Si}^{\mathrm{b}}=\frac{1}{3^{6}} \times \mathrm{Mi}=\frac{1}{729} \times \mathrm{Mi}
$$

Para que esté dentro de la misma octava no hay más que sumarle 10 octavas, es decir multiplicar por $2^{10}=1024$ :

$$
\mathrm{Si}^{\mathrm{b}}=\frac{2^{10}}{3^{6}} \times \mathrm{Mi}=\frac{1024}{729} \times \mathrm{Mi}
$$

Si nos quedamos con las notas más habituales, 7 notas naturales, 5 notas con sostenido y 5 notas con un bemol, la distribución que se obtiene dentro de la octava es la siguiente:

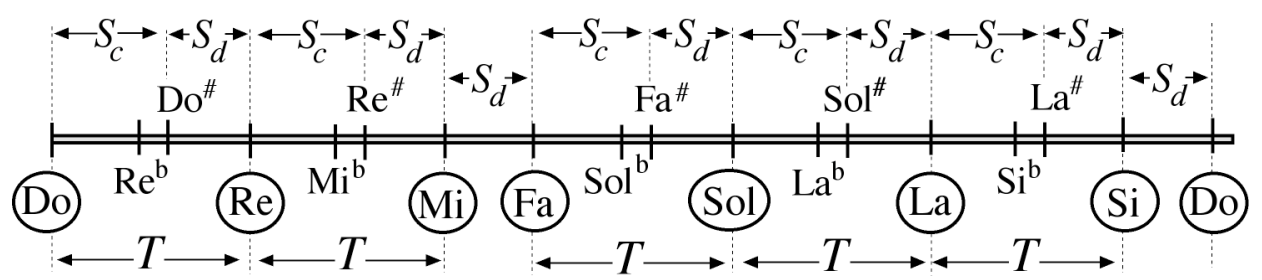

Fig. 2.5 Distribución de semitonos en la afinación pitagórica

La escala de Pitágoras considera un tono (9/8) y dos tipos de semitonos, uno cromático $(2187 / 2048)$ y otro diatónico (256/243). Como se puede observar (Fig. 2.5) el semitono cromático es más grande que el semitono diatónico y dos notas enarmónicas sonarán diferente.

s.c.

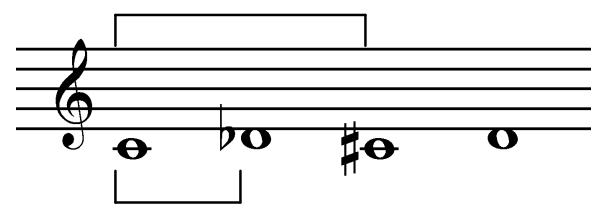

s.d.

A la diferencia que existe entre el semitono cromático y el diatónico se le llama coma pitagórica que también se puede obtener restando 7 octavas a la suma de 12 quintas justas.

$$
\text { Coma Pitagórica }=\frac{2187}{2048}: \frac{256}{243}=\frac{531441}{524288}
$$

Si representamos 11 quintas consecutivas de la afinación pitagórica y al resto le llamamos quinta del lobo (Fig. 2.6) obtenemos el círculo de quintas para el sistema pitagórico: 


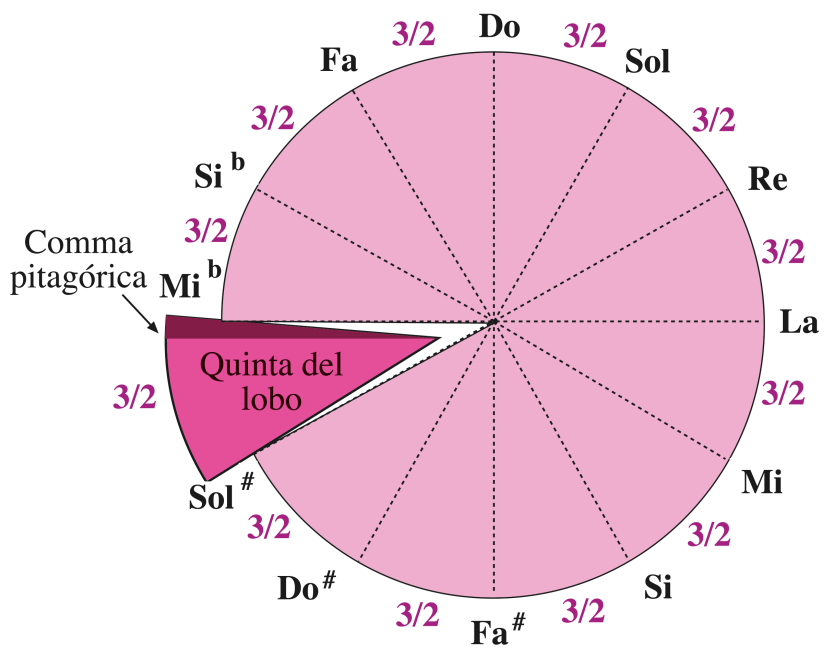

Fig. 2.6 Representación de la quinta del lobo en el círculo de quintas

Del método empleado por la afinación pitagórica no puede deducirse cuál es la cantidad de notas por octava que resulta más adecuada. Sin embargo, más tarde veremos que este número, desde luego no es arbitrario y que su secuencia es $7,12,53,665$, etc.

Finalizamos este apartado mostrando las frecuencias de 53 notas por octava fijando $\mathrm{La}_{4}=440 \mathrm{~Hz}$ :

\begin{tabular}{|c|c|c|c|c|c|}
\hline Nota & Frecuencia & Nota & Frecuencia & Nota & Frecuencia \\
\hline Do & 260,74074 & Mi & 330 & $\mathrm{Sol}^{\#}$ & 417,65625 \\
\hline $\mathrm{Si}^{\#}$ & 264,29809 & $\operatorname{Re}^{\# \#}$ & 334,50228 & $\mathrm{Fa}^{\# \# \#}$ & 423,35444 \\
\hline $\mathrm{La}^{\text {\#\# }}$ & 267,90398 & Do \#\#\# & 339,06598 & $\mathrm{Do}^{\mathrm{bbb}}$ & 428,23523 \\
\hline $\mathrm{Mi}^{\mathrm{bbb}}$ & 270,99261 & $\mathrm{Sol}^{\mathrm{bb}}$ & 342,97502 & $\mathrm{Si}^{\mathrm{bb}}$ & 434,07776 \\
\hline $\mathrm{Re}^{\mathrm{b}}$ & 274,68983 & $\mathbf{F a}$ & 347,65432 & La & 440 \\
\hline Do $^{\#}$ & 278,4375 & $\mathrm{Mi}^{\#}$ & 352,39746 & $\mathrm{Sol}^{\# \#}$ & 446,00304 \\
\hline $\mathrm{Si}^{\# \#}$ & 282,2363 & $\operatorname{Re}^{\# \# \#}$ & 357,20531 & $\mathrm{Fa}^{\# \# \# \#}$ & 452,08797 \\
\hline $\mathrm{Fa}^{\mathrm{bbb}}$ & 285,49016 & $\mathrm{La}^{\mathrm{bbb}}$ & 361,32348 & Dobb & 457,30003 \\
\hline $\mathrm{Mi}^{\mathrm{bb}}$ & 289,38517 & $\mathrm{Sol}^{\mathrm{b}}$ & 366,25311 & Sib & 463,5391 \\
\hline $\operatorname{Re}$ & 293,33333 & $\mathrm{Fa}^{\#}$ & 371,25 & La\# & 469,86328 \\
\hline Do ${ }^{\# \#}$ & 297,33536 & $\mathrm{Mi}^{\# \#}$ & 376,31506 & $\mathrm{Sol}^{\# \# \#}$ & 476,27375 \\
\hline $\mathrm{Si}^{\# \# \#}$ & 301,39198 & $\mathrm{Si}^{\mathrm{bbbb}}$ & 380,65354 & $\mathrm{Re}^{\mathrm{bbb}}$ & 481,76464 \\
\hline $\mathrm{Fa}^{\mathrm{bb}}$ & 304,86669 & $\mathrm{La}^{\mathrm{bb}}$ & 385,8469 & $\mathrm{Do}^{\mathrm{b}}$ & 488,33748 \\
\hline $\mathrm{Mi}^{\mathrm{b}}$ & 309,02606 & Sol & 391,11111 & $\mathbf{S i}$ & 495 \\
\hline $\operatorname{Re}^{\#}$ & 313,24219 & $\mathrm{Fa}^{\mathrm{\#}}$ & 396,44714 & $\mathrm{La}^{\# \#}$ & 501,75342 \\
\hline Do ${ }^{\# \# \#}$ & 317,51583 & $\mathrm{Mi}^{\mathrm{\# \#}}$ & 401,85598 & $\mathrm{Mi}^{\mathrm{bbbb}}$ & 507,53806 \\
\hline $\mathrm{Sol}^{\mathrm{bbb}}$ & 321,17643 & $\mathrm{Si}^{\mathrm{bbb}}$ & 406,48891 & $\operatorname{Re}^{\mathrm{bb}}$ & 514,46253 \\
\hline $\mathrm{Fa}^{\mathrm{b}}$ & 325,55832 & $\mathrm{La}^{\mathrm{b}}$ & 412,03475 & Do & 521,48148 \\
\hline
\end{tabular}

Tabla 2.1. Frecuencias en Hercios de $53+1$ notas de la afinación pitagórica fijando $\mathrm{La}_{4}=440 \mathrm{~Hz}$ 


\subsubsection{Afinación Justa: Sistema de Zarlino}

Con el nombre de afinación justa o de los físicos se conocen varios sistemas de afinación que, en la práctica, añaden el intervalo 5/4 a la afinación pitagórica para representar el intervalo de tercera (Fig 2. 7):

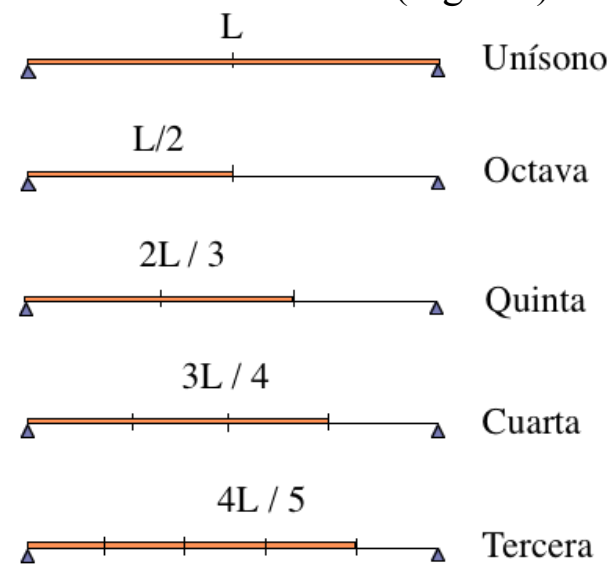

Fig 2. 7 Intervalos consonantes para la afinación justa

Utilizando razonamientos estrictamente numéricos, Arquitas de Tarento (430-360 a.C.) advirtió que los intervalos $2 / 1,3 / 2$ y 4/3 son de la forma $(n+1) / n$ y empleó la estructura para dividir la cuarta en tres intervalos,

que verifiquen esta relación, es decir,

$$
\frac{9}{8}, \frac{10}{9}, \frac{16}{15}
$$

$$
\frac{4}{3}=\frac{9}{8} \times \frac{10}{9} \times \frac{16}{15}
$$

Operando con estos nuevos intervalos surge un intervalo prohibido por los pitagóricos, el intervalo de tercera, puesto que

$$
\frac{9}{8} \times \frac{10}{9}=\frac{5}{4}
$$

A pesar de los razonamientos de Arquitas, la versión más antigua de la afinación justa se atribuye a Aristoxenos de Tarento (360-300 a.C.), un discípulo de Aristóteles que rechaza asociar las consonancias sonoras con relaciones numéricas. Sostenía que bastaba con el oído y la experiencia para conseguir la afinación, de ahí que a sus discípulos sean considerados armonistas por oído frente a los pitagóricos a los que se les conocía como armonistas por cálculo. 
Para Aristoxenos, a diferencia de los pitagóricos, los conceptos iniciales son las notas y a partir de ellas se obtienen los intervalos. Su afinación es prácticamente la misma ${ }^{18}$ que la de Zarlino que describiremos en este trabajo (véanse Monzo, 2003 y Bailache, 2003 ).

Aunque a partir de Aristoxenos, surgen multitud de pensadores que defienden la justa entonación, lo cierto es que hasta los siglos XVI y XVII la afinación dominante entre los teóricos era la pitagórica, y en la práctica de los músicos, la justa afinación y la afinación pitagórica se mezclaban sin ningún problema (ver Goldáraz, 1992).

A pesar de lo dicho, cuando se habla de justa entonación sin más, se hace referencia a la afinación de Gioseffo Zarlino (1517-1590), quien mucho antes de conocerse los armónicos, estableció que había una afinidad entre los sonidos cuyas frecuencias son proporcionales a 1, 2, 3, 4, 5, 6 y comprobó que éstos eran emitidos por cuerdas de longitudes

$$
\frac{1}{1}, \frac{1}{2}, \frac{1}{3}, \frac{1}{4}, \frac{1}{5}, \frac{1}{6}
$$

Así pues, el objetivo de Zarlino es conseguir qua las terceras mayores y menores sean justas. Sin embargo, como asegura J. Piles (Piles, 1982), la forma más sencilla de obtener el sistema de afinación de Zarlino es a través de una aproximación al sistema pitagórico en el que se han mejorado las terceras. Esta mejora consiste en aproximar la quinta justa por un intervalo parecido, 40/27, al que denominamos quinta sintónica, es decir, hacemos

$$
\frac{3}{2} \approx \frac{40}{27}
$$

con lo cual, el error que estamos asumiendo es $81 / 80$ (a este error se le llama coma sintónica). El paso siguiente es sustituir algunas de las quintas naturales por las quintas sintónicas ${ }^{19}$

$\Rightarrow$ Quintas ascendentes (multiplicar)

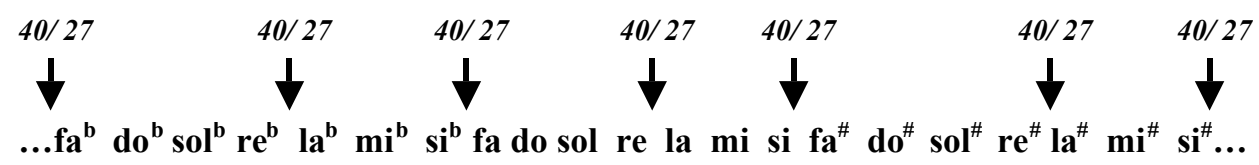

Quintas descendentes (dividir) $\Leftarrow$

\footnotetext{
18 Hay ligerísimas modificaciones que no se utilizan en la actaulidad y pueden consultarse, por ejemplo, en Chailley, Challan (1965) y Monzo (2003).

19 Dependiendo de cuáles sean las quintas naturales sustituidas, se obtiene la justa entonación de Zarlino, de Delezenne, etc.
} 
Si, como hacíamos en el sistema pitagórico, nos quedamos con 7 notas naturales, 5 notas con sostenido y 5 notas con un bemol, la distribución que se obtiene es la siguiente:

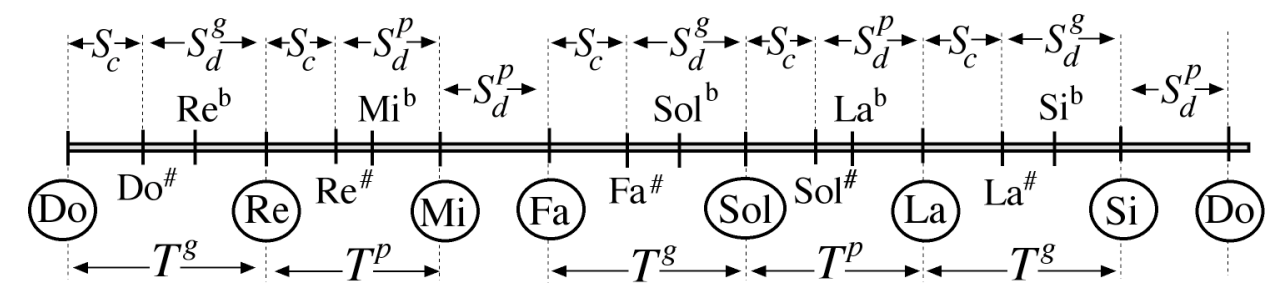

Fig. 2.8. Distribución de semitonos en la afinación de Zarlino

Se comprueba, por tanto, que el sistema de Zarlino diferencia dos tipos de tonos uno grande $(9 / 8)$ y uno pequeño (10/9) y tres tipos de semitonos uno cromático $(25 / 24)$ y dos diatónicos $(27 / 25)$ y $(16 / 15)$.

27/25 Semitono diatónico de tono grande

16/15 Semitono diatónico de tono pequeño

Al ser el semitono cromático más pequeño que los diatónicos la distribución en la escala es diferente a la del sistema pitagórico.

s.d.

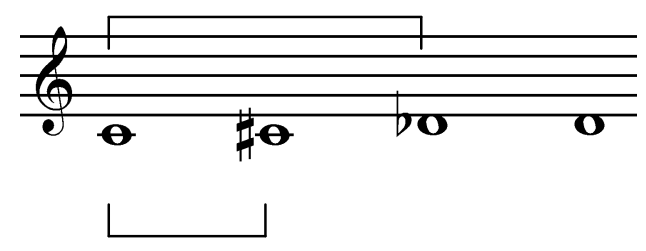

S.c.

Con este sistema, el círculo de quintas tampoco está cerrado. De hecho, a diferencia de lo que ocurre en el sistema pitagórico, la quinta del lobo es más grande que las justas

A continuación mostramos una tabla con las frecuencias de 50 notas $^{20}$ de la afinación de Zarlino fijando el $\mathrm{La}_{4}=440 \mathrm{~Hz}$.

\footnotetext{
${ }^{20}$ En la sección 2.3 se justifica por qué se ha elegido 50 notas.
} 


\begin{tabular}{|c|c|c|c|c|c|}
\hline Nota & Frecuencia & Nota & Frecuencia & Nota & Frecuencia \\
\hline Do & 264 & $\operatorname{Re}^{\# \#}$ & 335,69336 & $\mathrm{La}^{\mathrm{b}}$ & 422,4 \\
\hline $\mathrm{Si}^{\# \#}$ & 268,55469 & $\mathrm{Fa}^{\mathrm{b}}$ & 337,92 & Sol $^{\# \#}$ & 429,6875 \\
\hline $\operatorname{Re}^{b b}$ & 273,7152 & $\mathrm{Mi}^{\#}$ & 343,75 & $S i^{b b b}$ & 437,94432 \\
\hline Do & 275 & Sol ${ }^{b b b}$ & 350,35546 & La & 440 \\
\hline $\mathrm{Si}^{\# \# \#}$ & 279,74446 & $\mathrm{Fa}$ & 352 & Sol & 447,59114 \\
\hline Reb & 285,12 & $M i^{\# \#}$ & 358,07292 & $S i^{b b}$ & 456,192 \\
\hline Do & 286,45833 & Sol $^{b b}$ & 364,9536 & $\mathrm{La}^{\#}$ & 458,33333 \\
\hline $\mathrm{Mi}^{\mathrm{bbb}}$ & 291,96288 & $\mathrm{Fa}^{\#}$ & 366,66667 & $\mathrm{Do}^{\mathrm{bbb}}$ & 467,14061 \\
\hline $\operatorname{Re}$ & 297 & $\mathrm{Mi}^{\# \#}$ & 372,99262 & $S i^{b}$ & 475,2 \\
\hline Do"\#\# & 298,3941 & Sol $^{b}$ & 380,16 & $\mathrm{La}^{\# \#}$ & 477,43055 \\
\hline $\mathrm{Mi}^{\mathrm{bb}}$ & 304,128 & $\mathrm{Fa}^{\# \#}$ & 381,94444 & $\mathrm{Do}^{\mathrm{bb}}$ & 486,6048 \\
\hline $\operatorname{Re}^{\#}$ & 309,375 & $L a^{b b b}$ & 389,28384 & Si & 495 \\
\hline $\mathrm{Fa}^{\mathrm{bbb}}$ & 311,42707 & Sol & 396 & $L a^{\# \# \#}$ & 497,32349 \\
\hline $\mathrm{Mi}^{\mathrm{b}}$ & 316,8 & $\mathrm{Fa}^{\# \# \#}$ & 397,85879 & $\mathrm{Do}^{\mathrm{b}}$ & 506,88 \\
\hline $\operatorname{Re}^{\# \#}$ & 322,26562 & $\mathrm{La}^{\mathrm{bb}}$ & 405,504 & $\mathrm{Si}^{\#}$ & 515,625 \\
\hline $\mathrm{Fa}^{\mathrm{bb}}$ & 324,4032 & Sol $^{\#}$ & 412,5 & $\operatorname{Re}^{\mathrm{bbb}}$ & 525,53318 \\
\hline Mi & 330 & $S i^{b b b b}$ & 420,42655 & Do & 528 \\
\hline
\end{tabular}

Tabla 2.2 Frecuencias en Hercios de $50+1$ notas de la afinación zarlineana fijando $\mathrm{La}_{4}=440 \mathrm{~Hz}$

\subsubsection{Ventajas e inconvenientes de las afinaciones}

\section{Ventajas}

En las afinaciones, como los sonidos afinados se obtienen con números racionales, los intervalos que aparecen son naturales, es decir, que las notas musicales se corresponden con armónicos de la serie natural. Por ejemplo, en el sistema pitagórico están afinados todos los armónicos que son múltiplos de 2 y de 3 , mientras que en el sistema de Zarlino, están afinados los múltiplos de 2 , de 3 y de 5. Dicho de otro modo, el primer armónico que no está afinado en el sistema de Pitagóras es el quinto mientras que en el sistema de Zarlino es el séptimo.

\section{Inconvenientes}

La forma más sencilla de describir los problemas de las afinaciones es razonar sobre el círculo de quintas. En esencia, los problemas que presentan son los siguientes:

a) Al no cerrarse el círculo de quintas, el número de notas por octava debe fijarse incorporando nuevos razonamientos. 
b) Como las notas afinadas no están distribuidas de forma uniforme, la nota que se toma como origen del sistema de afinación es fundamental, y esto dificulta la trasposición.

En cuanto a la cantidad de notas, el hecho de fijar 7, 12 u otro número de notas no es una cuestión trivial. De hecho, no siempre se ha hecho con éxito. Por ejemplo, Robert Smith, en Harmonics, or the Philosophy of Musical Sounds (1749), propone que el temperamento de 5/18 de coma zarliniana se aproxime por un temperamento cíclico de 21 divisiones por octava. Sin embargo, se puede comprobar que en este temperamento el 21 no tiene ningún sentido, sino que, como bien afirma J. J. Goldáraz (1992), deben considerarse 50 divisiones.

Por otro lado, cuando queremos transponer una nota o pasaje de notas se dice que se ha hecho una trasposición. Por ejemplo, si la trasposición consiste en subir (o bajar) un intervalo $p / q$, hay que multiplicar (o dividir) las frecuencias de las notas por $p / q$.

Supongamos que en el sistema pitagórico contamos con 17 notas en una octava cuyas frecuencias en Hz. son:

\begin{tabular}{llllll}
\hline Nota & $H z$ & Nota & $H z$ & Nota & $H z$ \\
\hline Do & 260,7404 & $\mathrm{Mi}$ & 330 & $\mathrm{Sol}^{\#}$ & 417,6563 \\
$\mathrm{Re}^{\mathrm{b}}$ & 274,6898 & $\mathrm{Fa}$ & 347,6543 & $\mathrm{La}^{\mathrm{a}}$ & 440 \\
$\mathrm{Do}^{\#}$ & 278,4375 & $\mathrm{Sol}^{\mathrm{b}}$ & 366,2531 & $\mathrm{Si}^{\mathrm{b}}$ & 463,5391 \\
$\mathrm{Re}$ & 293,3333 & $\mathrm{Fa}^{\#}$ & 371,25 & $\mathrm{La}^{\#}$ & 469,8633 \\
$\mathrm{Mi}^{\mathrm{b}}$ & 309,0261 & $\mathrm{Sol}$ & 391,1111 & $\mathrm{Si}$ & 495 \\
$\mathrm{Re}^{\#}$ & 313,2422 & $\mathrm{La}^{\mathrm{b}}$ & 412,0347 & $\mathrm{Do}$ & 521,4808 \\
\hline
\end{tabular}

Tabla 2.3 Frecuencias en Hercios de 17 notas de la afinación pitagórica.

Si un violín afinado en el sistema pitagórico interpreta las notas descritas en A, las frecuencias que sonarán son las siguientes:

$$
260,7407,293,3333,330,391,1111,495,440
$$

Si ahora quiere trasportar el compás subiéndolo una cuarta aumentada (véase $\mathrm{B}$ ), las frecuencias serán

$371,25,417,6562,469,8633,2 \times 278,4375,2 \times 352.3975,2 \times 313,2422$.

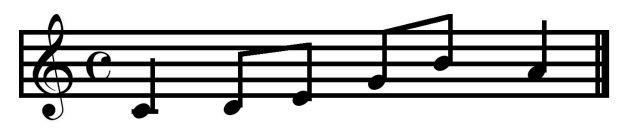

A

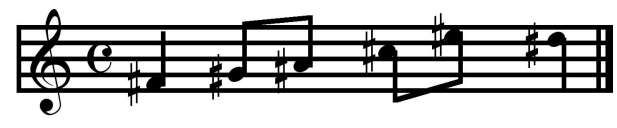

B 
La nota cuya frecuencia hemos subrayado, que en el pentagrama se representa con $\mathrm{Mi}^{\#}$ no se corresponde con ninguna nota afinada de las que aparecen en la tabla 2.3.

Es fácil comprender que si esto ocurre con el sistema pitagórico, en el que sólo aparece un tipo de tono, la situación se complica mucho más cuando se afina con el sistema de Zarlino en el que aparecen dos tipos de tonos.

\subsubsection{Comentarios}

Desde un punto de vista meramente aritmético podemos decir que el sistema pitagórico sólo maneja sonidos que se pueden obtener mediante potencias de $\mathbf{2}$ y de $\mathbf{3}$ a partir de una frecuencia dada $\mathbf{f}_{\mathbf{0}}$. La justa entonación añade al sistema pitagórico las potencias del $\mathbf{5}$. Vista esta secuencia lógica, la pregunta es evidente: ¿por qué no seguir con las potencias de 7 y de 9, etc.?

Las razones para detenernos en el 5 son de diversa índole. En primer lugar hay razones estéticas: el intervalo de séptima convive con dificultad con los intervalos de la afinación de Zarlino. Por otro lado, cada vez que se añaden nuevas frecuencias se está añadiendo inconvenientes a los sistemas de afinación. Sirva como resumen de estos razonamientos el fragmento de la carta, fechada el de 3 de mayo de 1760, que Leonhard Euler (1077-1783) escribió a Federica Carlota Ludovica von Brandenburg Schwedt, princesa de Anhalt Dessau (1745 - 1808), para instruirla sobre temas de música (Euler, 1990):

Carta VII: De los doce tonos del clavecín:

"Mi intención era presentar a Vuestra Alteza el verdadero origen de los sonidos empleados en la música, casi totalmente desconocido para los músicos; pues no es la Teoría lo que los ha conducido al conocimiento de los tonos, lo deben más bien a la fuerza oculta de la verdadera Armonía, actuando tan eficazmente en sus oídos que, por así decirlo, los forzó a recibir los tonos actualmente en uso, aunque no estén suficientemente decididos sobre su justa determinación. Ahora bien, los principios de la Armonía se reducen en último término a números, [...] el número 2 produce sólo octavas [...]. Después el número 3 produce los tonos

$$
C, c, \overline{\mathrm{c}}, \overline{\overline{\mathrm{c}}}, \overline{\mathrm{c}} \text {, }
$$

que difieren de los anteriores en una quinta. Pero introduzcamos también el número 5 y veamos cuál sería el tono que produce 5 vibraciones, mientras que el $F$ no hace más que una. [...] los músicos lo indican con la letra $\overline{\mathrm{a}},[\ldots]$ es llamado una tercera mayor y produce una consonancia muy agradable, estando contenido en una proporción de números bastante pequeña, 4 y 5 . [...] (Así) tendréis las teclas principales del clavecín que según los antiguos, constituye la escala llamada diatónica que deriva del número 2, del número 3 repetido tres veces y del número 5. 
No admitiendo más que estos tonos, se está en condiciones de componer muy bellas melodías, cuya belleza se fundamenta únicamente en la simplicidad de los números que producen estos tonos. [...]

Si se quisiera también introducir el número 7, el número de tonos de una octava sería mayor, y se llevaría toda la música a un grado más alto. Pero aqui la Matemática abandona la armonía a la Música."

3 de mayo de 1760

No obstante, en la actualidad hay afinaciones (generalmente en obras experimentales) en las que se utilizan intervalos justos de séptima u otros (Goldáraz, 1992) y a pesar de que la mayoría de compositores las consideran innecesarias, estas afinaciones no plantean ninguna dificultad matemática adicional. Por ejemplo, en Liern (1998) se construye una afinación que contiene las potencias de 3, 5 y 7 . Para ello se utiliza la aproximación,

$$
\frac{7}{4} \approx \frac{9}{5}
$$

con lo cual tenemos garantizado que se comete un error (comma) de $36 / 35$. La forma práctica de obtener esta afinación es aproximar la quinta sintónica por 32 / 21 , es decir, que hacemos

$$
\frac{32}{21} \approx \frac{40}{27} .
$$

Si ahora sustituimos la mitad de las quintas sintónicas

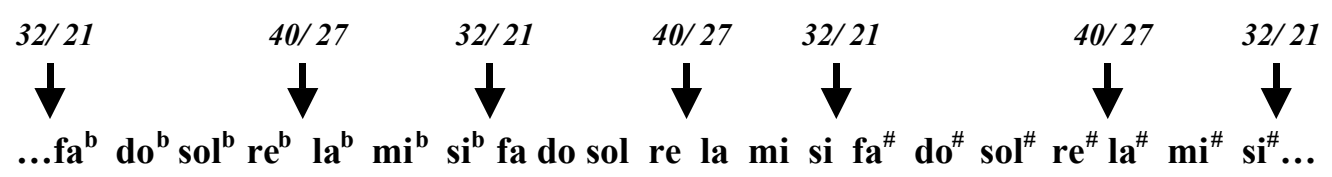

se obtienen las siguientes notas:

\begin{tabular}{cccccc}
\hline Nota & Frecuencia (Hz) & Nota & Frecuencia (Hz) & Nota & Frecuencia (Hz) \\
\hline $\mathrm{Do}^{\#}$ & 282.86 & $\mathrm{Do}$ & 264 & $\mathrm{Do}^{\mathrm{b}}$ & 246.40 \\
$\mathrm{Re}^{\#}$ & 318.21 & $\mathrm{Re}$ & 297 & $\mathrm{Re}^{\mathrm{b}}$ & 277.20 \\
$\mathrm{Mi}^{\#}$ & 353.57 & $\mathrm{Mi}$ & 330 & $\mathrm{Mi}^{\mathrm{b}}$ & 308 \\
$\mathrm{Fa}^{\#}$ & 377.14 & $\mathrm{Fa}$ & 352 & $\mathrm{Fa}^{\mathrm{b}}$ & 328.53 \\
$\mathrm{Sol}^{\#}$ & 424.28 & $\mathrm{Sol}$ & 396 & $\mathrm{Sol}^{\mathrm{b}}$ & 369.60 \\
$\mathrm{La}^{\#}$ & 471.43 & $\mathrm{La}$ & 440 & $\mathrm{La}^{\mathrm{b}}$ & 410.67 \\
$\mathrm{Si}^{\#}$ & 265.18 & $\mathrm{Si}$ & 495 & $\mathrm{Si}^{\mathrm{b}}$ & 462 \\
\hline
\end{tabular}

Tabla 2.4 Frecuencias en Hercios de un sistema de afinación que contiene las potencias del número 7 .

Evidentemente, este proceso podría ampliarse e ir añadiendo nuevas potencias de números primos. 


\subsection{Temperamentos regulares cíclicos}

Los temperamentos cíclicos surgen en la práctica para evitar, entre otros, los problemas que acabamos de analizar. Lo que se hace es disminuir las quintas "templar" de manera que se cierre el círculo de quintas, pero claro está, de manera que el resultado sea aceptable.

A continuación analizaremos los dos temperamentos más utilizados en nuestros días: El temperamento de 12 notas, que es un temperamento regular e igual y el temperamento de Holder, que es un temperamento regular mesotónico.

Matemáticamente, la forma de obtener los temperementos cíclicos es muy sencilla. Si queremos obtener un temperamento cíclico de $n$ notas dividimos el intervalo $[1,2]$ en $n$ subintervalos iguales. Para obtener el extremo inferior del $2^{\circ}$ subintervalo multiplicamos por $x$ el extremo inferior del $1^{\circ}$, para obtener el del $3^{\circ}$ multiplicamos el del $2^{\circ}$, es decir $\mathrm{x}^{2}$ por el 1 , y así sucesivamente hasta obtener el último que sería $\mathrm{x}^{\mathrm{n}}$ por 1 (véase Fig. 2.9).

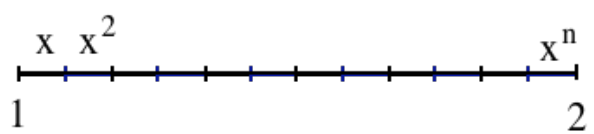

Fig. 2.9. Partición del intervalo $[1,2]$ en $n$ subintervalos iguales.

Con este proceso lo que aseguramos es que si multiplicamos el 1 por $x n$ veces debemos obtener el 2 , es decir

$$
x^{n} \times 1=2 \Rightarrow x=\sqrt[n]{2} .
$$

Por tanto, las notas afinadas en este sistema serán

$$
(\sqrt[\mathfrak{n}]{2})^{0},(\sqrt[n]{2})^{1},(\sqrt[n]{2})^{2}, \ldots,(\sqrt[n]{2})^{n-1}
$$

\subsubsection{Temperamento Igual (de 12 notas)}

El temperamento igual es regular y cíclico, divide la octava en 12 semitonos iguales, con lo que se cierra el círculo de quintas y se evita la quinta del lobo. Aunque el origen de este sistema es anterior al siglo XVII (Goldáraz, 1992) transcurrió mucho tiempo hasta que J. S. Bach (1685 - 1750), en su obra El Clave Bien Temperado donde realiza 48 Preludios y fugas (en dos libros) en todas las tonalidades, lograse su consagración. 
Hoy en día continúa siendo el sistema más empleado por sus ventajas teóricas y prácticas pero es el más pobre puesto que elimina algunas notas consideradas naturales que vienen dadas por la escala de armónicos. Su principal ventaja es la posibilidad de modular a cualquier tonalidad libremente sin las complicaciones de pasar por intervalos que están en la quinta del lobo. Las octavas son justas pero es el único intervalo en el que ocurre esto, las quintas son pequeñas y las terceras son muy grandes lo que acarrea demasiados problemas en los acordes mayores.

Por propia construcción, la distribución de semitonos en el sistema temperado de 12 notas resulta totalmente uniforme:

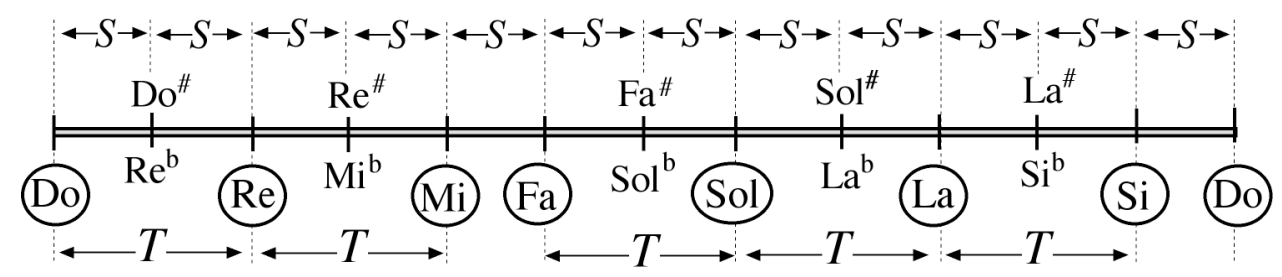

Fig 2. 10. Distribución de semitonos en el temperamento de 12 notas

\subsubsection{Sistema de Holder}

William Holder (1614-1697) utiliza un procedimiento mediante el cual divide la octava en 53 partes, notas o comas, de esta forma un tono contiene 9 comas, el semitono cromático 5 y el diatónico 4. El sistema utilizado por Holder no es más que una adaptación del sistema Pitagórico, comparando ambos sistemas dan resultados prácticamente iguales.

En el temperamento de Holder, si, nos quedamos con las notas más habituales: 7 notas naturales, 5 notas con sostenido y 5 notas con un bemol, la distribución que se obtiene es prácticamente la misma que en la afinación pitagórica:

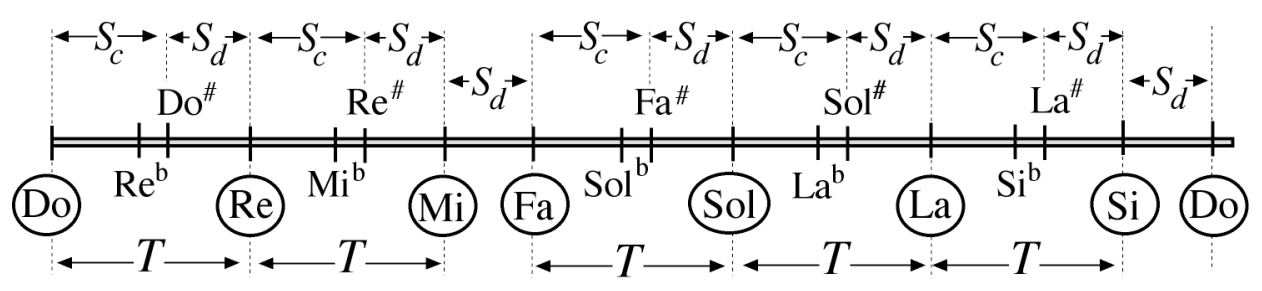

Fig 2. 11. Distribución de notas para el temperamento de Holder 


\subsubsection{Ventajas y desventajas de los temperamentos regulares cíclicos}

a) El Temperamento de 12 notas

Como hemos señalado, en este temperamento cada una de las doce partes es un semitono temperado. Todos los semitonos son iguales, por tanto, las notas enarmónicas coinciden, así $\mathrm{La}^{\#}=\mathrm{Si}^{\mathrm{b}}, \mathrm{Mi}^{\#}=\mathrm{Fa}$, etc. Obviamente, en este sistema sólo existe un tipo de tono y de quinta, desapareciendo así la quinta del lobo, estas características hacen que sea un temperamento con grandes ventajas:

a) Puede modularse libremente a cualquier tonalidad sin que existan intervalos impracticables

b) El número de notas resulta muy apropiado para la práctica musical.

Sin embargo, el temperamento igual de 12 notas cuenta con algunos inconvenientes:

a) No existen intervalos justos. Al obtener los intervalos mediante números irracionales, éstos no se corresponden exactamente con la serie armónica de ninguna nota.

b) Aunque las quintas son bastante buenas ( -2 cents más cortas que las justas), las terceras mayores están muy desviadas (hay una diferencia de +14 cents).

Según J. J. Goldáraz (Goldáraz, 1992) la desafinación de las terceras, junto con la igualdad de los semitonos "que empobrecían la expresividad musical, fue lo que hizo que se retrasase su aplicación general al menos dos siglos a partir de las primeras formulaciones del siglo XVI". Sin embargo, en la actualidad, estamos tan acostumbrados a este temperamento que el intervalo justo de tercera nos suele parecer excesivamente apagado.

En cualquier caso, surge un orden de prioridades a la hora de valorar las propiedades de los temperamentos. En términos generales, es perferible la perfección en las quintas que en las terceras (Lattard, 1988; Goldáraz, 1992).

\section{b) El Temperamento de Holder}

Desde el trabajo del profesor Robert Dussaut, Explicación de las comas en los distintos sistemas acústicos (Chailley, Challan, 1965), el sistema de Holder se ha considerado como un sistema de afinación idóneo para trabajar con la afinación pitagórica. 
Las ventajas de este sistema de afinación aparecen en los estudios teóricos. Por un lado, como veremos en los capítulos siguientes de este Trabajo de Investigación, las diferencias con el sistema pitagórico son inapreciables, sin embargo el hecho de dividir la octava en 53 comas-Holder iguales hace que sea mucho más fácil de manejar.

En cuanto a los inconvenientes, posee los de cualquier temperamento: los intervalos que aparecen no se corresponden exactamente con los sonidos de la serie armónica. Pero sin duda, el gran inconveniente para la práctica de este sistema es que 53 notas por octava resulta un número excesivamente elevado.

\subsection{Temperamentos irregulares}

Como un tratamiento exhaustivo de los temperamentos irregulares excede de los objetivos que nos hemos planteado en esta Memoria, sólo presentaremos a modo de ejemplo dos de ellos. En Goldáraz (1992) puede encontrarse un estudio detallado de estos temperamentos y de cómo diferentes teóricos llegaron a su construcción.

Ejemplo 2.3. El temperamento de Werckmeister de $1 / 3$ de comma cierra el círculo de quintas con 12 notas acortando 1/3 de comma pitagórica en tres quintas (ver Fig. 2.12):

$$
\text { Do-Sol, Sol-Re, Si-Fa }{ }^{\#}
$$

Si a la quinta natural le "restamos" 1/3 de coma pitagórica, se obtiene

$$
\frac{3}{2} \text { menos } \frac{1}{3} \text { de comma pitagórica } \Rightarrow \frac{\frac{3}{2}}{\sqrt[3]{\frac{531441}{524288}}}=\frac{\frac{3}{2}}{\sqrt[3]{\frac{3^{12}}{2^{19}}}}=\frac{\sqrt[3]{2^{16}}}{3^{3}} \approx 1,4932
$$

Por tanto, las quintas Do-Sol, Sol-Re, Si-Fa ${ }^{\#}$ en lugar de obtenerse al multiplicar la frecuencia más baja por 3/2, se obtienen al multiplicar por 1,4932 las frecuencias de la nota más grave, es decir,

$$
1,4932 \times \mathrm{DDo}=\text { Sol }, \quad 1,4932 \mathrm{x} \text { Sol }=\mathrm{Re}, \quad 1,4932 \times \mathrm{Si}=\mathrm{Fa}^{\#}
$$




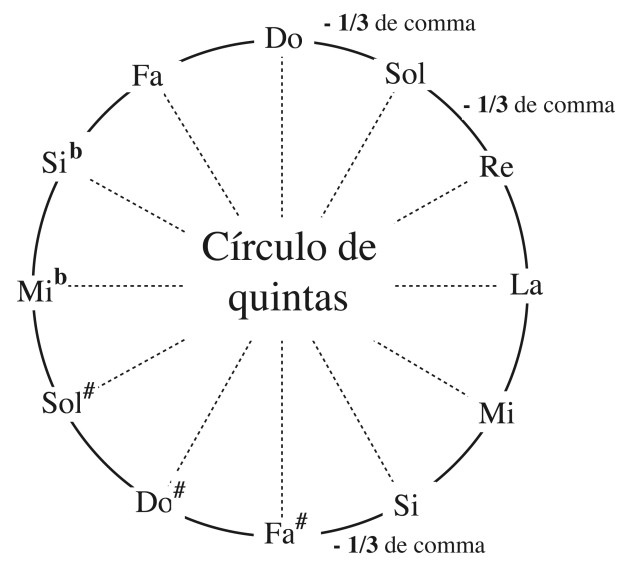

Fig. 2.12. Temperamento de Werckmeister de 1/3 de comma

Ejemplo 2.4. El temperamento de Neidhardt de $1 / 6$ y $1 / 12$ de comma reduce una comma pitagórica distribuyéndola de la forma siguiente (ver Fig. 2.13):

- - 1/6 de comma entre Do-Sol, Sol-Re, Re-La, La-Mi.

- $\quad$ - 1/12 de comma entre Mi-Si, Si-Fa ${ }^{\#}, \mathrm{Sol}^{\#}-\mathrm{Mi}^{\mathrm{b}}, \mathrm{Mi}^{\mathrm{b}}-\mathrm{Si}^{\mathrm{b}}$.

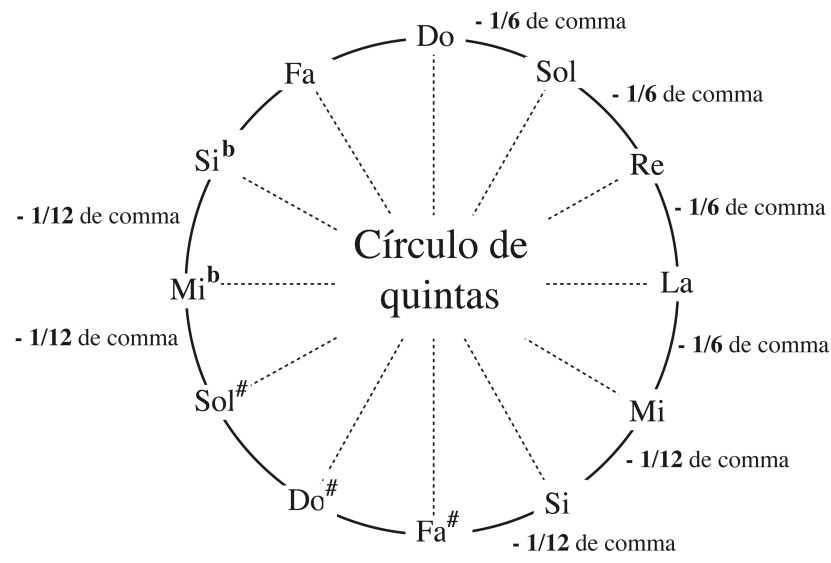

Fig. 2.13. Temperamento de Neidhardt de $1 / 6$ y $1 / 12$ de comma

Si a la quinta natural le "restamos" 1/6 y 1/12 de coma pitagórica, se obtiene

$$
\frac{3}{2} \text { menos } \frac{1}{6} \text { de comma pitagórica } \Rightarrow \frac{\frac{3}{2}}{\sqrt[6]{\frac{531441}{524288}}}=\frac{\frac{3}{2}}{\sqrt[6]{\frac{3^{12}}{2^{19}}}}=\frac{\sqrt[6]{2^{13}}}{3} \approx 1,4966
$$




$$
\frac{3}{2} \text { menos } \frac{1}{3} \text { de comma pitagórica } \Rightarrow \frac{\frac{3}{2}}{\sqrt[12]{\frac{531441}{524288}}}=\frac{\frac{3}{2}}{\sqrt[12]{\frac{3^{12}}{2^{19}}}}=\sqrt[12]{2^{7}} \approx 1,4983
$$

Con esto, las quintas Do-Sol, Sol-Re, Re-La, La-Mi en lugar de obtenerse al multiplicar la frecuencia más baja por 3/2, se obtienen al multiplicar por 1,4966 y las quintas $\mathrm{Mi}-\mathrm{Si}, \mathrm{Si}-\mathrm{Fa}^{\#}, \mathrm{Sol}^{\#}-\mathrm{Mi}^{\mathrm{b}}, \mathrm{Mi}^{\mathrm{b}}-\mathrm{Si}^{\mathrm{b}}$ multiplicando por 1,4983 .

\subsection{Un número adecuado de divisiones por octava}

Fijar el número de notas que deben aparecer en una octava ha sido, y es, un problema tanto para los musicólogos como para los estudiosos de la acústica musical. Sin embargo, parece razonable atender a dos tipos de criterios:

a) Criterios estéticos. El número de notas debe ser suficiente para crear música, y la elección debe hacerse de manera que las consonancias sean agradables.

b) Criterios técnicos. Las notas deben estar bien distribuidas dentro de la octava y, además, con el número fijado se debe intentar cerrar el círculo de quintas.

En cuanto a los criterios estéticos, conseguir un número suficiente para la creación musical no resulta ningún problema puesto que en la práctica es evidente que con 12 notas se consiguen buenos resultados para la música occidental. Sin embargo, los criterios técnicos no tienen una solución tan sencilla.

Evidentemente, en este aspecto sólo estamos interesados en analizar las afinaciones pitagórica y zarlineana, puesto que en los temperamentos igual y de Holder el número viene fijado de antemano como 12 y 53 notas respectivamente. Sin embargo, la cuestión también puede plantearse en éstos últimos como $i$ y por qué 12 o 53 y no otras cantidades?

Para ello, vamos a representar 70 notas de las afinaciones pitagórica y de Zarlino en el intervalo [1,2] (eje de ordenadas). La manera de comprobar qué número de notas es adecuado para cerrar el círculo de quintas consiste en analizar en qué número de notas se acerca más al 1 ó al 2. 


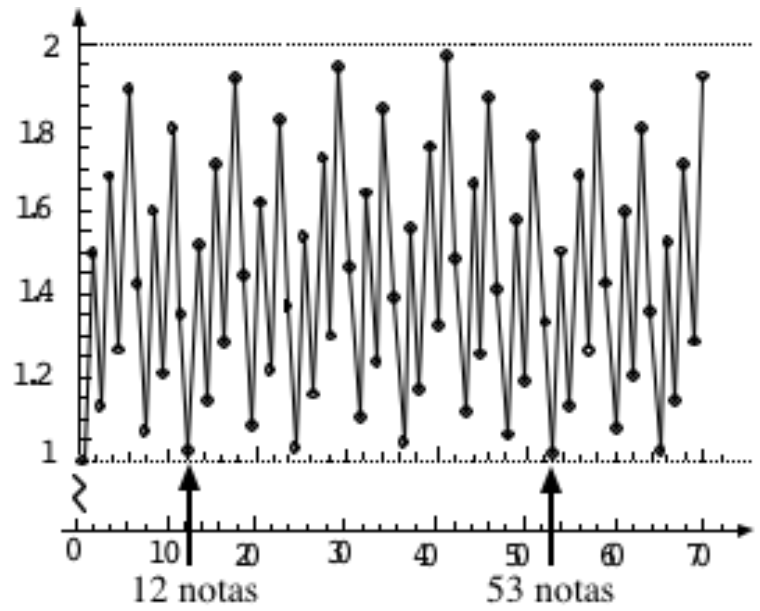

Fig. 2.14. Representación de 70 notas de la afinación pitagórica

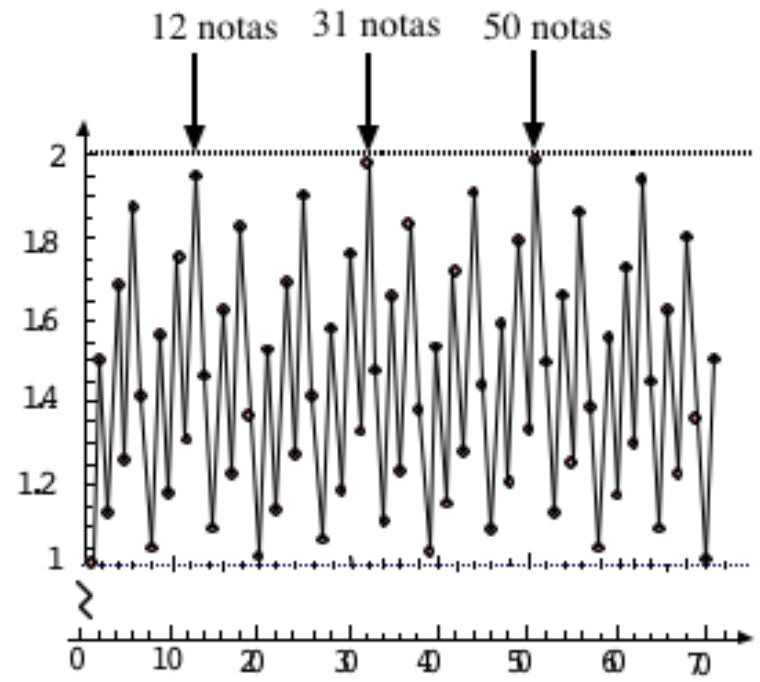

Fig. 2.15. Representación de 70 notas de la afinación de Zarlino

Para la afinación pitagórica podemos comprobar que las cantidades de notas adecuadas son 12 , 53, etc. y para el sistema de Zarlino son 12, 31, 50, etc. Si además hacemos un estudio pormenorizado de las afinaciones de 53 y 50 notas pitagórcas y zarlinianas (respectivamente), podemos comprobar que la distribución de notas es casi uniforme dentro de la octava.

Además si aceptamos estas cantidades podemos comprobar que se distribuyen adecuadamente en la octava. 


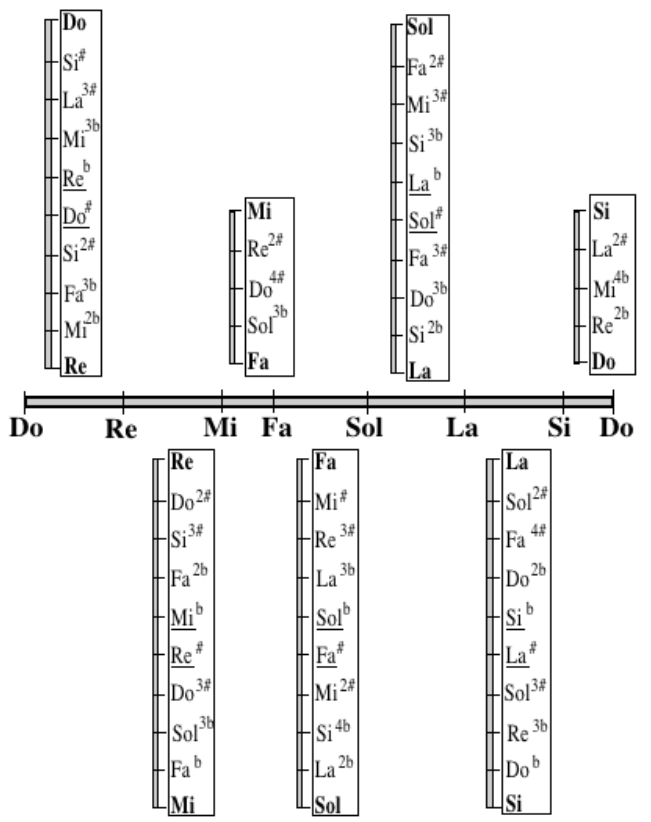

Fig. 2.16. Distribución de 53 notas de la afinación pitagórica

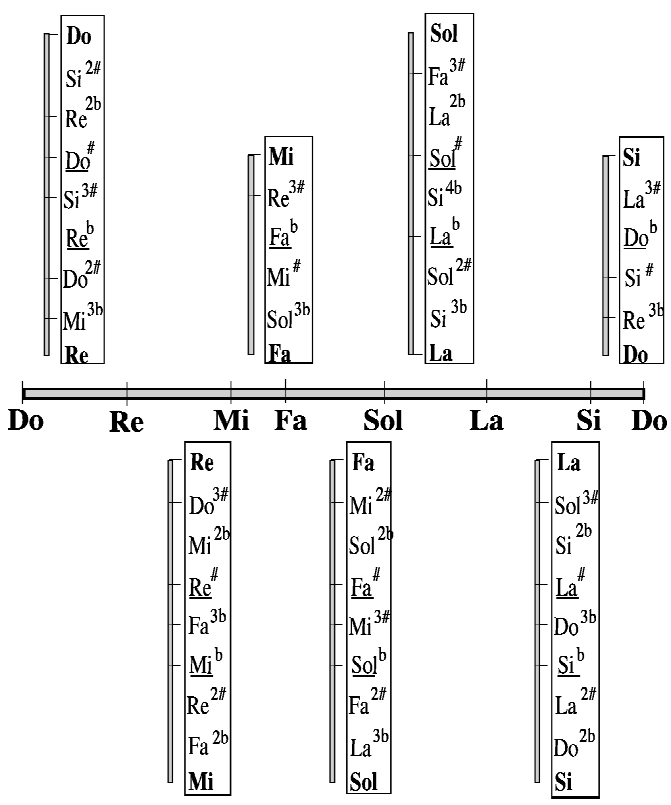

Fig. 2.17. Distribución de 50 notas de la afinación zarliniana

Antes comparar los cuatro sistemas de afinación entre sí, ya podemos establecer unas conclusiones generales:

a) Una división de la octava en 12 partes resulta muy adecuada para los cuatro sistemas de afinación motivo de estudio. 
b) El sistema temperado de Holder se aproxima mucho mejor al sistema de Pitágoras que al de Zarlino, en el que una división en 53 partes no estaría justificada.

\subsection{Comparación de los sistemas de afinación}

En esta sección mostramos las distancias en cents entre las notas de los diferentes sistemas haciendo tres tipos de análisis:

a) Comparación con el temperamento igual.

En las tablas 2.5, 2.6, 2.7 suponemos que el sistema de afinación patrón es el Temperamento Igual y medimos las distancias de sus notas con las del resto de sistemas. Como se puede observar en los gráficos, los sistemas de Pitágoras y de Holder (muy similares) mantienen unas distancias casi periódicas respecto del temperamento igual, mientras que en el de Zarlino no es así. Esto se debe a que el temperamento de 12 notas surge como aproximación al pitagórico, mientras que, como se ha visto en la sección anterior, la justa entonación aparece por otros criterios.

b) Distancias internas.

En la segunda parte (tablas 2.8, 2.9) medimos las distancias entre las notas consecutivas dentro de cada sistema de afinación. Por propia construcción en los temperamentos cíclicos de 12 y 53 notas las distancias entre ellas son constantes, por tanto para el temperamento de Holder la distancia entre notas es de 22,64 cents y en el temperamento de 12 notas es de 100 cents. En la afinación de Pitágoras las distancias oscilan entre los 19.5 y los 23.5 cents, como puede observarse en la figura $2.20 \mathrm{y}$, sin embargo en el sistema de Zarlino las oscilaciones son mucho mayores y van desde los 8.1 a los 32.9 cents (véase Fig. 2.21).

c) Comparación entre sistemas.

En la tercera parte (tablas $2.11,2.12,2.13$ ) analizamos distancias entre los sistemas pitagórico, zarliniano y holderiano dos a dos. En los gráficos 2.18, 2.19 y 2.20 se comprueba que los sistemas de Pitágoras y de Holder mantienen un comportamiento muy parejo, mientras que cuando se compara con el sistema de Zarlino, se producen distancias que pueden llegar hasta los 63 cents. Esto hace que las terceras justas del sistema de Zarlino tengan serias dificultades para convivir con los intervalos de las restantes afinaciones. 
1) En la tabla y el gráfico siguientes calculamos las distancias entre 53 notas ${ }^{21}$ del sistema pitagórico y el sistema Temperado

\begin{tabular}{|c|c|c|c|c|c|c|c|c|}
\hline Notas & $\mathrm{Hz}$ & Cents & Notas & $\mathrm{Hz}$ & Cents & Notas & $\mathbf{H z}$ & Cents \\
\hline Do & 260,740 & $-5,871$ & Mi & 330 & 1,955 & $\mathrm{Sol}^{\#}$ & 417,656 & 9,775 \\
\hline & 64,298 & 17,589 & $\operatorname{Re}^{\# \#}$ & 334,502 & 25,415 & & 423,354 & 33,235 \\
\hline & 267,903 & 41,049 & 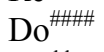 & 339,065 & 48,875 & & 428,235 & \\
\hline $\mathrm{Mi}^{\mathrm{bbb}}$ & 270,992 & $-39,099$ & $\mathrm{Sol}^{\mathrm{bb}}$ & 342,975 & $-31,279$ & $\mathrm{Si}^{\mathrm{bb}}$ & 434,077 & $-23,460$ \\
\hline $\mathrm{Re}^{\mathrm{b}}$ & 274,689 & $-15,639$ & $\mathbf{F a}$ & 347,654 & $-7,819$ & La & 440 & 0 \\
\hline &, 437 & & & & 15,640 & & 446,003 & 23,460 \\
\hline & & & & & 00 & & & 46,920 \\
\hline & 285,490 & $-48,875$ & $\mathrm{La}^{\mathrm{bbb}}$ & & $-41,055$ & $\mathrm{Do}^{\mathrm{bb}}$ & 300 & 235 \\
\hline $\mathrm{b}^{\mathrm{b}}$ & 289,385 & -25 & $\mathrm{Sol}^{\mathrm{b}}$ & & -17 , & Sil & & $-9,775$ \\
\hline & & & & 71 & 5,865 & $\mathrm{La}$ & 863 & 13,685 \\
\hline 册" & 297,335 & 21,505 & $\mathrm{Mi}^{\# \#}$ & 376, & 29,325 & $\mathrm{Sol}^{\# \# \#}$ & 476,274 & 37,145 \\
\hline $\mathrm{Si}^{\mathrm{i} \# \#}$ & 301,391 & 44,965 & $\mathrm{Si}^{\mathrm{bbbb}}$ & 380 & 49,170 & $\mathrm{Re}^{\mathrm{bbb}}$ & 481,765 & $-43,010$ \\
\hline & 304,866 & $-35,190$ & $\mathrm{La}$ & 385 & $-27,369$ & $\mathrm{Do}^{\mathrm{b}}$ & 488,337 & $-19,550$ \\
\hline $\mathrm{Mi}^{\mathrm{b}}$ & & & & & & & 495 & \\
\hline $\operatorname{Re}^{\#}$ & 313,2 & 11,729 & $\mathrm{Fa}^{\# \#}$ & & 50 & & 501,753 & 27,370 \\
\hline 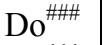 & 317,515 & 35,189 & $\mathrm{Mi}^{\# \#}$ & 401, & 43,010 & $\mathrm{Mi}^{\mathrm{bbbb}}$ & 507,538 & 47,215 \\
\hline & 321,176 & -44 & & 406, & $-37,145$ & $\operatorname{Re}^{\mathrm{bb}}$ & 514,463 & 9,775 \\
\hline & & $-21,505$ & & 412 , & $-13,685$ & & & \\
\hline
\end{tabular}

Tabla 2.5 Distancias del sistema pitagórico al sistema temperado de 12 notas.

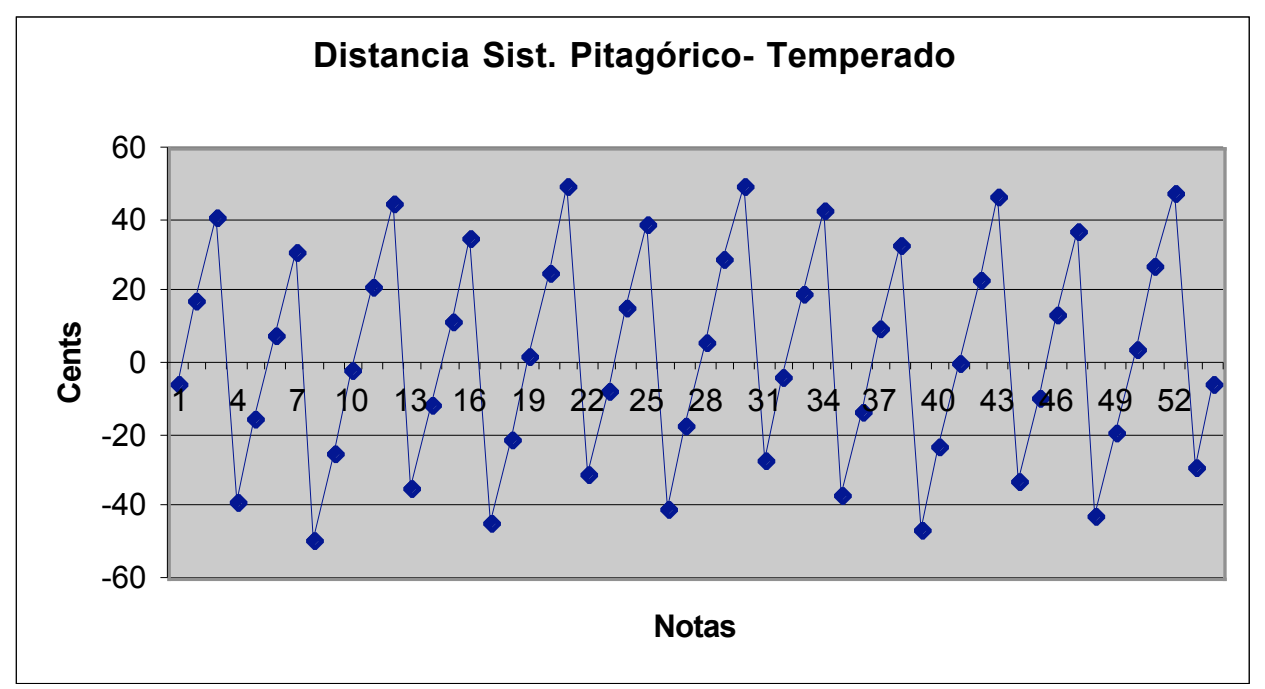

Fig. 2.18. Gráfico de las distancias del sistema pitagórico al sistema temperado de 12 notas.

${ }^{21}$ En la sección siguiente de este capítulo se da una justificación de que sean 53 las notas elegidas para el sistema de Pitágoras. 
2) En la tabla y el gráfico siguientes calculamos las distancias entre 50 notas $^{22}$ del sistema de Zarlino y el Temperado.

\begin{tabular}{|c|c|c|c|c|c|c|c|c|}
\hline Notas & $\mathbf{H z}$ & Cents & Notas & $\mathbf{H z}$ & Cents & Notas & $\mathbf{H z}$ & Cents \\
\hline Do & 264 & 15,641 & $\operatorname{Re}^{\text {\#\#\# }}$ & 335,693 & 31,568 & $\mathrm{La}^{\mathrm{b}}$ & 422,4 & 29,327 \\
\hline $\mathrm{Si}^{\# \#}$ & 268,555 & 45,255 & $\mathrm{Fa}^{\mathrm{b}}$ & 337,92 & 43,014 & $\mathrm{Sol}^{\# \#}$ & 429,687 & $-41,059$ \\
\hline $\operatorname{Re}^{\mathrm{bb}}$ & 273,715 & $-21,7935$ & $\mathrm{Mi}^{\#}$ & 343,75 & $-27,372$ & $\mathrm{Si}^{\mathrm{bbb}}$ & 437,944 & $-8,107$ \\
\hline $\mathrm{Do}^{\#}$ & 275 & $-13,6865$ & $\mathrm{Sol}^{\mathrm{bbb}}$ & 350,355 & 5,579 & $\mathbf{L a}$ & 440 & 0 \\
\hline $\mathrm{Si}^{\# \# \#}$ & 279,744 & 15,9275 & $\mathbf{F a}$ & 352 & 13,686 & $\mathrm{Sol}^{\# \# \#}$ & 447,591 & 29,614 \\
\hline $\mathrm{Re}^{\mathrm{b}}$ & 285,12 & 48,8795 & $\mathrm{Mi}^{\# \#}$ & 358,073 & 43,300 & $\mathrm{Si}^{\mathrm{bb}}$ & 456,192 & $-37,435$ \\
\hline $\mathrm{Do}^{\# \#}$ & 286,458 & $-43,0145$ & $\mathrm{Sol}^{\mathrm{bb}}$ & 364,954 & 76,252 & $\mathrm{La}^{\#}$ & 458,333 & $-29,328$ \\
\hline $\mathrm{Mi}^{\mathrm{bbb}}$ & 291,963 & $-10,0625$ & $\mathrm{Fa}^{\#}$ & 366,667 & $-15,641$ & $\mathrm{Do}^{\mathrm{bbb}}$ & 467,141 & 3,624 \\
\hline $\operatorname{Re}$ & 297 & 19,5515 & $\mathrm{Mi}^{\# \# \#}$ & 372,993 & 13,972 & $\mathrm{Si}^{\mathrm{b}}$ & 475,2 & 33,237 \\
\hline Do \#\#\# & 298,394 & 27,6585 & Sol $^{\mathrm{b}}$ & 380,160 & 46,924 & $\mathrm{La}^{\# \#}$ & 477,431 & 41,345 \\
\hline $\mathrm{Mi}^{\mathrm{bb}}$ & 304,128 & 60,609 & $\mathrm{Fa}^{\# \#}$ & 381,944 & $-44,969$ & $\mathrm{Do}^{\mathrm{bb}}$ & 486,605 & $-25,703$ \\
\hline $\operatorname{Re}^{\#}$ & 309,375 & $-9,776$ & $\mathrm{La}^{\mathrm{bbb}}$ & 389,284 & $-12,017$ & Si & 495 & 3,910 \\
\hline $\mathrm{Fa}^{\mathrm{bbb}}$ & 311,427 & 1,668 & Sol & 396 & 17,596 & $\mathrm{La}^{\# \# \#}$ & 497,323 & 12,017 \\
\hline $\mathrm{Mi}^{\mathrm{b}}$ & 316,8 & 31,282 & $\mathrm{Fa}^{\# \# \#}$ & 397,859 & 25,704 & $\mathrm{Do}^{\mathrm{b}}$ & 506,88 & 44,968 \\
\hline $\operatorname{Re}^{\# \#}$ & 322,266 & $-39,103$ & $\mathrm{La}^{\mathrm{bb}}$ & 405,504 & $-41,345$ & $\mathrm{Si}^{\#}$ & 515,625 & $-25,417$ \\
\hline $\mathrm{Fa}^{\mathrm{bb}}$ & 324,403 & $-27,658$ & $\mathrm{Sol}^{\#}$ & 412,5 & $-11,731$ & $\operatorname{Re}^{\mathrm{bbb}}$ & 525,533 & 7,533 \\
\hline Mi & 330 & 1,955 & $\mathrm{Si}^{\mathrm{bbbb}}$ & 420,426 & 21,220 & & & \\
\hline
\end{tabular}

Tabla 2.6 Distancias del sistema de Zarlino al sistema temperado de 12 notas.

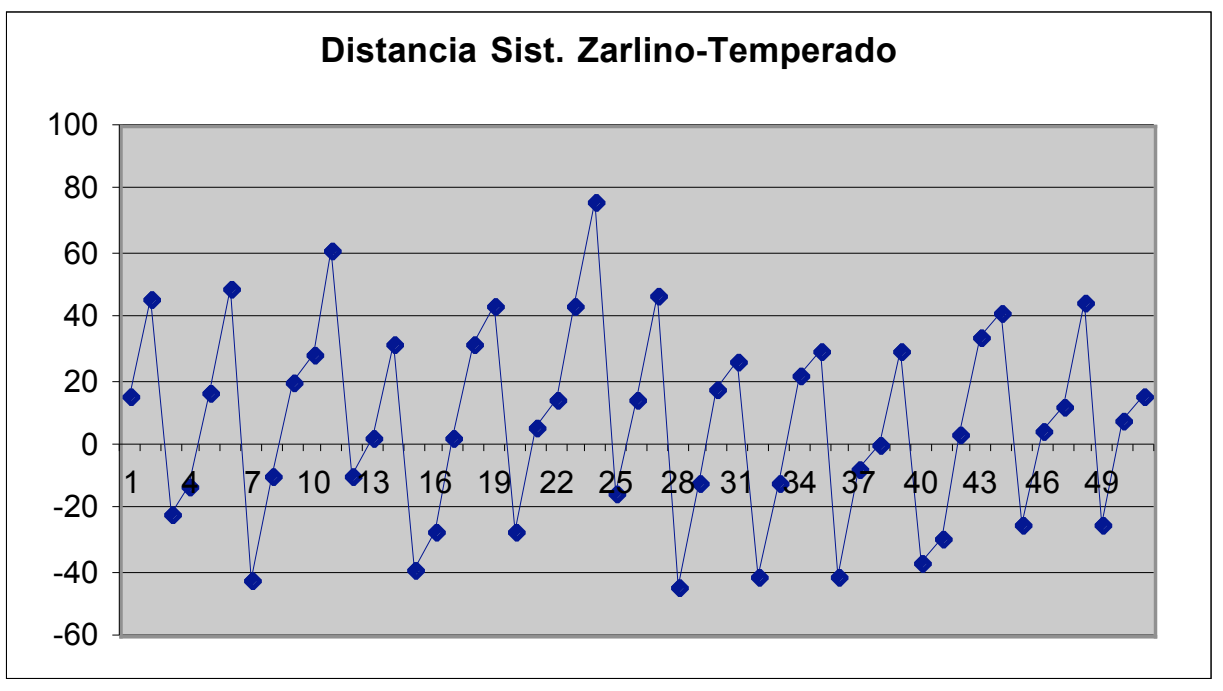

Fig. 2.19. Gráfico de las distancias del sistema de Zarlino al sistema temperado de 12 notas.

\footnotetext{
${ }^{22}$ En la sección siguiente de este capítulo se da una justificación de que sean 50 las notas elegidas para el sistema de Zarlino.
} 
3) En la tabla y el gráfico siguientes calculamos las distancias entre las 53 notas del sistema de Holder y el Temperado.

\begin{tabular}{|c|c|c|c|c|c|c|c|c|}
\hline Notas & $\mathrm{Hz}$ & Cents & Notas & $\mathrm{Hz}$ & Cents & Notas & $\mathbf{H z}$ & Cents \\
\hline Do & 260,771 & $-5,667$ & Mi & 329,986 & 1,887 & $\mathrm{Sol}^{\#}$ & 417,573 & 9,434 \\
\hline & 264,204 & 16,972 & & 334,331 & 24,5286 & & 423,071 & 32,075 \\
\hline $\mathrm{La}^{\mathrm{\# \#}}$ & 7,682 & 39,614 & \#\#\#\# & 8,732 & & & 28,640 & \\
\hline $\mathrm{Mi}^{\mathrm{bbb}}$ & 1,206 & $-37,737$ & Sol $^{\text {bb }}$ & 343,191 & $-30,190$ & $\mathrm{Si}^{\mathrm{bb}}$ & 34,283 & $-22,642$ \\
\hline $\operatorname{Re}^{\mathrm{b}}$ & 74,776 & $-15,097$ & $\mathbf{F a}$ & 47,709 & $-7,547$ & La & 440 & \\
\hline $\mathrm{Do}^{\#}$ & 8,394 & & & 286 & 15,092 & & 445,792 & 22,641 \\
\hline & & 36 & & & & & 661 & 45,284 \\
\hline $\mathrm{Fa}^{\mathrm{bbb}}$ & 5,771 & $-47,173$ & $\mathrm{La}^{\mathrm{bbb}}$ & 23 & 620 & $\mathrm{Do}^{\mathrm{bb}}$ & 457,606 & $-32,077$ \\
\hline $\mathrm{Mi}^{\mathrm{bb}}$ & 9,533 & $-24,5$ & $\mathrm{Sol}^{\mathrm{b}}$ & & -16 & & 463,630 & $-9,436$ \\
\hline & & & & & 559 & & 733 & 13,207 \\
\hline & 2 & 20 & & & 28,303 & Sol & 475,917 & 35,848 \\
\hline 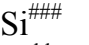 & 301,119 & 43,396 & $\mathrm{Si}^{\mathrm{bbbb}}$ & 444 & 50,945 & $\mathrm{Re}^{\mathrm{bbb}}$ & 482,182 & $-41,511$ \\
\hline $\mathrm{Fa}^{\mathrm{bb}}$ & 05,083 & -33 , & $\mathrm{La}^{\mathrm{bb}}$ & 60 & $-26,414$ & $\mathrm{Do}^{\mathrm{b}}$ & 488,530 & $-18,868$ \\
\hline $\mathrm{Mi}^{\mathrm{b}}$ & & & & & & & & 3,774 \\
\hline $\operatorname{Re}^{\#}$ & & 11,319 & & & 18 & $\mathrm{La}$ & 501,477 & 26 , \\
\hline & 317,291 & 33,9 & $\mathrm{Mi}^{\# \#}$ & 401, & 41 , & $\mathrm{Mi}^{\mathrm{bbbb}}$ & 508,078 & 49,056 \\
\hline & 321,468 & $-43,3$ & & 406 & -35 & $\mathrm{Re}^{\mathrm{bb}}$ & 514,767 & $-28,307$ \\
\hline & 25,699 & $-20,757$ & & & & & & \\
\hline
\end{tabular}

Tabla 2.7 Distancias del sistema de Holder al sistema temperado de 12 notas.

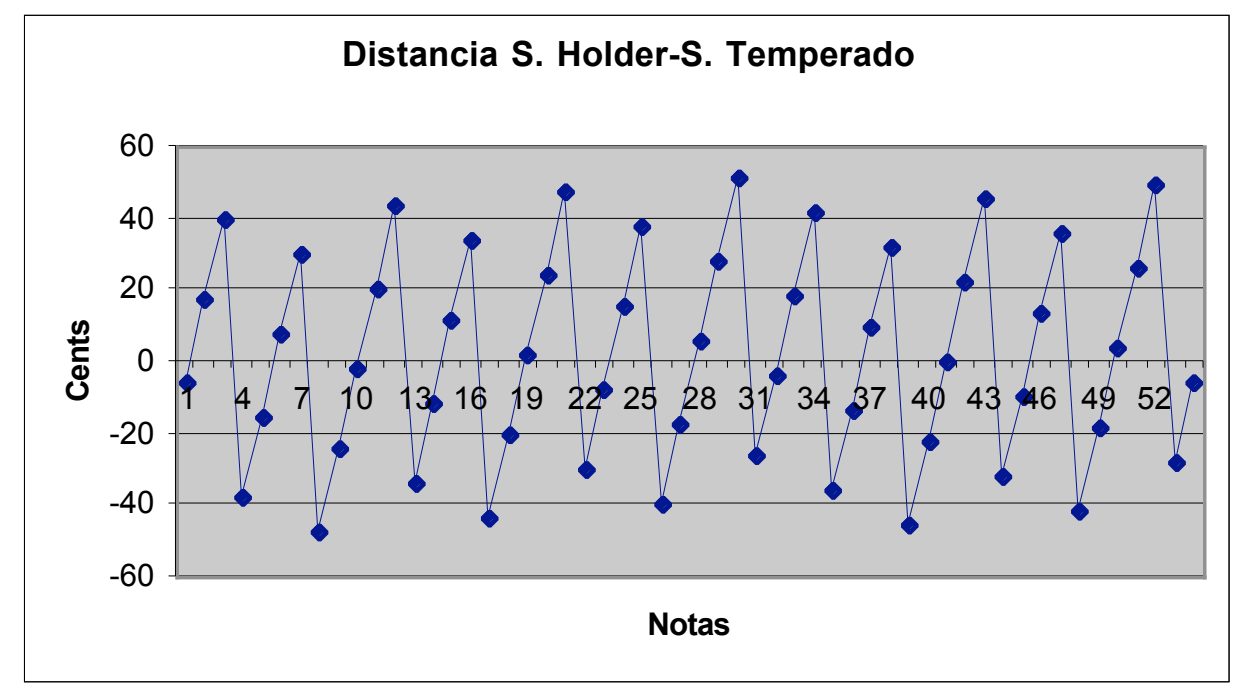

Fig. 2.20. Gráfico de las distancias del sistema de Holder al sistema temperado de 12 notas. 
4) En el siguiente gráfico podemos ver la diferencia en cents que existe entre las notas de un mismo sistema, en este caso sobre el sistema de Pitágoras. Las diferencias son siempre iguales y oscilan sobre dos valores 19 y 23 cents.

\begin{tabular}{|c|c|c|c|c|c|c|c|c|}
\hline Notas & $\mathrm{Hz}$ & Cents & Notas & $\mathrm{Hz}$ & Cents & Notas & $\mathbf{H z}$ & Cents \\
\hline Do & 260,741 & & $\mathbf{M i}$ & 330 & $-23,460$ & $\mathrm{Sol}^{\#}$ & 417,656 & $-23,460$ \\
\hline $\mathrm{Si}^{\#}$ & 264,298 & $-23,459$ & $\operatorname{Re}^{\# \#}$ & 334,502 & $-23,460$ & $\mathrm{Fa}^{\# \# \#}$ & 423,354 & $-23,459$ \\
\hline $\mathrm{La}^{\# \# \#}$ & 267,904 & $-23,460$ & Do & 339,066 & $-23,459$ & $\mathrm{Do}^{\mathrm{bbb}}$ & 428,235 & $-19,845$ \\
\hline $\mathrm{Mi}^{\mathrm{bbb}}$ & 270,993 & $-19,845$ & Sol $^{\text {bb }}$ & 342,975 & $-19,845$ & $\mathrm{Si}^{\mathrm{bb}}$ & 434,077 & $-23,460$ \\
\hline $\operatorname{Re}^{\mathrm{b}}$ & 274,689 & $-23,459$ & $\mathbf{F a}$ & 347,654 & $-23,460$ & La & 440 & $-23,460$ \\
\hline $\mathrm{Do}^{\#}$ & 278,437 & $-23,460$ & $\mathrm{Mi}^{\#}$ & 352,397 & $-23,460$ & $\mathrm{Sol}^{\# \#}$ & 446,003 & $-23,460$ \\
\hline $\mathrm{Si}^{\# \#}$ & 282,236 & $-23,460$ & $\operatorname{Re}^{\# \# \#}$ & 357,205 & $-23,460$ & $\mathrm{Fa}^{\# \# \# \#}$ & 452,088 & $-23,459$ \\
\hline $\mathrm{Fa}^{\mathrm{bbb}}$ & 285,490 & $-19,845$ & $\mathrm{La}^{\mathrm{bbb}}$ & 323 & $-19,845$ & $\mathrm{Do}^{\mathrm{bb}}$ & 457,300 & $-19,845$ \\
\hline $\mathrm{Mi}^{\mathrm{bb}}$ & 289,385 & $-23,459$ & $\mathrm{Sol}^{\mathrm{b}}$ & 366,253 & $-23,460$ & $\mathrm{Si}^{\mathrm{b}}$ & 463,539 & $-23,460$ \\
\hline $\operatorname{Re}$ & 293,333 & $-23,460$ & $\mathrm{Fa}^{\#}$ & 371,250 & $-23,460$ & $\mathrm{La}^{\#}$ & 469,863 & $-23,459$ \\
\hline $\mathrm{Do}^{\# \#}$ & 297,335 & $-23,460$ & $\mathrm{Mi}^{\# \#}$ & 376,315 & $-23,460$ & $\mathrm{Sol}^{\# \# \#}$ & 476,274 & $-23,460$ \\
\hline $\mathrm{Si}^{\# \# \#}$ & 301,392 & $-23,459$ & $\mathrm{Si}^{\mathrm{bbbb}}$ & 380,653 & $-19,845$ & $\operatorname{Re}^{\mathrm{bbb}}$ & 481,765 & $-19,845$ \\
\hline $\mathrm{Fa}^{\mathrm{bb}}$ & 304,867 & $-19,845$ & $\mathrm{La}^{\mathrm{bb}}$ & 385,847 & $-23,460$ & $\mathrm{Do}^{\mathrm{b}}$ & 488,337 & $-23,460$ \\
\hline $\mathrm{Mi}^{\mathrm{b}}$ & 309,026 & $-23,459$ & Sol & 391,111 & $-23,460$ & Si & 495 & $-23,460$ \\
\hline $\operatorname{Re}^{\#}$ & 313,242 & $-23,460$ & $\mathrm{Fa}^{\mathrm{\# \#}}$ & 396,447 & $-23,459$ & $\mathrm{La}^{\# \#}$ & 501,753 & $-23,460$ \\
\hline Do \#\#\# & 317,516 & $-23,459$ & $\mathrm{Mi}^{\# \# \#}$ & 401,856 & $-23,460$ & $\mathrm{Mi}^{\mathrm{bbbb}}$ & 507,538 & $-19,845$ \\
\hline $\mathrm{Sol}^{\mathrm{bbb}}$ & 321,176 & $-19,845$ & Sibbb & 406,489 & $-19,845$ & $\mathrm{Re}^{\mathrm{bb}}$ & 514,462 & $-23,459$ \\
\hline $\mathrm{Fa}^{\mathrm{b}}$ & 325,558 & $-23,459$ & $\mathrm{La}^{\mathrm{b}}$ & 412,035 & $-23,460$ & & & \\
\hline
\end{tabular}

Tabla 2.8 Distancias entre notas consecutivas del sistema pitagórico.

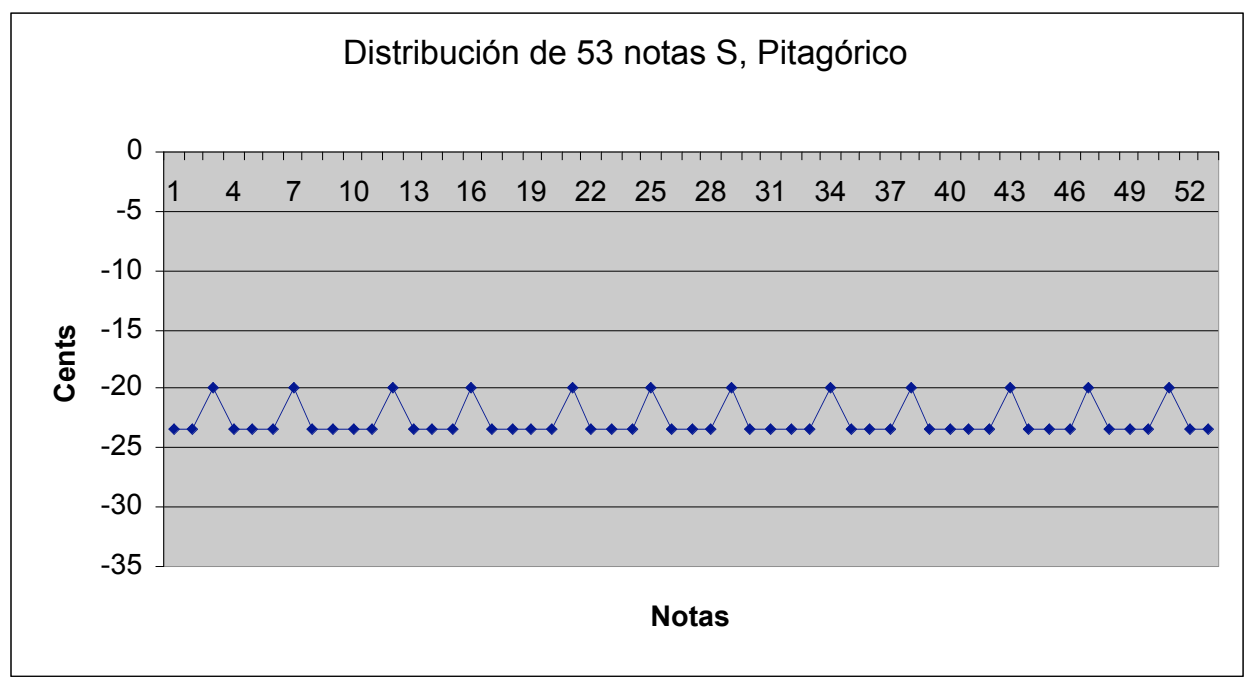

Fig. 2.21. Gráfico de las distancias entre notas consecutivas del sistema pitagórico. 
5) En la siguiente hemos comparado los resultados del sistema de Zarlino comparándolos con él mismo.

\begin{tabular}{|c|c|c|c|c|c|c|c|c|}
\hline Nota & $\mathrm{Hz}$ & Cents & Notas & $\mathbf{H z}$ & Cents & Notas & $\mathbf{H z}$ & Cents \\
\hline Do & 264 & & $\operatorname{Re}^{\# \# \#}$ & 335,693 & $-29,614$ & $\mathrm{La}^{\mathrm{b}}$ & 422,4 & $-8,107$ \\
\hline & 268,555 & $-29,614$ & & & $-11,445$ & & 429,687 & \\
\hline & 73,715 & $-32,952$ & & 43,75 & $-29,614$ & & 437,944 & $-32,952$ \\
\hline $\mathrm{Do}^{\#}$ & 275 & $-8,107$ & $\mathrm{Sol}^{\mathrm{bbb}}$ & 350,355 & $-32,9$ & $\mathbf{L a}$ & 440 & $-8,107$ \\
\hline & 79,744 & $-29,613$ & $\mathbf{a}$ & 352 & & & 447,5 & $-29,614$ \\
\hline $\mathrm{Re}^{\mathrm{b}}$ & 85,12 & $-32,952$ & $\mathrm{Mi}^{\# \#}$ & 358,073 & $-29,614$ & $\mathrm{Si}^{\mathrm{bb}}$ & 456, & $-32,952$ \\
\hline Do & & & $\mathrm{Sol}^{\mathrm{bb}}$ & & -32 & & 458, & \\
\hline $\mathrm{Mi}^{\mathrm{bbb}}$ & 291,963 & $-32,952$ & $\mathrm{Fa}^{\#}$ & 366,667 & & & 467,141 & $-32,952$ \\
\hline $\mathbf{R e}$ & & $-29,614$ & $\mathrm{Mi}^{\# \# \#}$ & 372,993 & $-29,6$ & $\mathrm{Si}^{\mathrm{b}}$ & 475,2 & $-29,614$ \\
\hline Do \#\#\# & 298,3 & $-8,107$ & $\mathrm{Sol}^{\mathrm{b}}$ & 80,160 & $-32,952$ & $\mathrm{La}^{\# \#}$ & 477,43 & $-8,107$ \\
\hline $\mathrm{Mi}^{\mathrm{bb}}$ & 304,128 & $-32,952$ & $\mathrm{Fa}^{\# \#}$ & 31,944 & & $\mathrm{Do}^{\mathrm{bb}}$ & 486,605 & ,952 \\
\hline $\operatorname{Re}^{\#}$ & & $-29,6$ & $\mathrm{La}^{\mathrm{bbb}}$ & 389,284 & -32, & $\mathbf{S i}$ & 495 & $-29,614$ \\
\hline $\mathrm{Fa}^{\mathrm{bbb}}$ & 311,427 & $-11,445$ & Sol & 396 & $-29,6$ & & 497,323 & $-8,107$ \\
\hline $\mathrm{Mi}^{\mathrm{b}}$ & 316,8 & $-29,614$ & $\mathrm{Fa}^{\# \# \#}$ & 397,859 & $-8,107$ & & 506,88 & $-32,952$ \\
\hline $\operatorname{Re}^{\# \#}$ & 322,266 & $-29,614$ & &, 504 & & & 515,6 & $-29,614$ \\
\hline $\mathrm{Fa}^{\mathrm{bb}}$ & 324,403 & $-11,445$ & $\mathrm{Sol}^{\#}$ & 412,5 & $-29,614$ & $\mathrm{Re}^{\mathrm{bbb}}$ & 525,533 & $-32,952$ \\
\hline Mi & 330 & $-29,614$ & & 420,426 & $-32,952$ & & & \\
\hline
\end{tabular}

Tabla 2.9 Distancias entre notas consecutivas del sistema de Zarlino.

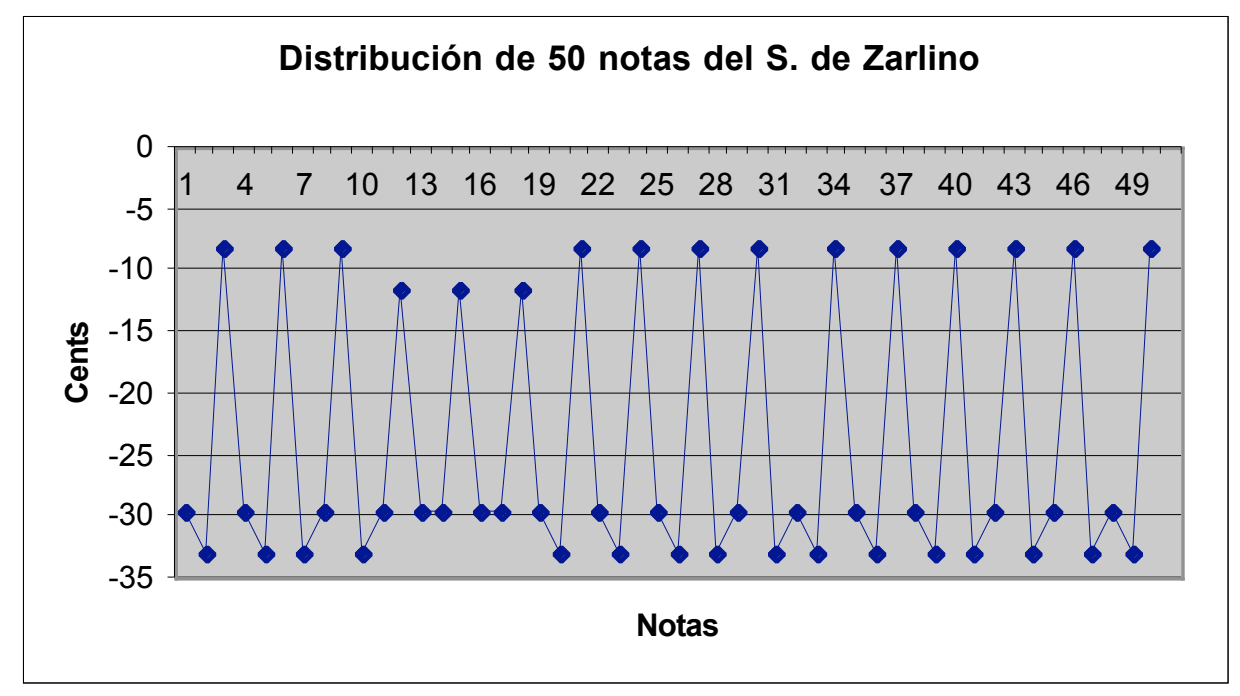

Fig. 2.22. Gráfico de las distancias entre notas consecutivas del sistema de Zarlino. 
Distancias Pitágoras/Zarlino

\begin{tabular}{|cccccccc|}
\hline Notas & Pitágoras & Zarlino & Dif. (cents) & Nota & Pitágoras & Zarlino & Dif. (cents) \\
\hline Do & 260,772 & 264 & $-21,302$ & $\mathrm{Fa}^{\#}$ & 371,206 & 366,667 & 21,299 \\
$\mathrm{Re}^{\mathrm{b}}$ & 274,776 & 285,120 & $-63,976$ & $\mathrm{Sol}$ & 391,142 & 396 & $-21,369$ \\
$\mathrm{Do}^{\#}$ & 278,394 & 275 & 21,236 & $\mathrm{La}^{\mathrm{b}}$ & 412,148 & 422,400 & $-42,537$ \\
$\mathbf{R e}$ & 293,345 & 297 & $-21,438$ & $\mathrm{Sol}^{\#}$ & 417,574 & 412,500 & 21,165 \\
$\mathrm{Mi}^{\mathrm{b}}$ & 309,099 & 316,800 & $-42,604$ & $\mathbf{L a}$ & 440 & 440 & 0 \\
$\mathrm{Re}^{\#}$ & 313,168 & 309,375 & 21,096 & $\mathrm{Si}^{\mathrm{b}}$ & 463,630 & 475,200 & $-42,673$ \\
$\mathrm{Fa}^{\mathrm{b}}$ & 325,699 & 337,920 & $-63,771$ & $\mathrm{La}^{\#}$ & 469,734 & 458,333 & 42,536 \\
$\mathbf{M i}$ & 329,987 & 330 & $-0,068$ & $\mathrm{Do}^{\mathrm{b}}$ & 488,53 & 506,888 & $-63,864$ \\
$\mathbf{F a}^{\mathbf{a}}$ & 347,709 & 352 & $-21,234$ & $\mathrm{Si}^{\#}$ & 494,961 & 495 & $-0,1364$ \\
$\mathrm{Mi}^{\#}$ & 352,286 & 343,750 & 42,465 & $\mathrm{Si}^{\#}$ & 528,408 & 515,625 & 42,396 \\
$\mathrm{Sol}^{\mathrm{b}}$ & 366,383 & 380,160 & $-63,905$ & & & & \\
\hline
\end{tabular}

Tabla 2.10 Distancias entre el sistema pitagórico y el de Zarlino.

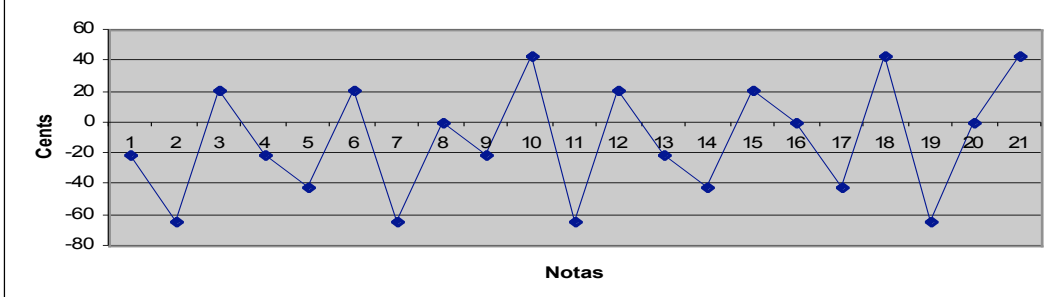

Fig. 2.23. Gráfico de las distancias entre el sistema pitagórico y el de Zarlino.

Distancias Holder/Zarlino

\begin{tabular}{|cccccccc|}
\hline Notas & Holder & Zarlino & Dif. (cents) & Nota & Holder & Zarlino & Dif. (cents) \\
\hline Do & 260,741 & 264 & $-21,505$ & $\mathrm{Fa}^{\#}$ & 371,25 & 366,667 & 21,505 \\
$\mathrm{Re}^{\mathrm{b}}$ & 274,689 & 285,12 & $-64,524$ & $\mathrm{Sol}^{\prime}$ & 391,111 & 396 & $-21,507$ \\
$\mathrm{Do}^{\#}$ & 278,437 & 275 & 21,503 & $\mathrm{La}^{\mathrm{b}}$ & 412,034 & 422,4 & $-43,016$ \\
$\mathbf{R e}$ & 293,333 & 297 & $-21,508$ & $\mathrm{Sol}^{\#}$ & 417,656 & 412,5 & 21,5053 \\
$\mathrm{Mi}^{\mathrm{b}}$ & 309,026 & 316,8 & $-43,013$ & $\mathbf{L a}^{\prime}$ & 440 & 440 & 0 \\
$\mathrm{Re}^{\#}$ & 313,242 & 309,375 & 21,505 & $\mathrm{Si}^{\mathrm{b}}$ & 463,539 & 475,2 & $-43,013$ \\
$\mathrm{Fa}^{\mathrm{b}}$ & 325,558 & 337,92 & $-64,521$ & $\mathrm{La}^{\#}$ & 469,863 & 458,333 & 43,013 \\
$\mathbf{M i}$ & 330 & 330 & 0 & $\mathrm{Do}^{\mathrm{b}}$ & 488,337 & 506,888 & $-64,548$ \\
Fa $^{\#}$ & 347,654 & 352 & $-21,508$ & $\mathrm{Si}^{\mathbf{1}}$ & 495 & 495 & 0 \\
$\mathrm{Mi}^{\#}$ & 352,397 & 343,75 & 43,010 & $\mathrm{Si}^{\#}$ & 528,596 & 515,625 & 43,012 \\
$\mathrm{Sol}^{\mathrm{b}}$ & 366,253 & 380,16 & $-64,519$ & & & & \\
\hline
\end{tabular}

Tabla 2.11 Distancias entre el sistema de Holder y el de Zarlino.

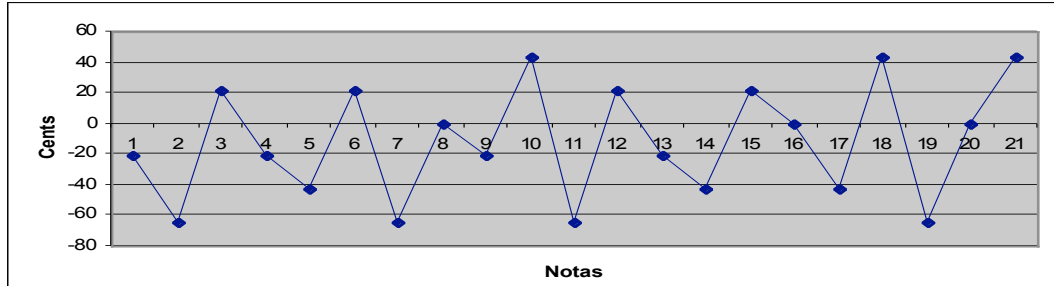

Fig. 2.24. Gráfico de las distancias entre el sistema de Holder y el de Zarlino. 
Distancias Pitágoras / Holder

\begin{tabular}{|c|c|c|c|c|c|c|c|}
\hline Notas & Pitágoras & Holder & Dif. (cents) & Nota & Pitágoras & Holder & Dif. (cents) \\
\hline Do & 260,740 & 260,771 & $-0,205$ & $\mathrm{Fa}^{\#}$ & 371,25 & 371,206 & 0,205 \\
\hline $\mathrm{Si}^{\#}$ & 264,298 & 264,204 & 0,616 & $\mathrm{Mi}^{\# \#}$ & 376,315 & 376,093 & 1,022 \\
\hline $\mathrm{La}^{\# \# \#}$ & 267,903 & 267,682 & 1,435 & $\mathrm{Si}^{\mathrm{bbbb}}$ & 380,653 & 381,044 & $-1,775$ \\
\hline $\mathrm{Mi}^{\mathrm{bbb}}$ & 270,992 & 271,206 & $-1,363$ & $\mathrm{La}^{\mathrm{bb}}$ & 385,847 & 386,060 & $-0,956$ \\
\hline $\operatorname{Re}^{b}$ & 274,689 & 274,776 & $-0,543$ & Sol & 391,111 & 391,141 & $-0,136$ \\
\hline $\mathrm{Do}^{\#}$ & 278,437 & 278,394 & 0,270 & $\mathrm{Fa}^{\# \#}$ & 396,447 & 396,291 & 0,682 \\
\hline $\mathrm{Si}^{\# \#}$ & 282,236 & 282,058 & 1,094 & $\mathrm{Mi}^{\# \# \#}$ & 401,856 & 401,508 & 1,499 \\
\hline $\mathrm{Fa}^{\mathrm{bbb}}$ & 285,490 & 285,771 & $-1,702$ & $\mathrm{Si}^{\mathrm{bbb}}$ & 406,489 & 406,793 & $-1,295$ \\
\hline $\mathrm{Mi}^{\mathrm{bb}}$ & 289,385 & 289,533 & $-0,884$ & $\mathrm{La}^{\mathrm{b}}$ & 412,035 & 412,148 & $-0,476$ \\
\hline $\operatorname{Re}$ & 293,333 & 293,344 & $-0,068$ & $\mathrm{Sol}^{\#}$ & 417,656 & 417,573 & 0,341 \\
\hline $\mathrm{Do}^{\# \#}$ & 297,335 & 297,207 & 0,748 & $\mathrm{Fa}^{\# \# \#}$ & 423,354 & 423,071 & 1,159 \\
\hline $\mathrm{Si}^{\# \# \#}$ & 301,391 & 301,119 & 1,569 & $\mathrm{Do}^{\mathrm{bbb}}$ & 428,235 & 428,640 & $-1,636$ \\
\hline $\mathrm{Fa}^{\mathrm{bb}}$ & 304,866 & 305,083 & $-1,228$ & $\mathrm{Si}^{\mathrm{bb}}$ & 434,077 & 434,283 & $-0,818$ \\
\hline $\mathrm{Mi}^{\mathrm{b}}$ & 309,026 & 309,099 & $-0,408$ & $\mathbf{L a}$ & 440 & 440 & 0 \\
\hline $\operatorname{Re}^{\#}$ & 313,242 & 313,168 & 0,410 & Sol $^{\# \#}$ & 446,003 & 445,792 & 0,819 \\
\hline Do \#\#\# & 317,515 & 317,291 & 1,226 & $\mathrm{Fa}^{\# \# \# \#}$ & 452,088 & 451,661 & 1,636 \\
\hline Sol $^{\text {bbb }}$ & 321,176 & 321,468 & $-1,571$ & $\mathrm{Do}^{\mathrm{bb}}$ & 457,300 & 457,606 & $-1,158$ \\
\hline $\mathrm{Fa}^{\mathrm{b}}$ & 325,558 & 325,699 & $-0,748$ & $\mathrm{Sib}$ & 463,539 & 463,630 & $-0,339$ \\
\hline Mi & 330 & 329,986 & 0,068 & $\mathrm{La}^{\#}$ & 469,863 & 469,733 & 0,477 \\
\hline $\operatorname{Re}^{\# \#}$ & 334,502 & 334,331 & 0,887 & $\mathrm{Sol}^{\# \# \#}$ & 476,274 & 475,917 & 1,297 \\
\hline Do & 339,065 & 338,732 & 1,706 & $\operatorname{Re}^{\mathrm{bbb}}$ & 481,765 & 482,182 & $-1,499$ \\
\hline $\mathrm{Sol}^{\mathrm{bb}}$ & 342,975 & 343,191 & $-1,089$ & $\mathrm{Do}^{\mathrm{b}}$ & 488,337 & 488,530 & $-0,682$ \\
\hline $\mathbf{F a}$ & 347,654 & 347,709 & $-0,272$ & $\mathbf{S i}$ & 495 & 494,960 & 0,136 \\
\hline $\mathrm{Mi}^{\#}$ & 352,397 & 352,286 & 0,548 & $\mathrm{La}^{\# \#}$ & 501,753 & 501,477 & 0,954 \\
\hline $\operatorname{Re}^{\# \# \#}$ & 357,205 & 356,924 & 1,364 & $\mathrm{Mi}^{\mathrm{bbbb}}$ & 507,538 & 508,078 & $-1,841$ \\
\hline $\mathrm{La}^{\mathrm{bbb}}$ & 361,323 & 361,623 & $-1,434$ & $\operatorname{Re}^{\mathrm{bb}}$ & 514,463 & 514,767 & $-1,024$ \\
\hline $\mathrm{Sol}^{\mathrm{b}}$ & 366,253 & 366,383 & $-0,614$ & & & & \\
\hline
\end{tabular}

Tabla 2.12 Distancias entre el sistema de Holder y el de Pitágoras.

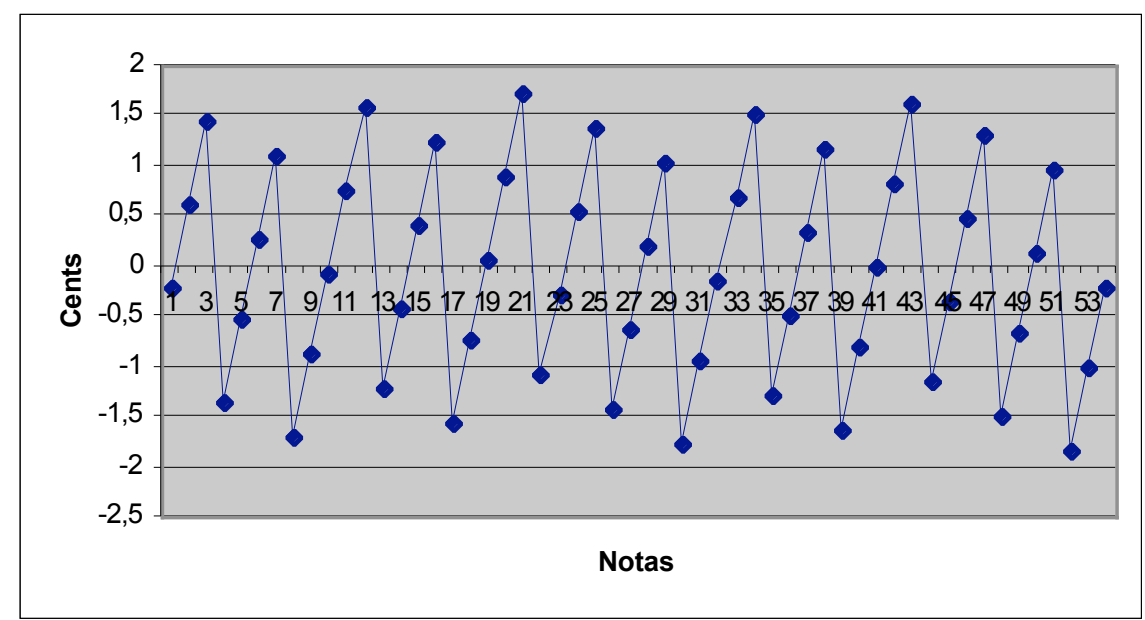

Fig. 2.25. Gráfico de las distancias entre el sistema pitagórico y el de Holder 


\subsection{Fracciones continuas y cantidad de notas por octava}

En la práctica, los músicos suelen resolver los problemas de afinación de forma intuitiva, dejando a los teóricos la cuestión cuál sería el número óptimo de notas por octava.

A lo largo de la historia, los teóricos han propuesto diferentes sistemas que justifican con razonamientos estéticos, lógicos y, en algunos casos, con cálculos que sólo son válidos para algunos sistemas o temperamentos. Conscientes de ello, y de la dificultad que entraña alcanzar ese número de notas de consenso, matemáticos y físicos, sobre todo a partir del primer tercio del S. $\mathrm{XX}$, idean métodos matemáticos capaces de zanjar la cuestión. Uno de ellos, es el uso de fracciones continuas que expondremos aquí brevemente.

\subsubsection{Fracciones continuas}

A partir de que en el siglo XVIII ${ }^{23}$ se estableciesen las bases teóricas de las fracciones continuas, han sido muchos sus campos de aplicación dentro y fuera de las Matemáticas. Entre sus propiedades, que las hacen especialmente útiles, está la sencillez para calcularlas. De hecho, las fracciones continuas formaban parte de los programas oficiales de Matemáticas de enseñanza secundaria hasta principios de los años 70, en los que la implantación de la Matemática Moderna supuso un viraje hacia una vertiente más estructuralista.

Una fracción continua es una expresión de la forma siguiente:

$$
c_{1}+\frac{1}{c_{2}+\frac{1}{c_{3} \cdots+\frac{1}{c_{n}}}}
$$

donde los números $c_{1}, c_{2}, \ldots, c_{\mathrm{n}}$ son números enteros positivos

\footnotetext{
${ }^{23}$ Las fracciones continuas son uno de los temas más interesantes dentro de la teoría de números, así como también uno de los más antiguos. Su origen se remonta a la antigua Grecia, específicamente Euclides (siglo III a. C.) estudió por primera vez este tipo de fracciones en el Libro 8 de los Elementos. En la Edad Moderna la teoría fue retomada por el matemático italiano Bombelli, en su libro L'Algebra parte maggiore dell' aritmética, Bologna 1572, en donde se utilizan fracciones continuas para calcular raíces cuadradas. Posteriormente Leonhard Euler en su memoria De fractionibus continuis, 1737 , dio los primeros pasos en la teoría, tal como se conoce en la actualidad. Finalmente, fue Joseph Louis Lagrange quien en 1768 formalizó esta teoría en su memoria Solution d'un problème d'arithmétique.
} 
En la práctica, lo que se hace es ir calculando las fracciones que resultan al ir añadiendo un nuevo cociente $\left(c_{\mathrm{i}}\right)$. A estas fracciones se les llama convergentes de la fracción continua. Evidentemente, para cada fracción los convergentes se pueden calcular operando con fracciones, pero resulta mucho más rápido aplicar las siguientes fórmulas que proporcionan directamente los resultados (véase, por ejemplo, Ivorra (2002)):

$$
\frac{n_{1}}{d_{1}}=\frac{c_{1}}{1}, \quad \frac{n_{2}}{d_{2}}=\frac{n_{1} \times c_{2}+1}{c_{2}}, \quad \frac{n_{i}}{d_{i}}=\frac{n_{i-1} \times c_{i}+n_{i-2}}{d_{i-1} \times c_{3}+d_{i-2}}, \quad \mathrm{i} \geq 3
$$

De entre sus muchas propiedades de las fracciones continuas, a nosotros nos interesa una especialmente (Baker, (1984), Ivorra (2002)):

Propiedad 1: Dado $n_{\mathrm{i}} / d_{\mathrm{i}}$ un convergente de una fracción continua del número real $\alpha$, si queremos una fracción que aproxime a $\alpha$ mejor que $n_{\mathrm{i}} / d_{\mathrm{i}}$ seguro que el denominador de la nueva fracción tiene que ser mayor de $d_{\mathrm{i}}$.

Antes de explicar la utilidad de esta propiedad, veamos cómo se calculan las fracciones continuas en la práctica:

Ejemplo 2.5. Calculamos la fracción continua de 17/12.

En primer lugar dividimos

$$
\begin{array}{r|l}
17 & 12 \\
5 & 1
\end{array} \Rightarrow \text { cociente } 1 \text {, resto } 5 \Rightarrow c_{1}=1
$$

El siguiente paso es dividir el divisor entre el resto.

$$
\begin{array}{r|l}
12 & 5 \\
2 & 2
\end{array} \Rightarrow \text { cociente } 2 \text {, resto } 2 \Rightarrow c_{2}=2
$$

Repetimos el razonamiento,

$$
\begin{array}{l|l}
5 & 2 \\
1 & 2
\end{array} \Rightarrow \text { cociente } 2 \text {, resto } 1 \Rightarrow c_{3}=2
$$

Y por último,

$$
2\left\lfloor\frac{1}{2} \Rightarrow \text { cociente } 2 \text {, resto } 0 \Rightarrow c_{4}=2\right.
$$

La fracción continua se construye de la forma siguiente: 


$$
1 \Rightarrow 1+\frac{1}{2} \Rightarrow 1+\frac{1}{2+\frac{1}{2}} \Rightarrow 1+\frac{1}{2+\frac{1}{2+\frac{1}{2}}}
$$

Para nuestro objetivo en el presente capítulo lo que necesitamos es calcular los convergentes:

$$
\frac{n_{1}}{d_{1}}=\frac{1}{1}=1, \quad \frac{n_{2}}{d_{2}}=\frac{1 \times 2+1}{2}=\frac{3}{2}, \quad \frac{n_{3}}{d_{3}}=\frac{3 \times 2+1}{2 \times 2+1}=\frac{7}{5}, \quad \frac{n_{4}}{d_{4}}=\frac{7 \times 2+3}{5 \times 2+2}=\frac{17}{12}
$$

y ordenándolos tenemos

$$
1<\frac{7}{5}<\frac{17}{12}<\frac{17}{12}<\frac{3}{2}
$$

Si aplicamos esta Propiedad 1, lo que significa es que si queremos fracción que aproxime a 17/12 mejor que 7/5 seguro que el denominador de la nueva fracción tiene que ser mayor de 5.

\subsubsection{Fracciones continuas y temperamentos mesotónicos}

La idea de utilizar fracciones continuas en música no es nueva. De hecho, en Barbour (1948), Schechter (1980), Hall \& Josic (2001) y Liern (2005), por ejemplo, pueden encontrarse diferentes usos de estas estructuras en música.

Consideramos un sistema de afinación que está generado por un único intervalo, como ocurre con la afinación pitagórica o los temperamentos mesotónicos, que se obtienen a partir de una quinta. Supongamos que esta quinta tiene el valor Q. Por lo que se ha descrito en la sección 2.1 de este capítulo, la sensación que proporciona el intervalo de quinta sería $\log _{2}(\mathrm{Q})$, al que para abreviar vamos a llamar $\alpha$, es decir,

$$
\alpha=\log _{2} Q
$$

Para conocer cual es el número de divisiones por octava adecuado, calcularemos la fracción continua de $\alpha$. Con esta fracción tenemos garantizadas dos cosas:

a) La aproximación es tan buena como se quiera (ver Ivorra, 2002).

b) Dado $n_{\mathrm{i}} / d_{\mathrm{i}}$ un convergente de una fracción continua del número real $\alpha$, si queremos una fracción que aproxime a $\alpha$ mejor que $n_{\mathrm{i}} / d_{\mathrm{i}}$ seguro que el denominador de la nueva fracción tiene que ser mayor de $d_{\mathrm{i}}$.

¿Qué significaría esto en un sistema de afinación concreto?. 
Veámoslo con el sistema pitagórico. En este caso la quinta es 3/2, por tanto debemos calcular la fracción continua de

$$
\alpha=\log _{2}\left(\frac{3}{2}\right) .
$$

A continuación damos 10 convergentes de esta fracción continua ${ }^{24}$

$$
0<\frac{1}{2}<\left[\frac{7}{12}\right]<\frac{31}{53}<\frac{389}{665}<\ldots<\log _{2}\left(\frac{3}{2}\right)<\ldots<\frac{9126}{15601}<\frac{179}{306}<\frac{24}{41}<\frac{3}{5}<1
$$

El denominador de cada uno de los convergentes nos indica cual es el mejor número de divisiones para una cierta precisión. Por ejemplo, si 5 notas nos parecen insuficientes, debemos recurrir a 12 y si queremos más precisión deben ser 41. Para una mayor precisión deberíamos escoger 53, 306, 665, etc. Pero cualquier valor intermedio entre estos no tendría ningún sentido porque que se consigue cerrar el círculo de quintas de manera más satisfactoria.

J. J. Goldáraz, en su obra Afinación y temperamento en la música occidental (1992), dedica dos capítulos a tratar diferentes temperamentos mesótonicos:

Capítulo 5. Circularidad de los temperamentos mesotónicos. División en partes iguales

Temperamento de $1 / 3$ de comma. 19 partes por octava. [...]

Temperamento de $1 / 4$ de comma. 31 partes.

Temperamento de 2/7 de comma. División en 50 partes [...]

Capítulo 6. Otras variedades del temperamento mesotónico.

Temperamento de $1 / 5$ de comma. 43 partes.

Temperamento de $2 / 9$ de comma. 74 partes.

Temperamento de $1 / 6$ de comma. 55 partes. [...]

Otros temperamentos mesotónicos.

- Temperamentos de 5/18 y de $1 / 11$ de comma, con 50 y 12 partes $^{25}$, respectivamente.

En ellos se razona con argumentos histórico-musicales el número de notas en los que se divide la octava en cada uno de ellos. Vamos a comprobar como se corresponden con los denominadores de sus fracciones continuas.

\footnotetext{
${ }^{24}$ Los pasos para llegar a estos convergentes se describen en los ejemplos siguientes.

${ }^{25}$ Estos temperamentos no aparecen como una sección específica, sino que son comentados de forma breve.
} 


\section{Cálculo de quintas}

Lo primero que debemos hacer es calcular qué quinta maneja cada uno de los sistemas de afinación. Sabemos por la aritmética de intervalos que, por ejemplo, una quinta menos un cuarto de comma significa "dividir la quinta entre la raíz cuarta de la comma", es decir

$$
\frac{3}{2}: \sqrt[4]{\frac{81}{80}}
$$

y quitar 2/9 de comma a una quinta es "dividir la quinta por la raíz novena de la comma elevada al cuadrado", es decir

$$
\frac{3}{2}: \sqrt[9]{\left(\frac{81}{80}\right)^{2}}
$$

Por lo tanto, las quintas de los temperamentos mesotónicos anteriores son las siguientes:

$$
\begin{aligned}
& \frac{3}{2} \text { menos } \frac{1}{4} \text { de comma } \Rightarrow \frac{\frac{3}{2}}{\sqrt[4]{\frac{81}{80}}}=\frac{\frac{3}{2}}{\sqrt[4]{\frac{3^{4}}{2^{4} 5}}}=\frac{\frac{3}{2}}{\frac{3}{2} \sqrt[4]{\frac{1}{5}}}=\sqrt[4]{5} \\
& \frac{3}{2} \text { menos } \frac{2}{7} \text { de comma } \Rightarrow \frac{\frac{3}{2}}{\sqrt[7]{\left(\frac{81}{80}\right)^{2}}}=\frac{\frac{3}{2}}{\sqrt[7]{\frac{3^{8}}{2^{8} 5^{2}}}}=\frac{\frac{3}{2}}{\frac{3}{2} \sqrt[7]{\frac{3}{2 \cdot 5^{2}}}}=\sqrt[7]{\frac{50}{3}} \\
& \frac{3}{2} \text { menos } \frac{1}{3} \text { de comma } \Rightarrow \frac{\frac{3}{2}}{\sqrt[3]{\frac{81}{80}}}=\frac{\frac{3}{2}}{\sqrt[3]{\frac{3^{4}}{2^{4} 5}}}=\frac{\frac{3}{2}}{\frac{3}{2} \sqrt[3]{\frac{3}{2 \cdot 5}}}=\sqrt[3]{\frac{10}{3}} \\
& \frac{3}{2} \text { menos } \frac{1}{5} \text { de comma } \Rightarrow \frac{\frac{3}{2}}{\sqrt[5]{\frac{81}{80}}}=\frac{\frac{3}{2}}{\sqrt[5]{\frac{3^{4}}{2^{4} 5}}}=\sqrt[5]{\frac{2^{4} 3^{5} 5}{3^{4} 2^{5}}}=\sqrt[5]{\frac{15}{2}} \\
& \frac{3}{2} \text { menos } \frac{2}{9} \text { de comma } \Rightarrow \frac{\frac{3}{2}}{\sqrt[9]{\left(\frac{81}{80}\right)^{2}}}=\frac{\frac{3}{2}}{\sqrt[9]{\frac{3^{8}}{2^{8} 5^{2}}}}=\sqrt[9]{\frac{2^{5} 3^{9} 5^{2}}{3^{8} 2^{9}}}=\sqrt[9]{\frac{75}{2}} \\
& \frac{3}{2} \text { menos } \frac{1}{6} \text { de comma } \Rightarrow \frac{\frac{3}{2}}{\sqrt[6]{\frac{81}{80}}}=\frac{\frac{3}{2}}{\sqrt[6]{\frac{3^{4}}{2^{4} 5}}}=\sqrt[6]{\frac{2^{4} 3^{6} 5}{3^{4} 2^{6}}}=\sqrt[6]{\frac{45}{4}}
\end{aligned}
$$




$$
\begin{aligned}
& \frac{3}{2} \text { menos } \frac{5}{18} \text { de comma } \Rightarrow \frac{\frac{3}{2}}{\sqrt[18]{\left(\frac{81}{80}\right)^{5}}}=\frac{\frac{3}{2}}{\sqrt[18]{\frac{3^{20}}{2^{20} 5^{5}}}}=\sqrt[18]{\frac{2^{2} 5^{5}}{3^{2}}}=\sqrt[18]{\frac{12500}{9}} \\
& \frac{3}{2} \text { menos } \frac{1}{11} \text { de comma } \Rightarrow \frac{\frac{3}{2}}{\sqrt[11]{\frac{81}{80}}}=\frac{\frac{3}{2}}{\sqrt[11]{\frac{3^{4}}{2^{4} 5}}}=\sqrt[11]{\frac{2^{11} 3^{4}}{3^{11} 2^{4} 5}}=\sqrt[11]{\frac{10935}{128}}
\end{aligned}
$$

\begin{tabular}{|c|c|c|c|c|c|c|c|c|}
\hline \multicolumn{9}{|c|}{ INTERVALO DE QUINTA DE ALGUNOS SISTEMAS DE AFINACIÓN } \\
\hline Temperamento & $\begin{array}{c}1 / 4 \mathrm{de} \\
\text { comma }\end{array}$ & $\begin{array}{c}2 / 7 \mathrm{de} \\
\text { comma }\end{array}$ & $\begin{array}{c}1 / 3 \mathrm{de} \\
\text { comma }\end{array}$ & $\begin{array}{c}1 / 5 \mathrm{de} \\
\text { Comma }\end{array}$ & $\begin{array}{c}2 / 9 \mathrm{de} \\
\text { comma }\end{array}$ & $\begin{array}{c}1 / 6 \mathrm{de} \\
\text { comma }\end{array}$ & $\begin{array}{l}5 / 18 \mathrm{de} \\
\text { comma }\end{array}$ & $\begin{array}{l}1 / 11 \mathrm{de} \\
\text { comma }\end{array}$ \\
\hline Generador & $\sqrt[4]{5}$ & 50 & 10 & 15 & 75 & 45 & 12500 & 10935 \\
\hline & & & 3 & $\sqrt{2}$ & 2 & 4 & 9 & $\sqrt[1]{128}$ \\
\hline
\end{tabular}

Tabla 2.13 Tamaño de las quintas de algunos temperamentos mesotónicos.

\section{Cálculo de las fracciones continuas}

Por lo que hemos expuesto en el ejemplo anterior, para conocer cuál es la cantidad adecuada de divisiones por octava, el primer paso es calcular la sensación que proporciona cada una de las quintas de la Tabla 2.13:

\begin{tabular}{ccccc}
\hline Generador & $\mathbf{1 / 4}$ de comma & 2/7 de comma & $\mathbf{1 / 3}$ de comma & 1/5 de comma \\
\hline$\alpha$ & $\frac{1}{4} \log _{2} 5$ & $\frac{1}{7} \log _{2}\left(\frac{50}{3}\right)$ & $\frac{1}{3} \log _{2}\left(\frac{10}{3}\right)$ & $\frac{1}{5} \log _{2}\left(\frac{15}{2}\right)$ \\
\hline Generador & $2 / 9$ de comma & $\mathbf{1 / 6}$ de comma & $\mathbf{5 / 1 8}$ de comma & $\mathbf{1 / 1 1}$ de comma \\
\hline$\alpha$ & $\frac{1}{9} \log _{2}\left(\frac{75}{2}\right)$ & $\frac{1}{6} \log _{2}\left(\frac{45}{4}\right)$ & $\frac{1}{18} \log _{2}\left(\frac{12500}{9}\right)$ & $\frac{1}{11} \log _{2}\left(\frac{10935}{128}\right)$ \\
\hline
\end{tabular}

Tabla 2.14 Generadores de algunos temperamentos mesotónicos.

En todos los temperamentos que se han descrito en la Tabla 2.13 los intervalos generadores son números irracionales, es decir que no admiten una representación decimal finita. Por tanto, para calcular la fracción continua con el método que hemos expuesto en la sección 2.7.1 aproximamos el número $\alpha$ por un número decimal que tenga un número de decimales suficiente para asegurar que vamos a alcanzar una buena precisión. 
Veamos un ejemplo con el temperamento de $1 / 4$ de comma generado por el intervalo

$$
\alpha=\log _{2}(\sqrt[4]{5}) \approx 0.58048202
$$

Expresamos el valor de $\alpha$ con una fracción:

$$
\begin{aligned}
& 0.58048202=\frac{58048202}{100000000}=\frac{29024101}{50000000} \\
& 29024101 \quad 50000000 \\
& 290241010 \quad \Rightarrow \text { cociente } 0 \text {, resto } 29024101 \\
& 50000000 \quad 29024101 \\
& 209758991 \quad \Rightarrow \text { cociente } 1 \text {, resto } 20975899 \\
& 29024101 \mid 20975899 \\
& 80482021 \quad \Rightarrow \text { cociente } 1 \text {, resto } 8048202 \\
& 20975899 \quad 8048202 \\
& 48794952 \Rightarrow \text { cociente } 2 \text {, resto } 4879495 \\
& 8048202 \mid 4879495 \\
& 31687071 \quad \Rightarrow \text { cociente } 1 \text {, resto } 3168707 \\
& 4879495 \lcm{3168707} \\
& 17107881 \quad \Rightarrow \text { cociente } 1 \text {, resto } 1710788 \\
& \begin{array}{l|l}
3168707 & 1710788 \\
1457919 & 1
\end{array} \Rightarrow \text { cociente } 1 \text {, resto } 1457919 \\
& 1710788 \mid 1457919 \\
& 2528691 \quad \Rightarrow \text { cociente } 1 \text {, resto } 252869 \\
& 1457919 \mid 252869 \\
& 1935745 \Rightarrow \text { cociente } 5 \text {, resto } 193574 \\
& 252869 \mid 193574 \\
& 592951 \Rightarrow \text { cociente } 1 \text {, resto } 59295 \\
& 193574 \lcm{59295}
\end{aligned}
$$




$$
\begin{aligned}
& 15689 \overline{3} \Rightarrow \text { cociente } 3 \text {, resto } 15689 \\
& 59295 \lcm{15689} \\
& 122283 \Rightarrow \text { cociente } 3 \text {, resto } 12228 \\
& 15689 \mid 12228 \\
& 34611 \Rightarrow \text { cociente } 1 \text {, resto } 3461 \\
& \begin{array}{l|l}
12228 & 3461 \\
1845 & 3
\end{array} \Rightarrow \text { cociente } 3 \text {, resto } 1845
\end{aligned}
$$

\begin{tabular}{|c|c|c|c|c|c|c|c|c|c|c|c|}
\hline $\mathrm{c}_{1}$ & $\mathrm{c}_{2}$ & $\mathrm{c}_{3}$ & $\mathrm{c}_{4}$ & $\mathrm{c}_{5}$ & $\mathrm{c}_{6}$ & $\mathrm{c}_{7}$ & $\mathrm{c}_{8}$ & $\mathrm{c}_{9}$ & $\mathrm{c}_{10}$ & $\mathrm{c}_{11}$ & $\mathrm{c}_{12}$ \\
\hline 0 & 1 & 1 & 2 & 1 & 1 & 1 & 1 & 5 & 1 & 3 & 3 \\
\hline$c_{13}$ & $\mathrm{c}_{14}$ & $\mathrm{c}_{15}$ & $c_{16}$ & $c_{17}$ & $\mathrm{c}_{18}$ & $\mathrm{c}_{19}$ & $\mathrm{c}_{20}$ & $\mathrm{c}_{21}$ & $\mathrm{c}_{22}$ & $\mathrm{c}_{23}$ & \\
\hline 1 & 3 & 1 & 1 & 7 & 17 & 1 & 1 & 1 & 1 & 2 & \\
\hline
\end{tabular}

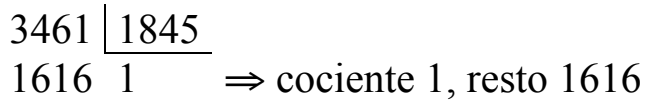

$$
\begin{aligned}
& 1845 \lcm{1616} \\
& 2291 \Rightarrow \text { cociente } 1 \text {, resto } 229 \\
& 1616 \frac{229}{7} \Rightarrow \text { cociente } 7 \text {, resto } 13 \\
& 229 \lcm{13} \\
& 8 \quad 17 \Rightarrow \text { cociente } 17 \text {, resto } 8 \\
& 5 \frac{13}{1} \Rightarrow \text { cociente } 1 \text {, resto } 5 \\
& \begin{array}{l|l}
8 & 5 \\
3 & 1
\end{array} \Rightarrow \text { cociente } 1 \text {, resto } 3 \\
& \begin{array}{l|l}
5 & 3 \\
2 & 1
\end{array} \Rightarrow \text { cociente } 1 \text {, resto } 2 \\
& 3 \mid 2 \\
& 11 \Rightarrow \text { cociente } 1 \text {, resto } 1 \\
& 2\lfloor 1 \\
& 02 \Rightarrow \text { cociente } 2 \text {, resto } 0
\end{aligned}
$$

Cocientes 
Entonces, los convergentes son:

$\frac{n_{1}}{d_{1}}=\frac{0}{1}=0, \quad \frac{n_{2}}{d_{2}}=\frac{1}{1}=1, \quad \frac{n_{3}}{d_{3}}=\frac{n_{2} \times c_{3}+n_{1}}{d_{2} \times c_{3}+d_{1}}=\frac{1 \times 1+0}{1 \times 1+1}=\frac{1}{2}$

$\frac{n_{4}}{d_{4}}=\frac{n_{3} \times c_{4}+n_{2}}{d_{3} \times c_{4}+d_{2}}=\frac{1 \times 2+1}{2 \times 2+1}=\frac{3}{5} \quad \frac{n_{5}}{d_{5}}=\frac{n_{4} \times c_{5}+n_{3}}{d_{4} \times c_{5}+d_{3}}=\frac{3 \times 1+1}{5 \times 1+1}=\frac{4}{7}$

$\frac{n_{6}}{d_{6}}=\frac{n_{5} \times c_{6}+n_{4}}{d_{4} \times c_{6}+d_{4}}=\frac{4 \times 1+3}{7 \times 1+5}=\frac{7}{5}, \quad \frac{n_{7}}{d_{7}}=\frac{n_{6} \times c_{7}+n_{5}}{d_{6} \times c_{7}+d_{5}}=\frac{7 \times 1+4}{12 \times 1+7}=\frac{11}{19}$

$\frac{n_{8}}{d_{8}}=\frac{n_{7} \times c_{8}+n_{6}}{d_{7} \times c_{8}+d_{6}}=\frac{11 \times 1+4}{19 \times 1+12}=\frac{18}{31}, \frac{n_{9}}{d_{9}}=\frac{n_{8} \times c_{9}+n_{7}}{d_{8} \times c_{9}+d_{7}}=\frac{18 \times 5+11}{31 \times 5+19}=\frac{101}{174}$

$\frac{n_{10}}{d_{10}}=\frac{n_{9} \times c_{10}+n_{7}}{d_{9} \times c_{10}+d_{7}}=\frac{101 \times 1+18}{174 \times 1+31}=\frac{119}{205}$

y una vez ordenados se tiene:

$$
0<\frac{1}{2}<\frac{4}{7}<\frac{11}{19}<\frac{101}{174}<\ldots<\log _{2}(\sqrt[4]{5})<\ldots<\frac{119}{205}<\left[\frac{18}{31}\right]<\frac{7}{12}<\frac{3}{5}<1
$$

Si procedemos de modo similar con cada uno de los temperamentos mencionados, se tiene:

Temperamento de 2/7 de comma:

$$
0<\frac{1}{2}<\frac{4}{7}<\frac{11}{19}<\frac{69}{119}<\ldots<\log _{2}\left(\sqrt[7]{\frac{50}{3}}\right)<\ldots<\frac{443}{764}<\left[\frac{29}{50}\right]<\frac{7}{12}<\frac{3}{5}<1
$$

Temperamento de $1 / 3$ de comma:

$$
0<\frac{1}{2}<\frac{4}{7}<\left[\frac{11}{19}\right]<\frac{744}{1285}<\ldots<\log _{2}\left(\sqrt[3]{\frac{10}{3}}\right)<\ldots<\frac{1477}{2551}<\frac{733}{1266}<\frac{7}{12}<\frac{3}{5}<1
$$

Temperamento de $1 / 5$ de comma:

$$
0<\frac{1}{2}<\frac{4}{7}<\frac{18}{31}<\frac{768}{1321}<\ldots<\log _{2}\left(\sqrt[5]{\frac{15}{2}}\right)<\ldots<\frac{793}{1364}<\left[\frac{25}{43}\right]<\frac{7}{12}<\frac{3}{5}<1
$$

Temperamento de 2/9 de comma:

$$
0<\frac{1}{2}<\frac{4}{7}<\frac{18}{31}<\frac{61}{105}<\ldots<\log _{2}\left(\sqrt[9]{\frac{75}{2}}\right)<\ldots<\frac{165}{284}<\left[\frac{43}{74}\right]<\frac{7}{12}<\frac{3}{5}<1
$$

Temperamento de 1/6 de comma: 


$$
0<\frac{1}{2}<\frac{4}{7}<\left[\frac{32}{55}\right]<\frac{71}{122}<\ldots<\log _{2}\left(\sqrt[6]{\frac{45}{4}}\right)<\ldots<\frac{536}{921}<\frac{39}{67}<\frac{7}{12}<\frac{3}{5}<1
$$

Temperamento de 5/18 de comma:

$$
0<\frac{1}{2}<\frac{4}{7}<\frac{11}{19}<\frac{707}{1219}<\ldots<\log _{2}\left(\sqrt[18]{\frac{12500}{9}}\right)<\ldots<\frac{736}{1269}<\left[\frac{29}{50}\right]<\frac{7}{12}<\frac{3}{5}<1
$$

Temperamento de 1/11 de comma:

$$
0<\frac{1}{2}<\frac{4}{7}<\frac{501267}{859315}<\ldots<\log _{2}\left(\sqrt[11]{\frac{10935}{128}}\right)<\ldots<\frac{501274}{859327}<\left[\frac{7}{12}\right]<\frac{3}{5}<1
$$

Puede comprobarse ${ }^{26}$ cómo la cantidad de notas óptima de cada uno de los sistemas aparece como uno de los denominadores.

NOTA: Este método sólo es válido cuando el sistema de afinación está generado por un único tipo de intervalo. Cuando hay más de uno, como ocurre con la justa entonación o los temperamentos irregulares, el procedimiento no tiene utilidad.

\subsection{Sensibilidad de percepción}

Aunque en nuestro trabajo no pretendemos profundizar en cuestiones de psicoacústica, creemos necesario hacer unas breves consideraciones acerca de la sensibilidad auditiva. Según J. Piles (1982), entre los musicólogos sigue habiendo varias escuelas $^{27}$ respecto a este tema que, grosso modo, podemos agrupar de la forma siguiente:

a) Los que, siguiendo los trabajos de Hermann von Helmotz (1821 1894), consideran que un un oído privilegiado y educado puede distinguir una diferencia de 2 cents, es decir que sería capaz de reconocer 100 niveles de altura en un tono.

b) Los que fijan la distancia mínima de percepción en un 4 -5 cents (a esta banda, en Liern (2003) se le denomina "banda de iso-afinación",28).

En cualquier caso, está claro que este umbral de percepción depende de muchos factores: la sensibilidad del oído, la edad del oyente, la educación y su

\footnotetext{
26 Hemos resaltado con corchetes [ ] los convergentes cuyo denominador es el número de divisiones por octava que los musicólogos consideran óptima (véase Goldáraz (1992)).

${ }^{27}$ En Haluska (2000) se afirma que, como media, puede aceptarse que dos notas que distan 12 cents pueden considerarse como un unísono.

${ }^{28}$ En el trabajo original se denomina isotuning band.
} 
práctica, el estado de ánimo, la región del índice acústico en el que están los sonidos, la intensidad y duración, etc.

En Piles (1982), se da a modo de orientación la siguiente

\begin{tabular}{lcc}
\hline Frecuencia en Hertz & $\begin{array}{c}\text { Niveles en un } \\
\text { tono }^{\mathbf{2 9}}\end{array}$ & $\begin{array}{c}\text { Amplitud de la } \\
\text { banda (cents) }\end{array}$ \\
\hline De 375 a 500 & 14 & 14,56 \\
De 500 a 750 & 20 & 10,2 \\
De 750 a 1000 & 28 & 7,4 \\
De 1000 a 1500 & 31 & 6,6 \\
De 1500 a 2000 & 39 & 5,24 \\
De 2000 a 3000 & 51 & 4 \\
De 3000 a 4000 & 48 & 4,24 \\
De 4000 a 6000 & 36 & 5,68 \\
De 6000 a 8000 & 20 & 10,2 \\
\hline
\end{tabular}

Tabla 2.15 Umbrales de percepción.

En el gráfico siguiente mostramos la relación entre la frecuencia y el umbral para distinguir los sonidos suponiendo, por supuesto, que el resto de propiedades físicas del sonido no han sido modificadas.

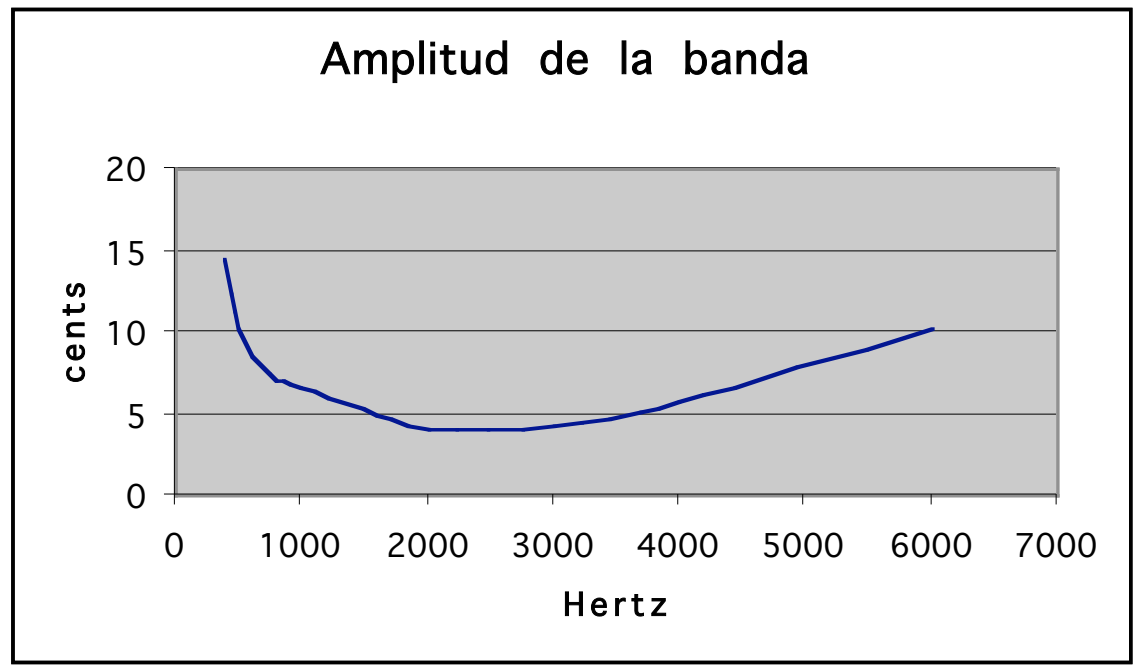

Fig. 2.26 Amplitudes de las bandas de percepción en función de la frecuencia

\footnotetext{
${ }^{29}$ Hemos conservado la denominación original de "niveles por tono" que aparece en Piles (1982). Por ejemplo, debemos entender por " 14 niveles" que el oído humano es capaz de distinguir 14 sonidos diferentes un tono y el siguiente.
} 
Estos valores nos sirven para hacer comparaciones globales entre los sistemas de afinación. Por ejemplo, el semitono cromático pitagórico y el tono pitagórico tienen 0.48 cents y 0.12 cents, respectivamente, más que los de Holder. Esto ha hecho que las rectificaciones que Holder introdujo en el sistema de afinación pitagórico no tuviesen éxito, debido a que el oído no era capaz de distinguir estas alteraciones. Esta es la razón por la que en el capítulo siguiente tratamos juntos el sistema pitagórico y el de Holder. 
"Si Schoemberg y sus discípulos se independizaron de la tonalidad, en Ionisation, Varèse se independiza incluso de las notas, es decir, de los sonidos temperados",

Diego Fischerman, 2005

\section{CAPITULO 3:} Afinación práctica: el intérprete y el compositor

En este capítulo abordamos de forma práctica los resultados teóricos de los capítulos anteriores, y lo hacemos desde dos vertientes: la del intérprete y la del compositor.

Para abordar el punto de vista del intérprete, se han realizado grabaciones en diferentes escenarios (varias trompetas, varios días, horas diferentes) intentando conseguir que los documentos sonoros objeto de estudio representen de la forma más fiel posible a la práctica habitual del intérprete. Hemos analizado estos archivos y a continuación mostramos ${ }^{1}$ los resultados obtenidos.

En el estudio se han seguido dos marcos conceptuales: la afinación estática, en el que cada nota es tratada de forma separada, y la afinación dinámica, con las notas dentro de su contexto. En la afinación estática se han grabado por una parte sonidos seriados (la escala cromática), y por otra, sonidos no seriados (notas sueltas con distintas posiciones). En la afinación dinámica se han grabado fragmentos de dos obras de estilos diferentes: Un fragmento del Concierto en Mi bemol Mayor, Hob. Vlle, N. 1 (1796) para trompeta y orquesta de Franz Joseph Haydn (1732-1809) y un fragmento del Adagio de Música para cuerda, percusión y celesta (1937) de Béla Bartók (1881-1945).

El objeto de estos experimentos es conocer las distintas variaciones de cada nota que suelen producirse en un instrumento de viento donde la afinación puede estar sujeta a la interpretación del ejecutante o a las características propias

\footnotetext{
${ }^{1}$ El número de datos que se ha manejado, así como los objetivos perseguidos en este trabajo, han desaconsejado técnicas estadísticas que fuesen más allá de la descripción mediante diagramas de frecuencias.
} 
del instrumento. Para ello hemos hecho que algunos parámetros del experimento no se hayan modificado. En concreto, siempre se graba al mismo intérprete y no se modifica.

Para abordar el punto de vista del compositor, es necesario hacer una breve referencia al microtonalismo como técnica compositiva. Desde la antigüedad se utilizó en las músicas no occidentales (india o árabe, por ejemplo) en la música griega (como se ha visto en el capítulo 2 de esta memoria), en la música medieval y en alguna música folclórica europea.

En el siglo XVI Nicolà Vicentino y Vicente Lusitano, polemizaron acerca de revivir el sistema griego (basado esencialmente en una división de la escala en 31 partes). En el siglo XVII, Christian Huygens propuso la división de la octava en 31 partes iguales, Willian Holder propuso dividirla en 53 sonidos y Chevé propuso una escala de 50 sonidos.

No obstante, hasta el siglo XX no se puede decir que estuviese en la base de la inspiración y la técnica de la propia composición musical. Los pioneros fueron Julián Carrillo y Carl Andreas Eitz, en la década de 1890, y Charles Ives, que a comienzos del siglo experimentó con piezas para dos pianos afinados a distancia de cuarto de tono entre ellos. En Europa, Alois Hába utilizó los cuartos de tono por primera vez en su Suite para orquesta de cuerda (1917) y fundó una escuela compositiva microtonal en el Conservatorio de Praga (1923). El mismo autor aplicó sus investigaciones en grandes obras como las óperas La madre (1929), con cuartos de tono, y Venga a nosotros tu reino (1939-1942), con sextos de tono. Béla Bartók utiliza el microtonalismo en El mandarín maravilloso (1919). En París, Carrillo extendió sus investigaciones al octavo y al dieciseisavo de tono. Ígor Markevitch utiliza los cuartos de tono en el ballet Ícaro (1932) y, por medio de la obra de Ivan Vishnegradski, estos procedimientos llegan hasta Pierre Boulez.

A partir de la Segunda Gerra Mundial, el microtonalismo pierde el carácter experimental y empieza a ser la corriente principal de composición. Surgió una clara distinción entre la mayoría de compositores que utilizaban giros microtonales para ampliar la base cromática de su música y un grupo más reducido que usaban diversos sistemas tonales más sistemáticamente, con lo que se rechazaba el temperamento igual aceptado desde 1735. Destacan, por ejemplo, Harry Partch, que investigó sobre una octava dividida en 43 intervalos y su adaptación a instrumentos de viento y de percusión, Eivind Groven y Ben Johnston que introdujeron el sistema de 53 intervalos iguales que había sido propiciado por varios teóricos, y Adriaan Fokker que construyó un órgano con una escala de 31 intervalos que podía producir terceras mayores puras y séptimas naturales. 
A pesar del desarrollo de las técnicas de ejecución, en especial de las digitaciones alternativas, la posibilidad total de introducción de todas estas escalas sólo fue posible con el advenimiento de los instrumentos electrónicos a partir de la segunda mitad del siglo XX.

En la segunda parte de este capítulo, lo que haremos será utilizar los cálculos realizados por Kepler en su obra Harmonices Mundi (1619) para obtener la Música de las Esferas, es decir la música que conforman los planetas y la luna en su movimiento alrededor de sus órbitas. Estos cálculos son la base para la composición de la obra Esferas que constituye la parte práctica de los sistemas de afinación. En la última parte del capítulo se incluye la partitura de la obra.

\subsection{Aspectos técnicos}

\subsubsection{Mediciones con el programa informático Audacity ${ }^{\circledR}$}

Las mediciones de los experimentos han sido realizadas con el programa informático gratuito Audacity ${ }^{\circledR 2}$. El funcionamiento del programa es sencillo. Al abrir este programa aparece una ventana en la que están los símbolos para reproducir y detener las grabaciones así como para modificar el volumen. Si pulsamos los comandos file y open podemos acceder al lugar donde tenemos guardado el archivo de audio y de esta manera aparece en la pantalla el espectro de la grabación.

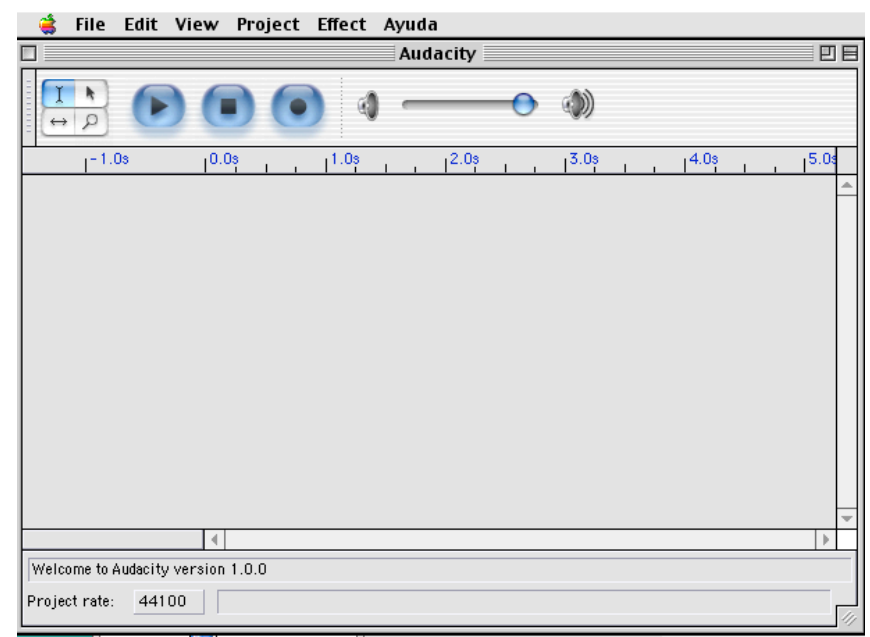

Fig. 3.1 Pantalla principal

Una vez tenemos el espectro en pantalla podemos, elegimos la herramienta _ para seleccionar el fragmento deseado y podemos escucharlo utilizando play.

\footnotetext{
${ }^{2}$ El programa Audacity puede obtenerse de manera gratuita en http://audacity.sourceforge.net
} 


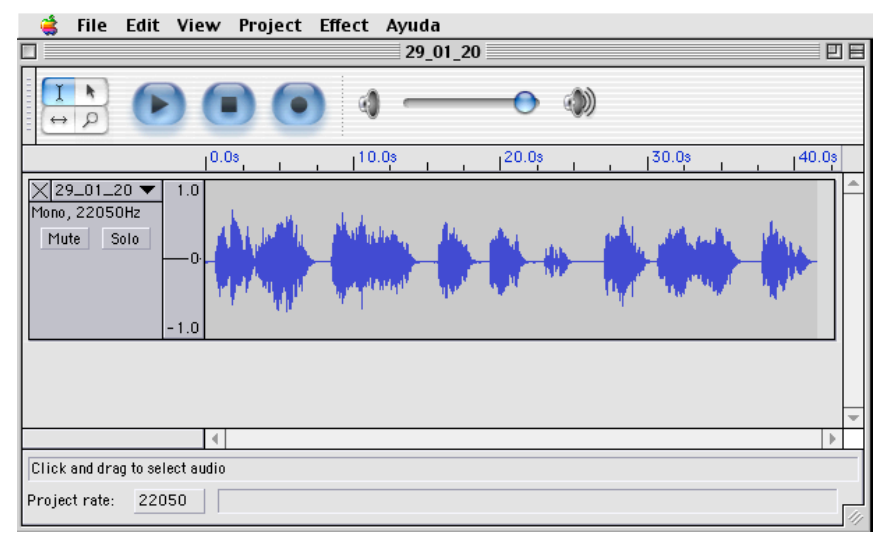

Fig. 3.2 Pantalla con el espectro

Tras seleccionar la parte que queremos analizar, seleccionamos en el menú la opción view y plot spectrum o si queremos podemos teclear $c t r l+U$, con lo que accederemos a otra ventana que nos muestra el valor de los armónicos en Herzios. Para saber la altura de esta nota solo hay que colocar el cursor sobre el primer pico que corresponde al primer armónico ya que el segundo pico corresponderá al segundo armónico (octava) el tercer pico al tercer armónico (quinta) y así sucesivamente.

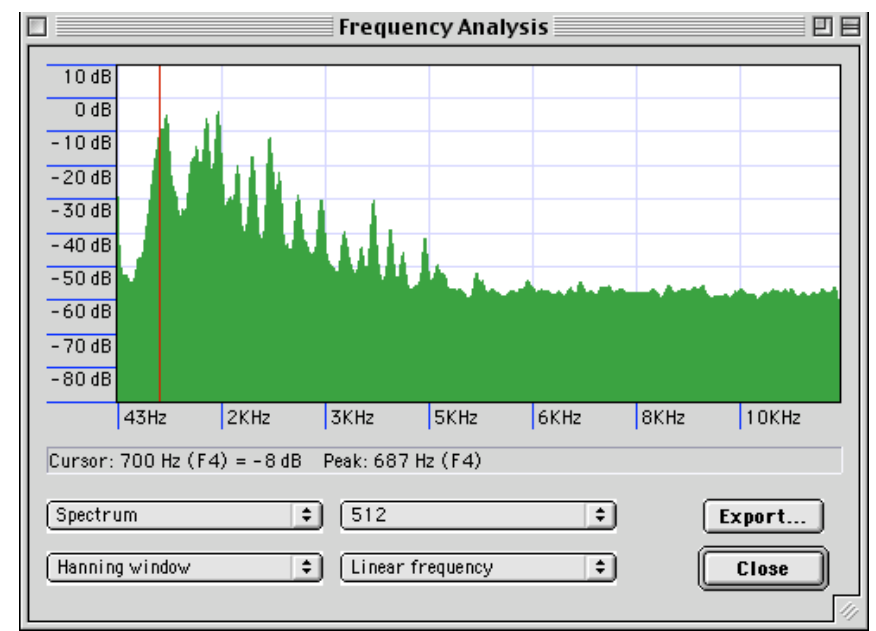

Fig. 3.3 Pantalla con los armónicos y su valor en $\mathrm{Hz}$

A continuación sólo resta anotar el valor en una tabla y continuar con la siguiente nota o fragmento de nota que queramos analizar.

\subsubsection{Mediciones con afinadores cromáticos}

Para las mediciones también se han utilizado los afinadores cromáticos descritos más adelante. Una vez realizadas las grabaciones se ha medido tres 
veces cada una de ellas con cada afinador y posteriormente se ha anotado en la correspondiente tabla. Los modelos que se han empleado son los afinadores cromáticos comerciales SEIKO modelo ST 747-100 (Fig.3.4) y KORG modelo CA 30 (Fig.3.5)

Ambos proporcionan la desviación respecto de la nota afinada expresada en cents y tienen salida digital, pero sólo el primero de ellos marca los dígitos correspondientes a los cents, mientras que el segundo refleja la desviación mediante una varilla que recorre una curva graduada.

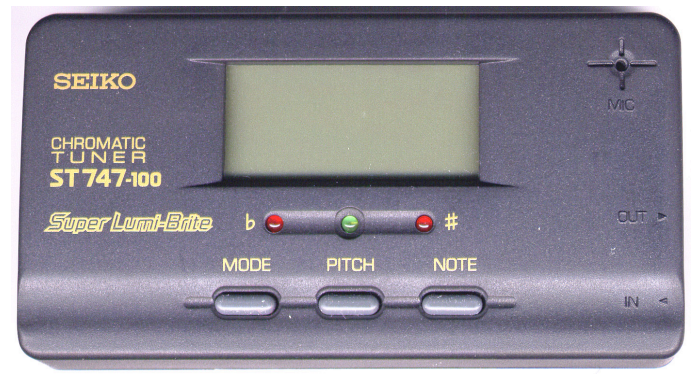

Fig.3.4 Afinador Seiko

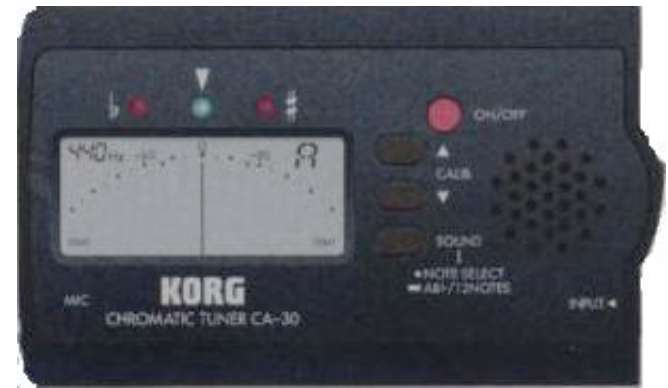

Fig.3.5 Afinador Korg

Se trata de dos modelos de gama media que están al alcance de cualquier persona, como ocurre con todos los elementos que se han utilizado en este trabajo. Así, como ya hemos dicho, nuestra intención es ofrecer la posibilidad de que un músico que disponga en su casa de estos elementos básicos pueda realizar él mismo las experiencias que a continuación detallamos.

\subsubsection{Trompetas empleadas}

Las grabaciones han sido realizadas en el aula de trompeta 2.8 del conservatorio "Narciso Yepes" de Lorca (Murcia). En el CD que se adjunta a esta memoria aparecen los documentos 22 y 23 de enero de 2003 han sido grabados con una trompeta en $\mathrm{si}^{\mathrm{b}}$ Yamaha $^{\circledR}$ Xeno modelo YTR8335 lacada y $\mathrm{n}^{\mathrm{o}}$ de serie 457223 (Fig. 3.6), al igual que los que aparecen en el referido CD señalados con si ${ }^{b}$. Los señalados con do o do2, do3, do4, son versiones de un mismo día. La trompeta en do utilizada es Vicent Bach ${ }^{\circledR}$ Corporation con campana 239 y tudel $7 \mathrm{R} \mathrm{n}{ }^{\circ}$ de serie $373178 \mathrm{CL}$ plateada (Fig. 3.7). Las grabaciones reseñadas como $\mathrm{mi}^{\mathrm{b}}$ corresponden a las realizadas con una trompeta en mi bemol Schilke ${ }^{\circledR}$ modelo E3L plateada y $n^{\circ}$ de serie 36601 (Fig. 3.8). En los que aparece Bach si ${ }^{\text {b }} 37$, las grabaciones se han realizado con una trompeta en si bemol Vicent Bach $^{\circledR}$ con campana modelo $37 \mathrm{y} \mathrm{n}^{\mathrm{o}}$ de serie $368491 \mathrm{ML}$ plateada (Fig. 3.9) que no pertenece al intérprete. Por último, en la interpretación del pasaje de Béla Bartók se ha utilizado también un piccolo Scherzer ${ }^{\mathbb{B}}$ en $\mathrm{si}^{\mathrm{b}}$ lacado fabricado por la casa $\mathrm{B} \& \mathrm{~S}^{\mathcal{C}}$ y con $\mathrm{n}^{\mathrm{o}}$ de serie 25720 (Fig. 3.10). 


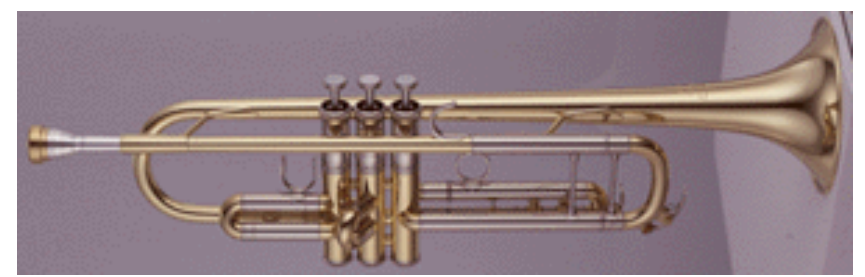

Fig. 3.6 Trompeta en $\mathrm{si}^{\mathrm{b}}$ Yamaha ${ }^{\circledR}$

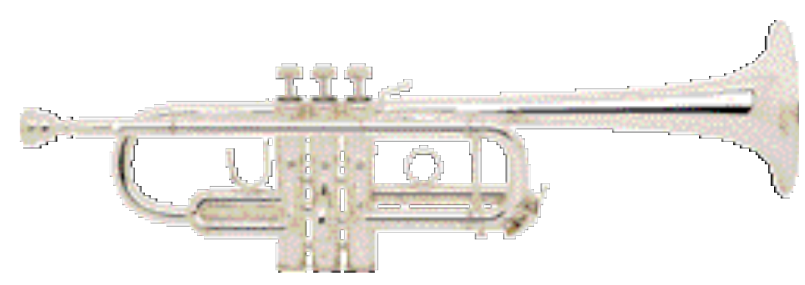

Fig. 3.7 Trompeta en do Bach $^{\circledR}$

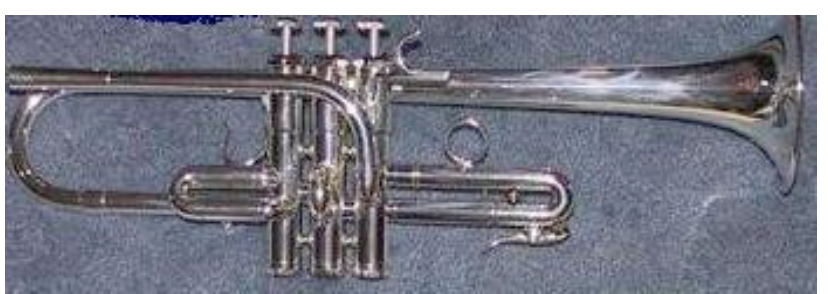

Fig. 3.8 Trompeta en mi ${ }^{\text {b }}$ Schilke ${ }^{\circledR}$

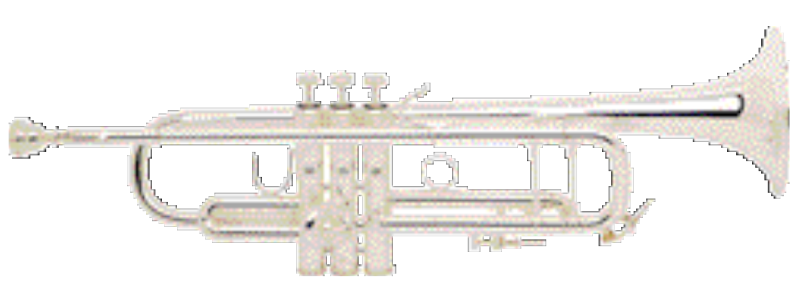

Fig. 3.9 Trompeta en $\mathrm{si}^{\mathrm{b}} \mathrm{Bach}^{\circledR}$

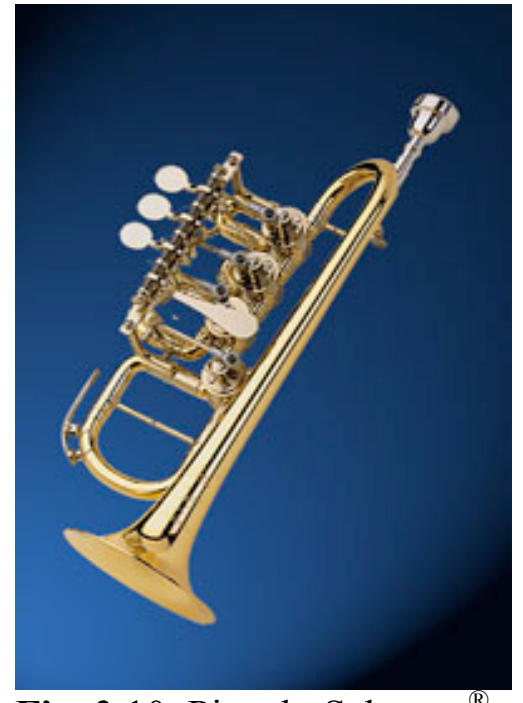

Fig. 3.10 Piccolo Scherzer ${ }^{\mathbb{R}}$ 


\subsection{Afinación estática}

\subsubsection{Experimento 1. Notas seriadas}

Hemos realizado 5 grabaciones de cada una de las notas de la escala cromática. Algunas de ellas, como pueden obtenerse con más de una posición, se han grabado con todas las digitaciones habituales excluyendo las se pueden obtener como armónicos. Hemos utilizado una trompeta en $\mathrm{si}^{\mathrm{b}}$ Yamaha $^{(}$ (Fig.3.6.), las notas estudiadas están comprendidas de la octava do 4 - do 5

y se obtienen con las posiciones siguientes:

\begin{tabular}{|llll|}
\hline Nota & Pistones & Nota & Pistones \\
\hline Do & 0 & Sol & 0 \\
Do\# & $1+2+3$ & Sol & $1+3$ \\
Re & $1+3$ & Lab & $2+3$ \\
Re\# & $2+3$ & La & $1+2$ \\
Mi & $1+2$ & La & 3 \\
Mi & 3 & Sib & 1 \\
Fa & 1 & Sib & $1+2+3$ \\
Fa\# & 2 & Si & 2 \\
Fa\# & $1+2+3$ & Si & $1+3$ \\
\hline
\end{tabular}

Tabla 3.1: Escala $\mathrm{Do}_{4}-\mathrm{Si}_{4}$ y sus correspondientes posiciones

A continuación mostramos una tabla (Tabla 3.2) que contiene el intervalo de variación de cada nota. Este intervalo ha sido construido tomando como extremos el valor más grave y más agudo de las grabaciones de cada nota. De acuerdo con la desviación observada y teniendo en cuenta las tablas de frecuencias de los diferentes sistemas de afinación que hemos presentado en el capítulo 2, hemos clasificado cada nota dentro del sistema de afinación al que pertenece.

No obstante, debemos señalar que en algunos casos esta clasificación no ha sido posible porque la nota grabada no forma parte de ninguno de los cuatro sistemas de afinación utilizados. 


\begin{tabular}{|c|c|c|c|c|c|}
\hline Nota & Variación & Clasificación & Nota & Variación & Clasificación \\
\hline Do & $(-3,+3)$ & Temperado & $\operatorname{Mi}(3) 4$ & $(-10,-5)$ & Ninguno \\
\hline Do 2 & $(+5,+15)$ & Zarlino & $\operatorname{Mi}(3) 5$ & $(-3,+3)$ & Temperado \\
\hline Do 3 & $(+5,+15)$ & Zarlino & $\mathrm{Fa}$ & $(-3,+3)$ & Temperado \\
\hline Do 4 & $(-3,+3)$ & Temperado & $\mathrm{Fa} 2$ & $(-3,+3)$ & Temperado \\
\hline Do 5 & $(+5,+15)$ & Zarlino & Fa 3 & $(-3,+3)$ & Temperado \\
\hline $\mathrm{Do}^{\#}$ & $(+18,+22)$ & Zarlino & $\mathrm{Fa} 4$ & $(-3,+3)$ & Temperado \\
\hline $\mathrm{Do}^{\#} 2$ & $(+18,+22)$ & Zarlino & Fa 5 & $(0,+5)$ & Temperado \\
\hline $\mathrm{Do}^{\#} 3$ & $(+18,+22)$ & Zarlino & $\mathrm{Fa}^{\#}$ & $(-3,+3)$ & Temperado \\
\hline Do $^{\#} 4$ & $(+20,+25)$ & Zarlino & $\mathrm{Fa}^{\#} 2$ & $(-3,+3)$ & Temperado \\
\hline $\operatorname{Do}^{\#} 5$ & $(+28,+32)$ & Ninguno & $\mathrm{Fa}^{\#} 3$ & $(-3,+3)$ & Temperado \\
\hline $\mathrm{Re}$ & $(+5,+15)$ & Ninguno & $\mathrm{Fa}^{\#} 4$ & $(-3,+3)$ & Temperado \\
\hline $\operatorname{Re} 2$ & $(-3,+3)$ & Temperado & $\mathrm{Fa}^{\#} 5$ & $(-5,0)$ & Temperado \\
\hline $\operatorname{Re} 3$ & $(-3,+3)$ & Temperado & $\mathrm{Fa}^{\#}(123)$ & $(+18,+22)$ & Ninguno \\
\hline $\operatorname{Re} 4$ & $(-3,+3)$ & Temperado & $\mathrm{Fa}^{\#}(123) 2$ & $(+5,+15)$ & Ninguno \\
\hline $\operatorname{Re} 5$ & $(+5,+15)$ & Ninguno & $\mathrm{Fa}^{\#}(123) 3$ & $(+5,+15)$ & Ninguno \\
\hline $\operatorname{Re}^{\#}$ & $(-3,+3)$ & Temperado & $\mathrm{Fa}^{\#}(123) 4$ & $(+5,+15)$ & Ninguno \\
\hline $\operatorname{Re}^{\#} 2$ & $(+18,+22)$ & Ninguno & $\mathrm{Fa}^{\#}(123) 5$ & $(+5,+15)$ & Ninguno \\
\hline $\operatorname{Re}^{\#} 3$ & $(-3,+3)$ & Temperado & Sol & $(+5,+15)$ & Zarlino \\
\hline $\operatorname{Re}^{\#} 4$ & $(-3,+3)$ & Temperado & Sol 2 & $(-3,+3)$ & Temperado \\
\hline $\operatorname{Re}^{\#} 5$ & $(-5,0)$ & Temperado & Sol 3 & $(-3,+3)$ & Temperado \\
\hline $\mathrm{Mi}$ & $(+20,+25)$ & Zarlino & Sol 4 & $(+18,+22)$ & Pitágoras \\
\hline Mi 2 & $(+5,+15)$ & Zarlino & Sol 5 & $(+5,+15)$ & Zarlino \\
\hline Mi 3 & $(+18,+22)$ & Zarlino & Sol(13) & $(-3,+3)$ & Temperado \\
\hline Sol(13) 2 & $(+5,+15)$ & Zarlino & $\mathrm{Si}^{\mathrm{b}} 2$ & $(-3,+3)$ & Temperado \\
\hline Sol(13)3 & $(+5,+15)$ & Zarlino & $\mathrm{Si}^{\mathrm{b}} 3$ & $(-3,+3)$ & Temperado \\
\hline Sol(13)4 & $(+5,+15)$ & Zarlino & $\mathrm{Si}^{\mathrm{b}} 4$ & $(-3,+3)$ & Temperado \\
\hline Sol(13)5 & $(-3,+3)$ & Temperado & $\mathrm{Si}^{\mathrm{b}} 5$ & $(-3,+3)$ & Temperado \\
\hline $\mathrm{La}^{\mathrm{b}}$ & $(-10,-5)$ & Ninguno & $\mathrm{Si}^{\mathrm{b}}(123)$ & $(+10,-10)$ & Ninguno \\
\hline $\mathrm{La}^{\mathrm{b}} 2$ & $(-15,-10)$ & Zarlino & $\mathrm{Si}^{\mathrm{b}}(123) 2$ & $(+10,-10)$ & Ninguno \\
\hline $\mathrm{La}^{\mathrm{b}} 3$ & $(-10,-5)$ & Ninguno & $\operatorname{Si}^{b}(123) 3$ & $(+10,-10)$ & Ninguno \\
\hline $\mathrm{La}^{\mathrm{b}} 4$ & $(-3,+3)$ & Temperado & $\operatorname{Si}^{\mathrm{b}}(123) 4$ & $(+10,-10)$ & Ninguno \\
\hline $\mathrm{La}^{\mathrm{b}} 5$ & $(-15,-10)$ & Zarlino & $\operatorname{Si}^{\mathrm{b}}(123) 5$ & $(-5,0)$ & Temperado \\
\hline $\mathrm{La}$ & $(+10,+15)$ & Ninguno & $\mathrm{Si}$ & $(-3,+3)$ & Temperado \\
\hline La 2 & $(+10,+15)$ & Ninguno & Si 2 & $(-3,+3)$ & Temperado \\
\hline La 3 & $(0,+5)$ & Temperado & Si 3 & $(-5,0)$ & Temperado \\
\hline La 4 & $(+20,0)$ & Ninguno & $\mathrm{Si} 4$ & $(-3,+3)$ & Temperado \\
\hline La 5 & $(-3,+3)$ & Temperado & Si 5 & $(-3,+3)$ & Temperado \\
\hline $\mathrm{La}(3)$ & $(-3,+3)$ & Temperado & $\operatorname{Si}(13)$ & $(+10,+15)$ & Ninguno \\
\hline $\mathrm{La}(3) 2$ & $(-5,0)$ & Temperado & $\operatorname{Si}(13) 2$ & $(+10,+15)$ & Ninguno \\
\hline $\mathrm{La}(3) 3$ & $(-3,+3)$ & Temperado & $\operatorname{Si}(13) 3$ & $(+10,+15)$ & Ninguno \\
\hline $\mathrm{La}(3) 4$ & $(-3,+3)$ & Temperado & $\operatorname{Si}(13) 4$ & $(-3,+3)$ & Temperado \\
\hline $\mathrm{La}(3) 5$ & $(-3,+3)$ & Temperado & $\operatorname{Si}(13) 5$ & $(+10,+15)$ & Ninguno \\
\hline $\mathrm{Si}^{\mathrm{b}}$ & $(-3,+3)$ & Temperado & & & \\
\hline
\end{tabular}

Tabla 3.2: Resultados del experimento 1

A grandes rasgos, observamos que en el 54\% de las notas, su afinación se corresponde con el sistema temperado, el más utilizado actualmente, en un $23 \%$ al sistema de Zarlino que corresponde a la afinación natural de los armónicos del instrumento. El 21\% pertenece a otros sistemas de afinación y sólo el 2\% de las 
grabaciones ha resultado corresponder exclusivamente a la afinación de Pitágoras/Holder.

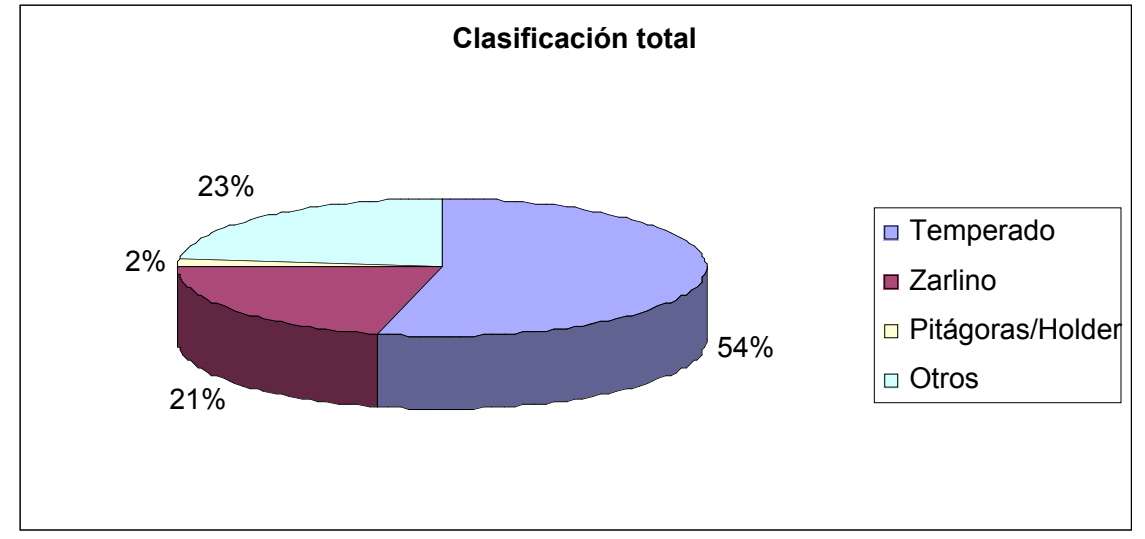

Fig. 3.11 Porcentaje de notas distribuidas por sistemas de afinación

Pero para el instrumentista resulta útil conocer cuáles son los resultados nota a nota. De ahí nuestro interés por el análisis que presentamos a continuación:

El $\mathrm{Do}_{4}$ aparece bien afinado ${ }^{3}$ en un $60 \%$ en el sistema de Zarlino y en un $40 \%$ en el temperado esto es debido a que se interpreta al aire sin pisar ningún pistón y su tendencia natural es afinar en el sistema de Zarlino, aunque el oído del intérprete hace que intente corregirla hacia la temperada ${ }^{4}$.

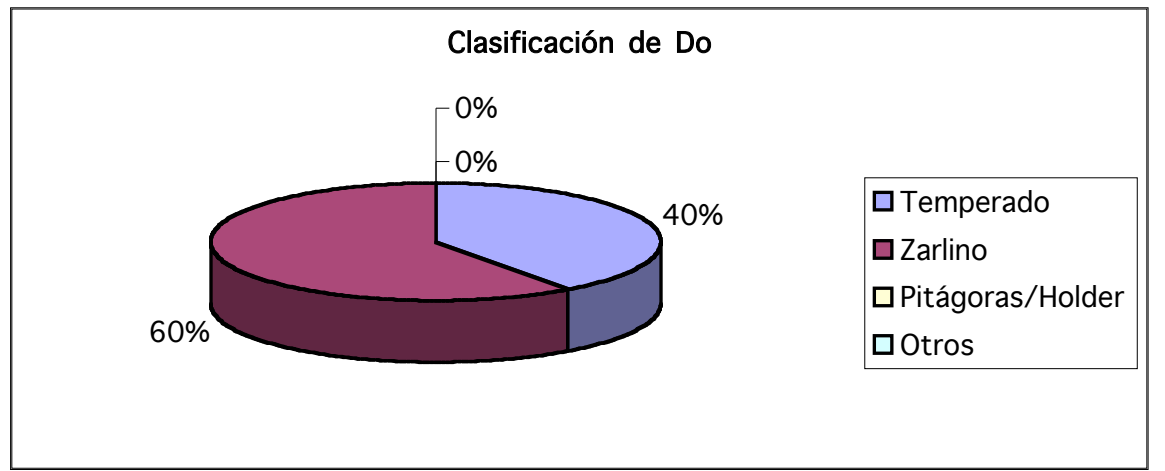

Fig. 3.12 Porcentaje en los que aparece la nota Do en cada sistema

Llama la atención algunas afinaciones, sobre todo las notas que se tocan accionando los tres pistones a la vez. Tanto el $\mathrm{Fa}^{\#}$ como el $\mathrm{Si}^{\mathrm{b}}$, interpretados con la posición $(1+2+3)$ se escapan de todos los sistemas empleados en este estudio, de hecho no pertenecen a ninguno de ellos. Sin embargo, el Do ${ }^{\#}$ que se interpreta con la misma posición, al no tener alternativas para ejecutarse, el oído del

\footnotetext{
${ }^{3}$ Como se utiliza el temperamento igual de 12 notas como sistema patrón, cuando utilizamos la expresión bien afinado hacemos referencia a este sistema.

${ }^{4}$ Cuando utilizamos la expresión temperado/a hacemos referencia al tempreamento igual de 12 notas.
} 
intérprete hace que éste se esfuerce para afinarlo correctamente. De esta manera el Do $^{\#}$ está bien afinado en un $80 \%$ en el sistema de Zarlino y sólo un $20 \%$ se escapa de los sistemas empleados en este experimento.

Tras interpretar el Do al aire y estar en un 60\% afinado en Zarlino, el oído obliga a modificar la afinación del Do en este mismo sistema. Así, esta nota que habitualmente esta desafinada en casi todos los modelos comerciales de trompetas que se encuentran en el mercado, hace que los intérpretes estén acostumbrados a modificar su afinación, bien de forma espontánea o bien con la ayuda de las válvulas que posee cada pistón.

Como se verá más adelante en el estudio de estas notas dependiendo de la posición utilizada, la posición $(1+2+3)$ es la que más problemas de afinación presenta ya que los resultados son los que se alejan más de cualquier sistema de afinación.

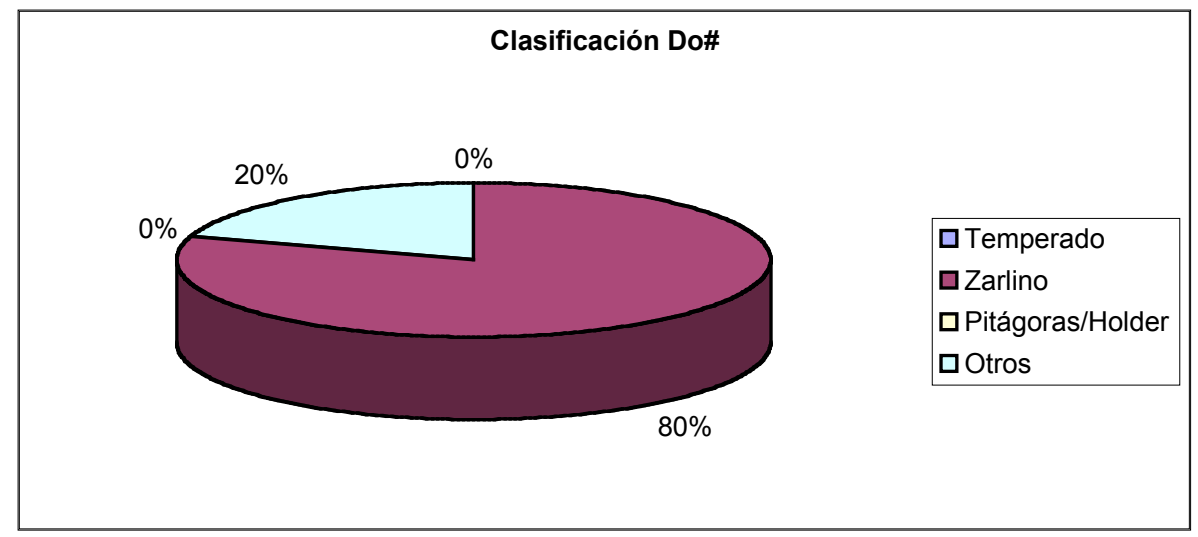

Fig. 3.13 Porcentaje en los que aparece la nota Do\# en cada sistema

El $\mathrm{Re}_{4}$ está afinado en un $60 \%$ en el sistema Temperado y en un $40 \%$ en otros sistemas, la posición empleada ha sido $(1+3)$ y suele quedar un poco alta y es habitual que los trompetistas corrijan esta nota sacando la válvula del tercer pistón.

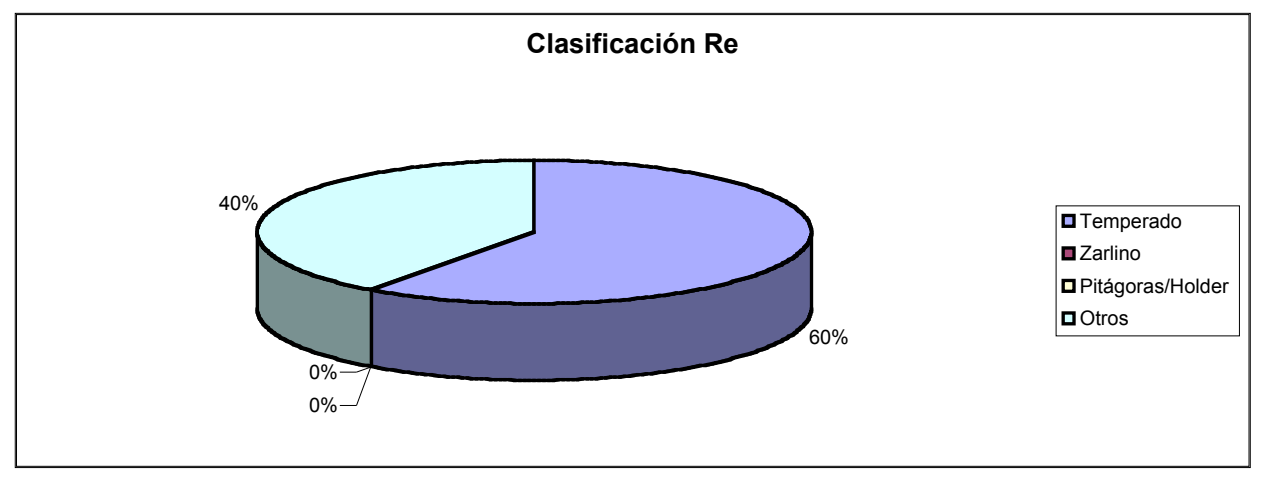

Fig. 3.14 Porcentaje en los que aparece la nota Re en cada sistema 
El $\mathrm{Re}_{4}^{\#}$ sólo se puede obtener con la posición $(2+3)$ y en un $80 \%$ de las ocasiones está bien afinada en el sistema temperado, sólo el $20 \%$ pertenece a otras afinaciones.

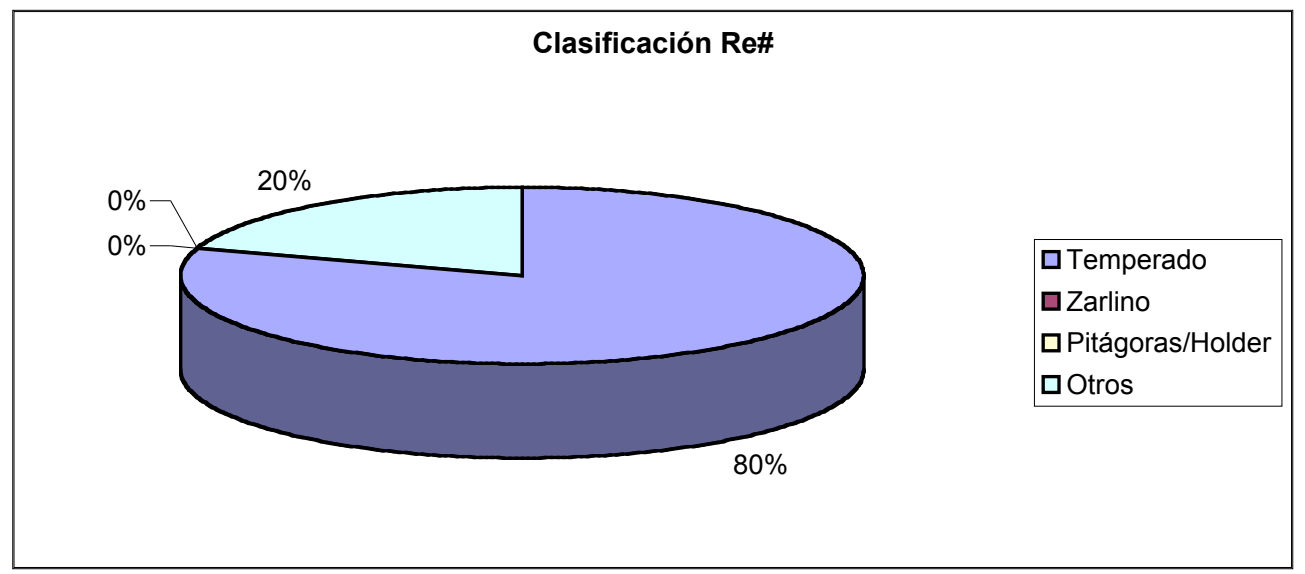

Fig. 3.15 Porcentaje en los que aparece la nota Re\# en cada sistema

$\mathrm{El} \mathrm{Mi}_{4}$ se puede tocar con dos posiciones diferentes una con $(1+2)$ y otra con un solo pistón (3). Con la posición $(1+2)$ la afinación predominante es la de Zarlino (un $80 \%$ ) mientras que la temperada aparece en un porcentaje mucho más reducido, el $20 \%$.

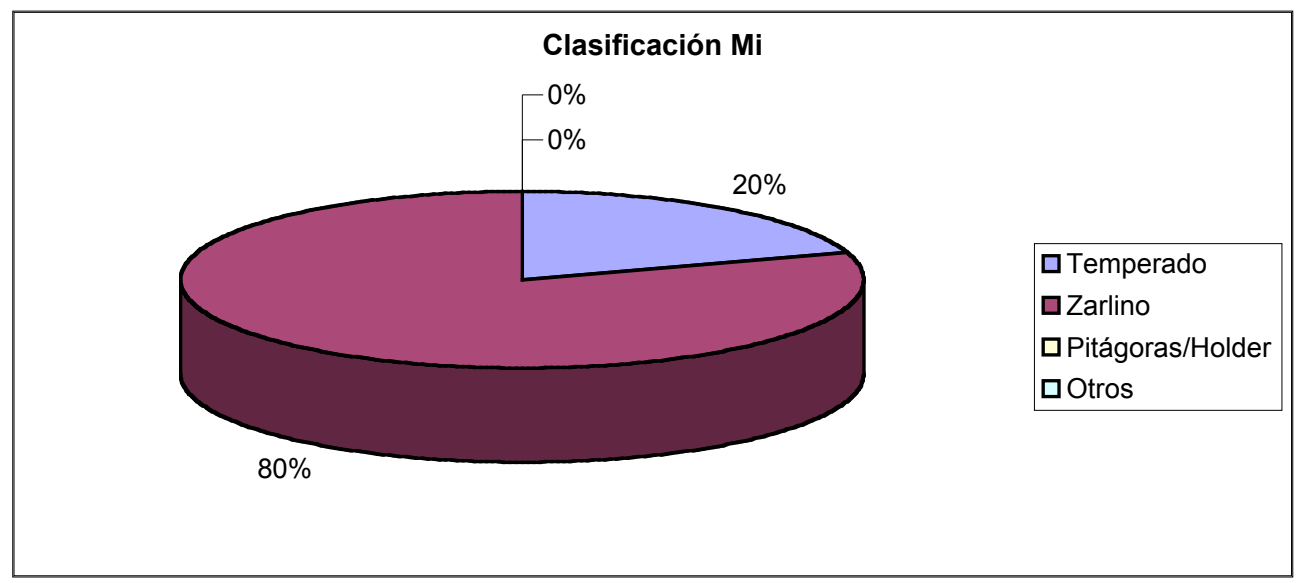

Fig. 3.16 Porcentaje en los que aparece la nota Mi en cada sistema

Con la posición (3) el $\mathrm{Mi}_{4}$ es en un $80 \%$ Temperado y sólo en un $20 \%$ se escapa de las afinaciones utilizadas para este experimento. Sin duda, esta posición es mucho más recomendable que la anterior puesto que la mayor parte de las veces está bien afinada, al contrario de lo que ocurría con la posición anterior. 


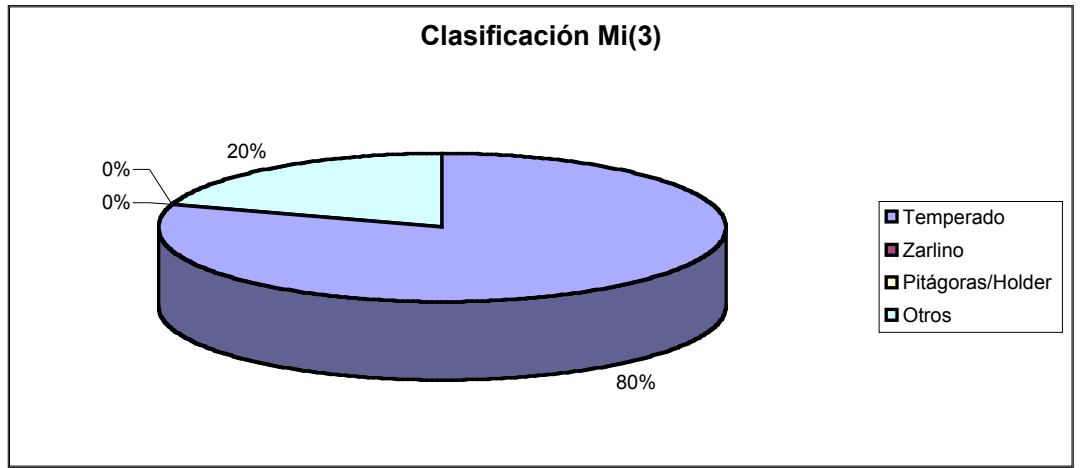

Fig. 3.17 Porcentaje en los que aparece la nota Mi(3) en cada sistema

El $\mathrm{Fa}_{4}$ sólo tiene una posible combinación para interpretarlo (el primer pistón). Aparece afinada en el sistema pitagórico en el 100\% de las grabaciones analizadas (Figura 3.18)

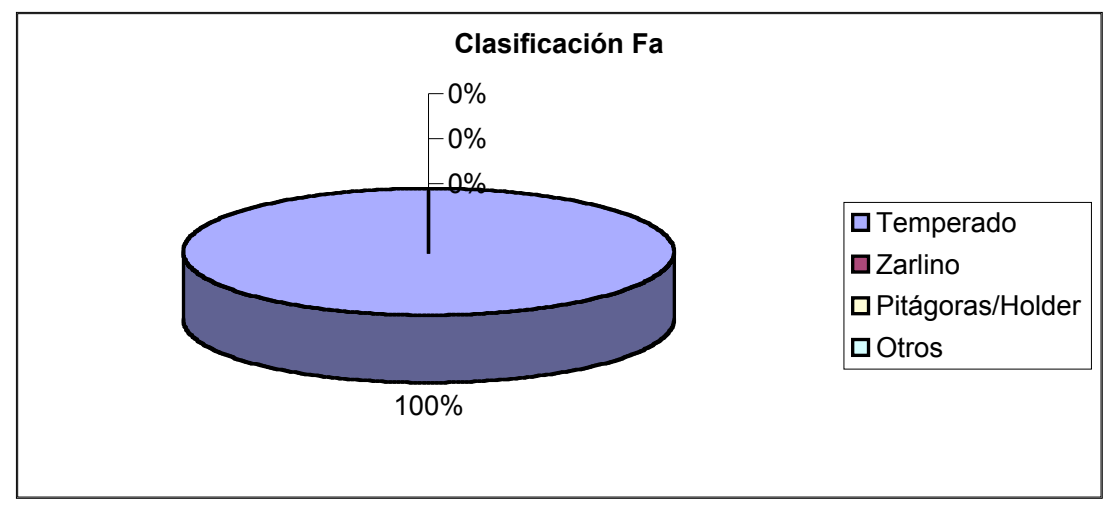

Fig. 3.18 Porcentaje en los que aparece la nota Fa en cada sistema

El $\mathrm{Fa}_{4}^{\#}$ se puede interpretar con dos posiciones $(2)$ y $(1+2+3)$, la posición (2) siempre está afinada en el sistema temperado (100\%) mientras que la posición $(1+2+3)$ es por el contrario la más desaconsejable ya que no aparece afinada en los sistemas empleados (Fig. 3.20).

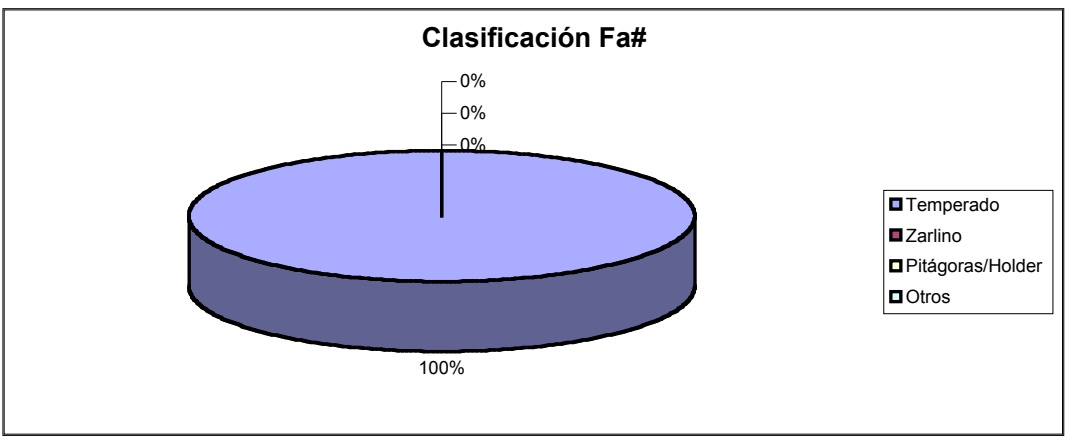

Fig. 3.19 Porcentaje en los que aparece la nota Fa\# en cada sistema 


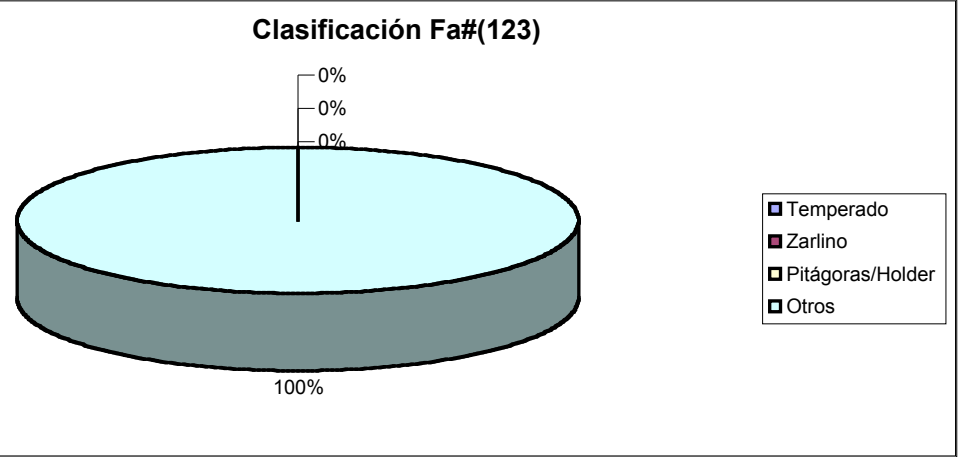

Fig. 3.20 Porcentaje en los que aparece la nota Fa\#(123) en cada sistema

El Sol 4 aparece afinado de igual manera en el sistema Temperado y en el de Zarlino (40\%). Sería lógico pensar que el instrumento tiende a afinar en Zarlino y que el oído humano corrige hacia el temperado. Un $20 \%$ de las grabaciones esta desafinadas respecto a los sistemas utilizados.

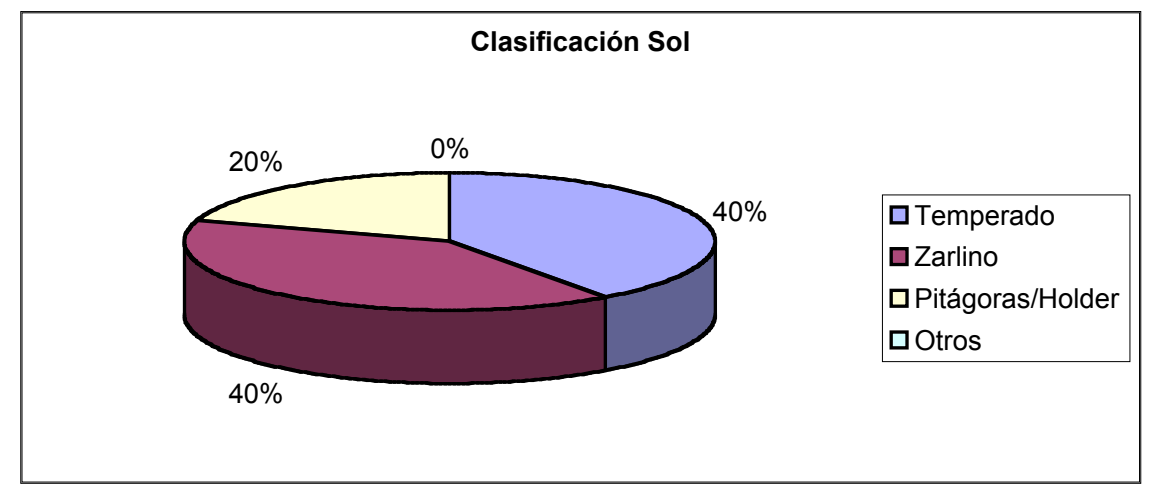

Fig. 3.21 Porcentaje en los que aparece la nota Sol en cada sistema

El $\mathrm{Sol}_{4}$ interpretado con la posición $(1+3)$ resulta afinado en un $60 \%$ en Zarlino y en un $40 \%$ en Temperado.

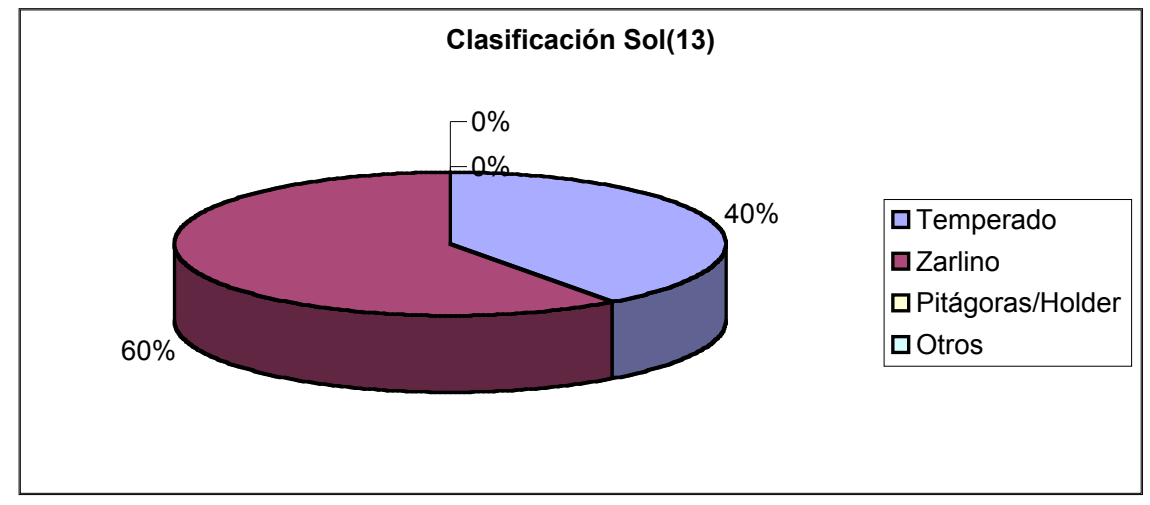

Fig. 3..22 Porcentaje en los que aparece la nota Sol(13) en cada sistema 
El $\mathrm{La}^{\mathrm{b}}{ }_{4}$ aparece fuera de los sistemas analizados en un $40 \%$ de los casos. El $60 \%$ restante se distribuye en un $40 \%$ para la afinación de Zarlino y sólo en un $20 \%$ para el sistema temperado.

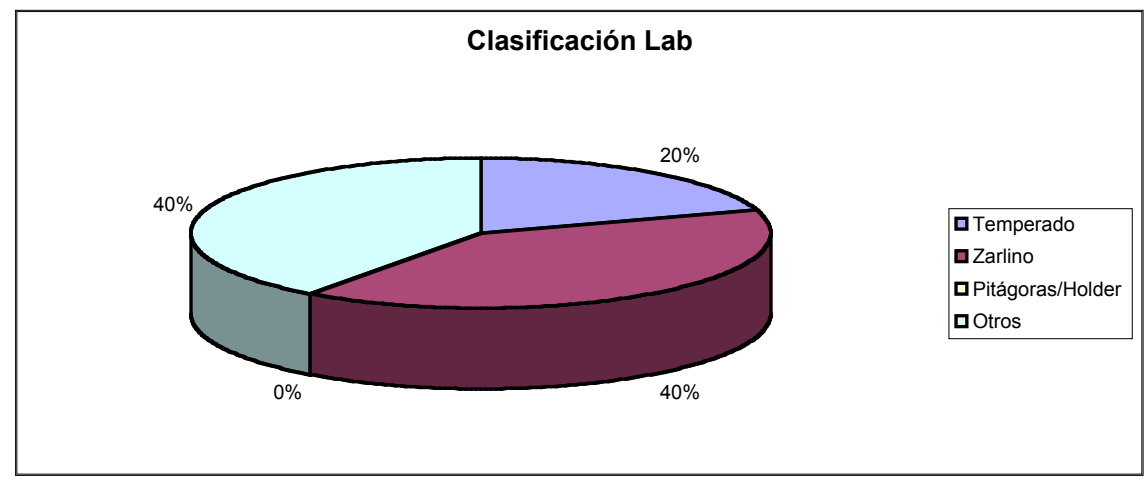

Fig. 3.23 Porcentaje en los que aparece la nota Lab en cada sistema

A partir de los resultados que mostramos en la figura 3.24, podemos comprobar que el $\mathrm{La}_{4}$ (con la posición que habitualmente utilizan todos los trompetistas $(1+2)$ ) presenta serios problemas de afinación, puesto que sólo en el $40 \%$ de las ocasiones está afinado en el sistema temperado y el resto $(60 \%)$ está fuera de las afinaciones utilizadas.

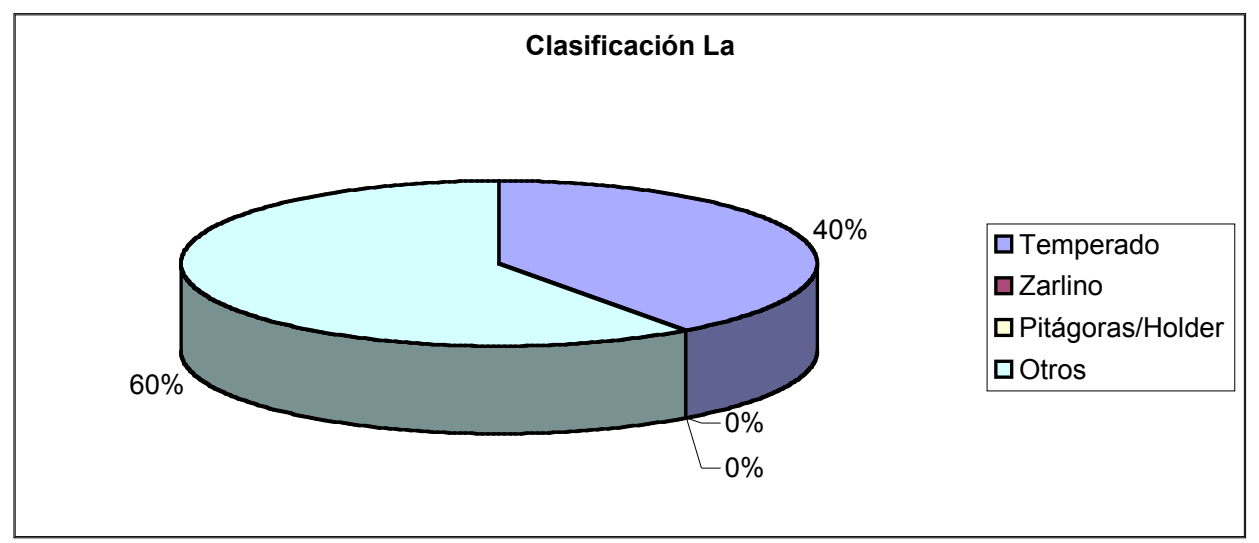

Fig. 3.24 Porcentaje en los que aparece la nota La en cada sistema

Sin embargo, con una posición menos utilizada (presionando el tercer pistón) que es considerada alternativa por los trompetistas, la afinación podría calificarse de perfecta en el sistema temperado (ver Fig. 3.25). 


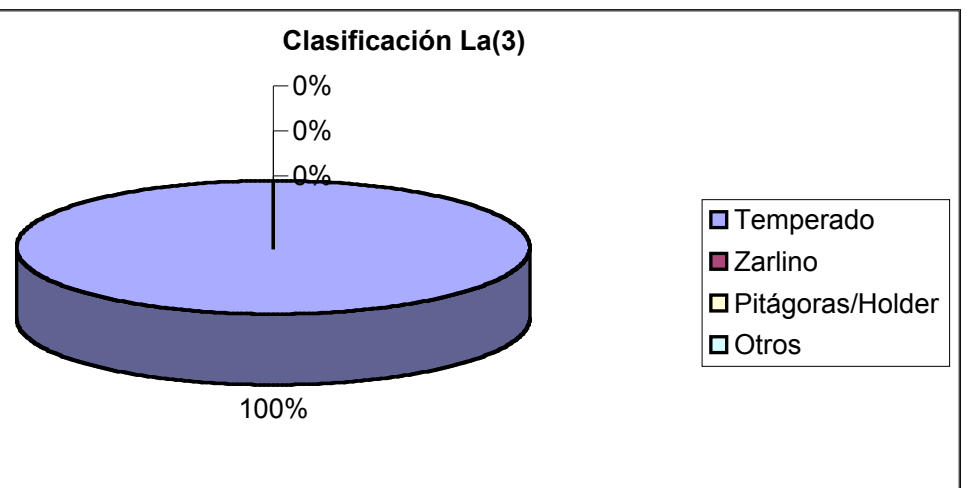

Fig. 3.25 Porcentaje en los que aparece la nota $\mathrm{La}(3)$ en cada sistema

El $\mathrm{Si}_{4}^{\mathrm{b}}{ }_{4}$ se interpreta con la posición (1), el $100 \%$ de las grabaciones están afinadas en el sistema temperado (Fig. 3.26) Interpretado con los tres pistones $(1+2+3){\text { el } \mathrm{Si}^{\mathrm{b}}}_{4}$ sólo está afinado en un $20 \%$. Esta posición apenas es utilizada ya que, como se muestra en las grabaciones, en un $80 \%$ de las ocasiones está fuera de las afinaciones utilizadas (véase Fig. 3.27).

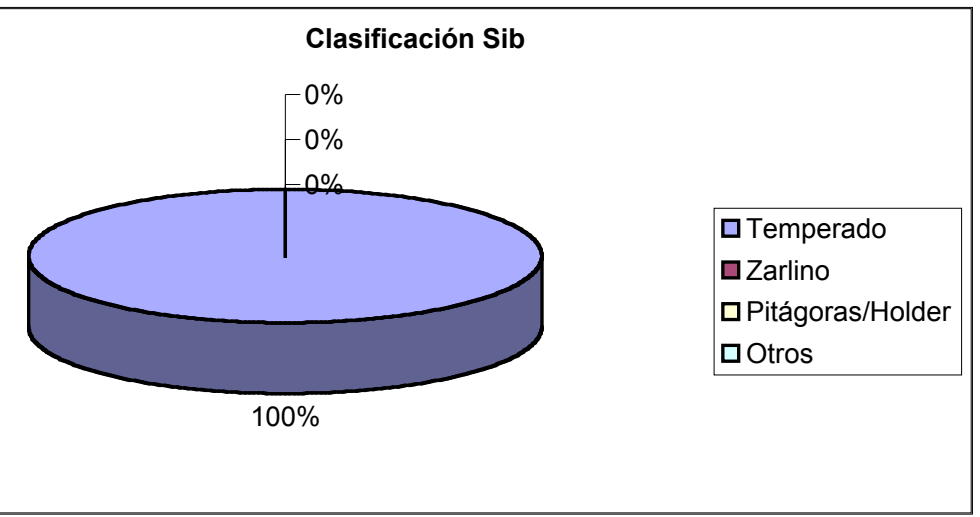

Fig. 3.26 Porcentaje en los que aparece la nota Sib en cada sistema

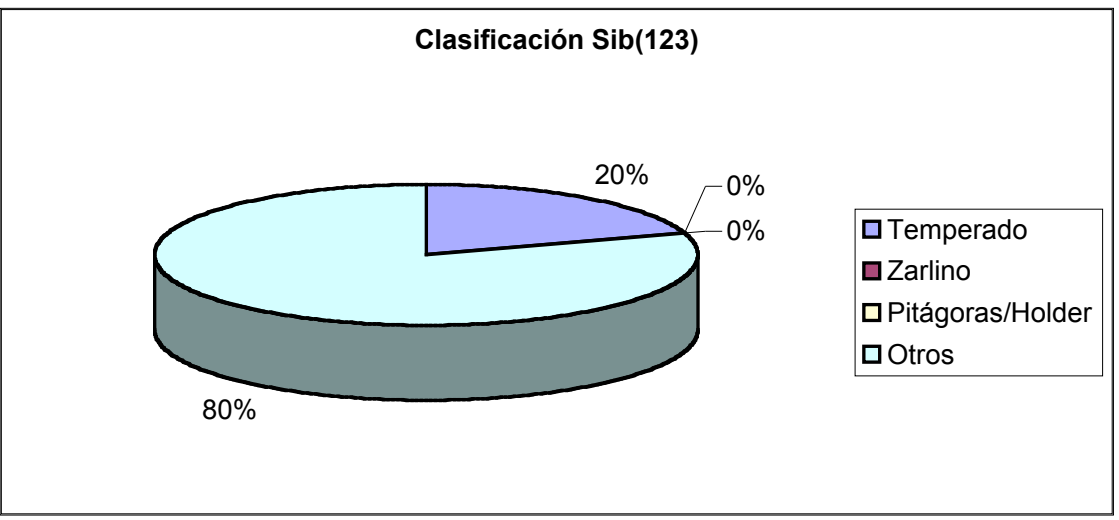

Fig. 3.27 Porcentaje en los que aparece la nota Sib(123) en cada sistema 
El $\mathrm{Si}_{4}$, en su posición habitual (presionando el segundo pistón) aparece afinada en el sistema temperado en la totalidad de las grabaciones realizadas (Fig. $3.28)$

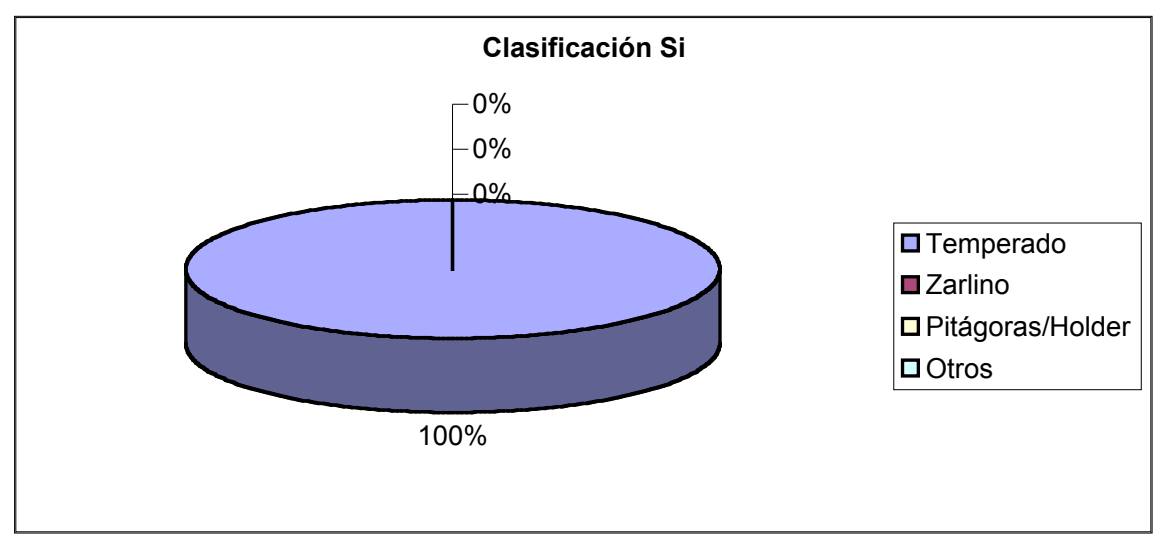

Fig. 3.28 Porcentaje en los que aparece la nota Si en cada sistema

Sin embargo, con la posición $(1+3)$ el si sólo está afinado en el sistema temperado en un $20 \%$ de los casos, mientras que en el $80 \%$ aparece fuera de las afinaciones empleadas.

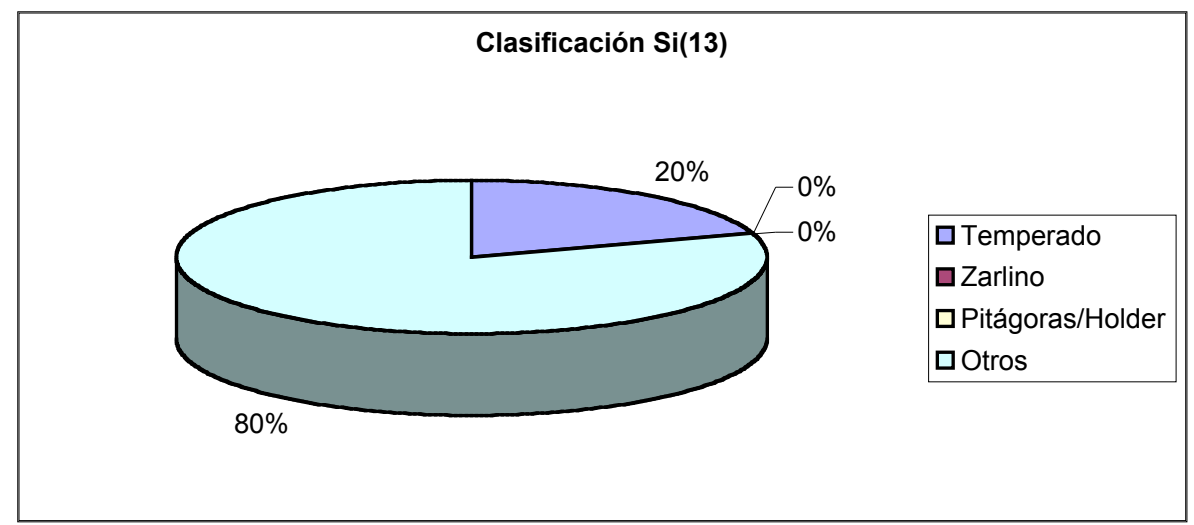

Fig. 3.29 Porcentaje en los que aparece la nota $\mathrm{Si}(13)$ en cada sistema

Si nuestro estudio acabase aquí, podría decirse que los resultados obtenidos nos permiten ser optimistas con los porcentajes de notas bien afinadas en el sistema temperado. Sin embargo, más adelante comprobaremos que cuando la experiencia no se realiza sobre la escala cromática, los resultados cambian sustancialmente. 


\subsubsection{Clasificación de las notas largas por la posición en la que se interpretan}

A continuación presentamos otra perspectiva de los resultados obtenidos en el experimento anterior. Como es sabido, la combinación de los tres pistones que tienen las trompetas modernas ofrece la posibilidad de ejecutar todas las notas de la escala cromática. Las posibles combinaciones son ocho, aunque hay dos posiciones que, a priori, producen las mismas notas: accionando los pistones primero y segundo o accionando sólo el tercero.

\begin{tabular}{|cl|}
\hline Posición & Pistones accionados \\
\hline $1^{\mathrm{a}}$ & 0 (al aire) \\
$2^{\mathrm{a}}$ & 2 \\
$3^{\mathrm{a}}$ & 1 \\
$4^{\mathrm{a}}$ & $1+2$ o 3 (alternativa) \\
$5^{\mathrm{a}}$ & $2+3$ \\
$6^{\mathrm{a}}$ & $1+3$ \\
$7^{\mathrm{a}}$ & $1+2+3$ \\
\hline
\end{tabular}

Tabla 3.3: Correspondencias entre la posición y los pistones accionados.

Los resultados que ofrecemos a continuación pertenecen a las notas que resultan de cada posición. Si anteriormente tratábamos las notas de forma individualizada, ahora agrupamos las notas que se interpretan accionando los mismos pistones. Dentro de la octava $\mathrm{Do}_{4}-\mathrm{Do}_{5}$ que es la que estamos utilizando, hay varias notas que se interpretan sin modificar la posición. En la tabla adjunta se detalla qué notas pertenecen a cada posición.

\begin{tabular}{|cl|}
\hline Posición & $\mathrm{Notas}^{\mathrm{a}}$ \\
\hline $1^{\mathrm{a}}$ & $\mathrm{Do}_{4} \mathrm{y} \mathrm{Sol}_{4}$ \\
$2^{\mathrm{a}}$ & $\mathrm{Fa}_{4}{ }_{4} \mathrm{y} \mathrm{Si}_{4}$ \\
$3^{\mathrm{a}}$ & $\mathrm{Fa}_{4} \mathrm{y} \mathrm{Sib} 4$ \\
$4^{\mathrm{a}}$ & $\mathrm{Mi}_{4} \mathrm{y} \mathrm{La}_{4}$ \\
$5^{\mathrm{a}}$ & $\mathrm{Re}_{4}^{\#} \mathrm{y} \mathrm{Sol}_{4}$ \\
$6^{\mathrm{a}}$ & $\mathrm{Re}_{4}, \mathrm{Sol}_{4} \mathrm{y} \mathrm{Si}_{4}$ \\
$7^{\mathrm{a}}$ & $\mathrm{Do}_{4}^{\#}, \mathrm{Fa}_{4}^{\#} \mathrm{y} \mathrm{La}_{4}$ \\
\hline
\end{tabular}

Tabla 3.4: Armónicos obtenidos con cada posición

$\mathbf{1}^{\mathrm{a}}$ Posición (0). Al aire. La primera posición tiende a estar afinada en el sistema de Zarlino, que es el natural del instrumento. En el mitad de las grabaciones la afinación fue así. En un 40\% la afinación resultó ser temperada y un 10\% de las notas no pudo considerarse que perteneciese a ninguno de los sistemas de afinación analizados. 


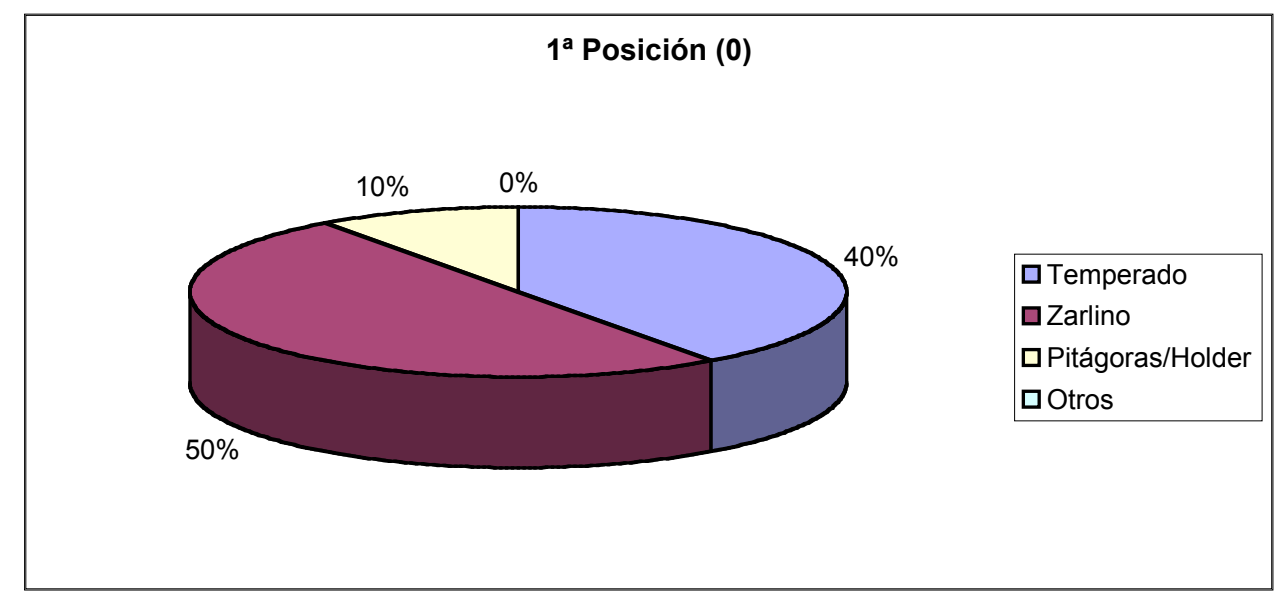

Fig. 3.30 Porcentaje en los que aparecen las notas de la $1^{\mathrm{a}}$ posición en cada sistema

$2^{\text {a }}$ Posición (2). Las notas obtenidas con esta posición están totalmente afinadas en el sistema temperado (100\%). En ninguna ocasión se produjo un resultado que con diferencias mayores a 5 cents respecto de las notas temperadas.

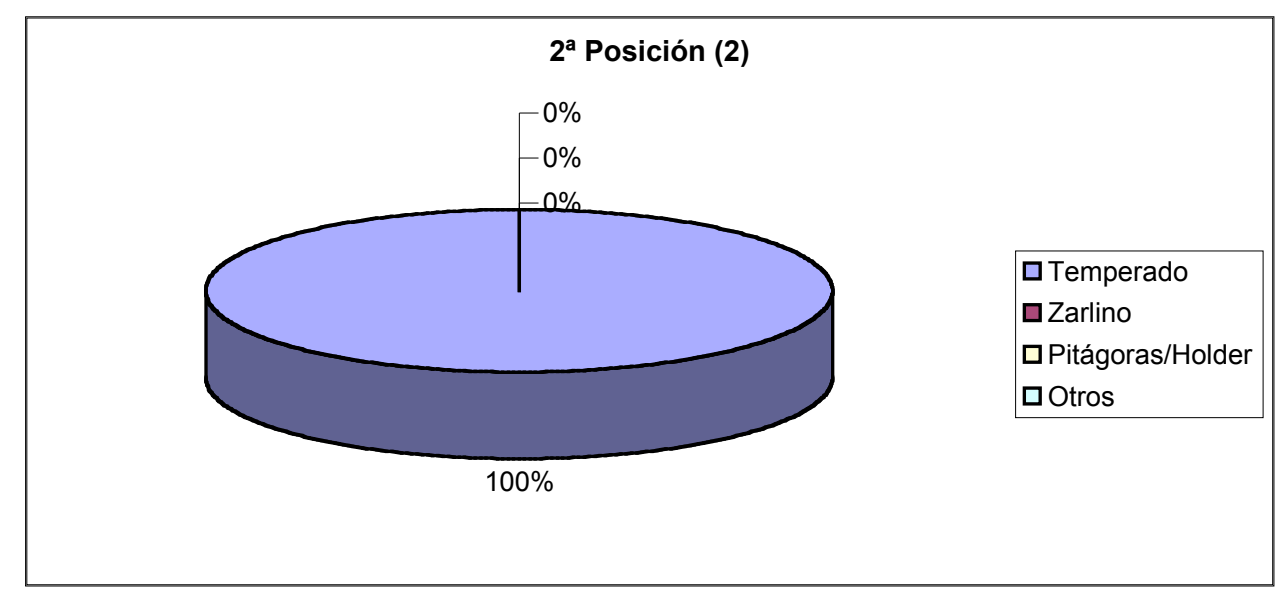

Fig. 3.31 Porcentaje en los que aparecen las notas de la $2^{\mathrm{a}}$ posición en cada sistema

$3^{a}$ Posición (1). Como ocurría con la segunda posición, las notas están todas dentro del sistema temperado con el margen de 5 cents que hemos impuesto en todo el trabajo. 


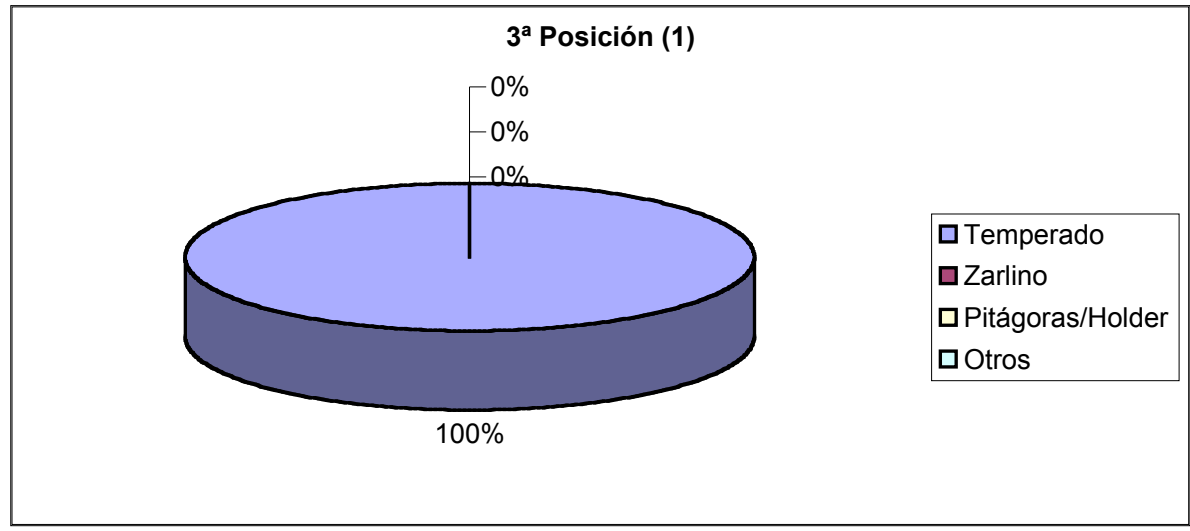

Fig. 3.32 Porcentaje en los que aparecen las notas de la $3^{\mathrm{a}}$ posición en cada sistema

$4^{a}$ Posición (1+2). Los resultados en esta posición son variados, un $40 \%$ de las grabaciones resultó pertenecer a Zarlino, un 30\% Temperado y otro 30\% fuera de toda afinación utilizada. Se trata por tanto de una posición en la que el oído del instrumentista juega un papel fundamental, puesto que no tiene garantías de que más de la tercera parte de las veces que se ejecuta esté bien afinada.

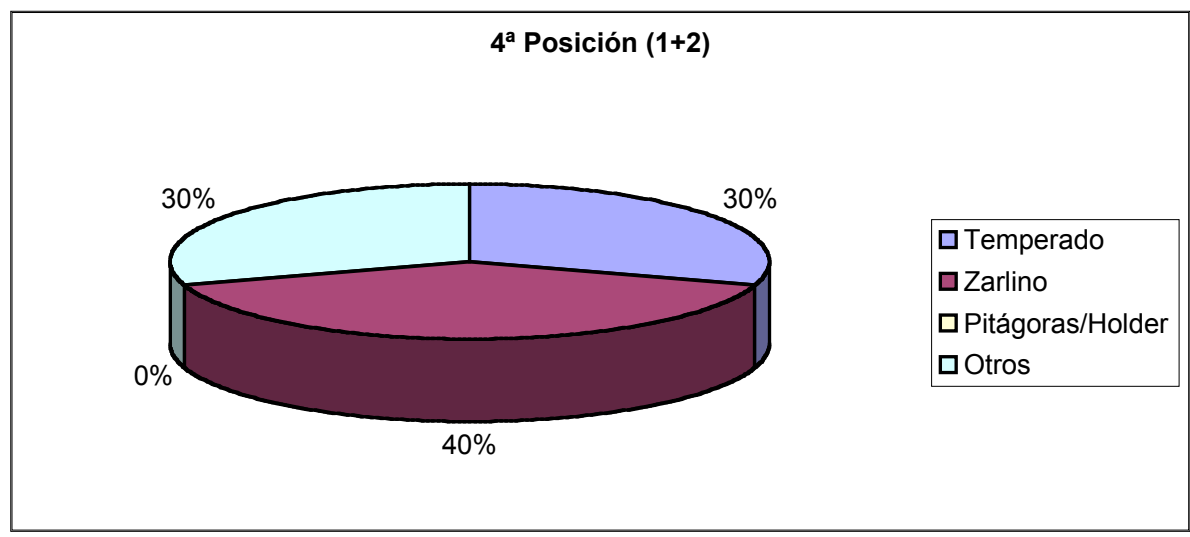

Fig. 3.33 Porcentaje en los que aparecen las notas de la $4^{\mathrm{a}}$ posición en cada sistema

$4^{a}$ posición alternativa (3). Pese a ser una posición que no se utiliza habitualmente, ofrece mejores resultados que la empleada con más frecuencia. El $90 \%$ de las veces ha producido notas afinadas en el sistema temperado resulta temperada y sólo $10 \%$ de las notas no están dentro de los sistemas estudiados. 


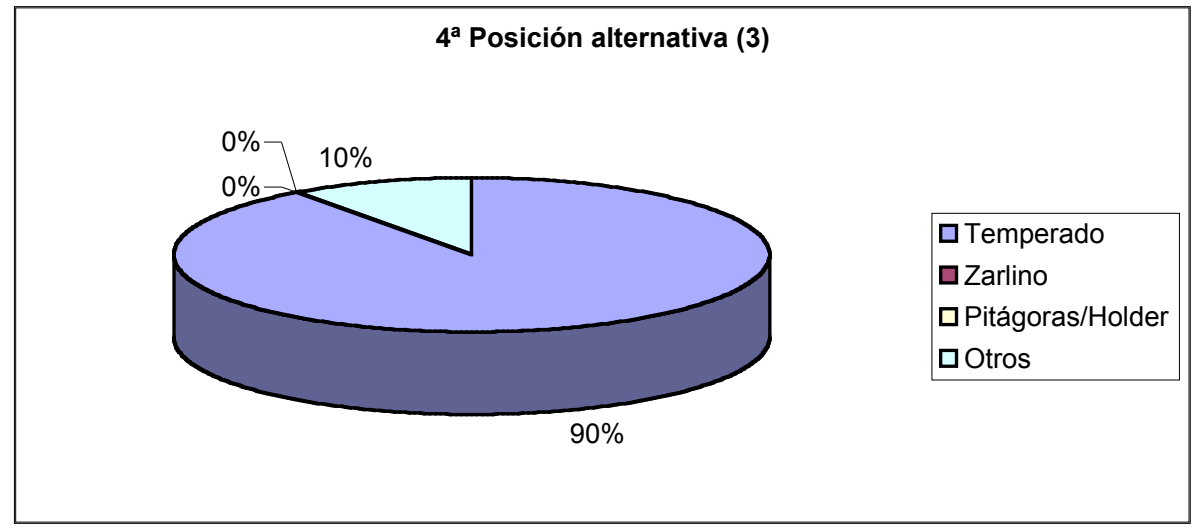

Fig. 3.34 Porcentaje en los que aparecen las notas de la $4^{\mathrm{a}}$ posición alternativa

$5^{a}$ Posición (2+3). Resulta aceptable el 50\% obtenido en esta posición en el sistema Temperado frente al $20 \%$ de Zarlino y al 30\% que no está afinado.

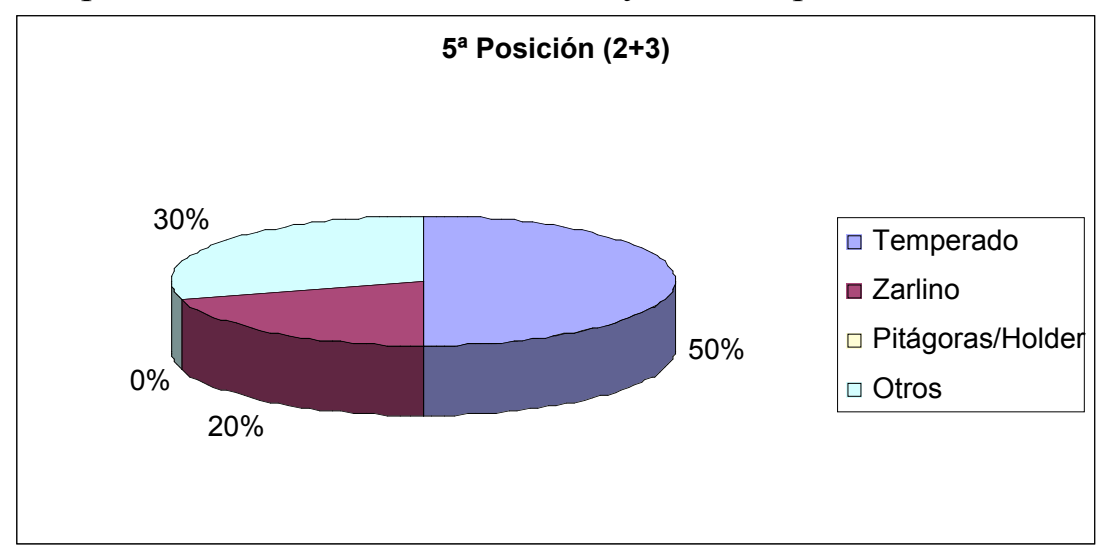

Fig. 3.35 Porcentaje en los que aparecen las notas de la $5^{\mathrm{a}}$ posición

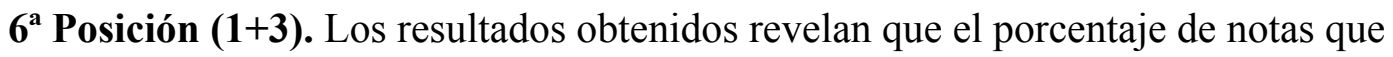
pertenecen al sistema temperado es el mismo que las que se alejan de cualquier sistema (40\%) y el porcentaje restante $(20 \%)$ es de Zarlino.

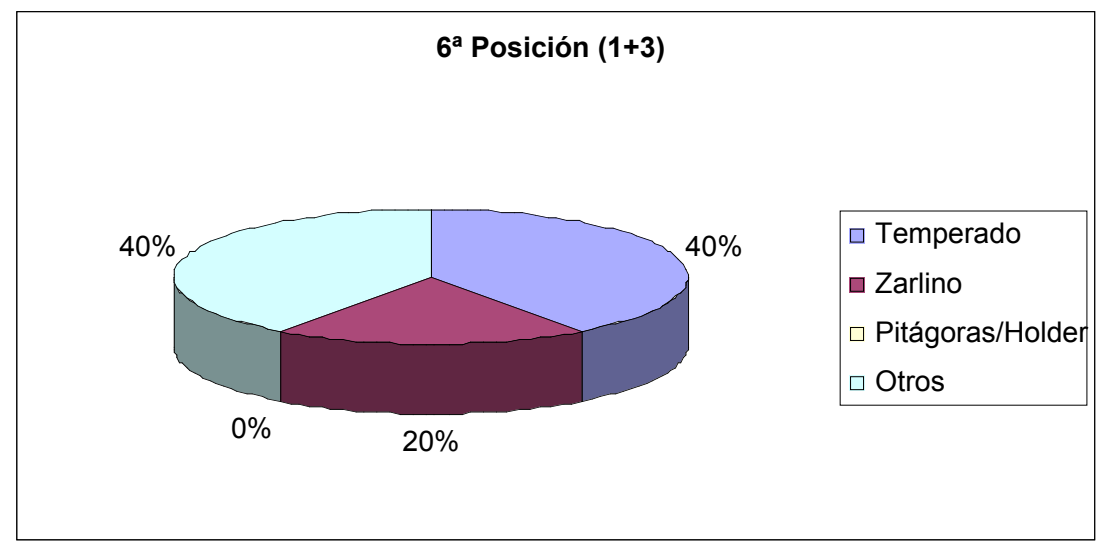

Fig. 3.36 Porcentaje en los que aparecen las notas de la $6^{\mathrm{a}}$ posición 
$7^{a}$ Posición $(\mathbf{1 + 2 + 3 )}$. La mayor parte de las grabaciones resultan completamente desafinadas, en un $66 \%$ estaban completamente alejadas de los sistemas empleados, un $27 \%$ pertenecían a Zarlino y sólo un $7 \%$ temperados.

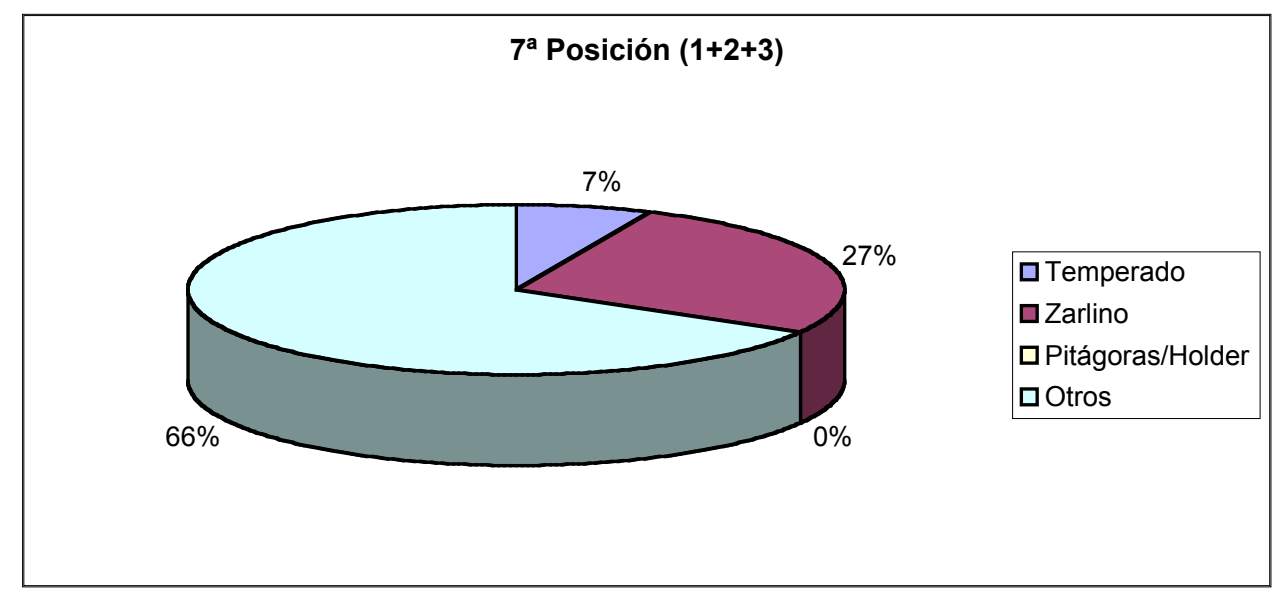

Fig. 3.37 Porcentaje en los que aparecen las notas de la $7^{\mathrm{a}}$ posición en cada sistema

Tras el experimento realizado y la obtención de sus correspondientes resultados podemos afirmar que cuantos menos pistones accionemos para emitir una nota más posibilidades de que su afinación sea temperada, a mayor utilización de pistones las posibilidades de éxito en la afinación descienden.

Es curioso que una posición $(1+2)$ que es utilizada habitualmente resulte con peores resultados que su alternativa (3) que casi siempre está afinada (90\%). La afinación de notas al aire sin accionar ningún pistón depende de la habilidad del intérprete ya que en ocasiones su afinación es la natural del instrumento.

\subsubsection{Experimento 2. Notas no seriadas}

Se han realizado 49 grabaciones de las notas $\mathrm{Fa}_{4}^{\#}, \mathrm{La}_{4}^{\#}, \mathrm{Do}_{5}^{\#}$ y La $\mathrm{La}_{5}$ con una trompeta en $\mathrm{si}^{\mathrm{b}}$ Yamaha ${ }^{\circledR}$ Xeno (ver Fig. 3.6), combinando las diferentes posiciones de los pistones para comprobar las afinaciones de cada una de ellas. Se han elegido 4 notas que se pueden interpretar en una trompeta en $\mathrm{Si}^{\mathrm{b}}$ en al menos dos posiciones diferentes. Dos de ellas se encuentran en la octava que está comprendida entre el do 4 y el do 5 y las otras dos entre el do 5 y el do . $_{6}$

El $\mathrm{Fa}_{4}^{\#}$ se puede tocar con dos combinaciones distintas de pistones, una con el segundo pistón (2) y otra con los tres a la vez $(1+2+3)$.

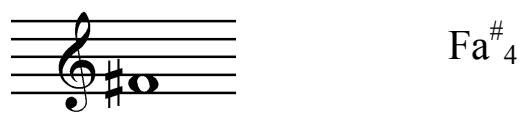


Tras las grabaciones y el posterior análisis con el programa informático Audacity ${ }^{\circledR}$ los resultados obtenidos se pueden resumir ${ }^{5}$ de la forma siguiente:

Con la posición (2) el 60\% pertenece a los sistemas Pitágoras/Holder y el $40 \%$ a Zarlino, en ningún caso aparecen afinaciones fuera de los sistemas utilizados aunque destaca la ausencia de la afinación temperada ya que en el experimento anterior el resultado era Temperado en el 100\% de las ocasiones.

Con la posición $(1+2+3)$ los resultados son parejos en Pitágoras/Holder y Zarlino (38\% y 37\%) respectivamente teniendo un $25 \%$ de afinaciones de otros sistemas. Continuamos sin obtener resultados temperados aunque en el experimento anterior con la escala cromática el $100 \%$ de los análisis resultó estar lejos de las todas las afinaciones empleadas.

El La ${ }_{4}^{\#}$ también se puede tocar con dos combinaciones, primer pistón sólo (1) y los tres pistones a la vez $(1+2+3)$.

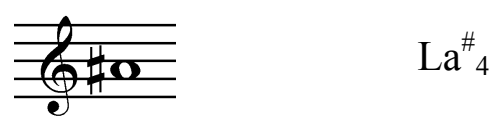

El La ${ }^{\#}, \mathrm{o} \mathrm{Si}^{\mathrm{b}}$ si hablamos en sistema temperado, con la primera posición (1) está en el $100 \%$ de las ocasiones totalmente fuera de los sistemas empleados, por otra parte cuando el experimento se realizó de forma seriada los resultados fueron completamente al contrario y el $100 \%$ obtenido entonces era Temperado.

Con la posición $(1+2+3)$ con la obtuvimos anteriormente pésimos resultados ha habido una mejora considerable puesto que el $57 \%$ resultó pertenecer al sistema de Zarlino y el restante $43 \%$ al sistema Temperado.

El Do ${ }_{5}{ }_{5}$ tiene tres combinaciones posibles, primer y segundo pistón $(1+2)$, tercer pistón solo (3) y los tres a la vez $(1+2+3)$.

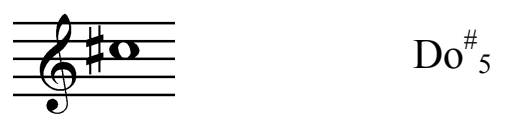

Utilizando la posición (3) el $60 \%$ resultó coincidir con los sistemas Pitágoras/Holder y el 40\% con el sistema de Zarlino.

Con la posición $(1+2)$, la más empleada por los instrumentistas para obtener esta nota, es curioso comprobar cómo el $40 \%$ de las ocasiones fue

\footnotetext{
${ }^{5}$ La exposición exhaustiva de los resultados puede encontrarse en el Apéndice de este trabajo.
} 
temperada mientras el resto, un amplio $60 \%$, estaba fuera del resto de sistemas de afinación.

Al igual que con las notas anteriores al utilizar la posición $(1+2+3)$ los resultados mejoran respecto al experimento anterior, la mitad de las grabaciones $(50 \%)$ resultó corresponder a Zarlino mientras el 33\% correspondió a Pitágoras/Holder y un $17 \%$ a otros sistemas.

El La $\mathrm{L}_{5}$ también tiene tres combinaciones, primer y segundo pistón $(1+2)$, tercer pistón (3) y segundo pistón (2).

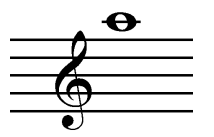

$\mathrm{La}_{5}$

El La ${ }_{5}$ al igual que la nota tratada anteriormente $\left(\mathrm{Do}_{5}^{\#}\right)$ se encuentra en una octava superior a la estudiada en el primer experimento y no poseemos resultados con los que comparar el sonido aunque sí podemos comparar los resultados que se obtuvieron con respecto a las posiciones empleadas.

Con el segundo pistón, posición (2), se obtiene como armónico apenas empleado para esta nota sin embargo nunca hemos hallado afinaciones fuera de los sistemas empleados. El 40\% resultó ser Temperado, idéntico resultado se obtuvo con respecto a Zarlino y el restante $20 \%$ se correspondió con los sistemas de Pitágoras/Holder.

Con la posición (3), que se utiliza como alternativa, se obtienen unos resultados excelentes siendo en un $80 \%$ Temperado y el $20 \%$ restante Pitágoras/Holder.

Empleando la posición habitual $(1+2)$ apenas se obtuvo un $40 \%$ para Pitágoras/Holder frente a un $60 \%$ que permanecía fuera de las afinaciones empleadas.

Resultados totales del experimento 2:

\begin{tabular}{|lc|}
\hline Sistema & $\mathrm{N}^{\mathrm{o}}$ de notas en el sistema \\
\hline Temperado & 11 \\
Zarlino & 16 \\
Pitágoras/Holder & 14 \\
Otros & 14 \\
\hline
\end{tabular}

Tabla 3.5: Resultados totales experimento 2 


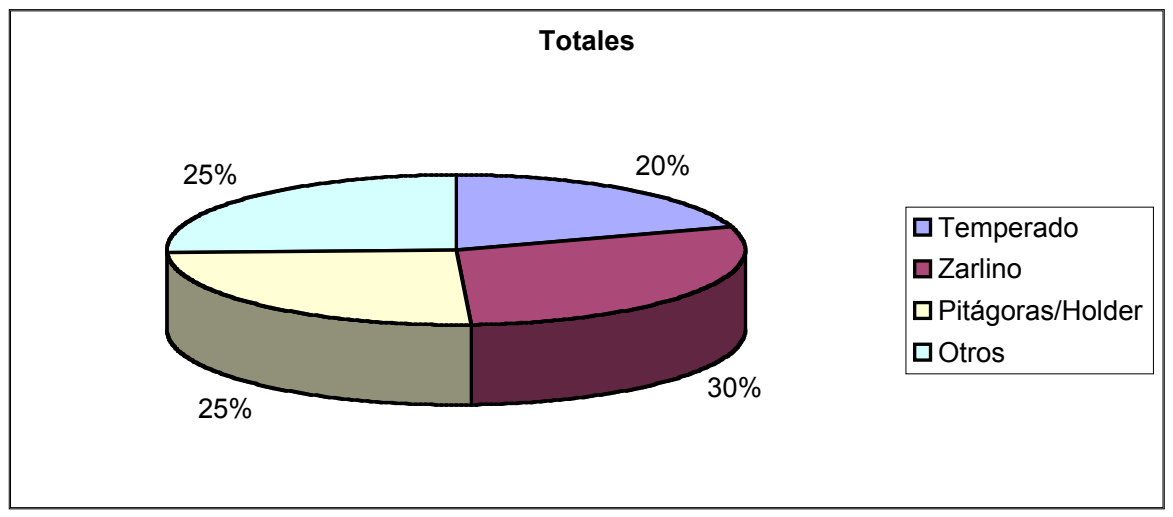

Fig. 3.38 Porcentaje en los que aparecen las notas en todas las posiciones

Los resultados totales muestran cómo sólo un $25 \%$ de las grabaciones no corresponde a ninguno de los 4 sistemas analizados, mientras el restante $75 \%$ está muy repartido sin que predomine ningún sistema sobre otro.

\subsection{Afinación dinámica}

3.3.1 Experimento 3. Concierto en Mi bemol Mayor, Hob. VIIe, N. 1 para trompeta y orquesta de Franz Joseph Haydn (1732-1809).

Se ha utilizado el siguiente fragmento de este concieto:
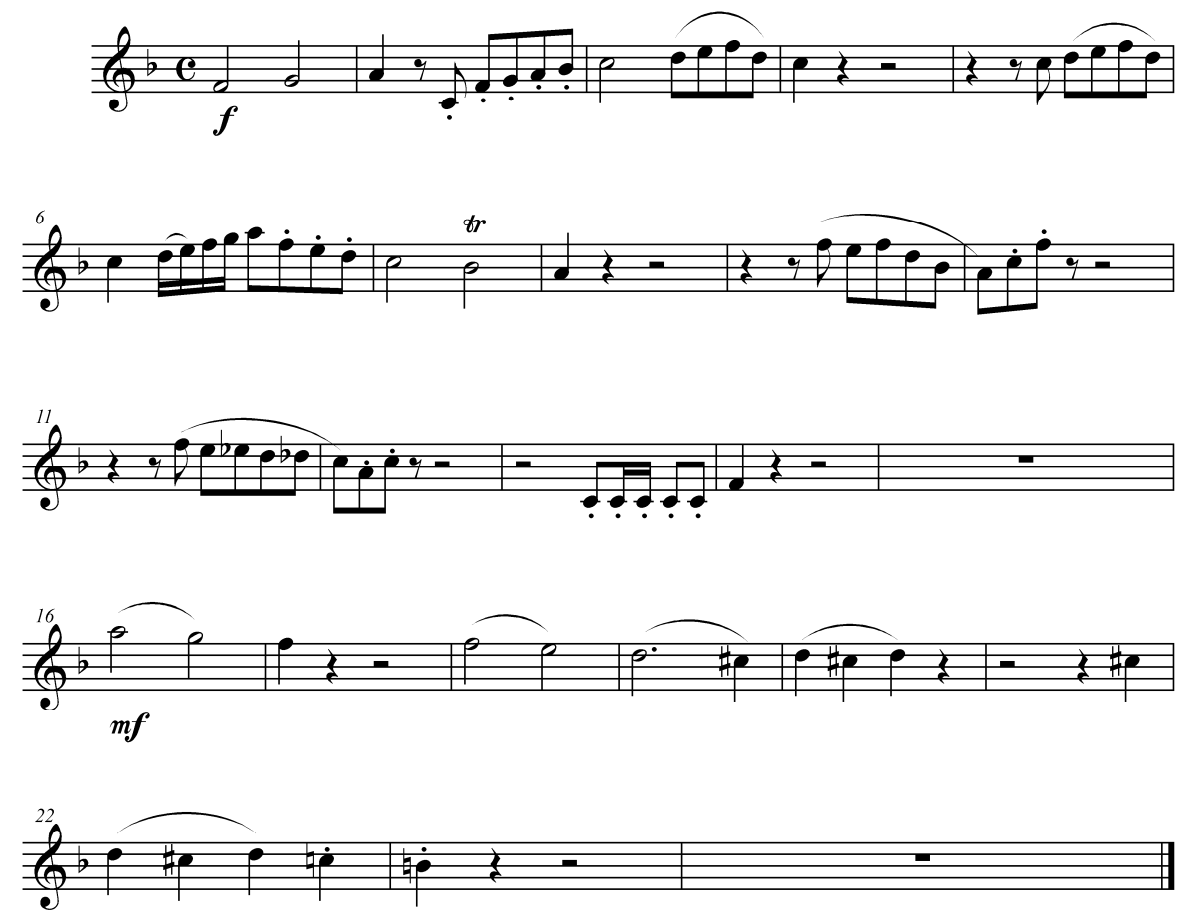
Se ha interpretado en 48 ocasiones los 23 compases del fragmento situado entre los compases 37 y 59, ambos inclusive, del primer tiempo (allegro) de la citada obra.

\section{a) Resultados globales}

Un estudio global de las grabaciones realizadas proporcionan los resultados siguientes:

\begin{tabular}{|lc|}
\hline Sistema & $\mathrm{N}^{\mathrm{o}}$ de notas en el sistema \\
\hline Temperado & 183 \\
Zarlino & 387 \\
Pitágoras/Holder & 332 \\
Otros & 248 \\
\hline
\end{tabular}

Tabla 3.6: Distribución por sistemas de las notas del concierto de Haydn

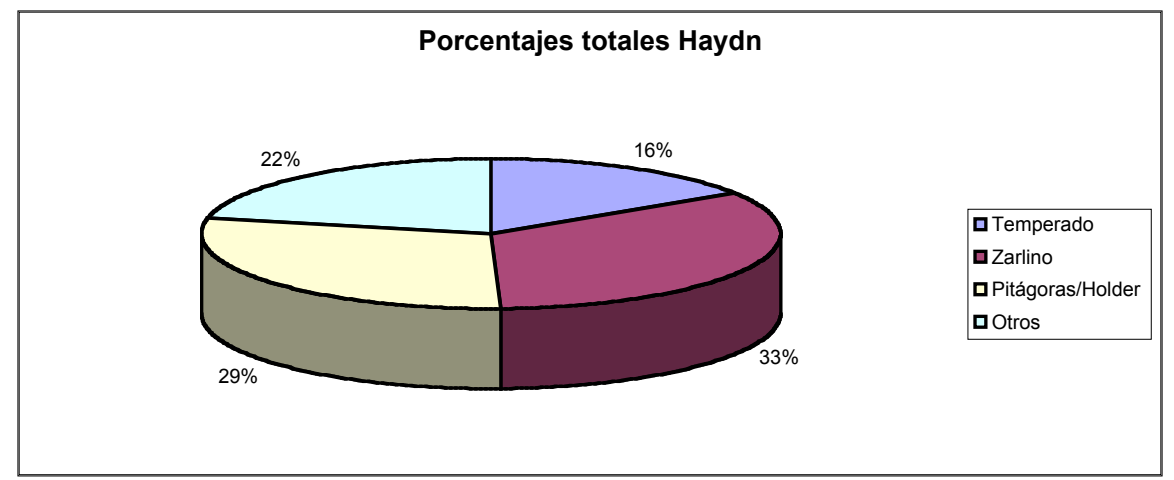

Fig. 3.39 Porcentaje en los que aparecen las notas del concierto de Haydn

Tan sólo un $22 \%$ de las grabaciones resultó estar fuera de todo sistema empleado mientras el sistema de Zarlino es el más frecuente con un 33\% seguido de Pitágoras/Holder con un 29\% y lejos de ellos el sistema Temperado con un $16 \%$.

Como advertíamos en la experiencia anterior, los resultados globales ya no son tan buenos como los que se obtenían cuando se trabajaba con la afinación estática para notas seriadas y no seriadas.

\section{b) Relación sistema de afinación-trompeta empleada}

A continuación presentamos un resumen de los porcentajes de notas afinadas en cada sistema según la trompeta utilizada en cada caso (para el concierto de Haydn): Yamaha ${ }^{\circledR} \mathrm{si}^{\mathrm{b}}$, Bach $^{\circledR} \mathrm{si}^{\mathrm{b}}$, Bach $^{\circledR}$ do y Schilke ${ }^{\circledR} \mathrm{mi}^{\mathrm{b}}$. 
Resultados con la trompeta Yamaha ${ }^{\circledR}$ en $\mathrm{si}^{\mathrm{b}}$ :

\begin{tabular}{|lc|}
\hline Sistema & $\mathrm{N}^{\mathrm{o}}$ de notas en el sistema \\
\hline Temperado & 64 \\
Zarlino & 161 \\
Pitágoras/Holder & 124 \\
Otros & 93 \\
\hline
\end{tabular}

Tabla 3.7: Resultados con trompeta $\mathrm{si}^{\mathrm{b}}$ Yamaha $^{\circledR}$

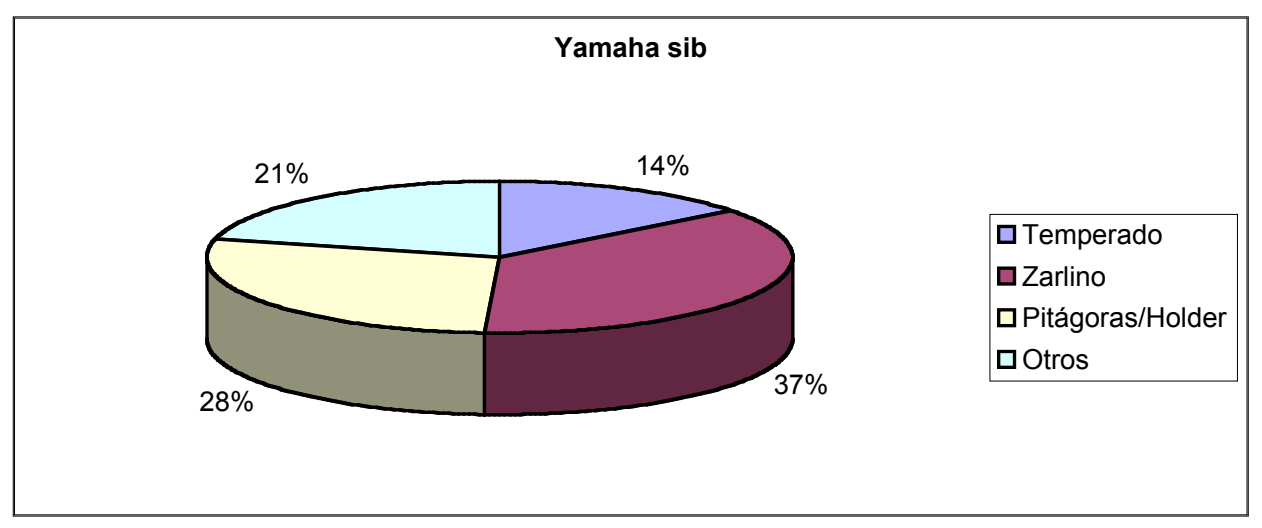

Fig. 3.40 Porcentajes con la trompeta Yamaha sib

Resultados con la trompeta $\mathrm{Bach}^{\circledR}$ en si ${ }^{\mathrm{b}}$ modelo 37:

\begin{tabular}{|lc|}
\hline Sistema & $\mathrm{N}^{\mathbf{0}}$ de notas en el sistema \\
\hline Temperado & 24 \\
Zarlino & 49 \\
Pitágoras/Holder & 40 \\
Otros & 49 \\
\hline
\end{tabular}

Tabla 3.8: Resultados con trompeta $\mathrm{Bach}^{\circledR}$ en $\mathrm{si}^{\mathrm{b}}$ modelo 37

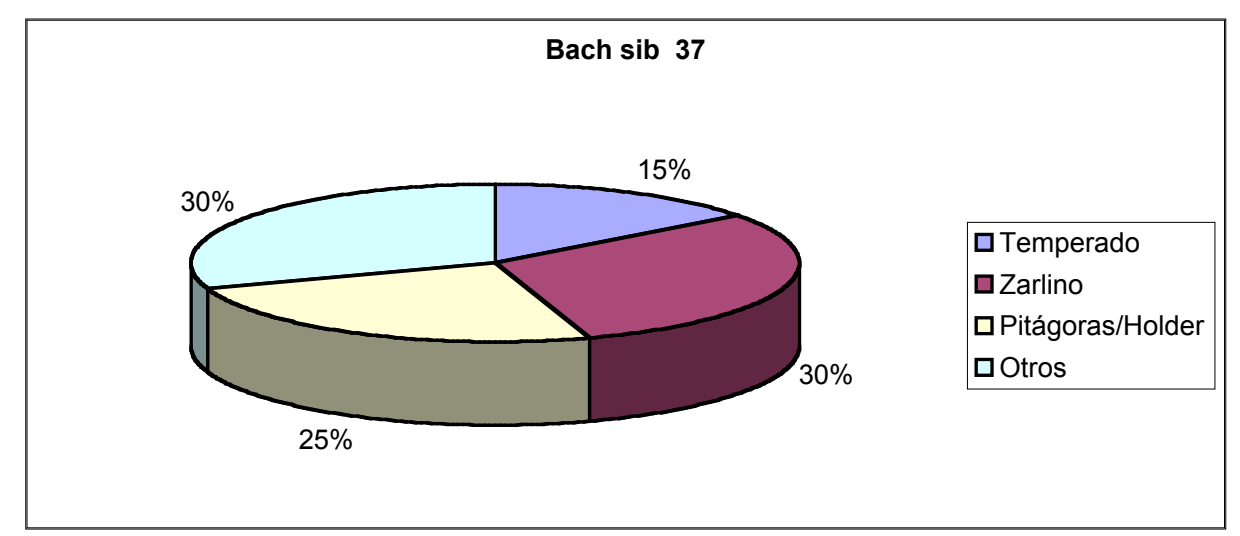

Fig. 3.41 Porcentajes con la trompeta Bach sib 37 
Resultados con la trompeta $\mathrm{Bach}^{\circledR}$ en do:

\begin{tabular}{|lc|}
\hline Sistema & $\mathrm{N}^{\mathrm{o}}$ de notas en el sistema \\
\hline Temperado & 40 \\
Zarlino & 78 \\
Pitágoras/Holder & 51 \\
Otros & 53 \\
\hline
\end{tabular}

Tabla 3.9: Resultados con trompeta $\mathrm{Bach}^{(R)}$ en do

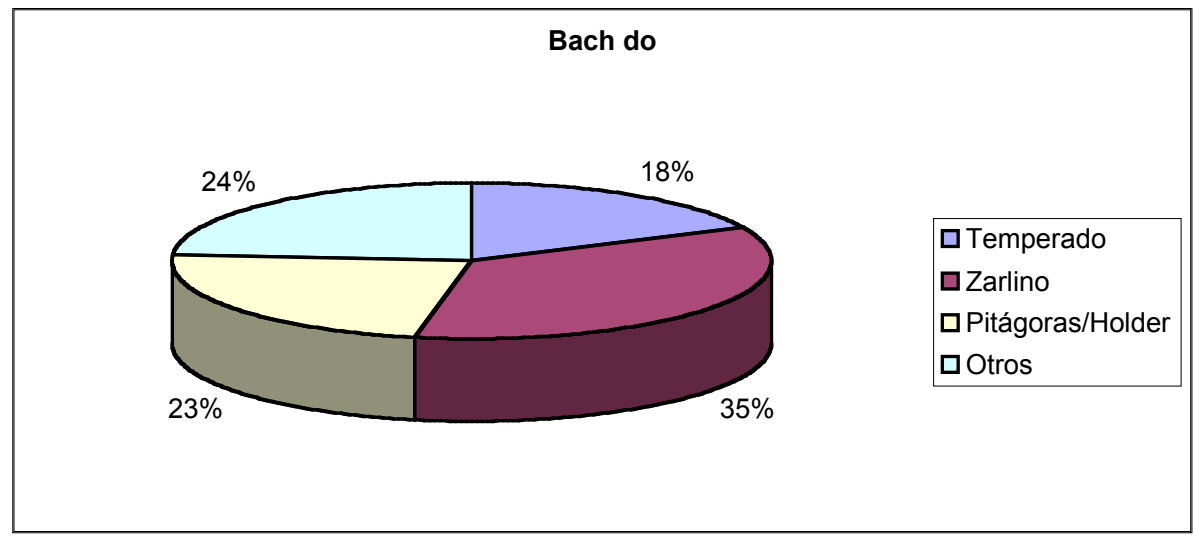

Fig. 3.42 Porcentajes con la trompeta Bach do

Resultados con la trompeta Schilke ${ }^{\circledR}$ en $\mathrm{mi}^{\text {b }}$ :

\begin{tabular}{|lc|}
\hline Sistema & $\mathrm{N}^{0}$ de notas en el sistema \\
\hline Temperado & 55 \\
Zarlino & 99 \\
Pitágoras/Holder & 87 \\
Otros & 60 \\
\hline
\end{tabular}

Tabla 3.10: Resultados con trompeta Schilke ${ }^{\circledR}$ en mi ${ }^{\mathrm{b}}$

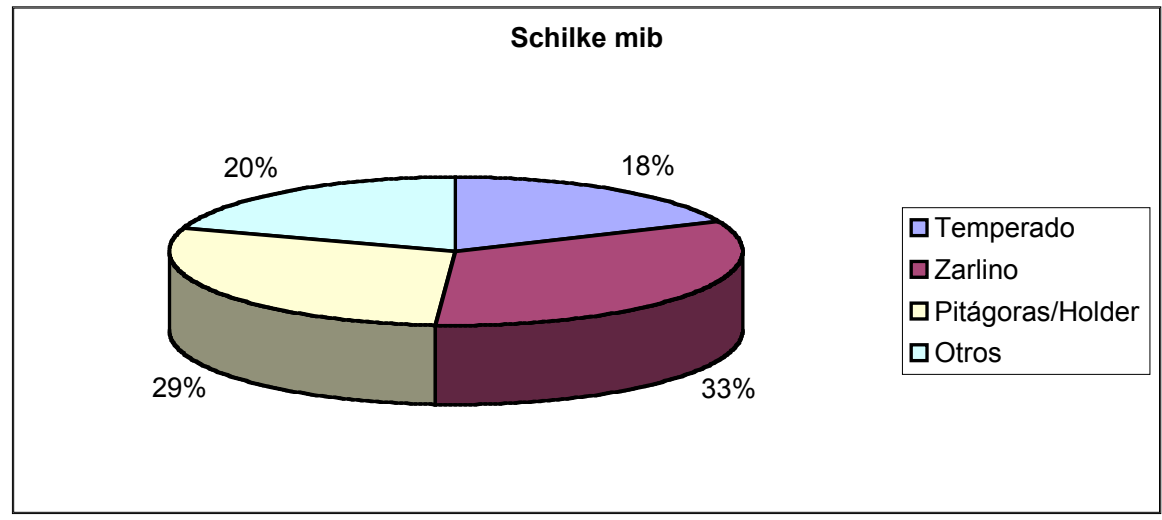

Fig. 3.43 Porcentajes con la trompeta Schilke mib 
Tras examinar los resultados según el tipo de trompeta empleada en cada grabación, podemos afirmar que la trompeta más recomendada desde el punto de vista de la afinación para interpretar este concierto es al trompeta en mi ${ }^{\mathrm{b}}$ aunque también podría utilizarse la trompeta en $\mathrm{si}^{\mathrm{b}}$ Yamaha $^{\circledR}$. Al recomendar el uso de estas trompetas hay que hacer constar que tres de las cuatro trompetas usadas para este experimento eran utilizadas por el intérprete habitualmente mientras que una de ellas (Bach ${ }^{\circledR}$ si $\left.^{\text {b }} 37\right)$ no lo era, así se puede comprobar que los peores resultados se han obtenido con un instrumento ajeno a la persona que lo tocaba y por lo tanto que no está acostumbrado a trabajar con él.

3.3.2 Experimento 4. Adagio de Música para cuerda, percusión y celesta (1937) de Béla Bartók (1881-1945).

Esta composición de Béla Bartók, como gran parte de su obra, constituye un material muy valioso para el estudio de los sistemas de afinación, de hecho Bartók fue un gran estudioso del tema, véase Benson (2004). siguientes:

El fragmento que hemos analizado es el formado por los tres compases

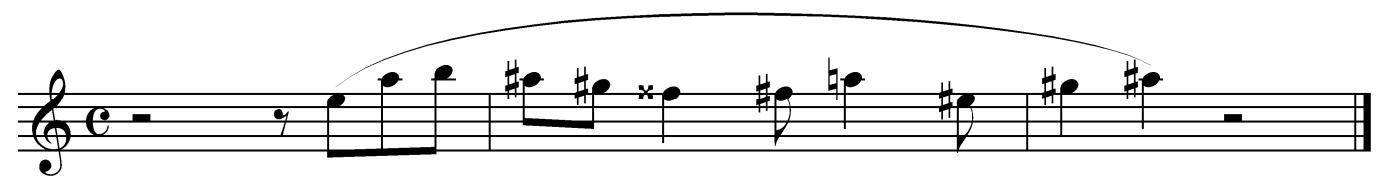

Se han realizado un total de 22 grabaciones de este fragmento con varias trompetas. Como hemos hecho con el fragmento anterior, presentamos primero los resultados globales y posteriormente analizamos, mediante la observación de la frecuencia con que se obtienen las notas afinadas en cada sistema, la relación entre la bondad de la afinación y la trompeta empleada.

\section{a) Resultados globales}

\begin{tabular}{|lc|}
\hline Sistema & $\mathrm{N}^{\mathrm{o}}$ de notas en el sistema \\
\hline Temperado & 71 \\
Zarlino & 96 \\
Pitágoras/Holder & 105 \\
Otros & 93 \\
\hline
\end{tabular}

Tabla 3.11: Resultados totales Adagio de Bartók 


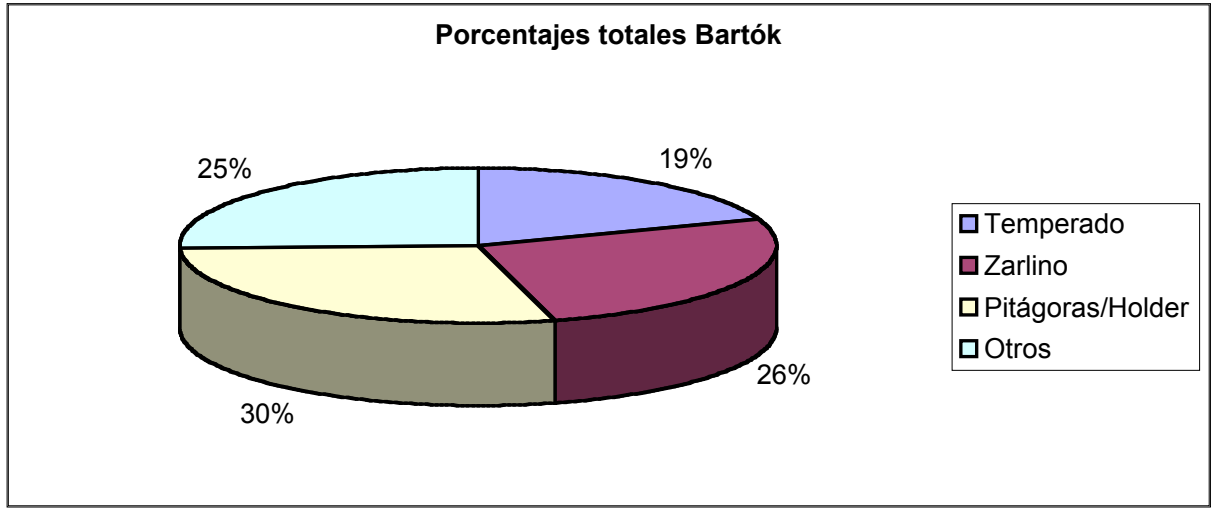

Fig. 3.44 Porcentaje en los que aparecen las notas del fragmento de Bartók

\section{b) Relación sistema de afinación-trompeta empleada}

Como hemos hecho anteriormente presentamos los resultados que ofrece el fragmento del Adagio de B. Bartok según la trompeta que se ha utilizado en cada grabación. Para este fragmento hemos utilizado las ya mencionadas Yamaha $^{\circledR} \mathrm{si}^{\mathrm{b}}, \mathrm{Bach}^{\circledR}$ do y Piccolo Scherzer ${ }^{\circledR}$ (ver figuras 3. 6, 3.7 y 3. 10).

Resultados con la trompeta Yamaha $^{\circledR}$ en $\mathrm{si}^{\mathrm{b}}$ :

\begin{tabular}{|lc|}
\hline Sistema & $\mathrm{N}^{\mathbf{o}}$ de notas en el sistema \\
\hline Temperado & 20 \\
Zarlino & 30 \\
Pitágoras/Holder & 30 \\
Otros & 31 \\
\hline
\end{tabular}

Tabla 3.12: Resultados con trompeta Yamaha ${ }^{\circledR}$ en $\mathrm{si}^{\mathrm{b}}$

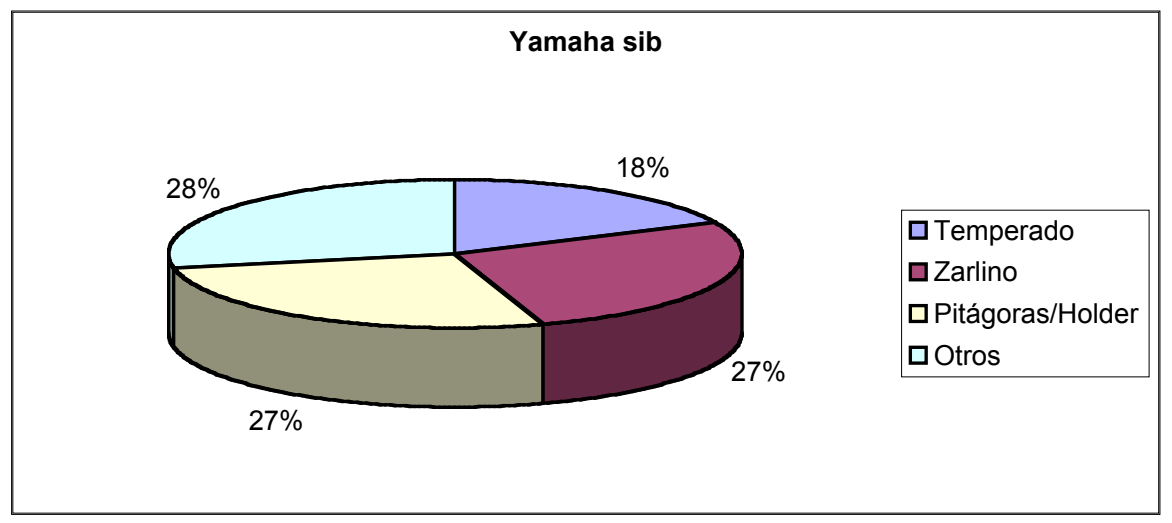

Fig. 3.45 Porcentajes con la trompeta Yamaha sib 
Resultados con la trompeta $\mathrm{Bach}^{\circledR}$ en do:

\begin{tabular}{|lc|}
\hline Sistema & $\mathrm{N}^{\mathbf{o}}$ de notas en el sistema \\
\hline Temperado & 18 \\
Zarlino & 32 \\
Pitágoras/Holder & 31 \\
Otros & 29 \\
\hline
\end{tabular}

Tabla 3.13: Resultados con trompeta $\mathrm{Bach}^{\circledR}$ en do

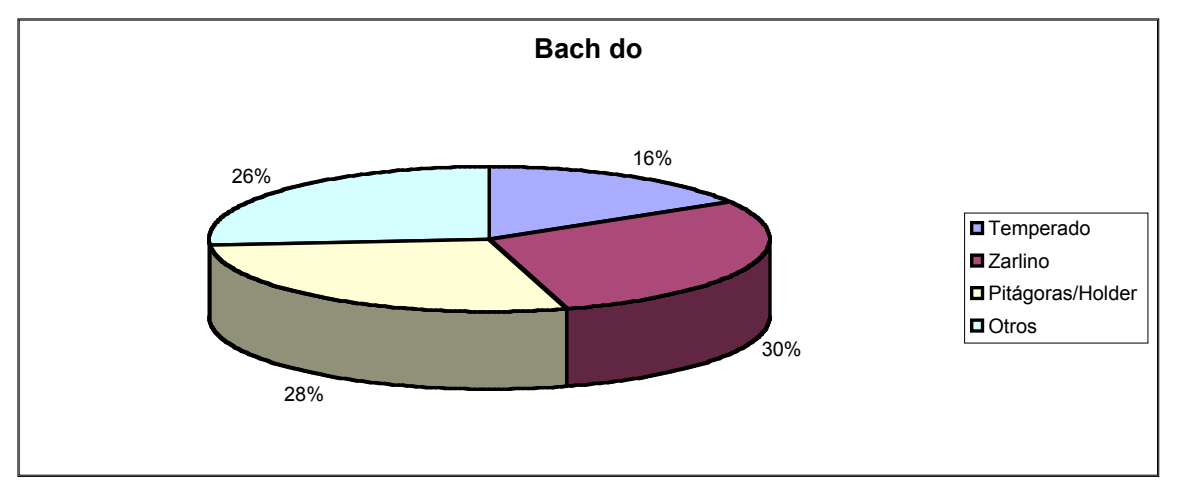

Fig. 3.46 Porcentajes con la trompeta Bach do

Resultados con la trompeta Piccolo Scherzer ${ }^{\circledR}$ en $\mathrm{si}^{\mathrm{b}}$ :

\begin{tabular}{|lc|}
\hline Sistema & $\mathrm{N}^{\mathrm{o}}$ de notas en el sistema \\
\hline Temperado & 32 \\
Zarlino & 36 \\
Pitágoras/Holder & 44 \\
Otros & 33 \\
\hline Tabla 3.14: Resultados con Piccolo Scherzer & ${ }^{(R)}$ en si $^{\mathrm{b}}$
\end{tabular}

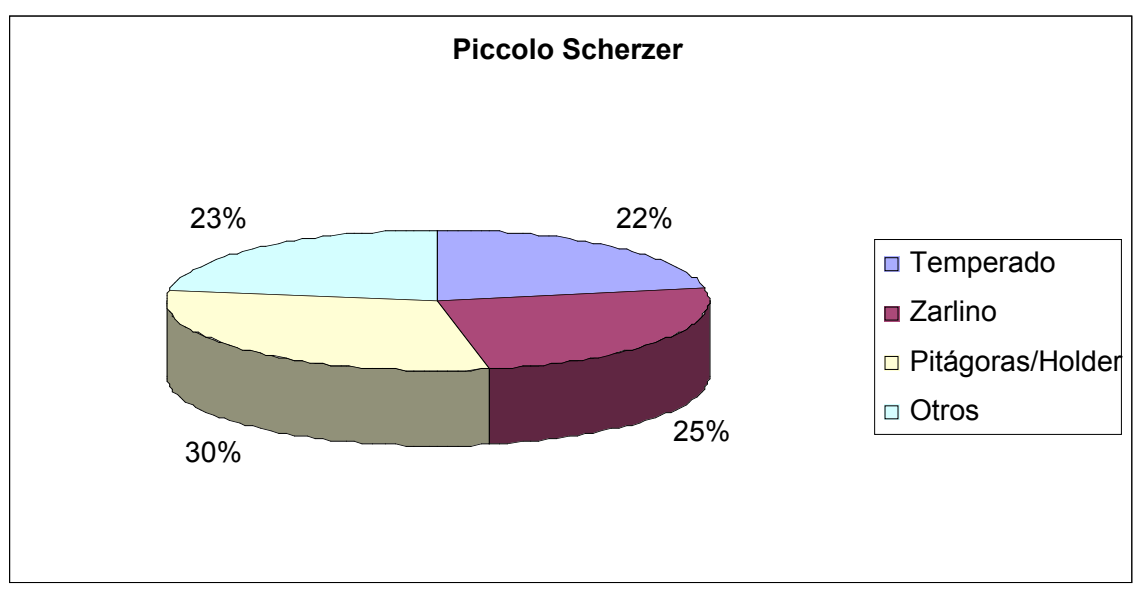

Fig. 3.47 Porcentajes con la trompeta Scherzer 
El instrumento más recomendable para interpretar el fragmento de B. Bartók es el piccolo Scherzer ${ }^{\mathbb{B}}$ en $\mathrm{si}^{\mathrm{b}}$, esto es debido a que la tesitura en que se encuentran las notas es más apropiada para este instrumento que para las trompeta en $\mathrm{si}^{\mathrm{b}}$ ó en do aunque las diferencias no hayan sido demasiado exageradas. intérprete.

Del análisis realizado ${ }^{6}$ podemos extraer varias conclusiones útiles para el

1. Como cabía esperar, los resultados obtenidos cuando se utiliza una trompeta que no es de uso habitual en el ejecutante, los resultados son sensiblemente peores que los obtenidos con sus instrumentos habituales.

2. En general, la afinación estática proporciona mejores resultados que la dinámica y también aparecen diferencias cuando el intérprete tiene referencias previas (notas seriadas) y cuando no las tiene (notas largas).

3. Las grabaciones seriadas de la escala cromática dan mejores resultados para el sistema temperado cuando menos pistones se utilizan (excepto al aire (0) que resulta mejor en Zarlino). Por tanto, cuando se emplean más pistones hay más posibilidades de no afinar correctamente.

4. En la afinación estática no seriada los resultados son diferentes puesto que el intérprete no tiene referencia alguna con respecto a otra nota.

5. En el estudio que hemos realizado de la escala cromática, el porcentaje correspondiente al sistema Temperado supera el 50\% del total, mientras que en el resto de experimentos los porcentajes se equilibran siendo este sistema el que presenta los resultados más bajos.

6. El sistema temperado es mayoritario cuando el intérprete toca pasajes muy trabajados, como la escala cromática. Sin embargo, cuando realiza algún pasaje de mayor dificultad o menos conocido por el instrumentista, el sistema empleado varía en función de otros factores. Cuando emite notas al aire su afinación se aleja del sistema Temperado y se acerca al de Zarlino. Por otra parte, los sistemas de Pitágoras y Holder que aparecen con una frecuencia muy baja en la escala cromática se igualan en los otros experimentos.

7. En el experimento 3, correspondiente al fragmento de Haydn, el sistema de Zarlino predomina sobre los demás.

\footnotetext{
${ }^{6}$ En el Apéndice de esta memoria se puede encontrar los resultados completos del análisis.
} 
8. En el experimento 4, correspondiente al fragmento de B. Bartók, los sistemas de Pitágoras y Holder obtienen resultados superiores al resto.

9. Como ocurre con la mayoría de instrumentos de viento, resulta un tópico no contrastable experimentalmente que la trompeta "afina en el sistema Temperado".

10. Finalmente, sería aconsejable en la medida de lo posible, que los compositores actuales tuvieran en cuenta este tipo de fenómenos y adecuasen las obras, y especialmente la notación, para evitar interpretaciones ambiguas que en ocasiones han provocado serias críticas hacia la música contemporánea.

\subsection{Las Matemáticas como fuente de inspiración del compositor}

En este se han analizado elementos científicos del Siglo XVII como base de la composición de una obra musical. Hemos necesitado otras variables musicales que le dan un carácter de música elaborada al estilo de algunos compositores del Siglo XX y XXI.

La música y la ciencia han seguido históricamente caminos paralelos, unas veces la práctica exigía una explicación científica y en otras ocasiones los experimentos que se producían en los laboratorios eran utilizados posteriormente por los compositores como parte de su material sonoro (piénsese, por ejemplo, en la música electroacústica). Sin embargo, música y matemáticas, que es la relación que a nosotros nos interesa, no siempre han evolucionado de manera conjunta. Habitualmente los músicos no tienen los conocimientos necesarios para explicar de manera científica qué es lo que realizan, y por otra parte los científicos no siempre poseen los conocimientos musicales necesarios para desarrollar sus ideas.

Algunos músicos a lo largo de la historia han dedicado grandes esfuerzos a cultivar la parcela común Música-Matemáticas. Así, Nino Rota (galardonado con un Oscar de la academia de Hollywood por componer la banda sonora de $E l$ Padrino $2^{a}$ parte, entre otras) alumno de Alfredo Cassella realizó su tesis doctoral en la Universidad de Milán sobre Gioseffo Zarlino. El musicólogo húngaro Ernö Lendvai afirma, según dice Mario Livio en La Proporción Áurea (2006), que Béla Bartók utilizó la Proporción Áurea en la fuga de la Música para cuerda, percusión y celesta. De la misma manera el matemático John F. Putz en 1995 intentó averiguar si W. A. Mozart había utilizado la proporción áurea en sus Sonatas para piano. En la Sonata $n^{\circ} 1$ en Do Mayor la proporción $62 / 38=1,63$ se acerca mucho a la Proporción Áurea $(1,6180339887 \ldots)$. 
No sólo los músicos se han preocupado por unificar la música con las matemáticas, la arquitectura encontró en la música la manera de reproducir la naturaleza. De la misma manera que un intervalo de quinta $(3 / 2)$ o de octava $(2 / 1)$ resulta bello por sí mismo, si utilizamos estas proporciones para construir superficies estas serán igualmente bellas. Este planteamiento, plasmado por Leon Battista Alberti (1404-1472) en su tratado de arquitectura De re aedificatoria, fue llevado a la práctica al construir el propio Alberti el templo de San Francisco en Rimini (1457-68).

\subsubsection{Introducción a la música contemporánea}

Antes de entrar a fondo en el análisis de la obra Esferas vamos resumir algunas tendencias que han dominado la música del Siglo XX, de esta manera podremos apreciar las cualidades de esta obra con respecto a sus predecesoras.

Desde 1900 hasta la Primera Guerra Mundial se considera un periodo de transición en el que los compositores evolucionan el sistema tonal llevándolo a su límite. Es el caso de Gustav Mahler, Richard Strauss, Ferrucio Buzón, Hans Pfitzner, Max Reger, Claude Debussy, Eric Satie o Alexander Skryabin, excepción hecha de Igor Stravinsky que durante esta época ya ha ido un paso más allá. Stravinsky con los ballets El pájaro de fuego (1910), Petrushka (1911) y La consagración de la primavera (1913) son un claro ejemplo de los avances que ofrece en ritmos, armonia, timbre, instrumentación...

"Con Arnold Schoenberg (1871-1951) llegamos al primero de los compositores que aunque educado en el mundo del último Romanticismo, alcanzó su madurez musical en los primeros años del Siglo XX y definió las líneas principales de la evolución estilística de los siguientes cincuenta años ${ }^{7}$."

Las posibilidades de la tonalidad son agotadas por los compositores de final del Siglo XIX y principios del XX, de esta manera Schoenberg propone la liberación de la tonalidad por medio de la atonalidad (sin tonalidad), $\mathrm{y}$ tras nueve años sin componer expone su sistema dodecafónico. El paso de la tonalidad al dodecafonismo tiene su paso intermedio en el atonalismo donde los acordes pierden sus funciones tonales sin dominantes, sensibles ni tónicas. El siguiente paso es el dodecafonismo propuesto por Schoenberg y seguido por sus dos alumnos Antón Webern y Aban Berg. Este sistema basado en una serie donde no se pueden repetir las notas hasta que haya sonado la serie entera, esta serie da lugar a tres series más, la serie retrógrada, la serie invertida y la serie retrógrada

${ }^{7}$ véase R. Morgan (1999) 
invertida. Las transposiciones de estas cuatro series básicas son los elementos de trabajo para esta nueva modalidad de escritura.

La corriente neoclasicista surge en Francia a raiz de un artículo que en 1918 publicó el poeta francés Jean Cocteau en la revista "Gallo y Arlequín" en que hacía notar la necesidad de un nuevo arte francés, independiente de la dominación alemana y su modelo no sería la música de las salas de concierto sino el de la música de los circos, del music-hall, de los café conciertos y del jazz (Morgan 1999). Dentro de este neoclasicismo musical destacan el grupo de los seis en Francia, Francis Poulenc (1899-1963), Darius Milhaud (1892-1974), Arthur Honegger (1892-1955), Georges Auric (1899-1983), Germaine Tailleferre (1892-1983) y Louis Durey (1888-1979).

Este lenguaje composicional claramente más económico fue seguido por otros compositores que vieron en esta corriente un modelo a seguir. Igor Stravinsky es sin duda el compositor que más evolucionó en cuanto a estilo durante toda su vida, en la Historia del soldado utiliza un conjunto poco numeroso y su estilo se basa en lo esencial, lo imprescindible.

Béla Bartók es otro de los compositores que fueron seducidos por esta tendencia y de esta época surgen obras como El príncipe de madera o El mandarín maravilloso.

Tras la segunda guerra mundial se intentó recuperar todo lo había sido destruido, la música había desaparecido de las salas de conciertos y su vuelta no fue igual. La generación de compositores que surgió experimentaron una fuerte reacción contra su herencia cultural. Oliver Messiaen (1908-1992) y Pierre Boulez (nacido en 1925), llevaron el serialismo a límites insospechados, empezaron siguieron los principios seriales del dodecafonismo y los adaptaron a las cualidades del sonido (melodía, ritmo, dinámica y timbre). Esta acumulación de series creó una música (serialismo integral) basada en una secuencia de proporciones melódicas, de duraciones y sonoridades.

Otro compositor europeo con gran influencia en el desarrollo del serialismo integal es Karlheinz Stockhausen (nacido en 1928). Stockhausen, que vivió en París, estudió con Messiaen y fue compañero y amigo de Boulez. Al igual que Boulez su punto de partida es la unidad (melodía, ritmo, etc.) que se combina con otras unidades para formar texturas que consisten en resultados individuales y muy separados entre sí.

Otra tendencia significativa del Siglo XX es la indeterminación. Compositores de principios de Siglo como Charles Ives (1874-1954) y Henry Cowell (1897-1965) utilizaron de manera ocasional y limitada elementos indeterminados, pero no es hasta mediado el Siglo XX cuando compositores como 
John Cage (1912-1992) o Edgar Varèse (1883-1965) lo utilizan como base de sus composiciones y esta tendencia es aceptada como tal. En la indeterminación los compositores utilizan de manera intencionada elementos de azar en la composición y en la interpretación, esto hace que la música no sea siempre igual, que cada interpretación sea sistemáticamente diferente. Además esta filosofía conlleva cambios que no solo afectan al oyente, los interpretes deben aprender un nuevo lenguaje que se ha creado para sonidos o efectos que antes no existían. Empiezan a aparecer nuevos signos que la música tradicional no recoge y que a dia de hoy están perfectamente estandarizados.

Aunque el serialismo integral y la indeterminación parecen corrientes contrapuestas, estuvieron muy ligadas en sus principios. La relación de amistad que sostuvieron John Cage y Pierre Boulez contribuyó en gran medida a ello. Ambos admiraban la música que hacía el otro y esto les llevó a componer de las dos formas.

La obra más conocida y probablemente vituperada de John Cage es sin duda alguna 4'33'" donde el pianista entra en el escenario se sienta en la banqueta del piano y permanece en silencio y sin tocar el piano durante 4 minutos y 33 segundos. Aquí Cage quiere escuchar los sonidos que se producen en la sala durante este tiempo y eso es su música. Durante la interpretación de esta obra, que nunca ha tenido la misma acogida, se ha podido escuchar desde la típica tos de un concierto tradicional a los gritos e insultos de quienes se han sentido ofendidos por que el pianista no ha tocado ni una sola nota.

A partir de 1960 una nueva generación de compositores americanos empiezan a trabajar con medios mucho más reducidos utilizando elementos musicales más básicos. Estos compositores entre los que se encuentran La Monte Young (nacido en 1935), Terry Riley (nacido en 1935), Steve Reich (nacido en 1936), Philip Glass (nacido en 1937) y John Adams (nacido en 1947) reciben la influencia de Cage aunque no les interesa la indeterminación. Esta corriente es conocida como minimalismo.

"Utiliza la misma información y la repite una y otra vez"."

Desde que la tonalidad desemboca en el dodecafonismo muchos compositores buscaron nuevas posibilidades de la tonalidad. El compositor checo Alois Haba (1893-1973) utilizando como base la escala temperada desarrolló un sistema microtonal en el que cada semitono se dividía en dos, formando así cuartos de tono. Con este sistema llegaron posteriormente más divisiones en tercios y sextos de tono que aunque fueron aceptados por algunos instrumentos,

\footnotetext{
${ }^{8}$ M. Nyman (1974) p.119.
} 
como el saxofón, resultaron de difícil aplicación para muchos otros y evidentemente imposible para los instrumentos de afinación fija como el piano(aunque se realizaron experimentos como tocar con dos pianos afinados a una distancia de cuarto de tono).

Por último, para finalizar este breve paseo por la música del Siglo XX trataremos la música electrónica. La evolución de la técnica ha traído la creación de nuevos instrumentos y el perfeccionamiento de los antiguos pero no llamamos música electrónica a la música que únicamente utiliza estos instrumentos sino que aprovecha todas sus posibilidades, sonidos grabados de la naturaleza, sonidos producidos artificialmente e incluso la mezcla de estos.

Tras la Segunda Guerra Mundial, Pierre Schaeffer (nacido en 1910) comenzó a realizar su música a partir de sonidos naturales previamente grabados. Con estos sonidos como base, que iban desde el canto de los pájaros a un tren pasando por el sonido de instrumentos naturales como el piano, realizaba un proceso de transformación variando la velocidad de la cinta, poniéndola al revés... a este tipo de música Schaeffer la llamó música concreta diferenciándola de la electrónica puesto que esta obtenía los sonidos por medios puramente electrónicos.

Hoy en día aunque no se abandonan los instrumentos tradicionales, se sigue haciendo música con sintetizadores y sobre todo por ordenador. Los grandes aparatos electrónicos se han sustituido por potentes ordenadores con muchas más posibilidades para generar música con un software específico para modificar cualquier parámetro del sonido $\left(\right.$ Matlab $^{\circledR}$, Soundforge $\left.{ }^{\circledR} \ldots\right)$. También se han desarrollado programas de edición musical a nivel de usuario y profesionales (Finale $^{\circledR}$, Sibelius ${ }^{\circledR}$, Cubase $^{\circledR} \ldots$ ) con los que cualquier músico puede escribir su música directamente al ordenador e imprimirla con una calidad optima, la escritura con lápiz y papel ha pasado a la historia.

\subsection{Composición de la obra Esferas}

Esferas ha sido concebida a partir de los cálculos que realizó Johannes Kepler (1551-1630) en su tratado Harmonices Mundi (1619) en el que asigna mediante complejas operaciones matemáticas unas determinadas notas a cada planeta del sistema solar. Hay que tener en cuenta que en la época de Kepler sólo se conocían seis planetas: Mercurio, Venus, Tierra, Marte, Júpiter y Saturno. Con posterioridad, otros investigadores descubrieron los tres restantes que hoy en día conocemos y que forman parte de nuestro sistema solar, Urano (1781), Neptuno (1846) y Plutón (1930), aunque recientemente la Unión Astronómica Internacional (UAI) ha excluido a Plutón como planeta de pleno derecho del sistema solar. Además, Kepler designa unas notas a otra esfera que aunque no es 
un planeta tiene una especial relevancia en la Historia, la Luna, con todo esto Kepler dice: Hic locum habet etiam (Aquí también tiene lugar la luna), aclarando que no se le considera como un planeta.

Como hemos dicho en el capítulo anterior, los pitagóricos, herederos de la tradición caldea, sostenían que las notas emitidas por los cuerpos celestes dependían de las proporciones aritméticas de sus órbitas alrededor de la Tierra. Exactamente igual que la longitud de las cuerdas de una lira determina sus tonos. Los sonidos que producía cada esfera se combinaban con los sonidos de las restantes produciendo una sincronía sonora especial conocida como la música de las esferas.

Desde el siglo VI a. C. hasta el siglo XVII fueron muchos los pensadores que se ocuparon de la armonía celestial, del Universo como un gran instrumento musical, pero quizá ninguno con la profundidad, la originalidad y la precisión de Johannes Kepler (1571-1630). Al determinar las proporciones armónicas, los pitagóricos buscaban a una mística de los números confusa y apenas inteligible, pero Kepler se decidió desde el principio a seguir su propio camino, "No pretendo demostrar nada a partir de la mística de los números, ni siquiera la considero posible".

El profundo sentimiento religioso de Kepler le marcaba un punto de partida diferente del de los pitagóricos. Su gran meta era "erigir el magnífico edificio del sistema armónico o escala musical, un edificio cuya disposición no es caprichosa como podría pensarse, no es una invención humana susceptible de modificaciones, sino que se muestra tan acorde con la razón y con la naturaleza que el mismísimo Dios creador lo reprodujo al concertar los movimientos celestes".

En su obra Harmonices Mundi, Kepler estableció que un astro debería emitir ${ }^{9}$ un sonido que es más agudo cuando su movimiento fuese más rápido, por lo que existen intervalos musicales bien definidos que están asociados a los diferentes planetas. De hecho no se conformó con suponer que las velocidades angulares de cada astro producían sonidos, sino que llegó a componer siete melodías que se correspondían con los seis planetas del sistema solar conocidos hasta entonces y la Luna. Al combinarse, estas melodías podían producir cuatro acordes distintos, siendo uno de ellos el acorde producido al inicio del universo, y otro de ellos el que sonaría a su término.

\footnotetext{
9 A pesar de su neopitagorismo, Kepler es consciente de la imposibilidad de percibir la música de las esferas: "Iam soni in coelo nulli existunt, nec tam turbulentus est motus, ut ex attritu aurae coelestis eliciatur stridor".
} 


\subsubsection{Cálculos de Kepler}

Kepler intentó comprender las leyes del movimiento planetario durante la mayor parte de su vida. En un principio consideró que el movimiento de los planetas debía cumplir las leyes pitagóricas de la armonía. En su visión cosmológica no era casualidad que el número de planetas conocidos en su época fuera uno más que el número de poliedros perfectos. Firme partidario del modelo copernicano, intentó demostrar que las distancias de los planetas al Sol venían dadas por esferas en el interior de poliedros perfectos, anidadas sucesivamente unas en el interior de otras. El orden, desde la mayor hasta la menor, era el siguiente:

\section{Saturno-Cubo-Júpiter-Tetraedro-Marte-Dodecaedro-Tierra- Icosaedro-Venus-Octaedro-Mercurio}

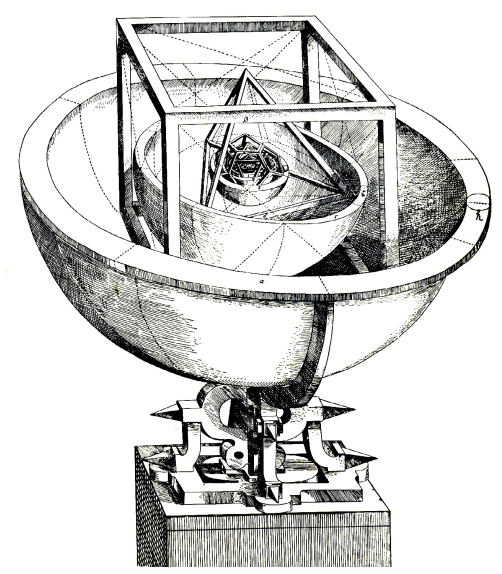

Fig. 3.48. Modelo presentado por Kepler en Misterium Cosmographicum (1596).

Kepler vio en este modelo cosmológico una celebración de la existencia, sabiduría y elegancia de Dios. De hecho, afirmó «yo deseaba ser teólogo; pero ahora me doy cuenta a través de mi esfuerzo de que Dios puede ser celebrado también por la astronomía».

Sin embargo, pronto advirtió que este modelo de poliedros perfectos no explicaba ${ }^{10}$ el movimiento de los planetas. La profunda religiosidad de Kepler, no le permitía aceptar que Dios no hubiera dispuesto que los planetas describieran figuras geométricas simples y con esta idea se dedicó a probar con toda suerte de combinaciones de círculos. Convencido de la imposibilidad de lograrlo con

${ }^{10}$ A la muerte de Tycho Brahe (1602), Kepler accede a todos los datos recopilados por Tycho. Mucho más precisos que los manejados por Copérnico, especialmente los relativos al movimiento retrógrado de Marte. A partir de ellos, Kepler advierte que su sistema de poliedros no era sostenible. 
círculos, usó óvalos y finalmente, con gran decepción, empleó elipses. Con ellas llegó a las famosas tres leyes ${ }^{11}$ que le revelaron como el mejor astrónomo de su época. Sin embargo, esta falta de simplicidad en el Universo, que Kepler vivió como un fracaso, fue compensada por la perfección de la Armonía Universal.

Aseguró, por primera vez, que las órbitas de los planetas describen una elipse alrededor del Sol y que éste se encuentra en uno de los focos de la elipse. Si expresamos la velocidad angular de cada planeta en segundos, podemos considerar que representa el número de vibraciones de un cierto tono, pero como la velocidad cambia a lo largo de la revolución, este tono recorrerá un intervalo musical. De acuerdo con las leyes de Kepler, la amplitud de este intervalo dependerá de la excentricidad de la órbita.

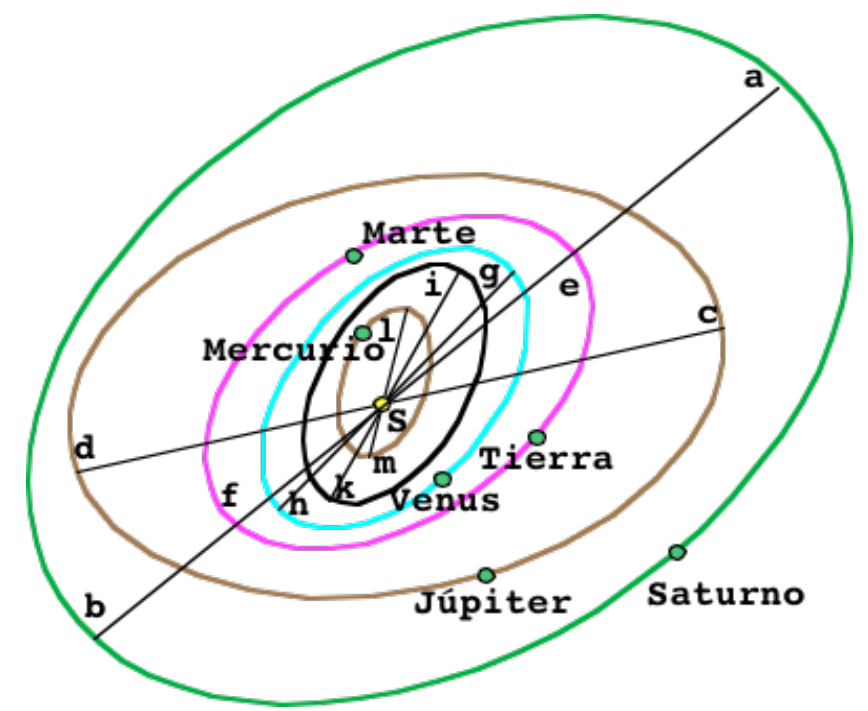

Fig 3.49. Modelo cosmológico de Kepler

Las letras a, c, e, g, i, indican la distancia más grande de cada planeta al Sol, (afelio) y las restantes las distancias más pequeñas (perihelio).

Los cálculos de las velocidades angulares proporcionaron la siguiente armonía de los planetas:

${ }^{11}$ Las tres leyes, publicadas en 1609 en su obra Astronomía Nova, pueden resumirse como:

1. Cada planeta describe, en sentido directo, una órbita elíptica, uno de cuyos focos está ocupado por el Sol.

2. El área descrita por el radiovector que une el centro de un planeta con el centro del Sol es proporcional al tiempo empleado en barrerla.

3. Los cuadrados de los tiempos de las revoluciones siderales de los planetas son proporcionales a los cubos de los semiejes mayores de sus órbitas. 


\begin{tabular}{|c|c|c|c|c|c|c|}
\hline Planeta & \multicolumn{2}{|c|}{ VELOCIDAD } & \multicolumn{2}{|c|}{ ANGULAR } & \multirow{2}{*}{$\frac{\text { ARMONÍA }}{4 / 5}$} & \multirow{2}{*}{$\begin{array}{r}\text { INTERVALO } \\
\text { Tercera }\end{array}$} \\
\hline Saturno & Afelio & 1'46' a & entre & 1'48' & & \\
\hline & Perihelio & 2,15 ' $\mathbf{b}$ & & $2^{\prime} 15^{\prime \prime}$ & & mayor \\
\hline Júpiter & Afelio & 4'30' $\mathbf{c}$ & entre & $4^{\prime} 35^{\prime \prime}$ & $5 / 6$ & Tercera \\
\hline & Perihelio & $5^{\prime} 30^{\prime \prime} \mathrm{d}$ & $\mathrm{y}$ & $5 ' 30^{\prime \prime}$ & & menor \\
\hline Marte & Afelio & 26 ' $14^{\prime \prime} \mathrm{e}$ & entre & $25^{\prime} 21^{\prime \prime}$ & $2 / 3$ & $\overline{\text { Quinta }}$ \\
\hline Ti & Perihelio & $38^{\prime} 1^{\prime \prime \prime} \mathbf{f}$ & $\begin{array}{c}\mathrm{y} \\
\text { antro }\end{array}$ & $\begin{array}{c}38^{\prime} 1^{\prime \prime} \\
57^{\prime}, "\end{array}$ & & \\
\hline Tierr & $\begin{array}{l}\text { Afello } \\
\text { Perihelio }\end{array}$ & $\begin{array}{r}57, \mathbf{g} \\
61,18^{\prime}, \mathbf{h}\end{array}$ & entre & $\begin{array}{l}57,28{ }^{\prime} \\
61,18 "\end{array}$ & $15 / 16$ & Semitono \\
\hline Venus & Afelio & $94^{\prime} 50^{\prime \prime}{ }_{\mathrm{i}}$ & entre & $94^{\prime} 50^{\prime \prime}$ & $24 / 25$ & $\underline{\text { Diesis }}$ \\
\hline Mercurio & $\begin{array}{l}\text { Perihelio } \\
\text { Afelio }\end{array}$ & $\begin{array}{l}97^{\prime} 37^{\prime \prime} \mathbf{k} \\
164^{\prime} 0^{\prime \prime} \mathbf{l}\end{array}$ & $\underset{\text { entre }}{\mathrm{y}}$ & $\begin{array}{l}98^{\prime} 47^{\prime \prime} \\
164^{\prime} 0^{\prime \prime}\end{array}$ & $5 / 12$ & Octava+ter- \\
\hline & Perihelio & $384^{\prime} 0$ "' f & $\mathrm{y}$ & 394' 0', & & cera mayor \\
\hline
\end{tabular}

Tabla 3.15: Velocidades angulares de los planetas

Fuente: Atlas de Música, 2, pág. 302

Además, de esta armonía interna, existía otra armonía que regía las relaciones entre los planetas. Para esto, Kepler comparó el afelio y el perihelio de un planeta con los del más próximo a él, obteniendo así dos tipos de intervalos:

a) Intervalo convergente: se obtiene comparando la distancia donde la velocidad es menor (afelio) para el planeta más externo con la distancia donde la velocidad es mayor (perihelio) para el planeta más interno.

b) Intervalo divergente: se obtiene comparando la distancia donde la velocidad es menor (afelio) para el planeta más interno con la distancia donde la velocidad es mayor (perihelio) para el planeta más externo.

Con estos dos tipos de intervalos calculó las siguientes proporciones:

\begin{tabular}{|lcc|}
\hline & CONVERGENCIA & DIVERGENCIA \\
\hline Saturno-Júpiter & $\frac{a}{d}=\frac{1}{3}$ & $\frac{b}{c}=\frac{1}{2}$ \\
Júpiter-Marte & $\frac{c}{f}=\frac{1}{8}$ & $\frac{d}{e}=\frac{5}{24}$ \\
Tierra-Venus & $\frac{c}{h}=\frac{5}{12}$ & $\frac{f}{g}=\frac{2}{3}$ \\
Venus-Mercurio & $\frac{g}{k}=\frac{3}{5}$ & $\frac{h}{i}=\frac{5}{8}$ \\
& $\frac{i}{m}=\frac{1}{4}$ & $\frac{k}{l}=\frac{3}{5}$
\end{tabular}

Tabla 3.16: Intervalos calculados por Kepler

Fuente: Atlas de Música, 2, pág. 302 
El paso siguiente era asignar una melodía a cada planeta (y a la Luna). Para ello, no hay más que tomar una nota arbitraria y a partir de ella, y basándose en todas las proporciones obtenidas, las melodías son las siguientes:
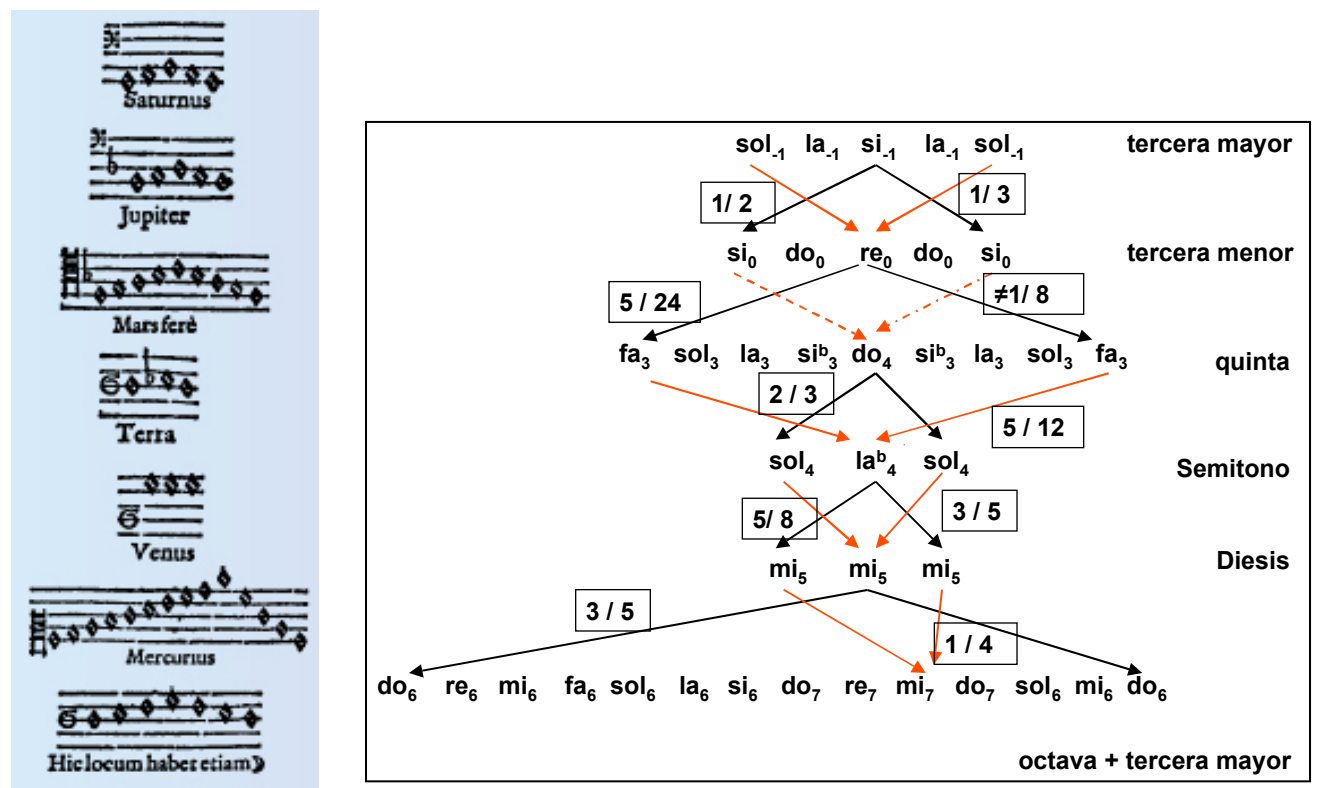

Fig 3.50. Música de las Esferas de Kepler

En el gráfico de la izquierda se reproducen los pentagramas originales de Kepler. En el esquema de la derecha se recogen los dos tipos de armonía manejados. La armonía interna proporciona los intervalos de cada planeta y la armonía externa relaciona los intervalos de cada planeta con los demás.

Es importante resaltar que el único planeta para el que la identificación proporción-nota musical no es exacta es para la Tierra, pero incluso este hecho sirvió a Kepler como muestra de la grandeza de Dios.

\subsubsection{Esferas}

En Esfera, los sonidos propuestos por Kepler se mezclan con otros actuales, de manera que se escuchan de forma simultánea las notas originales, completamente tonales y que representan la tercera mayor, la tercera menor, la quinta, el unísono, etc., junto con melodías elaboradas por el compositor a partir de sonidos actuales que huyen de la tonalidad. La única excepción a la música tonal más ortodoxa la constituyen las notas que representan a la Tierra: el semitono. Este intervalo, prohibido durante largo tiempo, es aceptado en el Barroco mientras sea utilizado con mesura y no como el material básico para la 
elaboración de una obra. Sin embargo, está presente en todos los cromatismos del S. XIX de los compositores más representativos de este periodo.

En la obra se combinan dos tipos de series, una establecida por Kepler y otra diseñada por el compositor variando la anterior. La técnica de composición, sin llegar al dodecafonismo, está inspirada en el método de Arnold Schömberg de modo que las series suenan completas y no se repiten hasta que no ha sonado la última nota de la serie. Éstas se transportan y se superponen de forma que en ocasiones resulta difícil reconocerlas.

"Tengo que confesarlo con toda franqueza: yo no podría hacer esto. Quiero decir que yo mismo tendría que trabajar dias enteros para poder averiguar cómo han sido utilizados los doce tonos, y hay muchos pasajes en los que sería casi imposible encontrar la solución. Creo que esta cuestión no tiene importancia y siempre lo he dicho así a mis discípulos. Puedo señalar una gran cantidad de ejemplos que ilustran la idea de este tipo de composición, pero en lugar de la aplicación puramente mecánica, puedo informarle de sus ventajas composicionales y estéticas."

$$
\text { Schömberg }{ }^{12}, 1938
$$

Los instrumentos elegidos para la obra no son un hecho casual, en el clasicismo F. J. Haydn, W. A. Mozart y L. V. Beethoven tuvieron su banco de pruebas en el cuarteto de cuerdas, formación para la que escribieron multitud de novedades que posteriormente aplicaron a sus obras mayores. Para Esferas se ha preferido la sonoridad de los metales que tienen una formación de cámara estable en el quinteto de metales.

\subsubsection{Análisis de la obra}

Ésta obra esta concebida para interpretarse tal y como esta escrita pero su estructura hace que puedan darse algunos cambios. La obra empieza con una introducción que abarca desde el comienzo hasta el compás 13. A partir de aquí se suceden cada uno de los planetas, la diferencia con las obras convencionales es que el orden de los planetas puede ser alterado con respecto al que esta escrito.

La obra esta estructurada en 7 tiempos: Introducción, Saturno, Júpiter, Tierra, Venus, Mercurio y Marte-La Música de las Esferas. La interpretación empieza por la introducción y termina con Marte-La Música de las Esferas, este último tiempo aunque junta un planeta con las melodías que conforman la música de las esferas debe ser interpretado como una sola unidad.

\footnotetext{
${ }^{12}$ Carta a Arthur W. Locke, 25 de mayo de 1938. Josef Rufer (1962), p. 141.
} 
Después de la introducción encontramos Saturno, Júpiter, Tierra, Venus, Mercurio y Marte para terminar con un final donde todos los planetas suenan en su versión primitiva (Kepler) mezclándose con las nuevas melodías y girando en torno a una nota determinada (SOL), de la misma forma que los planetas giran en torno a esta gran estrella.

\section{Introducción}

La introducción corre a cargo del trombón realizando una melodía donde predominan los intervalos de segunda melódica y armónicamente (como después veremos en la Tierra) mientras la tuba menciona las notas de Saturno como en cualquier obertura operística donde surgen algunos temas que serán desarrollados posteriormente. El glissando del trombón y el vibrato de cuarto de tono de la trompa se utilizan para dar al pasaje una sensación de indefinición, como si estuviéramos en un espacio infinito. De la misma manera, la tuba golpea la boquilla con la palma de la mano, a modo de instrumento de percusión, produciendo un sonido que reafirma la indeterminación comenzada por trombón y trompa. Los acordes finales de esta introducción que utilizan la interválica de Saturno sirven como tensión, a modo de dominante, que se descarga en el siguiente compás.

El siguiente compás en el original resulta el planeta Saturno pero el autor da libertad para que podamos intercambiar algunos de los planetas de manera que se puedan intercambiar e interpretar cada vez en un orden diferente como si giraran, así el siguiente compás podría ser la Tierra, Venus, Júpiter o Mercurio ya que es aconsejable interpretar desde Marte hasta el final como una sola unidad. Esta aleatoriedad que resulta al intercambiar en las distintas interpretaciones los diferentes planetas viene de la música aleatoria que durante el $\mathrm{S}$. XX se practicó en multitud de partituras pero en este caso las notas vienen dadas por el autor y la aleatoriedad solo se refiere al orden de interpretación de cada tiempo de la obra (planeta).

\section{Saturno}

Durante toda la obra se mezclan dos tipos de melodías, una, la realizada por Kepler mediante cálculos matemáticos (que en adelante la denominaremos A) y otra, realizada por el autor basada en la música serial (que en adelante denominaremos B). Estas dos melodías varían en cada tiempo pero suenan de forma individual o paralelamente durante toda la obra. Las series se utilizan siguiendo el método serial que propugnó A. Schömberg pero adaptando las normas puesto que se utilizan dos series en vez de una. 


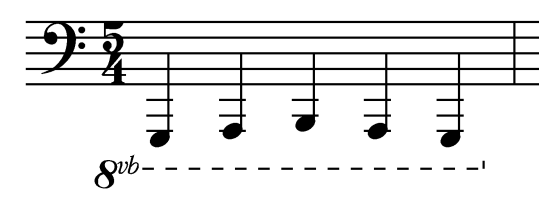

Saturno viene representado por Kepler por la tercera mayor y esta sucesión de notas ya aparece en la introducción en la tuba aunque ahora va pasando por los diferentes instrumentos mezclándose con la nueva melodía. La melodía con la tercera mayor la expone la tuba y es contestada en forma de fuga por la trompa y la trompeta a distancia de quinta y octava.

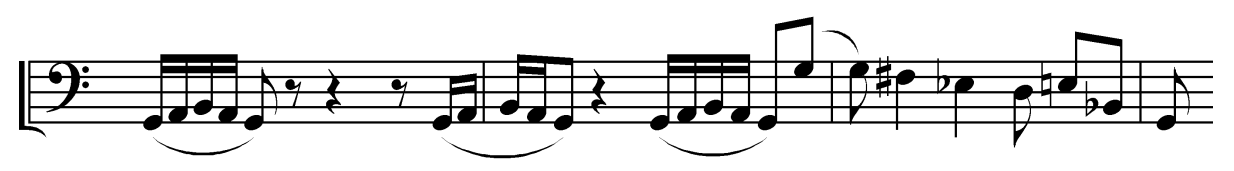

Una vez concluida esta exposición encontramos la nueva melodía (B) en la que priman los intervalos de segunda acompañada por unas corcheas a distancia de cuarta aumentada y la melodía anterior de $\operatorname{Kepler}(\mathrm{A})$.

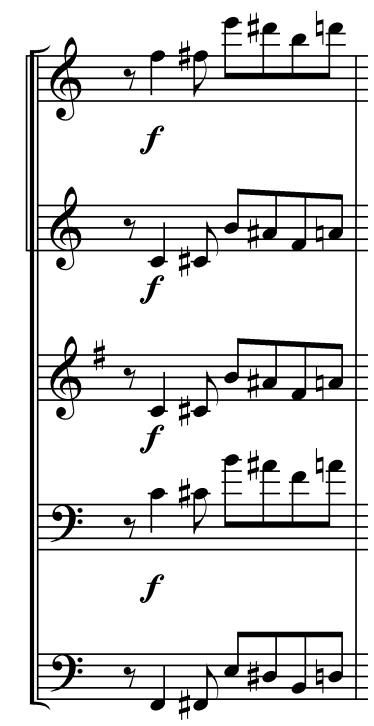

A partir del compás 27 la tuba, y posteriormente el trombón, interpretan por disminución la tercera mayor de Kepler acompañados por distintas melodías que ahora tienen como base la octava disminuida.

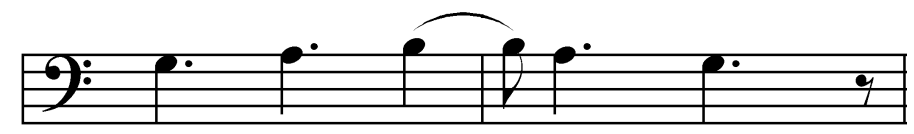

Seguidamente trombón y trompa realizan las corcheas a distancia de cuarta aumentada y el pasaje finaliza con una pequeña cadencia de la tuba. 


\section{Júpiter}

En Júpiter, Kepler nos propone el intervalo de tercera menor:

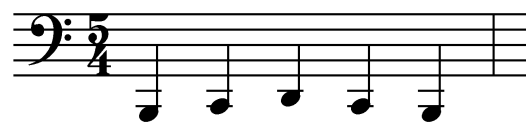

Este intervalo aparece por primera vez en la tuba y el trombón a distancia de octava en el primer compás con un motivo de corcheas que incluye la citada tercera menor, este motivo en forma de ostinato resulta la base rítmica de este tiempo.

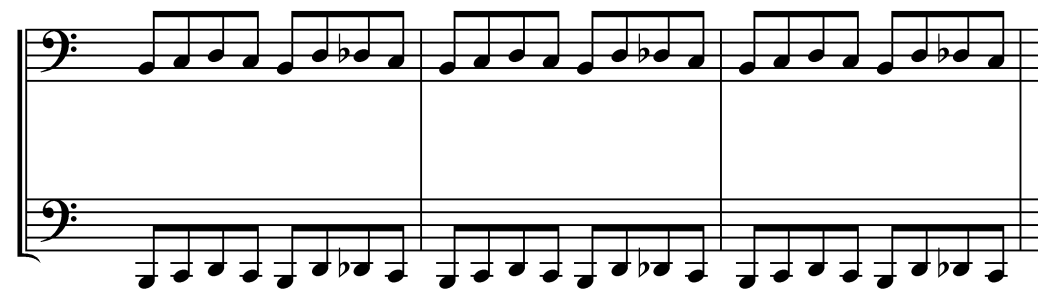

\section{Tierra}

En la tierra, Kepler, tras sus correspondientes cálculos, propone la segunda menor.

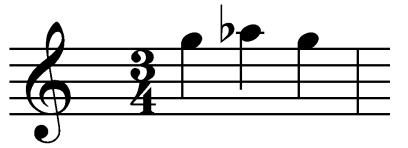

Este intervalo se puede apreciar de dos formas, melódica y rítmicamente. Esta parte esta realizada como si de un cuadro puntillista se tratara, si acercamos la mirada a la partitura veremos una serie de notas sueltas, como pinceladas, que apenas parecen decir nada, que no tienen continuación, pero si escuchamos la pieza esta sucesión de notas que forman grupos se enlazan entre ellos produciendo una sensación de unión y de cohesión.
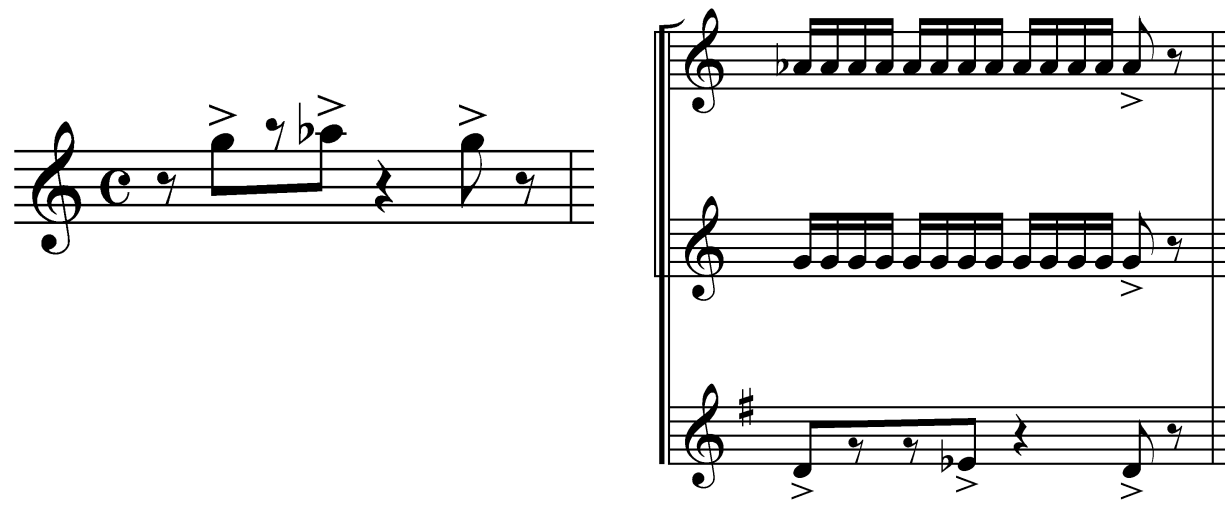
Al comienzo se escuchan unos breves sonidos distanciados por silencios de diferente duración, aquí el autor quiere rememorar el principio de una tierra despoblada y sin las maldades que el hombre le causa, posteriormente y junto con la melodía que representa a la luna la música crea un momento de confusión al sonar varias series juntas, con esto se quiere reproducir el ambiente actual en las ciudades con su tráfico la superpoblación, la polución, los ruidos ambientales, etc.

Para finalizar este fragmento la música se va deshaciendo, cada vez intervienen menos instrumentos y la serie que daba lugar a este planeta va desapareciendo, las series empiezan a sonar con menos notas hasta que desaparece todo y se queda la nada.

\section{Luna}

Kepler, además de asignar a cada planeta una serie de notas colocó en último lugar otra serie para la luna. El tratado esta en latín y dice: "aquí también hay un lugar para la luna”. Así la luna forma parte de este universo.

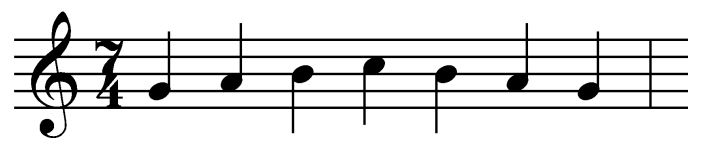

La luna no tiene asignado un tiempo exclusivo para ella como lo tienen los planetas, la luna es un satélite de la tierra y como tal se ha tratado. Durante la interpretación de la tierra podemos escuchar un motivo modificado con respecto al de Kepler y tratado a la manera de los impresionistas, como escala de tonos enteros.

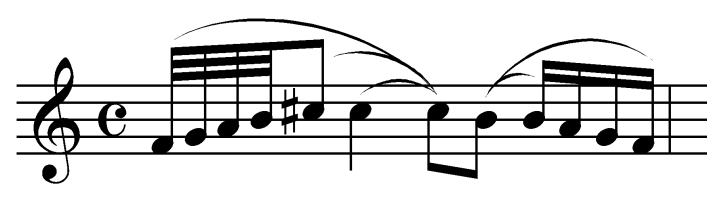

\section{Venus}

El motivo con que Kepler representa a Venus es el unísono. Una sucesión de tres notas con la misma altura.

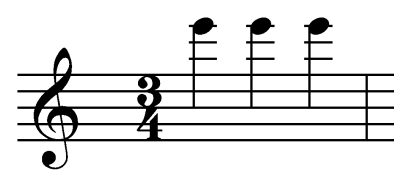

Este planeta que debe su nombre a la diosa romana del amor Venus, se sucede como tiempo lento que es a modo de intermedio, de reflexión. 


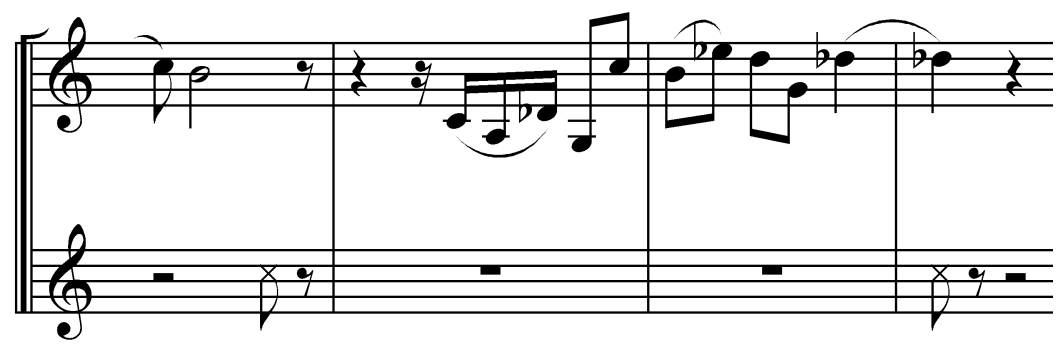

La instrumentación es muy sutil sucediéndose distintos solos e incluyendo efectos tímbricos y sonoros como el empleo de sordinas en las trompetas o el golpeo de la boquilla con la palma de la mano.

El movimiento termina con un acorde en el que se ha eliminado la tercera y solo suenan octava y quinta, de esta forma la sensación resultante para el oyente es de suspensión como si la música estuviera suspendida en el aire de igual manera que los planetas están suspendidos en el espacio.

\section{Mercurio}

En Mercurio, Kepler propone una escala diatónica ascendente de DoM. hasta la décima y un arpegio descendente hasta la tónica.

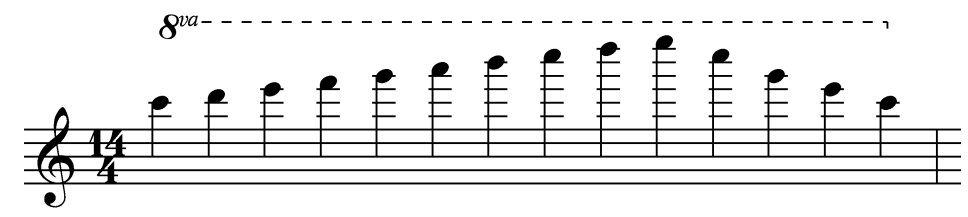

La traslación de las notas de Kepler no se hace de forma textual, la escala no parte de la tónica. Las tres primeras notas (do, re y mi) forman una disonancia a modo de cluster en la voz de las trompetas y trombón mientras que la trompa realiza la escala ascendente. La tuba completa el fragmento con el arpegio descendente. Para esta melodía se han utilizado cuatro instrumentos (observemos que la nota del trombón, mi, y la primera de la escala de la trompa, si, son la misma nota) y con ellos completamos no solo la melodía sino la armonía puesto que las trompetas mantienen sus sonidos. La serie original se mantiene igual sonando cada nota en el orden que aparece en el modelo pero con ligeras variaciones. 


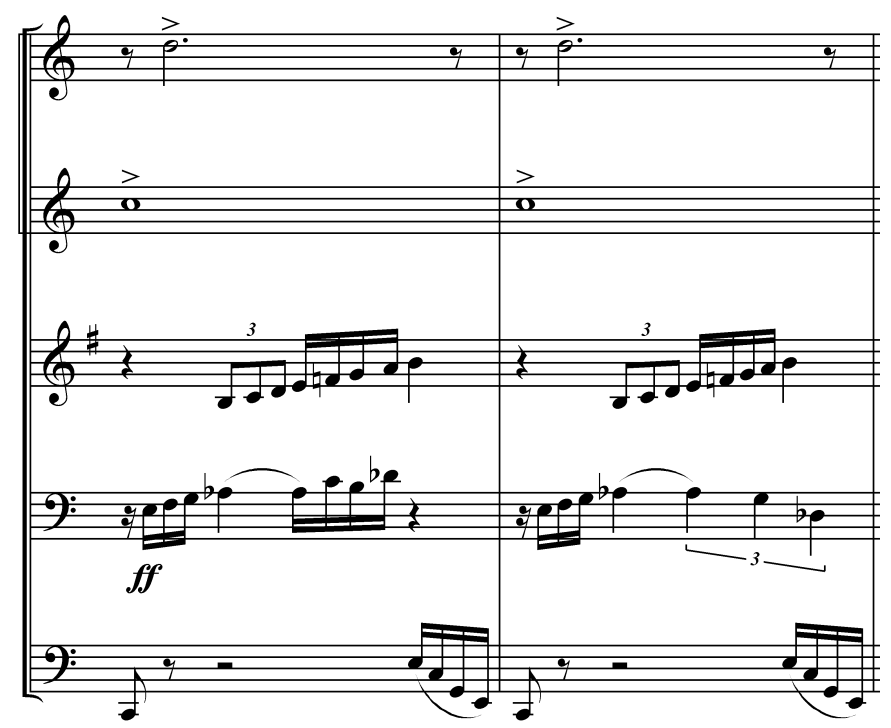

La serie original suena durante los dos primeros compases sola con el único adorno de la nota del trombón que oscila su afinación en un cuarto de tono. A partir del tercer compás el trombón asume un papel protagonista con la melodía de la segunda serie (B). Tras un enlace de tres compases con acordes en el que las trompetas abandonan la distancia de tono para sonar a distancia de semitono, la primera trompeta repite la segunda serie anteriormente interpretada por el trombón y un compás mas tarde la segunda trompeta a modo de segunda voz le acompaña hasta el final de este motivo, con un crescendo y un glissando que desembocan en progresión a modo de canon que poco a poco va estrechándose como si del final de una fuga se tratara hasta que la trompa interrumpe este discurso con un desgarrador sonido producido en su registro agudo que da fin al movimiento.

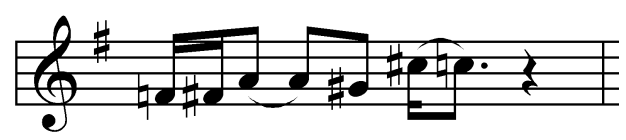

Motivo de la progresión

\section{Marte}

Anteriormente los movimientos de cada planeta se podían interpretar en un orden aleatorio pero es conveniente ejecutar Marte justo antes de la música de las esferas puesto que el enlace es más adecuado. No obstante el intérprete puede tratar a Marte como un planeta más y cambiar su orden en la ejecución. 


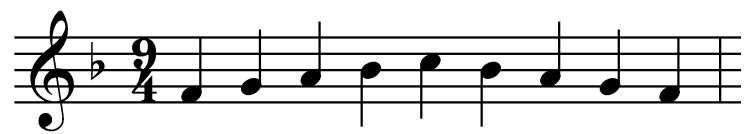

En Marte Kepler nos propone el intervalo de quinta en forma de escala, este motivo realizado en corcheas por la trompa esta presente durante todo el movimiento mientras el resto de instrumentos realizan el acompañamiento y las melodías de la segunda serie.

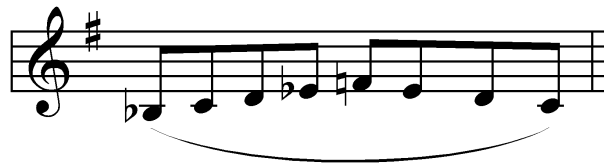

La serie $\mathrm{B}$ va pasando por cada instrumento, a excepción de la trompa, y cada vez que aparece suena un acorde en el final del motivo.

Marte termina con unas negras en la tuba mientras suenan las trompetas y la trompa a distancia de octavas.

\section{La música de las esferas}

La parte final de la obra concluye con una mezcla de las melodías que han sonado durante toda la obra. Primero a modo de reexposición el trombón repite el principio de la obra y posteriormente escuchamos cada una de las notas que hemos utilizado a partir de los cálculos de Kepler. Esta parte que es lenta y que gira siempre en torno a la nota sol

Esta sección de apenas 12 compases, se interpreta lentamente y el Sol esta siempre presente (como en el espacio) representado por la nota del mismo nombre (Sol) que envuelve el resto de melodías de la misma manera que la estrella ilumina los planetas.

Para finalizar a partir de la melodía que introduce la tuba en Saturno es ahora interpretada por todos los instrumentos con entradas en diferentes pulsaciones del compás. Al principio de manera textual y posteriormente alterada para, tras un compás de espera, finalizar con un presto en el que la tuba asume el protagonismo y encontrar un final rápido, con carácter y sobre todo enormemente conclusivo.

A continuación mostramos la partitura de la obra Esferas (que puede escucharse en el DVD que adjuntamos a esta memoria en el minuto 39 y 5 segundos). Las partichelas aparecen en el Apéndice. 


\subsubsection{Partitura de Esferas}

\section{Esferas}

Kepler en el Siglo XXI

José Ibáñez Barrachina
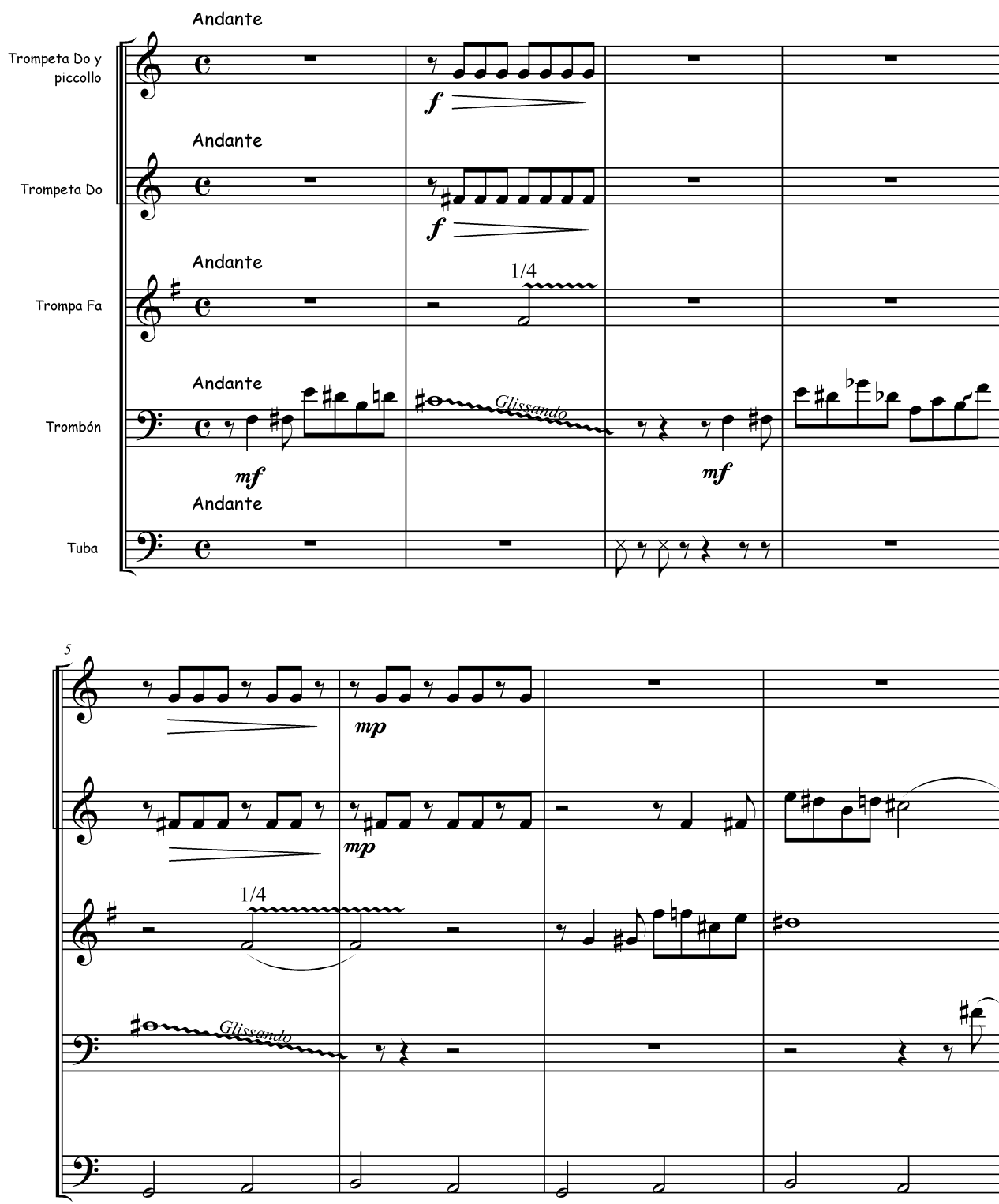

$m p$

2006 

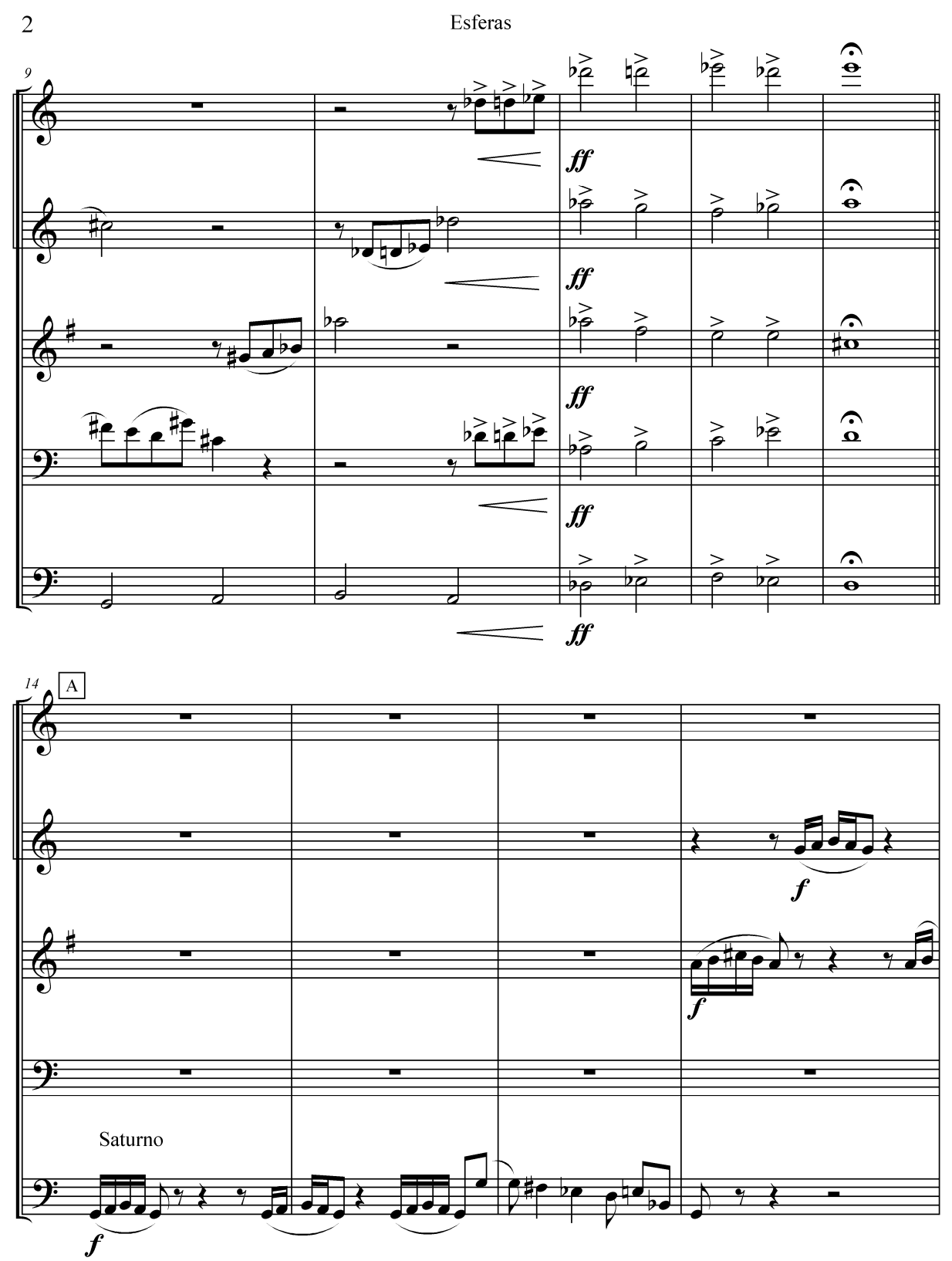

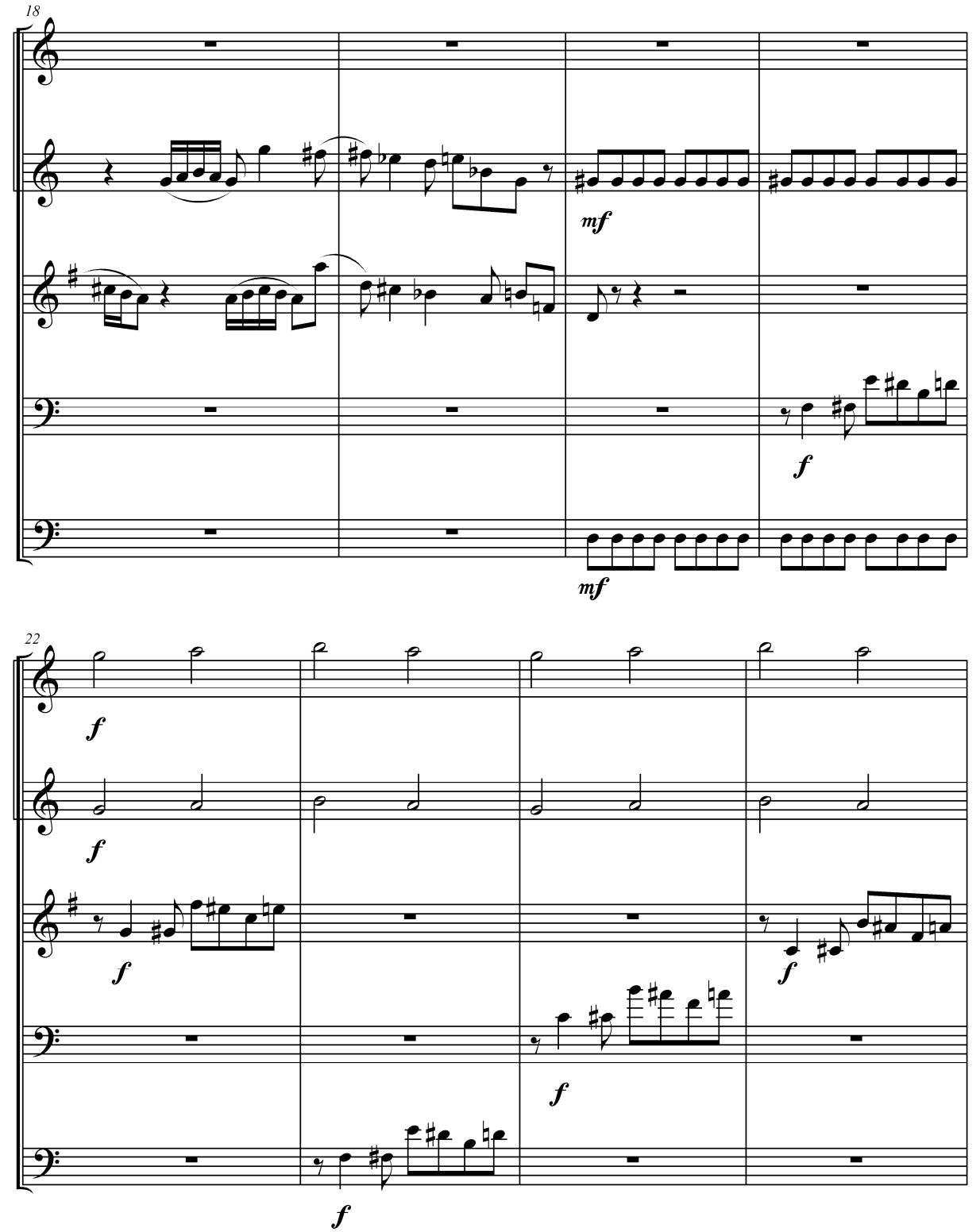
Capítulo 3

185

4

Esferas
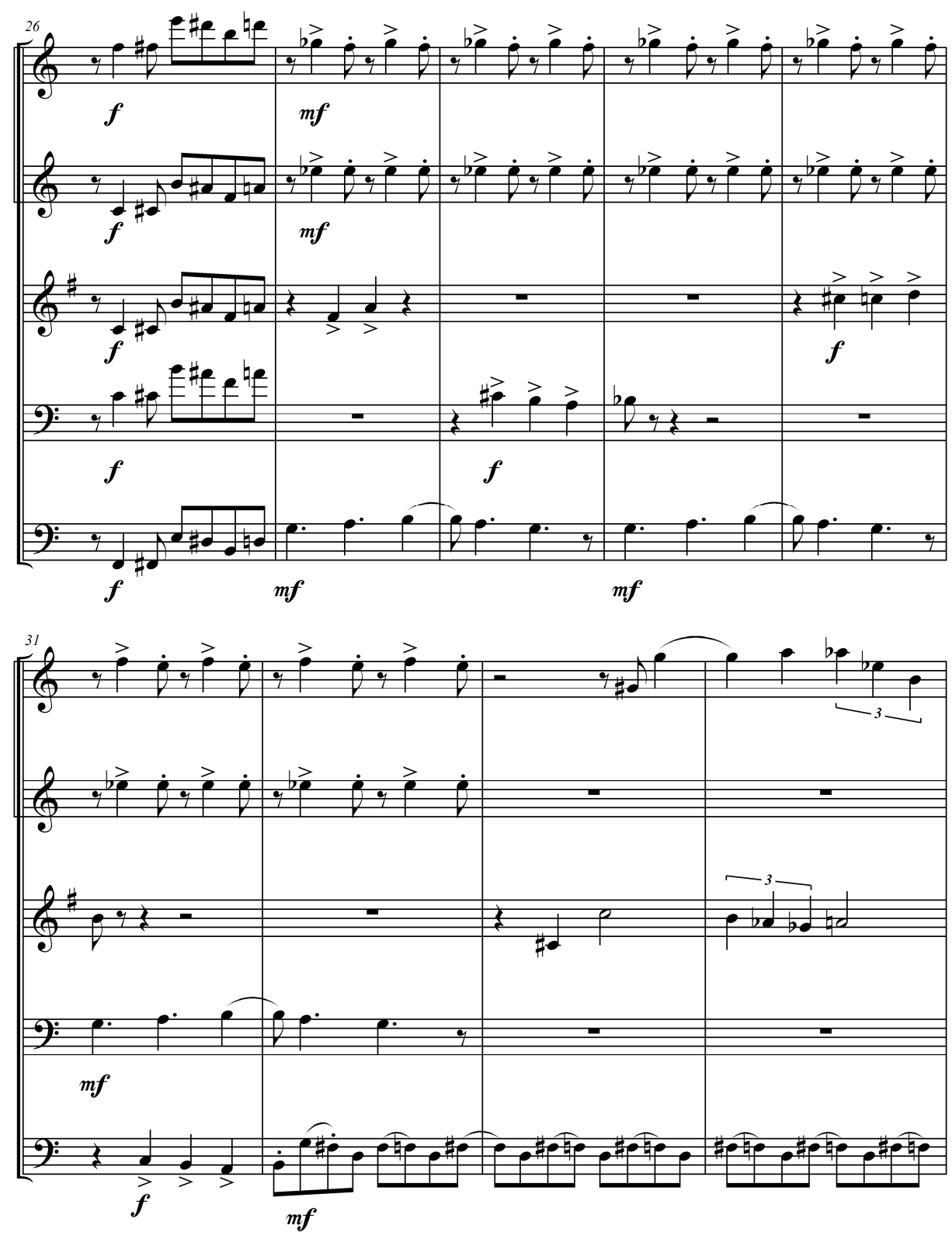

2006

José Ibáñez Barrachina

Universidad Politécnica de Valencia 

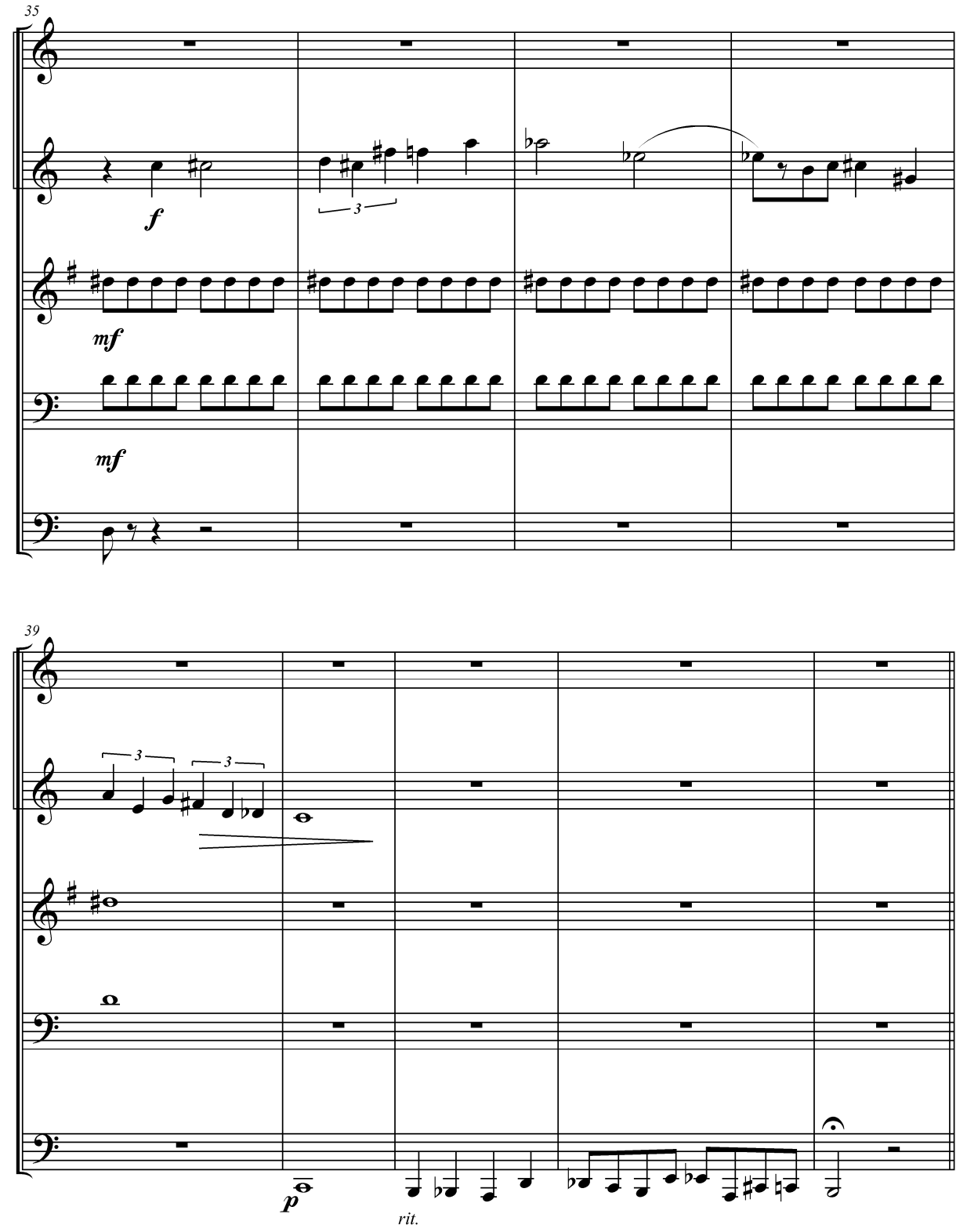
6

Esferas
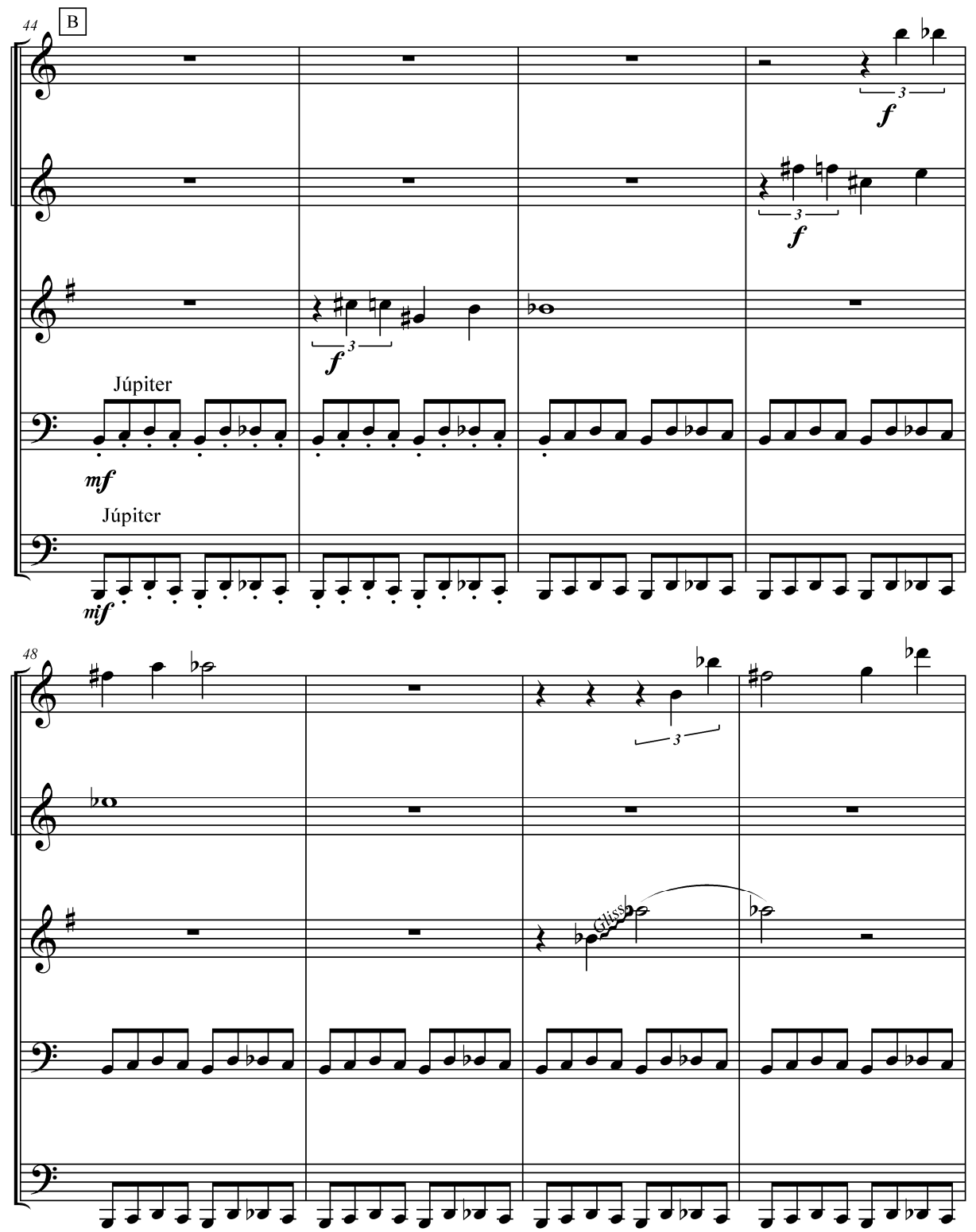

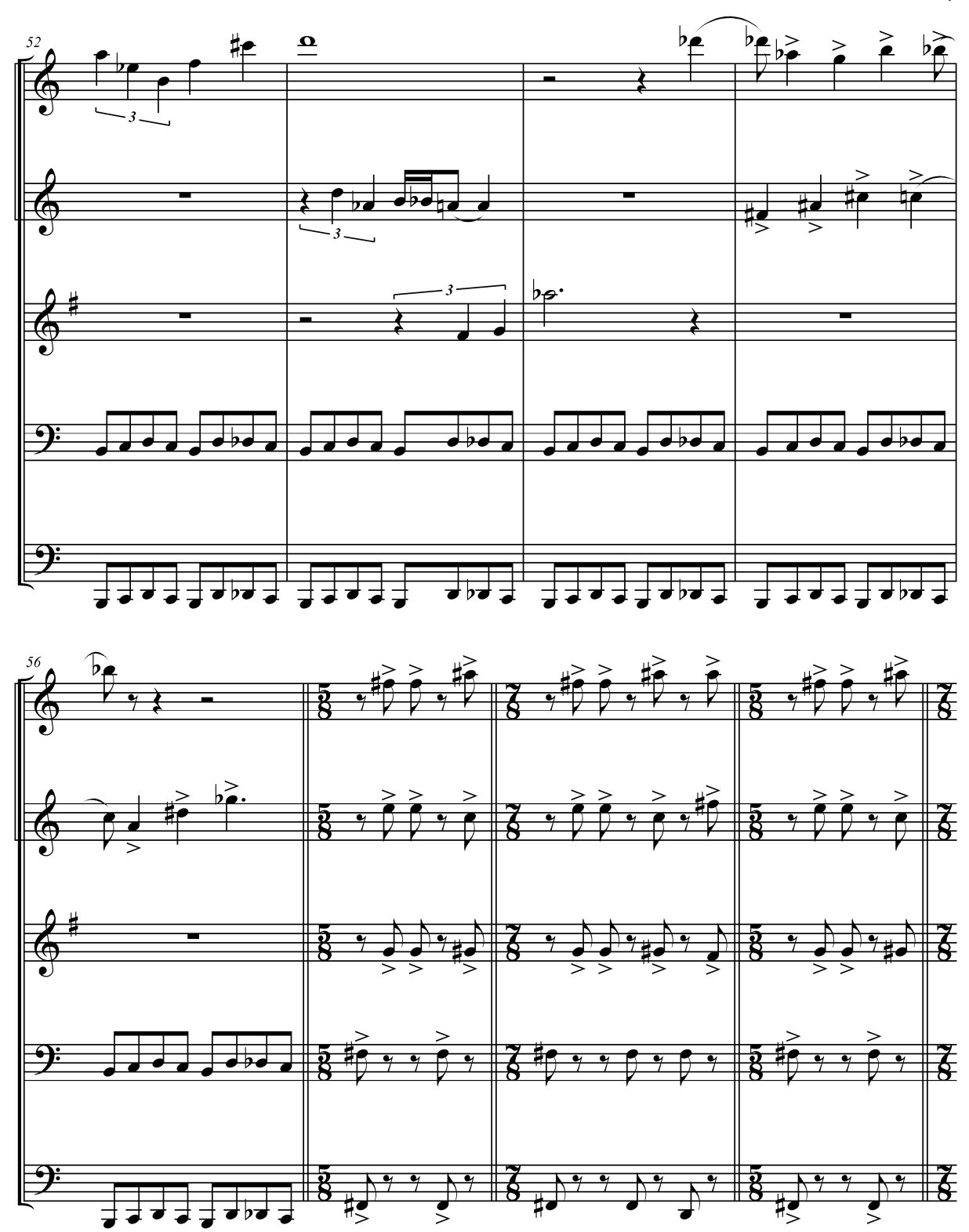
8
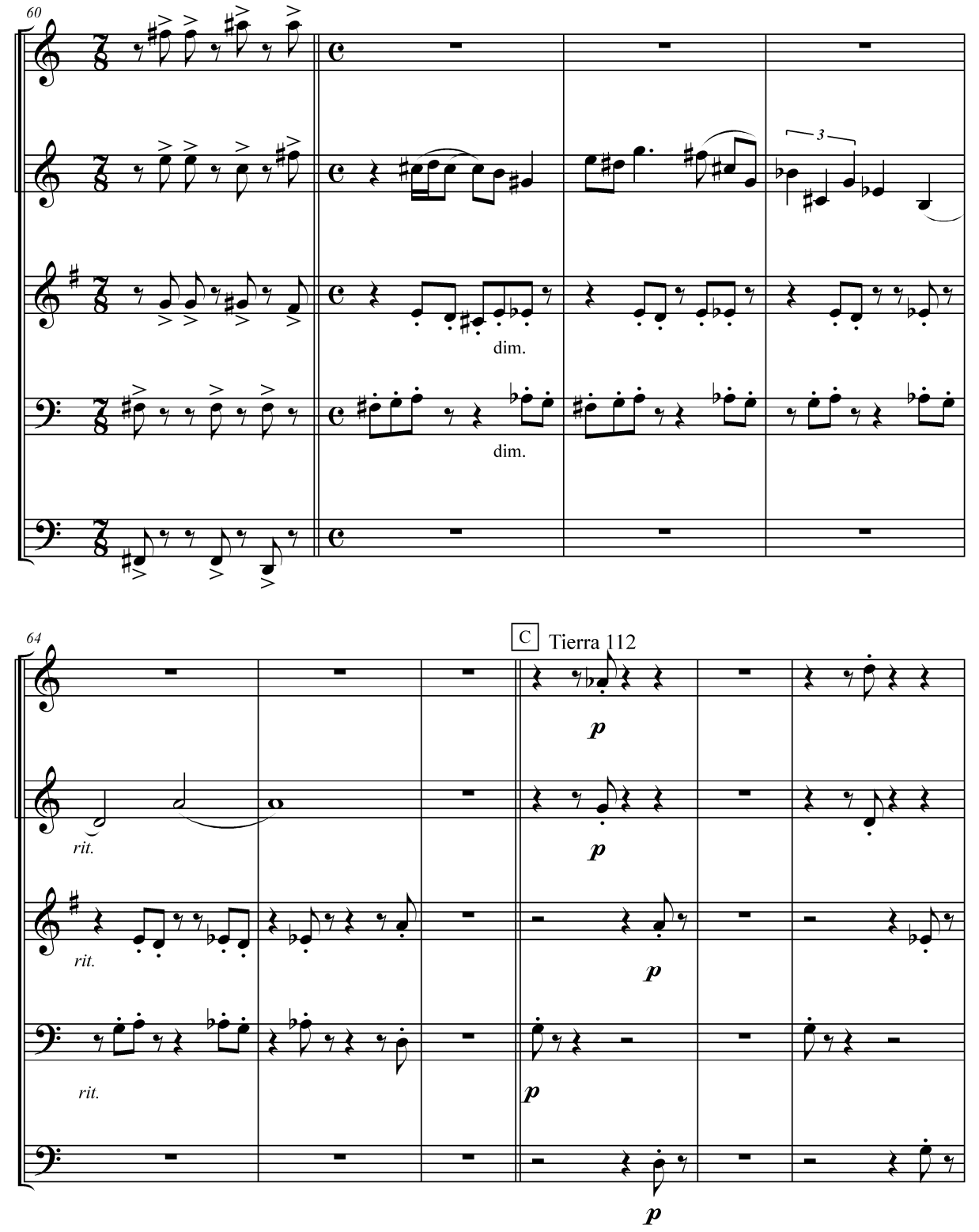

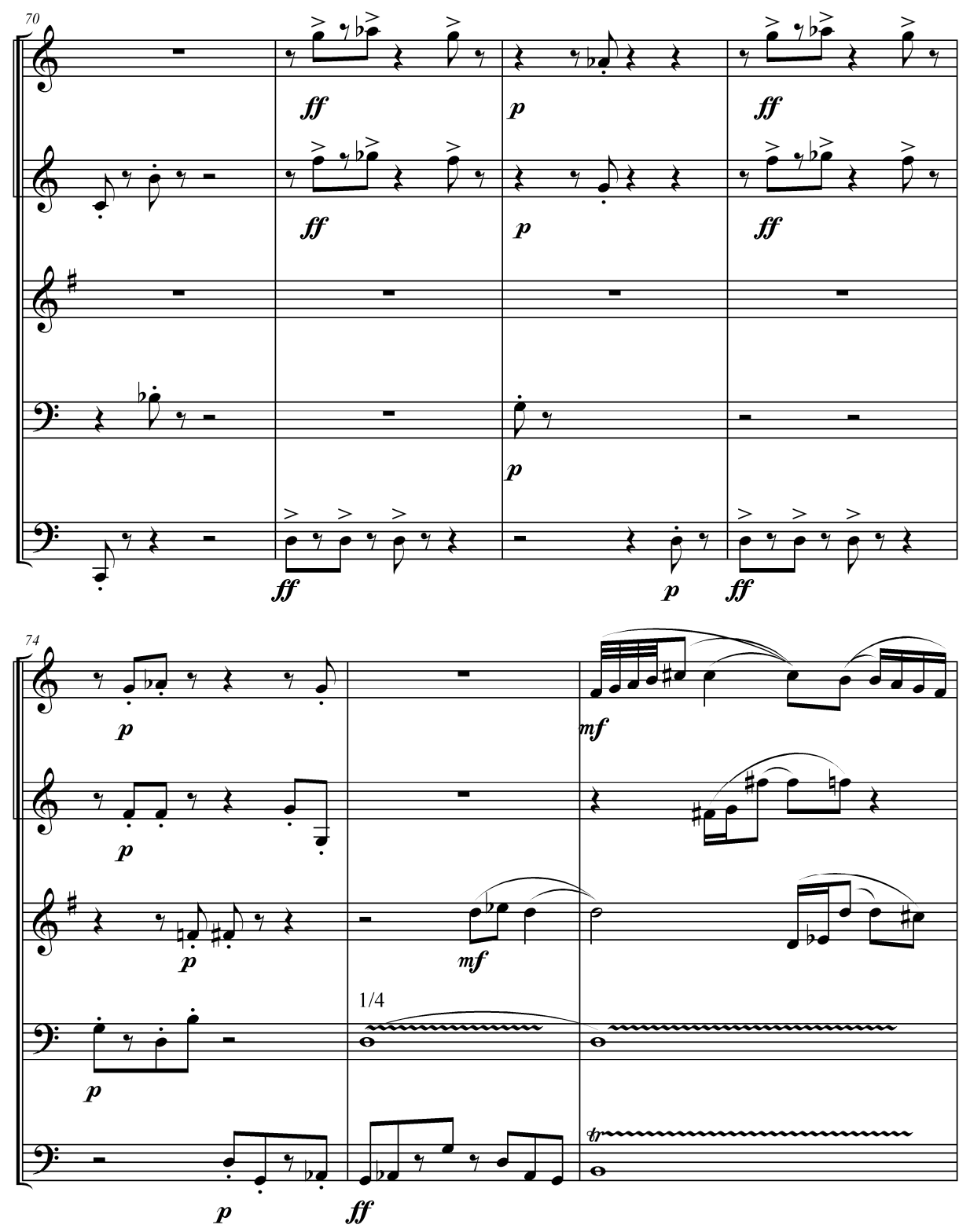
10 Esferas
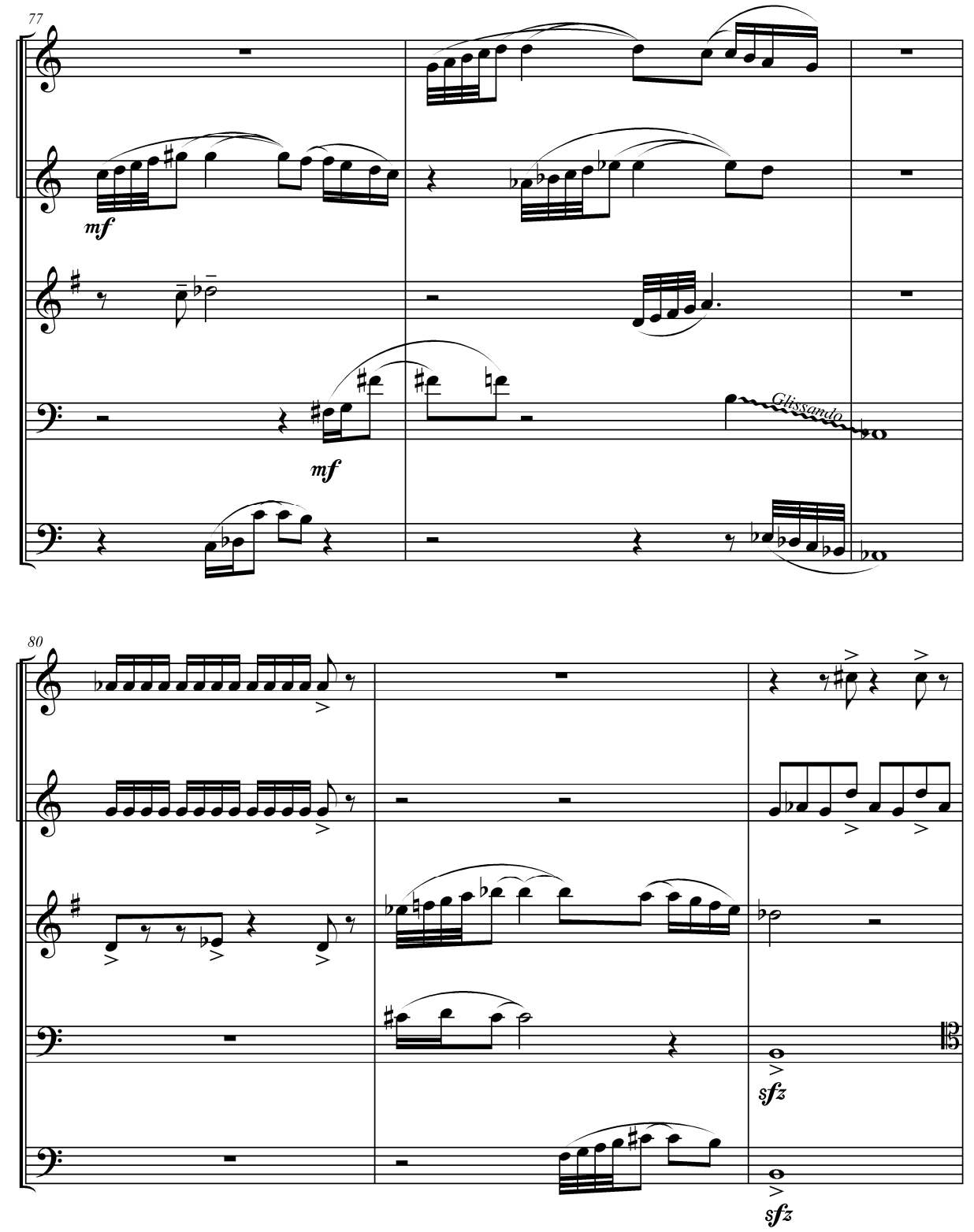

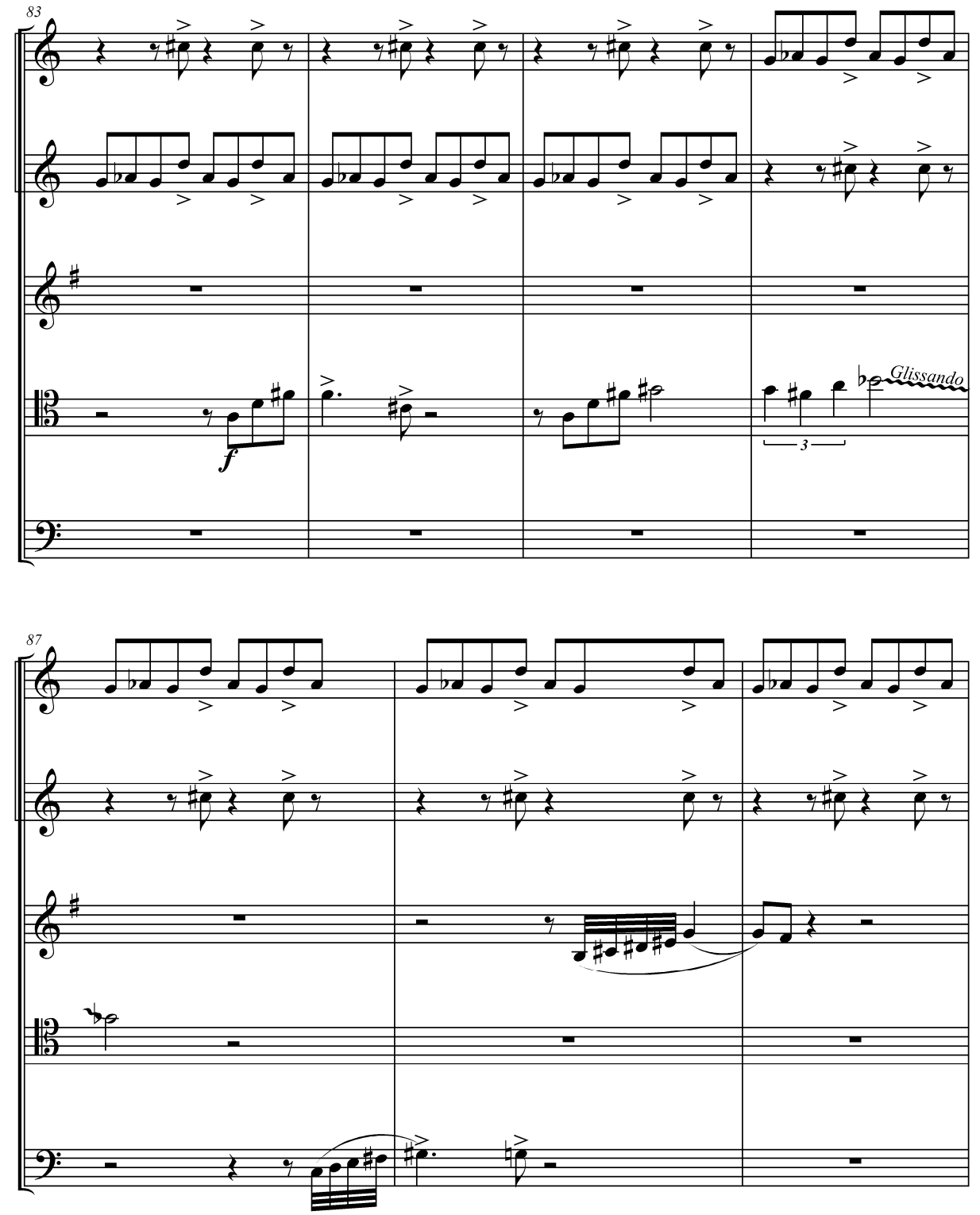
12
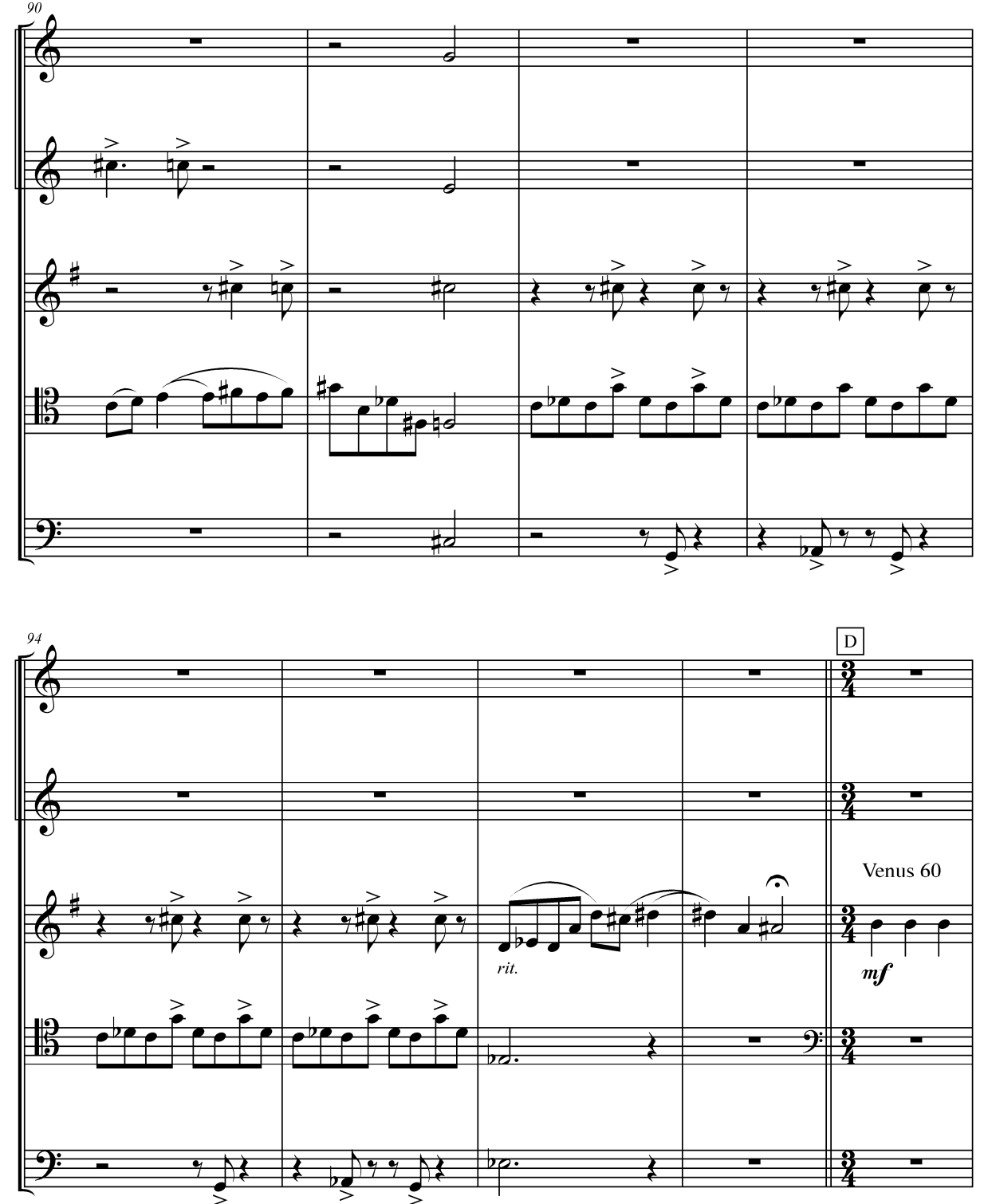

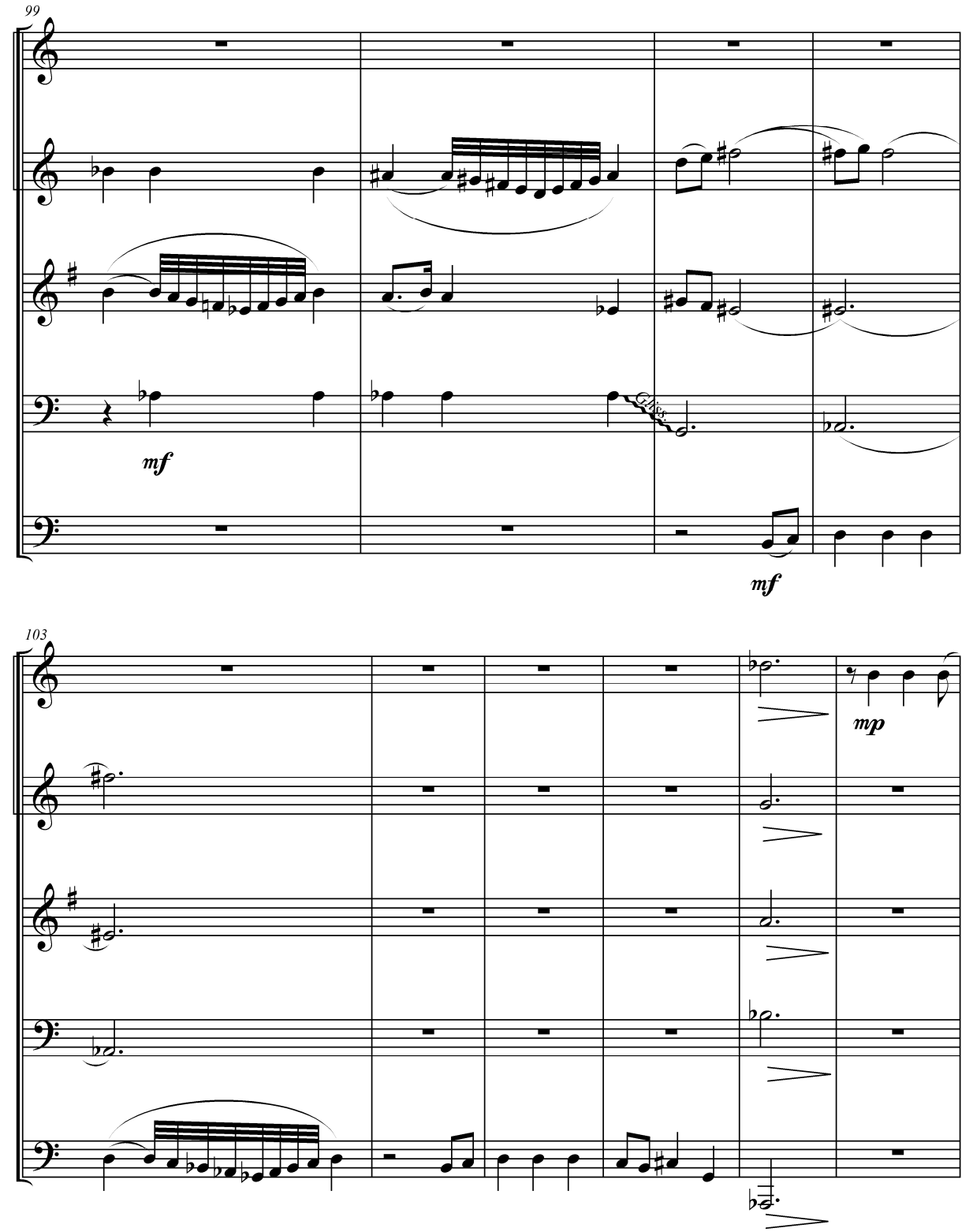

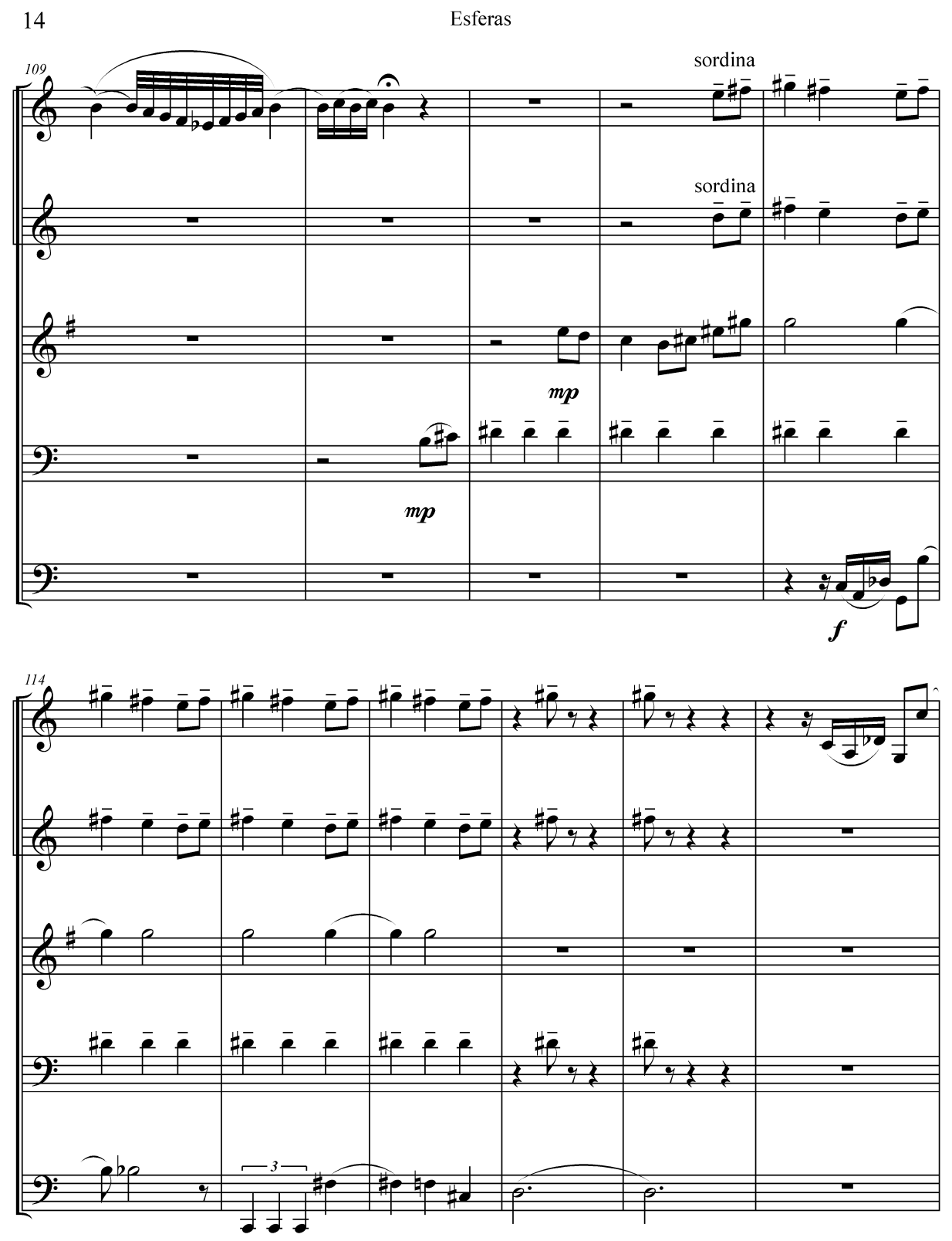

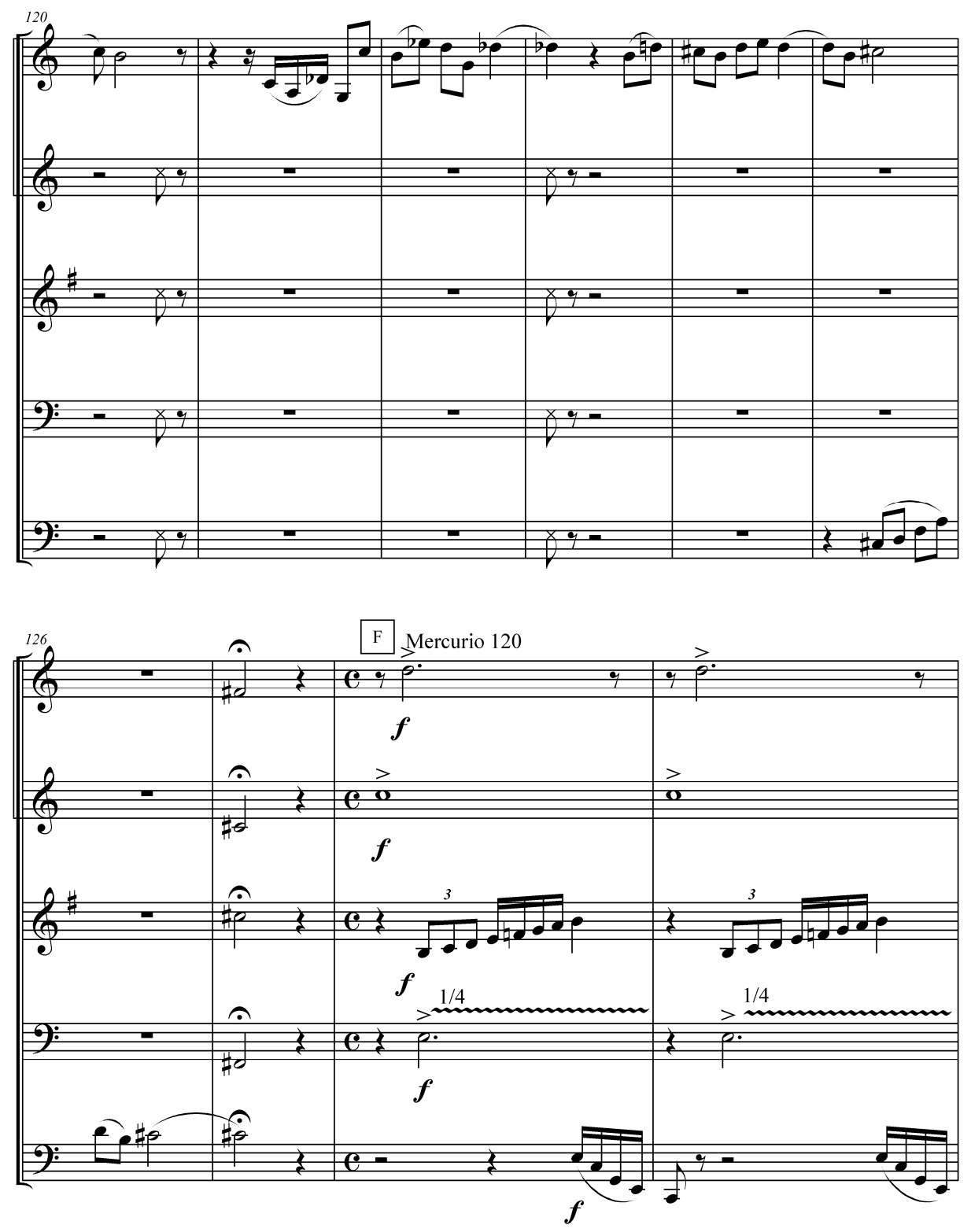

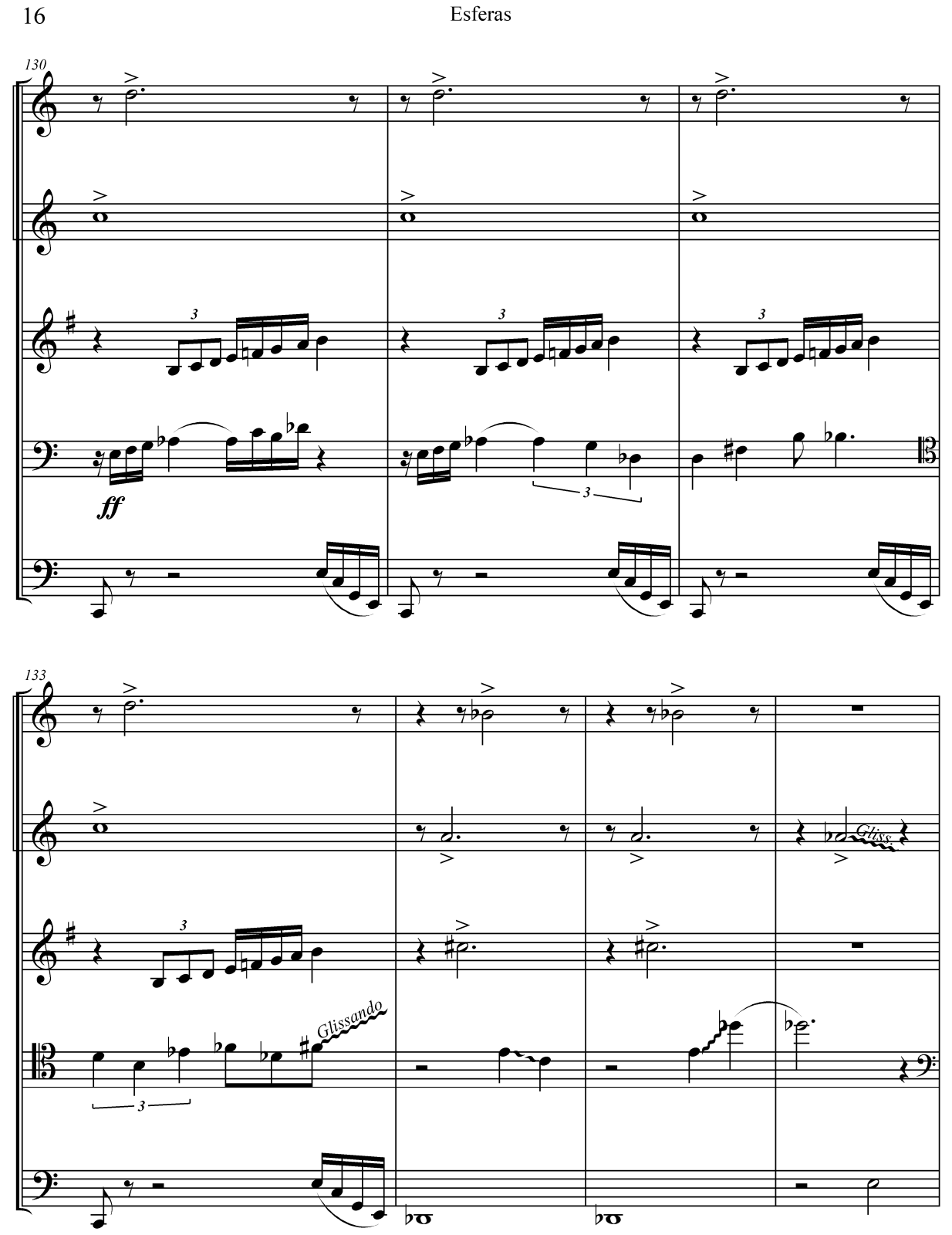

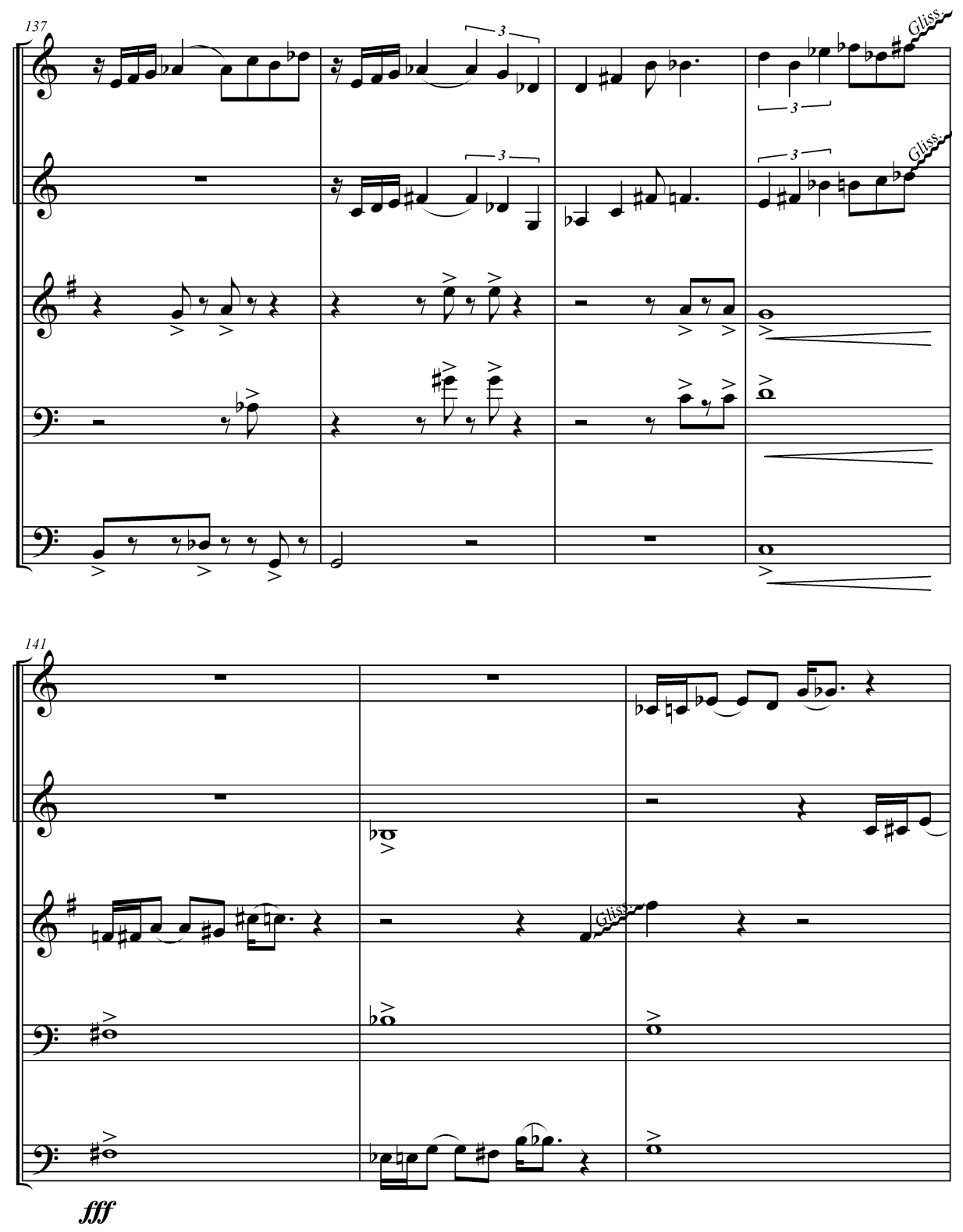
18
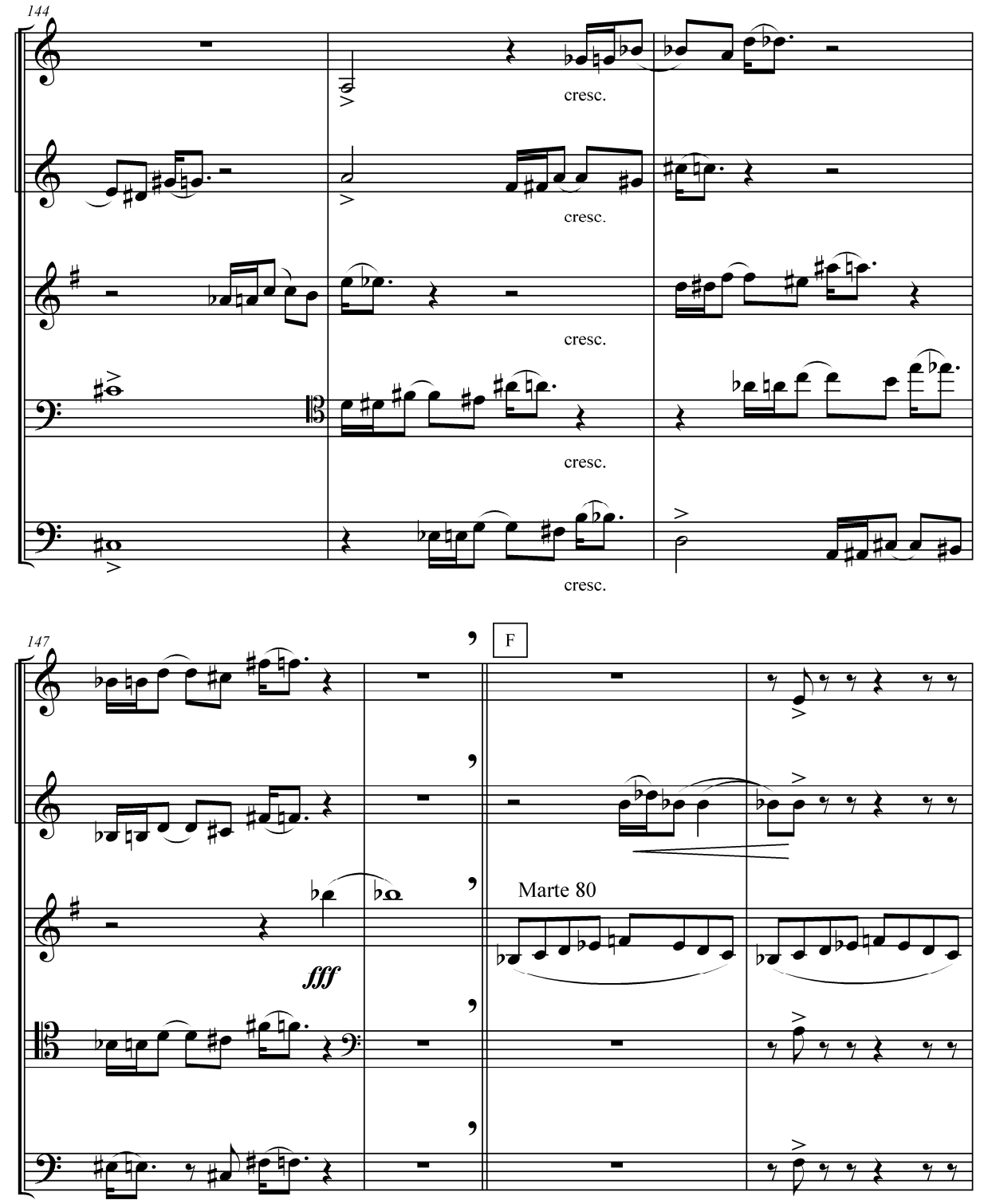

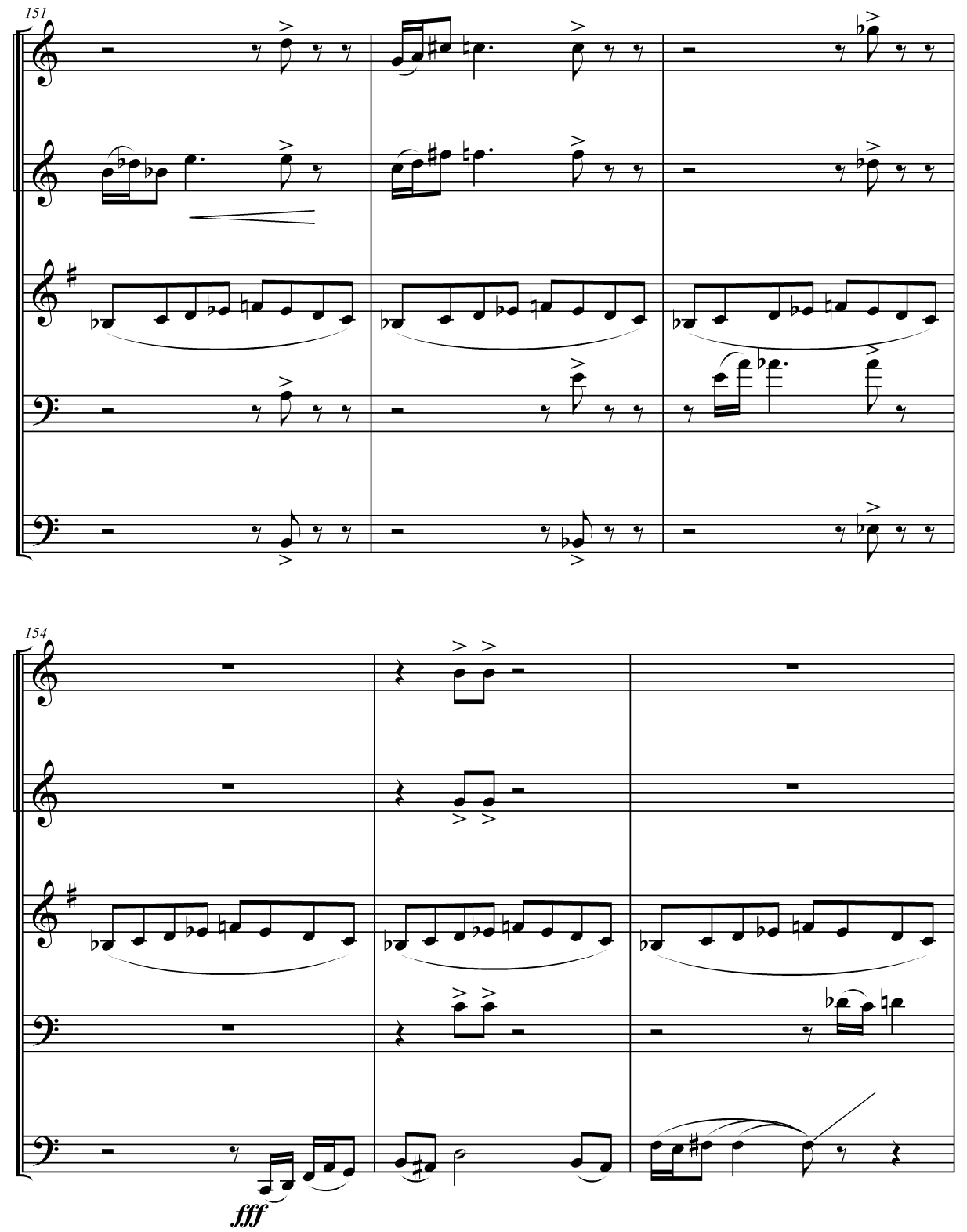
20

Esferas
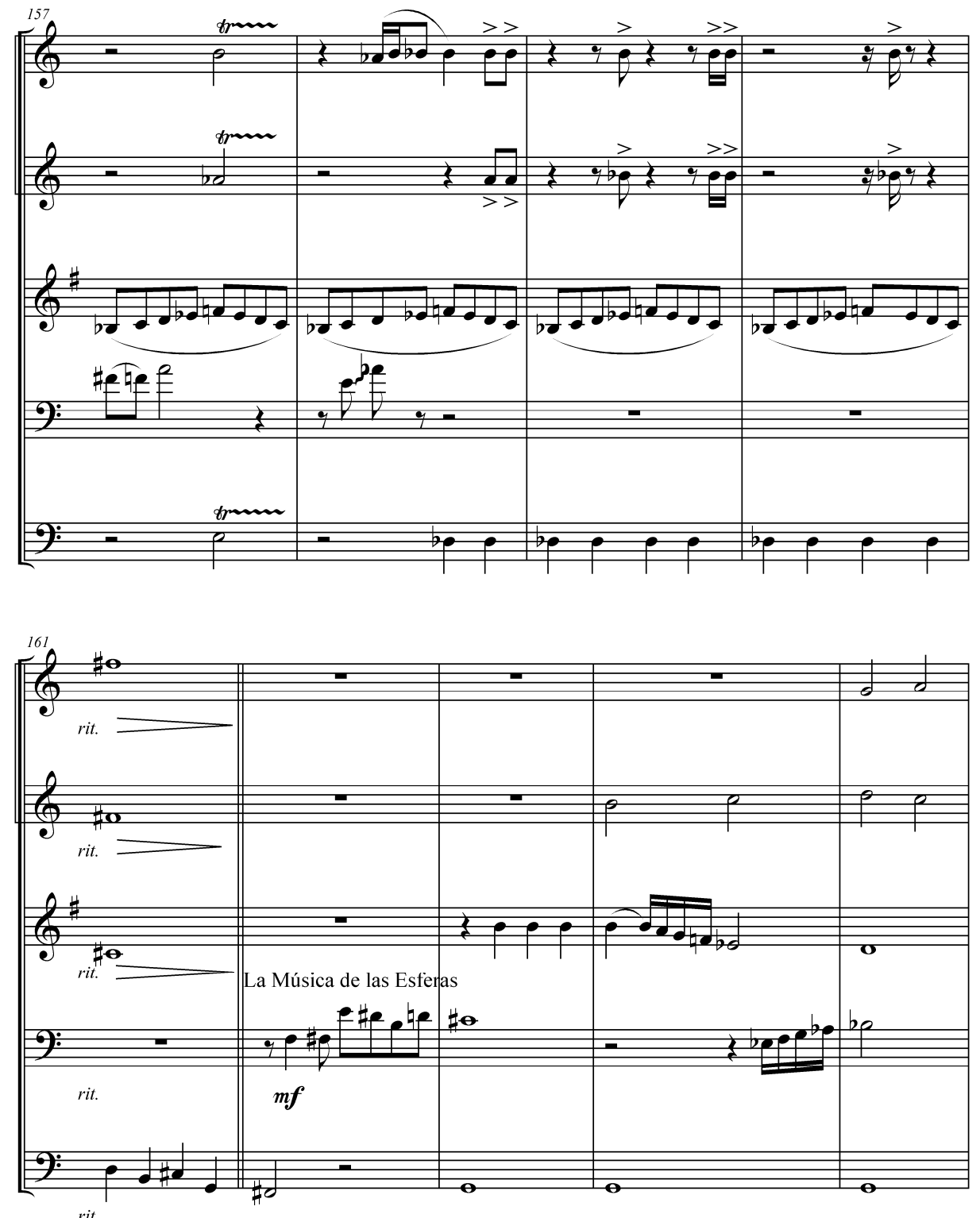

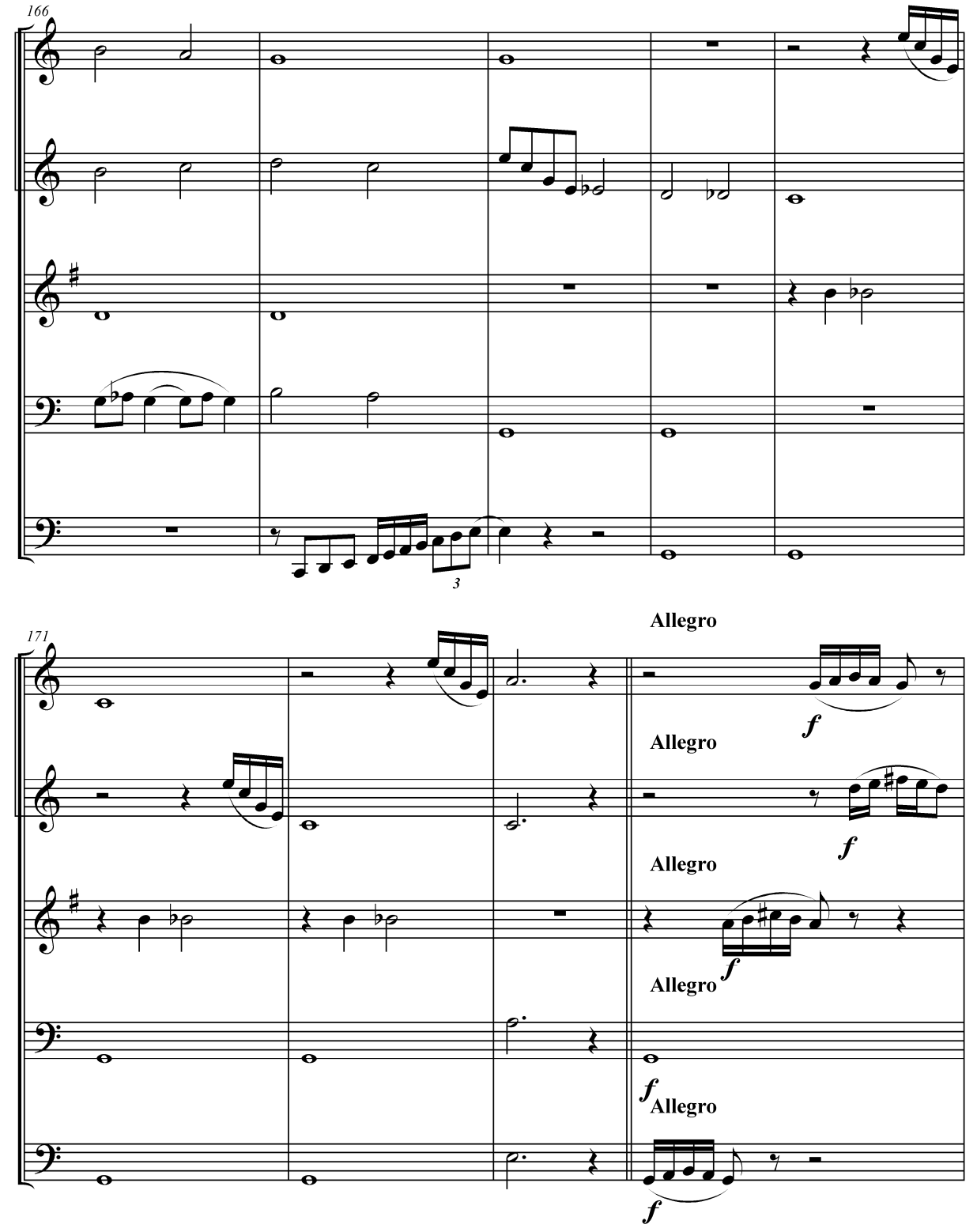

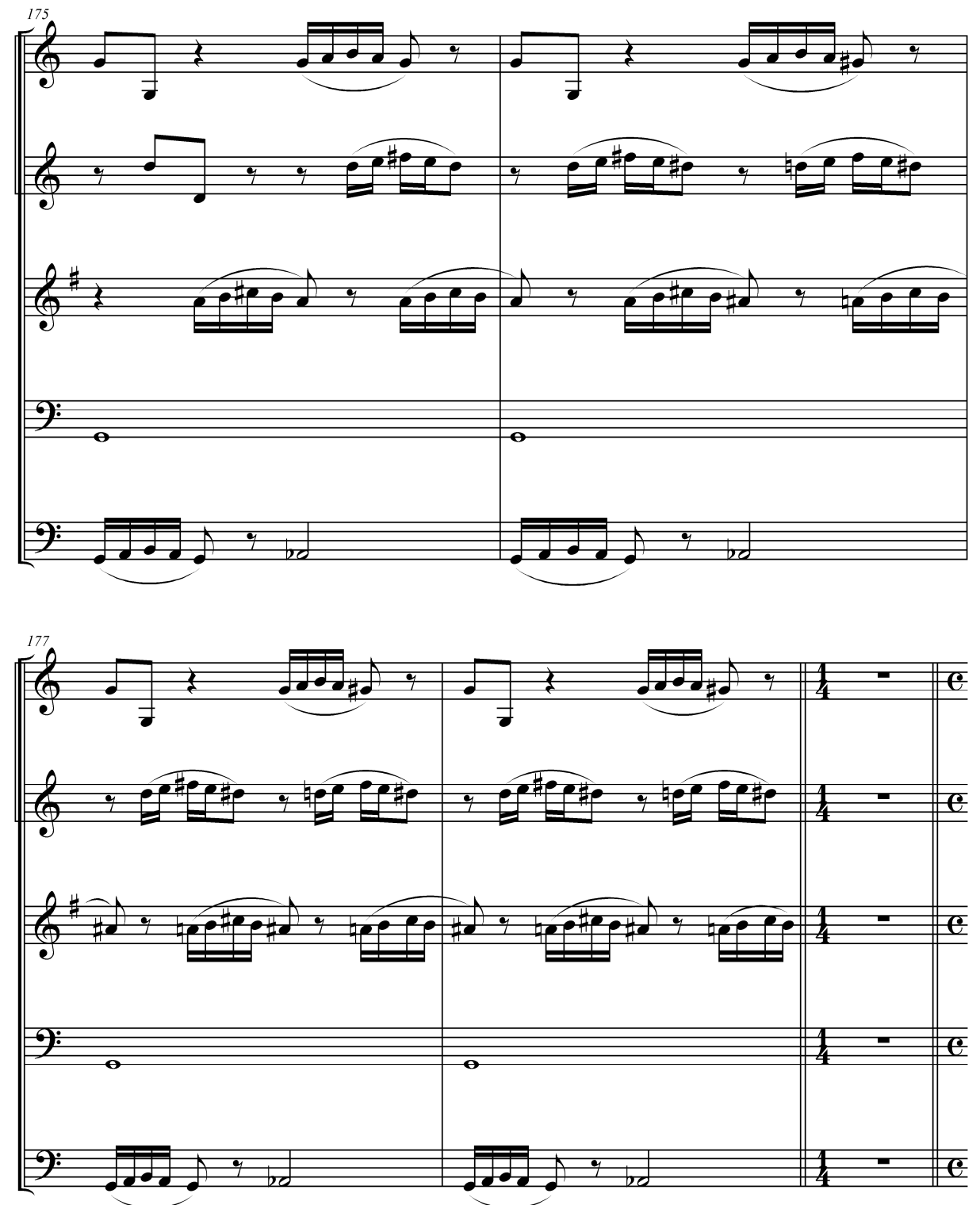


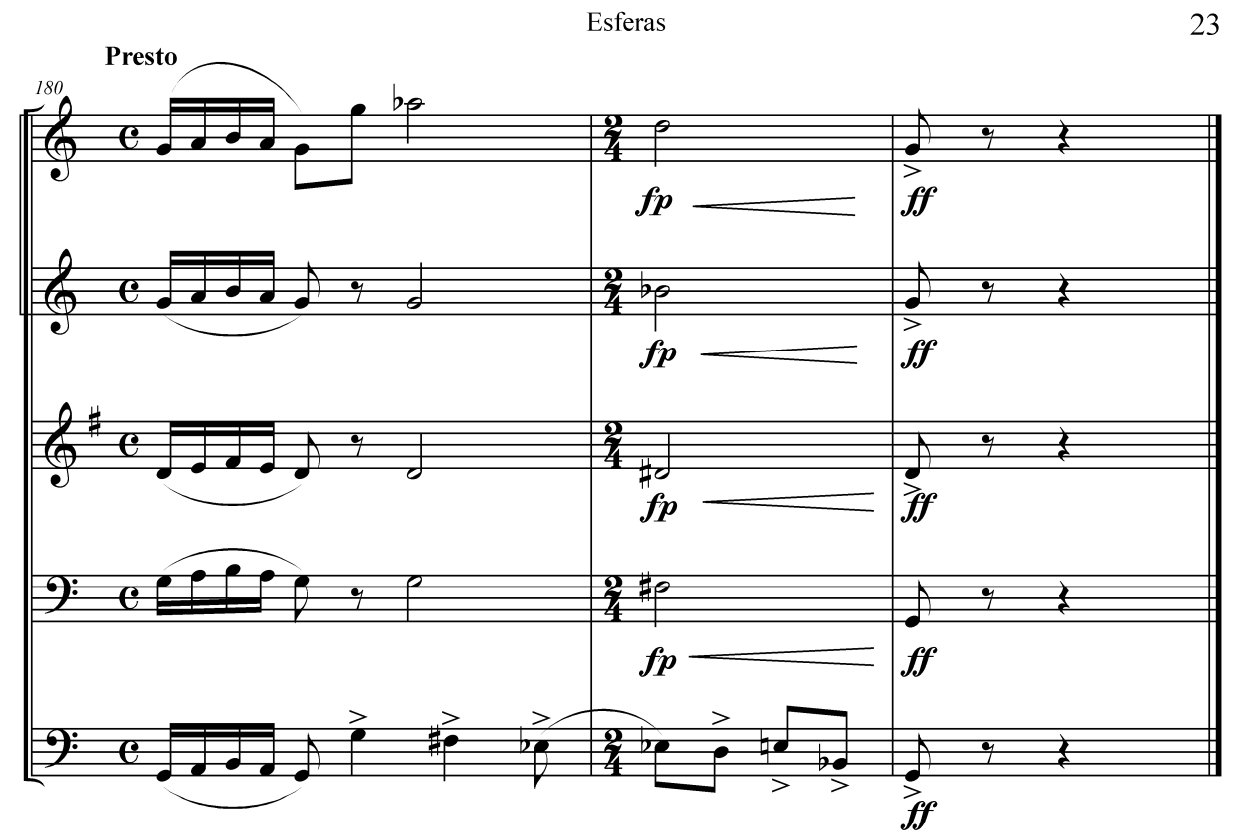


"La música crea orden en el caos; el ritmo impone unanimidad en la divergencia, la melodía impone continuidad en lo discontinuo, y la armonía impone compatibilidad en lo incongruente."

Yehudi Menuhin (Haluska, 2005)

\section{CAPÍTULO 4: Sistemas de afinación borrosos. Compatibilidad}

Azar e incertidumbre son palabras ligadas de forma más o menos directa con la teoría de las probabilidades. Así, cuando se ponen en una urna 7 bolas rojas y 3 blancas, la probabilidad de sacar una bola roja es 7/10 mientras que la de sacar una blanca es de 3/10. La extracción efectuada es aleatoria, se puede medir la suerte de sacar una bola blanca o una roja. Para ello es necesario conocer a priori la proporción de bolas introducidas de cada color.

Supongamos ahora que desconocemos la proporción de bolas de cada color y que sólo podemos realizar una extracción. En estas circunstancias ya no podemos medir la suerte. El fenómeno ya no se debe al azar, sino a la incertidumbre. Si solamente sabemos que pueden existir 10 bolas, pero si conocer la proporción, podemos afirmar que sacaremos una bola roja o una blanca, pero al desconocer la proporción no podemos dar una probabilidad a sacar una bola de un color o del otro.

Así pues, el azar es la incertidumbre medible mediante la probabilidad. A pesar de que en la conversación de cada día (y en los diccionarios) azar e incertidumbre se confunden, en el conocimiento científico no puede permitirse esta ambigüedad.

En este capítulo trataremos la incertidumbre a la que no se le puede aplicar la probabilidad, porque precisamente ésta es la que presenta la Música, y en la

\footnotetext{
${ }^{1}$ La cita se ha extraído de Haluska (2005) y la traducción es del autor de la memoria.
} 
mayoría de manifestaciones de la vida real en las que participan las decisiones de personas.

\title{
4.1 Introducción a la lógica borrosa
}

Cuando se hace un tratamiento matemático de cualquier fenómeno humano, el modelo empleado se ve afectado por los valores numéricos que han sido introducidos. Conviene ser conscientes de que, en muchos casos, la validez de los resultados puede depender de la asignación numérica a variables desconocidas, para las que sólo podemos tener en cuenta estimaciones o conjeturas. En el mejor de los casos es posible asignar cierta probabilidad a estas variables, pero en ocasiones incluso esto resulta artificial, pues no hay realmente ninguna base fundada para suponer que el parámetro en cuestión va a seguir una distribución de probabilidad concreta. Esto hace que se pueda distinguir entre una incertidumbre estocástica, donde es posible un tratamiento probabilístico, y una incertidumbre borrosa, donde este tratamiento no está justificado (Zimmermann, 1996; Kaufmann y Gil Aluja, 1987). En esta memoria sólo se contempla esta última.

Para establecer a qué nos referimos cuando hablamos de lógica borrosa, analicemos el siguiente ejemplo de B. Kosko²:

\begin{abstract}
"Sostened una manzana en la mano. ¿Es una manzana? Sí. El objeto que tenéis en la mano es uno de esos bultos del espacio-tiempo que pertenecen al que llamamos conjunto de manzanas [...] Dadle un mordisco; masticad este trozo y tragáoslo.[...] El objeto que tenéis en la mano ¿es todavía la manzana? ¿Sí o no? Pegadle otro mordisco. El nuevo objeto ¿es todavía una manzana? [...] La manzana pasa de serlo a no serlo, y a ser nada. Pero ¿cuándo ha pasado la línea que separa el ser manzana de no serlo? Cuando tenéis media manzana en la mano, tenéis tanto una manzana como no la tenéis. La media manzana es una manzana borrosa, gris entre el blanco y el negro. La borrosidad es grisura."
\end{abstract}

La cuestión que se plantea en el ejemplo es que disponer de mayor información no quiere decir contar con más hechos. Con más información se describen mejor los hechos, pero no se tienen imágenes más claras sobre ellos. La incertidumbre, la borrosidad, se mantiene en los propios hechos.

\footnotetext{
${ }^{2}$ B. Kosko (1993) Página 18
} 
La información sirve para obtener una información más clara, o más fiel de lo que estamos analizando, pero ¿se erradica con esto la borrosidad? Pensemos en una persona que tiene treinta y tres años. ¿Es viejo o joven?. Si añadimos información precisa, por ejemplo que nació el día ocho de junio de mil novecientos setenta y cuatro a las diez de la mañana, ¿esto aporta información? Realmente no es así. Sólo sabemos que dentro de un año será más viejo, pero nada más. Es decir, ser viejo o joven es un concepto borroso.

Cuesta todavía más distinguir una cosa de otra cuando aquélla es relativa. Por ejemplo, pensemos en la frontera entre arte y no arte. ¿Tiene sentido fijar una frontera nítida y claramente definida entre lo que es arte y lo que no lo es?

La Música cuenta de forma inherente con los dos tipos de incertidumbre que hemos introducido: por un lado la borrosidad de los propios conceptos y por otro, la borrosidad que surge al manejar conceptos que son más importantes por su relación con otros que en si mismos de forma aislada.

Pensemos en una partitura, por ejemplo, en el siguiente fragmento de Solus de Stan Friedman,

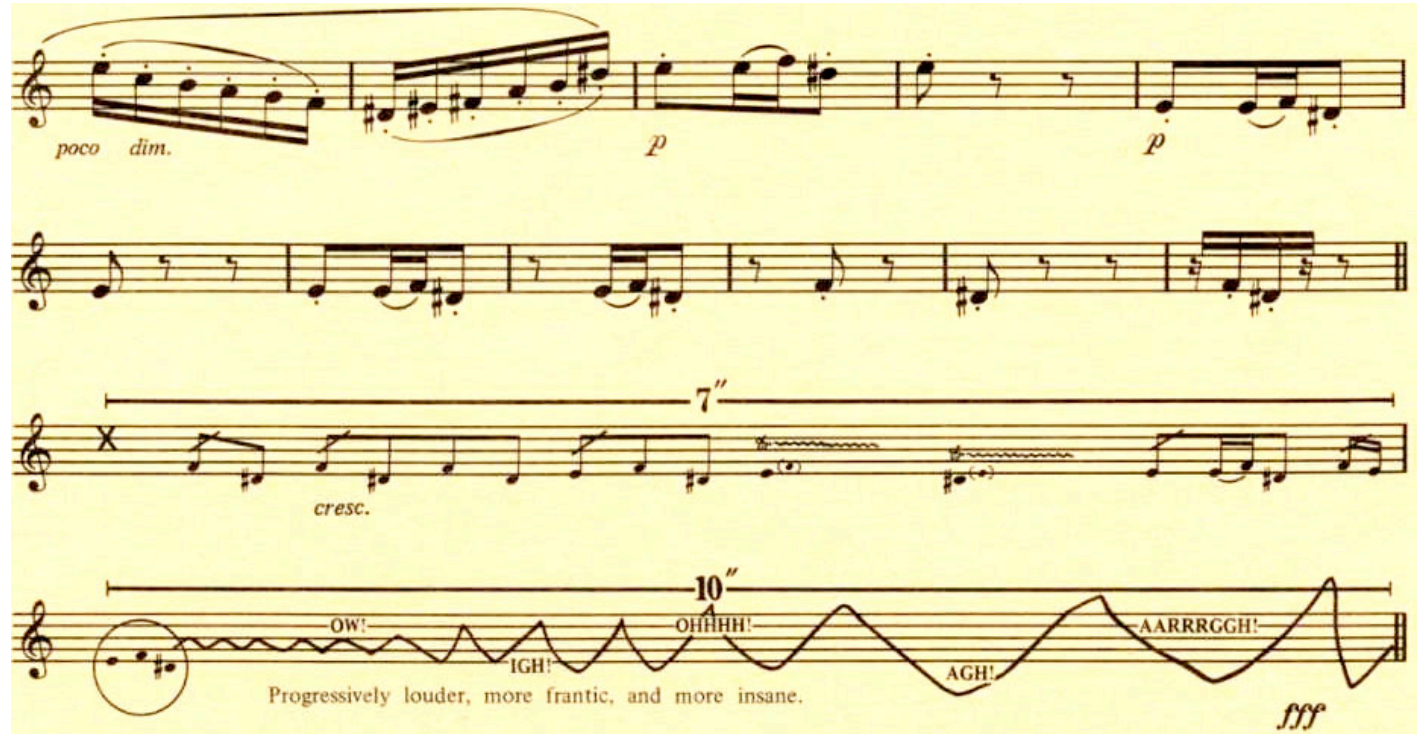

Fig. 4.1 Fragmento de Stan Friedman, 1975

Sin entrar en cuestiones psicológicas (como estado emocional de cada uno de los intérpretes) ni en las características arquitectónicas o ambientales de las salas de audición, la propia partitura contiene diversas fuentes de incertidumbre que conviene tener en cuenta:

a) Respecto de la altura de las notas. Cada familia de instrumentos afina, de forma natural, en sistemas de afinación distintos. Con ello, como se 
ha visto en el capítulo 2, un Lab no designa una única realidad físicoacústica (Haluska, 2005).

b) Respecto a la grafía del pentagrama. En la música contemporánea el compositor tiende a expresar, mediante gráficos o notación no estándar, algunos efectos que no tenían cabida en la música clásica (véase Fig. 4.1).

c) Respecto al tempo. A pesar de que en la actualidad hay una tendencia a sustituir las designaciones tradicionales de tempos ${ }^{3}$ por indicaciones más precisas de pulsaciones por minuto ${ }^{4}$, la imprecisión es inevitable, máxime cuando a estos se añaden términos que modifican la velocidad del movimiento de forma gradual ${ }^{5}$.

d) Respecto a los matices. Los términos que indican la intensidad del sonido (de menor a mayor, pianissimo, piano, mezzopiano, mezzoforte, forte, fortissimo) son imprecisos, sobre todo si se tiene en cuenta que a éstos se añaden términos que aumentan o disminuyen gradualmente la intensidad del sonido (crescendo, decrescendo, diminuendo) ${ }^{6}$.

A esta lista de fuentes de incertidumbre, podrían añadirse otras muchas que provienen de la propia naturaleza de la música interpretada. Piénsese, por ejemplo, en las variantes del Jazz en las que en mayor o menor medida la improvisación del intérprete juegan un papel esencial. No obstante, nuestro objetivo no es presentar un análisis exhaustivo de este fenómeno, sino remarcar que ante esta perspectiva, hacer un estudio de cualquier aspecto de la música que no tenga en cuenta la imprecisión, resultaría insuficiente o, en el mejor de los casos con escasa aplicabilidad a la práctica cotidiana de los músicos.

3

\begin{tabular}{|c|c|c|c|c|c|}
\hline Nombre & Pulsaciones/ minuto & Nombre & Pulsaciones/ minuto & Nombre & Pulsaciones/ minuto \\
\hline Largo & $0-50$ & Andante & $76-108$ & Presto & $168-200$ \\
\hline Larghetto & $50-66$ & Moderato & $108-120$ & Prestissimo & $200-207$ \\
\hline Adagio & $66-76$ & Allegro & $120-168$ & & \\
\hline
\end{tabular}

${ }^{4}$ Por ejemplo, negra $=120$ indica que en un minuto deben ejecutarse 120 negras.

5 Existen términos para acelerar el movimiento de forma gradual (accelerando, affrettando, animando, incalzando, stringendo, stretto), para decelerarlo (allargando, rallentando, ritardando, ritenendo, ritenuto, slargando). Además, hay términos que suspenden la regularidad del movimiento (ad libitum, a piacere, rubato, senza rigore, senza tempo) o que fuerzan a volver a ella (a tempo, in tempo, stesso tempo, primo tempo).

6 Además, existen términos que indican a la vez una disminución gradual de la intensidad y del tiempo: calando, perdendosi, smorzando, stringuendo. 
En esta memoria, como nuestro interés es el estudio de la afinación, nos dedicaremos sólo a la incertidumbre de la que ésta se ve afectada. Queda para trabajos futuros analizar otros aspectos de la incertidumbre en la música porque, conscientes de la imposibilidad de separar las manifestaciones artísticas de los avances tecnológicos, creemos que el interés tanto para músicos como para los que investigan en otras disciplinas científicas, está en que los modelos que se desarrollan sean capaces de explicar de la forma más fiel posible el fenómeno real que se está analizando.

\subsection{Los conjuntos borrosos}

A mediados de los años 60 Lotfi A. Zadeh (Azerbaiyán, 1921, actualmente profesor emérito de la Universidad de California en Berkeley) introduce ${ }^{7}$ la Teoría de Conjuntos Borrosos, cuyo objetivo era proporcionar las bases del razonamiento aproximado utilizando premisas imprecisas como instrumento para formular el conocimiento.

La idea principal contenida en un Conjunto Borroso (Fuzzy Set), que se encuadra dentro de la Lógica Multivaluada, es que el pensamiento humano no se basa en números, sino en 'etiquetas lingüísticas' que permiten que los objetos puedan pertenecer a una clase y a otra de forma suave y flexible. En la práctica, se habla de que alguien es "alto" o "bajo" (etiquetas lingüísticas) sin que por ello el interlocutor deje de tener la información necesaria.

En un conjunto clásico (crisp) se asigna el valor 0 ó 1 a cada elemento para indicar la pertenencia o no a dicho conjunto. Esta función, denominada función característica del conjunto, puede generalizarse de forma que los valores asignados a los elementos del conjunto caigan en un rango particular, y con ello indiquen el grado de pertenencia de los elementos al conjunto en cuestión. Esta función se llama función de pertenencia y el conjunto definido por ella se llama conjunto borroso.

La función de pertenencia $\mu_{\mathrm{A}}$ por la que un conjunto $\mathrm{A}$ se define, se expresa formalmente como

\footnotetext{
${ }^{7}$ En realidad, el origen podría fijarse en 1922 cuando Lukasiewicz cuestionaba la Lógica Clásica booleana (valores cierto y falso) y proponía una lógica de valores ciertos en el intervalo unidad como generalización de su lógica trivaluada. En los años 30 fueron propuestas lógicas multivaluadas para un número cualquiera de valores ciertos (igual o mayor que 2), identificados mediante números racionales en el intervalo [0, 1]. Posteriormente, en 1937, Max Black (1909 1989), publicó el artículo "Vagueness: An exercise in Logical Analysis" y en los años 1942 y 1950, Karl Menger (1902 - 1985), publicó en "Statistical Metrics" publicó dos artículos sobre relaciones borrosas de indistinguibilidad.
} 


$$
\mu_{\mathrm{A}}(\mathrm{x}) \in[0,1]
$$

Es decir, mientras que en un conjunto clásico los elementos pertenecen o no pertenecen a él totalmente (por ejemplo un número puede pertenecer o no al conjunto de los pares, pero no pertenecerá con un determinado grado), en los conjuntos borrosos hay grados de pertenencia. Para distinguirlos de los conjuntos clásicos, los conjuntos borrosos suelen expresarse mediante un tilde, es decir

$$
\tilde{A} \text { (conjunto borroso), } A \text { (conjunto clásico). }
$$

Un grado de pertenencia nulo se interpreta como no pertenencia, el 1 como pertenencia en el sentido booleano y los números intermedios reflejan una pertenencia incierta, que será interpretada de diversos modos según cada aplicación. La potencia de esta teoría se debe a que a través de la pertenencia a un conjunto se puede modelizar cualquier situación.

En el contexto que nos preocupa, si fijamos como nota patrón el La de 440 Hz., una nota de $442 \mathrm{~Hz}$., desde el punto de vista de la lógica booleana estaría desafinada. Sin embargo, para cualquier músico (o cualquier persona que la escuche) está nota no tiene el mismo "grado de desafinación" que otra de $450 \mathrm{~Hz}$. Es decir, cuando hablamos de desafinación en el sentido clásico (crisp), se pasa de afinado a desafinado con salto (figura 4.2), mientras que para la práctica musical este paso es gradual (figura 4.3).

Gráficamente, la situación que estamos planteando es la siguiente:

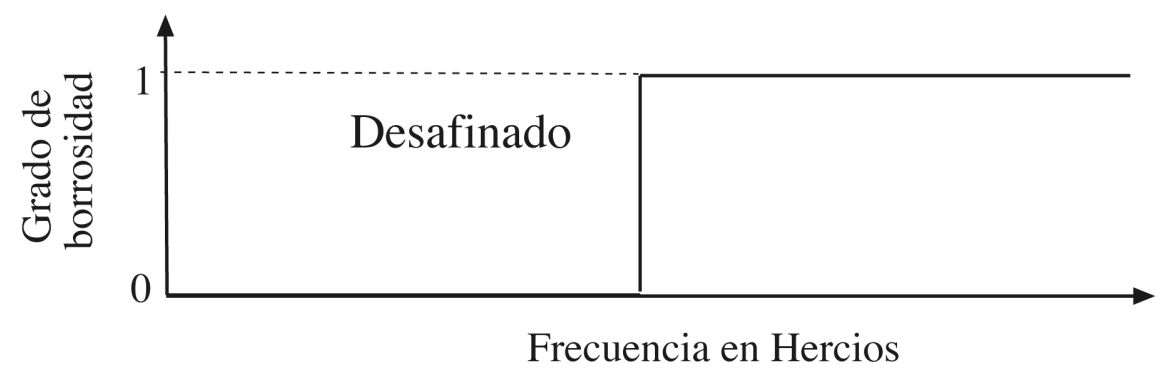

Fig. 4.2. Función de pertenencia clásica (crisp) para la afirmación "la nota está desafinada"

Fuente: Elaboración propia 
Sin embargo, resulta mucho más parecida a la percepción de la desafinación la función de pertenencia siguiente:

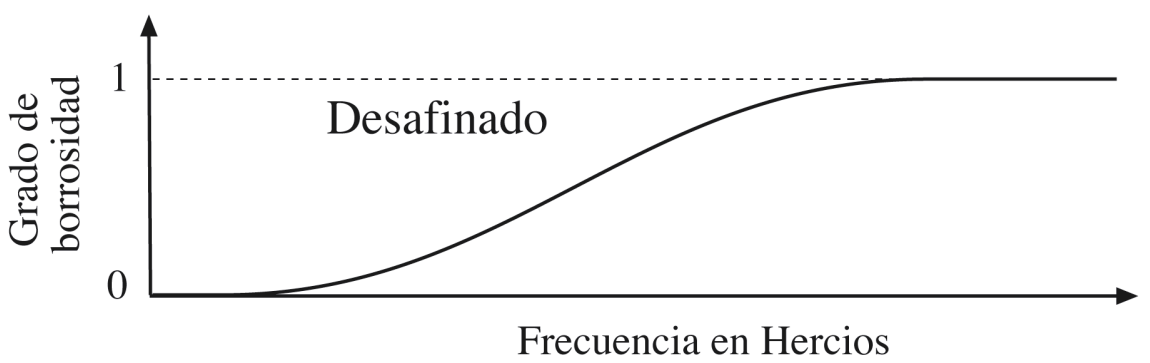

Fig. 4.3.Función de pertenencia borrosa para la afirmación "la nota está desafinada"

Fuente: Elaboración propia

En el seno de la teoría de subconjuntos borrosos una opción es más satisfactoria cuanto mayor sea su grado de pertenencia. Así, en general suele usarse el operador max-min que consiste en definir el grado de pertenencia de una solución a la decisión que se va a tomar como el mínimo de sus grados de pertenencia a los objetivos perseguidos y las condiciones con las que contamos:

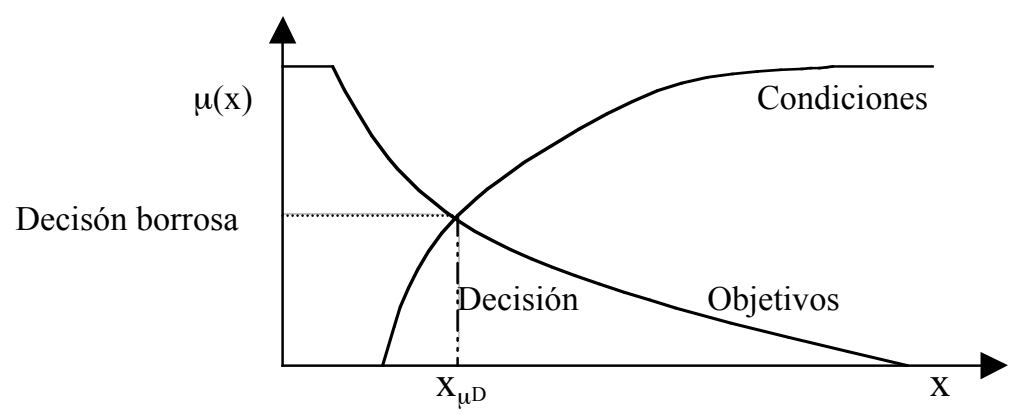

Fig. 4.4. Decisiones con lógica borrosa Fuente: Elaboración propia

Esto significa que buscamos las soluciones que combinan la mayor satisfacción posible tanto de nuestros objetivos como de las condiciones impuestas al problema tratado.

En el caso concreto de la afinación que estamos tratando, tanto la condición de afinado o desafinado se va perdiendo de forma gradual. Lo importante es fijar cuán flexibles somos con ambos conceptos. Esta idea puede expresarse mediante el gráfico siguiente: 


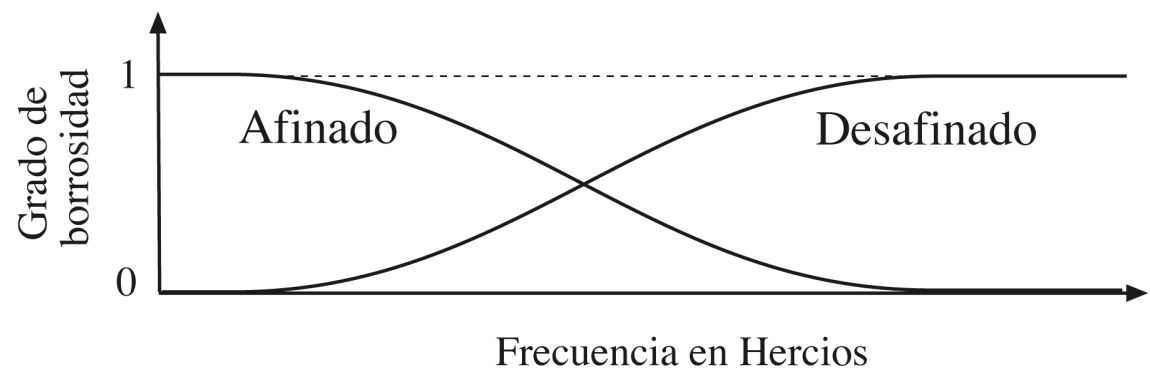

Fig. 4. 5. Función de pertenencia borrosa para "estar desafinada" y "estar desafinada"

Fuente: Elaboración propia

Por último, para acabar esta introducción vamos a dar algunas definiciones que resultarán útiles en el resto de la memoria:

- Llamaremos variable lingüistica a aquella noción o concepto que vamos a calificar de forma borrosa. Por ejemplo: la altura, la edad, el error, la variación del error... Le aplicamos el adjetivo "lingüística" porque definiremos sus características mediante el lenguaje hablado.

- Llamaremos universo de discurso al rango de valores que pueden tomar los elementos que poseen la propiedad expresada por la variable lingüística. En el caso de la variable lingüística 'altura de una persona normal', podría ser el conjunto de valores comprendido entre 1.4 y $2.3 \mathrm{~m}$.

- Llamamos valor lingüístico a las diferentes clasificaciones que efectuamos sobre la variable lingüística: en el caso de la altura, podríamos dividir el universo de discurso en los diferentes valores lingüísticos: por ejemplo bajo, mediano y alto.

Usando estos términos, también podría decirse que un conjunto borroso ${ }^{8}$ es un valor lingüístico junto a una función de pertenencia. El valor lingüístico es el "nombre" del conjunto, y la función de pertenencia se define como aquella aplicación que asocia a cada elemento del universo de discurso el grado con que pertenece al conjunto borroso.

\footnotetext{
${ }^{8}$ Por supuesto, esta forma de definir los conjuntos borrosos es equivalente a la que hemos expuesto en este apartado.
} 


\subsubsection{Niveles de satisfacción o de tolerancia}

La gran utilidad de la lógica borrosa para tratar con problemas de la vida real deriva de su capacidad para cuantificar la incertidumbre, normalmente a partir de la tolerancia que estamos dispuestos a admitir en nuestro grado de certeza.

Por ejemplo, supongamos que al ejecutar una nota no estamos dispuestos a admitir como afinadas a aquellas notas cuya frecuencia disten de una nota prefijada más del $65 \%$ de un cuarto de tono temperado. Esto significa que rechazaremos las notas que estén más allá de ese valor. Gráficamente, la situación es la siguiente:

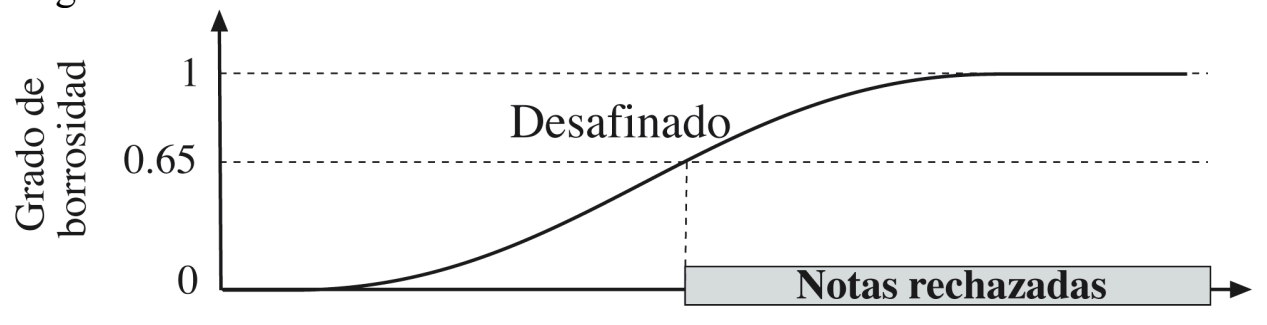

Frecuencia en Hercios

Fig. 4. 6. Niveles de tolerancia

Fuente: Elaboración propia

Básicamente, la idea es poder manejar situaciones afectadas de incertidumbre pero en las que podemos fijar topes ${ }^{9}$ para la incertidumbre o imprecisión con la que estamos trabajando.

Estas ideas se pueden expresar de forma rigurosa mediante el concepto de $\alpha$-corte (o nivel de pertenencia $\alpha$ ):

Definición 4.1. Dado un conjunto borroso $\tilde{A}$, con función de pertenencia $\mu_{\mathrm{A}}(\mathrm{x})$, se define como $\alpha$-corte de $\tilde{A}$, al conjunto de elementos que pertenecen al conjunto borroso $\tilde{A}$ con grado mayor o igual que $\alpha$, es decir:

$$
\mathrm{A}_{\alpha}=\left\{\mathrm{x} \in \mathrm{X} \text { de manera que } \mu_{\mathrm{A}}(\mathrm{x}) \geq \alpha\right\}
$$

En la Figura 4.6, el $\alpha$-corte para $\alpha=0.65$ es el conjunto de las notas que no son rechazadas.

Para nuestro objetivo, el concepto de $\alpha$-corte resulta muy útil, porque el valor del parámetro $\alpha$ servirá para expresar cuál es el límite de tolerancia que

\footnotetext{
${ }^{9}$ En el contexto de la lógica borrosa se les conoce como niveles de tolerancia.
} 
estamos dispuestos a admitir en las notas afinadas y a partir de él podremos establecer niveles de exigencia para que dos o más sistemas de afinación sean compatibles y puedan convivir de forma simultánea dentro de la misma agrupación musical.

Pero, con la lógica borrosa todo es cuestión de grado, incluso los números, la quintaesencia de la precisión. Los números parecen formas puras: o son o no son. Números pares o impares, no hay punto medio, no hay casos grises. Podría parecer que las matemáticas escapan de la dejadez de la lógica borrosa. Pero, en realidad, no es así. Pensemos en el número 0, que a algunas sociedades de la Antigüedad les llevó miles de años encontrarlo. El número cero pertenece al 100 por 100 al conjunto cero y que no hay otro número que pertenezca a él. Pero, ¿qué pasa con los números cercanos al cero o que casi o prácticamente son cero? En las situaciones en las que nos encontramos en el mundo real, es razonable suponer que 0.001 es "casi 0 " mientras que 35 no lo es. En el apartado siguiente trataremos este tema.

\subsection{Números borrosos}

Aunque matemáticamente los números borrosos pueden definirse directamente sin necesidad de recurrir a los intervalos de confianza, en este apartado hemos preferido introducir los intervalos como conceptos previos para llegar a los números de forma constructiva.

\subsubsection{Intervalos de confianza. Operaciones elementales.}

La forma más intuitiva de representar la incertidumbre de un número real es dar un intervalo de confianza en el que esté contenido el número. Así, por ejemplo, los números próximos al 3 podrían expresarse mediante el intervalo $[2.5,4]$.

Como veremos resulta sencillo operar con estos intervalos (véase Kaufmann y Gil Aluja, 1987):

Suma de intervalos de confianza:

La suma de dos intervalos [a, b], [c, d], es un nuevo intervalo dado por

$$
[a, b]+[c, d]=[a+c, b+d]
$$


Ejemplo: $[-3,5]+[2,3]=[-1,8]$

Resta de intervalos de confianza:

La diferencia entre dos intervalos $[a, b],[c, d]$, es un nuevo intervalo dado por

$$
[a, b]-[c, d]=[a, b]+[-d,-c]=[a-d, b-c] .
$$

Ejemplo: $[-3,5]-[2,3]=[-3,5]+[-3,-2]=[-6,3]$

Multiplicación de intervalos de confianza:

El producto de dos intervalos [a, b], [c, d], es el intervalo

$$
[a, b] *[c, d]=[\operatorname{Min}(a . c, a . d, \text { b.c, b.d), } \operatorname{Max}(\text { a.c, a.d, b.c, b.d) }] \text {. }
$$

Es decir, se realizan todas las multiplicaciones posibles entre los extremos de los intervalos y el intervalo producto está formado por el menor de esos productos como extremo inferior y el mayor de ellos como extremo superior.

Ejemplo: $[-3,5] *[2,3]$

Hacemos los cuatro productos posibles:

$$
-3.2=-6, \quad-3.3=-9, \quad 5.2=10, \quad 5.3=15,
$$

entonces, $[-3,5] *[2,3]=[-9,10]$

Inversa de un intervalo de confianza:

Dado el intervalo [a, b], la inversa del intervalo es

$$
[\mathrm{a}, \mathrm{b}]^{-1}=[\operatorname{Min}(1 / \mathrm{a}, 1 / \mathrm{b}), \operatorname{Max}(1 / \mathrm{a}, 1 / \mathrm{b})] .
$$

Es decir, se calcula $1 / \mathrm{a}$ y $1 / \mathrm{b}$ y se elige como extremo inferior al más pequeño y como superior al más grande.

Ejemplo: $[-3,5]^{-1}=[-1 / 3,1 / 5]$

División de intervalos de confianza:

El cociente de dos intervalos [a, b], [c, d], es el intervalo dado por 


$$
[\mathrm{a}, \mathrm{b}]:[\mathrm{c}, \mathrm{d}]=[\mathrm{a}, \mathrm{b}] *[\mathrm{c}, \mathrm{d}]^{-1}
$$

Ejemplo: $[-3,5]:[2,3]=[-3,5] *[2,3]^{-1}=[-3,5] *[1 / 3,1 / 2]$

Hacemos los cuatro productos posibles:

$$
-3.1 / 3=-1, \quad-3.1 / 2=-3 / 2, \quad 5.1 / 3=5 / 3, \quad 5.1 / 2=5 / 2,
$$

entonces, $[-3,5]:[2,3]=[-3 / 2,5 / 2]$

\subsubsection{Números borrosos. Operaciones con números borrosos triangulares.}

A partir del concepto de intervalo de confianza, podemos obtener un caso particular de conjuntos borrosos: los números borrosos, que sin duda son los conjuntos más utilizados y de mayor aplicabilidad a los problemas de la vida real.

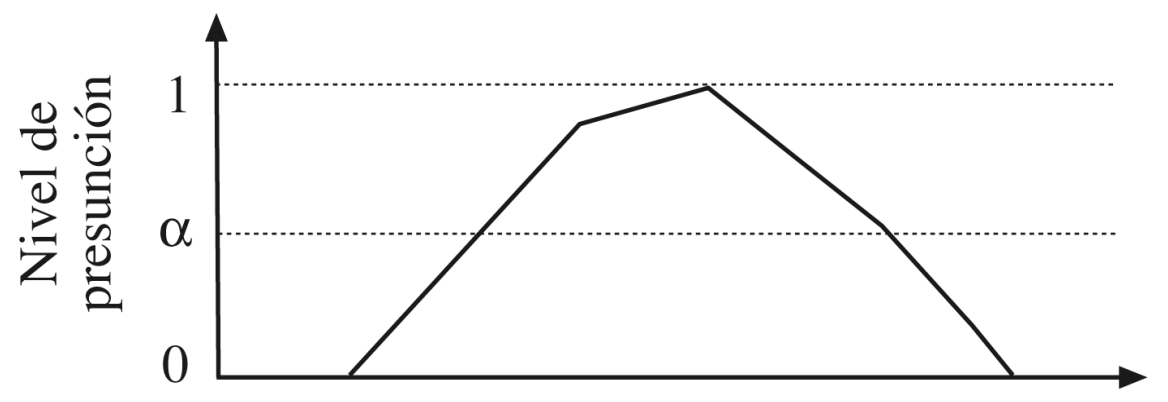

Fig. 4. 7. Función de pertenencia de un número borroso Fuente: Elaboración propia

Entre las múltiples definiciones equivalentes de número borroso, citaremos la que aparece en Kaufmann y Gil Aluja (1987) por tratarse de una definición constructiva que no utiliza más conceptos matemáticos que los expuestos anteriormente.

Definición 4.2. Un número borroso es una secuencia finita o infinita de intervalos de confianza con las siguientes propiedades: 
a) A cada nivel de presunción le corresponde un único intervalo de confianza ${ }^{10}$.

b) Los elementos que pertenecen al nivel de presunción $\alpha$, pertenecen a todos los niveles de presunción menor que $\alpha$.

c) Existe un intervalo y sólo uno que puede reducirse a un número real único.

\section{Operaciones con números borrosos}

Operar con números borrosos de forma global puede no resultar sencillo, porque la forma de la función de pertenencia de los números puede ser muy diversa. Lo que suele hacerse en estos casos es trabajar para un nivel de presunción dado. Si tenemos dos números A, B podemos sumarlos, restarlos, multiplicarlos y dividirlos para un nivel de presunción dado, puesto que en este caso operar con números borrosos se reduce a operar con intervalos de confianza, y con éstos, según acabamos de ver en la sección 4.3.1, el cálculo es sencillo.

Ejemplo 4.1: Dados los números borrosos $\tilde{A}, \tilde{B}$ de la figura 4. 8, vamos a calcular su suma, resta, multiplicación y división para el nivel de pertenencia 0.7.

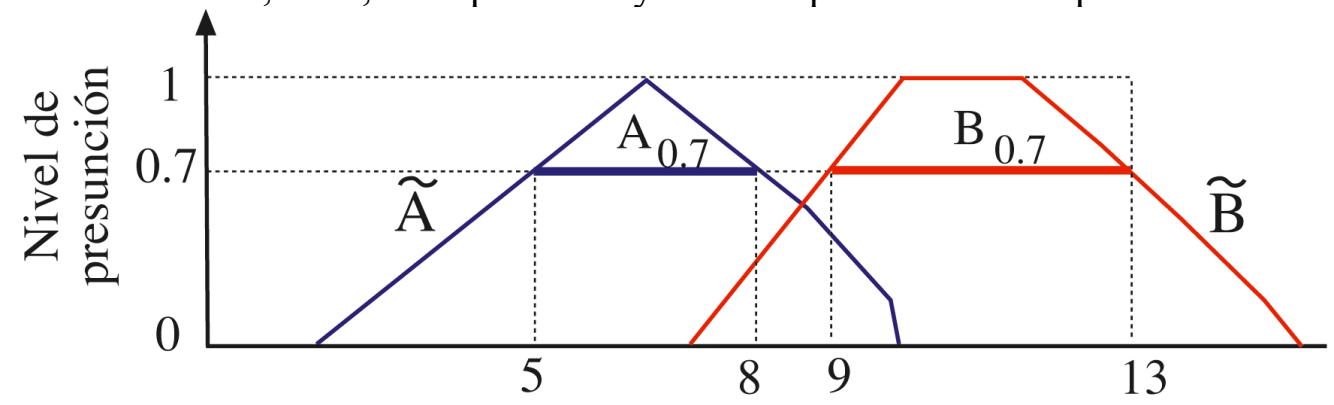

Fig. 4. 8. Función de pertenencia de un número borroso Fuente: Elaboración propia

Para operar con los números $\tilde{A}$ y $\tilde{B}$ al nivel $\alpha=0.7$, no tenemos más que operar con los intervalos $\mathrm{A}_{0.7}=[5,8]$ y $\mathrm{B}_{0.7}=[9,13]$. Con ello, al nivel 0.7 fijado tenemos

$$
\begin{aligned}
& \mathrm{A}_{0.7}+\mathrm{B}_{0.7}=[5,8]+[9,13]=[14,21] \\
& \mathrm{A}_{0.7}-\mathrm{B}_{0.7}=[5,8]-[9,13]=[-8,-1] \\
& \mathrm{A}_{0.7} * \mathrm{~B}_{0.7}=[5,8] *[9,13]=[45,104] \\
& \mathrm{A}_{0.7}: \mathrm{B}_{0.7}=[5,8] *[9,13]=[5 / 13,8 / 9]
\end{aligned}
$$

\footnotetext{
${ }^{10}$ Es decir, que dos intervalos de confianza diferentes no pueden tener el mismo valor $\alpha$. .
} 
Sin embargo, esta claro que saber cómo se opera en cada nivel no nos permite conocer qué ocurre al operar a nivel global. Para poder hacer operaciones entre los números sin tener que recurrir a cada nivel, necesitamos conocer cuál es la forma de los números operados. De entre todos los posibles números borrosos, los más sencillos de manejar, pero que representan gran cantidad de situaciones de la vida real son los números borrosos triangulares.

\section{Números borrosos triangulares}

Los números borrosos triangulares, NBT, son aquellos números borrosos cuyas funciones de pertenencia son lineales ${ }^{11}$, por tanto tienen forma de triángulo, tal y como aparece en la figura 4.9.

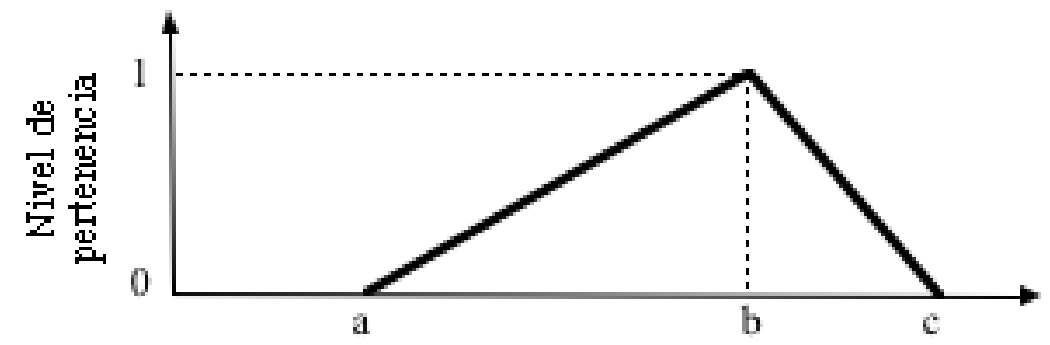

Fig. 4. 9. Función de pertenencia de un número borroso triangular Fuente: Elaboración propia

Estos números quedan perfectamente determinados por tres números reales que marcan dónde se encuentran los vértices del triángulo. Así, el NBT de la figura 4.9 puede citarse como

$$
\tilde{A}=(\mathrm{a}, \mathrm{b}, \mathrm{c}) \text {. }
$$

Cualquiera que sea la magnitud que está representada por el NBT anterior, el valor "a" marca el nivel por debajo del cuál no estamos dispuestos a aceptar que pertenezca al concepto que tratamos, el valor " $b$ " representa el valor cuya

11 En Kaufmann y Gil Aluja (1987), por ejemplo, puede verse que la expresión de la función de pertenencia para el número borroso triangular $\tilde{A}=(\mathrm{a}, \mathrm{b}, \mathrm{c})$ es

$$
\mu_{A}(x)= \begin{cases}1-\frac{b-x}{b-a}, & a \leq x<b \\ 1-\frac{x-b}{c-b}, & b \leq x<c \\ 0 & \text { en otro caso }\end{cases}
$$


pertenencia es máxima y el valor "c" marca el máximo valor que aceptamos como perteneciente al concepto.

Cuando los números borrosos involucrados son triangulares, podemos operar de forma global sin necesidad de recurrir a los niveles de pertenencia. triangulares:

En el siguiente gráfico mostramos la suma de dos números borrosos

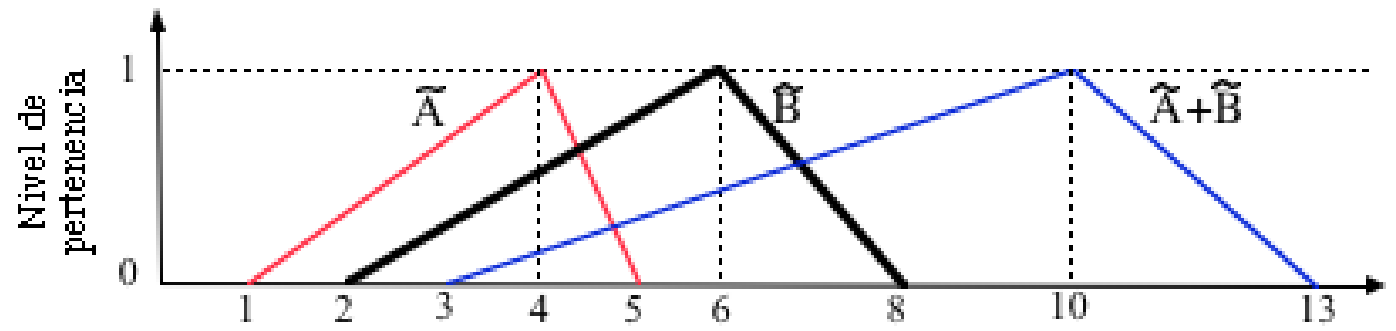

Fig. 4. 10. Suma de números borrosos triangulares

Fuente: Elaboración propia

La ventaja matemática que presentan los NBT es que al sumarlos, restarlos o multiplicarlos por un escalar, el resultado es un nuevo número borroso triangular, mientras que cuando efectuamos estas operaciones con números borrosos arbitrarios no conocemos, a priori, la forma del conjunto borroso resultante.

Suma de números borrosos triangulares:

La suma de los números $\tilde{A}=\left(\mathrm{a}_{1}, \mathrm{~b}_{1}, \mathrm{c}_{1}\right)$ y $\tilde{B}=\left(\mathrm{a}_{2}, \mathrm{~b}_{2}, \mathrm{c}_{2}\right)$ es el número borroso triangular dado por

$$
\tilde{A}+\tilde{B}=\left(\mathrm{a}_{1}, \mathrm{~b}_{1}, \mathrm{c}_{1}\right)+\left(\mathrm{a}_{2}, \mathrm{~b}_{2}, \mathrm{c}_{2}\right)=\left(\mathrm{a}_{1}+\mathrm{a}_{2}, \mathrm{~b}_{1}+\mathrm{b}_{2}, \mathrm{c}_{1}+\mathrm{c}_{2}\right)
$$

Ejemplo: $(1,4,5)+(2,6,8)=(3,10,13)$ (véase Fig 4.10).

Resta de números borrosos triangulares:

La resta de los números $\tilde{A}=\left(\mathrm{a}_{1}, \mathrm{~b}_{1}, \mathrm{c}_{1}\right)$ y $\tilde{B}=\left(\mathrm{a}_{2}, \mathrm{~b}_{2}, \mathrm{c}_{2}\right)$ es el número borroso triangular dado por

$$
\tilde{A}-\tilde{B}=\left(\mathrm{a}_{1}, \mathrm{~b}_{1}, \mathrm{c}_{1}\right)-\left(\mathrm{a}_{2}, \mathrm{~b}_{2}, \mathrm{c}_{2}\right)=\left(\mathrm{a}_{1}-\mathrm{c}_{2}, \mathrm{~b}_{1}-\mathrm{b}_{2}, \mathrm{c}_{1}-\mathrm{a}_{2}\right)
$$

Ejemplo: $(1,4,5)-(2,6,8)=(1-8,4-6,5-2)=(-7,-2,3)$. 
Multiplicación por un escalar:

Dado el NBT $\tilde{A}=\left(\mathrm{a}_{1}, \mathrm{~b}_{1}, \mathrm{c}_{1}\right)$ y un número real $\mathrm{k}$, el producto $\mathrm{k} \cdot \tilde{A}$ es el número borroso triangular dado por

$$
\mathrm{k} \cdot \tilde{A}=\left(\min \left(\mathrm{k} \cdot \mathrm{a}_{1}, \mathrm{k} \cdot \mathrm{c}_{1}\right), \mathrm{k} \cdot \mathrm{b}_{2}, \max \left(\mathrm{k} \cdot \mathrm{a}_{1}, \mathrm{k} \cdot \mathrm{c}_{1}\right)\right)
$$

Ejemplo: $-3 \cdot(1,4,5)=(\min (-3,-15),-12, \max (-3,-15))=(-15,-12,-3)$

NOTA: El producto o el cociente de dos NBT no es, en general, un número borroso triangular.

Para finalizar el apartado que dedicamos a lo números borrosos triangulares, incluimos una cuestión que facilita la notación. Cuando los NBT son simétricos, es decir que dado el valor que tiene el máximo de pertenencia, las tolerancias por exceso y defecto son las misma, la forma habitual de escribir el número es

$$
\tilde{A}=(\mathrm{a}, \delta) .
$$

$E l$ valor " $a$ " expresa el valor de mayor pertenencia y " $\delta$ " representa la desviación máxima permitida por exceso y por defecto (véase figura 4.11).

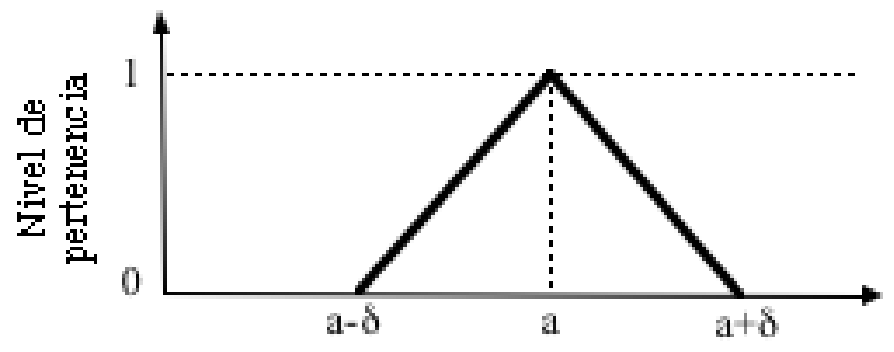

Fig. 4. 11. Número borroso triangular simétrico.

Fuente: Elaboración propia

NOTA: Una cuestión muy interesante desde el punto de vista matemático es determinar una ordenación de los números borrosos, puesto que en ocasiones un número será mayor que otro o no dependiendo de la situación real tratada. Como en el caso de la afinación está claro ${ }^{12}$ si una nota se percibe más aguda que otra, por ejemplo, no creemos necesario introducir esta discusión que puede encontrarse, por ejemplo en Kaufmann y Gil Aluja (1987) o Carlsson y Fullér (2002).

${ }^{12}$ De hecho se dispone de tecnología para determinarlo con gran precisión. 


\subsection{Sistemas borrosos de afinación}

Si no nos basamos en un análisis estrictamente teórico, una nota musical debe ser entendida como una banda de frecuencias alrededor de una frecuencia central $f$ y esto puede describirse mediante un conjunto borroso $\tilde{f}$ del que más adelante determinaremos cuál es su función de pertenencia.

La idea de expresar las notas musicales como conjuntos borrosos no es nueva (véanse Haluska (2000, 2005), Liern (2005)) y puede justificarse por varias razones:

a) Razones técnicas: La afinación exacta de las notas se ve alterada porque en pasajes rápidos, los músicos tienen que elegir digitaciones y posiciones que resulten cómodas. Por otro lado, la presión de los labios, la temperatura, la humedad, la acústica de la sala, etc. también modifican de forma sensible las frecuencias.

b) Razones psicológicas: Además de que la percepción de los intervalos no es la misma para todos, el estado de ánimo del músico afecta claramente en la afinación.

Como mostraremos en este apartado, la formulación de las notas como números borrosos será la que permita conectar los estudios teóricos, que hemos descrito en el capítulo dos de esta memoria, con el uso práctico de los músicos.

\subsubsection{Aportaciones de Garbuzov}

El musicólogo N. A. Garbuzov (1880-1955) revolucionó el estudio de los intervalos musicales sugiriendo ${ }^{13}$, en los años cuarenta, el concepto de "zonas"14 como sustituto del de intervalo en el contexto de la percepción. En un lenguaje actual, esta teoría podría resumirse como la sustitución del concepto de intervalo por la de conjunto borroso. Se trató de un trabajo de laboratorio en el que a partir de miles de pruebas le llevó a definir, con criterios estadísticos, los siguientes conjuntos:

\footnotetext{
${ }^{13}$ N. A. Garbuzov, en 1948, publicó el artículo "The zonal nature of the human aural perception" en el que hacía un estudio de la percepción de los intervalos musicales. A pesar de que se trata de uno de los primeros intentos por valorar de forma numérica este concepto, el trabajo pasó inadvertido por estar publicado en ruso en la Academia de Ciencias de Moscú y en una época en las que las investigaciones hechas en la URSS resultaban secretas para el mundo occidental. Debió transcurrir casi un cuarto de siglo hasta que, de la mano de Ján Haluska, los trabajos de Garbuzov empezaron a considerarse elementos clave dentro de la psicoacústica.

${ }^{14}$ Estas zonas se conocen en la actualidad como las zonas de Garbuzov.
} 


\begin{tabular}{lcc}
\hline Intervalo & Melódico & Armónico \\
\hline Unísono & $(-12,12)$ & $(-30,30)$ \\
Segunda menor & $(48,124)$ & $(66,130)$ \\
Segunda mayor & $(160,230)$ & $(166,230)$ \\
Tercera menor & $(272,330)$ & $(266,330)$ \\
Tercera mayor & $(372,430)$ & $(372,430)$ \\
Cuarta & $(472,530)$ & $(466,524)$ \\
Tritono & $(566,630)$ & $(566,630)$ \\
Quinta & $(672,730)$ & $(672,730)$ \\
Sexta menor & $(766,830)$ & $(766,830)$ \\
Sexta mayor & $(866,930)$ & $(866,924)$ \\
Séptima menor & $(966,1024)$ & $(966,1024)$ \\
Séptima mayor & $(1066,1136)$ & $(1066,1136)$ \\
\hline
\end{tabular}

Tabla 4.1. Zonas de Garbuzov expresadas en cents para intervalos armónicos y melódicos.

Fuente: Haluska (2005), página 58

Por ejemplo, en la práctica dos notas que distan entre -12 y 12 cents podemos suponer que son la misma nota (unísono) o si distan entre 372 y 430 cents entre ambas hay un intervalo de tercera mayor.

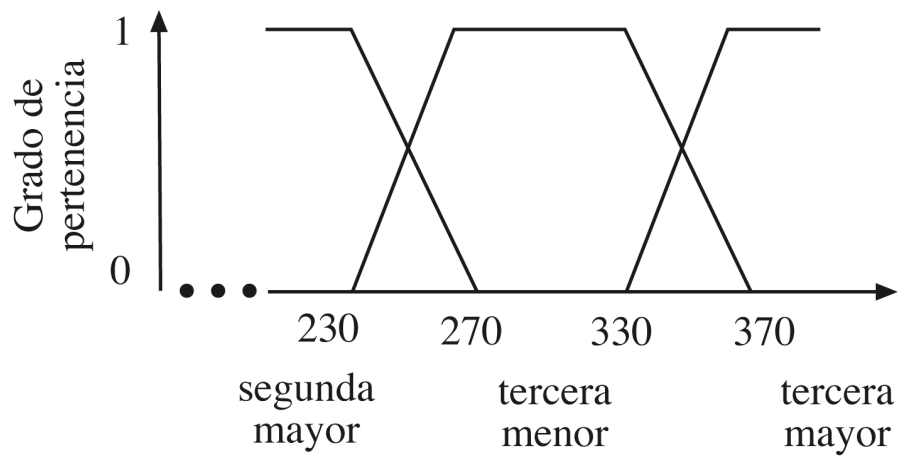

Fig. 4.12. Zonas de Garbuzov para el intervalo de tercera menor. Fuente: Haluska (2005), página 63. 
A partir de los resultados de la tabla 4.1, podría pensarse que conociendo las zonas de garbuzov gran parte de las dificultades expuestas en los capítulos 2 y 3 de esta memoria están resueltos, porque los sonidos que presentábamos como no afinados en el sistema temperado deberían estar dentro de las zonas propuestas por Garbuzov. Sin embargo, como veremos en el ejemplo siguiente, no es así.

Ejemplo 4.2: Analicemos las distancias del fragmento de Béla Bartók que hemos estudiado en el Experimento 4 de capítulo 3 de esta memoria:

Tomamos como patrón las notas del pentagrama afinadas en el sistema temperado de 12 notas. Entonces, la distancia de estas notas en cada uno de los sistemas y las notas temperadas es la siguiente:

\begin{tabular}{lccc}
\hline Nota & $\mathrm{d}$ (Pitag, temp.) & $\mathrm{d}$ (zarlino, temp.) & $\mathrm{d}$ (Holder, temp.) \\
\hline $\mathrm{Mi}$ & 2,6251 & 2,6251 & 2,5464 \\
$\mathrm{La}$ & 0 & 0 & 0 \\
$\mathrm{Si}$ & 3,9216 & 3,9216 & 3,7817 \\
La\# & 13,6868 & 7,8184 & 13,2151 \\
Sol\# & 9,7769 & 11,7284 & 9,4411 \\
Fa\#\# & 19,5491 & 44,9689 & 18,8634 \\
Fa\# & 5,8646 & 5,8646 & 5,6548 \\
La & 0 & 0 & 0 \\
Mi\# & 15,641 & 27,371 & 15,0886 \\
Sol\# & 9,7769 & 11,7284 & 9,4411 \\
La\# & 13,6868 & 7,8185 & 13,2151 \\
\hline
\end{tabular}

Tabla 4.2. Distancia en cents de las notas del fragmento de Béla Bartók (entre el temperamento igual de 12 notas y otros sistemas de afinación) Fuente: Elaboración propia

Para obtener una idea global, representamos gráficamente las distancias expresadas en la Tabla 4.2 comparándolas con la zona de Garbuzov: 


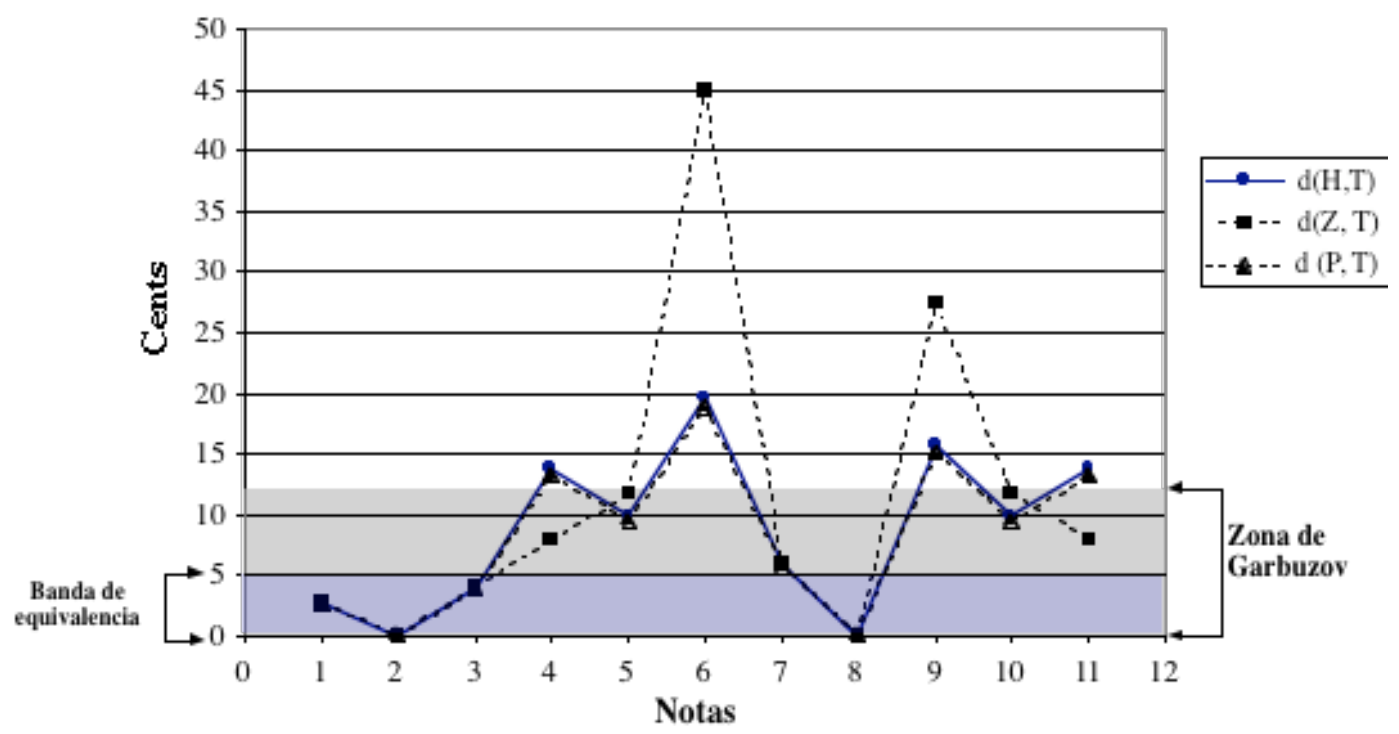

Fig. 4.13. Representación de las distancias expresadas en la Tabla 4.2.

Fuente: Elaboración propia

Como puede apreciarse en la figura 4.13, las distancias entre los distintos sistemas de afinación no sólo exceden la banda de equivalencia que se ha fijado en esta memoria ( \pm 5 cents), sino que en algunos casos resultan muy superiores a las zonas de Garbuzov (que en la gráfica aparecen sombreadas en gris).

Este hecho, por sí solo haría que adoptar los intervalos de confianza propuestos por Garbuzov resultasen insuficientes, pero es que además, la propuesta de Garbuzov no sólo afecta al concepto de intervalo como conjunto borroso, sino que necesariamente cada nota debe entenderse como un conjunto borroso en el que hay una banda o zona de frecuencias que tienen distintos grados de pertenencia a la nota.

Esta claro un modelo de intervalos musicales representados mediante intervalos de confianza representa mejor la percepción práctica de los intervalos y las notas musicales, pero plantea algunos inconvenientes que es necesario resolver:

a) ¿Qué ocurre con las bandas de frecuencias que podrían estar en más de un intervalo? (ver Fig. 4.14). 


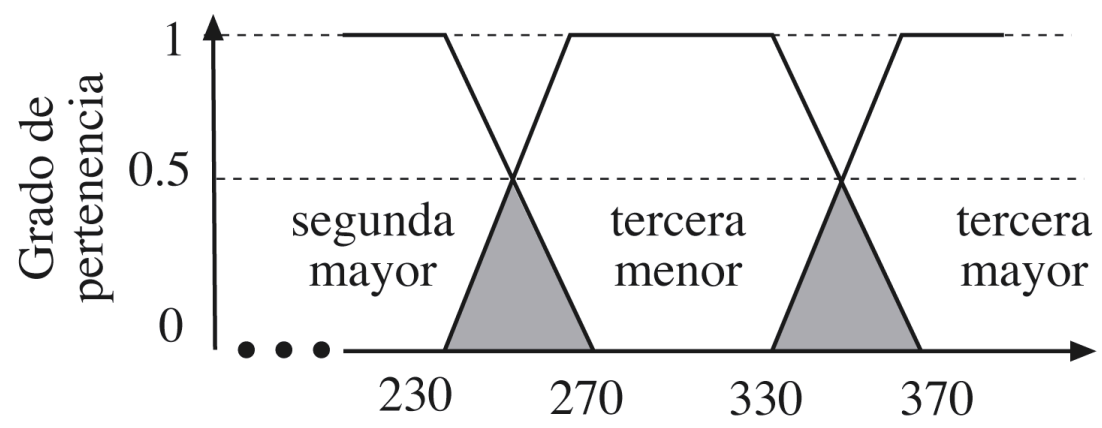

Fig. 4.14. Zonas comunes para varios intervalos Fuente: Elaboración propia

b) Si partimos de las notas como conjuntos borrosos, ¿los conjuntos borrosos que se obtienen para lo intervalos serían los mismos?

c) ¿Cómo se relaciona esto, desde el punto de vista teórico, con la teoría musical de más de veinticinco siglos?

En el resto del capítulo intentamos resolver éstas y otras cuestiones que surgen con la práctica musical.

\subsubsection{Notas como conjuntos borrosos}

Con lo expuesto anteriormente, una nota musical debe ser entendida como una banda de frecuencias alrededor de una frecuencia central $f$ y esto puede describirse mediante un conjunto borroso $\tilde{f}$. La idea de expresar las notas musicales como conjuntos borrosos no es nueva (Haluska (2000, 2005), Liern (2005)).

De forma más precisa, podemos considerar un sonido musical como un número borroso que refleja la sensación que produce una frecuencia $f$, es decir

$$
s=k \log _{2}\left(\frac{f}{f_{0}}\right), \mathrm{k} \text { una constante, }
$$

y cuya función de pertenencia refleje lo que los músicos utilizan en la práctica.

Con esta idea, podemos utilizar la información que proporcionan los afinadores cromáticos electrónicos. Estos afinadores, basados en las 12 notas del 
sistema temperado igual de 12 notas, dividen la octava en doce partes iguales. Cada una de estas partes tiene una amplitud de 100 cents.

Si representásemos esta situación en un segmento, la nota afinada crisp ocuparía el punto medio y los extremos se obtendrían sumando y restando 50 cents a la nota central. Como se verá en el ejemplo siguiente, la desviación respecto de la nota central nos permite construir la función de pertenencia.

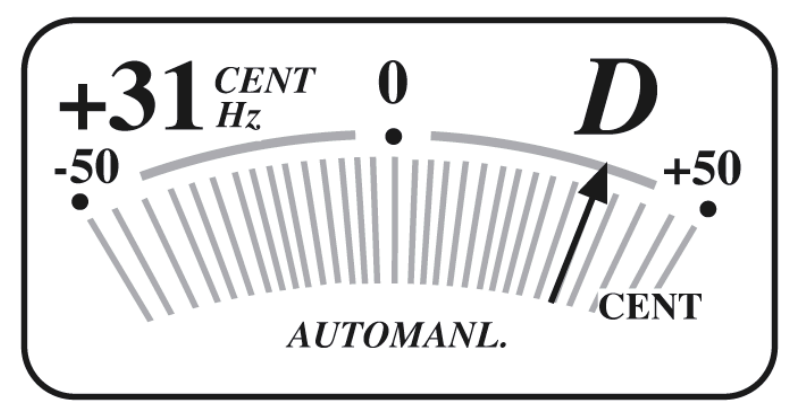

Fig. 4. 15. Respuesta de un afinador cromático al detectar $299 \mathrm{~Hz}$. Fuente: Elaboración propia

Ejemplo 4.3: Consideramos un afinador electrónico en el que se ha fijado la nota $\mathrm{La}_{4}=440 \mathrm{~Hz}$. Si detecta una nota $n$ cuya frecuencia es $299 \mathrm{~Hz}$, la salida del afinador sería la siguiente:

Nota: $\operatorname{Re}(\mathrm{D}), \quad$ Desviación: 31.1702 cents

En primer lugar, el afinador localiza la nota afinada más próxima a $n$ (en este caso la nota más próxima es $\mathrm{Re}$ ) Tras esto, determina la distancia entre $n$ y el Re es 31.1702.

A partir de ella podemos obtener un indicador del grado de verdad de la afirmación

$$
\text { “299 Hz. es un Re”. }
$$

Basta con calcular

$$
1-\frac{\text { Desviación }}{50}=1-\frac{31.1702}{50}=0.3766
$$

Desde luego, hay otras posibilidades para aproximarse al grado de verdad, pero la nuestra elección muestra la práctica de los músicos. En general, ellos 
consideran que 50 cents representa un cuarto de tono y, para una nota cuya desviación sea 25 cents, suelen decir que "la nota está desviada un octavo de tono".

Cuando el diapasón se ha fijado en $440 \mathrm{~Hz}$, el $\mathrm{Do}_{4}$ queda determinado por $\mathrm{Do}_{4}=2^{-3 / 4} \times 440 \mathrm{~Hz}$., y el intervalo de referencia es

$$
\left[f_{0}, 2 f_{0}\left[=\left[2^{-3 / 4} 440,2 \times 2^{-3 / 4} 440\left[=\left[2^{-3 / 4} 440,2^{1 / 4} 440[\text {. }\right.\right.\right.\right.\right.
$$

Una vez determinado este intervalo debemos trasladar cada frecuencia al intervalo $[1,2]$

Como decíamos en el capítulo 2, para trasladar una nota de frecuencia $f$ al intervalo [1, 2[, hacemos los pasos siguientes:

1. Dada la nota patrón $\mathrm{La}=440 \mathrm{~Hz}$, el intervalo de frecuencias audibles queda dividido en intervalos de octava.

$$
\left[f_{0}, 2 f_{0}\left[,\left[2 f_{0}, 2^{2} f_{0}\left[,\left[2^{2} f_{0}, 2^{3} f_{0}\left[, \ldots,\left[2^{n} f_{0}, 2^{n+1} f_{0}[\right.\right.\right.\right.\right.\right.\right.
$$

2. Comprobamos a que octava pertenece $f$. Por ejemplo, supongamos que $f$ está en $\left[2^{2} f_{0}, 2^{3} f_{0}[\right.$.

3. Dividimos la frecuencia $f$ por el Do correspondiente a su octava, es decir

$$
F=\frac{f}{2^{2} f_{0}}
$$

Al llevar la nota de $299 \mathrm{~Hz}$ al intervalo [1, 2[, obtenemos

$$
\begin{gathered}
n=\frac{299}{261.6256}=1.142855 \\
d(\text { Do }, n)=1200 \bullet \log _{2}(1.142855)=1200 \bullet 0.192642=231.1702
\end{gathered}
$$

Para interpretar el resultado, basta con pensar que la nota de $299 \mathrm{~Hz}$. dista 231.1702 desde el Do o sea que dista 31.1702 cents del Re (ver figura 4.15). 


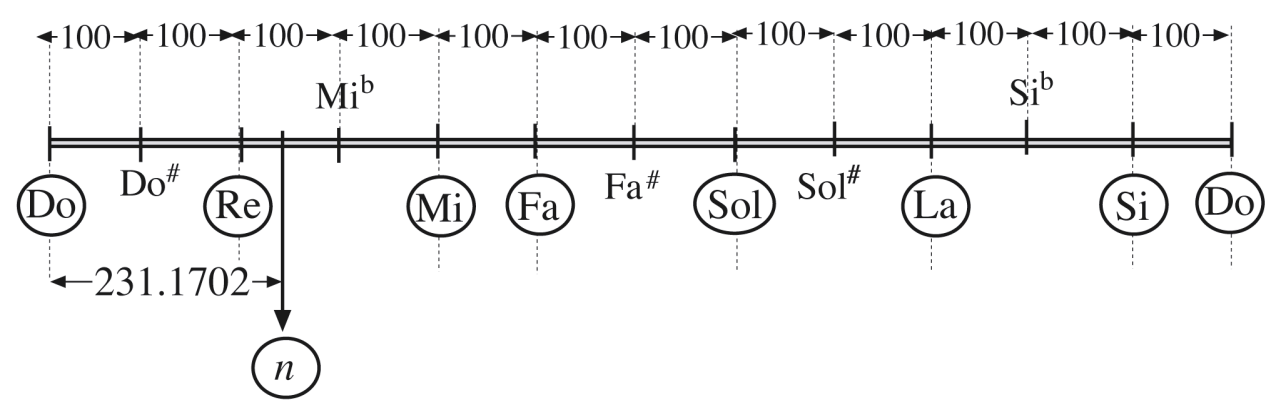

Fig. 4. 16. Distribución de los semitonos cromáticos temperados en la octava. Fuente: Elaboración propia

A continuación veremos cómo generalizar la forma de razonar del ejemplo anterior. Supongamos que el Re viene dado por el número borroso triangular siguiente

$$
\tilde{\operatorname{Re}}=\left(\operatorname{Re}, \frac{1}{24}\right)=\left(2^{\frac{1}{6}}, 2^{\frac{1}{6}-\frac{1}{24}}, 2^{\frac{1}{6}+\frac{1}{24}}\right),
$$

cuya función de pertenencia es ${ }^{15}$ de la forma siguiente:

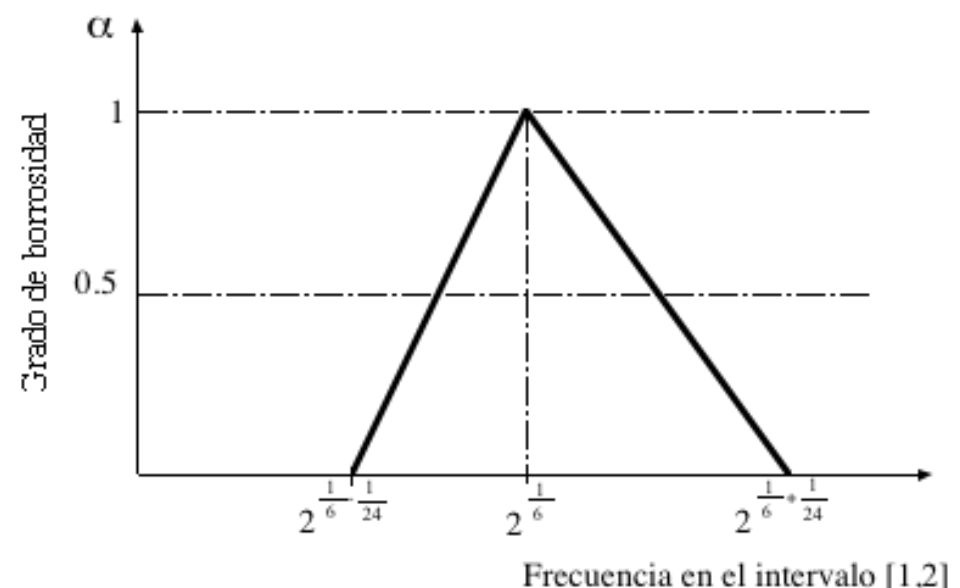

Fig. 4. 17. Número borroso triangular que representa al Re Fuente: Elaboración propia

${ }^{15}$ La expresión de esta función de pertenencia es

$$
\mu_{\tilde{\mathrm{R} e}}(x)= \begin{cases}1-24\left|\mathrm{Re}^{*}-x\right|, & \text { si }\left|\mathrm{Re}^{*}-x\right|<\frac{1}{24} \\ 0 & \text { en otro caso }\end{cases}
$$

(véanse Liern (2005), o Carlson y Fullér (2002), por ejemplo). 
Ahora bien, una cosa es el número borroso que produce la nota Re y otra la sensación que esta produce. En realidad, por propia construcción, cuando medimos la sensación estamos trabajando con logaritmos binarios, lo cual significa que la sensación que produce la nota crisp $2^{1 / 6}$ se obtiene calculando

$$
\log \left(2^{\frac{1}{6}}\right)=\frac{1}{6}
$$

Así, el número borroso que representa la sensación que produce la nota $\mathrm{Re}$, es el número borroso triangular simétrico

$$
A=\left(\frac{1}{6}, \frac{1}{24}\right),
$$

es decir, un número triangular simétrico en el que el lugar central lo ocupa 1/6 y los niveles de tolerancia son $1 / 24$.

La función de pertenencia de este número borroso puede representarse de la forma siguiente:

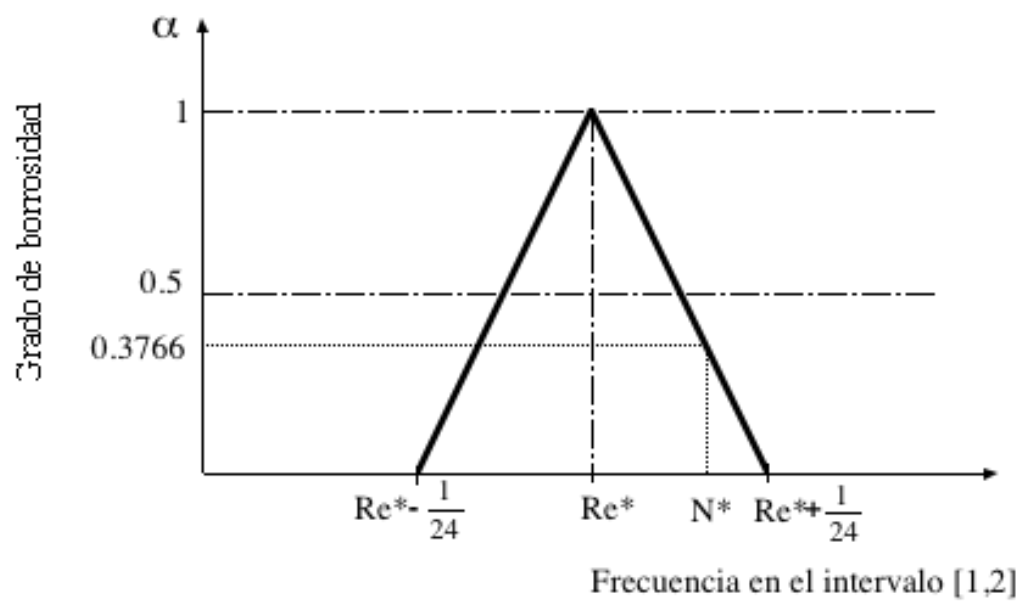

Fig. 4. 18. Número borroso triangular que representa la sensación producida por el Re.

Fuente: Elaboración propia

NOTA: Es importante destacar que la tolerancia que estamos asumiendo es la que fija el afinador cromático. Divide el semitono temperado en dos partes, cada una de 50 cents y concede una parte a la nota más grave y otra a la nota más aguda. En este caso 50 cents corresponden al Re y los otros 50 cents corresponden al Re\#. Por otro lado, como ocurre en la práctica habitual de los músicos, el grado de pertenencia al Re para notas que 
distan más de 50 cents es cero, puesto que en realidad estarían más próximas a otras notas que al Re.

Con esto, el grado de pertenencia de $\mathrm{N}=299 \mathrm{~Hz}$. al Re es

$$
\mu_{\tilde{\mathrm{R}} \mathrm{e}}(N)=\mu_{\tilde{\mathrm{R} e}}(n)=0.3766 .
$$

Generalizando los razonamientos que hemos hecho a partir del afinador cromático estamos en condiciones de establecer la definición de nota musical como un número borroso triangular (vése Liern (2005)):

Definición 4.3: Dado un número borroso triangular simétrico $\tilde{t}=(t, \delta)$ donde $t \mathrm{y}$ $\delta$ son números reales entre 0 y 1 . Una nota musical borrosa es el número borroso ${ }^{16}$ triangular $2^{\tilde{t}}=\left(2^{t}, 2^{t-\delta}, 2^{t+\delta}\right)$ (véase Figura 4.18)

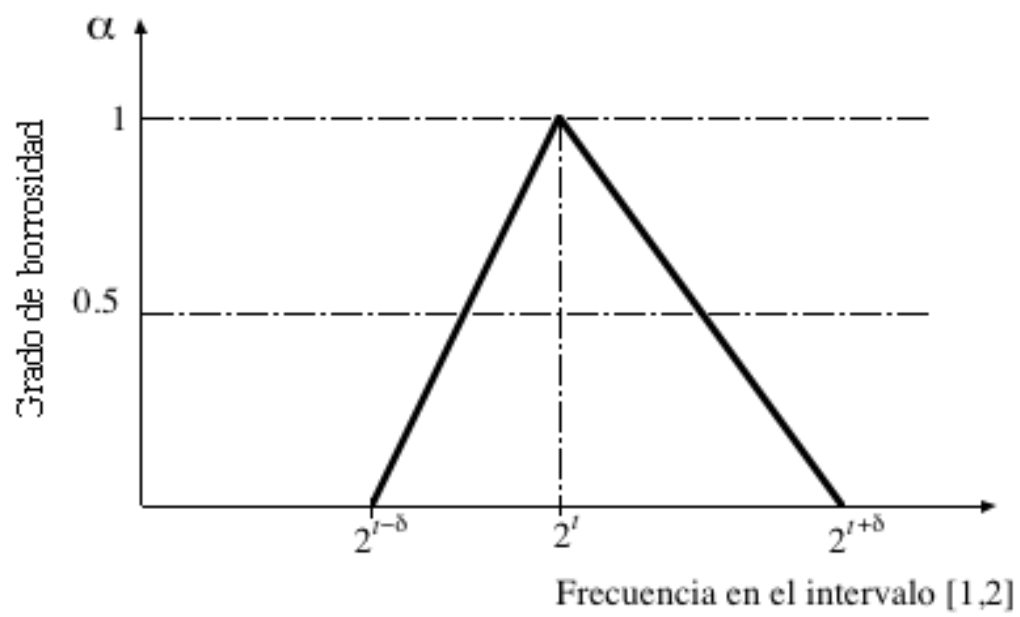

Fig. 4. 19. Número borroso triangular que representa una nota musical Fuente: Elaboración propia

${ }^{16}$ En Liern (2005) puede verse que la expresión de la función de pertenencia para el número borroso $2^{\tilde{t}}=\left(2^{t}, 2^{t-\delta}, 2^{t+\delta}\right)$ es

$$
\mu_{2^{t}}(x)= \begin{cases}1-\frac{2^{t}-x}{2^{t}-2^{t-\delta}}, & 2^{t-\delta}<x \leq 2^{t} \\ 1-\frac{2^{t}-x}{2^{t+\delta}-2^{t}}, & 2^{t}<x \leq 2^{t+\delta} \\ 0 & \text { en otro caso, }\end{cases}
$$


La medida de la incertidumbre ( y por tanto de la diferencia de sensación que produce) nos la da el número borroso triangular simétrico siguiente:

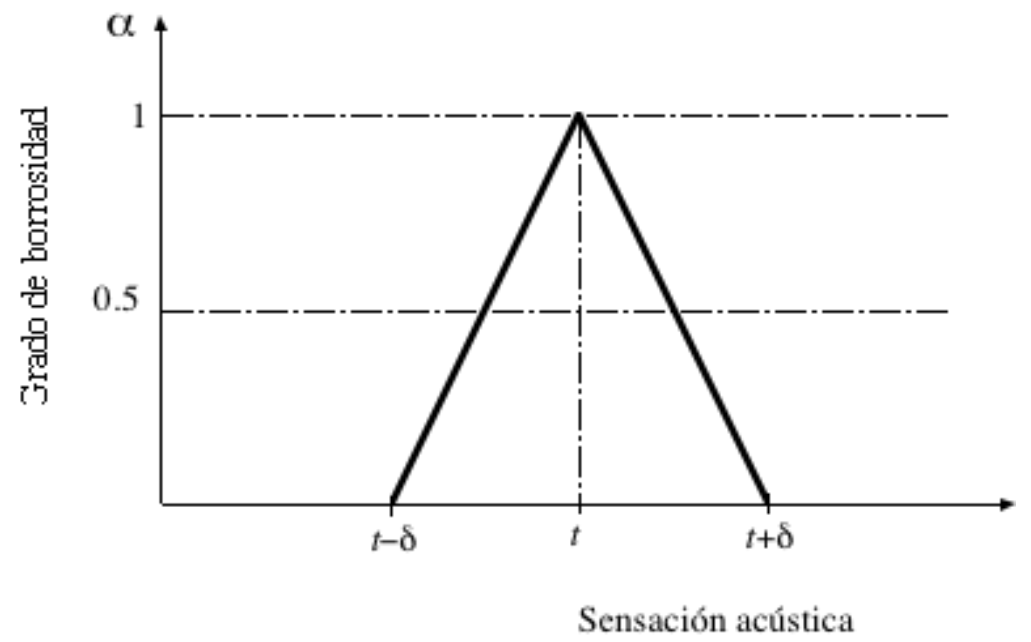

Fig. 4. 20. Sensación producida por una nota musical. Fuente: Elaboración propia.

El valor $\Delta=1200 \bullet \delta$. expresa en cents la incertidumbre que estamos asumiendo. Así, para un afinador cromático, en el que hay 12 notas, se tiene

$$
\delta=\frac{1}{2 q}=\frac{1}{2 \times 12}=\frac{1}{24}
$$

entonces, como cabía esperar, la tolerancia asumida es

$$
\Delta=1200 \times \frac{1}{24}=50 \text { cents. }
$$

Con lo expuesto hasta aquí hemos de sustituir la idea de representación de la notas habitual (ver figura 4.21) en la que las notas corresponden a una concepción puntual, por la de conjuntos borrosos que provocan una sensación que representamos mediante triángulos (ver figura 4.22). 


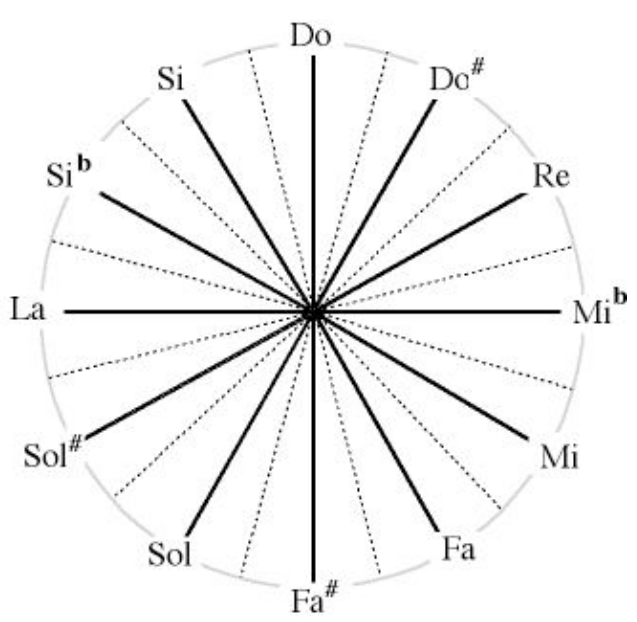

Fig. 4. 21. Representación (clásica) de las 12 notas del sistema temperado. Fuente: Elaboración propia.

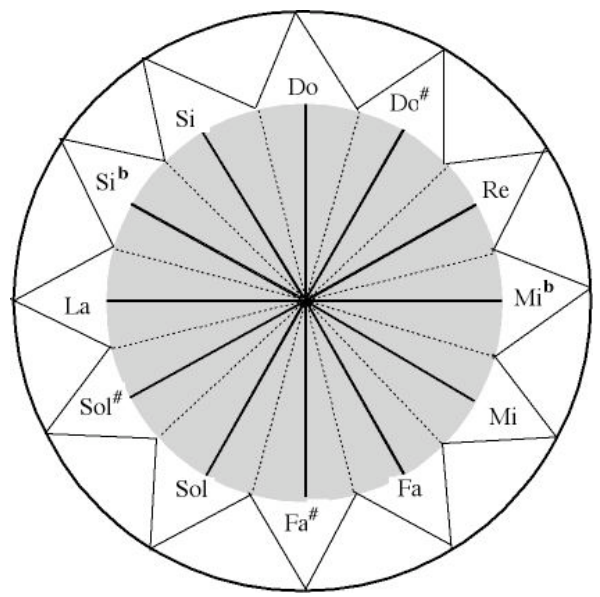

Fig. 4. 22. Representación (borrosa) de las 12 notas del sistema temperado. Fuente: Elaboración propia.

\subsubsection{Compatibilidad entre dos notas musicales}

Una vez establecido el concepto de nota musical borrosa, nuestro interés es determinar cuándo dos notas suenan bien juntas (son compatibles). Para ello necesitamos establecer criterios que permitan comparar números borrosos.

Básicamente, la idea es que cuando los triángulos, que representan la sensación que provocan dos notas diferentes, son muy parecidos, las notas sonarán bien juntas mientras que si no es así las notas no suenan bien juntas (o son incompatibles). 
Desde el punto de vista geométrico, cuando haya más intersección o zona común entre los triángulos que representan dos notas, éstas serán más parecidas y por tanto serán más compatibles en el sentido de que pueden convivir de forma simultánea sin que se produzcan sensaciones desagradables (véase Liern (2005)).

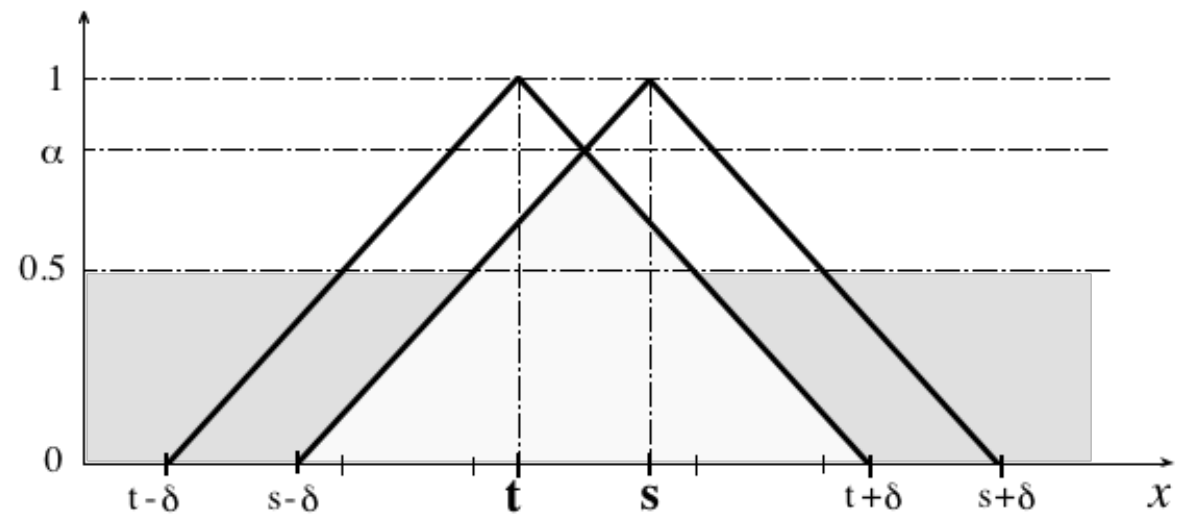

Fig. 4. 23. Compatibilidad entre dos notas musicales. Fuente: Elaboración propia.

Para medir el grado de compatibilidad que tienen dos notas $2^{\tilde{s}}, 2^{\tilde{t}}$ miramos en punto más alto de la intersección de los triángulos que las representan. En la figura 4.23 el nivel de compatibilidad entre ambas notas es bastante alto y está representado por $\alpha$.

Teniendo en cuenta que los números borrosos que representan la sensación de las notas son triangulares y simétricos, en Liern (2005) se demuestra que para conocer la compatibilidad entre dos notas es suficiente con conocer la distancia entre los puntos centrales de los triángulos. Por tanto, en la figura 4.23, para conocer la compatibilidad entre las notas que producen las sensaciones $\tilde{t}=(t, \delta)$ y $\tilde{s}=(s, \delta)$, bastaría con conocer la distancia entre $t$ y $s$, es decir,

$$
d(s, t)=|s-t| .
$$

A partir de este valor, en Liern (2005) se calcula ${ }^{17}$ el valor de compatibilidad entre las notas $2^{\tilde{s}}, 2^{\tilde{t}}$ como

$$
\operatorname{Compat}\left(2^{\tilde{s}}, 2^{\tilde{t}}\right)=1-\frac{|s-t|}{2 \delta} \text {. }
$$

Como en todo lo que vamos a estudiar la precisión fijada depende del número de notas, para un sistema de $\boldsymbol{q}$ notas, el valor $\delta$ viene dado por

\footnotetext{
${ }^{17}$ Para calcular el valor de la compatibilidad entre las dos notas de la figura 4.20, sólo hay que calcular la altura del tirangulo que aparece punteado en la figura.
} 


$$
\delta=\frac{1}{2 q}
$$

entonces, la compatibilidad se calcula de la forma siguiente:

$$
\operatorname{Compat}\left(2^{\tilde{s}}, 2^{\tilde{t}}\right)=1-\frac{|s-t|}{2 \delta}=1-\frac{|s-t|}{2 \times \frac{1}{2 q}}=1-q|s-t| .
$$

A pesar de que la última fórmula simplifica los cálculos, aún resulta más práctico poder calcular la compatibilidad de dos notas directamente a partir de sus frecuencias, es decir,

$$
\operatorname{Compat}\left(\tilde{f}_{1}, \tilde{f}_{2}\right)=1-\frac{d\left(f_{1}, f_{2}\right)}{2 \Delta}
$$

es decir

$$
\operatorname{Compat}\left(\tilde{f}_{1}, \tilde{f}_{2}\right)=1-\frac{\text { distancia entre } f_{1} \mathrm{y} f_{2} \text { en cents }}{\text { doble de la tolerancia permitida en cents }}
$$

A continuación mostramos un ejemplo de cómo utilizar esta fórmula y de cuál es el significado de su valor.

Ejemplo 4.4: Calculemos la compatibilidad del Mib de los sistemas de Pitágoras, Hölder, temperado y de Zarlino con 12 notas.

En la tabla 4.4 (o en el capítulo 2 de esta memoria) podemos comprobar que la distancia entre las notas Mib de cada uno de los sistemas es la siguiente:

$$
\begin{aligned}
& \text { d(Mib pitag., Mib temp. })=11,73, \quad \mathrm{~d} \text { (Mib pitag., Mib zar. })=43.01, \\
& \mathrm{~d}(\text { Mib pitag., Mib hold. })=0.41, \quad \mathrm{~d}(\text { Mib temp., Mib zar. })=31.28, \\
& \mathrm{~d}(\text { Mib temp., Mib hold. })=11.32, \quad \mathrm{~d} \text { (Mib hold., Mib zar. })=42.60,
\end{aligned}
$$

Como el número de notas es 12 , la tolerancia que estamos admitiendo es

$$
\Delta=1200 \times \frac{1}{2 \times 12}=\frac{1200}{2 \times 12}=50 \text { cents. }
$$

Entonces, la compatibilidad se calcula de la forma siguiente:

$$
\text { Compat(Mib (temperado), Mib (pitagórico) })=1-\frac{11.73}{100}=0.8827
$$


Compat(Mib (temperado), Mib (zarliniano)) $=1-\frac{31.28}{100}=0,68718$

Compat(Mib (temperado), Mib (holderiano)) $=1-\frac{11.32}{100}=0,88678$

Compat(Mib (holderiano), Mib (pitagórico)) $=1-\frac{0.41}{100}=0,99591$

Compat(Mib (zarliniano), Mib (pitagórico)) $=1-\frac{43.01}{100}=0,56987$

Compat(Mib (holderiano), Mib (zarliniano) $)=1-\frac{42.60}{100}=0,57396$

Para tener una idea de qué significan realmente estos valores, vamos a calcular la compatibilidad mínima que tienen las notas que se encuentran en la zona de Garbuzov. Es decir, consideramos dos notas de frecuencias $f_{1}, f_{2}$ de modo que la distancia entre ellas sea 12 cents (intervalo de tolerancia fijado por Garbuzov para el unísono). Para estas notas, la compatibilidad es:

$$
\operatorname{Compat}\left(f_{1}, f_{2}\right)=1-\frac{12}{100}=0,88 \text {. }
$$

Así, un nivel de compatibilidad de 0.88 o superior significaría que las notas se encuentran en lo que Garbuzov clasifica como unísono (ver la figura 4.24). Sin embargo, esto no significa que las notas sean percibidas como "exactamente iguales". Para que las notas fuesen indistinguibles en la práctica ${ }^{18}$, deberíamos recurrir a distancias cercanas a los 5 cents, para las que la compatibilidad es

$$
\operatorname{Compat}\left(n_{1}, n_{2}\right)=1-\frac{5}{100}=0,95 \text {, }
$$

(donde $n_{1}$ y $n_{2}$ son dos notas que distan 5 cents).

${ }^{18}$ Véase Piles (1992) o Liern (2005). 


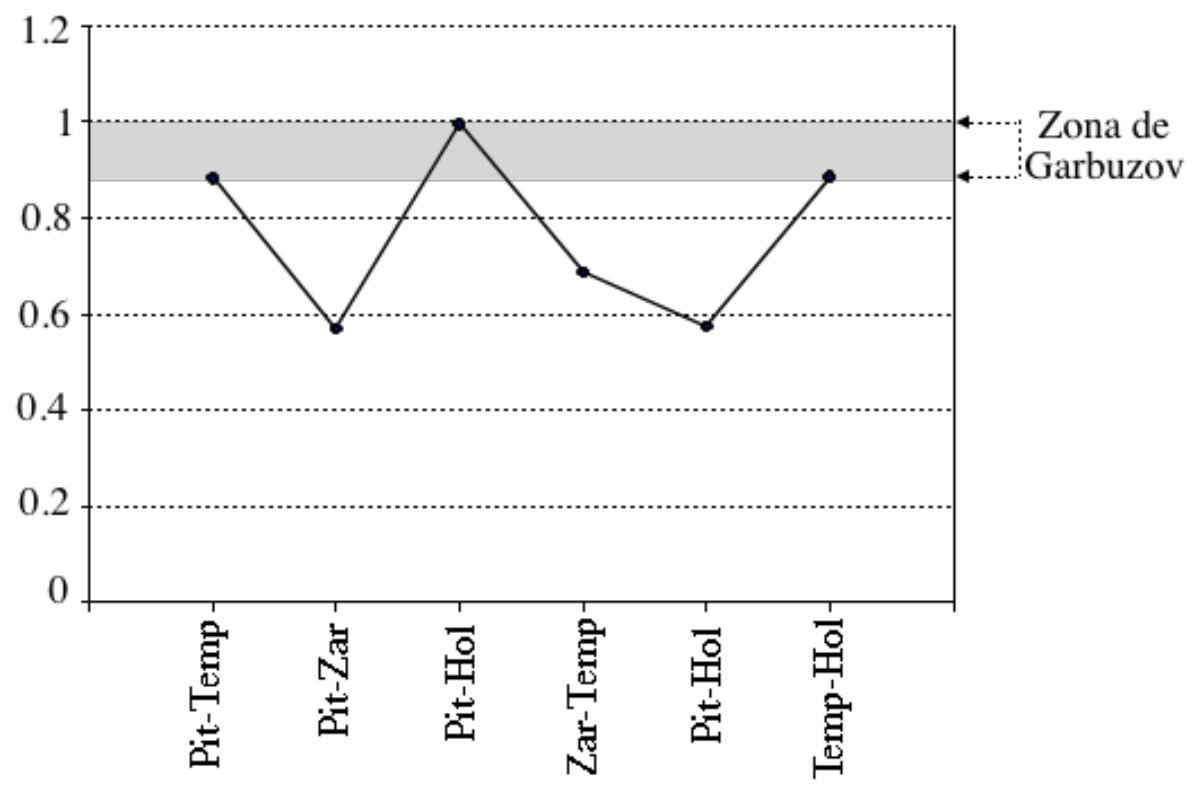

Fig. 4. 24. Compatibilidad del Mib entre sistemas de afinación diferentes. Fuente: Elaboración propia.

Ejemplo 4.5: Analicemos las relación entre las zonas de Garbuzov y la compatibilidad del fragmento de Béla Bartók del Ejemplo 4.2.

La primera cuestión que deberíamos tener clara es el número de notas por octava que debemos considerar. Las notas del fragmento son

Mi, la, si, la\#, sol\#, fa\#\#, fa\#, la, mi\#, sol\#, la\#.

Como aparece el fa con doble sostenido, trabajar con las doce notas del sistema temperado resulta poco apropiado para el resto de sistemas en los que el Fa\#\# tiene entidad propia.

Supondremos que el número de notas es $53^{19}$, y por tanto que nuestra tolerancia es de

$$
\Delta=1200 \times \frac{1}{2 \times 53}=\frac{1200}{2 \times 53}=11,32 \text { cents. }
$$

En este caso, la compatibilidad mínima exigida en la zona que Garbuzov propone para en unísono es

\footnotetext{
${ }^{19}$ La elección de 53 resulta muy apropiada como puede verse en el capítulo 2 de esta memoria.
} 


$$
\operatorname{Compat}\left(f_{1}, f_{2}\right)=1-\frac{12}{22,64}=0,47
$$

(donde $f_{1}$ y $f_{2}$ son dos notas que distan 12 cents).

En la tabla 4.3 mostramos la compatibilidad de estas notas con las del sistema temperado:

\begin{tabular}{|l|ccc|}
\hline Nota & Compat $(\mathrm{p}, \mathrm{t})$ & Compat $(\mathrm{z}, \mathrm{t})$ & Compat $(\mathrm{h}, \mathrm{t})$ \\
\hline $\mathrm{Mi}$ & 0,8841 & 0,8841 & 0,8875 \\
$\mathrm{La}$ & 1 & 1 & 1 \\
$\mathrm{Si}$ & 0,8268 & 0,8268 & 0,833 \\
$\mathrm{La} \#$ & 0,3955 & 0,6547 & 0,4163 \\
$\mathrm{Sol} \#$ & 0,5682 & 0,482 & 0,583 \\
Fa\#\# & 0,1366 & 0 & 0,1669 \\
Fa\# & 0,741 & 0,741 & 0,7502 \\
La & 1 & 1 & 1 \\
$\mathrm{Mi} \#$ & 0,3092 & 0 & 0,3336 \\
$\mathrm{Sol} \#$ & 0,5682 & 0,482 & 0,583 \\
La\# & 0,3955 & 0,6547 & 0,4163 \\
\hline
\end{tabular}

Tabla 4.3. Compatibilidad de las notas del fragmento de Béla Bartók (las notas que no están en las zonas de Garbuzov aparecen sombreadas.)

Fuente: Elaboración propia

No debemos pasar por alto una cuestión que podría conducir a situaciones conflictivas. ¿El número de notas que se tomen por octava podría determinar que unas notas pasasen de estar en la zona de Grabuzov a no estarlo?

Como cabía esperar, la respuesta es que si una nota está en la zona de Garbuzov para un sistema de afinación con un cierto número de notas, también lo estará para otra cantidad de notas. Es decir, que en este caso el La\#, Fa\#\# y La\# pitagóricos o holderianos y el Fa\#\# y Mi\# zarlinianos no están en la zona de Garbuzov de sus homólogas en el sistema de Hölder independientemente del número de notas por octava. La razón es que si estas notas distan más de 12 cents de sus homólogos, esta distancia es independiente del número de notas considerado. 


\subsubsection{Compatibilidad entre sistemas de afinación}

Con la compatibilidad entre las notas el estudio resultaría insuficiente, porque nosotros lo que necesitamos en realidad es conocer cuándo los sistemas de afinación son compatibles entre sí, y no nota a nota.

Las condiciones que buscamos entre dos sistemas compatibles son varias:

a) Que ambos sistemas tengan el mismo número de notas

b) Que ambos sistemas posean el mismo grado de imprecisión $\delta$.

c) Que dada una nota de uno de los sistemas, exista una y sólo una nota del otro sistema que sea compatible con ella ${ }^{20}$.

Por otro lado, esta claro que nuestra idea será fijar un nivel de exigencia, $\alpha$, y buscar si a ese nivel dos sistemas son equivalentes. De ahí que a la compatibilidad entre sistemas la llamemos $\alpha$-compatibilidad, porque es necesario expresar hasta qué punto son equivalentes. definición:

A todas estas condiciones responde de forma satisfactoria la siguiente

Definición 4.4: Consideramos dos sistemas con $n$ notas y una precisión $\delta$,

$$
\tilde{S}=\left\{\left(s_{1}, \delta\right),\left(s_{2}, \delta\right), \ldots,\left(s_{n}, \delta\right)\right\}, \tilde{T}=\left\{\left(t_{1}, \delta\right),\left(t_{2}, \delta\right), \ldots,\left(t_{n}, \delta\right)\right\}
$$

Decimos que $\tilde{S}$ y $\tilde{T}$ son $\alpha$-compatibles ( $\alpha$ un número real entre 0 y 1 ) si dada una nota de $2^{\tilde{s}_{i}}$ de $\tilde{S}(\delta)$ sólo hay una nota $2^{\tilde{t}_{j}}$ de $\tilde{T}(\delta)$ de manera que la compatibilidad entre $2^{\tilde{s}_{i}}$ y $2^{\tilde{t}_{j}}$ es, al menos, $\alpha$. Es decir,

$$
\operatorname{Compat}\left(2^{\tilde{s}_{i}}, 2^{\tilde{t}_{j}}\right) \geq \alpha
$$

Este concepto supone dos cosas:

1. Garantiza que para cada nota del sistema $\tilde{S}(\delta)$ hay una en el sistema $\tilde{T}(\delta)$ que es muy parecida. De hecho la sensación que producen ambas

\footnotetext{
${ }^{20}$ Si hubiese más de una nota compatible con una dada, se plantearía una confusión entre cuál es la que deberíamos elegir, y como se verá en el ejemplo siguiente esto hace inviable la compatibilidad.
} 
difieren menos de $1200 \bullet \delta$ cents. Por ejemplo, si tomamos 12 notas, $\delta=1 / 24$

2. Las equivalencias no pueden llevar a confusión, es decir para una nota de $\tilde{S}(\delta)$ no puede haber más de una nota de $\tilde{T}(\delta) \alpha$-compatible con ella. Es decir, que el Do de $\tilde{S}(\delta)$ sólo será $\alpha$-compatible con el Do de $\tilde{T}(\delta)$ y con ninguna nota más.

Si alguna de las dos condiciones que acabamos de mencionar no se verifica, los sistemas no serán compatibles, y esto significará en la práctica que instrumentos que afinan en dos sistemas no compatibles no pueden utilizarse simultáneamente en la misma agrupación musical.

A modo de ejemplo, vamos a ver un sistema de afinación de 41 notas que no es compatible con el sistema temperado. Este sistema fue propuesto por Paul von Jankó $^{21}$ (1856-1919), pero no tuvo la trascendencia de otros temperamentos. Quizá, una de las razones es que no es compatible con el sistema pitagórico (y aún menos con el de Zarlino).

Jankó que era musicólogo y matemático creó un nuevo piano, patentado en 1882, a base de seis filas de pequeñas teclas superpuestas, como en una máquina de escribir. Propagó su invento en el Conservatorio de Schawenka, en Berlín, a través de conciertos y en sus obras Eine neue klaviatur (1866) y Über mehr als 12-stuflige Temperaturen (1901), e intentó que su sistema tuviese éxito, pero lo cierto es que no fue así.

Ejemplo 4.6: Consideramos dos sistemas de afinación formado por 41 notas

$$
N=\left\{\begin{array}{l}
\mathrm{la}^{3 \mathrm{~b}}, \mathrm{mi}^{3 \mathrm{~b}}, \mathrm{si}^{3 \mathrm{~b}}, \\
\mathrm{fa}^{2 \mathrm{~b}}, \mathrm{do}^{2 \mathrm{~b}}, \mathrm{sol}^{2 \mathrm{~b}}, \mathrm{sol}^{2 \mathrm{~b}}, \mathrm{re}^{2 \mathrm{~b}}, \mathrm{la}^{2 \mathrm{~b}}, \mathrm{mi}^{2 \mathrm{~b}}, \mathrm{si}^{2 \mathrm{~b}}, \\
\mathrm{fa}^{\mathrm{b}}, \mathrm{do}^{\mathrm{b}}, \mathrm{sol}^{\mathrm{b}}, \mathrm{sol}^{\mathrm{b}}, \mathrm{re}^{\mathrm{b}}, \mathrm{la}^{\mathrm{b}}, \mathrm{mi}^{\mathrm{b}}, \mathrm{si}^{\mathrm{b}}, \\
\mathrm{fa}, \mathrm{do}, \mathrm{sol}, \mathrm{sol}, \mathrm{re}, \mathrm{la}, \mathrm{mi}, \mathrm{si}, \\
\mathrm{fa}^{\#}, \mathrm{do}^{\#}, \mathrm{sol}^{\#}, \mathrm{sol}^{\#}, \mathrm{re}^{\#}, \mathrm{la}^{\#}, \mathrm{mi}^{\#}, \mathrm{si}^{\#}, \\
\mathrm{fa}^{2 \#}, \mathrm{do}^{2 \#}, \mathrm{sol}^{2 \#}, \mathrm{sol}^{2 \#}, \mathrm{re}^{2 \#}, \mathrm{la}^{2 \#}, \mathrm{mi}^{2 \#}, \mathrm{si}^{2 \#}, \\
\mathrm{fa}^{3 \#}, \mathrm{do}^{3 \#}, \mathrm{sol}^{3 \#}
\end{array}\right\}
$$

21 En http://paginas.tol.itesm.mx/campus/L00280370/musicos.html o Lattard (1988) puede verse más información sobre este sistema de afinación. 
en el sistema pitagórico y un temperamento igual de 41 notas. Veamos que estos dos sistemas no son compatibles.

Como hemos dicho en el comentario a la definición 4.4, basta con que no se verifique alguna de las dos condiciones de la definición para que los sistemas no sean compatibles. Si calculamos la compatibilidad entre si3\# y do\# pitagórico y temperado (de 41 notas) se tiene

$$
\begin{aligned}
& \text { Compat }\left[\tilde{s} i^{3 \#} \text { (temperado), } \tilde{d} o^{\# \#}(\text { pitagórico })\right]=0.661499 \\
& \text { Compat }\left[\tilde{s} i^{3 \#} \text { (temperado), } \tilde{s} i^{3 \#}(\text { pitagórico })\right]=0.338502
\end{aligned}
$$

Gráficamente, la situación es la siguiente:

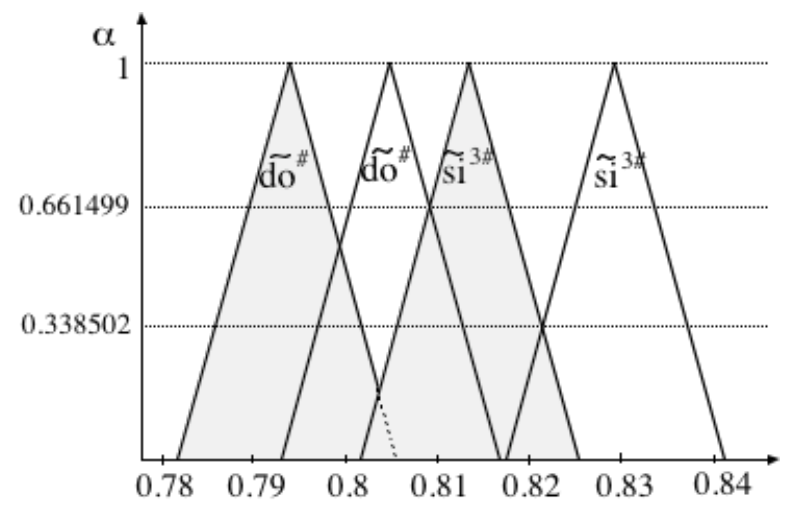

Fig. 4. 25. Compatibilidad entre algunas notas del ejemplo 4.5. (en gris aparecen las notas temperadas y en blanco las pitagóricas) Fuente: Elaboración propia.

Por tanto, los sistemas no pueden ser compatibles:

a) El Si3\# pitagórico y el $\mathrm{Si3 \#}$ temperado tienen menor grado de compatibilidad que el Do\# pitagórico y el Si3\# temperado.

b) El Do\# pitagórico y el Do\# temperado tienen menor grado de compatibilidad que el Do\# pitagórico y el Si3\# temperado.

Estas dos razones hacen que no se puedan asociar los sistemas nota a nota de forma única, por tanto se produciría una confusión que haría que la convivencia de ambos sistemas resultase inviable. 


\subsection{Sistemas temperado, pitagórico, de Zarlino y de Hölder. Compatibilidad.}

En este apartado vamos analizar el concepto de $\alpha$-compatibilidad para los sistemas estudiados en el capítulo 2 de esta memoria. Para ello, partimos de las frecuencias exactas de veintiuna ${ }^{22}$ notas de los sistemas pitagórico, temperado de 12 notas, zarliniano y holderiano, en la octava $\mathrm{Do}_{3}-\mathrm{Do}_{4}$. Si fijamos el $\mathrm{La}=440$ $\mathrm{Hz}$, las frecuencias son las siguientes (véase el segundo capítulo):

\begin{tabular}{|c|cccc|}
\hline NOTA & Pitágoras & Temperado & Zarlino $^{23}$ & Hölder \\
\hline Do & 260,74074 & 261,6265 & 264 & 260,7715 \\
Si\# & 264,29809 & 261,6265 & 515,625 & 264,204 \\
Reb & 274,68983 & 277,1826 & 285,12 & 274,776 \\
Do\# & 278,4375 & 277,1826 & 275 & 278,394 \\
Re & 293,33333 & 293,6648 & 297 & 293,3448 \\
Mib & 309,02606 & 311,127 & 316,8 & 309,099 \\
Re\# & 313,24219 & 311,127 & 309,375 & 313,168 \\
Fab & 325,55832 & 329,6275 & 337,92 & 325,699 \\
Mi & 330 & 329,6275 & 330 & 329,9869 \\
Fa & 347,65432 & 349,2282 & 352 & 347,709 \\
Mi\# & 352,39746 & 349,2282 & 343,75 & 352,286 \\
Solb & 366,25311 & 369,9944 & 380,16 & 366,383 \\
Fa\# & 371,25 & 369,9944 & 366,66667 & 371,206 \\
Sol & 391,11111 & 391,9954 & 396 & 391,1419 \\
Lab & 412,03475 & 415,3047 & 422,4 & 412,148 \\
Sol\# & 417,65625 & 415,3047 & 412,5 & 417,5739 \\
La & 440 & 440 & 440 & 440 \\
Sib & 463,5391 & 466,1638 & 475,2 & 463,63 \\
La\# & 469,86328 & 466,1638 & 458,33333 & 469,7337 \\
Dob & 488,33748 & 493,8833 & 506,88 & 488,53 \\
Si & 495 & 493,8833 & 495 & 494,9609 \\
\hline
\end{tabular}

Tabla 4.4. Frecuencia (en Hz.) de 21 notas de cuatro sistemas de afinación (fijando $\mathrm{La}=440 \mathrm{~Hz}$ ).

Fuente: Elaboración propia

\footnotetext{
22 Para realizar este estudio hemos ampliado a 21 el número de notas del sistema temperado utilizando 9 enarmonías: $\mathrm{Do}=\mathrm{Si} \#, \mathrm{Reb}=\mathrm{Do \#}, \mathrm{Mib}=\mathrm{Re} \#, \mathrm{Fab}=\mathrm{Mi}, \mathrm{Fa}=\mathrm{Mi}$, Solb=Fa\#, Lab=Sol\#, $\mathrm{Sib}=\mathrm{La}$, $\mathrm{Dob}=\mathrm{Si}$.

${ }^{23}$ Como se vio en el capítulo 2 de esta memoria, en el sistema de Zarlino, a diferencia de los otros tres sistemas, una nota alterada por un bemol es más aguda que cuando está alterada por un sostenido.
} 
A partir de las frecuencias expresadas en la tabla anterior podemos calcular la distancia de cada nota a sus homólogas en los cuatro sistemas de afinación.

\begin{tabular}{|c|c|c|c|c|c|c|}
\hline NOTA & $d(p, t)$ & $d(p, z)$ & $d(p, h)$ & $\mathrm{d}(\mathrm{z}, \mathrm{t})$ & $\mathrm{d}(\mathrm{z}, \mathrm{h})$ & $\mathrm{d}(\mathrm{t}, \mathrm{h})$ \\
\hline Do & 5,87119 & 21,5063 & 0,2046 & 15,6351 & 21,3017 & 5,66656 \\
\hline $\mathrm{Si} \#$ & 17,5888 & 43,0125 & 0,6164 & 25,42376 & 42,3961 & 16,9724 \\
\hline Reb & 15,6398 & 64,5189 & 0,543 & 48,87906 & 63,9759 & 15,0968 \\
\hline Do\# & 7,8202 & 21,5063 & 0,2705 & 13,68609 & 21,2358 & 7,54971 \\
\hline $\mathbf{R e}$ & 1,95521 & 21,5063 & 0,0682 & 19,5511 & 21,4381 & 1,88698 \\
\hline Mib & 11,7301 & 43,0126 & 0,4086 & 31,28248 & 42,604 & 11,3215 \\
\hline Re\# & 11,7299 & 21,5063 & 0,4101 & 9,776375 & 21,0962 & 11,3198 \\
\hline Fab & 21,5047 & 64,5189 & 0,7479 & 43,01416 & 63,7709 & 20,7568 \\
\hline Mi & 1,9553 & 0 & 0,0682 & 1,9553 & 0,06821 & 1,88709 \\
\hline $\mathbf{F a}$ & 7,81985 & 21,5063 & 0,2723 & 13,68644 & 21,234 & 7,54758 \\
\hline Mi\# & 15,6402 & 43,0126 & 0,5477 & 27,37242 & 42,4649 & 15,0925 \\
\hline Solb & 17,5949 & 64,5189 & 0,6139 & 46,92397 & 63,905 & 16,981 \\
\hline Fa\# & 5,86511 & 21,5063 & 0,2052 & 15,64118 & 21,3011 & 5,65991 \\
\hline Sol & 3,90985 & 21,5063 & 0,1364 & 17,59645 & 21,3699 & 3,77343 \\
\hline $\mathrm{Lab}$ & 13,685 & 43,0126 & 0,4758 & 29,32756 & 42,5368 & 13,2092 \\
\hline Sol\# & 9,77499 & 21,5063 & 0,341 & 11,7313 & 21,1652 & 9,43395 \\
\hline La & 0 & 0 & 0 & 0 & 0 & 0 \\
\hline $\mathrm{Sib}$ & 9,77513 & 43,0126 & 0,3395 & 33,23743 & 42,6731 & 9,43567 \\
\hline La\# & 13,6849 & 43,0126 & 0,4775 & 29,32772 & 42,5351 & 13,2074 \\
\hline Dob & 19,55 & 64,5189 & 0,6824 & 44,96886 & 63,8365 & 18,8676 \\
\hline $\mathbf{S i}$ & 3,91001 & 0 & 0,1364 & 3,910006 & 0,13642 & 3,77359 \\
\hline
\end{tabular}

Tabla 4.5. Distancia (en cents) entre 21 notas de cuatro sistemas de afinación ( $\mathrm{t}=$ temperado, $\mathrm{h}=$ holderiano, $\mathrm{p}=$ pitagórico, $\mathrm{z}=$ zarliniano) Fuente: Elaboración propia

En la tabla 4.5 aparecen sombreadas las distancias superiores a un octavo de tono temperado de modo que se pueda ver, grosso modo, la dificultad para que algunos sistemas puedan ser compatibles.

Para analizar la compatibilidad de forma rigurosa, debemos entender que las 21 notas que analizamos son números borrosos triangulares $\tilde{f}_{1}, \tilde{f}_{2}, \ldots, \tilde{f}_{21}$ en cuyo centro se encuentra la frecuencia expresada en la tabla 4.3 y con una tolerancia de

$$
\Delta=1200 \times \frac{1}{2 \times 21}=\frac{1200}{2 \times 21}=28,57 \text { cents. }
$$


Para calcular la compatibilidad entre las notas de los diferentes sistemas, tenemos en cuenta la fórmula que presentábamos en el apartado anterior:

$$
\operatorname{Compat}\left(f_{1}, f_{2}\right)=1-\frac{d\left(f_{1}, f_{2}\right)}{2 \Delta} \text {. }
$$

Sustituyendo el valor de $\Delta$ en la fórmula de la compatibilidad, tenemos

$$
\operatorname{Compat}\left(f_{1}, f_{2}\right)=1-\frac{d\left(f_{1}, f_{2}\right)}{2 \Delta}=1-\frac{d\left(f_{1}, f_{2}\right)}{2 \times \frac{1200}{2 \times 21}}=1-21 \frac{d\left(f_{1}, f_{2}\right)}{1200}
$$

\begin{tabular}{|c|c|c|c|c|c|c|}
\hline \multirow{2}{*}{$\frac{\text { NOTA }}{\text { Do }}$} & \multicolumn{2}{|c|}{$\operatorname{Comp}(p, t) \operatorname{Comp}(p, z$} & $\operatorname{Comp}(p, h$ & \multicolumn{3}{|c|}{$\operatorname{Comp}(z, t) \operatorname{Comp}(z, h) \operatorname{Comp}(t, h)$} \\
\hline & 0,89725 & 0,62364 & 0,99642 & 0,72639 & 0,62722 & 0,90084 \\
\hline $\mathrm{Si} \#$ & 0,6922 & 0,24728 & 0,98921 & 0,55508 & 0,25807 & 0,70298 \\
\hline Reb & 0,7263 & 0 & 0,9905 & 0,14462 & 0 & 0,73581 \\
\hline Do\# & 0,86315 & 0,62364 & 0,99527 & 0,76049 & 0,62837 & 0,86788 \\
\hline $\mathbf{R e}$ & 0,96578 & 0,62364 & 0,99881 & 0,65786 & 0,62483 & 0,96698 \\
\hline Mib & 0,79472 & 0,24728 & 0,99285 & 0,45256 & 0,25443 & 0,80187 \\
\hline Re\# & 0,79473 & 0,62364 & 0,99282 & 0,82891 & 0,63082 & 0,8019 \\
\hline $\mathrm{Fab}$ & 0,62367 & 0 & 0,98691 & 0,24725 & 0 & 0,63676 \\
\hline Mi & 0,96578 & 1 & 0,99881 & 0,96578 & 0,99881 & 0,96698 \\
\hline $\mathbf{F a}$ & 0,86315 & 0,62364 & 0,99524 & 0,76049 & 0,6284 & 0,86792 \\
\hline Mi\# & 0,7263 & 0,24728 & 0,99042 & 0,52098 & 0,25686 & 0,73588 \\
\hline Solb & 0,69209 & 0 & 0,98926 & 0,17883 & 0 & 0,70283 \\
\hline $\mathrm{Fa \#}$ & 0,89736 & 0,62364 & 0,99641 & 0,72628 & 0,62723 & 0,90095 \\
\hline Sol & 0,93158 & 0,62364 & 0,99761 & 0,69206 & 0,62603 & 0,93397 \\
\hline Lab & 0,76051 & 0,24728 & 0,99167 & 0,48677 & 0,25561 & 0,76884 \\
\hline Sol\# & 0,82894 & 0,62364 & 0,99403 & 0,7947 & 0,62961 & 0,83491 \\
\hline $\mathbf{L a}$ & 1 & 1 & 1 & 1 & 1 & 1 \\
\hline Sib & 0,82894 & 0,24728 & 0,99406 & 0,41834 & 0,25322 & 0,83488 \\
\hline La\# & 0,76051 & 0,24728 & 0,99164 & 0,48676 & 0,25564 & 0,76887 \\
\hline Dob & 0,65787 & 0 & 0,98806 & 0,21304 & 0 & 0,66982 \\
\hline $\mathrm{Si}$ & 0,93157 & 1 & 0,99761 & 0,93157 & 0,99761 & 0,93396 \\
\hline
\end{tabular}

Así, la compatibilidad entre las 21 notas es la siguiente:

Tabla 4.6. Compatibilidad entre 21 notas de cuatro sistemas de afinación $(\mathrm{t}=$ temperado, $\mathrm{h}=$ holderiano, $\mathrm{p}=$ pitagórico, $\mathrm{z}=$ zarliniano $)$.

Fuente: Elaboración propia 
Gráficamente, la es más fácil comprobar hasta qué nivel son compatibles las notas de los cuatro sistemas de afinación:

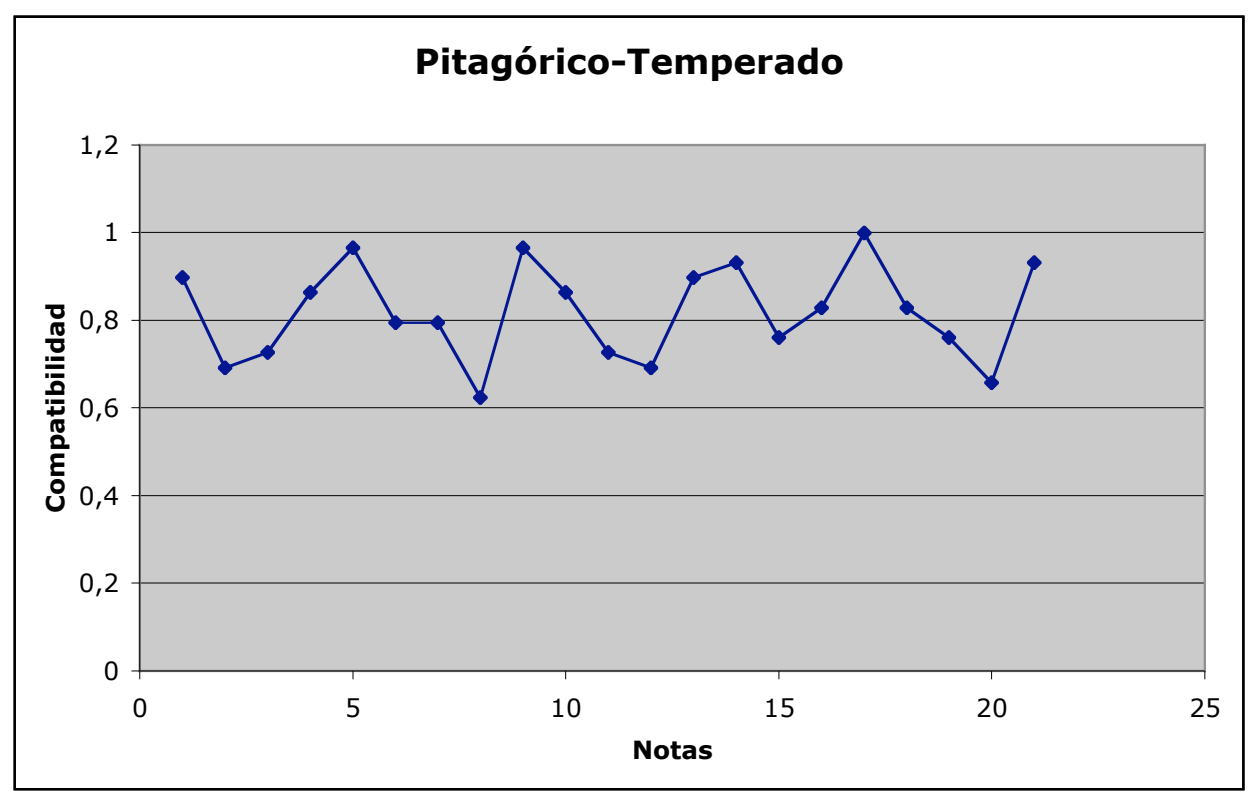

Fig. 4. 26. Compatibilidad entre 21 notas de los sistemas pitagórico y temperado. Fuente: Elaboración propia.

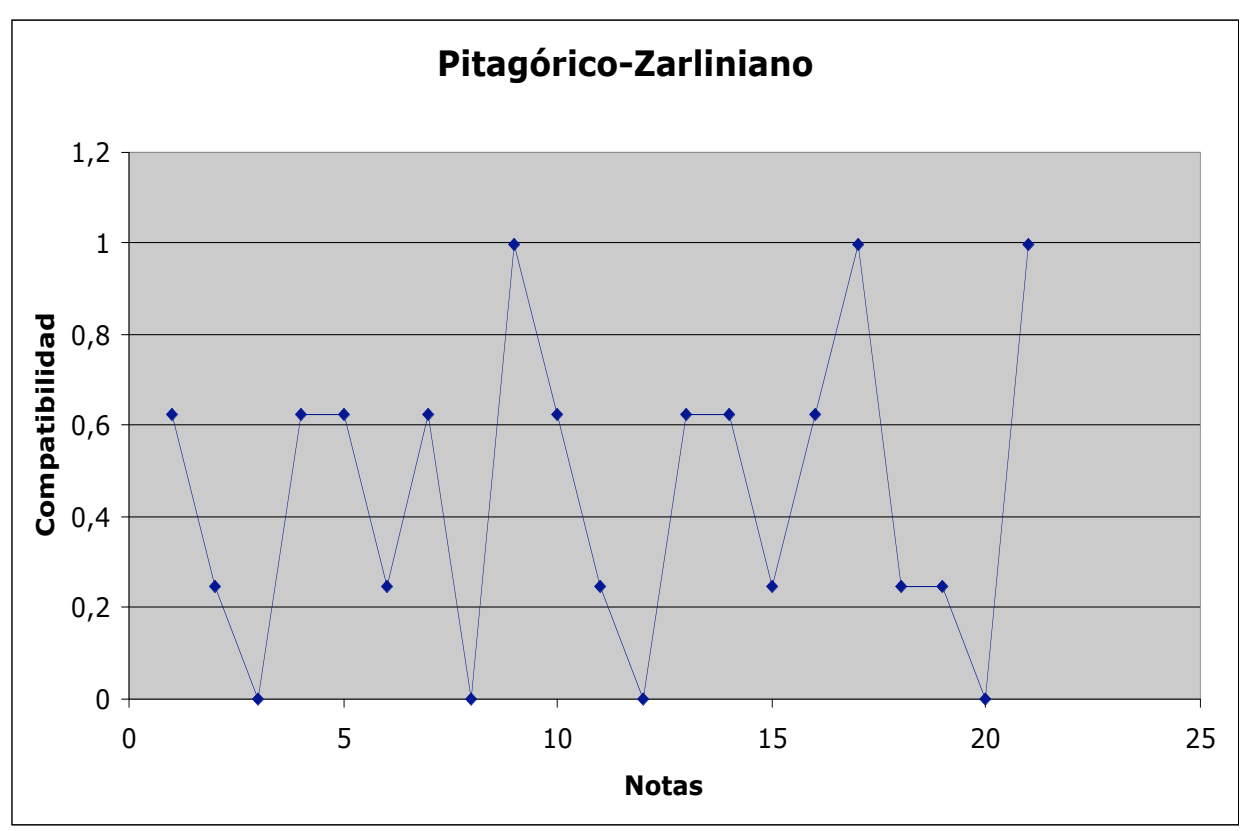

Fig. 4. 27. Compatibilidad entre 21 notas de los sistemas pitagórico y zarliniano. Fuente: Elaboración propia. 


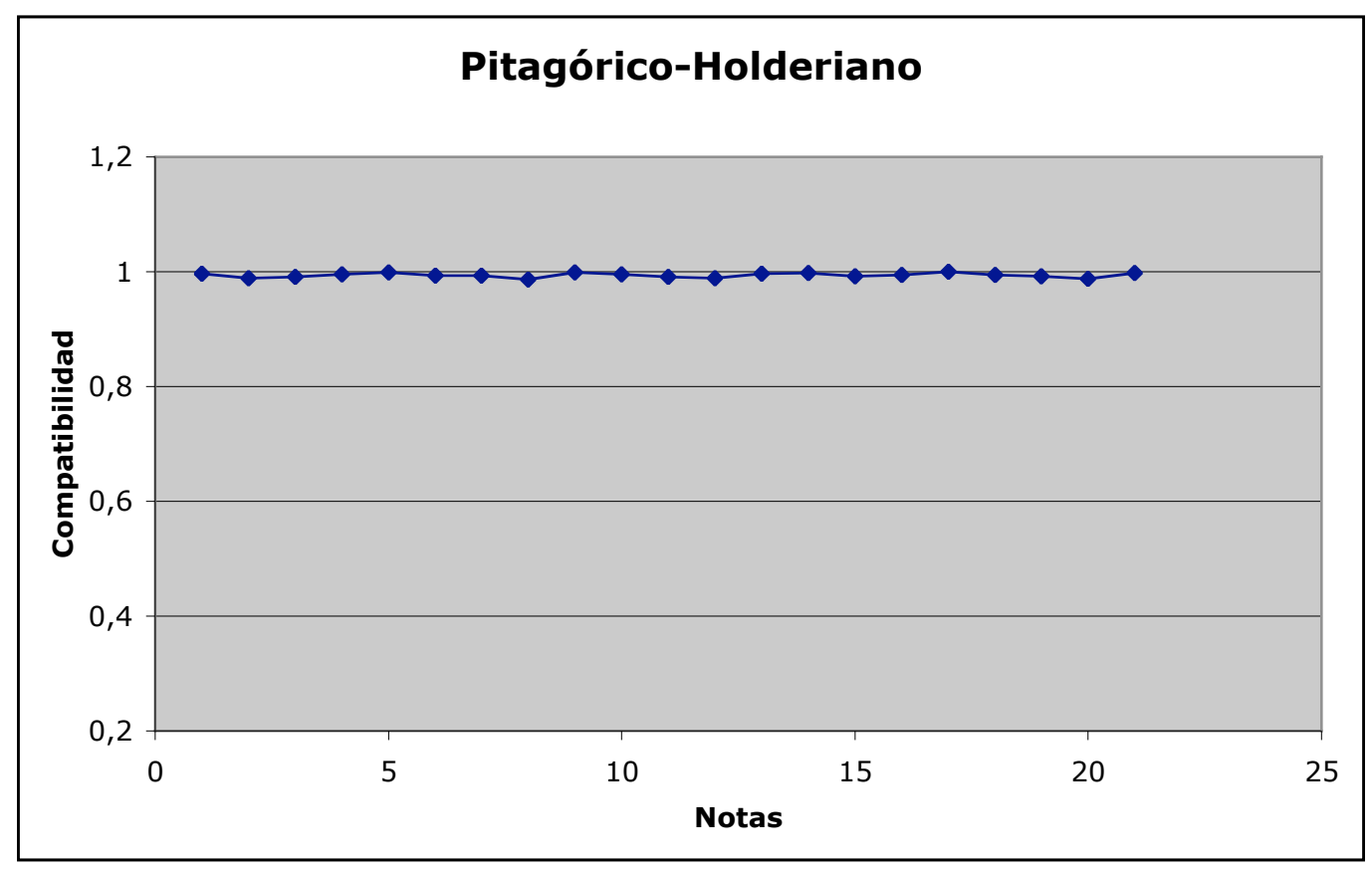

Fig. 4. 28. Compatibilidad entre 21 notas de los sistemas pitagórico y holderiano. Fuente: Elaboración propia.

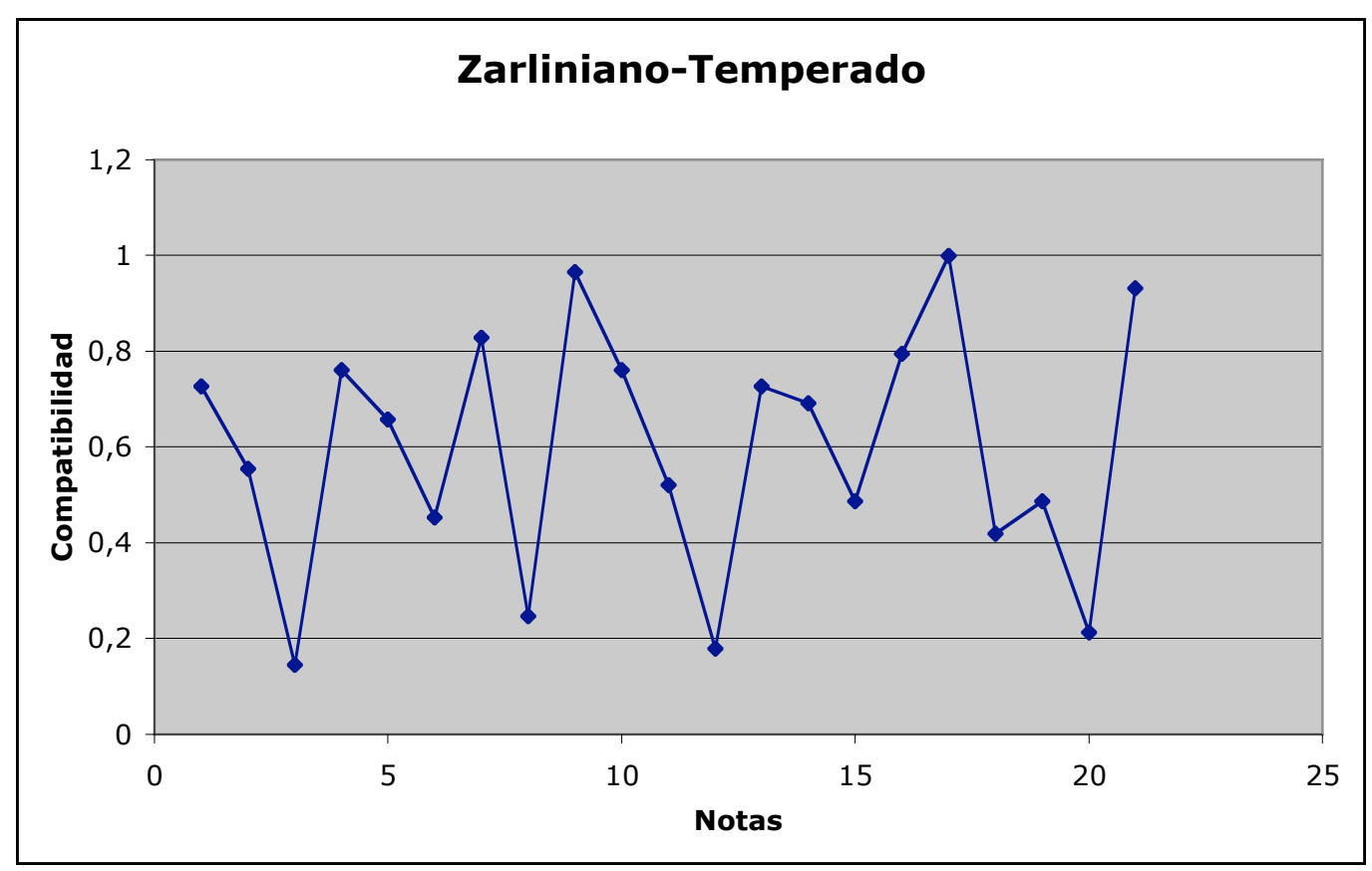

Fig. 4. 29. Compatibilidad entre 21 notas de los sistemas zarliniano y temperado. Fuente: Elaboración propia. 


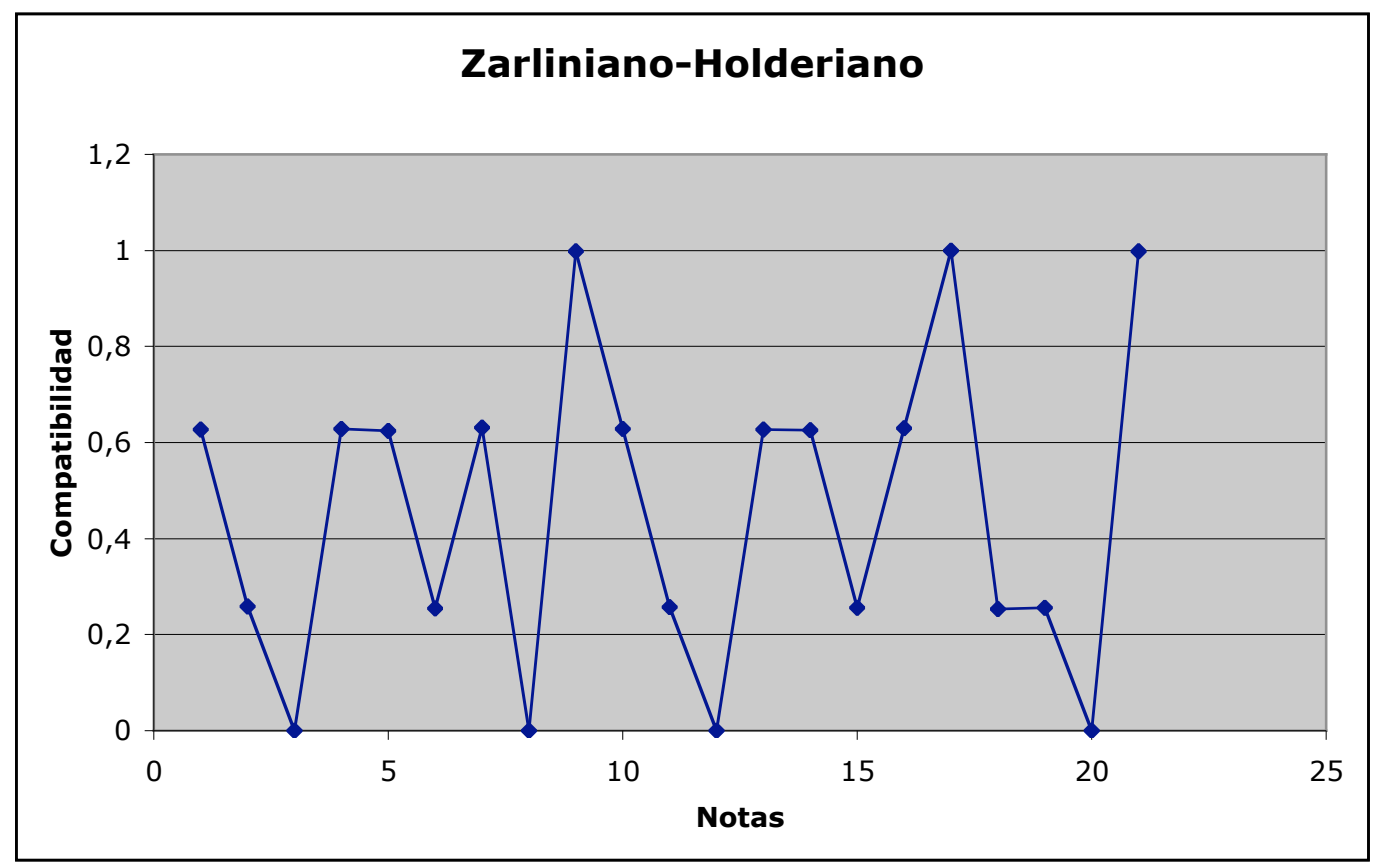

Fig. 4. 30. Compatibilidad entre 21 notas de los sistemas zarliniano y holderiano. Fuente: Elaboración propia.

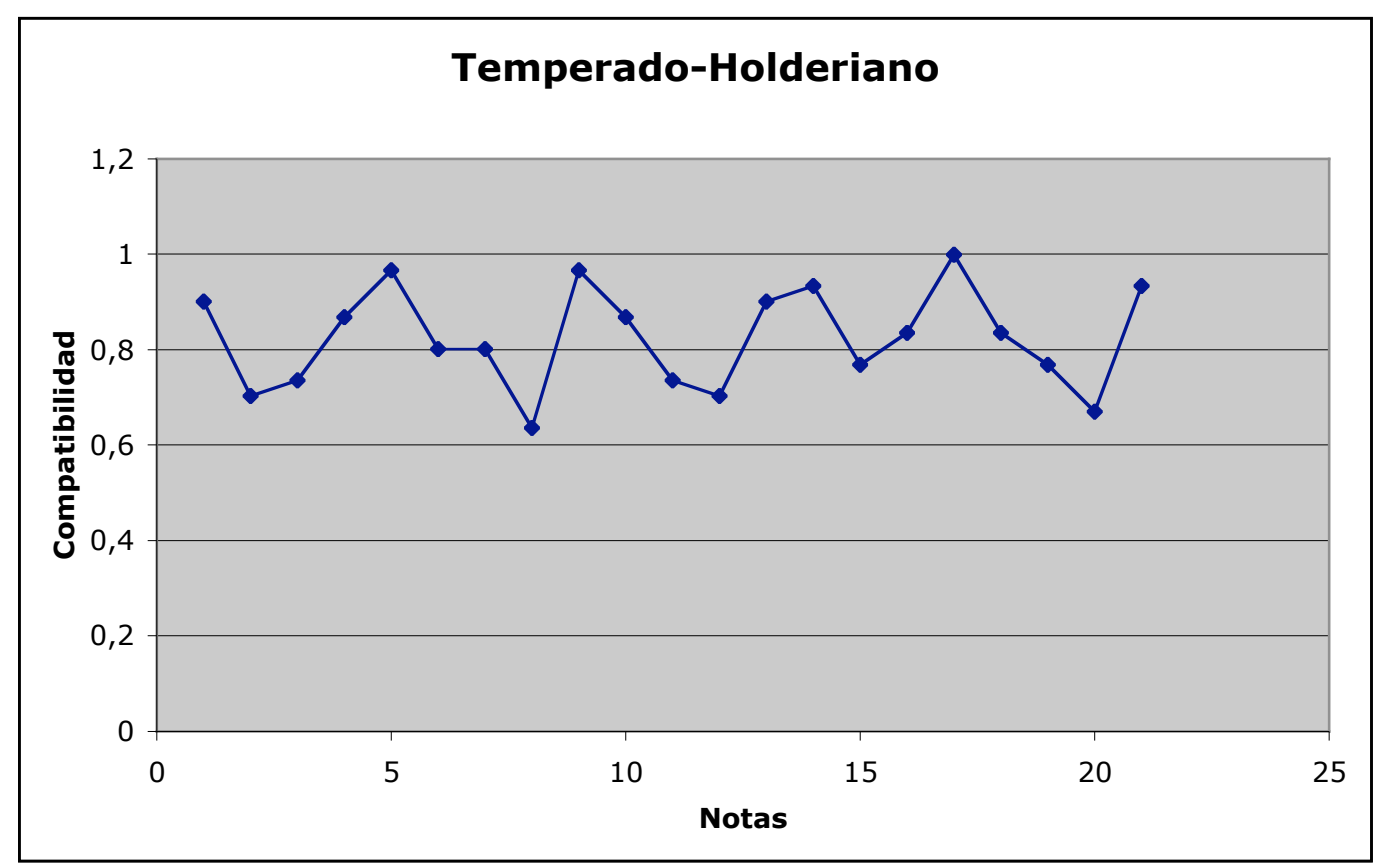

Fig. 4. 31. Compatibilidad entre 21 notas de los sistemas holderiano y temperado. Fuente: Elaboración propia. 
Hasta aquí, lo que hemos hecho es calcular la compatibilidad entre notas, pero no la compatibilidad entre los sistemas de forma global. Para ello, sería necesario comprobar que una nota, el Si pitagórico (por ejemplo) sólo es $\alpha$ compatible con el Si del resto de sistemas pero con ninguna otra nota.

Sin embargo, sin necesidad de hacer este estudio podemos extraer bastantes conclusiones:

a) Las 21 notas del sistema temperado no pueden ser compatibles con ninguno de los sistemas, porque como hemos establecido las siguientes igualdades:

$$
\begin{gathered}
\mathrm{Do}=\mathrm{Si} \#, \text { Reb=Do\#, Mib=Re\#, Fab=Mi, Fa=Mi\#, } \\
\text { Solb=Fa\#, Lab=Sol\#, Sib=La\#, Dob=Si. }
\end{gathered}
$$

Con ello, cualquier nota que sea $\alpha$-compatible con Do tiene que serlo en igual medida con Si\#, y esto induciría a confusión.

Como puede verse en las figuras 4.22, 4.25 y 4.27 hay notas del sistema temperado que son compatibles con las de los otros sistemas incluso con niveles muy elevados en los casos del sistema pitagórico y de Hölder. Sin embargo, este hecho no nos permite afirmar que éstos sistemas sean intercambiables con el temperado.

b) El sistema de Zarlino no es compatible con los de Pitágoras o Hölder para ningún nivel de exigencia, porque los niveles de compatibilidad para las notas Reb, Fab, Solb, Dob es cero.

c) Entre los sistemas de Pitágoras y de Hölder el nivel más bajo de compatibilidad entre notas es $\alpha=0,98806$ y se produce con el Dob. Para demostrar que ambos sistemas son compatibles a nivel $\alpha=0,98806$ habría faltaría comprobar que las notas sólo se asocian una a una, es decir que no se puede prestar a confusión.

No vamos a realizar esta comprobación por dos razones: en primer lugar, es un hecho conocido que el sistema pitagórico y el de Hölder son consideramos por la mayoría de musicólogos como equivalentes y, en segundo lugar, porque en el ejemplo próximo lo vamos a comprobar para 12 notas y la forma de hacerlo es idéntica.

A continuación veremos que el número de notas que utilizamos es decisivo para la $\alpha$-compatibilidad de los sistemas. 
Ejemplo 4.7: Analicemos la compatibilidad de los cuatro anteriores con 12 notas.

Evidentemente, las frecuencias de las notas y las distancias entre ellas son las mismas que aparecen en las tablas 4.3 y 4.4 respectivamente. Sin embargo el nivel de compatibilidad entre las notas no podemos extraerlo de la tabla 4.5, porque al variar el número de notas las fórmula para calcularla ha variado. Ahora, la tolerancia es

$$
\Delta=1200 \times \frac{1}{2 \times 12}=\frac{1200}{2 \times 12}=50 \text { cents, }
$$

y la fórmula para calcular la compatibilidad es la siguiente:

$$
\operatorname{Compat}\left(f_{1}, f_{2}\right)=1-\frac{d\left(f_{1}, f_{2}\right)}{2 \Delta}=1-\frac{d\left(f_{1}, f_{2}\right)}{2 \times \frac{1200}{2 \times 12}}=1-12 \frac{d\left(f_{1}, f_{2}\right)}{1200} \text {. }
$$

Con ellos, las compatibilidades para 12 notas son las siguientes:

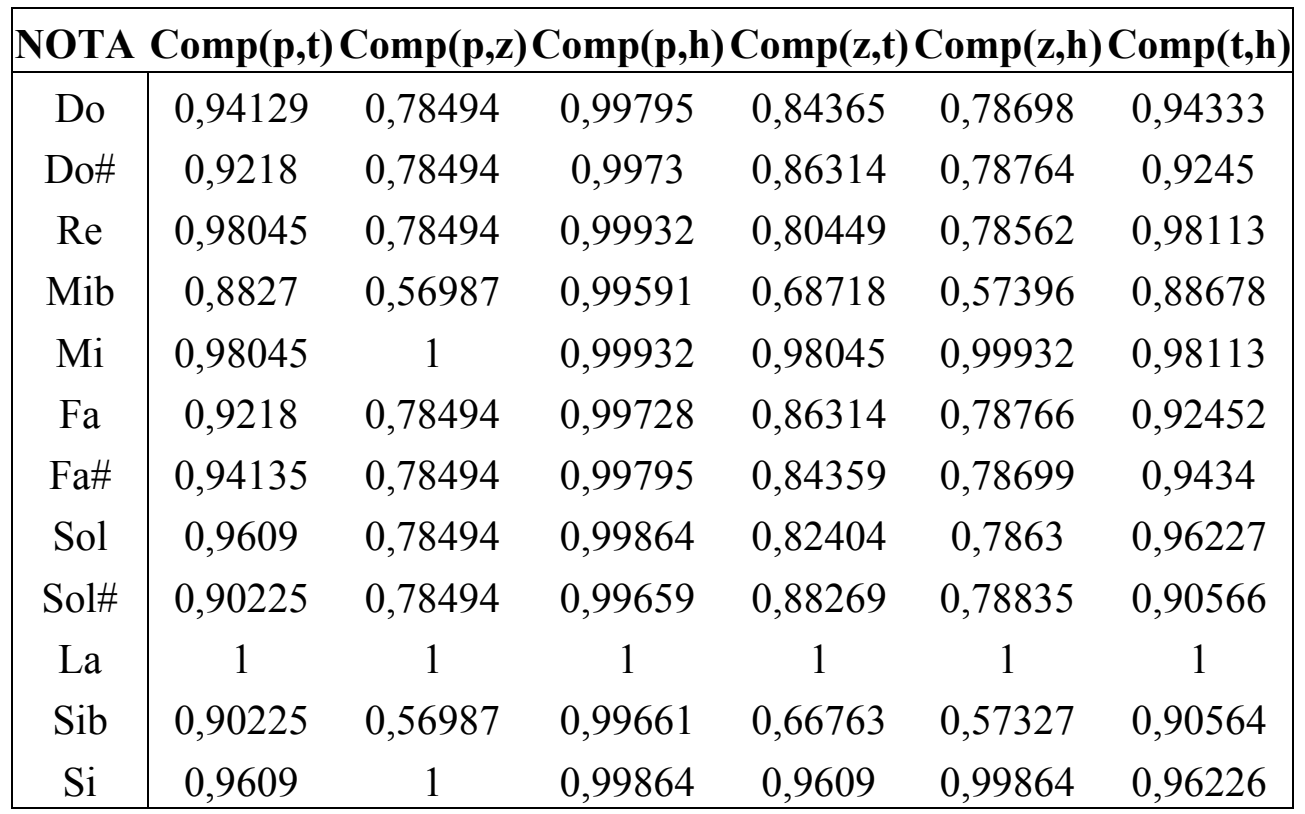

Tabla 4.7. Compatibilidad entre 21 notas de cuatro sistemas de afinación $(\mathrm{t}=$ temperado, $\mathrm{h}=$ holderiano, $\mathrm{p}=$ pitagórico, $\mathrm{z}=$ zarliniano $)$.

Fuente: Elaboración propia 
NOTA: Basta comparar esta las tablas 4.6 y 4.7 para comprobar cómo varía la compatibilidad según el número de notas.

Para obtener de forma más sencilla una visión global, representamos en un gráfico la compatibilidad entre los sistemas:

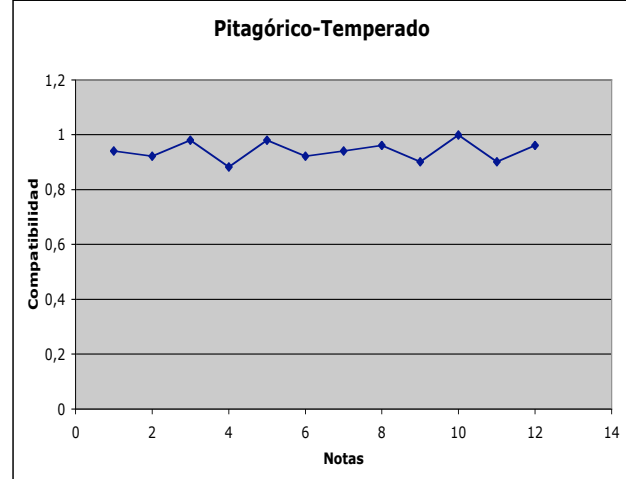

Pitagórico-Holderiano

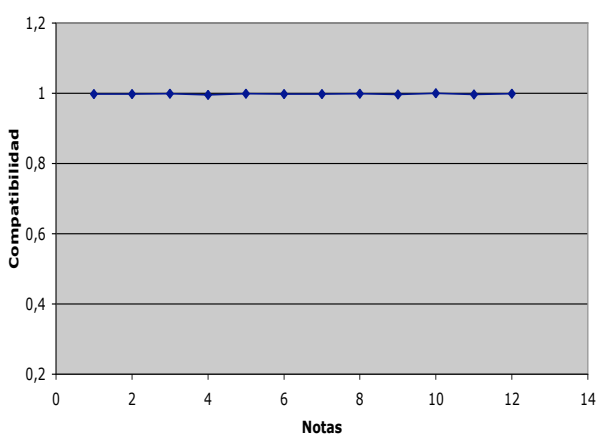

Zarliniano-Holderiano

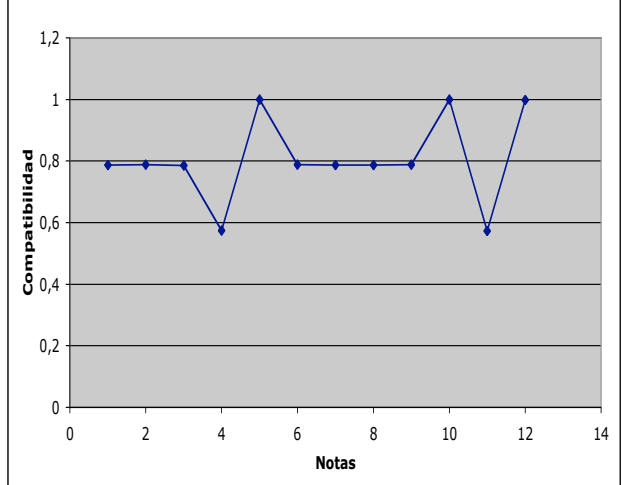

Pitagórico-Zarlino

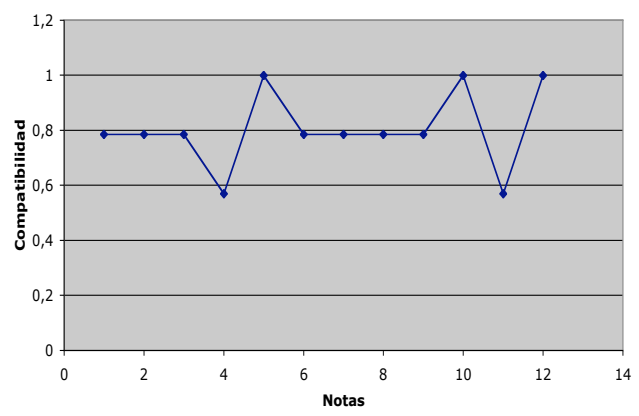

Zarliniano-Temperado

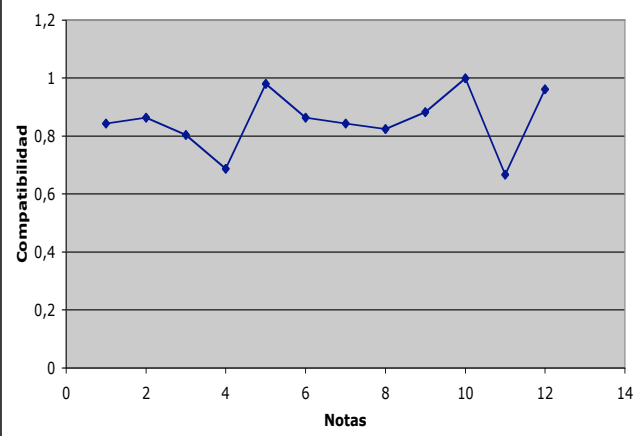

Temperado-Holderiano

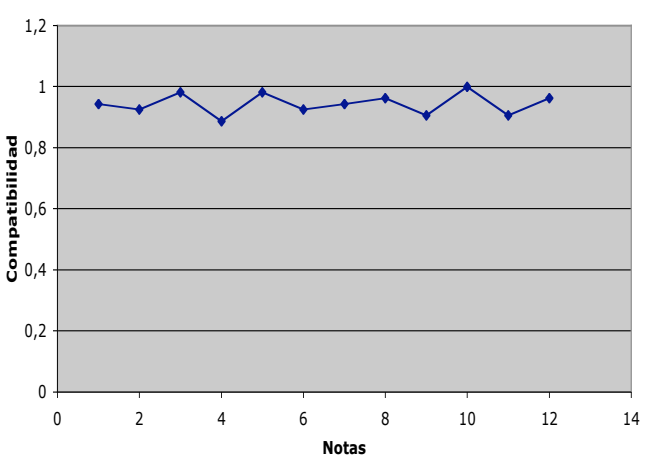

Fig. 4. 32. Compatibilidad entre 12 notas de los sistemas pitagórico, zarliniano, holderiano y temperado.

Fuente: Elaboración propia. 
Además de conocer la compatibilidad entre las notas, para poder afirmar que dos sistemas son compatibles, tenemos que comprobar que cada nota sólo es compatible con una (y sólo una) del otro sistema. A continuación estudiamos precisamente esta característica. Por ejemplo en la tabla 4.8 estudiamos la compatibilidad del Do pitagórico con todas las notas del sistema temperado, luego hacemos lo mismo con el Re pitagórico, y así sucesivamente. Para poder afirmar que estos sistemas son compatibles, tenemos que comprobar que el Do pitagórico sólo es compatible con el Do temperado.

\begin{tabular}{|c|cccccccccccc|}
\hline & Do & Do\# & Re & Mib & Mi & Fa & Fa\# & Sol & Sol\# & La & Sib & Si \\
\hline Do & $\mathbf{0 , 9 4}$ & 0 & 0 & 0 & 0 & 0 & 0 & 0 & 0 & 0 & 0 & 0 \\
Do\# & 0 & $\mathbf{0 , 9 2}$ & 0,08 & 0 & 0 & 0 & 0 & 0 & 0 & 0 & 0 & 0 \\
Re & 0 & 0,02 & $\mathbf{0 , 9 8}$ & 0 & 0 & 0 & 0 & 0 & 0 & 0 & 0 & 0 \\
Mib & 0 & 0 & 0,12 & $\mathbf{0 , 8 8}$ & 0 & 0 & 0 & 0 & 0 & 0 & 0 & 0 \\
Mi & 0 & 0 & 0 & 0 & $\mathbf{0 , 9 8}$ & 0,02 & 0 & 0 & 0 & 0 & 0 & 0 \\
Fa & 0 & 0 & 0 & 0 & 0,08 & $\mathbf{0 , 9 2}$ & 0 & 0 & 0 & 0 & 0 & 0 \\
Fa\# & 0 & 0 & 0 & 0 & 0 & 0 & $\mathbf{0 , 9 4}$ & 0,06 & 0 & 0 & 0 & 0 \\
Sol & 0 & 0 & 0 & 0 & 0 & 0 & 0,04 & $\mathbf{0 , 9 6}$ & 0 & 0 & 0 & 0 \\
Sol\# & 0 & 0 & 0 & 0 & 0 & 0 & 0 & 0 & $\mathbf{0 , 9}$ & 0,1 & 0 & 0 \\
La & 0 & 0 & 0 & 0 & 0 & 0 & 0 & 0 & 0 & $\mathbf{1}$ & 0 & 0 \\
Sib & 0 & 0 & 0 & 0 & 0 & 0 & 0 & 0 & 0 & 0,1 & $\mathbf{0 , 9}$ & 0 \\
Si & 0 & 0 & 0 & 0 & 0 & 0 & 0 & 0 & 0 & 0 & 0 & $\mathbf{0 , 9 6}$ \\
\hline
\end{tabular}

Tabla 4.8. Compatibilidad entre los sistemas pitagórico y temperado.

Fuente: Elaboración propia

\begin{tabular}{|c|rrrrrrrrrrrrr|}
\hline & Do & Do\# & Re & Mib & Mi & Fa & Fa\# & Sol & Sol\# & La & Sib & Si \\
\hline Do & $\mathbf{0 , 7 8}$ & 0,08 & 0 & 0 & 0 & 0 & 0 & 0 & 0 & 0 & 0 & 0 \\
Do\# & 0,08 & $\mathbf{0 , 7 8}$ & 0 & 0 & 0 & 0 & 0 & 0 & 0 & 0 & 0 & 0 \\
Re & 0 & 0 & $\mathbf{0 , 7 8}$ & 0 & 0 & 0 & 0 & 0 & 0 & 0 & 0 & 0 \\
Mib & 0 & 0 & 0,31 & $\mathbf{0 , 5 7}$ & 0 & 0 & 0 & 0 & 0 & 0 & 0 & 0 \\
Mi & 0 & 0 & 0 & 0,29 & $\mathbf{1}$ & 0 & 0 & 0 & 0 & 0 & 0 & 0 \\
Fa & 0 & 0 & 0 & 0 & 0,1 & $\mathbf{0 , 7 8}$ & 0,08 & 0 & 0 & 0 & 0 & 0 \\
Fa\# & 0 & 0 & 0 & 0 & 0 & 0,08 & $\mathbf{0 , 7 8}$ & 0 & 0 & 0 & 0 & 0 \\
Sol & 0 & 0 & 0 & 0 & 0 & 0 & 0 & $\mathbf{0 , 7 8}$ & 0,08 & 0 & 0 & 0 \\
Sol\# & 0 & 0 & 0 & 0 & 0 & 0 & 0 & 0,08 & $\mathbf{0 , 7 8}$ & 0,1 & 0 & 0 \\
La & 0 & 0 & 0 & 0 & 0 & 0 & 0 & 0 & 0 & $\mathbf{1}$ & 0 & 0 \\
Sib & 0 & 0 & 0 & 0 & 0 & 0 & 0 & 0 & 0 & 0,1 & $\mathbf{0 , 5 7}$ & 0 \\
Si & 0 & 0 & 0 & 0 & 0 & 0 & 0 & 0 & 0 & 0 & 0 & $\mathbf{1}$ \\
\hline
\end{tabular}

Tabla 4.9. Compatibilidad entre los sistemas pitagórico y zarliniano.

Fuente: Elaboración propia 


\begin{tabular}{|l|cccccccccccc|}
\hline & Do & Do\# & Re & Mib & Mi & Fa & Fa\# & Sol & Sol\# & La & Sib & Si \\
\hline Do & $\mathbf{0 , 9 9 8}$ & 0 & 0 & 0 & 0 & 0 & 0 & 0 & 0 & 0 & 0 & 0 \\
Do\# & 0 & $\mathbf{0 , 9 9 7}$ & 0,097 & 0 & 0 & 0 & 0 & 0 & 0 & 0 & 0 & 0 \\
Re & 0 & 0,095 & $\mathbf{0 , 9 9 9}$ & 0,094 & 0 & 0 & 0 & 0 & 0 & 0 & 0 & 0 \\
Mib & 0 & 0 & 0,098 & $\mathbf{0 , 9 9 6}$ & 0 & 0 & 0 & 0 & 0 & 0 & 0 & 0 \\
Mi & 0 & 0 & 0 & 0 & $\mathbf{0 , 9 9}$ & 0,095 & 0 & 0 & 0 & 0 & 0 & 0 \\
Fa & 0 & 0 & 0 & 0 & 0,09 & $\mathbf{0 , 9 9 7}$ & 0 & 0 & 0 & 0 & 0 & 0 \\
Fa\# & 0 & 0 & 0 & 0 & 0 & 0 & $\mathbf{1}$ & 0,096 & 0 & 0 & 0 & 0 \\
Sol & 0 & 0 & 0 & 0 & 0 & 0 & 0,1 & $\mathbf{0 , 9 9 9}$ & 0 & 0 & 0 & 0 \\
Sol\# & 0 & 0 & 0 & 0 & 0 & 0 & 0 & 0 & $\mathbf{0 , 9 9 7}$ & 0,09 & 0 & 0 \\
La & 0 & 0 & 0 & 0 & 0 & 0 & 0 & 0 & 0,094 & $\mathbf{1}$ & 0,094 & 0 \\
Sib & 0 & 0 & 0 & 0 & 0 & 0 & 0 & 0 & 0 & 0,09 & $\mathbf{0 , 9 9 7}$ & 0 \\
Si & 0 & 0 & 0 & 0 & 0 & 0 & 0 & 0 & 0 & 0 & 0 & $\mathbf{0 , 9 9 9}$ \\
\hline
\end{tabular}

Tabla 4.10. Compatibilidad entre las 12 notas de los sistemas de afinación pitagórico y holderiano.

Fuente: Elaboración propia

\begin{tabular}{|c|c|c|c|c|c|c|c|c|c|c|c|c|}
\hline & Do & Do\# & $\mathrm{Re}$ & Mib & $\mathrm{Mi}$ & $\mathrm{Fa}$ & $\mathrm{Fa \#}$ & Sol & Sol\# & $\mathrm{La}$ & $\mathrm{Sib}$ & $\mathrm{Si}$ \\
\hline Do & 0,787 & 0,081 & 0 & 0 & 0 & 0 & 0 & 0 & 0 & 0 & 0 & 0 \\
\hline Do\# & 0,08 & 0,788 & 0 & 0 & 0 & 0 & 0 & 0 & 0 & 0 & 0 & 0 \\
\hline $\operatorname{Re}$ & 0 & 0 & 0,786 & 0,309 & 0 & 0 & 0 & 0 & 0 & 0 & 0 & 0 \\
\hline Mib & 0 & 0 & 0 & 0,574 & 0,294 & 0 & 0 & 0 & 0 & 0 & 0 & 0 \\
\hline $\mathrm{Mi}$ & 0 & 0 & 0 & 0 & 0,999 & 0,095 & 0 & 0 & 0 & 0 & 0 & 0 \\
\hline $\mathrm{Fa}$ & 0 & 0 & 0 & 0 & 0 & $\mathbf{0 , 7 8 8} 0$ & 0,08 & 0 & 0 & 0 & 0 & 0 \\
\hline $\mathrm{Fa} \#$ & 0 & 0 & 0 & 0 & 0 & 0,0810 & 0,79 & 0 & 0 & 0 & 0 & 0 \\
\hline Sol & 0 & 0 & 0 & 0 & 0 & 0 & 0 & 0,786 & 0,082 & 0 & 0 & 0 \\
\hline Sol\# & 0 & 0 & 0 & 0 & 0 & 0 & 0 & 0,08 & 0,788 & 0 & 0 & 0 \\
\hline $\mathrm{La}$ & 0 & 0 & 0 & 0 & 0 & 0 & 0 & 0 & 0,094 & 10 & 0,094 & 0 \\
\hline $\mathrm{Sib}$ & 0 & 0 & 0 & 0 & 0 & 0 & 0 & 0 & 0 & 00 & $\mathbf{0 , 5 7 3} 0$ & 0,295 \\
\hline $\mathrm{Si}$ & 0 & 0 & 0 & 0 & 0 & 0 & 0 & 0 & 0 & 0 & $\begin{array}{ll}0 & \mathbf{0}\end{array}$ & 0,999 \\
\hline
\end{tabular}

Tabla 4.11. Compatibilidad entre las 12 notas de los sistemas de afinación zarliniano y holderiano.

Fuente: Elaboración propia 


\begin{tabular}{|l|cccccccccccc|}
\hline & Do & Do\# & Re & Mib & Mi & Fa & Fa\# & Sol & Sol\# & La & Sib & Si \\
\hline Do & $\mathbf{0 , 9 4}$ & 0 & 0 & 0 & 0 & 0 & 0 & 0 & 0 & 0 & 0 & 0 \\
Do\# & 0 & $\mathbf{0 , 9 2}$ & 0,02 & 0 & 0 & 0 & 0 & 0 & 0 & 0 & 0 & 0 \\
Re & 0 & 0,07 & $\mathbf{0 , 9 8}$ & 0,113 & 0 & 0 & 0 & 0 & 0 & 0 & 0 & 0 \\
$\mathrm{Mib}$ & 0 & 0 & 0 & $\mathbf{0 , 8 8 7}$ & 0 & 0 & 0 & 0 & 0 & 0 & 0 & 0 \\
$\mathrm{Mi}$ & 0 & 0 & 0 & 0 & $\mathbf{0 , 9 8}$ & 0,07 & 0 & 0 & 0 & 0 & 0 & 0 \\
$\mathrm{Fa}$ & 0 & 0 & 0 & 0 & 0,02 & $\mathbf{0 , 9 2}$ & 0 & 0 & 0 & 0 & 0 & 0 \\
$\mathrm{Fa \#}$ & 0 & 0 & 0 & 0 & 0 & 0 & $\mathbf{0 , 9 4}$ & 0,038 & 0 & 0 & 0 & 0 \\
$\mathrm{Sol}$ & 0 & 0 & 0 & 0 & 0 & 0 & 0,06 & $\mathbf{0 , 9 6 2}$ & 0 & 0 & 0 & 0 \\
$\mathrm{Sol} \#$ & 0 & 0 & 0 & 0 & 0 & 0 & 0 & 0 & $\mathbf{0 , 9 0 6}$ & 0 & 0 & 0 \\
$\mathrm{La}$ & 0 & 0 & 0 & 0 & 0 & 0 & 0 & 0 & 0,094 & $\mathbf{1}$ & 0,094 & 0 \\
$\mathrm{Sib}$ & 0 & 0 & 0 & 0 & 0 & 0 & 0 & 0 & 0 & 0 & $\mathbf{0 , 9 0 6}$ & 0 \\
$\mathrm{Si}$ & 0 & 0 & 0 & 0 & 0 & 0 & 0 & 0 & 0 & 0 & 0 & $\mathbf{0 , 9 6 2}$ \\
\hline
\end{tabular}

Tabla 4.12. Compatibilidad entre las 12 notas de los sistemas de afinación holderiano y temperado.

Fuente: Elaboración propia

\begin{tabular}{|l|cccccccccccc|}
\hline & Do & Do\# & Re & Mib & Mi & Fa & Fa\# & Sol & Sol\# & La & Sib & Si \\
\hline Do & $\mathbf{0 , 8 4 4}$ & 0,137 & 0 & 0 & 0 & 0 & 0 & 0 & 0 & 0 & 0 & 0 \\
Do\# & 0,156 & $\mathbf{0 , 8 6 3}$ & 0 & 0 & 0 & 0 & 0 & 0 & 0 & 0 & 0 & 0 \\
Re & 0 & 0 & $\mathbf{0 , 8 0 4}$ & 0 & 0 & 0 & 0 & 0 & 0 & 0 & 0 & 0 \\
Mib & 0 & 0 & 0,196 & $\mathbf{0 , 6 8 7}$ & 0 & 0 & 0 & 0 & 0 & 0 & 0 & 0 \\
Mi & 0 & 0 & 0 & 0,313 & $\mathbf{0 , 9 8}$ & 0 & 0 & 0 & 0 & 0 & 0 & 0 \\
Fa & 0 & 0 & 0 & 0 & 0,02 & $\mathbf{0 , 8 6 3}$ & 0,16 & 0 & 0 & 0 & 0 & 0 \\
Fa\# & 0 & 0 & 0 & 0 & 0 & 0,137 & $\mathbf{0 , 8 4}$ & 0 & 0 & 0 & 0 & 0 \\
Sol & 0 & 0 & 0 & 0 & 0 & 0 & 0 & $\mathbf{0 , 8 2 4}$ & 0,117 & 0 & 0 & 0 \\
Sol\# & 0 & 0 & 0 & 0 & 0 & 0 & 0 & 0,176 & $\mathbf{0 , 8 8 3}$ & 0 & 0 & 0 \\
La & 0 & 0 & 0 & 0 & 0 & 0 & 0 & 0 & 0 & $\mathbf{1}$ & 0 & 0 \\
Sib & 0 & 0 & 0 & 0 & 0 & 0 & 0 & 0 & 0 & 0 & $\mathbf{0 , 6 6 8}$ & 0 \\
Si & 0 & 0 & 0 & 0 & 0 & 0 & 0 & 0 & 0 & 0 & 0,332 & $\mathbf{0 , 9 6 1}$ \\
\hline
\end{tabular}

Tabla 4.13. Compatibilidad entre las 12 notas de los sistemas de afinación zarliniano y temperado.

Fuente: Elaboración propia 
Del estudio realizado podemos concluir que los cuatro sistemas analizados son compatibles ${ }^{24}$, dos a dos, es decir que verifican todas las condiciones exigidas en la definición de $\alpha$-compatibilidad. Sin embargo, los niveles máximos de compatibilidad muy diferentes:

a) El sistema pitagórico y el temperado son compatibles hasta el nivel 0,8827 .

b) El sistema pitagórico y el de Zarlino son compatibles hasta el nivel 0,56987 .

c) El sistema pitagórico y el de Hölder son compatibles hasta el nivel 0,99591 .

d) El sistema de Zarlino y el de Hölder son compatibles hasta el nivel 0,57327 .

e) El sistema temperado y el de Hölder son compatibles hasta el nivel 0,90564 .

f) El sistema de Zarlino y el temperado son compatibles hasta el nivel 0,66763 .

Esto, en la práctica, debe servir para asegurarnos si los sistemas de Pitágoras, Zarlino, Hölder y temperado pueden convivir en una misma agrupación musical sin dificultades.

Teniendo en cuenta los cálculos realizados en el ejemplo 4.4, el nivel de compatibilidad mínimo que debemos exigir a los sistemas para afirmar que sus notas homólogas se encuentran dentro de las misma zona de Garbuzov es

$$
\operatorname{Compat}\left(f_{1}, f_{2}\right)=1-\frac{12}{100}=0,88 \text {. }
$$

Esta valor, que hemos establecido como frontera en todo el capítulo, determina que la situación no sea la misma para todos los sistemas analizados:

a) Los sistemas de Pitágoras, Hölder y temperado presentan una compatibilidad superior a 0.88 , por tanto pueden convivir dentro de la misma agrupación, porque a pesar de que el oyente (con buen oído) puede apreciar ligeras perturbaciones entre las notas, éstas no supondrían dificultades para considerarlas como "afinadas".

b) La convivencia con el sistema de Zarlino es mucho más conflictiva porque, como muestra los bajos niveles de compatibilidad con los otros sistemas se producen distancias entre la misma nota de alrededor de 1/8 de tono temperado que, por supuesto se percibe perfectamente.

\footnotetext{
${ }^{24}$ Siempre que se esté utilizando 12 notas por octava en todos los sistemas.
} 
"Se debe obedecer sólo al oído, al sentimiento de cada uno por el sonido, a su impulso creativo, a la fantasía; nunca a la matemática o a la estética"

A. Schömberg (en D. Fischerman,2005)

\section{CAPÍTULO 5: Los sistemas de afinación en la práctica musical}

El último capítulo de esta memoria de doctorado, dedicado a realizar algunas prácticas con los sistemas de afinación borrosos, es el equivalente al Capítulo 3, en el que se describían algunas prácticas con los sistemas de afinación clásicos. Como continuación lógica del Capítulo 4, lo que haremos será analizar los dos líneas principales que se describen en este capítulo: la percepción de los intervalos (que crea la necesidad de establecer el concepto borroso de notas musicales) y la compatibilidad de las notas reales generadas por un músico y la compatibilidad entre los diferentes sistemas de afinación ( $\alpha$-compatibilidad).

Como ocurría en el tercer capítulo, los instrumentos técnicos que utilizaremos para el sonido son el programa Audacity ${ }^{\circledR}$ y los afinadores cromáticos SEIKO modelo ST 747-100 y KORG modelo CA 30; y para realizar los cálculos utilizamos la hoja de cálculo de EXCEL ${ }^{\circledR}$.

Hemos dividido el capítulo en dos secciones. En la primera de ellas estudiamos la percepción acústica de algunas notas e intervalos a partir de un test aplicado a una muestra de alumnos y profesores del Conservatorio Profesional de Música de Murcia y en la segunda parte estudiamos la $\alpha$-compatibilidad para los fragmentos de Haydn y Bartók analizados en el Capítulo 3. De hecho, el material sonoro que utilizaremos son las mismas grabaciones que se emplearon para el estudio de los sistemas de afinación clásicos.

La razón por la que no hemos hecho un estudio para notas sueltas (lo que en el Capítulo 3 denominábamos afinación estática) es porque pretendemos que en esta ocasión, la idea principal es la afinación en la práctica musical, y en ésta, 
cada una de las notas por separado pierde gran parte del interés que, sin duda, tiene en un estudio teórico.

\subsection{Test de percepción}

Aunque el oído humano sea capaz de escuchar sonidos que van desde $16 \mathrm{~Hz}$ hasta $20000 \mathrm{~Hz}$, dentro de esta gama de frecuencias resulta muy costoso reconocer sonidos de frecuencias similares. A este respecto se han realizado diferentes estudios sobre la percepción de los sonidos musicales. La mayoría de estudios realizados, a nivel docente, se centran en la capacidad del oído para escuchar ciertas frecuencias o realizan comparaciones entre el sistema temperado de 12 notas y otro sistema de afinación. En este sentido, cabe destacar el estudio realizado recientemente por Remigi Morant (2006), Percepción de la consonancia musical, en el que se han utilizado los sistemas de afinación de Zarlino y el temperamento igual de 12 notas. Por otro lado, existen experimentos llevados a cabo con material complejo, generalmente en laboratorios, cuya realización excede con mucho las posibilidades de la mayoría de profesores y alumnos de música.

El objetivo de nuestro test es analizar la percepción de la audición musical a través de la realización de 75 encuestas a estudiantes y profesores de música. El estudio que presentamos a continuación da un paso más y utiliza los cuatro sistemas de afinación que han sido analizados en esta memoria: los sistemas de Pitágoras, Zarlino, Hölder y el Temperamento igual de 12 notas. Con esta diversidad los resultados deben ser sensiblemente diferentes a los otros tests, puesto que cada audición contempla cuatro posibles soluciones diferentes.

La muestra elegida para responder al test contiene alumnos cuyas edades oscilan entre los 13 y 20 años y profesores de edades comprendidas entre los 24 y 39 años. La experiencia se ha desarrollado de la forma siguiente:

- Las audiciones se han realizado en clases con grupos de 15 alumnos.

- Para la producción de los sonidos utilizados en este test se ha empleado un ordenador personal Mackintosh ${ }^{\circledR}$ notebook y el programa informático tuning player implementado por los doctores Vicente Liern Carrión y Carlos Ivorra Castillo, ambos profesores titulares de la Facultat d'Economia de Valencia.

El programa tuning player, tiene un registro de dos octavas y es capaz de reproducir hasta 19 notas en cada una de las octavas. De esta manera podremos, por ejemplo, diferenciar entre sostenidos y bemoles cuando no se utilice el temperamento igual de 12 notas. Además, este programa dispone de diferentes 
tipos de instrumento: piano, órgano, trombón, etc. y puede reproducir las notas de manera consecutiva o de manera simultánea. La aplicación que nos resulta más interesante es que se puede elegir el sistema de afinación en el que queremos que cada sonido, escala o arpegio suene de entre estos cuatro, Pitágoras, Zarlino, Hölder y Temperamento Igual de 12 notas.

\section{Diseño del test}

El test consta de 8 preguntas. Siete de ellas se basan en la comparación entre notas sueltas, intervalos, escalas o acordes y propone respuestas concretas como qué nota está afinada u ordenar de mejor a peor afinados algunos sonidos. Además, hay una pregunta, la número 2, que interroga acerca del nombre de la nota, de manera que podamos conocer el porcentaje de la muestra capaz de reconocerla a partir de una nota de referencia, $\mathrm{la}_{4}=440 \mathrm{~Hz}$, de cuyo nombre se informa a los encuestados.

Al realizar este tipo de experiencias, conviene que alguna de las preguntas se pueda utilizar para calibrar la fiabilidad de la respuesta (piénsese por ejemplo en el cansancio, la indecisión, respuestas al azar, etc.). En este caso hemos utilizado la pregunta número 4 que cuestionaba: ¿Qué nota está más afinada?. Al elegir el $\mathrm{mi}_{4}$ cuya afinación es, en la práctica, indistinguible para los cuatro sistemas, hemos corroborado la tendencia a valorar mejor los sonidos centrales de una secuencia y descartar los extremos.

Cuando se realiza el experimento no se proporciona información relativa a lo que se va a escuchar. Esto significa que para responder no se conoce el sistema de procedencia de los sonidos.

\section{Objetivos del test}

Básicamente, el objetivo principal de nuestro test era cuantificar (en forma de porcentajes) cuestiones como las siguientes:

- ¿Puede el oído humano diferenciar dos notas que se llaman igual pero que suenan en diferente sistema de afinación?

- ¿Qué escala prefiere el oído, la habitual temperada u otra con más riqueza sonora?

- ¿Preferimos las terceras puras o nos conformamos con la tercera temperada 14 cents más grande?

Teniendo en cuenta estas consideraciones, el test que se pasó a cada una de las personas que formaron parte del experimento fue el siguiente: 


\section{TEST}

Nombre:

Apellidos:

Edad:

Nivel de estudio musicales

- ¿Es la misma nota?

$\mathrm{Si}$

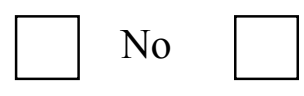

- ¿Qué nota es?

- ¿Qué nota es más aguda?
La primera
La segunda

- ¿Qué nota esta afinada?
$1 \square$

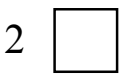
3
4

- Ordena de mejor a peor afinados los acordes siguientes:

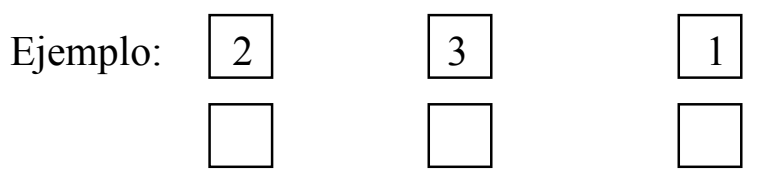

- Ordena de mejor a peor afinados los intervalos siguientes:

1.
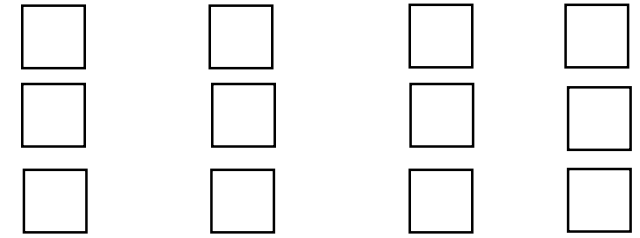

- Ordena de mejor a peor afinados las escalas diatónicas siguientes:
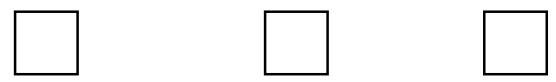

- Ordena de mejor a peor afinados las escalas cromáticas siguientes:
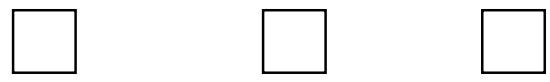
A continuación agrupamos, por el número de pregunta, los resultados de las 75 encuestas realizadas (los resultados detallados aparecen en el Anexo de esta memoria.

$1^{\text {a }}$ Pregunta: ¿Es la misma nota?

Se escuchan dos notas similares, sol $_{4}$ temperado y sol $_{4}$ pitagórico. La duración de cada nota es de 5 segundos y están separadas por 2 segundos. La primera nota, $\mathrm{sol}_{4}$ temperado, vibra a $391,9954 \mathrm{~Hz}$, mientras que la segunda, $\mathrm{sol}_{4}$ pitagórico, lo hace a $391,11111 \mathrm{~Hz}$. La distancia entre ambas notas es de

$$
d\left(\mathrm{sol}_{4}{ }^{\mathrm{pit}}, \mathrm{sol}_{4}{ }^{\mathrm{temp}}\right)=1200 \cdot\left|\log _{2}\left(\frac{391,9954}{391,1111}\right)\right|=3,9098 \text { cents }
$$
siguientes:

Se ofrecen dos únicas respuestas, sí o no, y los resultados son los

\begin{tabular}{cc}
\hline Respuesta & Número \\
\hline Sí & 69 \\
No & 6 \\
\hline
\end{tabular}

Tabla 4.1. Respuestas a la pregunta 1.

Fuente: Elaboración propia

La gran mayoría de respuestas correctas puede verse aún más clara en un gráfico que representa los porcentajes de cada respuesta:

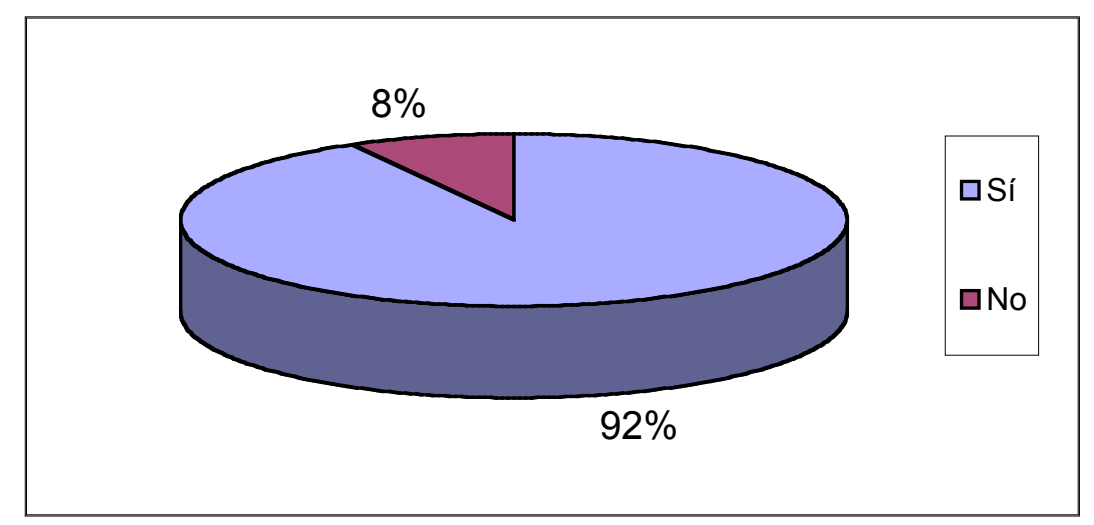

Fig. 5.1. Porcentajes de respuestas a la pregunta 1 .

Fuente: Elaboración propia 
El resultado ratifica la afirmación de que dos notas cuya distancia es inferior a 5 cents se perciben como la misma (véase Piles (1982), por ejemplo). El $92 \%$ de los encestados respondieron que sí era la misma nota mientras que sólo 6 personas dijeron que no (un 8\%). En nuestra opinión, el porcentaje de respuestas correctas responde más a la casualidad que a un "oído privilegiado" como es calificado por Piles en estos casos.

\section{$2^{\text {a }}$ Pregunta: ¿Qué nota es?}

Se da como referencia un $\mathrm{la}_{4}$ a $440 \mathrm{~Hz}$ que suena durante 5 segundos y posteriormente tras una pausa de 2 segundos un do\# $\#_{4}(560,5688 \mathrm{~Hz})$ de Zarlino que también suena durante 5 segundos.

Las respuestas se recogen el la tabla siguiente:

\begin{tabular}{lc}
\hline \multicolumn{1}{c}{ Respuesta } & Número \\
\hline Sol & 1 \\
$\mathrm{La}$ & 1 \\
$\mathrm{Si}$ & 2 \\
$\mathrm{Do}$ & 25 \\
$\mathrm{Do \#}$ & 23 \\
$\mathrm{Re}$ & 11 \\
$\mathrm{Mi}$ & 10 \\
$\mathrm{Fa}$ & 2 \\
\hline
\end{tabular}

Tabla 5.2. Frecuencias de cada una de las respuestas a la pregunta 2 .

Fuente: Haluska (2005), página 58

Recogemos en un gráfico los porcentajes anteriores:

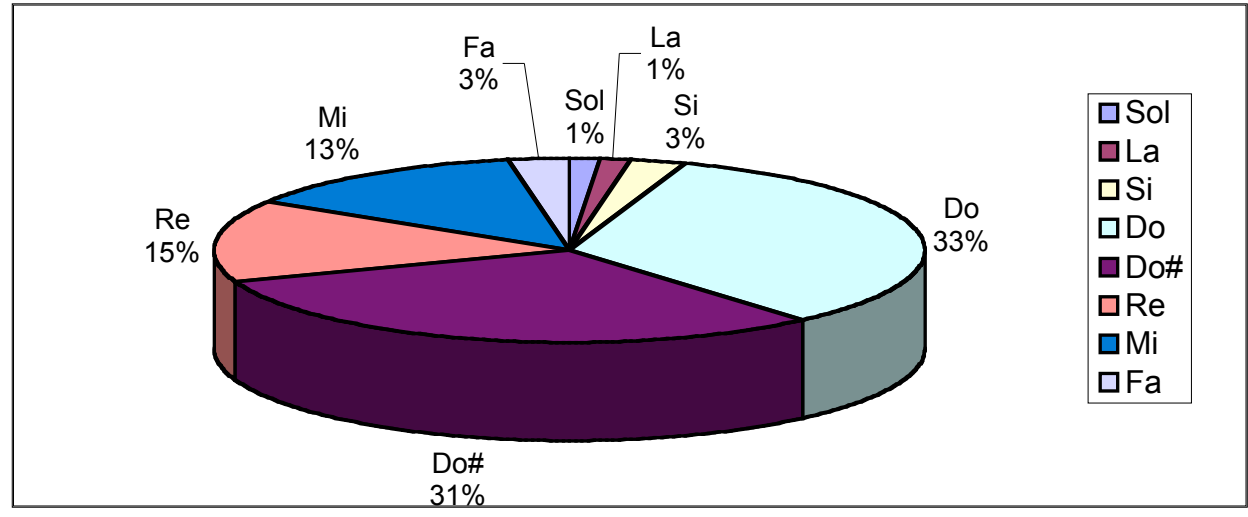

Fig. 5.2. Porcentajes de respuestas a la pregunta 2 .

Fuente: Elaboración propia 
Aunque 23 encuestados (31\%) dieron con la respuesta correcta, cabe destacar que 25 personas $(33 \%)$ se decantaron por la nota inmediatamente inferior, do. Menos importante resulta que el 15\% de los encuestados contestaron que la nota era re $(15 \%)$, muy probablemente debido a la poca costumbre de escuchar notas afinadas en el sistema de Zarlino y a que el do\# de zarlino está entre el do\# y el re temperados. El $10 \%$ aún fue más allá contestando que la nota era un mi.

Las respuestas correspondientes a otras notas son poco significativas puesto que sus porcentajes están entre el 1 y el $3 \%$. Es reseñable el hecho de que gran parte de las respuestas no sean correctas $(69 \%)$ pero los porcentajes más elevados se sitúan cerca de la nota do\# que es la correcta y a medida que las notas están mas lejanas estos porcentajes disminuyen.

$3^{\text {a }}$ Pregunta: ¿Qué nota es más aguda?

Al igual que en la primera pregunta, se dan dos notas que duran 5 segundos separadas entre ellas por un intervalo de 2 segundos. En este caso escuchamos un $\mathrm{lab}_{4}$ de Zarlino de $414,4362 \mathrm{~Hz}$ y otro sol\# 4 de Pitágoras de $417,65625 \mathrm{~Hz}$. La distancia entre estas notas es

$$
d\left(\operatorname{lab}_{4}{ }^{\text {zar }}, \text { sol\# }_{4}{ }^{\text {pit }}\right)=1200 \cdot\left|\log _{2}\left(\frac{414,4362}{417,65625}\right)\right|=13,3992 \text { cents }
$$

La distancia entre estas notas es perceptible por cualquier oído sano y, por tanto, los encuestados deberían escuchar los dos sonidos como notas diferentes. Otra cuestión es que este diferencia se asocie adecuadamente con ser más o menos aguda. De hecho, los encuestados han respondido lo siguiente:

\begin{tabular}{lc}
\hline Respuesta & Cantidad \\
\hline Primera & 19 \\
Segunda & 56 \\
\hline
\end{tabular}

Tabla 5.3. Respuestas a la pregunta 3 .

Fuente: Elaboración propia

Las 19 personas que respondieron mal, siempre reconocieron que se trataba de dos notas diferentes, porque nadie optó por dejar la pregunta sin contestar.

A continuación mostramos un gráfico en el que se representan los porcentajes de cada respuesta: 


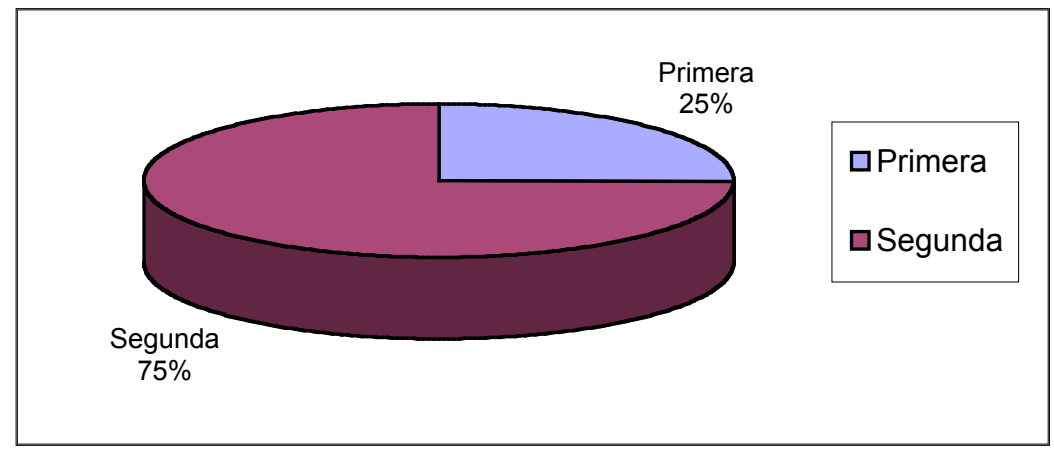

Fig. 5.3. Porcentajes de respuestas a la pregunta 3.

Fuente: Elaboración propia

En este caso la mayor parte de los encuestados (75\%) dio la respuesta correcta: reconoció la segunda nota como más aguda que la primera. El 25\% restante no supo asociar la diferencia de frecuencias con "ser más aguda".

4 ${ }^{\mathrm{a}}$ Pregunta: ¿Qué nota esta afinada?

Escuchamos cuatro notas, una de cada uno de los sistemas estudiados, Temperamento Igual de 12 notas, Hölder, Zarlino y Pitágoras. Todas corresponden a un $\mathrm{mi}_{4}$ con $329,6275 \mathrm{~Hz}, 329,9869986 \mathrm{~Hz}, 330 \mathrm{~Hz}$ y $330 \mathrm{~Hz}$ respectivamente. Con estas cuatro notas, muy similares entre ellas, se trata de escoger la más afinada. Las distancias, en cents, son las siguientes:

\begin{tabular}{lllll}
\hline Mi & Temperada & S. Hölder & S. Zarlino & S. Pitágoras \\
\hline Temperada & 0 & 1,887 & 1,955 & 1,955 \\
S. Hölder & 1,887 & 0 & 0,07 & 0,07 \\
S. Zarlino & 1,955 & 0,07 & 0 & 0 \\
S. Pitágoras & 1,955 & 0,07 & 0 & 0 \\
\hline
\end{tabular}

Tabla 5.4. Distancia en cents del Mi en los diferentes sistemas estudiados Fuente: Elaboración propia

La utilidad de esta pregunta es calibrar, de algún modo ,la reacción de los encuestados, puesto que las diferencias son inapreciables para un oído normal.

\begin{tabular}{lc}
\hline Respuesta & Cantidad \\
\hline Temperada & 13 \\
Holder & 32 \\
Zarlino & 21 \\
Pitágoras & 9 \\
\hline
\end{tabular}

Tabla 5.5. Respuestas a la pregunta 4

Fuente: Elaboración propia 


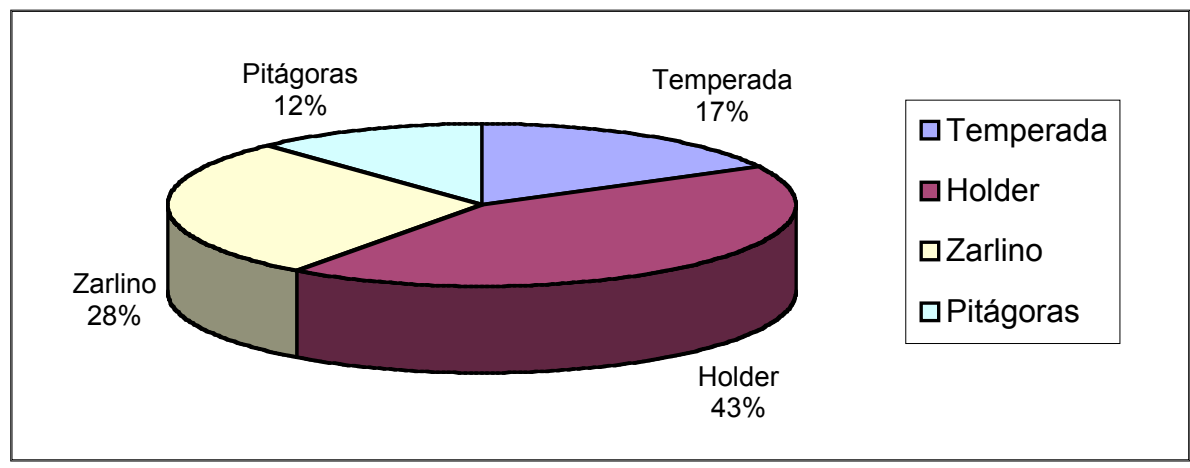

Fig. 5.4. Porcentajes de respuestas a la pregunta 4 .

Fuente: Elaboración propia

La elección del sistema de Hölder Holder (43\%) y de Zarlino (28\%) fente a los otros se debe a la secuencia en que fue escuchada, porque en realidad no existía una razón objetiva para elegir una frente a otra.

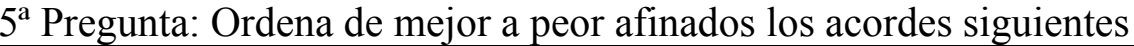

Presentamos tres acordes perfectos mayores $(\mathrm{do}+\mathrm{mi}+$ sol $)$ en los sistemas pitagórico, zarliniano y holderiano con el objeto de comprobar que acorde les resultaba más agradable al oído. Las distancias para los intervalos de tercera mayor y quinta justa en estos sistemas son:

\begin{tabular}{lrlrr}
\hline Tercera mayor & S. Pitágoras & S. Zarlino & S. Temperado & S. Holder \\
\hline S. Pitágoras & 0 & 21,5062896 & 7,82000346 & 0,27283365 \\
S. Zarlino & 21,5062896 & 0 & 13,6862861 & 21,2334559 \\
S. Temperado & 7,82000346 & 13,6862861 & 0 & 7,54716981 \\
S. Holder & 0,27283365 & 21,2334559 & 7,54716981 & 0 \\
\hline
\end{tabular}

Tabla 5.6. Distancia en cents para la tercera mayor en los sistemas estudiados Fuente: Elaboración propia

\begin{tabular}{llllr}
\hline Quinta justa & S. Pitágoras & S. Zarlino & S. Temperado & S. Holder \\
\hline S. Pitágoras & 0 & 0 & 1,955000865 & 0,068208413 \\
S. Zarlino & 0 & 0 & 1,955000865 & 0,068208413 \\
S. Temperado & 1,955000865 & 1,955000865 & 0 & 1,886792453 \\
S. Holder & 0,068208413 & 0,068208413 & 1,886792453 & 0 \\
\hline
\end{tabular}

Tabla 5.7. Distancia en cents para la quinta justa en los sistemas estudiados Fuente: Elaboración propia 
A los encuestados se les advirtió de que se trataba de un acorde en tres sistemas de afinación diferente y se numeraron como 1, 2, 3, sin informarles de qué afinación se correspondía con cada número. Se hizo sonar cada acorde 5 segundos y, entre cada acorde se hizo una pausa de 2 segundos. siguientes:

Las respuestas producidas se correspondieron con las ordenaciones

\begin{tabular}{lc}
\hline Respuesta & Cantidad \\
\hline Zar/Pit/Temp & 7 \\
Pit/Temp/Zar & 19 \\
Temp/Zar/Pit & 6 \\
Pit/Zar/Temp & 7 \\
Temp/Pit/Zar & 31 \\
Zar/Temp/Pit & 5 \\
\hline
\end{tabular}

Tabla 5.8. Respuestas a la pregunta 5 .

Fuente: Elaboración propia.

En la figura 5.5 se aprecia más fácilmente los porcentajes en los que fueron elegidas las diferentes ordenaciones:

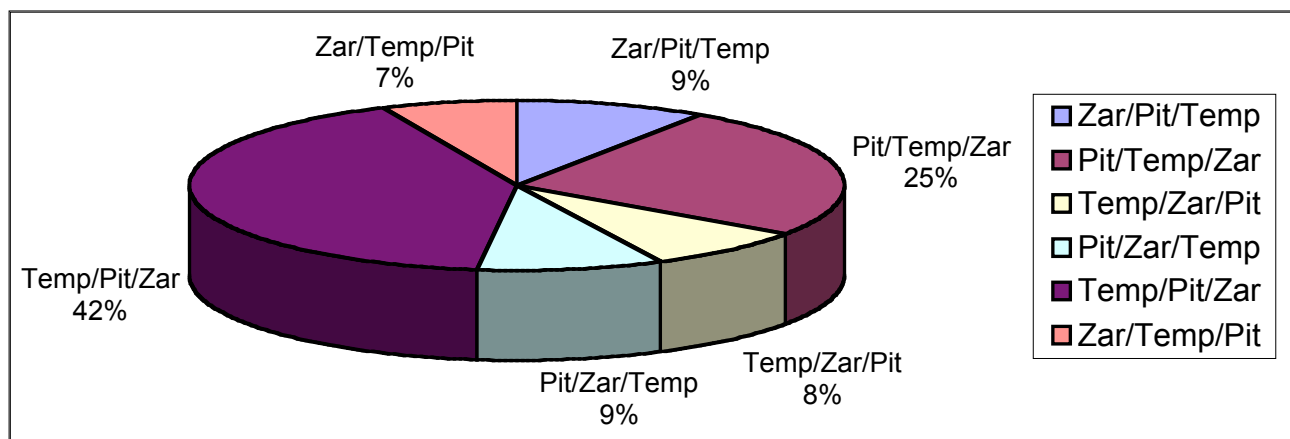

Fig. 5.5. Porcentajes de respuestas a la pregunta 5. Fuente: Elaboración propia

En cuanto a los acordes mayores, el 42\% (31) prefirió en primer lugar el acorde temperado después el pitagórico y finalmente el de Zarlino. La segunda opción más elegida con un 25\% (19) fue Pitágoras, Temperado y Zarlino. Es decir, que pese a ser el más rico desde el punto de vista armónico, el acorde perfecto mayor que menos ha gustado es el de Zarlino. 
6 Pregunta: Ordena de mejor a peor afinados los intervalos siguientes

Esta pregunta se divide en tres partes, en cada una de ellas trataremos un intervalo diferente, quinta justa, tercera mayor y cuarta justa.

$\underline{\text { Intervalo de quinta }}$

Para esta pregunta se han escogido las notas $\mathrm{do}_{4}$ y sol $_{4}$ que distan entre sí una quinta justa. Las distancias entre los distintos conceptos de quinta para cada sistema de afinación pueden verse en la Tabla 5.7.

Se ha escuchado este intervalo tres veces, la primera correspondiente al sistema Pitagórico, la segunda a Zarlino y la tercera al Temperamento igual de 12 notas. En la respuesta se pide que ordenen de mejor a peor afinados estos intervalos y el resultado es el siguiente:

En primer lugar, se ha preferido, con 26 respuestas (34\%), la combinación Pitágoras/ Temperado/Zarlino, en segundo lugar con 23 respuestas (31\%) Temperado/ Pitágoras/Zarlino. Las demás respuestas quedan lejos de las ya citadas puesto que la de mayor porcentaje es un $12 \%$, muy lejos de los anteriormente citados.

De nuevo, el hábito a escuchar la afinación temperada se pone de manifiesto $\mathrm{y}$, de hecho los encuestados prefieren la quinta temperada o pitagórica casi por igual. Además, a partir de los resultados podemos afirmar que el intervalo de quinta que menos gusta es el de Zarlino. Los resultados son los siguientes

\begin{tabular}{lc}
\hline Respuesta & Cantidad \\
\hline Zar/Pit/Temp & 8 \\
Temp/Pit/Zar & 23 \\
Pit/Zar/Temp & 6 \\
Pit/Temp/Zar & 26 \\
Temp/Zar/Pit & 3 \\
Zar/Temp/Pit & 9 \\
\hline
\end{tabular}

Tabla 5.9. Respuestas a la pregunta 6 (intervalo de quinta). Fuente: Elaboración propia.

Como puede verse en la tabla 5.7, la distancia entre las diferentes opciones de quinta es muy pequeña (en la práctica imperceptible), por tanto la elección de una opción u otra proporciona más información acerca de la afinación del do de referencia que a la propia del intervalo (véase Piles, 1982). 


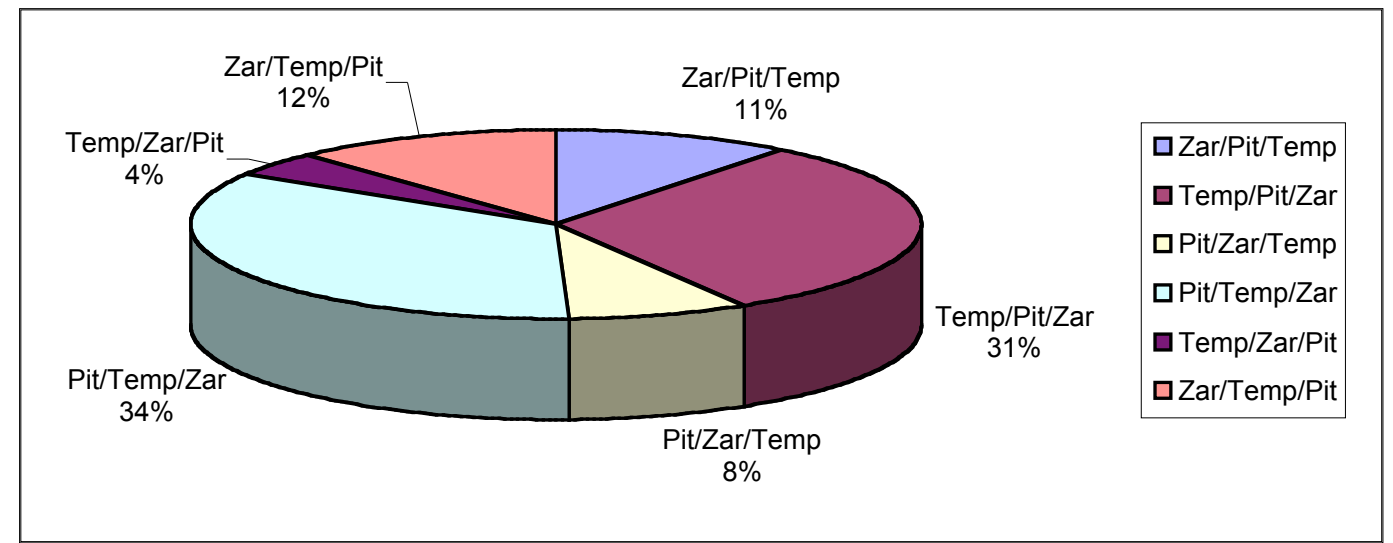

Fig. 5.6. Porcentajes de respuestas a la pregunta 6 (intervalo de quinta)

Fuente: Elaboración propia

\section{$\underline{\text { Intervalo de tercera }}$}

En esta pregunta se escuchan las notas $\mathrm{fa}_{4}$ y la $\mathrm{l}_{4}$ que distan entre sí una tercera mayor. Se sigue el mismo procedimiento que en preguntas anteriores, se escucha tres veces en primer lugar la tercera de Zarlino, en segundo lugar la de Pitágoras y en tercero la Temperada. Las distancias para este itervalo pueden consultarse en la tabla 5.6.

La respuesta mayoritaria ha sido la ordenación Temperado-ZarlinoPitágoras con un 30\% (22 respuestas), a continuación encontramos la serie Temperado-Pitágoras-Zarlino con un 20\% (15 respuestas) y con un $19 \%$ (14 respuestas) la serie Zarlino-Temperado-Pitágoras. Las demás respuestas oscilan entre el $13 \%$ y el $9 \%$. Para la tercera, a pesar del hábito del sistema temperado, se ha preferido la tercera zarliniana a la pitagórica, cosa que resulta totalmente con la teoría, puesto que es el sistema de Zarlino el único (de los estudiados) que presenta la tercera mayor justa.

Las respuestas han sido las siguientes:

\begin{tabular}{cc}
\hline Respuesta & Cantidad \\
\hline Zar/Pit/Temp & 10 \\
Zar/Temp/Pit & 14 \\
Temp/Pit/Zar & 15 \\
Pit/Zar/Temp & 7 \\
Temp/Zar/Pit & 22 \\
Pit/Temp/Zar & 7 \\
\hline
\end{tabular}

Tabla 5.10. Respuestas a la pregunta 6 (intervalo de tercera) Fuente: Elaboración propia. 


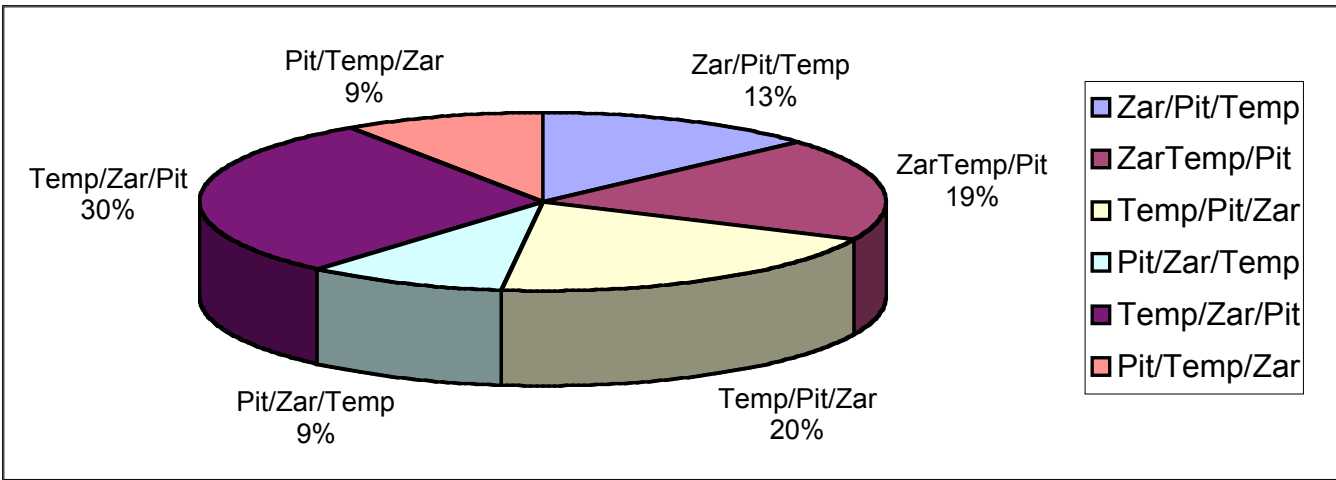

Fig. 5.7. Porcentajes de respuestas a la pregunta 6 (intervalo de tercera).

Fuente: Elaboración propia

\section{$\underline{\text { Intervalo de cuarta }}$}

En esta pregunta escuchamos el intervalo de cuarta justa formado entre las notas sol $_{4} \mathrm{y} \mathrm{do}_{5}$. Las distancias, en cents, para este intervalo en los diferentes sistemas de afinación son las siguientes:

\begin{tabular}{lrrrr}
\hline Cuarta justa & S. Pitágoras & S. Zarlino & S. Temperado & S. Holder \\
\hline S. Pitágoras & 0 & 0 & 1,95500087 & 0,06820841 \\
S. Zarlino & 0 & 0 & 1,95500087 & 0,06820841 \\
S. Temperado & 1,95500087 & 1,95500087 & 0 & 1,88679245 \\
S. Holder & 0,06820841 & 0,06820841 & 1,88679245 & 0 \\
\hline
\end{tabular}

Tabla 5.11. Distancia en cents para la tercera mayor en los sistemas estudiados Fuente: Elaboración propia

NOTA: Al ser la quinta y la cuarta intervalos complementarios (su suma es una octava), en las tablas 5.7 y 5.11 las distancias son las mismas.

El procedimiento que hemos seguido es el mismo que en los intervalos anteriores y el orden con el que suena el intervalo es el siguiente: TemperadoZarlino -Pitágoras.

En esta ocasión observamos una respuesta que supera el 50\% del total, en concreto el 53\% (40 de las 75 encuestas realizadas). El orden que nos ofrece en esta respuesta es Temperado-Pitágoras-Zarlino. Ahora bien, como ocurría en el caso de la quinta, aunque la cuarta temperada es la preferida con rotundidad, la distancia entre las diferentes versiones de cuarta no es suficiente como para poder ser percibida por un oído normal (Piles, 1982). 
Los resultados obtenidos son los siguientes:

\begin{tabular}{lc}
\hline Respuesta & Cantidad \\
\hline Temp/Zar/Pit & 6 \\
Temp/Pit/Zar & 40 \\
Zar/Pit/Temp & 5 \\
Pit/Temp/Zar & 17 \\
Pit/Zar/Temp & 3 \\
Zar/Temp/Pit & 4 \\
\hline
\end{tabular}

Tabla 5.12. Respuestas a la pregunta 6 (intervalo de cuarta) Fuente: Elaboración propia.

y gráficamente, los porcentajes son los siguientes:

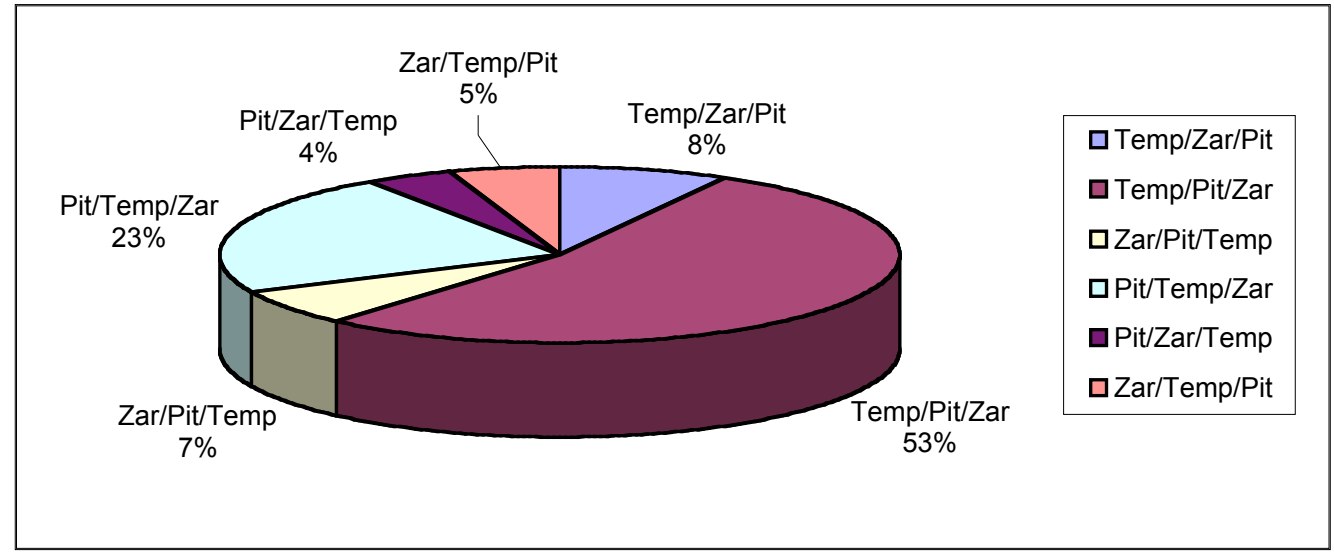

Fig. 5.8. Porcentajes de respuestas a la pregunta 6 (intervalo de cuarta). Fuente: Elaboración propia

Como resumen de las respuestas a la pregunta 6 podemos establecer las siguientes conclusiones:

- La costumbre de utilizar el sistema temperado hace que los intervalos que suenan en este sistema siempre quedan muy bien situados a la hora de establecer las preferencias de los encuestados.

- Cuando se analiza la quinta o la cuarta, los sistemas temperado y pitagórico tienen resultados muy parecidos, aunque sólo en este último aparecen los intervalos justos. el sistema Zarlino es el menos aceptado

- Para la tercera, que es el único intervalo en el que las diferencias son apreciables, los encuestados el sistema de Zarlino, que es el que proporciona terceras naturales, queda muy bien situado.

$7^{\text {a }}$ Pregunta: Ordena de mejor a peor afinados las escalas diatónicas siguientes 
Para esta pregunta escuchamos tres veces cada escala diatónica comprendida entre la octava $\mathrm{do}_{4} \mathrm{y} \mathrm{do}_{5}$. Como en todos los ejemplos, la nota que ha marcado el resto de frecuencias ha sido el $\mathrm{la}_{4}$ a $440 \mathrm{~Hz}$. Es decir, que la sensación que tendrán los encuestados es que algunas escalas están más agudas que otras, puesto que el valor en el valor del do 4 ocurre así (ver capítulo 2). El orden en que suenan las escalas es Pitágoras-Tem-perado-Zarlino.

Sin lugar a dudas, los encuestados prefirieron la escala temperada, después la más parecida, la pitagórica, y por último la de Zarlino. Es decir que la mayoría prefirió el orden Temperado-Pitágoras-Zarlino con 43 respuestas (58\%), en segundo lugar con 25 respuestas (33\%), se respondió Pitágoras-TemperadoZarlino. El resto de respuestas apenas merecen mención puesto que en ningún caso superan el $4 \%$.

Las respuestas obtenidas son las siguientes:

\begin{tabular}{lc}
\hline Respuesta & Cantidad \\
\hline Pit/Temp/Zar & 25 \\
Temp/Pit/Zar & 43 \\
Temp/Zar/Pit & 3 \\
Zar/Pit/Temp & 2 \\
Pit/Zar/Temp & 1 \\
Zar/Temp/Pit & 1 \\
\hline
\end{tabular}

Tabla 5.13. Respuestas a la pregunta 7 .

Fuente: Elaboración propia.

En el gráfico se ve claramente el predominio de la afinación temperada (o pitagórica frente a la de Zarlino):

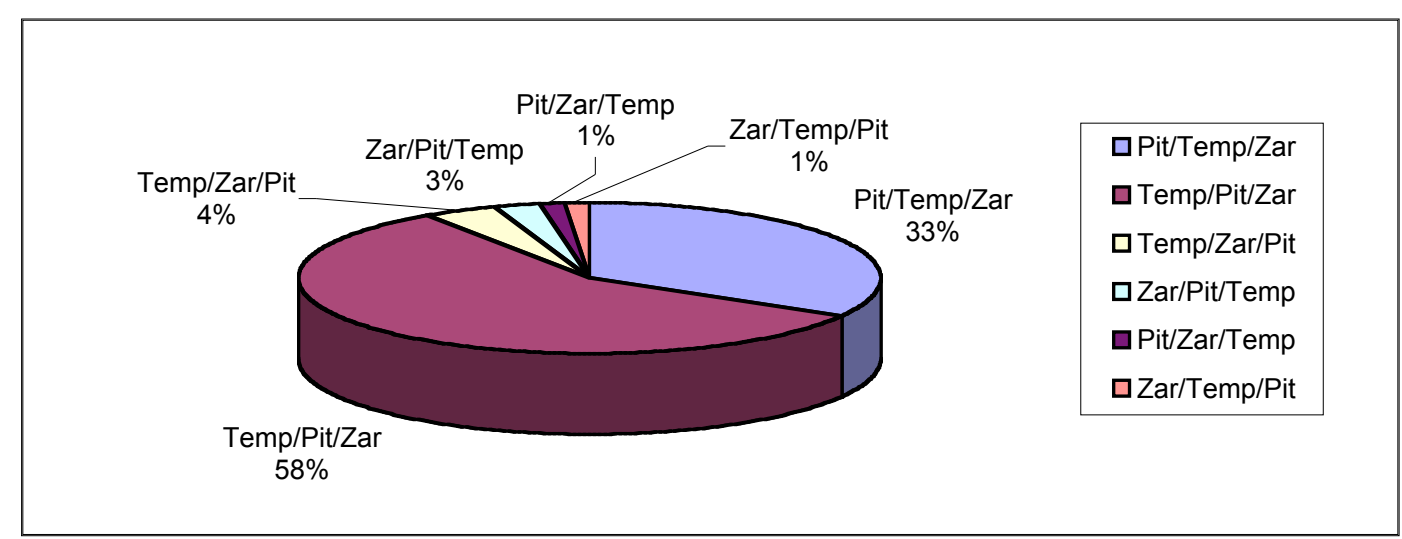

Fig. 5.9. Porcentajes de respuestas a la pregunta 7 .

Fuente: Elaboración propia

$8^{a}$ Pregunta: Ordena de mejor a peor afinados las escalas cromáticas siguientes 
Para esta pregunta escuchamos tres veces cada escala cromática. La única forma de poder compararlas es que todas ellas tengan 12 notas. Para ello, hemos elegido las notas

Do-do\#-re-re\#-mi-fa-fa\#-sol-sol\#-la-la\#si-do, en la octava do $\mathrm{do}_{4} \mathrm{do}_{5}$. El orden en que suenan las escalas es TemperadaPitagórica-Zarlino.

El orden preferido ha sido Temperada-Pitagórica-Zarlino, un 58\% (43 respuestas). En segundo lugar la ordenación Pitágoras-Temperado-Zarlino obtuvo el $37 \%$ ( 28 respuestas) y el resto de respuestas no son relevantes puesto que oscilan entre el 1\% y el 3\%. De nuevo vuelve a darse la posible permutación entre el sistema temperado y el de Pitágoras y se deja en último lugar el de Zarlino.

Los resultados son los siguientes:

\begin{tabular}{lc}
\hline Respuesta & Cantidad \\
\hline Pit/Temp/Zar & 28 \\
Temp/Zar/Pit & 2 \\
Temp/Pit/Zar & 43 \\
Pit/Zar/Temp & 1 \\
Zar/Pit/Temp & 1 \\
\hline
\end{tabular}

Tabla 5.14. Respuestas a la pregunta 8 .

Fuente: Elaboración propia.

Como puede apreciarse en el gráfico, sólo un 4\% de las respuestas ha situado la escala de diatónica de Zarlino en el primer o segundo lugar de preferencia:

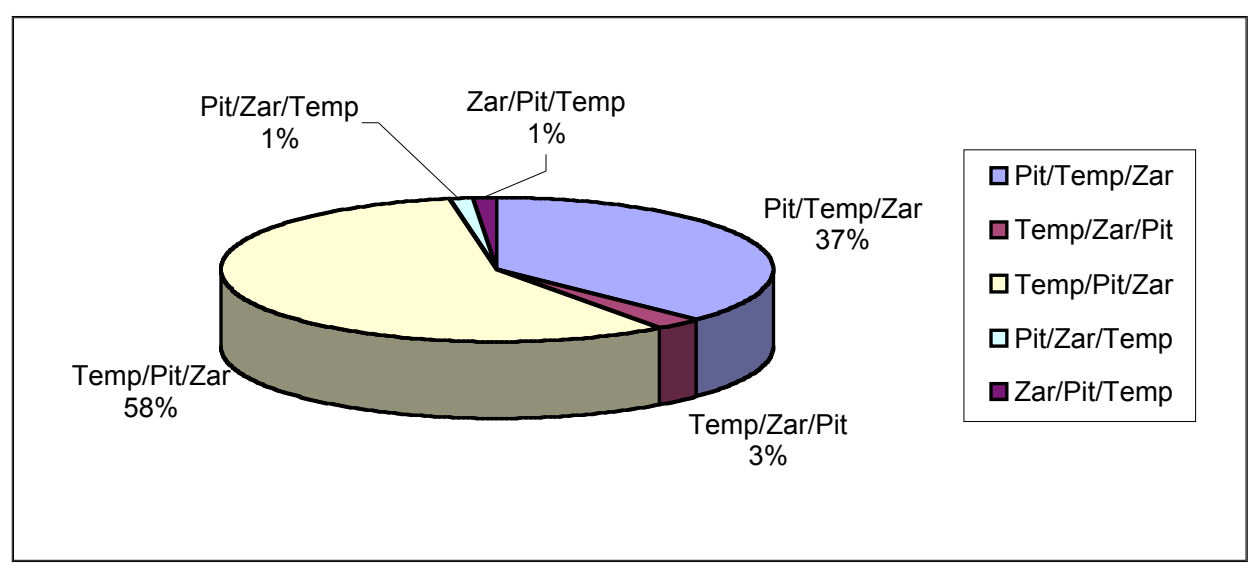

Fig. 5.10. Porcentajes de respuestas a la pregunta 8 .

Fuente: Elaboración propia 


\section{Comparación con otros test}

Entre los trabajos consultados, el que persigue unos fines más parecidos es el desarrollado por Remigi Morant (Morant, 2006) en el que se comparaban el sistema temperado y el de Zarlino. Por esta razón, hemos estimado conveniente comparar nuestros resultados con los de Morant. En ambos se comparan las diferentes consonancias, la quinta, la cuarta y la tercera. A partir de estos intervalos y en ambos se estudia el acorde perfecto mayor. Sin embargo, en Morant además, se estudia el acorde menor, el tritono y la sucesión de acordes IIV-V-I que representarían un modelo básico de cadencia. Además, en el presente estudio se realizan comparaciones entre notas similares, escalas diatónicas y cromáticas. En cuanto a las octavas, su estudio se basaría en la altura de la nota de partida dependiendo del sistema que utilizáramos ya que en todos los sistemas existentes la relación 2/1 es la utilizada para obtener dicho intervalo por lo que todas las octavas resultarían del mismo tamaño con la salvedad del punto de inicio.

Por otro lado, la posibilidad de poder realizar el test mediante sonidos patrón cuyo timbre es muy similar al de los instrumentos convencionales, gracias al programa tuning player, puede hacer que los resultados resulten sensiblemente diferentes.

El aspecto en el que se puede establecer directamente la comparación entre ambas experiencias es si consideran afinados los intervalos de quinta, tercera y cuarta con diferentes sistemas de afinación.

A continuación presentamos dos tablas que contienen los porcentajes de encuestados que consideran los intervalos en los sistemas de afinación temperado y de Zarlino.

\begin{tabular}{ccc}
\hline Intervalos temperados & Test de Morant & Test de Ibáñez \\
\hline Tercera & $75 \%$ & $50 \%$ \\
Cuarta & $75 \%$ & $61 \%$ \\
Quinta & $25 \%$ & $35 \%$ \\
\hline
\end{tabular}

Tabla 5.15. Comparación con otras experiencias. Intervalos. Fuente: Elaboración propia.

\begin{tabular}{ccc}
\hline Intervalos zarlinianos & Test de Morant & Test de Ibáñez \\
\hline Tercera & $25 \%$ & $32 \%$ \\
Cuarta & $25 \%$ & $12 \%$ \\
Quinta & $75 \%$ & $23 \%$ \\
\hline
\end{tabular}

Tabla 5.16. Comparación con otras experiencias. Intervalos.

Fuente: Elaboración propia. 
En nuestro caso, al no haber preguntado si el intervalo estaba bien afinado, sino que los ordenasen de mejor a peor afinados, hemos dado como "bien afinado" aquel sistema de afinación que ocupaba el primer lugar en la ordenación.

En la tabla 5.15 las preferencias por el temperamento igual de 12 notas es evidente para los intervalos de tercera y cuarta para ambos trabajos pero los porcentajes varían sensiblemente hallando diferencias de hasta el $25 \%$. Para Morant la quinta es preferida por un $75 \%$ en Zarlino (ver tabla 5. 16) mientras que en el presente trabajo los encuestados han preferido en un $44 \%$ el sistema de Pitágoras frente al 35\% del temperamento igual de 12 notas y el $23 \%$ de Zarlino.

Aunque el resto de cuestiones no son comparables entre ambas experiencias, lo cierto es que las conclusiones so muy parecidas, en el sentido de que al estar habituados al sistema temperado, suele ser éste el preferido frente a otros.

\subsection{Análisis de compatibilidad}

En esta sección vamos a estudiar la compatibilidad de las notas de los fragmentos de Haydn y Bartók analizados en el capítulo 3. El esquema de trabajo que seguimos es el siguiente:

1. Partimos de las grabaciones analizadas en el capítulo 3.

2. Anotamos el rango de frecuencias obtenidas para cada una de las notas en el total de las grabaciones. Por ejemplo, la nota Mi emitida por el intérprete está entre el Mi de menor frecuencia (menor Mi) y el Mi de mayor frecuencia (mayor Mi), es decir

$$
\text { Rango del Mi }=[\text { menor Mi, mayor Mi }]
$$

3. Calculamos la compatibilidad para cada uno de los sistemas y cada una de las notas de los fragmentos según se indicaba en el capítulo 4. Para el caso del Mi, la compatibilidad estará comprendida (en cada uno de los sistemas) entre la compatibilidad del menor Mi y del mayor Mi.

4. Como uno de los sistemas analizados es el temperado de 12 notas, supondremos que todos los sistemas de afinación tienen 12 notas. Entonces, siguiendo con el ejemplo del $\mathrm{Mi}$, el rango de compatibilidad para el Mi será

[Compat(menor Mi, Mi teórico), Compat(mayor Mi, Mi teórico)] 
o bien

[Compat(mayor Mi, Mi teórico), Compat(menor Mi, Mi teórico)],

dependiendo de que Compat(menor Mi, Mi teórico) sea mayor o menor que Compat(mayor Mi, Mi teórico). Además, tal como se indicaba en el capítulo anterior, estas compatibilidades se calculan de la forma siguiente:

$$
\begin{aligned}
& \text { Compat }(\text { menor Mi, Mi teórico })=1-12 \frac{d(\text { menor Mi, Mi teórico })}{1200}, \\
& \text { Compat }(\text { mayor Mi, Mi teórico })=1-12 \frac{d(\text { mayor Mi, Mi teórico })}{1200} .
\end{aligned}
$$

La razón por la que no analizamos cada una de las notas sino que elegimos el rango de frecuencias para la misma nota (punto 2 del esquema) es que, cuando se analiza un fragmento, por breve que sea, el uso de números borrosos triangulares para cada una de las notas (tal y como se hace en el capítulo 4) no es adecuado. Resulta poco práctico representar en un mismo gráfico alrededor de 30 triángulos para calcular sus intersecciones con la nota teórica. Está claro que la compatibilidad de todas estas notas estará entre la mejor y la peor de todas ellas, y éste será el hecho que tengamos en cuenta en todo el análisis siguiente.

Los principales objetivos que nos hemos planteado con este análisis de estos dos fragmentos son:

1. Comprobar si al tratar las notas como conjunto borrosos, es decir al aceptar la flexibilidad que permite el concepto de nota borrosa, las conclusiones a la que llegábamos en el capítulo 3 siguen siendo válidas $\mathrm{o}$, por el contrario deben ser modificadas o precisadas.

2. Poder contribuir a que el músico mejore su interpretación. Por ejemplo, si para una nota, las grabaciones de mayor frecuencia son las que resultan más compatibles, convendrá que el intérprete cuide la afinación en ese sentido.

\subsubsection{Fragmento de Haydn}

Como en el capítulo 3, hemos analizado 48 grabaciones de 23 compases del Concierto en Mi bemol Mayor, Hob. VIIe, N. 1 para trompeta y orquesta de Franz Joseph Haydn (1732-1809): 

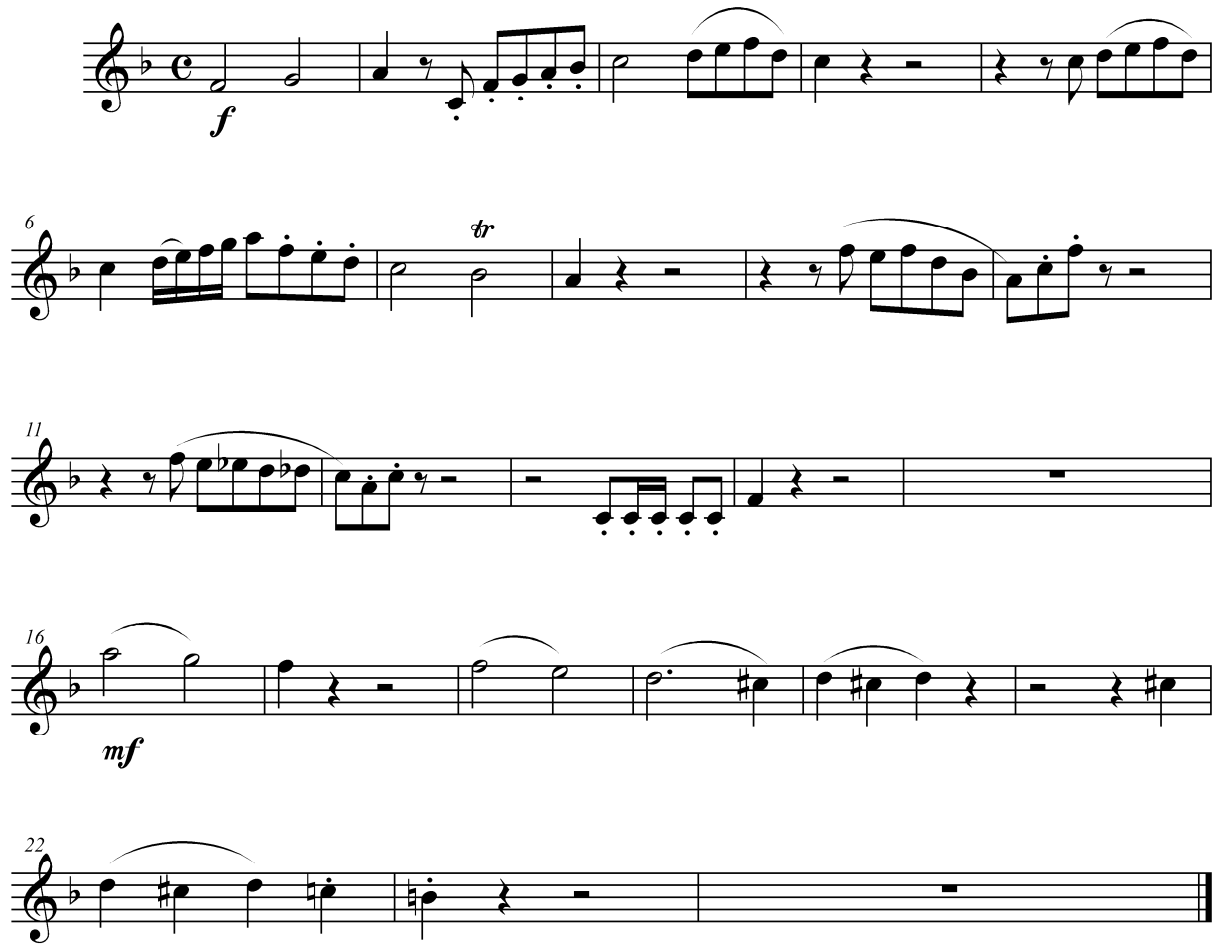

Las notas diferentes que aparecen en el fragmento son:

Mib, Fa, Sol, Sib grave, Lab, Sib agudo, Do, Re, Mib agudo, Fa agudo Sol agudo, Reb agudo, Si, La

En el capítulo 3, concluíamos que estas notas pertenecen en su mayoría a los sistemas pitagórico y de Zarlino. En concreto, los porcentajes son los que se muestran en el gráfico siguiente:
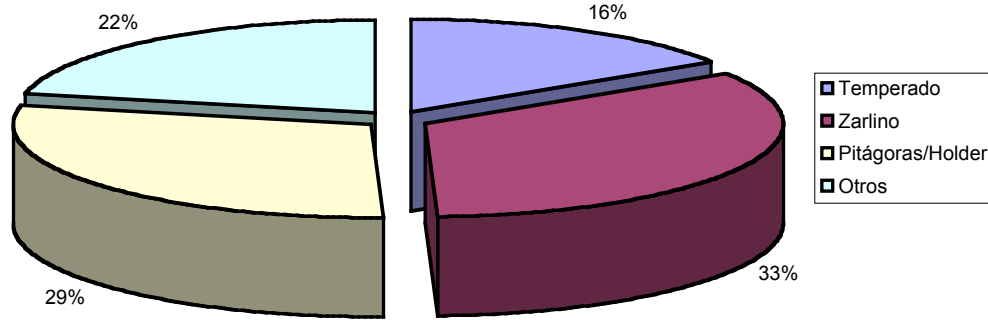

Fig. 5.10. Porcentaje de notas en cada uno de los sistemas (ver Experimento 3 del capítulo 3)

Fuente: Elaboración propia 
A continuación recogemos en una tabla las mayores y menores frecuencias de cada una de las notas grabadas (medidas con el programa Audacity) y las afinaciones exactas en cada uno de los sistemas.

\begin{tabular}{lllllll}
\hline Nota & Menor & Mayor & Pitágoras & Zarlino & Temp. (12) & Holder \\
\hline Mi bemol & 305 & 316 & 309,0261 & 310,8272 & 311,127 & 309,0990 \\
Fa & 346 & 356 & 347,6543 & 350,3555 & 349,2282 & 347,7090 \\
Sol & 376 & 398 & 391,1111 & 396 & 391,9954 & 391,1419 \\
Sib grave & 226 & 239 & 231,7695 & 233,5703 & 233,0819 & 231,8150 \\
Lab & 406 & 414 & 412,0347 & 414,4362 & 415,3047 & 412,148 \\
Sib agudo & 453 & 479 & 463,5391 & 467,1406 & 466,1638 & 463,6300 \\
Do & 502 & 533 & 521,4815 & 528 & 523,253 & 521,5431 \\
Re & 571 & 598 & 586,6667 & 594 & 587,3296 & 586,6898 \\
Mib agudo & 587 & 636 & 618,0521 & 621,6544 & 622,254 & 618,1980 \\
Fa agudo & 668 & 713 & 695,3086 & 700,7109 & 698,4564 & 695,4180 \\
Sol agudo & 781 & 795 & 782,2222 & 792 & 783,9908 & 782,2839 \\
Reb agudo & 548 & 570 & 549,3797 & 559,4889 & 554,3652 & 549,5520 \\
Si & 487 & 498 & 495 & 497,3235 & 493,8833 & 494,960 \\
La & 440 & 443 & 440 & 440 & 440 & 440 \\
\hline
\end{tabular}

Tabla 5.17. Frecuencia de las notas del fragmento de Haydn.

Fuente: Elaboración propia.

En las cuatro tablas siguientes calculamos los niveles de compatibilidad de las notas del fragmento en cada sistema.

\begin{tabular}{rrrrrrrr}
\hline Nota & \multicolumn{1}{c}{ Menor Mayor Pitágoras } & $\begin{array}{c}\text { Distancia } \\
\text { Menor-pit. }\end{array}$ & \multicolumn{1}{c}{$\begin{array}{c}\text { Distancia } \\
\text { Mayor-pit. }\end{array}$} & $\begin{array}{l}\text { Compatib. } \\
\text { Menor-pit. }\end{array}$ & $\begin{array}{c}\text { Compatib. } \\
\text { Mayor-pit. }\end{array}$ \\
\hline 1 & 305 & 316 & 309,0261 & 22,70333882 & 38,63504005 & 0,772966612 & 0,613649599 \\
2 & 346 & 356 & 347,6543 & 8,257675091 & 41,06856891 & 0,917423249 & 0,589314311 \\
3 & 376 & 398 & 391,1111 & 68,2149833 & 30,22793934 & 0,317850167 & 0,697720607 \\
4 & 226 & 239 & 231,7695 & 43,6415435 & 53,18387118 & 0,563584565 & 0,468161288 \\
5 & 406 & 414 & 412,0347 & 25,5433361 & 8,237912273 & 0,744566639 & 0,917620877 \\
6 & 453 & 479 & 463,5391 & 39,81598383 & 56,801543 & 0,601840162 & 0,43198457 \\
7 & 502 & 533 & 521,4815 & 65,91445037 & 37,8233522 & 0,340855496 & 0,621766478 \\
8 & 571 & 598 & 586,6667 & 46,86043129 & 33,12525531 & 0,531395687 & 0,668747447 \\
9 & 587 & 636 & 618,0521 & 89,24154592 & 49,55796869 & 0,107584541 & 0,504420313 \\
10 & 668 & 713 & 695,3086 & 69,36639729 & 43,49837148 & 0,306336027 & 0,565016285 \\
11 & 781 & 795 & 782,2222 & 2,707119546 & 28,05165489 & 0,972928805 & 0,719483451 \\
12 & 548 & 570 & 549,3797 & 4,353251434 & 63,78997988 & 0,956467486 & 0,362100201 \\
13 & 487 & 498 & 495 & 28,20810346 & 10,46066052 & 0,717918965 & 0,895393395 \\
14 & 440 & 443 & 440 & 0 & 11,76381004 & 1 & 0,8823619 \\
\hline
\end{tabular}

Tabla 5.18. Compatibilidad del fragmento de Haydn. Sistema pitagórico.

Fuente: Elaboración propia. 


\begin{tabular}{ccclcccc}
\hline Nota & Menor Mayor & Zarlino & $\begin{array}{c}\text { Distancia } \\
\text { Menor-zar. }\end{array}$ & $\begin{array}{c}\text { Distancia } \\
\text { Mayor-zar. }\end{array}$ & $\begin{array}{l}\text { Compatib. } \\
\text { Menor-zar. }\end{array}$ & $\begin{array}{c}\text { Compatib. } \\
\text { Mayor-zar. }\end{array}$ \\
\hline 1 & 305 & 316 & 310,8272 & 32,76421749 & 28,57416139 & 0,672357825 & 0,714258386 \\
2 & 346 & 356 & 350,3555 & 21,65700776 & 27,66923624 & 0,783429922 & 0,723307638 \\
3 & 376 & 398 & 396 & 89,72132208 & 8,721600557 & 0,102786779 & 0,912783994 \\
4 & 226 & 239 & 233,5703 & 57,04087809 & 39,78453659 & 0,429591219 & 0,602154634 \\
5 & 406 & 414 & 414,4362 & 35,60435645 & 1,823108073 & 0,643956436 & 0,981768919 \\
6 & 453 & 479 & 467,1406 & 53,21494493 & 43,40258189 & 0,467850551 & 0,565974181 \\
7 & 502 & 533 & 528 & 87,42067849 & 16,31712408 & 0,125793215 & 0,836828759 \\
8 & 571 & 598 & 594 & 68,36662253 & 11,61906408 & 0,316333775 & 0,883809359 \\
9 & 587 & 636 & 621,6544 & 99,30270469 & 39,49680992 & 0,006972953 & 0,605031901 \\
10 & 668 & 713 & 700,7109 & 82,76548289 & 30,09928588 & 0,172345171 & 0,699007141 \\
11 & 781 & 795 & 792 & 24,21345833 & 6,545316111 & 0,757865417 & 0,934546839 \\
12 & 548 & 570 & 559,4889 & 35,92033908 & 32,22289223 & 0,640796609 & 0,677771078 \\
13 & 487 & 498 & 497,3235 & 36,31539844 & 2,353365543 & 0,636846016 & 0,976466345 \\
14 & 440 & 443 & 440 & 0 & 11,76381004 & 1 & 0,8823619 \\
\hline
\end{tabular}

Tabla 5.19. Compatibilidad del fragmento de Haydn. Sistema de Zarlino. Fuente: Elaboración propia.

\begin{tabular}{rrlllrlrr}
\hline Nota & Menor Mayor & $\begin{array}{c}\text { Temp } \\
(12)\end{array}$ & \multicolumn{1}{c}{$\begin{array}{c}\text { Distancia } \\
\text { Menor-tem. }\end{array}$} & $\begin{array}{c}\text { Distancia } \\
\text { Mayor-tem. }\end{array}$ & $\begin{array}{c}\text { Compatib. } \\
\text { Menor-tem. }\end{array}$ & $\begin{array}{c}\text { Compatib. } \\
\text { Mayor-men. }\end{array}$ \\
\hline 1 & 305 & 316 & 311,127 & 34,43322787 & 26,90515101 & 0,655667721 & 0,73094849 \\
2 & 346 & 356 & 349,2282 & 16,07762724 & 33,24861675 & 0,839223728 & 0,667513832 \\
3 & 376 & 398 & 391,9954 & 72,1248753 & 26,31804733 & 0,278751247 & 0,736819527 \\
4 & 226 & 239 & 233,0819 & 53,41704425 & 43,40837043 & 0,465829558 & 0,565916296 \\
5 & 406 & 414 & 415,3047 & 39,2285657 & 5,447317319 & 0,607714343 & 0,945526827 \\
6 & 453 & 479 & 466,1638 & 49,59111109 & 47,02641574 & 0,504088889 & 0,529735843 \\
7 & 502 & 533 & 523,253 & 71,78557659 & 31,95222598 & 0,282144234 & 0,68047774 \\
8 & 571 & 598 & 587,3296 & 48,81552293 & 31,17016367 & 0,511844771 & 0,688298363 \\
9 & 587 & 636 & 622,254 & 100,9717151 & 37,82779953 & 0 & 0,621722005 \\
10 & 668 & 713 & 698,4564 & 77,18634944 & 35,67841933 & 0,228136506 & 0,643215807 \\
11 & 781 & 795 & 783,9908 & 6,617011547 & 24,14176289 & 0,933829885 & 0,758582371 \\
12 & 548 & 570 & 554,3652 & 19,9929632 & 48,15026811 & 0,800070368 & 0,518497319 \\
13 & 487 & 498 & 493,8833 & 24,29809733 & 14,37066666 & 0,757019027 & 0,856293333 \\
14 & 440 & 443 & 440 & & 0 & 11,76381004 & 1 & 0,8823619 \\
\hline
\end{tabular}

Tabla 5.20. Compatibilidad del fragmento de Haydn. Sistema temperado. Fuente: Elaboración propia. 


\begin{tabular}{rllllllll}
\hline Nota & Menor Mayor & Hölder & $\begin{array}{c}\text { Distancia } \\
\text { Menor-hol. }\end{array}$ & $\begin{array}{c}\text { Distancia } \\
\text { Mayor-hol. }\end{array}$ & $\begin{array}{c}\text { Compatib. } \\
\text { Menor-hol. }\end{array}$ & $\begin{array}{c}\text { Compatib. } \\
\text { Mayor-hol. }\end{array}$ \\
\hline 1 & 305 & 316 & 309,099 & 23,11169293 & 38,22668594 & 0,768883071 & 0,617733141 \\
2 & 346 & 356 & 347,709 & 8,53004639 & 40,79619761 & 0,914699536 & 0,592038024 \\
3 & 376 & 398 & 391,1419 & 68,35131262 & 30,09161002 & 0,316486874 & 0,6990839 \\
4 & 226 & 239 & 231,815 & 43,98137863 & 52,84403605 & 0,560186214 & 0,47155964 \\
5 & 406 & 414 & 412,148 & 26,01931993 & 7,761928443 & 0,739806801 & 0,922380716 \\
6 & 453 & 479 & 463,63 & 40,15544548 & 56,46208135 & 0,598445545 & 0,435379186 \\
7 & 502 & 533 & 521,5431 & 66,11894031 & 37,61886226 & 0,338810597 & 0,623811377 \\
8 & 571 & 598 & 586,6898 & 46,92859729 & 33,05708931 & 0,530714027 & 0,669429107 \\
9 & 587 & 636 & 618,198 & 89,65018014 & 49,14933447 & 0,103498199 & 0,508506655 \\
10 & 668 & 713 & 695,418 & 69,63876858 & 43,22600018 & 0,303612314 & 0,567739998 \\
11 & 781 & 795 & 782,2839 & 2,843670168 & 27,91510427 & 0,971563298 & 0,720848957 \\
12 & 548 & 570 & 549,552 & 4,896127081 & 63,24710423 & 0,951038729 & 0,367528958 \\
13 & 487 & 498 & 494,96 & 28,06820011 & 10,60056388 & 0,719317999 & 0,893994361 \\
14 & 440 & 443 & 440 & & 0 & 11,76381004 & 1 & 0,8823619 \\
\hline
\end{tabular}

Tabla 5.21. Compatibilidad del fragmento de Haydn. Sistema de Hölder. Fuente: Elaboración propia.

La forma más práctica de presentar las compatibilidades que aparecen en las tablas anteriores es representar gráficamente dos series. Una de ellas (la de color rosa) representa, una a una y para cada sistema, la compatibilidad de las notas de mayor frecuencia y la otra (la de color azul) las de menor frecuencia.

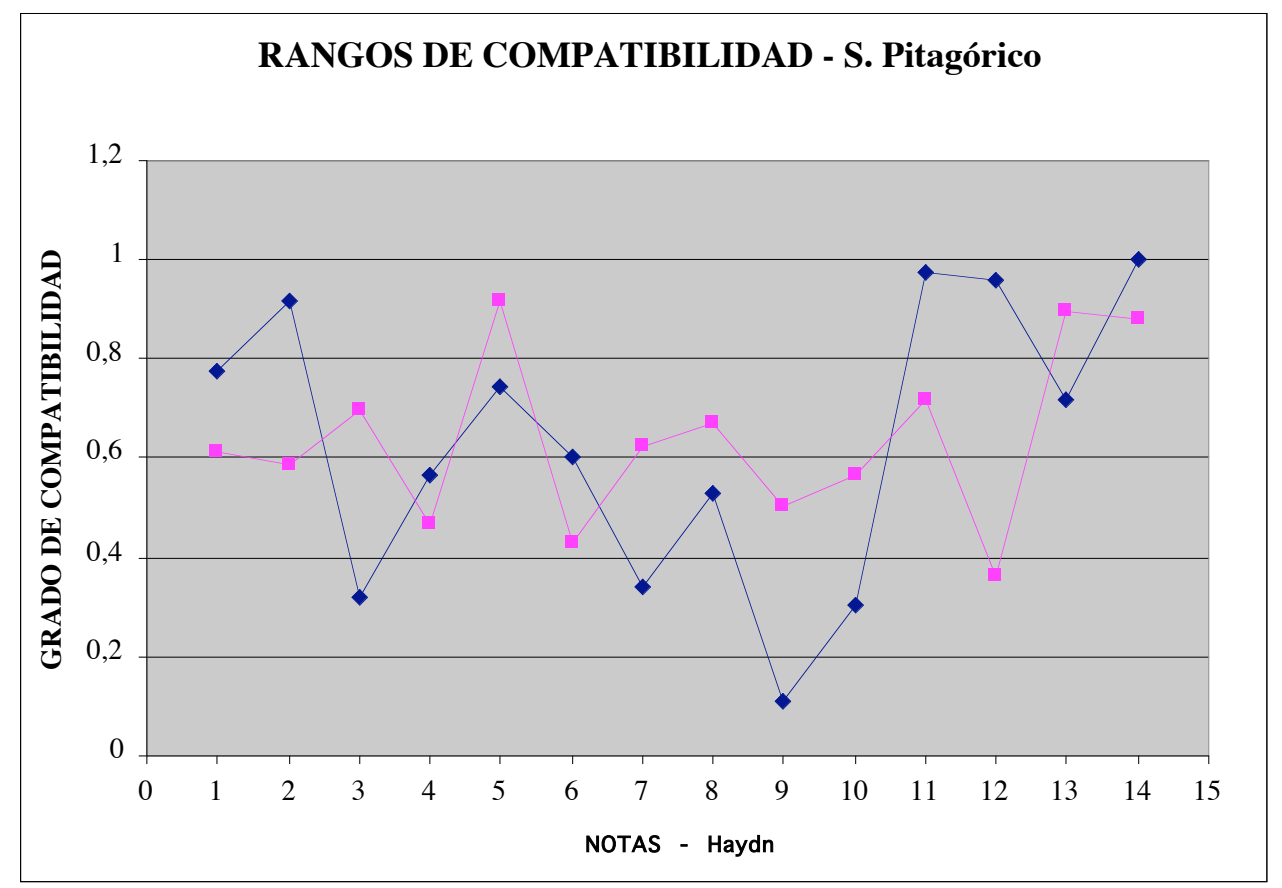

Fig. 5.11. Rangos de compatibilidad para el sistema pitagórico Fuente: Elaboración propia. 


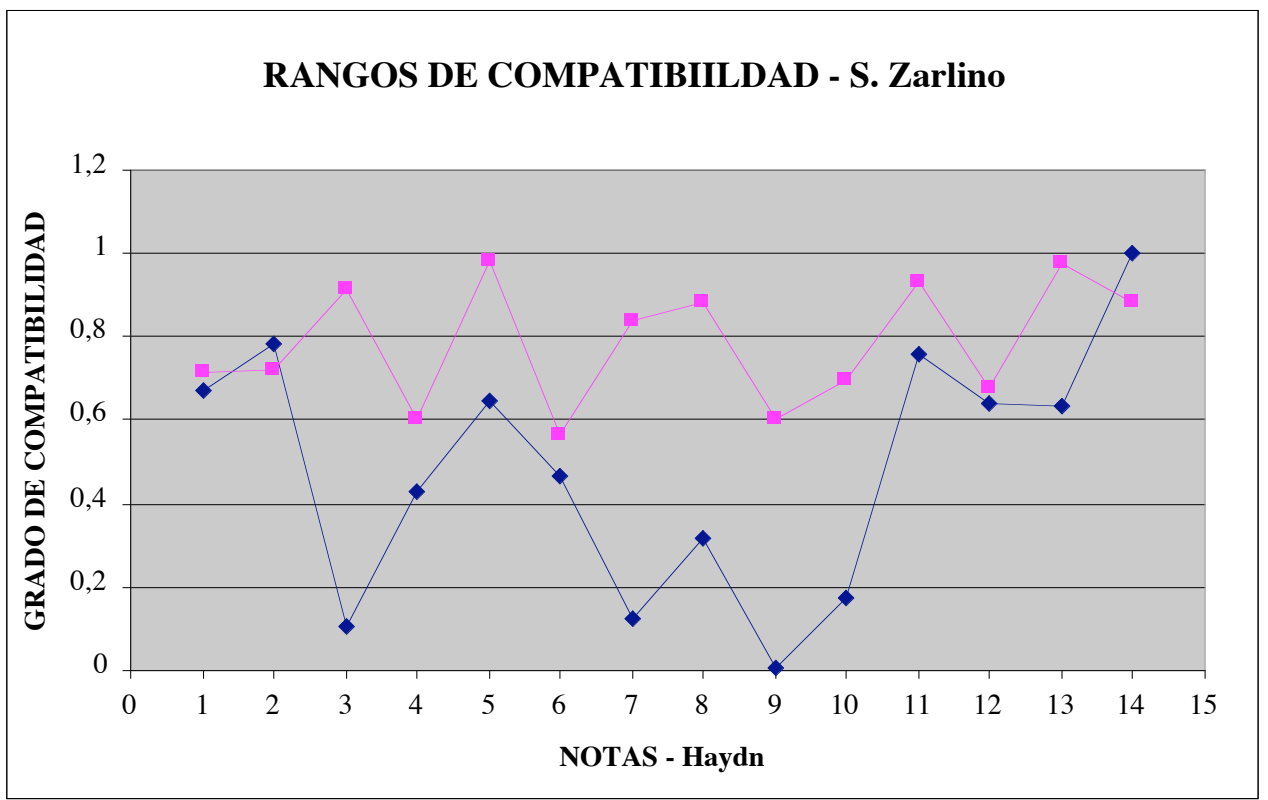

Fig. 5.12. Rangos de compatibilidad para el sistema de Zarlino. Fuente: Elaboración propia

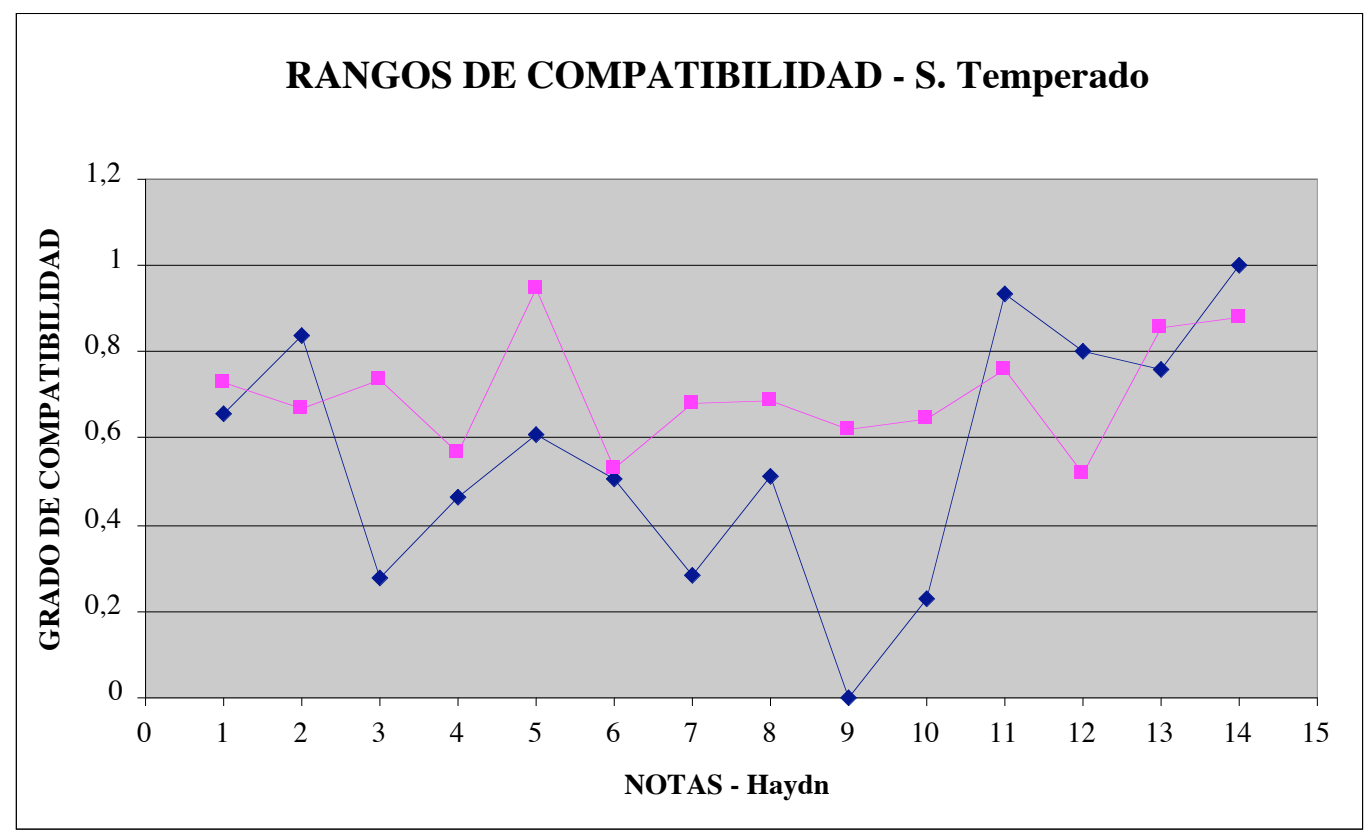

Fig. 5.13. Rangos de compatibilidad para el sistema temperado.

Fuente: Elaboración propia 


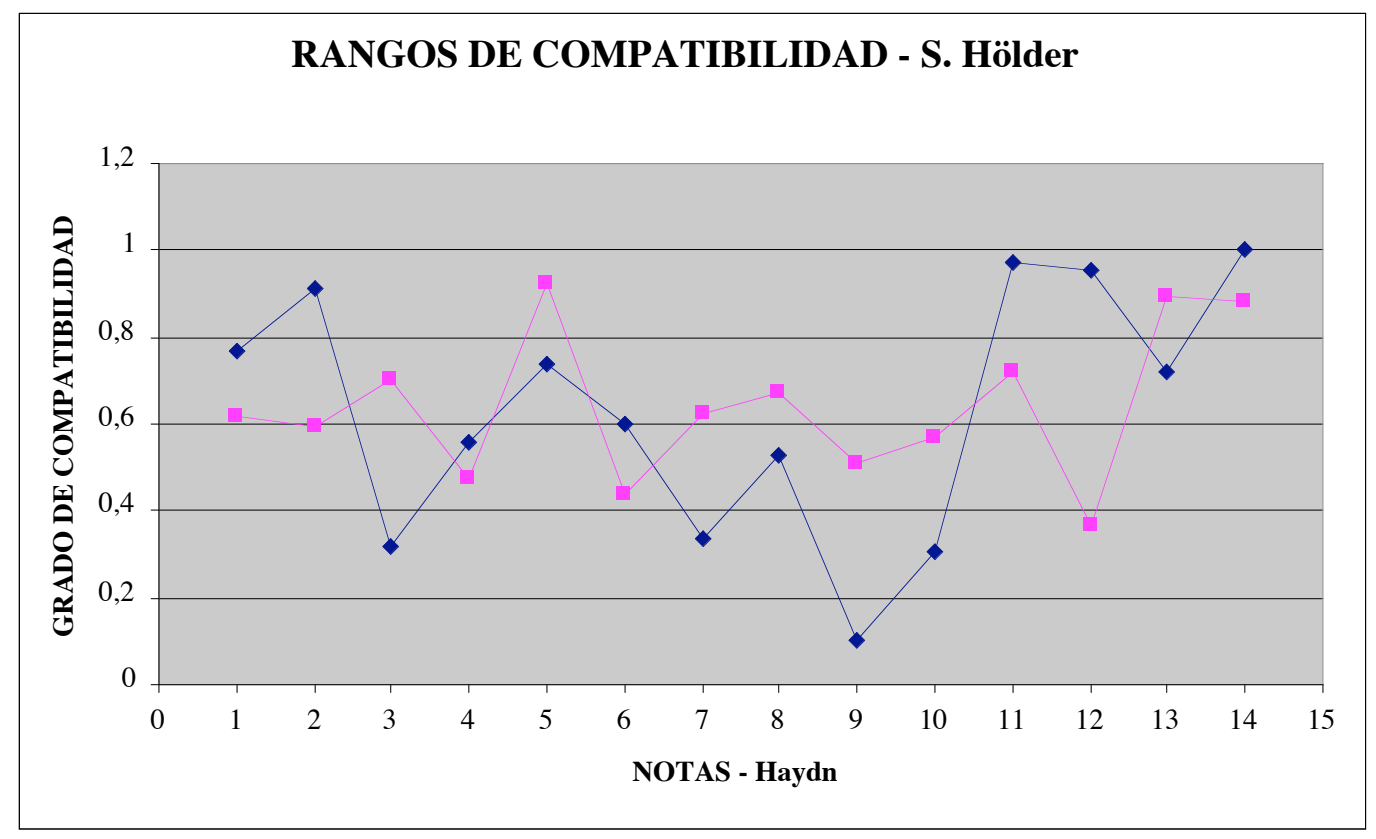

Fig. 5.14. Rangos de compatibilidad para el sistema de Hölder. Fuente: Elaboración propia

A partir de los gráficos, vemos que las conclusiones a las que llegábamos en el capítulo 3, deben precisarse:

1. El sistema más compatible con las notas grabadas es el de Zarlino (en el capítulo 3 se afirmaba que un $33 \%$ de las notas eran de este sistema).

2. Los sistemas de Pitágoras o Hölder, que en la Experiencia 3 ocupaban los lugares $2^{\circ}$ y $3^{\circ}$ en cuanto a pertenencia de notas, cuando tratamos con mayor flexibilidad las notas (sistemas de afinación borrosos) ocupan las últimas posiciones.

3. Como se acepta en la práctica cotidiana, el grado de compatibilidad del sistema temperado es bueno (excepto en una nota, para las frecuencias mayores siempre superior al 0,66).

\subsubsection{Fragmento de Béla Bartók}

A continuación calculamos la $\alpha$-compatibilidad de tres compases del Adagio de Música para cuerda, percusión y celesta (1937) de Béla Bartók (18811945):

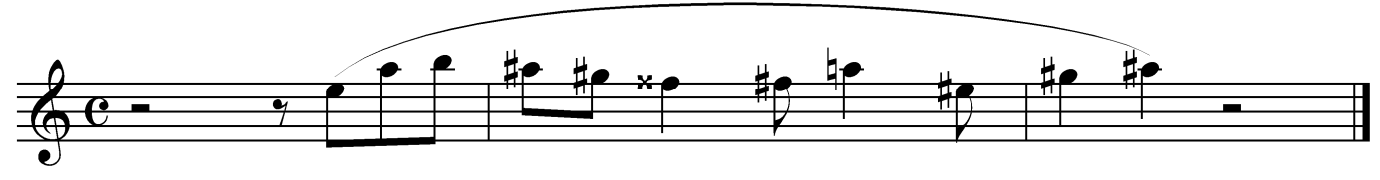


Se han analizado 22 grabaciones interpretadas por el autor de esta memoria con diferentes trompetas (descritas en el capítulo 3). A modo de ejemplo, en el capítulo 4 habíamos analizado la compatibilidad de las notas de este fragmento tomando como referencia el sistema temperado ${ }^{1}$. Los resultados obtenidos eran los siguientes:

\begin{tabular}{cccc}
\hline Nota & Compat $(\mathrm{p}, \mathrm{t})$ & Compat $(\mathrm{z}, \mathrm{t})$ & Compat $(\mathrm{h}, \mathrm{t})$ \\
\hline $\mathrm{Mi}$ & 0,8841 & 0,8841 & 0,8875 \\
$\mathrm{La}$ & 1 & 1 & 1 \\
$\mathrm{Si}$ & 0,8268 & 0,8268 & 0,833 \\
$\mathrm{La} \#$ & 0,3955 & 0,6547 & 0,4163 \\
$\mathrm{Sol} \#$ & 0,5682 & 0,482 & 0,583 \\
$\mathrm{Fa \# \#}$ & 0,1366 & 0 & 0,1669 \\
$\mathrm{Fa} \#$ & 0,741 & 0,741 & 0,7502 \\
$\mathrm{La}$ & 1 & 1 & 1 \\
$\mathrm{Mi} \#$ & 0,3092 & 0 & 0,3336 \\
Sol\# & 0,5682 & 0,482 & 0,583 \\
La\# & 0,3955 & 0,6547 & 0,4163 \\
\hline
\end{tabular}

Tabla 5.22. Compatibilidad con del sistema temperado (ver Tabla 4.3)

Fuente: Elaboración propia

Los resultados expresados en la Tabla 5.22 son útiles a un nivel teórico, pero no responden a lo que ocurre en la práctica, puesto que para los cálculos se han considerado las frecuencias teóricas exactas de cada una de las notas. Por eso, como hacíamos con el fragmento anterior, analizaremos qué ocurre con las frecuencias reales de las notas recogidas en las grabaciones.

Como hacíamos con el fragmento de Haydn, analizaremos las notas diferentes que aparecen en el fragmento Bartók:

$$
\text { Mi, La, Si, La \#, Sol \#, Fa \#\#, Fa\#, Mi\#.. }
$$

En la tabla 5.23 mostramos cuáles han sido las frecuencias mayores y menores en las 22 grabaciones y las frecuencias exactas en cada uno de los sistemas estudiados:

1 Como veremos más adelante, la consistencia de considerar el sistema temperado como referencia, que no se justifico en capítulos precedentes, queda justificada en este capítulo. 


\begin{tabular}{lllllll}
\hline Nota & Menor & Mayor & Pitágoras & Zarlino & Temp. (12) & Holder \\
\hline $\mathrm{Mi}$ & 659 & 666 & 660 & 660 & 659,2552 & 659,9739 \\
$\mathrm{La}$ & 878 & 889 & 880 & 880 & 880 & 880 \\
$\mathrm{Si}$ & 974 & 996 & 990 & 994,6469 & 987,7666 & 989,9219 \\
$\mathrm{La} \#$ & 925 & 943 & 939,7266 & 950,4 & 932,3276 & 939,4674 \\
$\mathrm{Sol} \#$ & 826 & 840 & 835,3125 & 840,8531 & 830,6094 & 835,1479 \\
$\mathrm{Fa} \mathrm{\# \#}$ & 786 & 794 & 792,8943 & 795,7176 & 783,9908 & 792,5820 \\
$\mathrm{Fa \#}$ & 742 & 752 & 742,5 & 745,9852 & 739,9888 & 742,4120 \\
$\mathrm{Mi} \#$ & 699 & 710 & 704,7949 & 704 & 698,4564 & 704,5720 \\
\hline
\end{tabular}

Tabla 5.23. Frecuencia de las notas del fragmento de Bartók.

Fuente: Elaboración propia.

Utilizando los datos de la tabla 5.23, en las cuatro tablas siguientes calculamos la a-compatibilidad de las notas respecto a cada uno de los sistemas:

\begin{tabular}{ccllllll}
\hline \multicolumn{2}{c}{ Nota Menor } & Mayor Pitágoras & $\begin{array}{c}\text { Distancia } \\
\text { Menor-pit. }\end{array}$ & $\begin{array}{l}\text { Distancia } \\
\text { Mayor-pit. }\end{array}$ & $\begin{array}{l}\text { Compatib. } \\
\text { Menor-pit. }\end{array}$ & $\begin{array}{l}\text { Compatib. } \\
\text { Mayor-pit. }\end{array}$ \\
\hline 1 & 659 & 666 & 660 & 2,625071085 & 15,66738339 & 0,973749289 & 0,843326166 \\
2 & 878 & 889 & 880 & 3,939100787 & 17,61587437 & 0,960608992 & 0,823841256 \\
3 & 974 & 996 & 990 & 28,20810346 & 10,46066052 & 0,717918965 & 0,895393395 \\
4 & 925 & 943 & 939,7266 & 27,34526489 & 6,020021438 & 0,726547351 & 0,939799786 \\
5 & 826 & 840 & 835,3125 & 19,40909485 & 9,687960643 & 0,805909051 & 0,903120394 \\
6 & 786 & 794 & 792,8943 & 15,11909032 & 2,412543542 & 0,848809097 & 0,975874565 \\
7 & 742 & 752 & 742,5 & 1,166206881 & 22,00996319 & 0,988337931 & 0,779900368 \\
8 & 699 & 710 & 704,7949 & 14,29323497 & 12,73864785 & 0,85706765 & 0,872613521 \\
\hline
\end{tabular}

Tabla 5.24. Compatibilidad del fragmento de Bartók. Sistema pitagórico. Fuente: Elaboración propia.

\begin{tabular}{ccclllll}
\hline \multicolumn{2}{c}{ Nota Menor } & Mayor & Zarlino & $\begin{array}{c}\text { Distancia } \\
\text { Menor-zar. }\end{array}$ & $\begin{array}{c}\text { Distancia } \\
\text { Mayor-zar. }\end{array}$ & $\begin{array}{c}\text { Compatib. } \\
\text { Menor-zar. }\end{array}$ & $\begin{array}{c}\text { Compatib. } \\
\text { Mayor-zar. }\end{array}$ \\
\hline 1 & 659 & 666 & 660 & 2,625071085 & 15,66738339 & 0,973749289 & 0,843326166 \\
2 & 878 & 889 & 880 & 3,939100787 & 17,61587437 & 0,960608992 & 0,823841256 \\
3 & 974 & 996 & 990 & 36,31522438 & 2,353539598 & 0,636847756 & 0,976464604 \\
4 & 925 & 943 & 939,7266 & 46,89776461 & 13,53247829 & 0,531022354 & 0,864675217 \\
5 & 826 & 840 & 835,3125 & 30,85439633 & 1,757340834 & 0,691456037 & 0,982426592 \\
6 & 786 & 794 & 792,8943 & 21,27263636 & 3,741002502 & 0,787273636 & 0,962589975 \\
7 & 742 & 752 & 742,5 & 9,273385822 & 13,90278425 & 0,907266142 & 0,860972158 \\
8 & 699 & 710 & 704,7949 & 12,33956791 & 14,69231491 & 0,876604321 & 0,853076851 \\
\hline
\end{tabular}

Tabla 5.25. Compatibilidad del fragmento de Bartók. Sistema de Zarlino. Fuente: Elaboración propia. 


\begin{tabular}{|c|c|c|c|c|c|c|c|}
\hline Nota & Menor & Mayor & $\begin{array}{c}\text { Temp. } \\
(12)\end{array}$ & $\begin{array}{c}\text { Distancia } \\
\text { Menor-temp. }\end{array}$ & $\begin{array}{c}\text { Distancia } \\
\text { Mayor-temp. }\end{array}$ & $\begin{array}{c}\text { Compatib. } \\
\text { Menor-temp. }\end{array}$ & $\begin{array}{c}\text { Compatib. } \\
\text { Mayor-temp. }\end{array}$ \\
\hline 1 & 659 & 666 & 660 & 0,670296517 & 17,62215796 & 0,993297035 & 0,82377842 \\
\hline 2 & 878 & 889 & 880 & 3,939100787 & 17,61587437 & 0,960608992 & 0,823841256 \\
\hline 3 & 974 & 996 & 990 & 24,29809733 & 14,37066666 & 0,757019027 & 0,856293333 \\
\hline 4 & 925 & 943 & 939,7266 & 13,66033266 & 19,70495367 & 0,863396673 & 0,802950463 \\
\hline 5 & 826 & 840 & 835,3125 & 9,634100614 & 19,46295488 & 0,903658994 & 0,805370451 \\
\hline 6 & 786 & 794 & 792,8943 & 4,431105393 & 21,96273925 & 0,955688946 & 0,780372607 \\
\hline 7 & 742 & 752 & 742,5 & 4,698901985 & 27,87507205 & 0,95301098 & 0,721249279 \\
\hline 8 & 699 & 710 & 704,7949 & 1,346874044 & 28,37875686 & 0,98653126 & 0,716212431 \\
\hline
\end{tabular}

Tabla 5.26. Compatibilidad del fragmento de Bartók. Sistema temperado. Fuente: Elaboración propia.

\begin{tabular}{rlllrrrl}
\hline \multicolumn{2}{c}{ Nota Menor Mayor } & Hölder & $\begin{array}{c}\text { Distancia } \\
\text { Menor-hol. }\end{array}$ & $\begin{array}{c}\text { Distancia } \\
\text { Mayor-hol. }\end{array}$ & $\begin{array}{c}\text { Compatib. } \\
\text { Menor-hol. }\end{array}$ & $\begin{array}{c}\text { Compatib. } \\
\text { Mayor-hol. }\end{array}$ \\
\hline 1 & 659 & 666 & 660 & 2,556607294 & 15,73584718 & 0,974433927 & 0,842641528 \\
2 & 878 & 889 & 880 & 3,939100787 & 17,61587437 & 0,960608992 & 0,823841256 \\
3 & 974 & 996 & 990 & 28,07152294 & 10,59724104 & 0,719284771 & 0,89402759 \\
4 & 925 & 943 & 939,7266 & 26,86768155 & 6,497604772 & 0,731323184 & 0,935023952 \\
5 & 826 & 840 & 835,3125 & 19,0679181 & 10,02913739 & 0,809320819 & 0,899708626 \\
6 & 786 & 794 & 792,8943 & 14,4370689 & 3,094564964 & 0,855629311 & 0,96905435 \\
7 & 742 & 752 & 742,5 & 0,961011426 & 22,21515864 & 0,990389886 & 0,777848414 \\
8 & 699 & 710 & 704,7949 & 13,74562445 & 13,28625837 & 0,862543756 & 0,867137416 \\
\hline
\end{tabular}

Tabla 5.27. Compatibilidad del fragmento de Bartók. Sistema de Hölder. Fuente: Elaboración propia.

Creemos interesante destacar que, a pesar de que, teóricamente, el fragmento de Bartók presentaba más dificultades para la afinación en los diferentes sistemas (capítulos 3 y 4), en la práctica, los grados de compatibilidad son más elevados que en los del fragmento de Haydn. En cualquier caso, esto se comprueba mejor si representamos gráficamente los grados de compatibilidad.

En los gráficos siguientes la línea de color rosa representa, una a una y para cada sistema, la compatibilidad de las notas de mayor frecuencia y la de color azul las de menor frecuencia. 


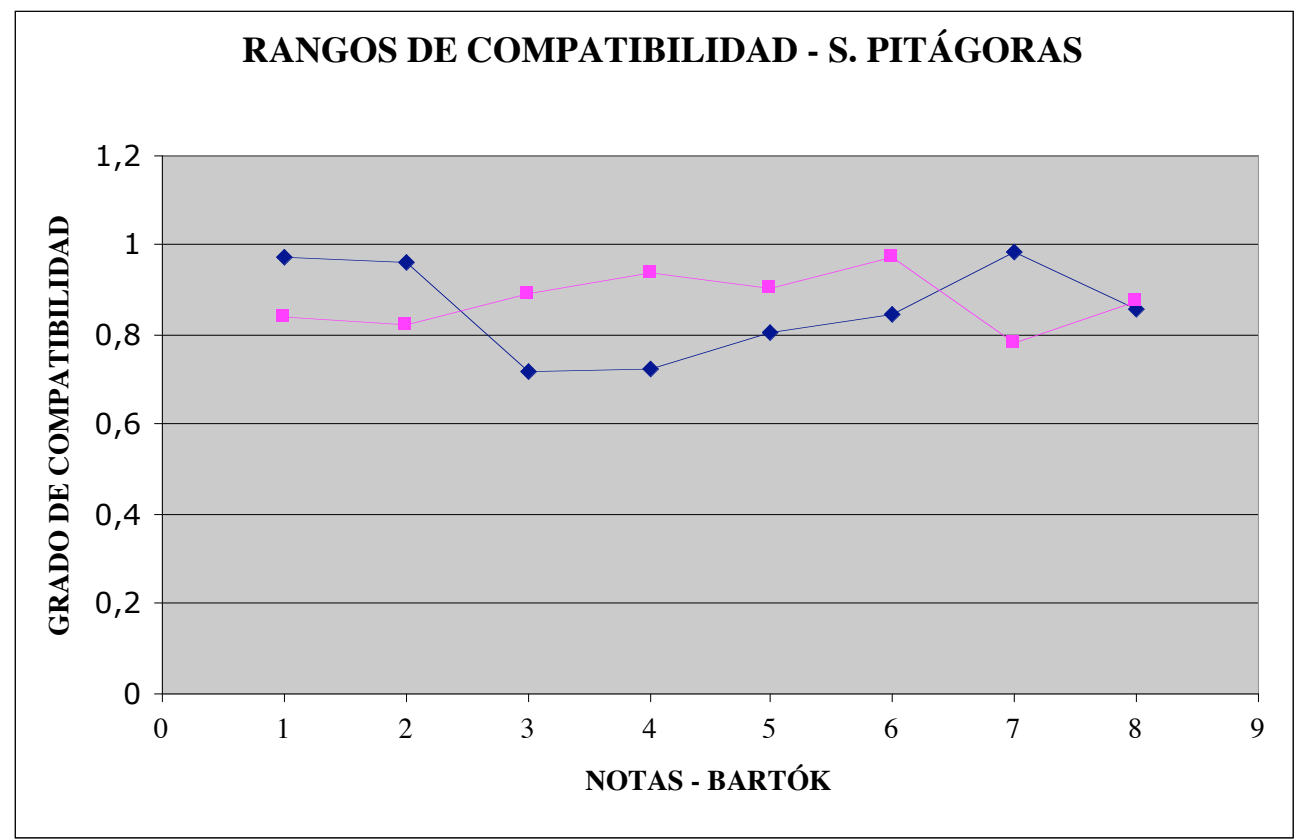

Fig. 5.15. Rangos de compatibilidad para el sistema pitagórico.

Fuente: Elaboración propia

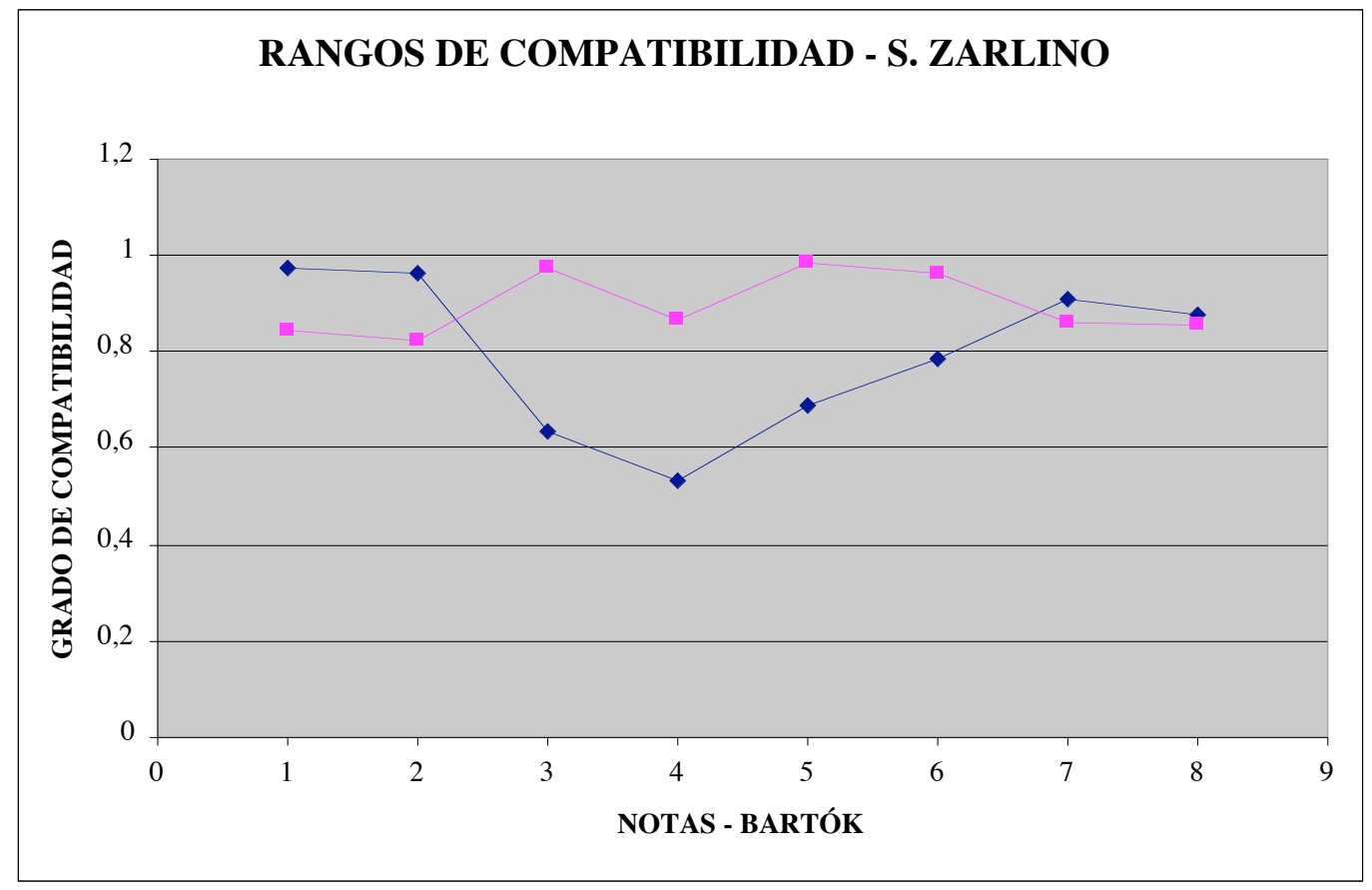

Fig. 5.16. Rangos de compatibilidad para el sistema de Zarlino. Fuente: Elaboración propia 


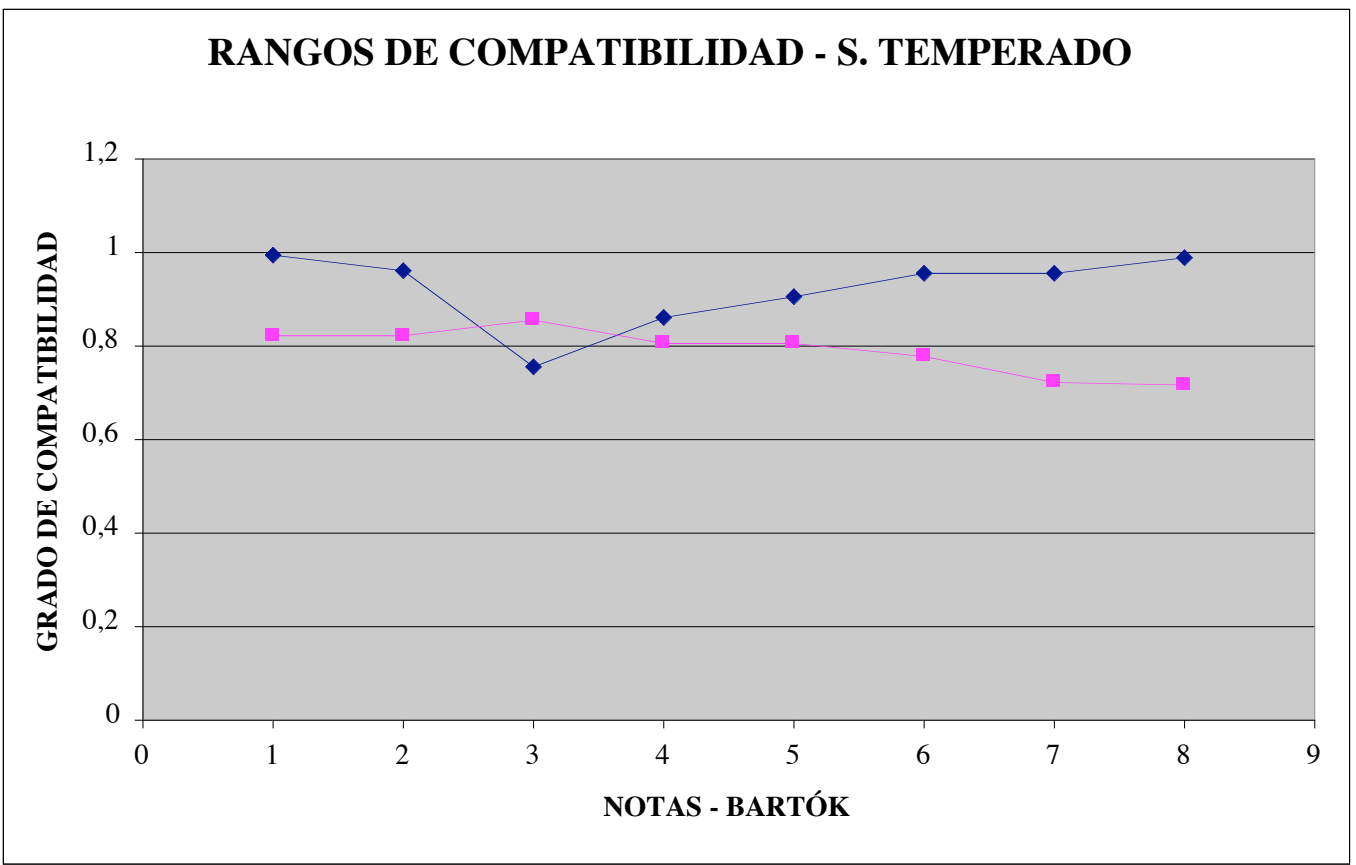

Fig. 5.17. Rangos de compatibilidad para el sistema temperado.

Fuente: Elaboración propia

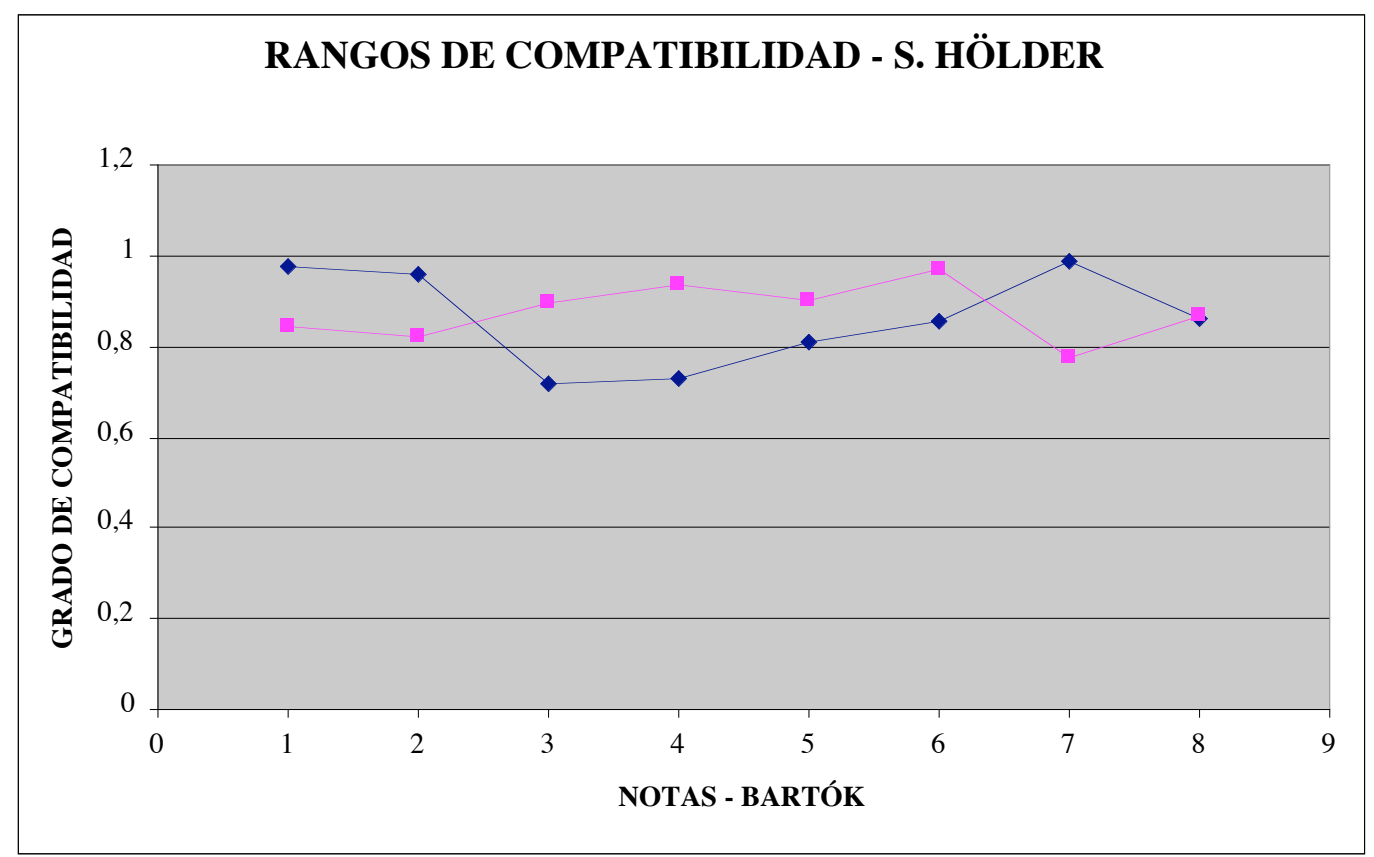

Fig. 5.18 Rangos de compatibilidad para el sistema de Hölder.

Fuente: Elaboración propia 
En este caso, la obra Música para cuerda, percusión y celesta fue concebida dentro del sistema de afinación pitagórico. En principio, podría pensarse que esto debería reducir el nivel de compatibilidad con el sistema temperado. Sin embargo, como puede apreciarse en los gráficos, la compatibilidad con el sistema temperado es mejor que la que se obtiene con el sistema de Zarlino, y muy similar a la obtenida para el sistema pitagórico.

Los resultados globales que se obtuvieron en el capítulo 3, mostraron que, para el fragmento de Bartók, las diferencias entre el sistema temperado y el resto de los sistemas de afinación era más acusada que con el fragmento de Haydn. Gráficamente, los porcentajes de notas pertenecientes a cada sistema son:

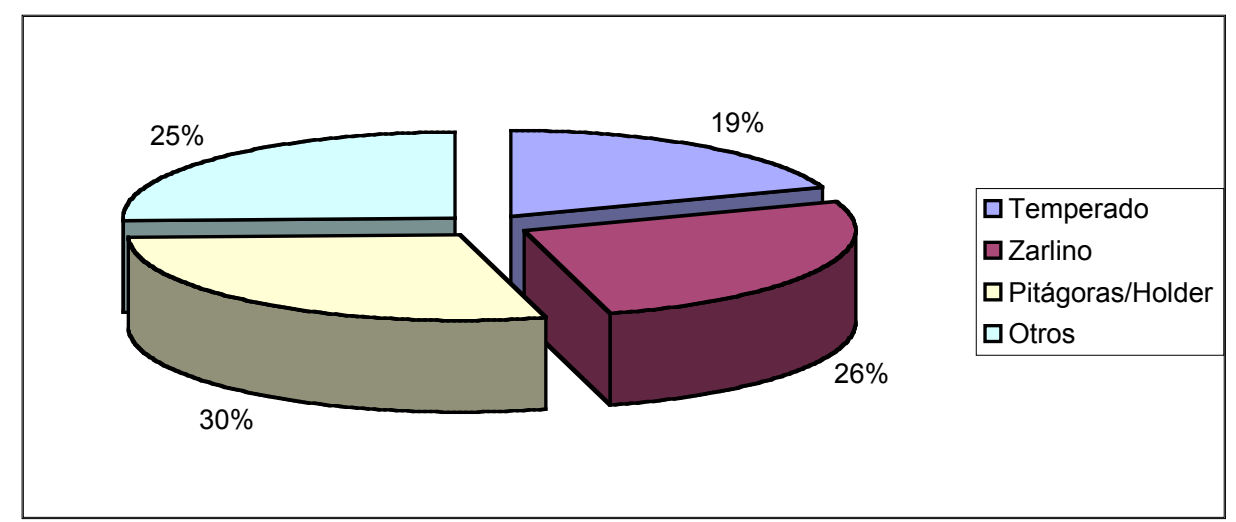

Fig. 5.19. Porcentaje de notas en cada uno de los sistemas (ver Experimento 4 del capítulo 3)

Fuente: Elaboración propia

De nuevo, la posibilidad de flexibilizar la afinación exacta de las notas mediante los conceptos de la lógica borrosa hace que el análisis resulte más preciso y acorde con la realidad, puesto que en la práctica, la obra de Béla Bartók se interpreta de forma satisfactoria dentro de agrupaciones cuya referencia es el sistema temperado. 


\section{CONCLUSIONES}

En esta sección mostramos los resultados que, a nuestro juicio, son más interesantes. Por tanto, hemos evitado confeccionar un listado exhaustivo que no haría más que repetir gran parte de las conclusiones que se han intercalado a lo largo de los capítulos anteriores.

Dados los objetivos y las características de este trabajo, las conclusiones a las que se llega pueden clasificarse en tres grupos: conceptuales, metodológicas y de orden práctico. Por tanto, creemos más útil desglosar las principales conclusiones y resultados obtenidos en estos apartados.

\section{a) Resultados conceptuales}

Aunque no era un objetivo específico de este trabajo, determinar de forma precisa cada uno de los conceptos que maneja el músico en su práctica habitual, resulta muy enriquecedor. Cuando éste es capaz de utilizar las unidades, interpretar los gráficos, etc. no sólo se puede entender mejor parte de la problemática de los músicos y musicólogos de toda la Historia de la Música, sino que además estos conocimientos pueden revertir en un incremento de su calidad musical. A grandes rasgos, desde el punto de vista teórico los resultados son los siguientes:

- Damos métodos para obtener las notas de los sistemas de afinación de Pitágoras, de Zarlino, de Holder y Temperado de 12 notas. 
- Mediante los métodos propuestos analizamos las ventajas e inconvenientes de estos sistemas de afinación.

- Utilizando la sensación de altura como distancia, se compara cada uno de los sistemas de afinación mencionados con ellos mismos y con el resto. Con esto se consigue describir la estructura interna de los sistemas y la compatibilidad con los demás, hecho que resulta fundamental para analizar la convivencia dentro de una misma agrupación musical.

- Se argumenta por qué, en las afinaciones, la cantidad de notas diferentes por octava puede ser 12, 53, 665, etc. (para la afinación pitagórica) o 50, por ejemplo, para la afinación de Zarlino. Se muestra que estas cifras no son arbitrarias y que de hecho en ellas está la génesis de los temperamentos cíclicos.

- Además, se ha resumido la historia de la trompeta destacando su vertiente acústica y mostrando cómo ha llegado hasta su estado actual.

\section{b) Resultados metodológicos}

Es muy habitual que los músicos cuenten con un afinador cromático electrónico que les sirva de apoyo para afinar. Lo cierto es que, normalmente, suele comprobarse la afinación de algunas notas sueltas y a partir de la desviación respecto de la nota afinada en el sistema temperado toman una decisión acerca de sacar las bombas, las boquillas, etc. Lo cierto es que es una solución rápida. Sin embargo, si la decisión no precisa de tanta urgencia, un estudio detallado de la afinación del propio instrumento está al alcance de un gran número de músicos. En concreto, nuestras sugerencias son las siguientes:

- Utilización de programas informáticos (de los que todos los usuarios de ordenador pueden disponer) para analizar y mejorar la interpretación musical. En particular se propone:

i. Uso del programa EXCEL ${ }^{\circledR}$ para obtener las notas, calcular las distancias entre ellas y representarlo gráficamente.

ii. Uso del programa AUDACITY ${ }^{\circledR}$ para analizar la afinación de una nota de forma mucho más precisa y completa que los afinadores cromáticos comerciales.

- Se expone cómo recoger los datos y cómo tratarlos, de manera que cualquier músico que así lo desee pueda repetir las experiencias él mismo. 
- Si el músico dispone de más de un instrumento, analizar las tendencias de la afinación utilizando los métodos expuestos en este trabajo permite elegir cuál es el más adecuado para cada tipo de música.

\section{c) Resultados prácticos}

Cuando presentábamos esta memoria de investigación, hacíamos referencia a un trabajo de N. A. Garbuzov (véase Haluska, 2000) en el que se obtenían los porcentajes de notas afinadas en varios sistemas de afinación utilizando el violín. En aquel trabajo se comprobaba que los porcentajes de notas afinadas en el sistema temperado eran bastante reducidos y nosotros lanzábamos, como uno de los retos de nuestro trabajo, un análisis parecido para la trompeta, pero haciendo el estudio más exhaustivo. Entre los resultados prácticos de nuestro estudio podemos destacar los siguientes:

- Hemos comprobado una tendencia a la desafinación (entendiendo como tal el alejamiento del sistema temperado) de las notas en las que se utiliza mayor número de pistones.

- Cuando el intérprete no utiliza como referencia otras notas, el porcentaje de notas afinadas dentro del sistema temperado disminuye considerablemente. Así, en el estudio que hemos realizado de la escala cromática, más del $50 \%$ de las notas son temperadas, mientras que en el resto de las experiencias los porcentajes entre los sistemas de afinación se equilibran, siendo precisamente el sistema temperado el que presenta los resultados más bajos.

- Si el músico ejecuta pasajes muy trabajados por él, como la escala cromática, en los que recuerda la afinación, ésta suele ser completamente temperada, mientras que cuando son menos conocidos por el instrumentista, el sistema empleado varía en función de otros factores. Además, en los pasajes de mayor dificultad, al no poder elegir libremente la digitación, de nuevo el intérprete se aleja del sistema temperado.

- Los sistemas de Pitágoras/Holder y Zarlino que aparecen con una frecuencia muy baja en la escala cromática se igualan al resto de sistemas cuando se analiza en su contexto (afinación dinámica). En concreto, en el fragmento de Haydn el sistema de Zarlino predomina sobre los demás y en el de Bartók los sistemas de Pitágoras y Holder son los que obtienen resultados superiores al resto.

- La afirmación "la trompeta afina en el sistema temperado" no sale reforzada por los resultados experimentales. De hecho, a la vista de lo que ocurre con la escala cromática o con las notas largas no seriadas, lo cierto es que "el trompetista puede afinar en el sistema temperado". 
Se han tenido en cuenta todos los datos obtenidos en este estudio para elaborar una obra musical que esta pensada para ser interpretada en el sistema de Zarlino puesto que los instrumentos utilizados son de viento metal y su afinación natural es ésta. En la obra, entendida como ejercicio práctico del estudio teórico realizado en el capítulo 2, además de las conclusiones que se ha recogido a lo largo del capítulo 3 , hemos conseguido

- Utilizar elementos antiguos extraídos de los cálculos de Kepler y conjugarlos con series de notas actuales.

- Mezclar músicas con cinco siglos de diferencia pese a que una es tonal y la otra no. Las notas de Kepler son tonales y las series contemporáneas no lo son. Esto produce una mezcla de sonoridades nueva que no se había realizado con anterioridad.

- Mostrar, una vez más, que en Música, las Matemáticas en particular, y la Ciencia en general, pueden ser una fuente de inspiración, que debe ser tenida en cuenta.

Haciendo uso de razonamientos basados en la lógica borrosa, hemos comprobado que algunas notas que, a priori, podría considerarse que no estaban perfectamente afinadas la única herramienta para decidir si la dábamos por buena o no era el oído. A través del concepto de compatibilidad entre notas y sistemas de afinación, podemos establecer criterios que determinan cuándo dos o más afinaciones diferentes pueden convivir dentro de la misma agrupación musical.

El análisis de dos fragmentos (de Haydn y Béla Bartók) con todas las técnicas expuestas en esta memoria hemos podido comprobar qué notas y qué sistemas resultan compatibles. Este resultado resulta especialmente interesante a los intérpretes porque precisamente en las notas que se excluyen como compatibles es donde el músico debe esforzarse para que, a través de la presión, la elección de posiciones alternativas, etc, se consiga la mayor compatibilidad posible entre todos los sistemas de afinación

Por último, no queremos acabar estas conclusiones sin aconsejar (dentro de nuestra modesta opinión), especialmente a los compositores y directores de agrupaciones que tengan en cuenta las diferentes formas de afinar, porque con ello se podrían conseguir varias mejoras:

- Fidelidad a la obra original del autor

- Mayor número de notas (o de intervalos) claramente definidos.

- Universalidad en la notación

quizá con ello se evitarían interpretaciones ambiguas y versiones poco rigurosas que, en ocasiones, han motivado grandes críticas hacia la música contemporánea. 


\section{FUTURAS LÍNEAS DE INVESTIGACIÓN}

Como se ha advertido en la Introducción de esta tesis, el estudio de la afinación es sólo una parte del proyecto que hemos emprendido. No obstante, como resultaría demasiado utópico establecer un listado de acciones futuras que, cuando son a muy largo plazo, suelen constituir más un deseo que un plan de trabajo con visos de realidad, hemos preferido citar aquellas cuestiones que pensamos abordar en un breve plazo de tiempo. Las hemos clasificado por la propiedad del sonido a la que hace referencia.

a) Afinación

1) Extender el análisis a más instrumentos, utilizando más fragmentos para el estudio.

2) Diseñar un programa, a ser posible con $\mathrm{EXCEL}^{\circledR}$, que permita automatizar el cálculo de las frecuencias de las notas afinadas, las distancias entre ellas y la representación gráfica de las distancias para los sistemas de afinación siguientes:

Afinacion pitagórica

Justa entonación: Variantes de Aristógenes, Delezenne, Euler, Kepler, Ptlotomeo, Ramos, Salinas y Zarlino Temperamentos mesotónicos de $1 / 4,1 / 3$ y $2 / 7$ de comma. Temperamentos mesotónicos de 1/5, 2/9 y 1/6 de comma. Temperamentos iguales.

Temperamentos irregulares: Werckmeister I (1/4 de comma), Werckmeister II (1/3 de comma), Neidhart I (1/12 y 1/16 de comma), Valloti (1/6 de comma), Marpurg I (1/3 de comma), Kirnberg (1/2 de comma). 
3) Hacer un estudio detallado de la aparición y evolución histórica de cada uno de los sistemas de afinación que hemos citado.

4) Modificar el programa Audacity ${ }^{\circledR}$ de manera que se automatice la medición de las frecuencias, con lo cual el estudio será mucho menos costoso.

5) Desarrollar el estudio de los sistemas de afinación borrosos e implementarlo en un programa informático que realice los cálculos de forma automática.

6) Desarrollar herramientas informáticas que permitan estudiar el grado de compatibilidad entre notas y sistemas de afinación de forma rápida.

b) Timbre

1) Cuando se estudia el timbre surgen dificultades técnicas y conceptuales (series de Fourier, medida de intensidad de los armónicos, etc.) que hacen que rara vez participen músicos en estos análisis. Para nosotros constituye un reto el intento de sistematizar el estudio del timbre con programas como Audacity ${ }^{\circledR}$ o similares.

2) Analizar cómo afecta el timbre en los distintos tipos de música que se interpretan.

\section{c) Intensidad}

1) Muchas de las conclusiones a las que se suele llegar cuando se trabaja con la afinación, se obtienen suponiendo que ésta es independiente de la intensidad. Sin embargo, cualquier músico es consciente de que, por ejemplo los instrumentos de viento tienden a quedarse bajos cuando suenan muy fuerte. Nuestra intención es analizar, utilizando obras que lo permitan, la relación entre la afinación y la intensidad.

2) Una vez establecida, al menos de forma aproximada una relación afinación-intensidad analizaremos el comportamiento de diferentes instrumentos de viento e intérpretes. 


\section{BIBLIOGRAFÍA}

G. Abraham (1986), Historia universal de la música, Taurus ediciones, Madrid

J. Arnau Amo (1987), Música e Historia, Servicio de Publicaciones de la Universidad Politécnica de Valencia, Valencia

J. Aguila (2006), 1945-2006: ¿Es transmisible la experiencia del serialismo?, Entrevista con Pierre Boulez, Revista 12 notas número 17 pp.11-29

J. Agulló (1989), Acústica musical, Ed. Prensa Científica S.A., Barcelona.

R. Ainsley (2002), Enciclopedia de la música clásica, Parramón ediciones, Barcelona

L. Alberti (1974), El libro de la música, Queromón editores, Madrid

R. Andrés (2001), Diccionario de instrumentos musicales de la antigüedad a J. S. Bach, Ediciones Península, Barcelona

Anónimo (2003) La pequeña crónica de Ana Magdalena Bach, Ed. Juventud, Barcelona

L. Andrés, V. Alberola (1997), La trompeta Vol.1, Ed. Rivera, Valencia.

L. Andrés, V. Alberola (2001), La trompeta Vol.1b, Ed. Rivera, Valencia.

L. Andrés, V. Alberola (2007), Atlas enciclopédico de la trompeta, Ed. Rivera, Valencia. 
E. Antokoletz (1984), The music of Béla Bartók, University of California Press, Los Angeles.

N. Ardley (1988), Music, Dorling Kindersley Limited, London

ARVAL (1995), Temas de Lenguaje musical Vol.1. Ed. Piles, Valencia.

A. Ashton (2005), El armonógrafo, las matemáticas de la música, Ediciones Oniro, Barcelona.

G. Assayag, H. G. Feichtinger y J. F. Rodrigues (2002), Mathematics and music, Springer, Berlín.

W. W. Austin (1984), La música en el S. XX vol. 1 y 2, Taurus ediciones, Madrid.

A. Baker (1984), A concise introduction to the theory of numbers, Ed. Cambridge University Press.

P. Bailache (2003), Travaux en historie de l'acoustique musicale, htpp://bailache.humana.univ-nantes.fr/thmusique/index.htm.

A. Baines (1969), Musical instruments throughthe ages, Penguin books, London.

A. Baines (1974), Brass Instruments: their history and development, Faber and Faber, London.

A. Baines (1983), European and american musical instruments, Chancellor press, London.

E. Banús (2002), El legado musical del siglo $X X$, Ediciones Universidad de Navarra, Pamplona.

J. M. Barbour (1948), Music and ternary continued fractions, The American Mathematical Monthly, 55, pp. 545-555. Washington.

J. M. Barbour (2004), Tuning and temperament, Dover editions, New York.

A. H. Benade (1990) Fundamentals of musical acoustics, General publishing company, Toronto.

D. Benson (2004), Mathematics and Music, http://www.math.uga.edu/djb/

J. E. Berendt (1986), Jazz: su origen y desarrollo, Fondo de Cultura Económica, Mexico. 
M. Bernal Ripoll (1999), El temperamento de Nassarre: Estudio Matemático, Revista de Musicología, 22, pp. 157-174.

F. Bonanni (1964), Antique musical instruments and their players, Dover, New York.

P. Boulez (1963), Penser la musique aujourd'hui, Éditions Gonthier, Paris.

P. Boulez (1966), Relevés d'aprenti, Éditions du Seuil, Paris.

P. Boulez (2001), Puntos de referencia, Editorial Gedisa, Barcelona.

P. Boulez (2003), La escritura del gesto, Editorial Gedisa, Barcelona.

V. Bozal (1996), Historia de las ideas estéticas y de las teorias artísticas contemporáneas, Editorial Visor, Madrid.

J. Brand, C. Hailey y D. Harris (1987), The Berg-Schoenberg correspondence, Macmillan Press, London

W. F. Bynum et al. (1986), Diccionario de historia de la ciencia, Ed Herder, Barcelona.

J. Cage (2005), Silence, Árdora ediciones, Madrid

A. Calvo-Manzano Ruiz (1993), Acústica físico-musical, Ed. Real Musical, Madrid.

R. de Candé (2002), Nuevo diccionario de la música, Ediciones Robinbook, Barcelona.

C. Carlsson y R. Fullér (2002), Fuzzy Reasoning in Decision Making and Optimization, Ed. Physica-Verlag, Heidelberg.

A. Carse (1939), Musical wind instruments, Macmillan, London.

T. Catalán (2003), Sistemas compositivos temperados en el siglo $X X$, Ed. Piles, Valencia.

J. Chailley, H. Challan (1965), Teoría completa de la música, Ed. Alphonse Leduc, Paris.

A. Charles Soler (2002), Análisis de la música española del Siglo XX, Rivera Editores, Valencia. 
T. Charlier (1946), Études transcendantes, Alphonse Leduc, París.

G. Chase (1943), La música de España, Librería Hachette, Buenos Aires

C. Dalhaus (1987), Scohenberg and the new music, Cambridge University press, New York.

C. Dahlhaus (1997), Fundamentos de la Historia de la música, Editorial Gedisa, Barcelona

R. Descartes (1992), Compendio de música, Ed Tecnos, Madrid.

U. Dibelius (2004), La música contemporánea a partir de 1945, Ediciones Akal, Madrid.

D. Diderot (1987), Historia de la Filosofía en la Enciclopedia Vol.1, (Edición preparada por J.M.Bermudo), Ed Horsori, Barcelona.

A. M. de Diego Beade y M. Merino de la Fuente (1988), Fundamentos físicos de la música, Instituto de ciencias de la educación, Valladolid.

E. Domínguez Bovi (1944), Nociones de Historia de la Música, Tipografía Colón, Valencia.

R. Donington (1962), The instruments of music, Methuen, London.

K. Eidam (1999), La verdadera vida de Johann Sebastián Bach, Siglo XXI de España editores, Madrid

Enciclopedia Salvat de los grandes compositores (1981), Salvat, Pamplona

Enciclopedia Salvat de los grandes temas de la música (1983), Salvat, Pamplona

Enciclopedia de Historia de la Música Codex (1965), Codex, Madrid

G. Eskelin (2004), Mentiras que me contaba mi profesor de música, Idea books, Cornellà de Llobregat.

R. Esteve Ed. (2001), Música y palabras. Cartas escogidas de los grandes compositores, Editorial Océano, Barcelona.

F. Estévez Díaz (1990), Acústica musical, Opera 3 ediciones musicales, Madrid 
L. Euler (1990), Cartas a una princesa de Alemania sobre diversos temas de Física y Filosofía, Ed. Universidad de Zaragoza, Zaragoza.

A. Eximeno (1978), Del Origen y reglas de la música, Editora Nacional, Madrid

M. de Falla (1950), Escritos sobre música y músicos, Editorial Espasa-Calpe, Buenos Aires.

G. Fernández De la Gándara y Miguel Lorente (1998), Acústica Musical, Ed. Instituto Complutense de Ciencias Musicales, Madrid.

M. Fernández (2000), Acústica para todos, ¡Incluidos los músicos!, Producciones Agruparte, Vitoria-Gasteiz.

D. Fischerman (2005), Escrito sobre música, Editorial Paidós, Buenos Aires.

J. Forner y J. Wilbrandt, (1993), Contrapunto creativo, Editorial Labor, Barcelona

N. A. Garbuzov (1948), The zonal nature of the human aural perception (en ruso), Izdatelstvo Akademii Nauk SSSR, Moscú, (en J. Halusca, The Mathematical Theory of Tone Systems, Fuzzy Sets and Systems, Ed. Marcel Dekker, Inc., Bratislava, 2005.)

J. L. García del Busto (1986), Tomás Marco, Servicio de publicaciones Universidad de Oviedo, Oviedo.

J. M. García Laborda (2004), La música moderna y contemporánea a través de los escritos de sus protagonistas, Editorial doble J, Sevilla

Doris Geller (2004), Tratado práctico de entonación para instrumentistas y cantantes, Idea books, Cornellà de Llobregat.

T. Gerou (2004), Diccionario esencial de la notación musical, Ediciones Robinbook, Barcelona

M. Gillies (1993), The Bartók companion, Faber and Faber, London

J. Girbau (1985), Les matemàtiques i les escales musicals, Butlletí de la secció de matemàtiques de la Societat Catalana de Ciències, 18, pp. 3-25, Barcelona.

J. J. Goldáraz Gaínza (1992), Afinación y Temperamento en la música occidental, Ed. Alianza Editorial, Madrid. 
J. J. Goldáraz Gaínza (2004), Afinación y temperamentos históricos, Ed. Alianza Editorial, Madrid.

J. J. Goldáraz Gaínza (2005), Las músicas del siglo $X X$, Editorial Dykinson, Madrid.

C. Gómez Amat y Joaquín Turina Gómez (1995), Pequeña Historia de la música, Alianza Editorial, Madrid.

J. V. González Valle, A. Ezquerro, N. Iglesias, C. J. Gosálves y J. Crespí (1996), Normas internacionales para la catalogación de fuentes musicales históricas, Arco libros, Madrid.

Gran Enciclopedia Larousse (1992), Ed. Planeta, Barcelona.

M. J. Grant (2001), Serial music, serial aesthetics, Cambridge University Press, New York.

D. J. Grout y C. V. Palisca (2004), Historia de la música occidental 1 y 2, Alianza Música, Madrid.

R. W. Hall, y K.Josic (2001), The Mathematics of Musical Instruments, The American Mathematical Monthly, 108, pp. 347-357, Washington.

J. Haluska (2000), Equal Temperament and Pythagorean Tuning: a geometrical interpretation in the plane, Fuzzy Sets and Systems, 114, pp. 261-269, Amsterdam.

J. Haluska (2005), The Mathematical Theory of Tone Systems, Fuzzy Sets and Systems, Ed. Marcel Dekker, Inc., Bratislava.

H. Hartog (1961), European music in the twentieth century, Pelican Books, London.

The Harvard Dictionary of Music (1986), Harvard University Press.

L. Henrique (1999), Instrumentos musicais, Fundação Calouste Gulbenkian, Lisboa.

L. Henrique (2002), Acústica musical, Fundação Calouste Gulbenkian, Lisboa.

G. Hernández (2002), Dime como suena y te diré que es, SARC Diputació de Valencia, Valencia 
E. T. A. Hoffmann (2003), Cuentos de música y músicos, Ediciones Akal, Madrid

B. Hopkin (1998), Musical instrument desing, See sharp press, Tucson.

J. Ibáñez Barrachina (2003), La trompeta en la música contemporánea, Conservatorio Profesional de Música de Valencia.

J. Ibáñez Barrachina y V. Liern (2003), Música i Matemátiques: Afinació, partituras i formules matemátiques, Universitat de Valencia.

J. Ibáñez Barrachina (2004), V Jornades de Música, Músiques i interdisciplinarietat, Universitat de Barcelona.

J. Ibáñez Barrachina y V. Liern (2006), Análisis matemático de la afinación de la trompeta, Congreso de Acústica Tecniacústica 2006. Universidad Politécnica de Gandia. Octubre 2006.

J. Ibáñez Barrachina y V. Liern (2006), Música inspirada en los cálculos de Kepler, VIII Conferencia de Decanos y Directores de Matemáticas. Universidad Politécnica de Valencia. Noviembre 2006.

J. Ibáñez Barrachina (2006), Esferas, VIII Conferencia de Decanos y Directores de Matemáticas. Universidad Politécnica de Valencia. Noviembre 2006.

J. Jeans (1968), Science \& Music, Dover Publications, New York

J. Jeans (1983), Matemáticas de la música en Sigma: El mundo de las Matemáticas Vol.6, Ed. Grijalbo, Barcelona.

J. J. Josephs (1969), La física del sonido musical, Ed. Reverté Mexicana S.A., México D.F.

W. Kandinsky (1987), Arnold Schoenberg, Alianza Editorial, Madrid.

A. Kaufmann, J. Gil Aluja (1987), Técnicas operativas para el tratamiento de la incertidumbre, Ed. Hispano Europea, Barcelona.

M. Kennedy (2004), Oxford concise dictionary of Music, Oxford University Press, New York.

L. E. Kinsler et al. (1995), Fundamentos de Acústica, Ed Limusa, México D.F.

B. Kosko (1993), Pensamiento borroso, Ed. Grijalbo-Mondadori, Barcelona.

H. Kunitz (1998), Die instrumentation 7: Trompete, Breitkopf \& Härtel, Leipzig 
J. Lattard (1988), Gammes et temperaments musicaux, Ed. Masson, Paris.

C. Larkin (2004), The virgin enciclopedia of Jazz, Virgin books, London.

N. Lebrecht (1997), El mito del maestro, Acento Editorial, Madrid.

E. Leipp (1980), Acoustique et musique, Éditions Masson, Paris.

J. Lester (2005), Enfoques analíticos de la música del Siglo XX, Ediciones Akal, Madrid.

V. Liern (1990), Taller de Música y Matemáticas, Primer Congreso Iberoamericano de Educación Matemática, Sevilla.

V. Liern (1993), Aristógeno versus Pitágoras: dos criterios matemáticos para la afinación musical, XIXth International Congress of History of Science, Zaragoza.

V. Liern (1993), Las matemáticas de la afinación musical, IV Congreso Internacional sobre Investigación en la enseñanza de las Ciencias y las Matemáticas, Barcelona.

V. Liern (1994a), La música y sus materiales: una ayuda para la clase de Matemáticas, Suma, 14, pp. 60-64, Granada.

V. Liern (1994b), Métodos numéricos en música, Epsilon, 30, pp. 51-60, Sevilla.

V. Liern (1994c), Algoritmos matemáticos y afinación musical, Educación Matemática, 6, pp. 45-55, Mexico D.F.

V. Liern (1998), Sistemes discrets amb dinàmica inestable, Primera Trobada Catalana de Matemàtiques, Barcelona.

V. Liern (2005), Fuzzy tuning systems: the mathematics of the musicians, Fuzzy Sets and Systems, 150 , pp. 35-52.

G. Ligety (2001), Neuf essais sur la musique, Éditions Contrechamps, Genève.

Mario Livio (2006), La proporción áurea, Editorial Ariel, Barcelona

J. Llinares et al. (1991), Acústica arquitectónica y urbanística, Ed. Universidad Politécnica de Valencia, Valencia. 
E. López Chavarri (1971), Nociones de Estética Musical, Unión Musical Española Editores, Madrid

E. López Chavarri (1984), Catecismo de Historia de la Música, Unión Musical Española Editores, Madrid

M. Lustig (2000), Posaunen und trompeten, Stiftung Kloster Michaelstein, Halberstadt

R. Maconie (1997), The science of music, Oxford University Press, New York.

T. Mann (2002), Ensayos sobre música, teatro y literatura, Alba Editorial, Barcelona

T. Marco (1970), Música española de vanguardia, Ediciones Guadarrama, Madrid

T. Marco (1983), Historia de la música española (S.XX) vol. 6, Alianza editorial, Madrid.

T. Marco (2002), Pensamiento musical y Siglo XX, Fundación autor, Madrid.

J. J. Matras (1977), Le son, Ed Presses Universitaires de France, Paris.

C. Mauclair (1942), Los héroes de la orquesta, Ediciones Ave, Barcelona

E. Mende (1978), Arbre généalogique illustré des cuivres européens depuis le début du Moyen Age. Ed. BIM, Suiza.

U. Michels (1994), Atlas de Música 1 y 2, Ed. Alianza Editorial, Madrid.

M. Mila (2003), Breve Historia de la música, Editorial península, Barcelona

A. Millán (1991), La Trompeta Historia y Técnica, Ed. Mater Música, Zaragoza.

D. Mitchell (1972), El lenguaje de la música moderna, Editorial Lumen, Barcelona.

J. L. Monzo (2003), The measurement of Aristoxenus's Divisions of the Tetrachord, htpp://www.ixpress.com/interval/monzo/aristoxenus/318tet.htm, Ed. Yale University Press.

R. Morant (2006), Percepción de la consonancia musical, Universidad Politécnica de Gandia, Trabajo de Investigación.

R. Morgan (1998a), La música del Siglo XX. Ed. Akal, Madrid. 
R. Morgan (1998b), Antología de la música del Siglo XX. Ed. Akal, Madrid.

A. Muller (1999) Instruments, musiques et musicians de l'antiquité classique, Cahiers de la maison de la recherche, Lille.

D. Nelly (2003), Icons of Jazz, The brown reference group, London

J. Neubauer (1986), The Emancipation of Music from Languaje. Departure from Mimesis in Eigteenth-Century Aesthetics, Ed Yale University Press.

J. R. Newman (1983), Sigma: El Mundo de las Matemáticas Vol.6, Ed. Grijalbo, Barcelona.

M. Nyman (1974) Experimental music: Cage and Beyond, Cassell and Collier Macmillan, Londres.

T. de Olazábal (1954), Acústica musical y organología, Ed. Ricordi Americana, Buenos Aires.

F. Onnen (1967), Enciclopedia de la Música, Afrodisio Aguado EditoresLibreros, Madrid

R. Osserman (1993), Rational and irrational: Music and Mathematics en "Essays in Humanistic Mathematics", Mathematical Association of America pp.53-59.

K. Pahlen (1969), Sintesis del saber musical, Emecé editores, Buenos Aires.

F. J. Peralta Coronado (1999), Matemáticas y Bellas Artes, Cátedra nova, 19, pp. 239-242, Badajoz.

J. Peralta (2003), Matemáticas para no desafinar, La Gaceta de la Real Sociedad Matemática Española.

G. Perle (1996), Twelve-tone tonality, University of California Press, Los Angeles

G. Perle (2006), Composición serial y atonalidad, Idea books, Cornellà de Llobregat.

J. Piles Estellés (1982), Intervalos y gamas, Ed. Piles, Valencia.

R. Prevel (2002), Orfebres de la música, Ediciones Robinbook, Barcelona. 
D. Randel (1986), The new Harvard dictionary of music, The Belknap press of Harvard university press, Cambridge.

C. A. Reichen (1965), Historia de la Astronomía, Ed. Continente, S.A., Madrid.

M. Remnant (2002), Historia de los instrumentos musicales, Ediciones Robinbook, Barcelona

H. Riemann (1930), Compendio de instrumentación, Editorial Labor, Barcelona.

A. Robertson y D. Stevens (1989), Historia general de la Música Vol.1, Ed. Alpuerto, Madrid.

J. G. Roederer (1977), Acústica y psicoacústica de la música, Editorial Ricordi americana, Buenos Aires.

T. D. Rossing (1990), The science of sound, Addison-Wesley publishing company, Toronto.

J. Rufer (1962), The works of Arnold Schoenberg: a catalogue of hiscompositions, writings and paintings, Faber and Faber, London

S. Sadie (1980) The new Grove dictionary of music and musicians, Macmillan Publishers, London.

S. Sadie (1984), The new Grove dictionary of musical instruments, Macmillan Publishers, London.

C. Sachs (1940), The history of musical instruments, W. W. Norton \& company, New York.

A. Salazar (1928), Música y músicos de hoy: Ensayos sobre la música actual, Editorial mundo latino, Madrid

C. Samuel (1965), Panorama de la música contemporánea, Ediciones Guadarrama, Madrid.

A. Schaeffner (1936), Origine des instruments de musique, Payot, Paris.

D. Schell (2002), Optimality in musical melodies and harmonics progressions: The travelling musician, European Journal of Operational Research, 140, pp.354372, Amsterdam.

H. Scherchen (1997), El arte de dirigir la orquesta, SpanPress Universitaria, E.E.U.U. 
A. Schoenberg (1975), Style and idea, Faber and Faber, London.

A. Schoenberg (2005), Funciones estructurales de la armonía, Idea Books, Barcelona.

E. Schwartz y B. Childs (1998), Contemporany composers on contemporary music, Da capo press, New York.

M. Serres (1989), Historia de las ciencias, Ed. Cátedra, Madrid.

B. R. Simms (1986), Music of the twentieth century an antology, Schirmer Books, New York.

B. R. Simms (1996), Music of the twentieth century style and structure, Schirmer Books, New York.

B. Sluchin y R. Caussé (1991), Sourdines des cuivres, Editions de la maison des ciencias de l'homme, Paris.

R. Smith Brindle (1966), Serial composition, Oxford University Press, Oxford.

L. Somfai (1996), Béla Bartók, Composition, concepts and autograph sources, University of California Press, Los Angeles.

F. Sopeña (1958), Historia de la música española contemporánea, Ediciones Rialp, Madrid.

I. Stewart (1996), Matemàticas de la escala musical, Investigación y Ciencia, Barcelona.

L. Stokovski (1954), Música para todos nosotros, Espasa-Calpe, Madrid.

I. Stravinsky (1986), Poética musical, Taurus ediciones, Madrid.

J. Subirá (1966), Compendio de Historia de la música, Compañía Bibliográfica Española, Madrid.

E. H. Tarr (1977), La Trompette son historie de l'antiquité à nos jours, Ed. Payot Laussanne, Suiza.

E. H. Tarr (1999), The art of Baroque trumpet playing vol.1, Schott Musik International $\mathrm{GmbH} \& \mathrm{Co}$. KG, Mainz 
R. Taton (1985), Historia general de las Ciencias Vol.1, Destino S.A., Barcelona.

C. Terni (1983), Música práctica de Bartolomé Ramos de Pareja, Joyas Bibliográficas, Madrid.

F. R. Tranchefort (1980), Les instruments de musique dans le monde 2 vol., Éditions du Seuil, Paris.

M. Valls Gorina (1971), Diccionario de la Música, Alianza Editorial, Madrid

M. Valls Gorina (1978), Para entender la música, Alianza Editorial, Madrid.

J. D. Vander Weg (2001), Serial music and serialism, Routledge, New York.

L. Vaillant (1969), Traité pédagogique de trompette et de cornet, Alphonse Leduc, Paris

F. Vera (1937), Historia de la Ciencia, Ed. Iberia, Barcelona.

J. Villa Rojo (2003), Notación y grafía musical en el Siglo XX, Iberautor promociones culturales, Madrid.

M. Wade-Matthews (2004), Musical Instruments, Annes Publishing Ltd. London.

E. W. White (1986), Stravinsky, Salvat editores, Barcelona.

I. Xenakis (1971), Formalized music, Indiana University Press.

Descarga del programa informático Audacity

http://audacity.sourceforge.net 


\section{Literatura para trompeta}

La literatura para trompeta es muy extensa durante el Barroco o el Romanticismo pero casi inexistente en el periodo clásico, afortunadamente durante el S. XX y XXI la evolución técnica en la construcción e interpretativa han hecho que muchos compositores confíen en este instrumento y le dediquen multitud de obras como solista. La música contemporánea no ha sido muy bien recibida en algunos círculos donde se realiza una defensa a ultranza de la música clásica, barroca y romántica pero se ha abierto su propio espacio teniendo hoy en día festivales donde solo se interpreta esta música. La trompeta junto con el saxofón o el trombón son el banco de pruebas de muchos compositores que realizan todas sus innovaciones con estos instrumentos. Además son instrumentos propicios para realizar multitud de efectos sonoros nuevos.

A continuación ofrecemos una lista de obras para trompeta pertenecientes al periodo contemporáneo que son de gran relevancia, muchas de ellas han sido utilizadas para la confección de este capítulo.

Alary, A. Morceau de Concours. (1958), Alphonse Leduc, Paris. Trompeta y Piano

Albrespic, Jacques. Francia (1922-1987) Lied et Scherzo, 1961. Alphonse Leduc, Paris Trompeta y Piano

Alcocer, Luis. España (*1934) Fantasia en Do menor. 1998, Editorial Casa Beethoven, Barcelona. Trompeta y Banda

Antheil, George. USA (1900-1959) Sonata. 1955, Weintraub Music Co. Trompeta y Piano

Arutunian, Alexander. Armenia (*1920) Concierto. 1950, Real Musical, Madrid. Trompeta y Orquesta

Arutunian, Alexander. Armenia (*1920) Tema y Variaciones. 1986, Real Musical, Madrid. Trompeta y Orquesta

Arutunian, Alexander. Armenia (*1920) Aria et Scherzo. 1987, Alphonse Leduc, Paris. Trompeta y Piano dedicada a Timofei Dockshitzer

Bacri, Nicolas. Francia (*1961) Concierto. 1993, Durand Editions Musicales, Paris. Trompeta y Orquesta, encargo para concurso Toulon (Francia)

Balay, Guillaume. Francia (1871-1943) Prelude et Ballade. 1952, Alphonse Leduc, Paris. Trompeta y Piano dedicada a Alexandre Petit

Balay, Guillaume. Francia (1871-1943) Andante y Allegro. 1958, IMC, New York. Trompeta y Piano

Balay, Guillaume. Francia (1871-1943) Pieza de Concurso Alphonse Leduc, Paris. Trompeta y Piano

Balissat Jean. Suiza (*1936) Kaleidoscope 1996 Tpta y Perc. Para concur. Ginebra 
Berio, Luciano. Italia (*1925) Sequenza X. 1984, Universal Edition, Milan. Trompeta y resonancia de Piano, dedicada a Thomas Stevens

Bernstein, Leonard. USA, (1918-1990) Rondo for Lifey. 1949, G.Schirmer, Trompeta y Piano

Beucamp, Albert. Arlequinade. 1948, Alphonse Leduc, Paris. Trompeta y Piano Birthwistle, Harrison. Inglaterra (*1934) Endless Parade. 1986/87, Universal Editions, Milan. Trompeta y Orquesta

Bitsch, Marcel. Francia (*1921) Quatre variations sur un theme du Scarlatti. 1950, Alphonse Leduc, Paris. Trompeta y Piano dedicada a Eugene Foveau y Raymond Sabarich

Bitsch, Marcel. Francia (*1921) Fantasietta. 1950, Alphonse Leduc, Paris. Trompeta y Piano

Blanquer, Amando. España (1935-2005) Concierto. 1993, Gerard Billaudot Editeur, Paris. Trompeta y Orquesta

Bolling, Claude. Francia (*1930) Toot Suite. 1982, Editions Caid Publishing, USA. Trompeta y Piano Jazz

Bonneau, Paul. Francia (1918-1995) Suite. 1944, Alphonse Leduc, Paris. Trompeta y Piano

Börtz, Daniel. Suecia (*1943) Songs and Dances. 1995, Trompeta y Orquesta Boulez, Pierre. Francia (*1925) ...Explosante-Fixe. 1971, 1991/93 Universal Editions, Milan. Flautas, ensemble (2 trompetas) y ordenador

Bozza, Eugene. Francia (1905-1991) Caprice $n^{\circ} 1$. 1943, Trompeta y Piano

Bozza, Eugene. Francia (1905-1991) Caprice $n^{\circ} 2$. 1943, Alphonse Leduc, Paris. Trompeta y Piano

Bozza Eugene Francia 1905-1991 Badinage 1950 Alphonse Leduc, Paris Trompeta y Piano

Bozza, Eugene. Francia (1905-1991) Dialogo. 1954, Alphonse Leduc, Paris. 2 Trompetas

Bozza Eugene Francia 1905-1991 Rustiques 1955 Alphonse Leduc, Paris Trompeta y Piano

Bozza Eugene Francia 1905-1991 Rhapsodie 1957 Alphonse Leduc, Paris Trompeta y Piano

Bozza, Eugene. Francia (1905-1991) Frigariana. 1968, Alphonse Leduc, Paris. Trompeta y Piano

Bozza, Eugene. Francia (1905-1991) Lied. Alphonse Leduc, Paris. Trompeta y Piano

Bozza, Eugene. Francia (1905-1991) Cornettina. Trompeta y Piano

Bozza, Eugene. Francia (1905-1991) Concertino. Trompeta y Piano

Brenta, Gaston. Belgica (1902-1969) Concertino. 1958, Trompeta y Piano

Brenta, Gaston. Belgica (1902-1969) Fanfare pour le roi. 1960, 4 Trompetas y Timbales

Bruns, Victor. Finlandia (1904-1996) Concierto. 1972, Edition Breitkopf, Leipzig. Trompeta y Orquesta

Busser, Henri. Andante et Scherzo. 1954, Alphonse Leduc, Paris. Trompeta y Piano 
Campo Frank USA *1927 Times. 1979, Dario Music, Trompeta sola, dedicada a Thomas Stevens

Casterede, Jacques. Francia (*1926) Sonatina. 1956, Alphonse Leduc, Paris. Trompeta y Piano

Casterede, Jacques. Francia (*1926) Breves Rencontres. 1965, Alphonse Leduc, Paris. Trompeta y Piano

Chaynes, Charles. Francia, Concierto. 1956, Alphonse Leduc, Paris. Trompeta y Orquesta

Colomer, Juan Jose. España (*1966) Sonata. 2002, Rivera editores, Valencia. Trompeta y Piano

Colomer, Juan José. España (*1966) Viñetas sinfónicas 2003, Trompeta y Orquesta

Constant, Franz. (1910- ) Allegro Op.17. 1959, Trompeta y Piano

Constant, Franz. (1910- ) Concierto Op. 12. 1965, Trompeta y Orquesta

Constant, Franz. (1910- ) Minute Op. 25. 1969, Trompeta y Piano

Constant, Franz. (1910- ) Movimento Op. 105. 1982, Trompeta y Piano

Constant, Franz. (1910- ) Festival Op.124. 1987, Trompeta y Organo

Constant, Marius. Rumanía (*1925) Alleluias. 1980, Editions Salabert, Paris. Trompeta y Organo

Cosma Edgar. Francia *1925 Concierto, 1987, Gerard Billaudot Editeur, Paris. para concurso de Toulon.

Damase, Jean Michel. Francia (*1928) Trois Prières sans paroles. 1993, Editions Henry Lemoine, Paris. Trompeta y Organo

Davies, Peter Maxwell. Inglaterra (*1934) Sonata. 1955, Schoot \& Co. LTD. London. Trompeta y Piano

Davies, Peter Maxwell. Inglaterra (*1934) Concierto. 1988, Boosey \& Hawkes Music Publishers Limiter, London. Trompeta y Orquesta, Dedicado John Wallace

Davies Peter Maxwell Inglaterra (*1934) Strathclyde concerto $n^{o} 3.1990$, Boosey \& Hawkes Music Publishers Limiter, London Trompa, Trompeta y Orquesta

Davies, Peter Maxwell. Inglaterra (*1934) Litany for a ruined chapel between sheep and shore. Trompeta sola

Delerue, Georges. Francia (1925-1992) Concertino. 1951, Alphonse Leduc, Paris. Trompeta y Orquesta. Dedicada a Eugene Foveau y Raymond Sabarich

Denisov, Edison. Rusia (1929-1996) Solo para Trompeta. 1972, Trompeta sola

Desenclos, Alfred. Francia (1912-1971) Incantation, Thréne et Danse. 1953, Alphonse Leduc, Paris. Trompeta y Orquesta

Dubois, Pierre-Max. Francia (1930-1995) Coral "La vieille aunée s'en est allée". 1954, Alphonse Leduc, Paris. Trompeta y Piano

Dubuis, Claude. Francia (*1925) Seis piezas. 1972, Gerard Billaudot Editeur, Paris. Trompeta y Piano

Eben, Petr. Checoslovaquia (*1929) Okna (vidrieras.) 1980, Editio Supraphon, Praga. Trompeta y Organo. 
Emig, Ralf. (*1959) Sonata e Variazioni. 1984, Bote \& Bock, Berlín. Trompeta sola dedicada a Malte Burba

Emmanuel, Maurice. Francia (1868-1938) Sonata. 1951, Trompeta y Piano dedicada a Eugene Foveau.

Farcy, P. Francia. Sonorités. 1964, Editions M. R. Braun, Paris. Trompeta y Piano

Farkas Ferenc. Hungría (1905-2000) Concertino V. 1985 Editio Musica, Budapest Trompeta y Orquesta.

Feld, Jindrich. Checoslovaquia (*1925) Intermezzo. 1964, Alphonse Leduc, Paris. Trompeta y Piano.

Fenton, George. Inglaterra $(* 1949)$ Five parts of the dance.

Ferrer, Ferran. España (*1966) Eolo el Rey. 1999, Rivera Editores, Valencia. Trompeta y Piano

Ferrer, Ferran. España (*1966) Hydra Concierto. 2001, Trompeta y Banda

Fiser, Lubos. Checoslovaquia (1935-1999) Dialog. 1996, Editions BIM, Bulle, Suiza. Trompeta y Organo.

Forsyth, Malcolm. Canadá (*1936) Concierto. 1987, Trompeta y Orquesta.

Françaix, Jean. Francia (*1912) Sonatina. 1952, Editions Max Eschig, Paris. Trompeta y Piano

Friedman Stanley. USA *1951 Solus. 1975, The Brass Press, Nashville, Trompeta sola.

Friedman, Stanley. USA (*1951) La Pintura. 1992, Editions BIM, Bulle, Suiza. Trompeta y Quinteto de Metal.

Gallois Montbrun, Raymond. Francia (1918-1994) Scherzo. 1950, Alphonse Leduc, Paris. Trompeta y Piano.

Gaudron, René. Francia. Andante y Allegro Moderato. 1966, Editions M. R. Braun, Paris. Trompeta y Piano.

Gaudron, Rene. Francia. Souvenirs d'asie. Trompeta y Piano.

Goedicke, Alexander. Rusia (1877-1957) Estudio de Concierto. 1946, Trompeta y Piano.

Gotovsky, Ida. Francia (*1933) Concierto. 1973, Editions Musicales Tasanlantiques, Paris. Trompeta y Orquesta.

Gregson, Edgard. Inglaterra (*1945) Concierto. 1983, Novello \& Company Limited, Trompeta y Orquesta, dedicada a J. Watson.

Grimal Olmos, Rafael. Cuba (*1945) Sonata. 1991, Editorial Casa Beethoven, Barcelona. Trompeta y Piano.

Hakim, Naji. República de Líbano (*1955) Rondó for Christmas. 1988, Trompeta y Organo.

Hakim, Naji. República de Líbano (*1955) Sonata. 1994, UMP, Tompeta y Organo.

Hauta-Aho, Teppo. Finlandia (*1941) Fantasy. 1986, M/S. Trompeta y Orquesta.

Henderson, Robert. USA (*1948) Variation Movements 1967. Western International Music, INC, Los Angeles, Trompeta sola.

Henze Hans Werner. Alemania (*1926) Sonatina. 1976. Dunster Music/Schoot, Trompeta sola. 
Henze Hans Werner. Alemania. (*1926) Réquiem. 1990. B. Schoott's Söhne, Mainz, Piano solo trompeta concertante y Orquesta.

Hétu, Jacques. Canadá $(* 1938)$ Concierto. 1987, Trompeta y pequeña Orquesta.

Hindemith, Paul. Alemania (1895-1963) Sonata. 1940, B. Schoott's Söhne, Mainz. Trompeta y Piano.

Holmboe, Vang. Suecia (1909-1996) Concierto $n^{\circ} 11$. 1948, Viking/Wihelm Hansen, Mainz, Trompeta y Orquesta.

Honegger, Arthur. Suiza (1892-1955) Intrada. 1947, Editions Salabert, Paris, Trompeta y Piano.

Hovhannes, Alan. USA (*1911) Prayer of St. Gregory. 1946, Peer International Corporation, USA. Trompeta y Organo.

Howarth, Elgar. Inglaterra (*1935) Toy. 1994, Rosehill Music Company Limited, London. Trompeta sola dedicada a M. y A. Hardenberger.

Howarth, Elgar. Inglaterra $(* 1935)$ Concierto. Trompeta y Orquesta.

Hubeau, Jean. Francia (1917-1992) Sonata. 1943, Trompeta y Piano dedicada a Jean Bernard.

Hummel, Bertold. Alemania (1925-2002) Invocaciones. (1978) B. Schoott's Söhne, Mainz. Trompeta y Piano.

Hvoslef, Ketil. Noruega (*1939) Concierto. 1969, Trompeta y Orquesta.

Hvoslef, Ketil. Noruega (*1939) Tromba solo. 1990, Editions BIM, Bulle, Suiza. Trompeta sola.

Jansen, Pierre. Francia (*1930) Procesional. Gerard Billaudot Editeur, Paris. Trompeta y Organo.

Jevtic, Ivan. Yugoslavia (*1947) Concierto $n^{\circ} 1$. 1974, Gerard Billaudot Editeur, Paris Trompeta y Orquesta.

Jevtic, Ivan. Yugoslavia (*1947) Divertimento. 1980, 2 Trompetas y Orquesta.

Jevtic, Ivan. Yugoslavia (*1947) Que le jour est beau. 1985, Trompeta píccolo y Orquesta.

Jevtic, Ivan. Yugoslavia (*1947) Concierto $n^{\circ} 21987$ Gerard Billaudot Editeur, Paris Trompeta y Orquesta Para concurso M. André.

Jevtic, Ivan. Yugoslavia (*1947) Per tromba sola. 1991, Gerard Billaudot Editeur, Paris. Trompeta sola

Jirko, Ivan. (1926-1978) Concierto. 1975, Panton, Praga. Trompeta y Orquesta.

Jolivet, André. Francia (1905-1974) Concertino. 1948, Durand Editions Musicales, Paris Trompeta y Orquesta.

Jolivet, André. Francia (1905-1974) $2^{\circ}$ Concierto. 1954, Hengel \& Cie Editeurs, Paris Trompeta y Orquesta.

Jolivet, André. Francia (1905-1974) Arioso Baroco. 1968, Gerard Billaudot Editeur, Paris, Trompeta y Organo.

Jolivet, André. Francia (1905-1974) Aria de Bravura.

Jolivet, André. Francia (1905-1974) Heptade. 1971, Gerard Billaudot Editeur, Paris, Trompeta y Percusión.

Kagel, Mauricio. Argentina (*1931) Old/New. 1970, Universal Edition, Milan. Para trompeta sola. 
Kauffmann, Jean. Francia. Andantino et Allegro. 1973, Gerard Billaudot Editeur, Paris. Trompeta y Piano.

Kauffmann, Jean. Francia. Badinage. 1978, Gerard Billaudot Editeur, Paris. Trompeta y Piano.

Ketting, Otto. Holanda (*1935) Intrada. 1958, Donemus, Ámsterdam. Trompeta sola.

Killmayer, Wilhelm. Alemania (*1927) Tre Pezzi. 1969, B. Schoott's Söhne, Mainz. Trompeta y Piano.

Kraft, William. USA (*1923) Encounters III. 1971, New Music West, Altadena, Trompeta y Percusión.

Krol, Bernhard. Alemania (*1920) Magnificat-Variationen. 1965, N. Simrock, Hamburgo. Trompeta y Organo, escrita a partir del Magnificat de Bach.

Krol, Bernhard. Alemania *1920 Fantasia Nocturna. 1972, Bote \& Bock, Berlín, Trompeta y Organo.

Kupferman, Meyer. USA (*1926) Three ideas. 1967, General Music Publishing Co., Inc. Boston. Trompeta y Piano.

Kupferman, Meyer. USA (*1926) The fires of Prometeus. 1986, Soundspells Productions. Trompeta y 2 Pianos en eco.

Ligeti, György. Rumania (*1923) Die grosse Schildkröten. Universal Edition, Milan. Dura 30 segundos.

Ligeti, György. Rumania (*1923) Mysteries of the Macabre. 1974-77, B. Schott's Sohne, Trompeta o Soprano y Orquesta.

Linkola, Jukka. Finlandia (*1955) Concierto. 1988, M/S. Trompeta y Orquesta.

Mabboux, Philippe. Francia (*1957) Triptyque. 1999, Editions BIM, Bulle, Suiza. Trompeta y Organo.

Martinsson, Rolf. Suecia (*1956) Bridge,. Trumpet Concerto $n^{\circ} 1$, Op.47. 1998, STIM, Stockholm. Trompeta y Orquesta.

Martinu, Bohuslav. Checoslovaquia (1890-1959) Sonatina. 1957, Alphonse Leduc, Paris. Trompeta y Piano.

Michel, Jean François. Francia (*1957) Oriental Express. 1990, EMR. Trompeta sola.

Muñoz Orero, Juan. España (*) Dodeca-Trumpet. Rivera Editores, Valencia. Trompeta y Piano.

Nimmons, Phil. Canadá (*1923) Concierto. 1988, Trompeta y Orquesta.

Nyman, Michael. Inglaterra (*1944) Flugalhorn \& piano. 1991, Dedicada a Graham Ashton.

Pakhmutova, Alexandra. Rusia (*1929) Concierto. 1955, Trompeta y Orquesta. Pärt, Arvo. Estonia (*1935) Concerto Piccolo über B-A-C-H. 1994, Sikorski, Trompeta y Orquesta.

Persichetti, Vincent. USA (1915-1987) The hollow men. 1944, Elkam-Vogel, INC, Pensylvania. Trompeta y Organo.

Persichetti, Vincent. USA (1915-1987) Parable XIV. 1975, Elkam-Vogel, INC, Pensylvania, Trompeta sola.

Picavais, Lucien. Francia. Piece pour Concours. 1965, Gerard Billaudot Editeur, Paris. Trompeta y Piano. 
Pichaureau, Claude. Francia Aristolochos 1974, Alphonse Leduc, Paris. Trompeta y Organo.

Planel, Robert. Francia (1908-1994) Concierto. 1973, Trompeta y Orquesta dedicada a Maurice André.

Plog, Anthony. Alemania (*1947) Four themes on paintings Edvard... 1990, $\mathrm{M} / \mathrm{S}$. Trompeta y Organo.

Poot, Marcel. Belgica (1901-1988) Estudio de Concierto. 1933, Trompeta y Piano dedicada a A. Goeyens.

Rabe, Folke. Suecia (*1935) Shazam. 1984, Edition Reimers AB, Stockholm, Trompeta sola dedicado a Hakan Hardenberger.

Rabe, Folke. Suecia (*1935) Sardine Sarcophagus. 1995, Trompeta y Sinfonietta.

Revueltas, Silvestre. Mexico (1899-1940) Two Little Serious Pieces. Peer International, New York, Trompeta piccolo, Oboe, Clarinete y Saxo Barítono.

Reynolds, Verne. USA (*1926) Signals. 1976, Wimbledon Music INC, Los Angeles, Trompeta, Tuba y coro de Metales.

Reynolds, Verne. USA (*1926) Fantasy Etudes. 1979, Trompeta y Piano.

Ropartz, Guy. Francia (1864-1955) Andante y Allegro. 1941, Southern Music Company, San Antonio-Texas. Trompeta y Piano.

Sandström, Jan. Suecia (*1954) Concierto $n^{\circ} 2$. 1987, Trompeta y Orquesta.

Sauguet, Henri. Francia (1901-1989) Non morietur in aeternum. Gerard Billaudot Editeur, Paris, Trompeta y Organo.

Scelsi, Giancinto. Italia (1905-1988) Vier Stücke für Trompette solo. Trompeta sola.

Schmitt, Florent. Francia (1870-1958) Suite Op. 133. 1955, Durand Editions Musicales, Paris, Trompeta y Piano.

Schröter, Heinz. Fanfarette. 1963, Alphonse Leduc, Paris, Trompeta sola.

Segerstam, Leif. Finlandia (*1944) Concierto $n^{\circ}$ 2. 1985-90 M/S. Trompeta y Orquesta.

Serrano Alarcón, Luis. España (1972) Meditación y Danza. 1995, Editorial Piles, Valencia, Trompeta y piano.

Stevens, Halsey. USA (1908-1989) Sonata. 1959, Editon Peters, New York. Trompeta y Piano.

Stevens, Thomas. USA (*1938) Variations on Clifford Intervals. 1983, Editions BIM, Bulle, Suiza. Trompeta, Vibráfono y Contrabajo.

Stevens, Thomas. USA (*1938) A New Carnaval of Venice. 1985, Alphonse Leduc, Paris, 4 Trompetas y Piano.

Stevens, Thomas. USA (*1938) Triangles. 1987, Stepanian Music, ASCAP, Tres Trompetas.

Stockhausen, Karlheinz. Alemania (*1928) Aries, 1977, Trompeta y música electrónica.

Scout, Gordon. USA (*1952) DUO (dance-song). 1977, Studio 4 Productions, Trompeta y Marimba.

Szokola, Sandor. Concierto. Alphonse Leduc, Paris, Trompeta y Orquesta. 
Takemitsu, Toru. Japón (1930-1996) Paths. 1994, B. Schoott's Söhne, Mainz. En memoria de Witold Lutoslawski.

Tamberg, Eino. Estonia (*1930) Concerto $n^{\circ} 1$ Op. 42. 1972, Editions Marc Reift, Trompeta y Orquesta.

Thilde, Jean. Francia. Variations sur un Theme de Paganini. 1978, Gerard Billaudot Editeur, Paris. Trompeta sola.

Timis, Vasile. Rumania Concierto. 1989, Editorial Muzicala, Bucarest. Clarinete, Trompeta, Piano, Orquesta de cuerdas y Percusión.

Tisné, Antoine. Francia (*1932) Heraldiques. 1975, Gerard Billaudot Editeur, Paris. Trompeta y Piano.

Tisné, Antoine. Francia (*1932) Emotion. 1984, Editions IMD, Paris. Trompeta sola, recitador y coreografía.

Tomasi, Henri. Francia (1901-1971) Concierto. 1946, Alphonse Leduc, Paris. Trompeta y Orquesta.

Tomasi, Henri. Francia (1901-1971) Triptique. 1957, Alphonse Leduc, Paris. Trompeta y Piano.

Tomasi, Henri. Francia (1901-1971) Variaciones Gregorianas sobre un Salve Regina. 1964, Alphonse Leduc, Paris. Trompeta y Orquesta u Organo.

Tomasi, Henri. Francia (1901-1971) Semana Santa en Cuzco. 1964, Alphonse Leduc, Paris, Trompeta y Piccolo + Orq. Camara.

Tosi, Daniel. Francia (*1953) Mundial - Concerto. 1994/95, Editions BIM, Bulle, Suiza. Trompeta y Piano, Percusión (ad lib.).

Vainberg, Moisei. Polonia (1919-1996) Concierto. 1967, Trompeta y Orquesta.

Valero Castells, Andrés. España (*1973) La Catedral. 1991, 5 Trompetas.

Valero Castells, Andrés. España (*1973) Concierto $n^{\circ} 1$ 1. 1994, Editions BIM, Bulle, Suiza. Trompeta y Orquesta dedicada a Guy Touvron.

Valero Castells, Andrés. España (*1973) Impromptu. 1995, Trompeta sola dedicada a Maurice Benterfa.

Van der Velde, Renier. Belgica (1910-1993) Concierto. 1940, Trompeta y Orquesta.

Van der Velde, Renier. Belgica (1910-1993) Entrada. 2 Trompetas y 2 Trombones.

Van der Velde, Renier. Belgica (1910-1993) Triptiek. 1977, 2 Trompetas y 2 Trombones.

Vizzutti, Allen. USA (*) Cascades. 1981, The Brass Press, Nashville, Trompeta sola dedicada a ITG.

Watkins, Michael Blake. Inglaterra (*1948) Concierto. 1988, Trompeta y Orquesta.

Watkins, Michael Blake. Inglaterra (*1948) La mort de l'aigle. 1993, Trompeta sola, dedicada a Hakan Hardenberger.

Weiner, Stanley. Belgica (1925-1991) Cinq Pieces. 1973, Gerard Billaudot Editeur, Paris. Trompeta sola dedicada a Maurice André.

Weiner, Stanley. Belgica (1925-1991) Concierto. 1978, Gerard Billaudot Editeur, Paris. Trompeta y Orquesta dedicado a Maurice André.

Wessman, Harri. Finlandia $\left({ }^{*} 1949\right)$ Concierto. 1987, M/S. Trompeta y Orquesta. 
Zbinden, Julien François. Francia $(* 1917)$ Concertino. 1946, B. Schoott's Söhne, Mainz, Trompeta y Orquesta.

Zbinden, Julien François. Francia (*1917) Dialogue 1972/73 Gerard Billaudot Editeur, Paris, Piccolo y Organo.

Zimmermann, Bernd Alois. Alemania (1918-1970) Nobody Knows The Trouble I See. 1954, B. Schoott's Söhne, Mainz, Trompeta y Orquesta. 


\section{APÉNDICE:}

Este capítulo contiene consta de dos partes. La primera de ellas contiene los archivos utilizados en los capítulos prácticos de esta memoria y la segunda aparece en un DVD que contiene los archivos sonoros de las grabaciones utilizados en las prácticas y la interpretación de la obra "Esferas" realizada en la VIII Conferencia de Decanos y Directores de Matemáticas en la Universidad Politécnica de Valencia (noviembre 2006).

\section{A.1 Resultados para las notas largas}

En esta sección mostramos los resultados de 50 grabaciones de 4 notas, $\mathrm{Fa}_{4}{ }^{\#}, \mathrm{La}_{4}{ }^{\#}, \mathrm{Do}_{5}{ }^{\#} \mathrm{y} \mathrm{La}$, que pueden obtenerse con varias posiciones de los pistones. Las posiciones de cada una de ellas son las siguientes:

$\mathrm{Fa}_{4}{ }^{\#}$ con el $2^{\mathrm{o}}$ pistón o con los tres pistones $\left(1^{\circ}+2^{\circ}+3^{\circ}\right)$.

$\mathrm{La}_{4}^{\#}$ con el $1^{\text {er }}$ pistón o con los tres pistones $\left(1^{\circ}+2^{\circ}+3^{\circ}\right)$.

$\mathrm{Do}_{5}{ }^{\#}$ con el $3^{\text {er }}$ pistón, con los pistones $2^{\circ}+3^{\circ}$ o con los tres pistones $\left(1^{\mathrm{o}}+2^{\mathrm{o}}+3^{\mathrm{o}}\right)$.

$\mathrm{La}_{5}$ con el $2^{\circ}$ pistón, con el $3^{\mathrm{er}}$ pistón, o con los pistones $1^{\circ}+2^{\circ}$.

Hemos grabado cinco veces cada nota en cada una de las posiciones, aunque una de las grabaciones, la del $\mathrm{La}_{4}{ }^{\#}$, no tenía suficiente calidad para ser analizada.

Cada grabación tiene una duración de 6 segundos aproximadamente, y las frecuencias que recogemos en la tabla siguiente son las frecuencias medias del 
primer tercio de grabación (I), del segundo tercio (II), del tercer tercio (III) y de toda la grabación (M).

\begin{tabular}{|c|c|c|c|c|c|c|c|c|c|c|c|}
\hline Nota & I & II & III & M & Sistema & Nota & I & II & III & M & Sistema \\
\hline $\mathrm{Fa}^{\#} 2 \mathrm{a}$ & 323 & 323 & 324 & 324 & Zarlino & $\mathrm{Do}^{\#} 12 \mathrm{~b}$ & 493 & 493 & 492 & 493 & Temperado \\
\hline $\mathrm{Fa}^{\#} 2 \mathrm{~b}$ & 326 & 325 & 326 & 325 & Pitág/Holder & $\mathrm{Do}^{\#} 12 \mathrm{c}$ & 493 & 492 & 491 & 492 & Temperado \\
\hline $\mathrm{Fa}^{\#} 2 \mathrm{c}$ & 325 & 324 & 324 & 324 & Zarlino & $\mathrm{Do}^{\#} 12 \mathrm{~d}$ & 491 & 492 & 491 & 491 & Otros \\
\hline $\mathrm{Fa}^{\#} 2 \mathrm{~d}$ & 325 & 324 & 324 & 325 & Pitág/Holder & $\mathrm{Do}^{\# 1} 12 \mathrm{e}$ & 492 & 490 & 490 & 491 & Otros \\
\hline $\mathrm{Fa}^{\#} 2 \mathrm{e}$ & 325 & 325 & 326 & 325 & Pitág/Holder & $\begin{array}{l}\operatorname{Do}^{\#} 123 \\
\mathrm{a}\end{array}$ & 500 & 498 & 498 & 499 & Otros \\
\hline $\mathrm{Fa}^{\# 1} 123 \mathrm{a}$ & 332 & 331 & 332 & 331 & $\begin{array}{l}\text { Pit/Hol y } \\
\text { Zar. }\end{array}$ & $\begin{array}{l}\operatorname{Do}^{\#} 123 \\
\mathrm{~b}\end{array}$ & 498 & 497 & 496 & 497 & Zarlino \\
\hline $\mathrm{Fa}^{\#} 123 \mathrm{~b}$ & 333 & 331 & 332 & 332 & Otros & $\begin{array}{l}\operatorname{Do}^{\#} 123 \\
\mathrm{c}\end{array}$ & 503 & 499 & 498 & 500 & Pitág/Holder \\
\hline $\mathrm{Fa}^{\#} 123 \mathrm{c}$ & 331 & 331 & 331 & 331 & $\begin{array}{l}\text { Pit/Hol y } \\
\text { Zar. }\end{array}$ & $\begin{array}{l}\operatorname{Do}^{\#} 123 \\
d\end{array}$ & 498 & 497 & 497 & 497 & Zarlino \\
\hline $\mathrm{Fa}^{\#} 123 \mathrm{~d}$ & 331 & 331 & 332 & 331 & $\begin{array}{l}\text { Pit/Hol y } \\
\text { Zar. }\end{array}$ & $\begin{array}{l}\operatorname{Do}^{\#} 123 \\
\mathrm{e}\end{array}$ & 496 & 496 & 495 & 495 & $\begin{array}{l}\text { Pit/Hol y } \\
\text { Zar. }\end{array}$ \\
\hline $\mathrm{Fa}^{\#} 123 \mathrm{e}$ & 334 & 333 & 333 & 333 & Otros & $\mathrm{La} 2 \mathrm{a}$ & 782 & 785 & 785 & 783 & Temperado \\
\hline $\mathrm{La}^{\#} 1 \mathrm{a}$ & 410 & 409 & 410 & 410 & Otros & $\mathrm{La} 2 \mathrm{~b}$ & 779 & 783 & 783 & 779 & Zarlino \\
\hline $\mathrm{La}^{\#} 1 \mathrm{~b}$ & 409 & 408 & 408 & 409 & Otros & $\mathrm{La} 2 \mathrm{c}$ & 777 & 785 & 785 & 781 & Pitág/Holder \\
\hline $\mathrm{La}^{\#} 1 \mathrm{c}$ & 409 & 409 & 409 & 409 & Otros & $\mathrm{La} 2 \mathrm{~d}$ & 783 & 783 & 784 & 783 & Temperado \\
\hline $\mathrm{La}^{\#} 1 \mathrm{~d}$ & 409 & 409 & 409 & 409 & Otros & $\mathrm{La} 2 \mathrm{e}$ & 775 & 784 & 782 & 779 & Zarlino \\
\hline $\mathrm{La}^{\#} 1 \mathrm{e}$ & 409 & 409 & 408 & 409 & Otros & La3 a & 783 & 784 & 784 & 783 & Temperado \\
\hline $\mathrm{La}^{\#} 123 \mathrm{a}$ & 415 & 414 & 413 & 414 & Temp. y Zar. & $\mathrm{La} 3 \mathrm{~b}$ & 785 & 785 & 785 & 785 & Temperado \\
\hline $\mathrm{La}^{\#} 123 \mathrm{c}$ & 414 & 413 & 413 & 414 & Temp. y Zar. & $\mathrm{La} 3 \mathrm{c}$ & 784 & 785 & 784 & 784 & Temperado \\
\hline $\mathrm{La}^{\#} 123 \mathrm{~d}$ & 412 & 413 & 413 & 413 & Zarlino & La3 d & 785 & 785 & 785 & 785 & Temperado \\
\hline $\mathrm{La}^{\#} 123 \mathrm{e}$ & 414 & 414 & 413 & 414 & Temp. y Zar. & La3 e & 782 & 783 & 783 & 782 & Pitág/Holder \\
\hline Do 3 a & 481 & 488 & 488 & 485 & Pitág/Holder & La12 a & 791 & 791 & 791 & 791 & Pitág/Holder \\
\hline $\mathrm{Do}^{\#} 3 \mathrm{~b}$ & 485 & 488 & 488 & 488 & Pitág/Holder & La12 b & 791 & 789 & 789 & 790 & Otros \\
\hline $\mathrm{Do}^{\#} 3 \mathrm{c}$ & 482 & 488 & 485 & 486 & Zarlino & La12 c & 792 & 791 & 792 & 792 & Pitág/Holder \\
\hline $\mathrm{Do}^{\#} 3 \mathrm{~d}$ & 490 & 490 & 489 & 489 & Pitág/Holder & La12 d & 789 & 790 & 789 & 789 & Otros \\
\hline $\mathrm{Do}^{\#} 3 \mathrm{e}$ & 485 & 487 & 486 & 486 & Zarlino & La12 e & 790 & 790 & 790 & 790 & Otros \\
\hline $\operatorname{Do}^{\#} 12 \mathrm{a}$ & 492 & 491 & 490 & 491 & Otros & & & & & & \\
\hline
\end{tabular}


Estudio del $\mathrm{Fa}_{4}^{\#}$ utilizando la posición (2)

$\begin{array}{ll}\mathrm{Fa}^{\#} 2 \mathrm{a} & \text { Zarlino } \\ \mathrm{Fa}^{\#} 2 \mathrm{~b} & \text { Pitágoras/Holder } \\ \mathrm{Fa}^{\#} 2 \mathrm{c} & \text { Zarlino } \\ \mathrm{Fa}^{\#} 2 \mathrm{~d} & \text { Pitágoras/Holder } \\ \mathrm{Fa}^{\#} 2 \mathrm{e} & \text { Pitágoras/Holder }\end{array}$

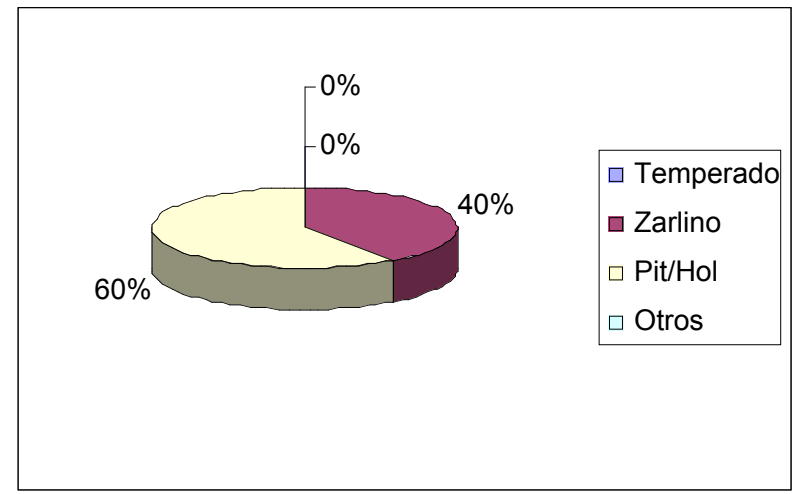

Estudio del $\mathrm{Fa}_{4}^{\#}$ utilizando la posición $(1+2+3)$

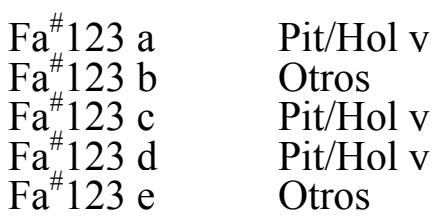

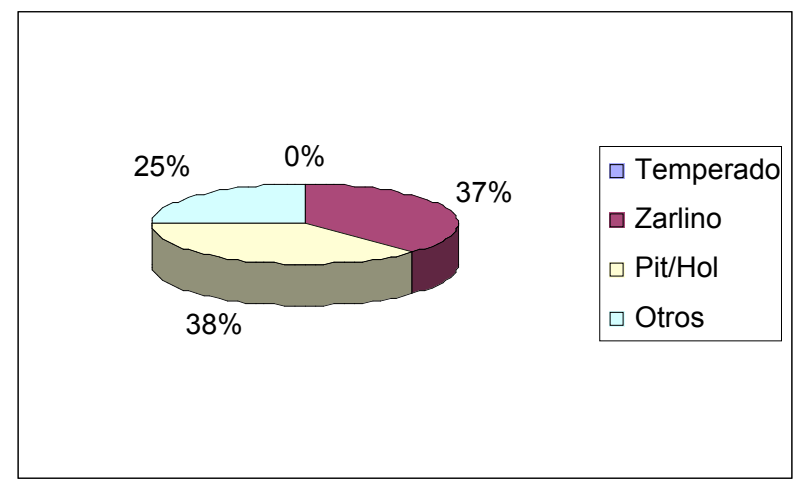

Estudio del $\mathrm{La}_{4}^{\#}$ utilizando la posición (1)

$\begin{array}{ll}\mathrm{La}_{\#}^{\#} 1 \mathrm{a} & \text { Otros } \\ \mathrm{La}^{\#} 1 \mathrm{~b} & \text { Otros } \\ \mathrm{La}^{\#} 1 \mathrm{c} & \text { Otros } \\ \mathrm{La}_{\#}^{\#} 1 \mathrm{~d} & \text { Otros } \\ \mathrm{La}^{\#} 1 \mathrm{e} & \text { Otros }\end{array}$

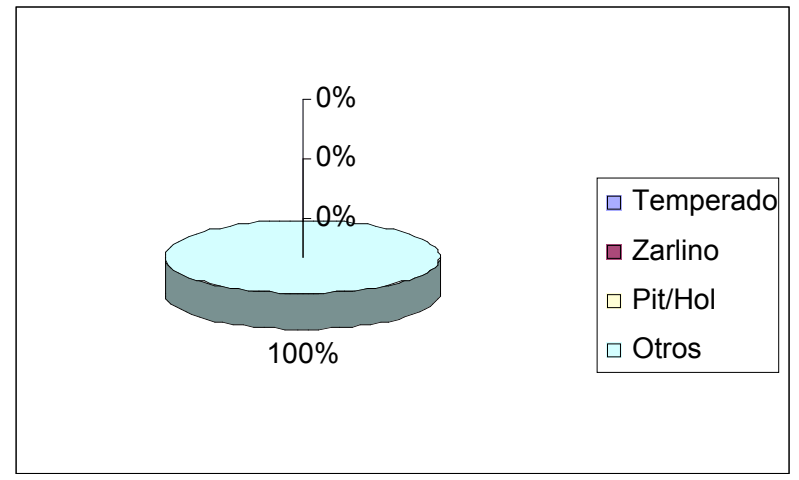


Estudio del $\mathrm{La}_{4}^{\#}$ utilizando la posición $(1+2+3)$

$\begin{array}{ll}\mathrm{La}_{\#}^{\# 123} \text { a } & \text { Temp. v Zar. } \\ \mathrm{La}_{\#} 123 \mathrm{c} & \text { Temp. v Zar. } \\ \mathrm{La}^{\#} 123 \mathrm{~d} & \text { Zarlino } \\ \mathrm{La}^{\#} 123 \mathrm{e} & \text { Temp. v Zar. }\end{array}$

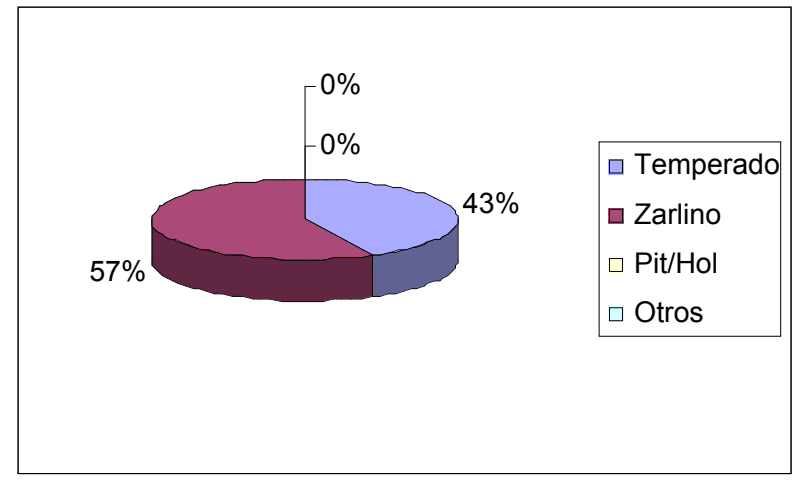

Estudio del $\mathrm{Do}_{5}^{\#}$ utilizando la posición (3)

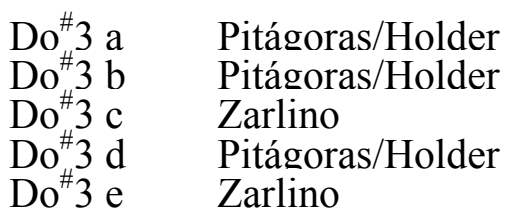

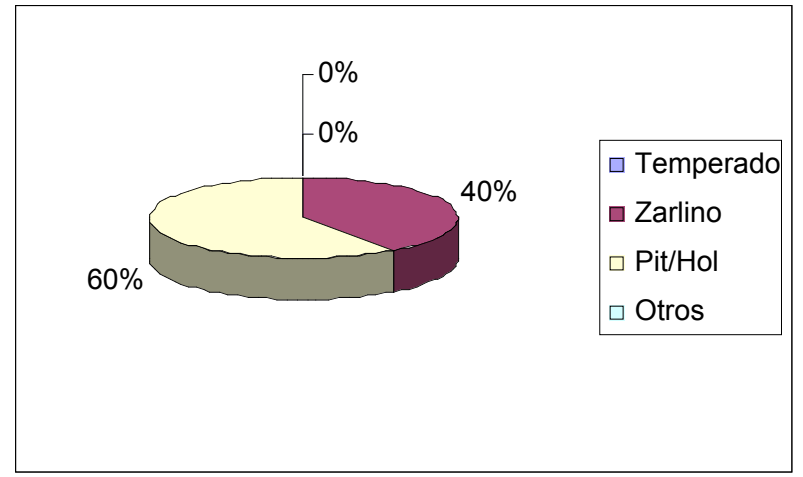

Estudio del $\mathrm{Do}^{\#}{ }_{5}$ utilizando la posición $(1+2)$

$\begin{array}{ll}\text { Do }_{\# 12}^{\#} \mathrm{a} & \text { Otros } \\ \text { Do }_{\# 12 \mathrm{~b}} & \text { Temperado } \\ \text { Do }_{\#}^{\#} 12 \mathrm{c} & \text { Temperado } \\ \text { Do }_{\#}^{\# 12} \mathrm{~d} & \text { Otros } \\ \text { Do }^{\# 12} \mathrm{e} & \text { Otros }\end{array}$

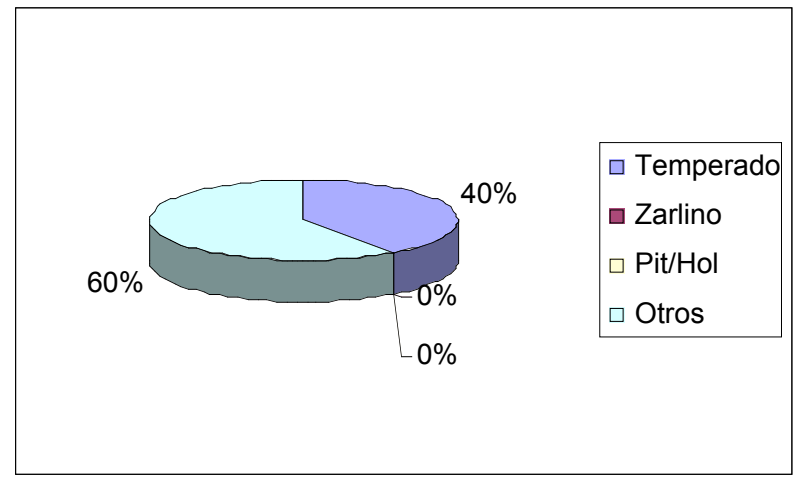


Estudio del $\mathrm{Do}_{5}^{\#}$ utilizando la posición $(1+2+3)$

$\begin{array}{ll}\text { Do }_{\# 123}^{\#} \text { a } & \text { Otros } \\ \text { Do }_{123} \text { b } & \text { Zarlino } \\ \text { Do }^{\# 123 ~ c} & \text { Pitágoras/Holder } \\ \text { Do }^{\# 123 ~ d ~} & \text { Zarlino } \\ \text { Do } 123 \text { e } & \text { Pit/Hol v Zar. }\end{array}$

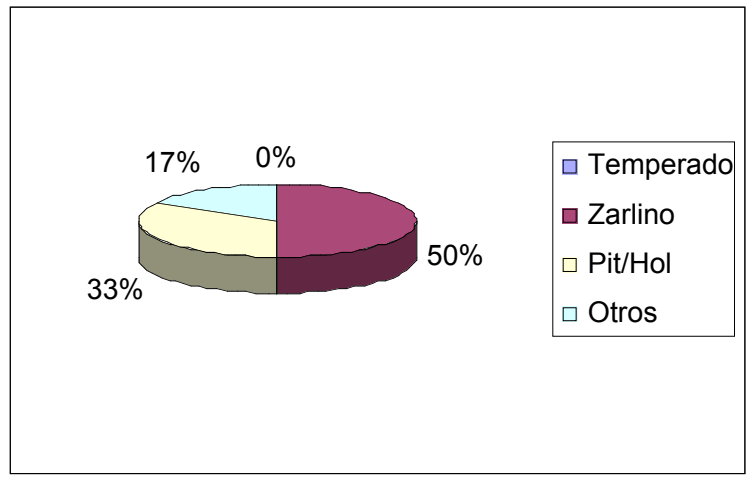

Estudio del La $\mathrm{L}_{5}$ utilizando la posición (2)

$\begin{array}{ll}\text { La2 a } & \text { Temperado } \\ \text { La2 b } & \text { Zarlino } \\ \text { La2 c } & \text { Pitágoras/Holder } \\ \text { La2 d } & \text { Temperado } \\ \text { La2 e } & \text { Zarlino }\end{array}$

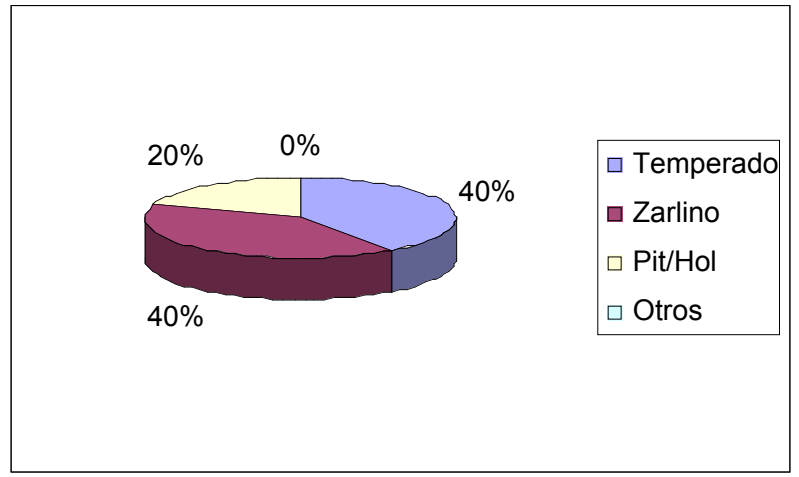

Estudio del La 5 utilizando la posición (3)

$\begin{array}{ll}\text { La3 a } & \text { Temperado } \\ \text { La3 b } & \text { Temperado } \\ \text { La3 c } & \text { Temperado } \\ \text { La3 d } & \text { Temperado } \\ \text { La3 e } & \text { Pitágoras/Holder }\end{array}$

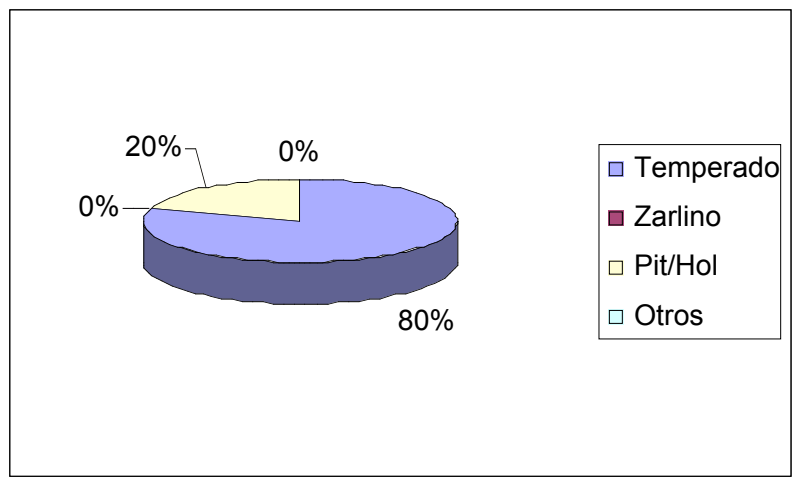


Estudio del $\mathrm{La}_{5}$ utilizando la posición $(1+2)$

La12 a

La12 b

La12 c

La12 d

La12 e
Pitágoras/Holder

Otros

Pitágoras/Holder

Otros

Otros

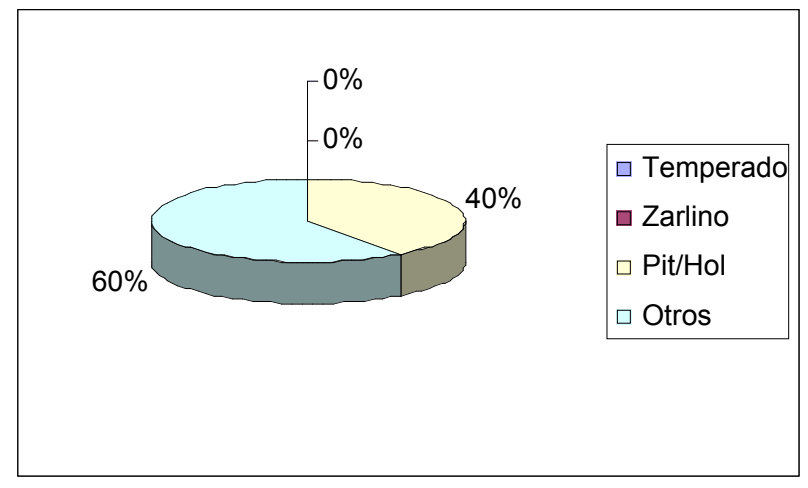

Resultados totales

$\begin{array}{ll}\text { Sistema } & \begin{array}{l}\mathrm{N}^{\mathrm{o}} \mathrm{de} \\ \text { notas }\end{array} \\ \text { Temperado } & 11 \\ \text { Zarlino } & 16 \\ \text { Pitágoras/Holder } & 14 \\ \text { Otros } & 14\end{array}$

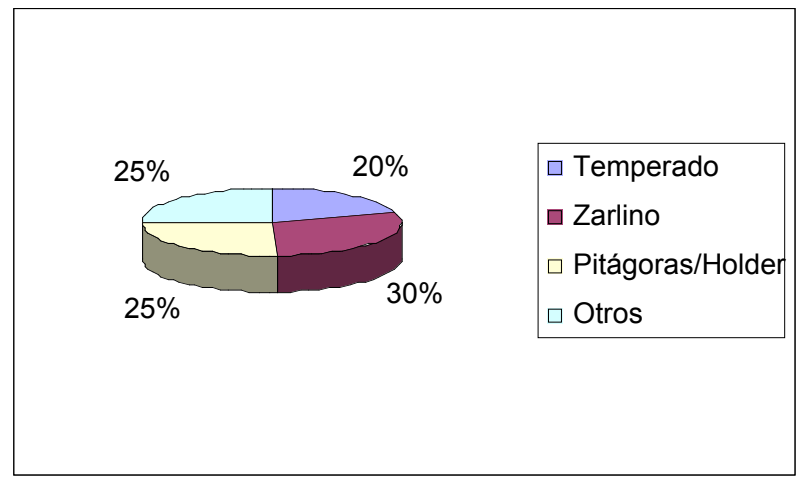

\section{A. 2. Resultados para los fragmentos}

En las dos subsecciones siguientes mostraremos los resultados de nuestro estudio dinámico de la afinación.

En el fragmento del concierto de Haydn hemos estudiado 17 grabaciones realizadas en seis días diferentes $(3,4,5,6,10,11$ y 12 de febrero de 2003) con cuatro trompetas. Dos de ellas en $\mathrm{Si}^{\mathrm{b} 1}$ (marcas Yamaha ${ }^{\circledR}$ y $\mathrm{Bach}^{\circledR}$ ), una en Do $\left(\right.$ marca $\mathrm{Bach}^{\circledR}$ ) y otra en $\mathrm{Mi}^{\mathrm{b}}$ (marca Schilke ${ }^{\circledR}$ ). El número de grabaciones ${ }^{2}$ por trompeta ha sido el siguiente:

${ }^{1}$ Cuando en los resultados sólo ponemos $\mathrm{si}^{\mathrm{b}}$ nos referimos a la trompeta de la marca Yamaha ${ }^{\circledR}$, y para referirnos a la trompeta Bach en $\mathrm{si}^{\mathrm{b}}$ lo hacemos constar explícitamente.

${ }^{2}$ El número de veces que se ha grabado con cada trompeta responde a la comodidad y la naturalidad del intérprete, condiciones éstas que se perseguían en el estudio. 


$\begin{array}{ll}\text { Bach }^{\circledR} \text { en } \mathrm{Si}^{\mathrm{b}} & 6 \text { grabaciones } \\ \text { Yamaha }^{\circledR} \text { en } \mathrm{Si}^{\mathrm{b}} & 4 \text { grabaciones } \\ \text { Bach }^{\circledR} \text { en Do } & 3 \text { grabaciones } \\ \text { Schilke }^{\circledR} \text { en } \mathrm{Mi}^{\mathrm{b}} & 4 \text { grabaciones }\end{array}$

De estas grabaciones, 15 tenían una buena calidad para ser analizadas y han sido agrupadas por días en las tablas de resultados y los gráficos que muestran los porcentajes de notas que pertenecen a cada sistema de afinación.

Del fragmento de Béla Bartók hemos analizado 22 grabaciones realizadas con tres trompetas: Bach $^{\circledR}$ en Do, Yamaha ${ }^{\circledR}$ en $\mathrm{Si}^{\mathrm{b}}$ y Piccolo Scherzer ${ }^{\circledR}$. El número de grabaciones realizado con cada una de ellas ha sido el siguiente:

$\begin{array}{ll}\text { Bach }^{\circledR} \text { en Do } & 7 \text { grabaciones } \\ \text { Yamaha }^{\circledR} \text { en } \mathrm{Si}^{\text {b }} & 7 \text { grabaciones } \\ \text { Piccolo Scherzer } & 8 \text { grabaciones }\end{array}$

A continuación mostramos los resultados sin comentarios porque éstos aparecen el el capítulo 3 de la tesis. 


\section{A.2.1 Resultados para el concierto de Haydn}

Resultados de la grabación 3-02-2003 mi ${ }^{\text {b }}$

\begin{tabular}{|c|c|c|c|c|c|c|c|}
\hline $\mathbf{N}^{\mathbf{0}}$ & Nota & $\mathbf{H z}$ & Sistema & $\mathbf{N}^{\mathbf{0}}$ & Nota & $\mathbf{H z}$ & Sistema \\
\hline & $\mathrm{Mi}^{\mathrm{b}}$ & 313 & Pitágoras/Holder & 35 & $\mathrm{La}^{\mathrm{b}}$ & 409 & Otros \\
\hline & $\mathrm{Fa}$ & 354 & Otros & 36 & Sọl & 392 & Pitágoras/Holder \\
\hline & Sol & 397 & Zarlino & 37 & $\mathrm{Si}^{\mathrm{b}}$ & 460 & Zarlino \\
\hline & $\mathrm{Si}^{\mathrm{b}}$ & 233 & Temperado & 38 & $\mathrm{Mi}_{\mathrm{b}}^{\mathrm{b}}$ & 619 & Pitágoras/Holder \\
\hline & $\mathrm{Mi}^{\mathrm{b}}$ & 305 & Zarlino & 39 & $\mathrm{Mi}^{\mathrm{b}}$ & 618 & Pitágoras/Holder \\
\hline & $\mathrm{Fa}$ & 353 & Pitágoras/Holder & 40 & $\mathrm{Re}_{\mathrm{b}}$ & 589 & Temperado \\
\hline & Sol & 389 & Pitágoras/Holder & 41 & $\mathrm{Re}^{\mathrm{b}}$ & 553 & Temperado \\
\hline & $\mathrm{La}^{\mathrm{b}}$ & 409 & Otros & 42 & Do & 520 & Pitágoras/Holder \\
\hline & $\mathrm{Si}^{\mathrm{b}}$ & 459 & Zarlino & & $\mathrm{Si}_{\mathrm{h}}$ & 492 & Temperado \\
\hline 10 & Do & 527 & Zarlino & 44 & $\mathrm{Si}^{\mathrm{b}}$ & $46 \overline{3}$ & Pitágoras/Holder \\
\hline & $\operatorname{Re}_{\mathrm{b}}$ & 577 & Pitágoras/Holder & 45 & Sol & 387 & Pitágoras/Holder \\
\hline & $\mathrm{Mi}^{\mathrm{O}}$ & 614 & Otros & 46 & $\mathrm{Si}_{\mathrm{C}}^{\mathrm{i}} \mathrm{i}$ & 459 & Zarlino \\
\hline & Do & 510 & Otros & 47 & $\mathrm{Si}_{\mathrm{i}}^{\mathrm{O}}$ & 229 & Zarlino \\
\hline & $S_{i}^{1} \cdot \mathrm{b}$ & 458 & Zarlino & 48 & $\operatorname{Si}_{i}^{b}$ & 233 & Temperado \\
\hline & $\begin{array}{l}\text { S1 } \\
\text { Do }\end{array}$ & $\begin{array}{l}400 \\
525\end{array}$ & $\begin{array}{l}\text { Zarlino } \\
\text { Zarlino }\end{array}$ & 50 & Sib & 235 & Temperado \\
\hline & $\mathrm{Re}_{\mathrm{b}}$ & 580 & Otros & 51 & $\mathrm{Si}^{\mathrm{b}}$ & 229 & Temperado \\
\hline & $\mathrm{Mi}^{\mathrm{b}}$ & 612 & Otr & 52 & $\mathrm{Mi}^{\mathrm{b}}$ & 311 & erado \\
\hline & D.p & 513 & Pitágoras/Holder & 53 & Sol & 786 & Temperado \\
\hline & $\mathrm{Si}^{\mathrm{i}}$ & 461 & Zarli & 54 & $\mathrm{Fa}$ & 690 & Otros \\
\hline & Do & 523 & Temperado & & $\mathrm{Mi}_{\mathrm{b}}^{\mathrm{O}}$ & 616 & Pitágoras/Holder \\
\hline 3 & $\mathrm{Re}_{\mathrm{b}}$ & $\begin{array}{l}5 / 5 \\
610\end{array}$ & Utros & 56 & M11 & 620 & Temperado \\
\hline & $\mathrm{Fa}$ & 668 & Pitágoras/Holder & 58 & Do & 520 & Pitágoras/Holder \\
\hline & Sol & 78 & rado & & $\mathrm{Si}$ & 493 & Temperado \\
\hline & $\mathrm{Mi}^{\mathrm{b}}$ & 62 & Zarli1 & & Do & & Pitágoras/Holder \\
\hline & $\mathrm{Re}$ & 58 & Otr & 61 & $\mathrm{Si}$ & 491 & Ten \\
\hline & Dop & & Zarl & 62 & De & 526 & Zarlino \\
\hline & $\mathrm{Si}^{\mathrm{b}}$ & & Zarl & & $\mathrm{Si}$ & & Temperado \\
\hline 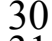 & Sol & 39 & Otros & 64 & Do & 524 & Temperado \\
\hline & $\mathrm{Mi}^{\mathrm{D}}$ & 618 & Pitág./Holder y Zarlino & 65 & $\mathrm{Si}$ & 493 & Temperado \\
\hline & $\mathrm{Re}_{\mathrm{f}}$ & & Zarlino & 66 & $\mathrm{D}, \mathrm{g}$ & 524 & perado \\
\hline & M11 & & $\begin{array}{l}\text { Pitágoras/Ho } \\
\text { Otros }\end{array}$ & & & 459 & Zarlino \\
\hline & & & Utros & 68 & & 441 & Iodos \\
\hline
\end{tabular}

Porcentajes de los resultados de la grabación 3-02-2003 mib

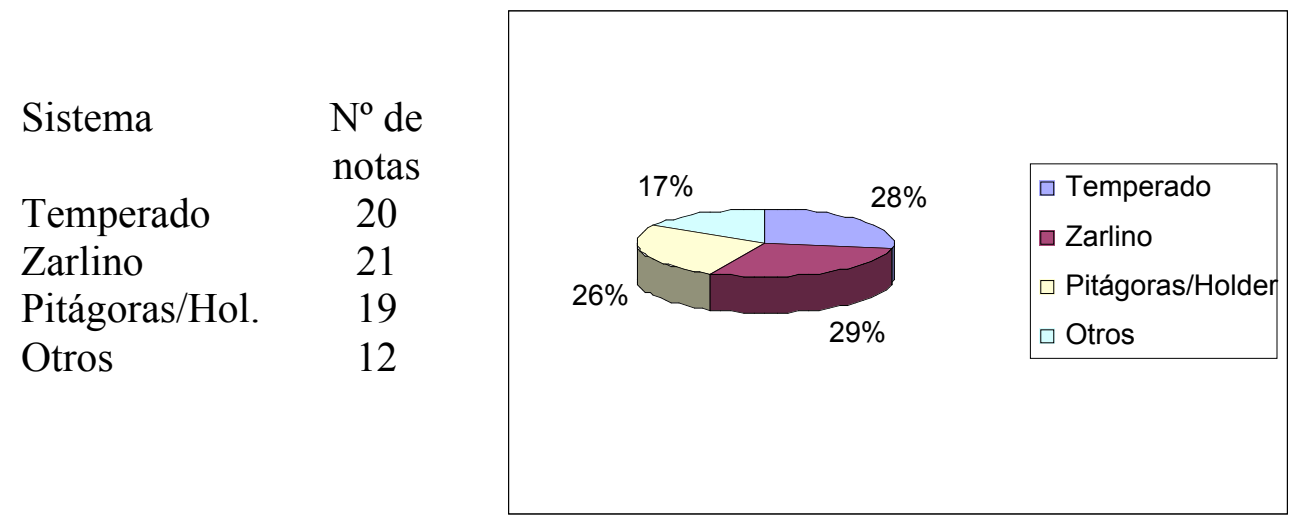


Resultados de la grabación 3-02-2003 si ${ }^{\text {b }}$

\begin{tabular}{|c|c|c|c|c|c|c|c|}
\hline $\mathbf{N}^{0}$ & Nota & $\mathrm{Hz}$ & Sistema & $\mathbf{N}^{0}$ & Nota & $\mathrm{Hz}$ & Sistema \\
\hline & $\mathrm{Mi}^{\mathrm{b}}$ & 312 & Temperado & 35 & $\mathrm{La}^{\mathrm{b}}$ & 410 & Pitágoras/Holder \\
\hline & $\mathrm{Fa}$ & 350 & Temperado y Zarlino & 36 & Sol & 394 & Otros \\
\hline & Sol & 394 & Otros & 37 & $\mathrm{Si}^{\mathrm{b}} \mathrm{b}$ & 462 & Pitágoras/Holder \\
\hline & $\mathrm{Si}^{\mathrm{b}}$ & 231 & Pitágoras/Holder & 38 & $\mathrm{Mi}_{\mathrm{b}}^{\mathrm{b}}$ & 624 & Temperado \\
\hline & $\mathrm{Mi}^{\mathrm{o}}$ & 310 & Zarlino & 39 & $\mathrm{Mi}^{\mathrm{O}}$ & 623 & Temperado \\
\hline & $\mathrm{Fa}$ & 347 & Pitágoras/Holder & 40 & $\mathrm{Re}_{\mathrm{b}}$ & 596 & $\begin{array}{l}\text { Zarlino } \\
\text { Ditónoratur }\end{array}$ \\
\hline & Sol & 390 & Otros & $\begin{array}{l}41 \\
42\end{array}$ & Do & 527 & $\begin{array}{l}\text { Pitagoras/Holder } \\
\text { Zarlino }\end{array}$ \\
\hline & $\mathrm{Si}^{\mathrm{b}}$ & 463 & Pitágoras/Holder & 43 & $\mathrm{Si}_{\mathrm{b}}$ & 494 & Temperado \\
\hline 0 & Do & 525 & Zarlino & 44 & $\mathrm{Si}^{\mathrm{b}}$ & 469 & Pitágoras/Holder \\
\hline & $\mathrm{Re}_{\mathrm{b}}$ & 590 & Otros & 45 & Sol & 385 & Pitágoras \\
\hline & $\mathrm{Mi}^{\mathrm{O}}$ & 616 & Pitágoras/Holder & 46 & $\mathrm{Si}_{\substack{\mathrm{S} \\
\mathrm{i}} \mathrm{b}}^{\mathrm{u}}$ & 462 & Pitágoras/Holder \\
\hline & $\mathrm{Si}^{\mathrm{b}}$ & $\begin{array}{l}512 \\
462\end{array}$ & $\begin{array}{l}\text { Utros } \\
\text { Pitágoras/Holder }\end{array}$ & $\begin{array}{l}47 \\
48\end{array}$ & $\begin{array}{l}S 1 \\
S i b\end{array}$ & 230 & $\begin{array}{l}\text { Utros } \\
\text { Zarlino }\end{array}$ \\
\hline 15 & $\mathrm{Si}^{\mathrm{b}}$ & 461 & Otros & 49 & $\mathrm{Si}^{\mathrm{b}}$ & 235 & Pitágoras/Holder \\
\hline & Do & 524 & erado y Zarlino & 50 & $\mathrm{Si}_{\mathrm{b}}^{\mathrm{D}}$ & 237 & Zarlino \\
\hline & $\mathrm{Re}_{\mathrm{b}}$ & $\begin{array}{l}584 \\
621\end{array}$ & $\begin{array}{l}\text { Zarlino } \\
\text { Zarlino }\end{array}$ & $\begin{array}{l}51 \\
52\end{array}$ & $\mathrm{Sl}_{1}^{\circ} \mathrm{b}$ & 236 & $\begin{array}{l}\text { Otros } \\
\text { Pitánon }\end{array}$ \\
\hline c & Do & 510 & Otr & 53 & Sol & 789 & Ot \\
\hline & $\mathrm{Si}^{\mathrm{b}}$ & 464 & Pitágoras/Holder & 54 & $\mathrm{Fa}$ & 701 & Zarlino \\
\hline & Do & 510 & & 55 & $\mathrm{Mi}_{\mathrm{h}}^{\mathrm{b}}$ & & \\
\hline & $\operatorname{Re}_{b}$ & $5 / 7$ & Pitágoras/Holder & 56 & $\mathrm{Mi}^{\mathrm{O}}$ & 624 & Zarlino \\
\hline & $\mathrm{Mi}$ & & Pitá & & $\operatorname{Re}$ & & \\
\hline & Sal & 690 & Pitágoras & 58 & Do & 520 & Pitágoras/Holder \\
\hline & $\mathrm{Mi}^{\mathrm{b}}$ & 621 & Zar & & $\begin{array}{l}\mathrm{SI} \\
\mathrm{Do}\end{array}$ & $\begin{array}{l}493 \\
522-1\end{array}$ & $\begin{array}{l}\text { lemperc } \\
\text { Pitáoora }\end{array}$ \\
\hline & $\mathrm{Re}$ & & Otr & 61 & $\mathrm{Si}$ & 493 & Ten \\
\hline & D.p & 51 & Zarl & & Do & 521 & oras/Holder \\
\hline & $\mathrm{Si}^{\mathrm{O}}$ & & & & $\mathrm{Si}$ & & era \\
\hline & Sof & 394 & Otro & 64 & $D_{C} 0$ & 527 & Zarlino \\
\hline & & $\begin{array}{l}022 \\
589\end{array}$ & erado y Zarlıno & 03 & S1 & & Ten \\
\hline & $\mathrm{Mi}^{\mathrm{b}}$ & & Zarl & $6^{\prime}$ & $\mathrm{Si}^{\mathrm{b}}$ & 463 & Pitá \\
\hline & Do & & Pitágoras/Holder & 68 & $\mathrm{La}$ & 441 & Todos \\
\hline
\end{tabular}

Porcentajes de los resultados de la grabación 3-02-2003 si ${ }^{\text {b }}$

$\begin{array}{lc}\text { Sistema } & \mathrm{N}^{\mathrm{o}} \mathrm{de} \\ \text { notas } \\ \text { Temperado } & 13 \\ \text { Zarlino } & 23 \\ \text { Pitágoras/Hol. } & 24 \\ \text { Otros } & 14\end{array}$

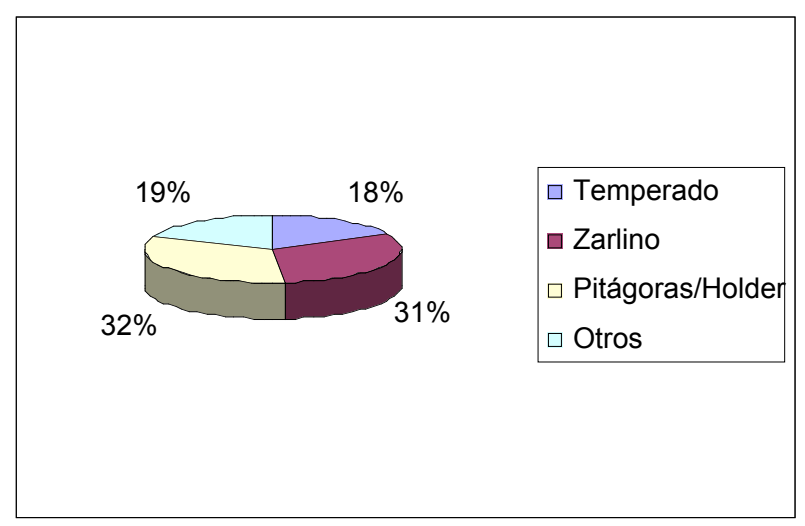


Resultados de la grabación 4-02 2003 mi $^{\text {b }}$

\begin{tabular}{|c|c|c|c|c|c|c|c|}
\hline $\mathbf{N}^{0}$ & Nota & $\mathbf{H z}$ & Sistema & $\mathbf{N}^{\mathbf{0}}$ & Nota & $\mathbf{H z}$ & Sistema \\
\hline & $\mathrm{Mi}^{\mathrm{b}}$ & 311 & Temperado & 35 & $\mathrm{La}^{\mathrm{b}}$ & 407 & Pitágoras/Holder \\
\hline 2 & $\mathrm{Fa}$ & 352 & Pitágoras/Holder & 36 & Sol & 392 & Temperado \\
\hline 3 & Sol & 394 & Otros & 37 & $\mathrm{Si}^{\mathrm{b}}$ & 459 & Zarlino \\
\hline 4 & $\mathrm{Si}^{\mathrm{b}}$ & 230 & Otros & 38 & $\mathrm{Mi}^{\mathrm{b}}$ & 617 & Pitágoras/Holder \\
\hline 5 & $\mathrm{Mi}^{\mathrm{b}}$ & 307 & Otros & 39 & $\mathrm{Mi}^{\mathrm{b}}$ & 612 & Otros \\
\hline 6 & $\mathrm{Fa}$ & 348 & Pitágoras/Holder & 40 & $\mathrm{Re}_{\mathrm{b}}$ & 583 & Zarlino \\
\hline 7 & Sol & 376 & Pitágoras/Holder & 41 & $\mathrm{Re}^{\mathrm{b}}$ & 550 & Pitág/Holder y Zarlino \\
\hline 8 & $\mathrm{La}^{\mathrm{b}}$ & 406 & Pitágoras/Holder & 42 & Do & 530 & Pitág/Holder y Zarlino \\
\hline & $\mathrm{Si}^{\mathrm{b}}$ & 456 & Zarlino & 43 & $\mathrm{Si}_{\mathrm{b}}$ & 487 & Zarlino \\
\hline 10 & Do & 522 & Pitágoras/Holder & 44 & $\mathrm{Si}_{\mathrm{N}}^{\mathrm{0}}$ & 464 & Pitágoras/Holder \\
\hline 11 & $\mathrm{Re}_{\mathrm{b}}$ & 579 & Pitágoras/Holder & 45 & Sibl & 384 & $\begin{array}{l}\text { Otros } \\
\text { Pitágoras/Holder }\end{array}$ \\
\hline 13 & 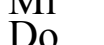 & 513 & $\begin{array}{l}\text { Uitáóoras/Holder } \\
\text { Pithor }\end{array}$ & $\begin{array}{l}40 \\
47\end{array}$ & Sib & 229 & Tarling \\
\hline 14 & $\mathrm{Si}^{\mathrm{b}}$ & 458 & Zarlino & 48 & $\mathrm{Si}_{\mathrm{r}}^{\mathrm{b}}$ & 230 & Zarlino \\
\hline 15 & $\mathrm{Si}^{\mathrm{b}}$ & 457 & Pitágoras/Holder & 49 & $\mathrm{Si}_{\mathrm{i}}^{\mathrm{b}}$ & 232 & Pitágoras/Holder \\
\hline 16 & Do & 507 & Pitágoras/Holder & 50 & $\mathrm{Si}_{\mathrm{b}}^{\mathrm{b}}$ & 230 & Zarlino \\
\hline 17 & $\mathrm{Re}_{\mathrm{b}}$ & 581 & Otros & 51 & $\mathrm{Si}^{\mathrm{b}}$ & 233 & Temperado \\
\hline 19 & Do & 510 & Otros & 53 & 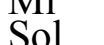 & 305 & Temnerado \\
\hline 20 & $\mathrm{Si}^{\mathrm{b}}$ & 459 & Zarlino & 54 & $\mathrm{Fa}$ & 691 & Otros \\
\hline & Do & 526 & Zarlino & & & 613 & Otros \\
\hline 22 & $\operatorname{Re}_{b}$ & 574 & Zarlino & 56 & $\mathrm{Mi}^{\mathrm{b}}$ & 617 & Pitágoras/Holder \\
\hline & $\mathrm{Mi}^{\mathrm{D}}$ & 610 & Pitágoras/Holder & 57 & $\operatorname{Re}$ & 579 & Pitágoras/Holder \\
\hline 24 & $\mathrm{Fa}$ & 687 & Zarlino & 58 & Do & 517 & Zarlino \\
\hline & Sol & 784 & Temperado & 59 & $\mathrm{Si}$ & 490 & Pitágoras/Holder \\
\hline & $\mathrm{Mi}^{\circ}$ & & Otros & & Do & & \\
\hline 27 & $\mathrm{Re}$ & 580 & Pitágoras/Holder & 61 & $\mathrm{Si}$ & 489 & Pitágoras/Holder \\
\hline & Dip & 520 & Pitágoras/Holder & 62 & Do & 519 & Pitágoras/Holder \\
\hline & $\mathrm{Si}^{\mathrm{D}}$ & 45 & Zarlino & & $\mathrm{Si}$ & & Zarlino \\
\hline 30 & Sol & 392 & Temperado & 64 & Do & 507 & Pitágoras/Holder \\
\hline & $\mathrm{Mi}^{\circ}$ & 614 & Otros & 65 & $\mathrm{Si}$ & 487 & Zarlino \\
\hline & $\operatorname{Re}_{b}$ & & Pitágoras/Holder & 66 & Do & 512 & Pitágoras/Holder \\
\hline 3. & $\mathrm{Mi}^{\mathrm{O}}$ & 614 & $\begin{array}{l}\text { Otros } \\
\text { Zarling }\end{array}$ & 67 & $\mathrm{Si}^{\mathrm{i}}$ & 460 & Zarlino \\
\hline & & 521 & Zarlino & 68 & $\mathrm{La}$ & & 1 odos \\
\hline
\end{tabular}

Porcentajes de los resultados de la grabación 4-02 2003mib

$\begin{array}{lc}\text { Sistema } & \begin{array}{c}\mathrm{N}^{\mathrm{o}} \text { de } \\ \text { notas }\end{array} \\ \text { Temperado } & 7 \\ \text { Zarlino } & 21 \\ \text { Pitágoras/Hol. } & 30 \\ \text { Otros } & 14\end{array}$

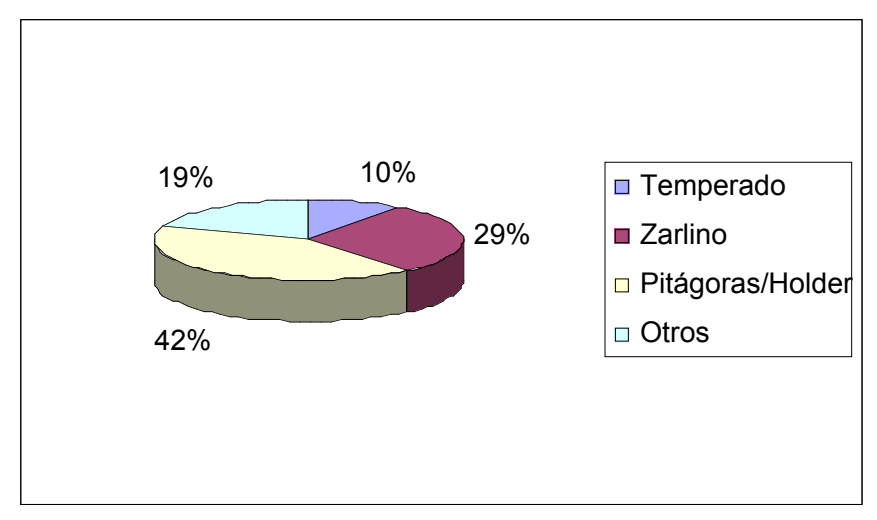


Resultados de la grabación 4-02-2003 si $^{\mathrm{b}}$

\begin{tabular}{|c|c|c|c|c|c|c|c|}
\hline $\mathbf{N}^{\mathbf{0}}$ & Nota & $\mathbf{H z}$ & Sistema & $\mathbf{N}^{\mathbf{0}}$ & Nota & $\mathbf{H z}$ & Sistema \\
\hline & $\mathrm{Mi}^{\mathrm{b}}$ & 312 & Zarlino & 35 & $\mathrm{La}$ & 410 & Otros \\
\hline 2 & $\mathrm{Fa}$ & & Zarlino & 36 & Sol & 394 & Otros \\
\hline 3 & Sol & 396 & Zarlino & 37 & $\mathrm{Si}^{\mathrm{b}}$ & 460 & Zarlino \\
\hline 4 & $\mathrm{Si}^{\mathrm{b}}$ & 232 & Pitágoras/Holder & 38 & $\mathrm{Mi}_{\mathrm{b}}^{\mathrm{b}}$ & 621 & Zarlino \\
\hline 5 & $\mathrm{Mi}^{\mathrm{b}}$ & 307 & Otros & 39 & $\mathrm{Mi}^{\mathrm{b}}$ & 619 & Pitágoras/Holder \\
\hline 6 & $\mathrm{Fa}$ & 346 & Pitágoras/Holder & 40 & $\mathrm{Re}_{\mathrm{b}}$ & 593 & Zarlino \\
\hline 7 & Sol & 390 & Zarlino & 41 & $\mathrm{Re}^{\mathrm{b}}$ & 551 & Zarlino \\
\hline & $\mathrm{La}^{\mathrm{b}}$ & 409 & Otros & 42 & Do & 533 & Otros \\
\hline 9 & $\mathrm{Si}^{\mathrm{b}}$ & 462 & oras/Holder & 43 & $\mathrm{Si}_{\mathrm{b}}$ & 491 & Otros \\
\hline 10 & Do & 523 & Temperado & 44 & $\mathrm{Si}^{\mathrm{b}}$ & 471 & Pitágoras/Holder \\
\hline 11 & $\operatorname{Re}_{\mathrm{h}}$ & 582 & Otro & 45 & Sol & 395 & Zarlino \\
\hline 12 & $\mathrm{Mi}^{\mathrm{D}}$ & 607 & Zarli & 46 & $\mathrm{Si}_{\mathfrak{a}}^{\mathrm{b}} \mathrm{b}$ & 462 & Pitágoras/Holder \\
\hline 13 & Pib & 512 & Utros & 47 & \begin{tabular}{l}
$S 1$ \\
$S_{1}$ \\
\hdashline
\end{tabular} & 231 & Pitágoras/Holder \\
\hline 12 & $\begin{array}{l}S S_{b} \\
S i b\end{array}$ & $\begin{array}{l}460 \\
458\end{array}$ & $\begin{array}{l}\text { Zarlino } \\
\text { Zarlino }\end{array}$ & $\begin{array}{l}48 \\
49\end{array}$ & $\begin{array}{l}S_{1} \\
S_{i}\end{array}$ & $\begin{array}{l}233 \\
239\end{array}$ & Temperado \\
\hline 16 & Do & 518 & Otros & 50 & Si & 233 & Temperado \\
\hline 17 & $\mathrm{Re}_{\mathrm{b}}$ & 575 & Otrc & 51 & $\mathrm{Si}^{\mathrm{b}}$ & 233 & erado \\
\hline & $\mathrm{Mi}^{\mathrm{D}}$ & 608 & Zarlino & 52 & $\mathrm{Mi}^{\mathrm{D}}$ & 310 & Zarlino \\
\hline 19 & Do & 511 & Otro & 53 & Sol & 786 & Otr \\
\hline 20 & $\mathrm{Si}^{\mathrm{O}}$ & 458 & Zarli & 54 & $\mathrm{Fa}$ & 698 & perado \\
\hline & Do & 530 & oras/Holder & 55 & $\mathrm{Mi}_{\mathrm{b}}^{\mathrm{b}}$ & 619 & \\
\hline & $\mathrm{Re}_{\mathrm{H}}$ & 57 & Pitág & 56 & $\mathrm{Mi}^{\mathrm{b}}$ & 620 & Zarlino \\
\hline 2. & $\mathrm{Mi}^{\mathrm{b}}$ & 610 & Pitá & 57 & $\mathrm{Re}$ & & Otr \\
\hline & $\mathrm{Fa}$ & & Pit & 58 & Do & & \\
\hline 25 & Sol & 786 & Otr & 59 & $\mathrm{Si}$ & 491 & Otr \\
\hline 26 & $\mathrm{Mi}^{\circ}$ & 619 & Zar & 60 & Do & & iperado \\
\hline & $\mathrm{Re}$ & & ras/Holder & 61 & $\mathrm{Si}$ & & Otr \\
\hline 2 & Do & 52 & as/Holder & 62 & Do & & Pitágoras/Holder \\
\hline & & & Zar & & & & \\
\hline 3( & Sol & 39 & Otr & 64 & Do & & perado \\
\hline 3. & $\mathrm{Mi}^{\mathrm{D}}$ & 617 & oras/Holder & 65 & $\mathrm{Si}$ & 49 & berado \\
\hline & $\operatorname{Re}_{h}$ & & Pitágoras/Holder & 66 & $\mathrm{D}, \mathrm{g}$ & & \\
\hline 3 & $\mathrm{Mi}^{\mathrm{O}}$ & 612 & & 67 & $\mathrm{Si}^{\mathrm{D}}$ & 460 & \\
\hline & Do & & Zarlino & 68 & $\mathrm{La}$ & 441 & Todos \\
\hline
\end{tabular}

Porcentajes de los resultados de la grabación 4-02-2003 si

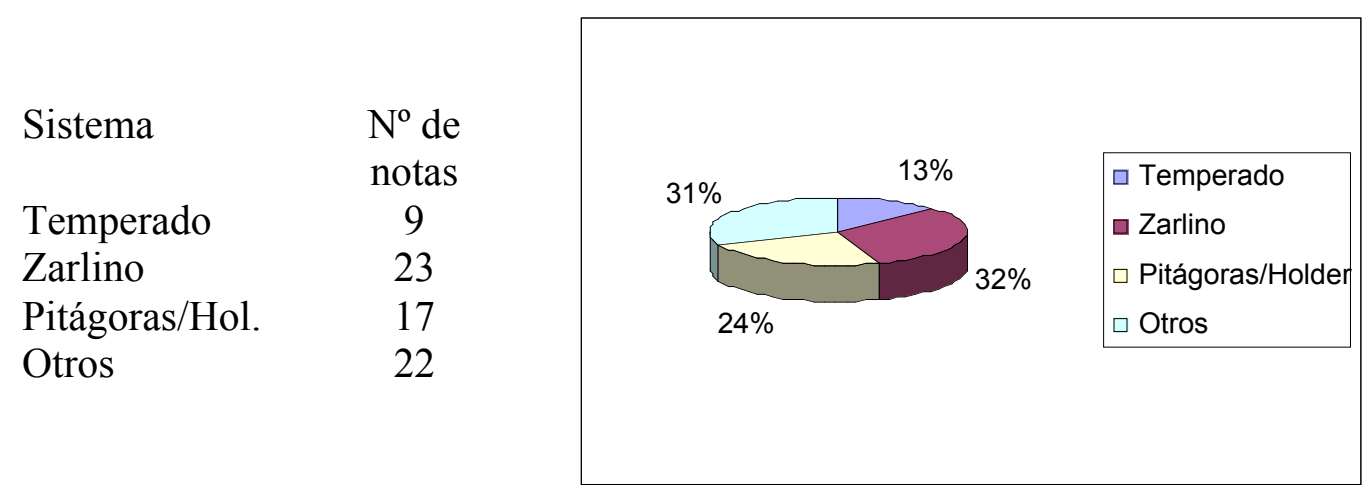


Resultados de la grabación 5-02-2003 mi

\begin{tabular}{|c|c|c|c|c|c|c|c|}
\hline $\mathbf{N}^{\mathbf{0}}$ & Nota & $\mathbf{H z}$ & Sistema & $\mathbf{N}^{\mathbf{0}}$ & Nota & $\mathbf{H z}$ & Sistema \\
\hline 1 & $\mathrm{Mi}^{\mathrm{b}}$ & 314 & Pitágoras/Holder & 35 & $\mathrm{La}^{\mathrm{b}}$ & 409 & Otros \\
\hline 2 & $\mathrm{Fa}$ & 353 & Pitágoras/Holder & 36 & Sol & 397 & Temperado \\
\hline 3 & Sol & 395 & Zarlino & 37 & $\mathrm{Si}^{\mathrm{b}}$ & 468 & Temperado \\
\hline 4 & $\mathrm{Si}^{\mathrm{b}}$ & 230 & Zarlino & 38 & $\mathrm{Mi}_{\mathrm{b}}^{\mathrm{b}}$ & 624 & Zarlino \\
\hline 5 & $\mathrm{Mi}^{\mathrm{b}}$ & 309 & Pitágoras/Holder y Zarlino & 39 & $\mathrm{Mi}^{\mathrm{b}}$ & 623 & Zarlino \\
\hline 6 & $\mathrm{Fa}$ & 351 & Zarlino & 40 & $\mathrm{Re}_{\mathrm{b}}$ & 586 & Pitágoras/Holder \\
\hline & Sol & 388 & Zarlino & 41 & $\operatorname{Re}^{b}$ & 551 & Otros \\
\hline & $\mathrm{La}^{\mathrm{b}}$ & 408 & Otros & 42 & Do & 529 & Pitágoras/Holder \\
\hline 9 & $\mathrm{Si}^{\mathrm{D}}$ & 462 & Otros & 43 & $\underset{C}{S} i_{b}$ & 491 & Otros \\
\hline 10 & $\begin{array}{l}\mathrm{Do} \\
\mathrm{Re}\end{array}$ & $\begin{array}{l}523 \\
583\end{array}$ & Temperado & $\begin{array}{l}44 \\
45\end{array}$ & Sol & $\begin{array}{l}468 \\
386\end{array}$ & $\begin{array}{l}\text { Zarlino } \\
\text { Pitáooras/Holder }\end{array}$ \\
\hline 12 & $\mathrm{Mi}^{\mathrm{b}}$ & 618 & Pitág./Holder y Zarlino & 46 & $\mathrm{Si}_{1}^{\mathrm{b}}$ & 462 & Pitágoras/Holder \\
\hline & $\mathrm{D} p$ & 514 & Pitágoras/Holder & 47 & $\mathrm{Si}_{\mathrm{a}}^{\mathrm{b}}$ & 232 & Pitágoras/Holder \\
\hline 14 & $\mathrm{Si}_{\mathrm{b}}^{\mathrm{b}}$ & 461 & Otro & 48 & $\mathrm{Si}_{\mathrm{h}}^{\mathrm{b}}$ & 233 & Temperado \\
\hline & $\mathrm{Si}^{\mathrm{D}}$ & 456 & Zarlino & 49 & $\mathrm{Si}_{\substack{\mathrm{b} \\
\mathrm{b}}}^{\mathrm{b}}$ & 232 & Pitágoras/Holder \\
\hline 16 & Do & 524 & Temperado & 50 & $\mathrm{Si}_{\mathrm{S}}^{\mathrm{i}} \mathrm{b}$ & 232 & Pitágoras/Holder \\
\hline $\begin{array}{l}17 \\
18\end{array}$ & $\begin{array}{l}\mathrm{Re}_{\mathrm{b}} \\
\mathrm{Mi}^{\mathrm{b}}\end{array}$ & $\begin{array}{l}582 \\
619\end{array}$ & $\begin{array}{l}\text { Otros } \\
\text { Zarlin }\end{array}$ & $\begin{array}{l}51 \\
52\end{array}$ & $\mathrm{Si}^{\mathrm{u}}$ & 235 & Pitágoras/Holder \\
\hline 19 & Do & 523 & erado & 53 & Sol & 790 & Otros \\
\hline 20 & $\mathrm{Si}^{\mathrm{b}}$ & 459 & Zarlino & 54 & $\mathrm{Fa}$ & 698 & Temperado \\
\hline & Do & 525 & & 55 & $\mathrm{Mi}_{\mathrm{b}}^{\mathrm{b}}$ & 624 & Zarlịno \\
\hline 2 & $\operatorname{Re}_{\mathrm{h}}$ & 574 & Zarlino & 56 & $\mathrm{Mi}^{\mathrm{b}}$ & 623 & Zarlino \\
\hline & $\mathrm{Mi}_{\mathrm{C}}{ }^{-}$ & 616 & Otrs & 57 & $\mathrm{Re}$ & 583 & Zar \\
\hline & $\mathrm{Fa}$ & & & 58 & Do & & \\
\hline & Sof & 787 & Otros & 59 & S1 & 494 & Temperado \\
\hline & $\mathrm{Mi}_{\mathrm{Di}}{ }^{\mathrm{O}}$ & & Te & & Do & & \\
\hline & Do & & 1 emperado y Zarl & & & & Otros \\
\hline & $\mathrm{Si}^{\mathrm{b}}$ & $\begin{array}{l}52 \\
46\end{array}$ & $\begin{array}{l}\text { Pitág } \\
\text { Pitó }\end{array}$ & 02 & Do & 527 & Zarlino \\
\hline & Sol & 39 & Zarli & 64 & Do & 525 & $\begin{array}{l}\text { Uarlin } \\
\text { Zarlino }\end{array}$ \\
\hline & $\mathrm{Mi}^{\mathrm{b}}$ & 623 & Temperado & 65 & $\mathrm{Si}$ & 493 & Temperado \\
\hline & $\operatorname{Re}_{\mathrm{h}}$ & 58 & Pitág./Holder y Temperado & 66 & $\mathrm{Dg}$ & 528 & Zarlino \\
\hline & $\mathrm{Mi}^{\mathrm{b}}$ & 62 & Pitágor & 67 & $\mathrm{Si}^{\mathrm{b}}$ & 462 & Otros \\
\hline & Do & & Temperado & 68 & $\mathrm{La}$ & 442 & Todos \\
\hline
\end{tabular}

Porcentajes de los resultados de la grabación 5-02-2003 mi

$\begin{array}{lc}\text { Sistema } & \begin{array}{c}\mathrm{N}^{\mathrm{o}} \text { de } \\ \text { notas }\end{array} \\ \text { Temperado } & 14 \\ \text { Zarlino } & 28 \\ \text { Pitágoras/Hol. } & 18 \\ \text { Otros } & 16\end{array}$

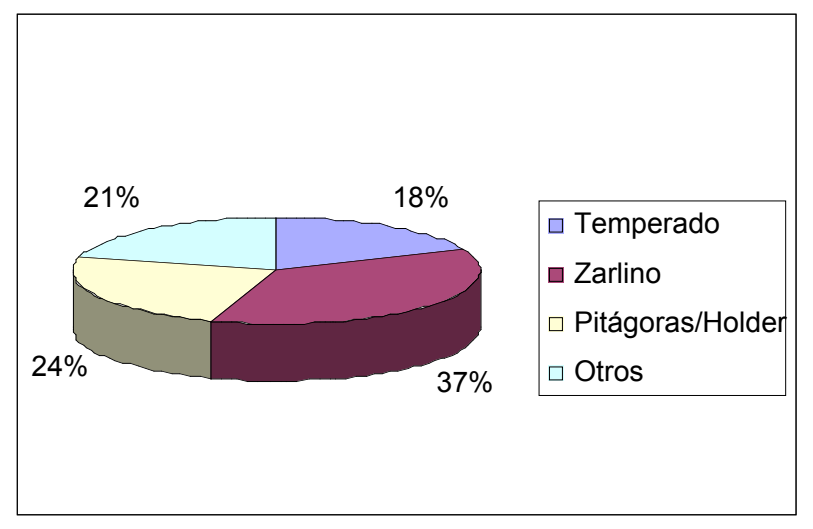


Resultados de la grabación 5-02-2003 si

\begin{tabular}{|c|c|c|c|c|c|c|c|}
\hline $\mathbf{N}^{0}$ & Nota & $\mathrm{Hz}$ & Sistema & $\mathbf{N}^{\mathbf{0}}$ & Nota & $\mathrm{Hz}$ & Sistema \\
\hline 1 & $\mathrm{Mi}^{\mathrm{b}}$ & 316 & Zarlino & 35 & $\mathrm{La}^{\mathrm{b}}$ & 411 & Pitág./Holder y \\
\hline 2 & $\mathrm{Fa}$ & 356 & Pitágoras/Holder & 36 & Sol & 392 & Temperado \\
\hline $\begin{array}{l}3 \\
4\end{array}$ & Sol & 397 & Zarlino & 37 & $\mathrm{Si}^{\mathrm{b}} \mathrm{b}$ & 466 & Temperado \\
\hline $\begin{array}{l}4 \\
5\end{array}$ & $\begin{array}{l}\mathrm{Sl}_{\text {b }} \\
\mathrm{Mi}^{\mathrm{b}}\end{array}$ & $\begin{array}{l}235 \\
313\end{array}$ & $\begin{array}{l}\text { Pitágoras/Holder } \\
\text { Pitáoras/Holder }\end{array}$ & 38 & $\begin{array}{l}M 1_{b}^{\circ} \\
M i^{b}\end{array}$ & $\begin{array}{l}632 \\
629\end{array}$ & $\begin{array}{l}\text { Zarlino } \\
\text { Otros }\end{array}$ \\
\hline 6 & $\mathrm{Fa}$ & 353 & Pitágoras/Holder & 40 & $\mathrm{Re}_{\mathrm{h}}$ & 593 & Pitágoras/Holder \\
\hline 7 & Sol & 385 & Pitágoras/Holder & 41 & $\operatorname{Re}^{b}$ & 560 & Zarlino \\
\hline & $\mathrm{La}_{\mathrm{C}}^{\mathrm{b}}$ & 414 & Zarlino & 42 & Do & 529 & Pitág./Holder Zarlino \\
\hline 10 & $\begin{array}{l}\text { S1 } \\
\text { Do }\end{array}$ & $\begin{array}{l}4 / 2 \\
528\end{array}$ & $\begin{array}{l}\text { Otros } \\
\text { Zarlino }\end{array}$ & $\begin{array}{l}43 \\
44\end{array}$ & S l & $\begin{array}{l}495 \\
476\end{array}$ & $\begin{array}{l}\text { Pitág./Holder Zarlino } \\
\text { Pitág /Holder }\end{array}$ \\
\hline 11 & $\mathrm{Re}_{\mathrm{b}}$ & 593 & Zarlino & 45 & Sol & 384 & Pitág./Holder \\
\hline 12 & $\mathrm{Mi}^{\mathrm{b}}$ & 605 & Otros & 46 & $\mathrm{Si}_{b}^{\mathrm{b}}$ & 466 & Temperado \\
\hline 13 & $\mathrm{D} g$ & 519 & Otros & 47 & $\mathrm{Si}_{b}^{b}$ & 235 & Pitágoras/Holder \\
\hline 14 & $\mathrm{Si}_{\mathfrak{a}}^{\mathrm{i}}{ }_{\mathrm{b}}^{\mathrm{b}}$ & 465 & Pitágoras/Holder & 48 & $\mathrm{Si}_{\substack{\mathrm{i} \\
\mathrm{b}} \mathrm{b}}^{\mathrm{b}}$ & 235 & Pitágoras/Holder \\
\hline 16 & S1 & 467 & Temperado y Zarlino & 49 & Sib & 238 & Pitágoras/Holder \\
\hline & $\mathrm{Re}$ & 590 & $\begin{array}{l}\text { Zarlino } \\
\text { Otros }\end{array}$ & 51 & Sib & 235 & Utros \\
\hline & $\mathrm{Mi}^{\mathrm{b}}$ & 626 & Pitágoras/Holder & 52 & $\mathrm{Mi}^{\mathrm{b}}$ & 316 & Zarlino \\
\hline 19 & $\mathrm{D} p$ & 517 & Zarlino & 53 & Sol & 792 & Pitágoras/Holder \\
\hline & $\mathrm{Si}^{\mathrm{b}}$ & 462 & Pitágoras/Holder & 54 & $\mathrm{Fa}_{\cdot \mathrm{b}}$ & 705 & Pitágoras/Holder \\
\hline 21 & Do & 526 & Zarlino & 55 & $\mathrm{Mi}_{\mathrm{b}}^{\mathrm{u}}$ & 628 & Pitágoras/Holder \\
\hline 23 & $\mathrm{Mi}^{\mathrm{b}}$ & 573 & Zarlino & 56 & $\mathrm{Mi}_{\mathrm{O}}$ & 632 & Zarlino \\
\hline 24 & $\mathrm{Fa}$ & 708 & Otros & 58 & Do & 530 & Pitágoras/Holder \\
\hline 25 & Sol & 795 & Zarlino & & $\mathrm{Si}$ & 498 & Zarlino \\
\hline 26 & $\mathrm{Mi}^{\mathrm{b}}$ & 628 & Pitágoras/Holder & 60 & Do & 530 & Pitágoras/Holder \\
\hline 27 & $\operatorname{Re}$ & 586 & Pitág./Holder y & 61 & $\mathrm{Si}$ & 496 & Pitág./Holder y \\
\hline 28 & Do & 527 & Zarlino & 62 & Do & 530 & Pitágoras/Holder \\
\hline & $\mathrm{Si}_{C}^{\mathrm{b}}$ & 464 & Pitágoras/Holder & 63 & $\mathrm{Si}$ & 493 & Temperado \\
\hline & & 396 & Zarlino & 64 & Do & 524 & Temperado \\
\hline & & & Pitágoras/Holder & & & & Pitag./Holder y \\
\hline 32 & $\operatorname{Re}_{b}$ & 591 & Otros & 66 & Do & 529 & Pitágoras/Holder \\
\hline $\begin{array}{l}33 \\
34\end{array}$ & $\begin{array}{l}\mathrm{Mi}^{\circ} \\
\mathrm{Do}\end{array}$ & $\begin{array}{l}625 \\
524\end{array}$ & $\begin{array}{l}\text { Pitágoras/Holder } \\
\text { Temperado }\end{array}$ & $\begin{array}{l}67 \\
68\end{array}$ & $\mathrm{Si}^{\mathrm{b}}$ & 461 & Otros \\
\hline & & & Temperado & & & & \\
\hline
\end{tabular}

Porcentajes de los resultados de la grabación 5-02-2003 si

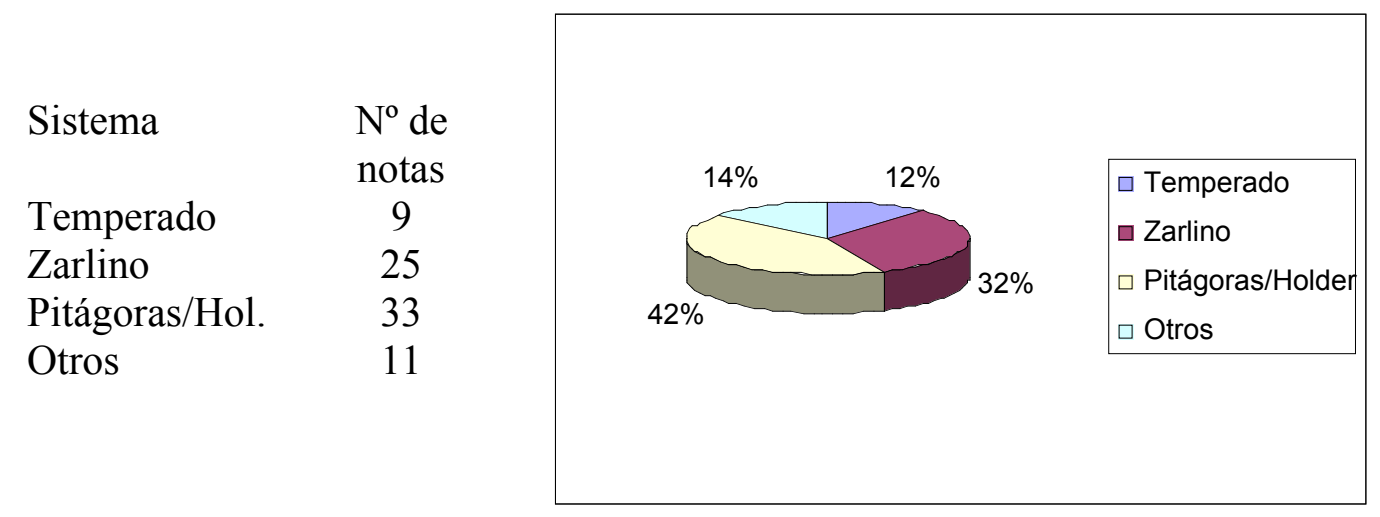




\section{Resultados de la grabación 6-02-2003 mi}

\begin{tabular}{|c|c|c|c|c|c|c|c|}
\hline $\mathbf{N}^{\mathbf{0}}$ & Nota & $\mathbf{H z}$ & Sistema & $\mathbf{N}^{\mathbf{0}}$ & Nota & $\mathbf{H z}$ & Sistema \\
\hline & $\mathrm{Mi}^{\mathrm{b}}$ & 315 & Otros & 35 & $\mathrm{La}^{\mathrm{b}}$ & 409 & Otros \\
\hline & $\mathrm{Fa}$ & 354 & Otros & 36 & Sol & 393 & Temperado \\
\hline & Sol & 397 & Pitágoras/Holder y Zarlino & 37 & $\mathrm{Si}^{\mathrm{b}}$ & 463 & Pitágoras/Holder \\
\hline & $\mathrm{Si}^{\mathrm{b}}$ & 233 & Temperado & 38 & $\mathrm{Mi}_{\mathrm{b}}^{\mathrm{b}}$ & 624 & Temperado y Zarlino \\
\hline & $\mathrm{Mi}^{\mathrm{b}}$ & 307 & Otros & 39 & $\mathrm{Mi}^{\mathrm{D}}$ & 623 & Temperado y Zarlino \\
\hline 6 & $\mathrm{Fa}$ & 348 & Pitág./Holder y Temperado & 40 & $\operatorname{Re}_{b}$ & 588 & Temperado \\
\hline & Sol & 388 & Zarlino & 41 & $\operatorname{Re}^{b}$ & 548 & Pitágoras/Holder \\
\hline & $\mathrm{La}_{\mathrm{b}}^{\mathrm{b}}$ & 411 & Pitágoras/Holder & 42 & Do & 528 & Zarlino \\
\hline & $\mathrm{Si}^{\mathrm{i}}$ & 463 & ras/Holder & 43 & $\mathrm{Si}_{\mathfrak{a}}$ & 494 & Temperado \\
\hline 10 & Do & 526 & Zarlino & 44 & $\mathrm{Si}^{\mathrm{b}}$ & 472 & Otros \\
\hline & $\operatorname{Re}_{b}$ & 576 & Otro & 45 & Sol & 388 & Zarlino \\
\hline & $\mathrm{Mi}^{\mathrm{b}}$ & 611 & Zarlino & 46 & $\mathrm{Si}$ & 472 & Otros \\
\hline & $\mathrm{D}, \mathrm{g}$ & 512 & Otros & 47 & $\mathrm{Si}_{\mathrm{N}}^{\mathrm{b}} \mathrm{b}$ & 231 & Otros \\
\hline 4 & $\mathrm{~S}_{\mathrm{N}}^{\mathrm{i}} \mathrm{b}$ & 461 & Otros & 48 & $\mathrm{Si}_{\mathrm{b}}^{\mathrm{o}}$ & 235 & Otrs \\
\hline 5 & $\mathrm{Si}^{\circ}$ & 461 & Otros & 49 & $\mathrm{Si}_{\mathrm{h}}^{\mathrm{o}}$ & 230 & Zarlino \\
\hline 16 & Do & 525 & Zạlino & 50 & $\mathrm{Si}_{\mathrm{b}}^{\mathrm{D}}$ & 232 & oras/Holder \\
\hline & $\operatorname{Re}_{\mathrm{b}}$ & $\begin{array}{l}571 \\
600\end{array}$ & Pitágoras/Holder & 51 & $\mathrm{Si}_{\mathrm{i}}^{\mathrm{b}}$ & 232 & Pitágoras/Holder \\
\hline & 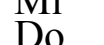 & $\begin{array}{l}609 \\
517\end{array}$ & Pitágoras/Holder & 52 & 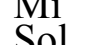 & $\begin{array}{l}315 \\
791\end{array}$ & \\
\hline & $\mathrm{Si}^{\mathrm{b}}$ & 459 & $\begin{array}{l}\text { Utros } \\
\text { Zarlin }\end{array}$ & $\begin{array}{l}53 \\
54\end{array}$ & Fol & $\begin{array}{l}191 \\
699\end{array}$ & Utros \\
\hline & Do & 522 & Pitág./Holder y Temperado & 55 & $\mathrm{Mi}^{\mathrm{b}}$ & 624 & \\
\hline 2 & $\mathrm{Re}_{\mathrm{h}}$ & 585 & Pitág./Holder y Zarlino & 56 & $\mathrm{Mi}^{\mathrm{b}}$ & 624 & Zan \\
\hline 3 & $\mathrm{Mi}^{\mathrm{O}}$ & 61 & Zarl & & $\mathrm{Re}$ & 590 & \\
\hline & $\mathrm{Fa}$ & 679 & ras/Holder & 58 & Do & & \\
\hline & Sol & 785 & Tem & 59 & $\mathrm{Si}$ & 495 & 5older Zarlino \\
\hline & $\mathrm{Mi}$ & 620 & Zarlit & 60 & Do & & \\
\hline 28 & Re & 582 & Otros & 62 & S1 & 495 & Pitág./Holder Zarlino \\
\hline & $\mathrm{Si}^{\mathrm{b}}$ & 464 & $\begin{array}{l}\text { Utros } \\
\text { Pitágoras }\end{array}$ & 63 & Si & & Zar \\
\hline 30 & Sol & 39 & Holder y Zarlino & 64 & Do & 528 & Zarl \\
\hline & $\mathrm{Mi}^{\mathrm{D}}$ & & Temperado y Zarlino & 65 & $\mathrm{Si}$ & 494 & perado \\
\hline & $\operatorname{Re}_{b}$ & 598 & Zarlịno & 66 & $\mathrm{D}, \mathrm{g}$ & 527 & Zar \\
\hline & & 619 & & & $\mathrm{~S} 1$ & 463 & oras/Holder \\
\hline & & 522 & Pitágoras/Holder & 68 & $\mathrm{La}$ & 443 & Toc \\
\hline
\end{tabular}

Porcentajes de los resultados de la grabación 6-02-2003 mi

$\begin{array}{lc}\text { Sistema } & \mathrm{N}^{\mathrm{o}} \text { de } \\ \text { notas } \\ \text { Temperado } & 14 \\ \text { Zarlino } & 29 \\ \text { Pitágoras/Hol. } & 20 \\ \text { Otros } & 18\end{array}$

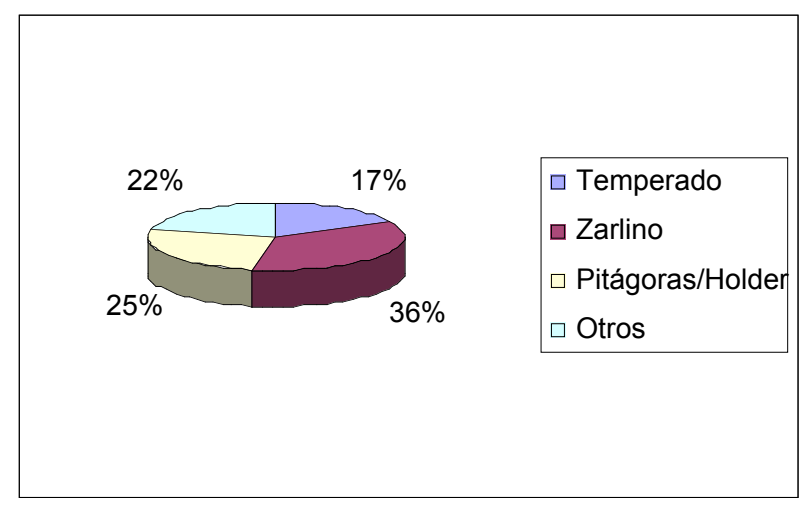


Resultados de la grabación 6-02-2003 si

\begin{tabular}{|c|c|c|c|c|c|c|c|}
\hline$N^{0}$ & Nota & $\mathbf{H z}$ & Sistema & $\mathbf{N}$ & Nota & $\mathbf{H z}$ & Sistema \\
\hline 1 & $\mathrm{Mi}^{\mathrm{b}}$ & 314 & Pitágoras/Holder & 3. & $\mathrm{La}^{\mathrm{b}}$ & 411 & Otros \\
\hline 2 & $\mathrm{Fa}$ & 353 & Pitágoras/Holder & & Sọl & 398 & Zarlino \\
\hline 3 & Sol & 398 & Zarlino & 3 & $\mathrm{Si}^{\mathrm{b}}$ & 467 & Zarlino \\
\hline 4 & $\mathrm{Si}^{\mathrm{b}}$ & 230 & Zarlino & $3 \xi$ & $\mathrm{Mi}_{\mathrm{b}}^{\mathrm{b}}$ & 623 & Temperado y Zarlino \\
\hline 5 & $\mathrm{Mi}^{\mathrm{b}}$ & 314 & Pitágoras/Holder & 39 & $\mathrm{Mi}^{\mathrm{b}}$ & 622 & Temperado y Zarlino \\
\hline 6 & $\mathrm{Fa}$ & $\begin{array}{l}349 \\
301\end{array}$ & Temperado & 4( & $\operatorname{Re}_{b}$ & 590 & Otros \\
\hline & Sol & 391 & Temperado & 4 & $\operatorname{Re}^{\mathrm{b}}$ & 551 & Zarlino \\
\hline 8 & $\mathrm{~L} \mathrm{a}^{\mathrm{b}}$ & 412 & Pitág./Holder y Zarlino & & Do & 527 & Zạrlino \\
\hline & $\mathrm{Si}^{\mathrm{O}}$ & 458 & Zarlino & 4. & $\mathrm{Si}_{\mathrm{C}}: \mathrm{b}$ & 494 & Pitág./Holder y Zarlino \\
\hline & Do & $\begin{array}{l}585 \\
525 \\
325\end{array}$ & Zarrino & 4 & S1 1 & $\begin{array}{l}479 \\
200\end{array}$ & Otros \\
\hline & $\mathrm{Mi}^{\mathrm{b}}$ & 619 & Zarlino & 4 & $S_{i b}$ & $\begin{array}{l}389 \\
467\end{array}$ & $\begin{array}{l}\text { Zarlino } \\
\text { Zarlino }\end{array}$ \\
\hline & Do & 509 & Otros & 4 & $\mathrm{Si}^{\mathrm{b}}$ & 231 & Otros \\
\hline 14 & $\mathrm{Si}_{\mathrm{i}}^{\mathrm{b}}$ & 468 & Zarlino & 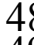 & $\mathrm{Si}_{\mathrm{a}}^{\mathrm{b}} \mathrm{b}$ & 228 & Zarlino \\
\hline & $\mathrm{Si}^{\mathrm{D}}$ & 460 & Zarlino & 45 & $\mathrm{Si}_{\substack{\mathrm{b} \\
\mathrm{b}}}^{\mathrm{b}}$ & 229 & Zarlino \\
\hline 16 & Do & 518 & Otros & 5 & $\mathrm{Si}_{\mathrm{b}}^{\mathrm{O}}$ & 231 & Pitágoras/Holder \\
\hline & $\operatorname{Re}_{\mathrm{b}}$ & 581 & Otros & 5 & $\mathrm{Si}_{\mathrm{i}}^{\mathrm{i}}$ & 233 & Temperado \\
\hline 19 & Do & 514 & Pitágoras/Holder & & Sol & 789 & Otros \\
\hline & $\mathrm{Si}^{\mathrm{b}}$ & 465 & Temperado & 5 & $\mathrm{Fa}$ & 700 & Zarlino \\
\hline & Do & 510 & Otros & & $\mathrm{Mi}_{\mathrm{b}}^{\mathrm{b}}$ & 623 & Temperado y Zarlino \\
\hline & $\operatorname{Re}_{\mathrm{h}}$ & 578 & Pitágoras/Holder & 5 & $\mathrm{Mi}^{\mathrm{b}}$ & 623 & Temperado y Zarlino \\
\hline & $\mathrm{Mi}^{\mathrm{D}}$ & 619 & & & & & \\
\hline & $\mathrm{Fa}$ & 680 & Otros & & Do & 524 & Temperado \\
\hline & Sol & 790 & Otros & 5 & Si & 494 & Temperado \\
\hline & $\mathrm{Re}$ & 58 & $\begin{array}{l}\text { emperado y Zarlino } \\
\text { Zarlino }\end{array}$ & 6 & $\mathrm{Si}$ & 495 & $\begin{array}{l}\text { Zarríno } \\
\text { Pitág./Holder y Zarlino }\end{array}$ \\
\hline & Do & 517 & Otros & & Do & 522 & Pitágoras/Holder \\
\hline & $\mathrm{Si}^{\mathrm{b}}$ & 460 & Zạrlino & & $\mathrm{Si}$ & 492 & Otros \\
\hline & Sol & 397 & Pitágoras/Holder & & Do & 519 & Otros \\
\hline & $\mathrm{Mi}^{\mathrm{i}}$ & 620 & Zarlino & & $\mathrm{Si}$ & 493 & Temperado \\
\hline & $\mathrm{Re}_{\mathrm{b}}$ & & Zarlino & & $\mathrm{Dg}$ & & Pitágoras/Holder \\
\hline & $\mathrm{Mi}^{\mathrm{O}}$ & 619 & Zarlino & 6 & $\mathrm{Si}^{\circ}$ & 463 & Pitágoras/Holder \\
\hline & Do & 515 & Pitág./Holder y Zarlino & & $\mathrm{La}$ & 441 & Todos \\
\hline
\end{tabular}

Porcentajes de los resultados de la grabación 6-02-2003 si

$\begin{array}{lc}\text { Sistema } & N^{o} \text { de notas } \\ \text { Temperado } & 13 \\ \text { Zarlino } & 35 \\ \text { Pitágoras/Hol. } & 15 \\ \text { Otros } & 17\end{array}$

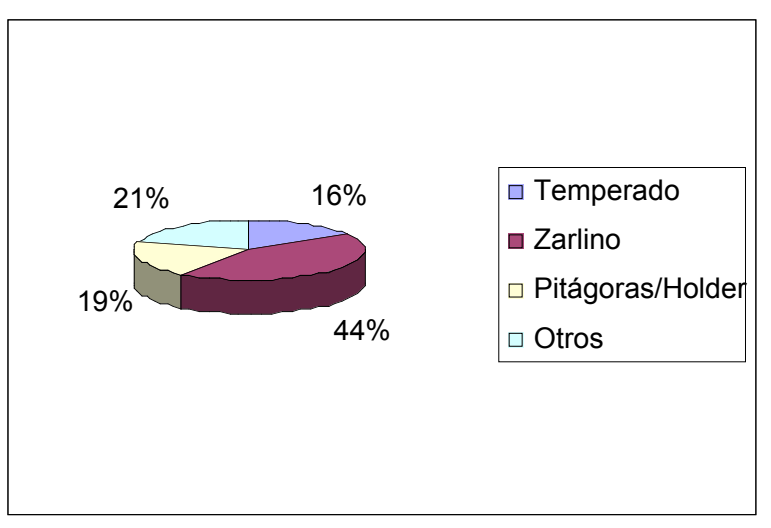


Resultados de la grabación 10-02-2003 do

\begin{tabular}{|c|c|c|c|c|c|c|c|}
\hline $\mathbf{N}^{0}$ & Nota & $\mathbf{H z}$ & Sistema & $\mathbf{N}$ & Nota & $\mathbf{H z}$ & Sistema \\
\hline 1 & $\mathrm{Mi}^{\mathrm{b}}$ & 313 & Pitágoras/Holder & 35 & $\mathrm{La}$ & 407 & Pitágoras/Holder \\
\hline 2 & $\mathrm{Fa}$ & 351 & Zarlino & 36 & Sol & 391 & Temperado \\
\hline 3 & Sol & 394 & Otros & 37 & $\mathrm{Si}^{\mathrm{b}}$ & 468 & Zarlino \\
\hline 4 & $\mathrm{Si}^{\mathrm{b}}$ & 230 & Zarlino & 38 & $\mathrm{Mi}_{\mathrm{b}}^{\mathrm{b}}$ & 622 & Temperado \\
\hline 5 & $\mathrm{Mi}^{\mathrm{b}}$ & 307 & Otros & 39 & $\mathrm{Mi}^{\mathrm{b}}$ & 621 & Temperado y Zarlino \\
\hline 6 & $\mathrm{Fa}$ & 351 & Zarlino & 40 & $\operatorname{Re}_{b}$ & 584 & Zarlino \\
\hline 7 & Sol & 389 & Zarlino & 41 & $\mathrm{Re}^{\mathrm{b}}$ & 555 & Temperado \\
\hline 8 & $\mathrm{La}^{\mathrm{b}}$ & 409 & Otros & 42 & Do & 527 & Zarlino \\
\hline $\begin{array}{l}9 \\
10\end{array}$ & $\mathrm{Si}^{\mathrm{b}}$ & 459 & Zarlino & 43 & $\mathrm{Si}_{\mathrm{W}}$ & 494 & Temperado \\
\hline 10 & Do & 523 & Temperado & & $\mathrm{Si}^{\mathrm{D}}$ & 465 & Temperado \\
\hline $\begin{array}{l}11 \\
12\end{array}$ & $\begin{array}{l}\mathrm{Re}_{\mathrm{b}} \\
\mathrm{Mi}^{\mathrm{b}}\end{array}$ & $\begin{array}{l}573 \\
615\end{array}$ & $\begin{array}{l}\text { Zarlino } \\
\text { Otros }\end{array}$ & $\begin{array}{l}45 \\
46\end{array}$ & $\begin{array}{l}\text { Sol } \\
\mathrm{Si}^{b}\end{array}$ & $\begin{array}{l}383 \\
459\end{array}$ & $\begin{array}{l}\text { Zarlino } \\
\text { Zarlino }\end{array}$ \\
\hline 13 & Do & 510 & Otros & 47 & $\mathrm{Si}^{\mathrm{b}}$ & 231 & Otros \\
\hline 14 & $\mathrm{Si}_{b}^{\mathrm{b}}$ & 457 & Pitágoras/Holder & & $\mathrm{Si}_{\mathrm{b}}^{\mathrm{b}}$ & 236 & Otros \\
\hline & $\mathrm{Si}^{\mathrm{b}}$ & 460 & Zarlino & 49 & $\mathrm{Si}_{\mathrm{b}}^{\mathrm{b}}$ & 235 & Otros \\
\hline 16 & Do & 524 & Temperado & 50 & $\mathrm{Si}_{\mathrm{b}}^{\mathrm{b}}$ & 229 & Zarlino \\
\hline $\begin{array}{l}17 \\
18\end{array}$ & $\operatorname{Re}{ }^{b}$ & 578 & $\begin{array}{l}\text { Pitágoras/Holder } \\
\text { Pitáooras/Holder }\end{array}$ & 51 & $\mathrm{Si}^{\mathrm{i}} \mathrm{b}$ & 231 & $\begin{array}{l}\text { Otros } \\
\text { Ditónang/Holdar }\end{array}$ \\
\hline $\begin{array}{l}10 \\
19\end{array}$ & $\begin{array}{l}\text { V11 } \\
\text { Do }\end{array}$ & $\begin{array}{l}002 \\
510\end{array}$ & $\begin{array}{l}\text { Ptragoras/Holder } \\
\text { Otros }\end{array}$ & 53 & $\begin{array}{l}\text { Vi1 } \\
\text { Sol }\end{array}$ & $\begin{array}{l}313 \\
791\end{array}$ & $\begin{array}{l}\text { Pitagoras/Holder } \\
\text { Pitágoras/Holder }\end{array}$ \\
\hline 20 & $\mathrm{Si}^{\mathrm{b}}$ & 458 & Zarlino & 54 & $\mathrm{Fa} \cdot \mathrm{b}$ & 699 & Zarlino \\
\hline & Do & 521 & Pitágoras/Holder & & $\mathrm{Mi}_{\mathrm{b}}^{\mathrm{b}}$ & 619 & Pitág./Holder y Zarlino \\
\hline 22 & $\operatorname{Re}_{b}$ & 577 & Pitágoras/Holder & 5 & $\mathrm{Mi}^{\mathrm{O}}$ & 620 & Zarlino \\
\hline & $\mathrm{Mi}^{\mathrm{b}}$ & 590 & Otros & & $\operatorname{Re}$ & 579 & /Holder \\
\hline 24 & $\mathrm{Fa}$ & 682 & Otros & & Do & 523 & Temperado \\
\hline & Sol & 785 & Temperado & & $\mathrm{Si}$ & 491 & Otros \\
\hline & $\mathrm{Mi}^{\circ}$ & 618 & Pitág. /Holder y Zarlino & 60 & Do & 521 & Pitágoras/Holder \\
\hline & Re & 591 & Utros & & & 492 & Temperado \\
\hline 28 & Dog & & & & Do & 523 & Temperado \\
\hline & Sol & 458 & Zarlino & & $\mathrm{Si}$ & 490 & Pitágoras/Holder \\
\hline & Mib & $\begin{array}{l}394 \\
619\end{array}$ & $\begin{array}{l}\text { Utros } \\
\text { Pitáo /Hold }\end{array}$ & & Si & $\begin{array}{l}523 \\
403\end{array}$ & Tempers \\
\hline 32 & $\mathrm{Re}_{1}$ & 576 & Otros & & Do & 525 & Zarlino \\
\hline 33 & $\mathrm{Mi}^{\mathrm{b}}$ & 619 & Pitág./Ho & & $\mathrm{Si}^{\mathrm{b}}$ & 461 & Otr \\
\hline 34 & Do & 520 & Pitágoras/Holder & 68 & $\mathrm{La}$ & 443 & Todos \\
\hline
\end{tabular}

Porcentajes de los resultados de la grabación 10-02-2003 do

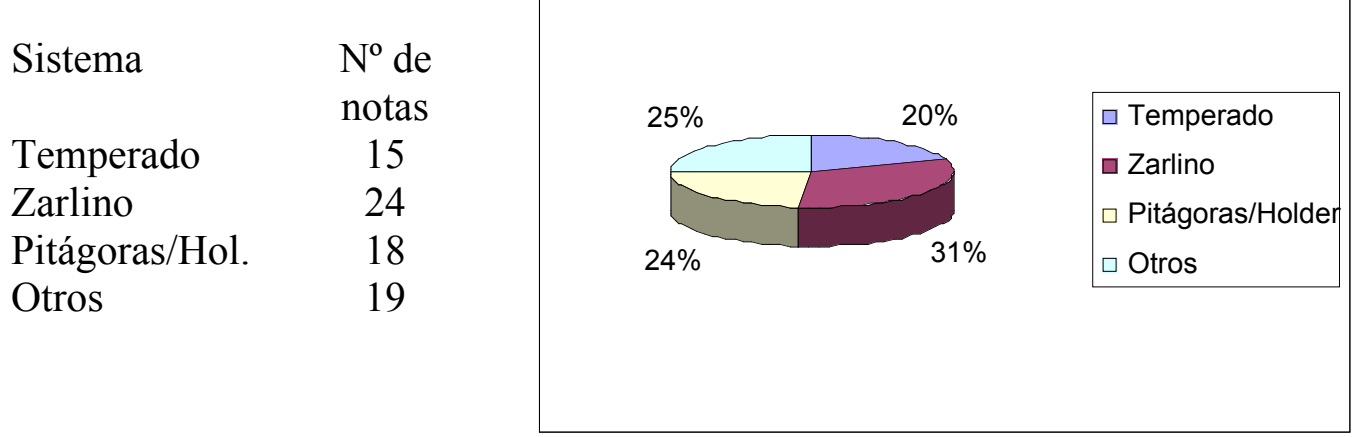


Resultados de la grabación 10-02-2003 si $^{\text {b }}$

\begin{tabular}{|c|c|c|c|c|c|c|c|}
\hline $\mathbf{N}^{0}$ & Nota & $\mathbf{H z}$ & Sistema & $\mathbf{N}^{0}$ & Nota & $\mathbf{H z}$ & Sistema \\
\hline & $\mathrm{Mi}^{\mathrm{b}}$ & 313 & Pitágoras/Holder & 35 & $\mathrm{La}^{\mathrm{b}}$ & 410 & Otros \\
\hline 2 & $\mathrm{Fa}$ & 352 & Pitágoras/Holder y & 36 & Sol & 395 & Pitágoras/Holder \\
\hline 3 & Sol & 396 & Pitágoras/Holder y & 37 & $\mathrm{Si}^{\mathrm{b}}$ & 469 & Pitágoras/Holder \\
\hline 4 & $\mathrm{Si}^{\mathrm{b}}$ & 229 & $\begin{array}{l}\text { Zarluno } \\
\text { Zarlino }\end{array}$ & 38 & $\mathrm{Mi}^{\mathrm{b}}$ & 624 & Zarlino \\
\hline $\begin{array}{l}4 \\
5\end{array}$ & $\mathrm{Mi}^{\mathrm{b}}$ & 307 & Otros & 39 & $\mathrm{Mi}^{\mathrm{b}}$ & 622 & Temperado \\
\hline 6 & $\mathrm{Fa}$ & 347 & Pitágoras/Holder & 40 & $\mathrm{Re}_{\mathrm{b}}$ & 585 & Zarlino \\
\hline 7 & Sol & 389 & Zarlino & 41 & $\operatorname{Re}^{b}$ & 553 & Temperado \\
\hline 8 & $\mathrm{La}^{\mathrm{b}}$ & 411 & Pitágoras/Holder & 42 & Do & 524 & Temperado \\
\hline 9 & $\mathrm{Si}^{\mathrm{O}}$ & 459 & Zarlino & 43 & $\mathrm{Si}$ & 495 & Pitágoras/Holder y \\
\hline 10 & Do & 521 & Pitágoras/Holder & 44 & $\mathrm{Si}^{\mathrm{b}}$ & 466 & Temperado \\
\hline & $\operatorname{Re}_{b}$ & 577 & Otros & 45 & Sol & 386 & Pitágoras/Holder \\
\hline 12 & $\mathrm{Mi}^{\mathrm{b}}$ & 610 & Pitágoras/Holder & 46 & $\mathrm{Si}_{-\mathrm{b}}^{\mathrm{b}}$ & 459 & Zarlino \\
\hline 13 & Dep & 508 & Pitágoras/Holder & 47 & $\mathrm{Si}_{\mathrm{S}}^{\mathrm{b}}$ & 231 & Pitágoras/Holder \\
\hline 14 & $\begin{array}{l}\mathrm{Si}_{\mathrm{Si}}^{\mathrm{v}} \\
\mathrm{Si}\end{array}$ & $\begin{array}{l}459 \\
458\end{array}$ & $\begin{array}{l}\text { Zarlino } \\
\text { Zarlino }\end{array}$ & 48 & 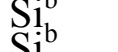 & $\begin{array}{l}231 \\
230\end{array}$ & Pitágoras/Holder \\
\hline 16 & Do & 521 & Pitágoras/Holder & 50 & $\mathrm{Si}^{\mathrm{b}}$ & 231 & Pitágoras/Holder \\
\hline 17 & $\operatorname{Re}_{b}$ & 583 & Zarlino & 51 & $\mathrm{Si}^{\mathrm{b}}$ & 231 & Pitágoras/Holder \\
\hline 18 & $\mathrm{Mi}^{\mathrm{b}}$ & 610 & Pitágoras/Holder & 52 & $\mathrm{Mi}^{\mathrm{b}}$ & 313 & Pitágoras/Holder \\
\hline 19 & Dop & 511 & Otros & 53 & Sol & 789 & Otros \\
\hline 20 & S1 & 462 & Pitágoras/Holder & 54 & $\mathrm{Fa}$ & 701 & Zarlino \\
\hline 22 & $\begin{array}{l}\text { Do } \\
\text { Re }\end{array}$ & $\begin{array}{l}515 \\
575\end{array}$ & Zarlino & 5 & $M 1 ;$ & 623 & Temperado y Zarlino \\
\hline 23 & $\mathrm{Mi}^{\mathrm{b}}$ & 613 & $\begin{array}{l}\text { Utros } \\
\text { Otros }\end{array}$ & $\begin{array}{l}50 \\
57\end{array}$ & IV1 & 021 & Temperado y Zarlino \\
\hline 24 & $\mathrm{Fa}$ & 685 & Pitágoras/Holder & 58 & Do & 516 & Pitágoras/Holder \\
\hline 25 & Sol & 781 & Pitágoras/Holder & 59 & $\mathrm{Si}$ & 491 & Otros \\
\hline 26 & $\mathrm{Mi}^{\mathrm{b}}$ & 617 & Pitágoras/Holder & 60 & Do & 521 & Pitágoras/Holder \\
\hline & $\mathrm{Re}$ & 590 & Otros & & $\mathrm{Si}$ & 492 & Temperado \\
\hline & Do & $7=$ & Otros & 62 & Do & 525 & Zarlino \\
\hline & S1 & 459 & Zarlino & 63 & Si & 490 & Pitágoras/Holder \\
\hline 30 & Sol & 395 & Zarlino & 64 & Do & 516 & Zarlino \\
\hline 32 & $\begin{array}{l}\text { IVII } \\
\mathrm{Re}\end{array}$ & 583 & $\begin{array}{l}\text { Zros } \\
\text { Zarlino }\end{array}$ & 66 & $\begin{array}{l}\text { Do } \\
\text { Do }\end{array}$ & $\begin{array}{l}471 \\
525\end{array}$ & $\begin{array}{l}\text { Utros } \\
\text { Zarlino }\end{array}$ \\
\hline 33 & $\mathrm{Mi}^{\mathrm{b}}$ & 613 & Otros & 67 & $\mathrm{Si}^{\mathrm{b}}$ & 457 & Pitágoras/Holder \\
\hline 34 & Do & 509 & Pitágoras/Holder & 68 & $\mathrm{La}$ & 441 & Todos \\
\hline
\end{tabular}

Porcentajes de los resultados de la grabación 10-02-2003 si ${ }^{\mathrm{b}}$

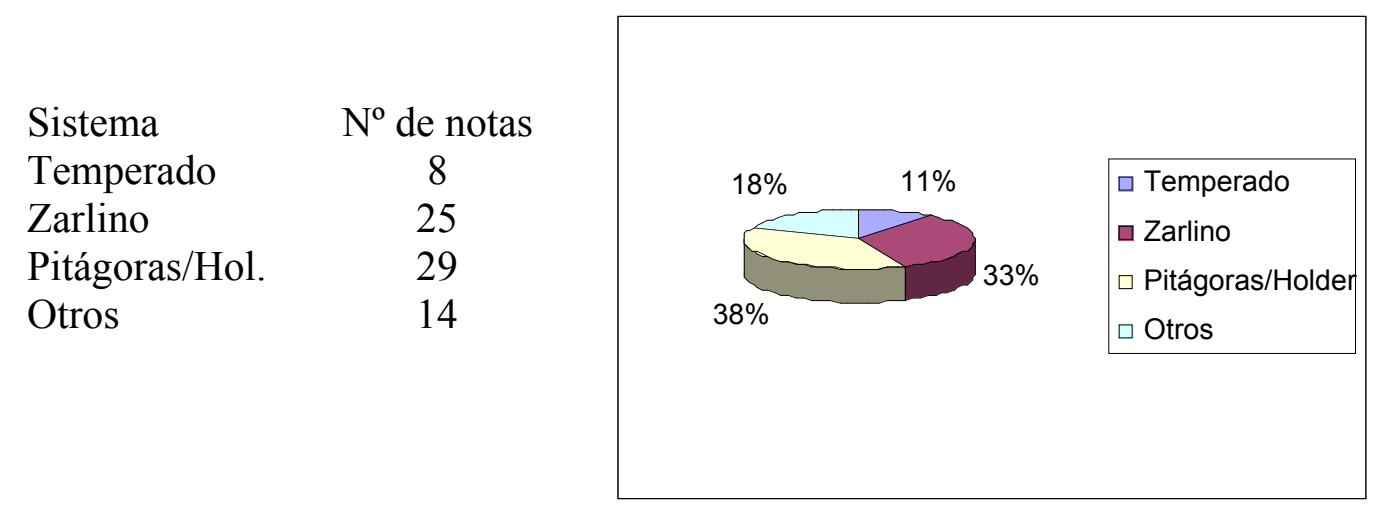


Resultados de la grabación 10-2-2003 Bach si 37

\begin{tabular}{|c|c|c|c|c|c|c|c|}
\hline $\mathbf{V}^{\mathbf{0}}$ & Nota & $\mathbf{H z}$ & Sistema & $\mathbf{N}^{\mathbf{0}}$ & Nota & $\mathbf{H z}$ & Sistema \\
\hline 1 & $\mathrm{Mi}^{\mathrm{b}}$ & 311 & Temperado y Zarlino & 35 & $\mathrm{La}^{\mathrm{b}}$ & 408 & Otros \\
\hline 2 & $\mathrm{Fa}$ & 353 & Pitágoras/Holder y Zarlịno & 36 & Sọl & 393 & Temperado \\
\hline 3 & Sol & 396 & Pitágoras/Holder y Zarlino & 37 & $\mathrm{Si}^{\mathrm{b}}$ & 461 & Otros \\
\hline 4 & $\mathrm{Si}^{\mathrm{b}}$ & 230 & Zarlino & 38 & $\mathrm{Mi}_{\mathrm{b}}^{\mathrm{b}}$ & 617 & Pitágoras/Holder \\
\hline 5 & $\mathrm{Mi}^{\mathrm{b}}$ & 307 & Otros & 39 & $\mathrm{Mi}^{\mathrm{b}}$ & 617 & Pitágoras/Holder \\
\hline 6 & $\mathrm{Fa}$ & 346 & Pitágoras/Holder & 40 & $\mathrm{Re}_{\mathrm{h}}$ & 596 & Zarlino \\
\hline 7 & Sol & 391 & Pitágoras/Holder & 41 & $\mathrm{Re}^{\mathrm{b}}$ & 548 & Zarlino \\
\hline 8 & $\mathrm{La}^{\mathrm{b}}$ & 409 & Otros & 42 & Do & 529 & Pitágoras/Holder \\
\hline & $\mathrm{Si}^{\mathrm{b}}$ & 458 & Zarlino & 43 & $\mathrm{Si}_{\mathrm{a}}$ & 489 & Pitágoras/Holder \\
\hline 10 & Do & 516 & Otros & 44 & $\mathrm{Si}^{\mathrm{b}}$ & 464 & Pitágoras/Holder \\
\hline & $\operatorname{Re}_{b}$ & 573 & Zarlino & 45 & Sộ & 384 & Pitágoras/Holder \\
\hline & $\mathrm{Mi}^{\mathrm{O}}$ & 610 & Pitágoras/Holder & 46 & $\mathrm{Si}_{\mathrm{C}}^{\mathrm{i}} \mathrm{b}$ & 460 & Zarlino \\
\hline & Do & 505 & Zarlino & 47 & 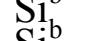 & 229 & Zarlino \\
\hline 1 & 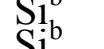 & $\begin{array}{l}457 \\
455\end{array}$ & Pitágoras/Holder & 48 & $\underset{\mathrm{S}}{\mathrm{Si}} \mathrm{i}_{\mathrm{b}}^{\mathrm{b}}$ & $\begin{array}{l}232 \\
230\end{array}$ & Pitágoras/Holder \\
\hline 16 & Do & 513 & Pitágoras/Holder & 50 & $\mathrm{Si}^{\mathrm{b}}$ & 230 & Zarlino \\
\hline & $\mathrm{Re}_{\mathrm{b}}$ & 579 & Pitágoras/Holder & 51 & $\mathrm{Si}^{\mathrm{b}}$ & 230 & Zarlino \\
\hline & $\mathrm{Mi}^{\mathrm{b}}$ & 609 & Holder & 52 & $\mathrm{Mi}^{\mathrm{b}}$ & 310 & Zarlino \\
\hline 19 & Do & 507 & Holder & 53 & Sol & 787 & Otros \\
\hline & $\mathrm{Si}^{\mathrm{i}}$ & 457 & Pitágoras/Holder & 54 & $\mathrm{Fa}$ & 695 & Pitágoras/Holder \\
\hline & $\begin{array}{l}\text { Do } \\
\text { Re }\end{array}$ & $\begin{aligned} 510 \\
573\end{aligned}$ & $\begin{array}{l}\text { Utros } \\
\text { Zarlino }\end{array}$ & $\begin{array}{l}55 \\
56\end{array}$ & $\begin{array}{l}M 1 \\
M i\end{array}$ & $\begin{array}{l}616 \\
621\end{array}$ & $\begin{array}{l}\text { Utros } \\
\text { Zarlino }\end{array}$ \\
\hline & $\mathrm{Mi}^{\mathrm{b}}$ & 587 & Temperado & 57 & $\mathrm{Re}$ & 580 & Otros \\
\hline & $\mathrm{Fa}$ & 702 & Otro & & Do & 509 & Otros \\
\hline & Sol & 784 & Temperado & & $\mathrm{Si}$ & 490 & Otros \\
\hline & $\mathrm{Mi}^{\mathrm{b}}$ & 612 & Otros & 60 & Do & & Pitágoras/Holder \\
\hline & Re & $5 / 5$ & Otros & 61 & S1 & 490 & Otros \\
\hline & Dog & 508 & Pitágoras/Holder & & Do & 513 & Pitágoras/Holder \\
\hline & 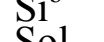 & 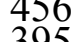 & Zarli & & S1 & 489 & Pitágoras/Holder \\
\hline & Sol & & $\begin{array}{l}\text { Zarlino } \\
\text { Otros }\end{array}$ & & Co & 509 & Otros \\
\hline & & 59 & Otro & 6 & Do & 519 & $\mathrm{Ot}$ \\
\hline & $\mathrm{Mi}^{\mathrm{b}}$ & 61 & & & $\mathrm{Si}^{\mathrm{b}}$ & 459 & Zarlino \\
\hline & Do & 50 & Zarlino & 68 & $\mathrm{La}$ & 440 & Todos \\
\hline
\end{tabular}

\section{Porcentajes de los resultados de la grabación 10-2-2003 Bach si 37}

$\begin{array}{lc}\text { Sistema } & N^{o} \text { de notas } \\ \text { Temperado } & 5 \\ \text { Zarlino } & 22 \\ \text { Pitágoras/Hol. } & 24 \\ \text { Otros } & 23\end{array}$

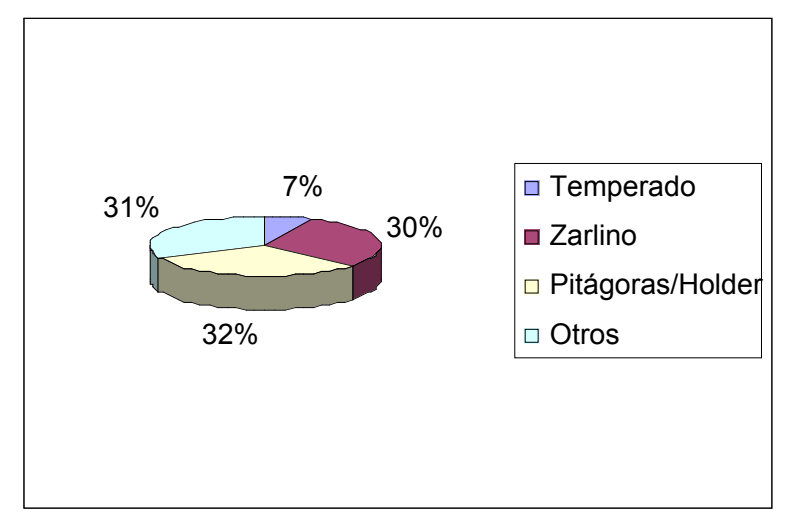


Resultados de la grabación 11-02-2003 do

\begin{tabular}{|c|c|c|c|c|c|c|c|}
\hline $\mathbf{N}^{0}$ & Nota & $\frac{\mathrm{Hz}}{215}$ & Sistema & $\frac{\mathbf{N}^{0}}{25}$ & Nota & $\mathbf{H z}$ & Sistema \\
\hline 1 & $\mathrm{Mi}^{b}$ & 315 & Otros & 35 & $\mathrm{La}_{\mathrm{a}}$ & 410 & Otros \\
\hline 2 & $\mathrm{Fa}$ & 354 & Otros & 36 & Sol & 393 & Otros \\
\hline$\overline{3}$ & Sol & 397 & Zarlino & 37 & $\mathrm{Si}_{\mathrm{b}}^{\mathrm{b}}$ & 461 & Otros \\
\hline 4 & $\mathrm{Si}^{\mathrm{i}} \mathrm{b}$ & 229 & Zarlino & 38 & $\mathrm{Mi}_{\mathrm{b}}^{\mathrm{b}}$ & 624 & Zarlino \\
\hline 5 & $\mathrm{Mi}^{\mathrm{b}}$ & 313 & Pitágoras/Holder & 39 & $\mathrm{Mi}^{\mathrm{b}}$ & 620 & Zarlino \\
\hline 6 & $\mathrm{Fa}$ & 349 & Temperado & 40 & $\mathrm{Re}_{\mathrm{b}}$ & 596 & Zarlino \\
\hline 8 & SOl & $\begin{array}{l}309 \\
409\end{array}$ & $\begin{array}{l}\text { Zarlino } \\
\text { Otros }\end{array}$ & $\begin{array}{l}41 \\
42\end{array}$ & $\begin{array}{l}\mathrm{Re} \\
\mathrm{Do}\end{array}$ & $\begin{array}{l}349 \\
524\end{array}$ & Temperado y Zarlino \\
\hline 9 & $\mathrm{Si}^{\mathrm{b}}$ & 461 & Otros & 43 & $\mathrm{Si}_{\mathrm{b}}$ & 491 & Otros \\
\hline 10 & Do & 523 & Temperado & 44 & $\mathrm{Si}^{\mathrm{b}}$ & 464 & Pitágoras/Holder \\
\hline 11 & $\operatorname{Re}_{\mathrm{b}}$ & 581 & Otros & 45 & Sol & 385 & Pitágoras/Holder \\
\hline 12 & $\mathrm{Mi}^{\mathrm{b}}$ & 618 & Pitág./Holder y Zarlino & 46 & $\mathrm{Si}_{\mathfrak{\alpha}}^{\mathrm{b}}$ & 461 & Otros \\
\hline & Do & 516 & Otros & 47 & $\mathrm{Si}_{\mathrm{a}}^{\mathrm{b}}$ & 231 & Pitágoras/Holder \\
\hline 14 & $\begin{array}{l}S 1 \\
\text { Sib }\end{array}$ & 457 & Pitágoras/Holder & 48 & $\underset{\mathrm{S}}{\mathrm{S}} \stackrel{\mathrm{b}}{\mathrm{b}}$ & 234 & Zarlino \\
\hline 16 & $\begin{array}{l}\text { D1 } \\
\text { Do }\end{array}$ & 524 & $\begin{array}{l}\text { Pitagoras/Holder } \\
\text { Temperado }\end{array}$ & 50 & Si & 232 & Pitágoras/Holder \\
\hline 17 & $\operatorname{Re}_{\mathrm{b}}$ & 581 & Otros & 51 & $\mathrm{Si}^{\mathrm{b}}$ & 230 & Zarlino \\
\hline & $\mathrm{Mi}^{\mathrm{D}}$ & 619 & Pitág./Holder y Zarlino & 52 & $\mathrm{Mi}^{\mathrm{D}}$ & 314 & Pitágoras/Holder \\
\hline 19 & D.p & 519 & Otros & 53 & Sol & 791 & Zarlino \\
\hline & $\mathrm{Si}^{\circ}$ & 461 & Otros & 54 & $\mathrm{Fa}$ & 704 & Pitágoras/Holder \\
\hline & $\begin{array}{l}\text { Do } \\
\text { Re }\end{array}$ & 522 & $\begin{array}{l}\text { Pitagoras/Holder } \\
\text { Tarlino }\end{array}$ & 55 & Mis & 623 & Temperado y Zarlino \\
\hline 2 & $\mathrm{Mi}^{\mathrm{b}}$ & 620 & $\begin{array}{l}\text { Zarluno } \\
\text { Zarlino }\end{array}$ & 57 & $\begin{array}{l}\text { IVII } \\
\mathrm{Re}\end{array}$ & $\begin{array}{l}623 \\
581\end{array}$ & $\begin{array}{l}\text { lemperado y Zarlino } \\
\text { Otros }\end{array}$ \\
\hline & $\mathrm{Fa}$ & 690 & Otros & & Do & 525 & Zarlino \\
\hline & Sol & 790 & Zarlino & 59 & $\mathrm{Si}$ & 492 & Otros \\
\hline & $\mathrm{Mi}^{\circ}$ & 622 & Temperado & 60 & Do & 521 & Pitágoras/Holder \\
\hline & $\mathrm{Re}$ & 581 & Otros & 61 & $\mathrm{Si}$ & 491 & Otros \\
\hline & Dib & 518 & Otros & 62 & Do & 526 & Zarlino \\
\hline & 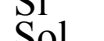 & $\begin{array}{l}460 \\
304\end{array}$ & Zarlino & 63 & S1 & 490 & Otros \\
\hline & $\mathrm{Mi}^{\mathrm{b}}$ & $\begin{array}{l}394 \\
621\end{array}$ & $\begin{array}{l}\text { Utros } \\
\text { Temperado y Zarlino }\end{array}$ & $\begin{array}{l}64 \\
65\end{array}$ & $\mathrm{Si}^{\mathrm{DO}}$ & 325 & $\begin{array}{l}\text { Pitagoras/Holder } \\
\text { Temperado }\end{array}$ \\
\hline & $\mathrm{Re}_{\mathrm{b}}$ & 581 & Otros & 66 & Do & 527 & Pitágoras/Holder \\
\hline & $\mathrm{Mi}^{\mathrm{b}}$ & 620 & Zarlino & 67 & $\mathrm{Si}^{\mathrm{b}}$ & 459 & Zarlino \\
\hline & Do & 518 & Otros & 68 & $\mathrm{La}$ & 442 & Todos \\
\hline
\end{tabular}

Porcentajes de los resultados de la grabación 11-02-2003 do

$\begin{array}{lc}\text { Sistema } & \mathrm{N}^{\mathrm{o}} \text { de notas } \\ \text { Temperado } & 10 \\ \text { Zarlino } & 25 \\ \text { Pitágoras/Hol. } & 17 \\ \text { Otros } & 24\end{array}$

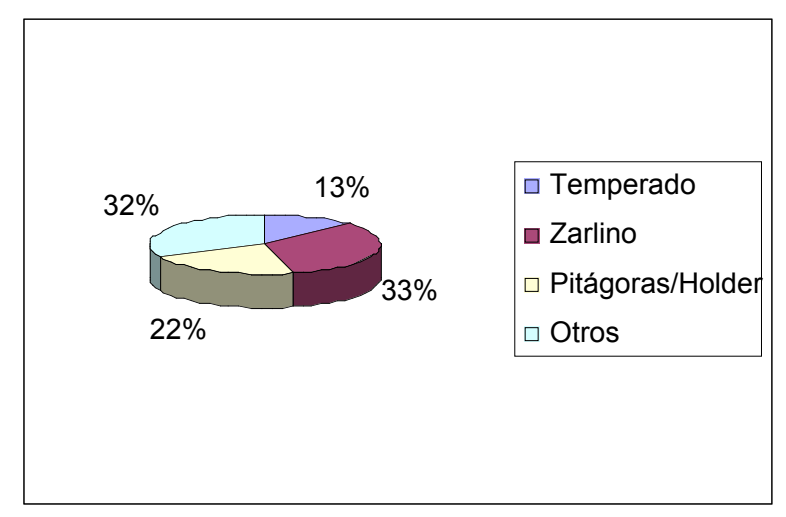




\section{Resultados de la grabación 11-02-2003 si}

\begin{tabular}{|c|c|c|c|c|c|c|c|}
\hline $\mathbf{N}^{0}$ & Nota & $\mathbf{H z}$ & Sistema & $\mathbf{N}^{0}$ & Nota & $\mathbf{H z}$ & Sistema \\
\hline 1 & $\mathrm{Mi}^{\mathrm{b}}$ & 315 & Otros & 35 & La & 410 & Otros \\
\hline 2 & $\mathrm{Fa}$ & 355 & Otros & 36 & Sol & 396 & Pitágoras/Holder y \\
\hline 3 & Sol & 396 & Pitág./Holder Zarlino & 37 & $\mathrm{Si}^{\mathrm{b}}$ & 460 & $\begin{array}{l}\text { Zarlino } \\
\text { Zarlino }\end{array}$ \\
\hline 4 & $\mathrm{Si}^{\mathrm{b}}$ & 230 & Zarlino & 38 & $\mathrm{Mi}_{\mathrm{b}}^{\mathrm{b}}$ & 627 & Pitágoras/Holder \\
\hline 5 & $\mathrm{Mi}^{\mathrm{b}}$ & 313 & Pitágoras/Holder & 39 & $\mathrm{Mi}^{\mathrm{b}}$ & 626 & Pitágoras/Holder \\
\hline 6 & $\mathrm{Fa}$ & 347 & Pitágoras/Holder & 40 & $\mathrm{Re}_{\mathrm{b}}$ & 596 & Zarlino \\
\hline 7 & Sol 1 & 390 & Zarlino & 41 & $\mathrm{Re}^{\mathrm{b}}$ & 557 & Pitágoras/Holder \\
\hline 8 & $\mathrm{La}^{\mathrm{b}}$ & 413 & Zarlino & 42 & Do & 522 & Pitág./Holder Temperado \\
\hline 9 & $\mathrm{Si}^{\mathrm{b}}$ & 461 & Otros & 43 & $\mathrm{Si}_{\mathrm{N}} \mathrm{b}$ & 495 & Pitág./Holder y Zarlino \\
\hline 10 & Do & $\begin{array}{l}523 \\
582\end{array}$ & Temperado & 44 & Sol & $\begin{array}{l}474 \\
388\end{array}$ & $\begin{array}{l}\text { Zarlino } \\
\text { Zarlino }\end{array}$ \\
\hline 12 & $\mathrm{Mi}^{\mathrm{b}}$ & 621 & Temperado y Zarlino & $\begin{array}{l}4 J \\
46\end{array}$ & $\mathrm{Si}^{\mathrm{b}}$ & $\begin{array}{l}300 \\
462\end{array}$ & Otros \\
\hline 13 & Do & 515 & Zarlino & 47 & $\mathrm{Si}^{\mathrm{b}}$ & 229 & Zarlino \\
\hline 14 & $\underset{\mathrm{C}_{i}}{\mathrm{i}} \mathrm{b}$ & 464 & Pitágoras/Holder & 48 & $\mathrm{Si}_{\mathrm{a}}^{\mathrm{b}} \mathrm{b}$ & 236 & Otros \\
\hline 15 & $\mathrm{Si}^{\circ}$ & $\begin{array}{l}457 \\
523\end{array}$ & Pitágoras/Holder & $\begin{array}{l}49 \\
50\end{array}$ & $\begin{array}{l}\mathrm{Si}_{\mathrm{Si}}^{\mathrm{i}} \\
\mathrm{i}_{\mathrm{b}}^{\mathrm{b}}\end{array}$ & $\begin{array}{l}226 \\
232\end{array}$ & $\begin{array}{l}\text { Otros } \\
\text { Pitáogras/Holder }\end{array}$ \\
\hline 17 & $\mathrm{Re}_{\mathrm{H}}$ & 583 & Zarlino & 51 & $\mathrm{Si}^{\mathrm{b}}$ & 233 & $\begin{array}{l}\text { Temperado } \\
\text { Tem }\end{array}$ \\
\hline 18 & $\mathrm{Mi}^{\mathrm{b}}$ & 623 & Temperado y Zarlino & 52 & $\mathrm{Mi}^{\mathrm{b}}$ & 315 & Otros \\
\hline 19 & D.p & 513 & Pitágoras/Holder & 53 & Sol & 794 & Zarlino \\
\hline 20 & & & Temperado y Zarlino & 54 & $\mathrm{Fa}_{\mathrm{b}}$ & 707 & Otros \\
\hline 21 & Do & 515 & Pitágoras/Holder & 55 & $\mathrm{Mi}_{\mathrm{b}}^{\mathrm{b}}$ & 627 & Pitágoras/Holder \\
\hline 22 & $\operatorname{Re}_{b}$ & 581 & Otros & 56 & $\mathrm{Mi}^{\mathrm{b}}$ & 627 & Pitágoras/Holder \\
\hline 24 & $\mathrm{Fa}$ & $\begin{array}{l}020 \\
713\end{array}$ & $\begin{array}{l}\text { Pitágoras/Holder } \\
\text { Pitágoras/Holder }\end{array}$ & 58 & Do & $\begin{array}{l}591 \\
523\end{array}$ & $\begin{array}{l}\text { Uros } \\
\text { Temperado }\end{array}$ \\
\hline & Sol & 795 & Zarlino & 59 & $\mathrm{Si}$ & 494 & Pitág./Holder y Zarlino \\
\hline & $\mathrm{Mi}^{\mathrm{b}}$ & 624 & Zarlino & 60 & Do & 525 & Zarlino \\
\hline & $\mathrm{Re}$ & 584 & Zarlino & 61 & $\mathrm{Si}$ & 495 & Pitág./Holder y Zarlino \\
\hline 28 & $\mathrm{D} g$ & 4 & Otros & & Do & & Pitágoras/Holder \\
\hline & Sol & 461 & Otros & 63 & $\mathrm{Si}$ & 493 & Temperado \\
\hline & & & $\begin{array}{l}\text { Pitag./Holde } \\
\text { Zarlino }\end{array}$ & 64 & Do & 524 & Temperado \\
\hline 31 & $\mathrm{Mi}^{\mathrm{b}}$ & 636 & Temperado y Zarlino & 65 & $\mathrm{Si}$ & 495 & Pitág./Holder y Zarlino \\
\hline 32 & $\operatorname{Re}_{b}$ & 586 & Pitágoras/Holder & 66 & $\mathrm{D} \rho$ & 527 & Zarlino \\
\hline $\begin{array}{l}35 \\
34\end{array}$ & $\begin{array}{l}\text { M1 } \\
\text { Do }\end{array}$ & $\begin{array}{l}624 \\
514\end{array}$ & $\begin{array}{l}\text { Zarlino } \\
\text { Pitágoras/Holder }\end{array}$ & $\begin{array}{l}67 \\
68\end{array}$ & $\begin{array}{l}\mathrm{Si}^{\circ} \\
\mathrm{La}\end{array}$ & $\begin{array}{l}461 \\
443\end{array}$ & $\begin{array}{l}\text { Otros } \\
\text { Todos }\end{array}$ \\
\hline
\end{tabular}

Porcentajes de los resultados de la grabación 11-02-2003 si ${ }^{\mathrm{b}}$

$\begin{array}{lc}\text { Sistema } & \mathrm{N}^{\mathrm{o}} \text { de notas } \\ \text { Temperado } & 12 \\ \text { Zarlino } & 30 \\ \text { Pitágoras/Hol. } & 26 \\ \text { Otros } & 15\end{array}$

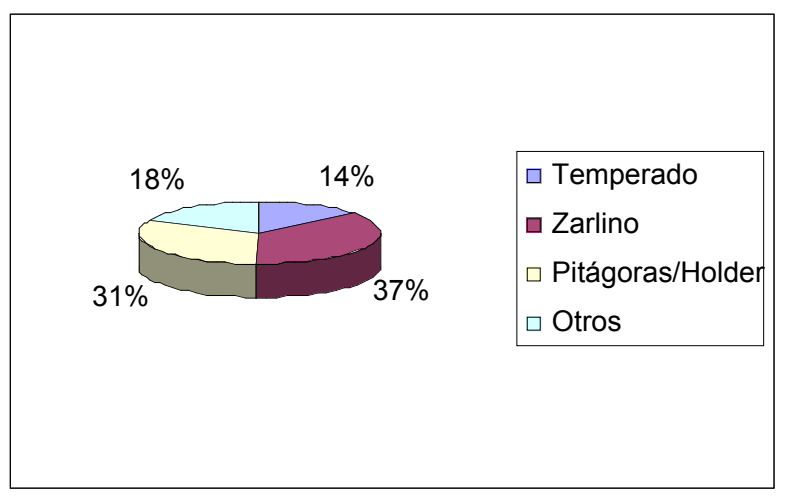


Resultados de la grabación 11-2-2003 Bach si 37

\begin{tabular}{|c|c|c|c|c|c|c|c|}
\hline $\mathbf{N}^{\mathbf{0}}$ & Nota & $\mathbf{H z}$ & Sistema & $\mathbf{N}^{\mathbf{0}}$ & Nota & $\mathbf{H z}$ & Sistema \\
\hline 1 & $\mathrm{Mi}^{\mathrm{b}}$ & 315 & & 35 & $\mathrm{La}$ & 411 & Pitágoras/Holder \\
\hline 2 & $\mathrm{Fa}$ & 353 & Pitágoras/Holder & 36 & Sol & 395 & Zarlino \\
\hline$\overline{3}$ & Sol & 398 & Zarlino & 37 & $\mathrm{Si}^{\mathrm{b}}$ & 463 & Pitágoras/Holder \\
\hline 4 & $\mathrm{Si}^{\mathrm{b}}$ & 232 & Temperado & 38 & $\mathrm{Mi}_{\mathrm{b}}^{\mathrm{b}}$ & 625 & Pitágoras/Holder . \\
\hline 5 & $\mathrm{Mi}^{\mathrm{b}}$ & 312 & Temperado y Zarlino & 39 & $\mathrm{Mi}^{\mathrm{b}}$ & 623 & Temperado y Zarlino \\
\hline 6 & $\mathrm{Fa}$ & 346 & Otros & 40 & $\operatorname{Re}_{b}$ & 590 & Otros \\
\hline 7 & Sol & 392 & Temperado & 41 & $\operatorname{Re}^{\mathrm{b}}$ & 558 & Zarlino \\
\hline & $\mathrm{La}^{\mathrm{b}}$ & 409 & Otros & 42 & Do & 526 & Zarlino \\
\hline 9 & $\mathrm{Si}^{\mathrm{b}}$ & 460 & Zarlino & 43 & $\mathrm{Si}$ & 496 & Zarlino \\
\hline 10 & Do & 518 & Otros & 44 & $\mathrm{Si}^{\mathrm{D}}$ & 477 & Zarlino \\
\hline 11 & $\operatorname{Re}_{h}$ & 581 & Otros & 45 & Sol & 392 & Temperado \\
\hline & $\mathrm{Mi}^{\mathrm{O}}$ & 620 & Zarlino & 46 & $\mathrm{Si}_{\substack{\mathrm{i} \\
\mathrm{b}}}^{\mathrm{b}}$ & 465 & Temperado \\
\hline & Do & 510 & Otros & 47 & S1 ${ }_{C}^{0}$ & 234 & Zarlino \\
\hline 14 & $\mathrm{~S}_{\mathrm{C}} \mathrm{b}_{\mathrm{b}}$ & 464 & Pitágoras/Holder & 48 & $\underset{C}{S} \underset{i}{\mathrm{i}} \mathrm{b}$ & 233 & Temperado \\
\hline 16 & Do & $\begin{array}{l}456 \\
521\end{array}$ & $\begin{array}{l}\text { Zarlino } \\
\text { Pitágoras/Holder }\end{array}$ & $\begin{array}{l}49 \\
50\end{array}$ & $\begin{array}{l}\mathrm{S} 1 \\
\text { Sib } \\
i\end{array}$ & 226 & Pitágoras/Holder \\
\hline 17 & $\mathrm{Re}$ & 58 & 1tros & & & & Pitagoras/Holder \\
\hline 18 & $\mathrm{Mi}^{\mathrm{b}}$ & 62 & Temperado & 52 & $\mathrm{Mi}^{\mathrm{b}}$ & 315 & Otros \\
\hline 19 & Do & 515 & Pitágoras/Holder & 53 & Sol & 794 & Zarlino \\
\hline 20 & $\mathrm{Si}^{\mathrm{b}}$ & 476 & Pitágoras/Holder & 54 & $\mathrm{Fa}$ & 706 & Pitágoras/Holder \\
\hline & Do & 512 & Otros & 55 & $\mathrm{Mi}_{\mathrm{b}}^{\mathrm{D}}$ & 624 & Temperado y Zarlino \\
\hline 22 & $\operatorname{Re}_{\mathrm{b}}$ & 578 & Pitágoras/Holder & 56 & $\mathrm{Mi}^{\mathrm{b}}$ & 624 & Temperado y Zarlino \\
\hline & $\mathrm{Mi}^{\mathrm{i}}$ & 622 & Temperado y Zarlino & 57 & Re & 585 & Zarlino \\
\hline & $\mathrm{Fa}$ & & Otros & & Do & & Pitágoras/Holder \\
\hline 25 & Sol & 790 & Otros & 59 & $\mathrm{Si}$ & 493 & Temperado \\
\hline & $\mathrm{Mi}^{\mathrm{i}}$ & 623 & Temperado y Zarlino & 60 & Do & 518 & Otros \\
\hline & $\mathrm{Re}$ & & Zarlino & 61 & $\mathrm{Si}$ & & Temperado \\
\hline 28 & $\mathrm{D} \rho$ & 516 & Zarlino & 62 & Do & 527 & Zarlino \\
\hline & $\mathrm{Si}^{\mathrm{D}}$ & 463 & Pitágoras/Holder & & & 492 & Temperado \\
\hline 30 & Sol & 395 & Zarlino & 64 & Do & 518 & Otros \\
\hline 31 & $\mathrm{Mi}_{\mathrm{D}}$ & 621 & Temperado & 65 & S1 & 492 & Temperado \\
\hline & $\operatorname{Re}_{b}$ & & Zarlịno & & $\mathrm{D}, \mathrm{g}$ & & Temperado \\
\hline & M1 & 624 & Zarlino & $6 \%$ & $\mathrm{Si}^{\circ}$ & 460 & Zarlino \\
\hline 34 & Do & 512 & Otros & 68 & La & 442 & Todos \\
\hline
\end{tabular}

\section{Porcentajes de los resultados de la grabación 11-2-2003 Bach si 37}

$\begin{array}{lc}\text { Sistema } & \text { No }^{0} \text { de notas } \\ \text { Temperado } & 19 \\ \text { Zarlino } & 27 \\ \text { Pitágoras/Hol. } & 16 \\ \text { Otros } & 16\end{array}$

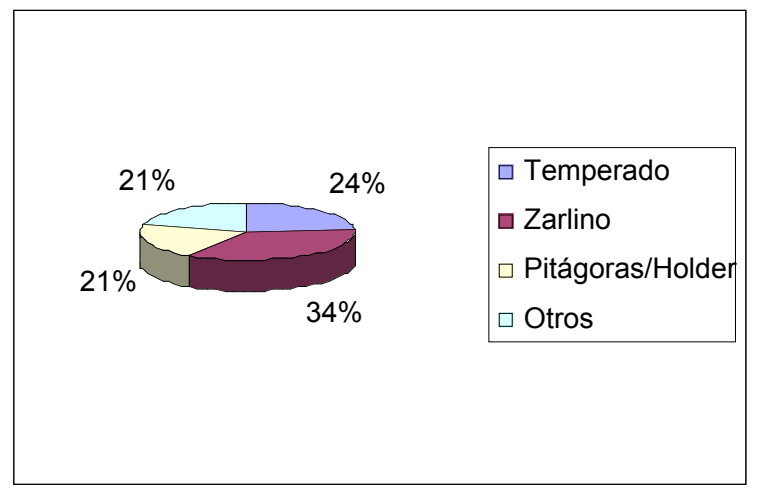


Resultados de la grabación 12-02-2003 do

\begin{tabular}{|c|c|c|c|c|c|c|c|}
\hline $\mathbf{N}^{\mathbf{0}}$ & Nota & $\mathbf{H z}$ & Sistema & $\frac{\mathbf{N}^{0}}{25}$ & Nota & $\mathbf{H z}$ & Sistema \\
\hline & $\mathrm{Mi}^{\mathrm{b}}$ & 314 & Pitágoras/Holder & 35 & $\mathrm{La}_{\mathrm{a}}$ & 410 & Otros \\
\hline 2 & $\mathrm{Fa}$ & 352 & Pitág./Holder y Zarlino & 36 & Sopl & 393 & Temperado \\
\hline & Sol & 396 & Pitág./Holder y Zarlino & 37 & $\mathrm{Si}^{\mathrm{b}}$ & 466 & Temperado \\
\hline & $\mathrm{Si}^{\mathrm{i}} \mathrm{b}$ & 231 & Pitágoras/Holder & 38 & $\mathrm{Mi}_{\mathrm{b}}^{\mathrm{u}}$ & 623 & Temperado y Zarlino \\
\hline & $\mathrm{Mi}^{\mathrm{b}}$ & 311 & Temperado y Zarlino & 39 & $\mathrm{Mi}^{\mathrm{b}}$ & 622 & Temperado y Zarlino \\
\hline & $\mathrm{Fa}$ & 348 & Pitágoras/Holder & 40 & $\mathrm{Re}_{\mathrm{b}}$ & 583 & Zarlino \\
\hline & $\mathrm{La}^{\mathrm{b}}$ & 411 & Pitágoras/Holder & $\begin{array}{l}41 \\
42\end{array}$ & $\begin{array}{l}\text { Re } \\
\text { Do }\end{array}$ & $\begin{array}{l}5 / 0 \\
530\end{array}$ & $\begin{array}{l}\text { Pitag./Holder y Zarino } \\
\text { Pitágoras/Holder }\end{array}$ \\
\hline & $\mathrm{Si}^{\mathrm{b}}$ & 461 & Otros & 43 & $\mathrm{Si}_{\mathrm{b}}$ & 496 & Pitág./Holder y Zarlino \\
\hline & Do & 524 & Temperado & 44 & $\mathrm{Si}^{\mathrm{b}}$ & 468 & Zarlino \\
\hline & $\operatorname{Re}_{\mathrm{h}}$ & 581 & Otros & 45 & Sol & 387 & Pitágoras/Holder \\
\hline & $\mathrm{Mi}^{\mathrm{O}}$ & $\begin{array}{l}620 \\
510\end{array}$ & $\begin{array}{l}\text { Zarlino } \\
\text { Zitónorat }\end{array}$ & 46 & $\mathrm{Si}_{\mathrm{S}}^{\mathrm{u}} \mathrm{b}$ & 462 & Pitágoras/Holder \\
\hline & $\begin{array}{l}\mathrm{DO} \\
\mathrm{Si}\end{array}$ & $\begin{array}{l}519 \\
161\end{array}$ & $\begin{array}{l}\text { Pitagoras/Holder } \\
\text { Otros }\end{array}$ & 48 & Sib & 230 & $\begin{array}{l}\text { Zarlino } \\
\text { Pit́ngorac/Holder }\end{array}$ \\
\hline 1 & $\mathrm{Si}^{\mathrm{b}}$ & 457 & Pitágoras/Holder & $\begin{array}{l}48 \\
49\end{array}$ & Si & 232 & $\begin{array}{l}\text { Pitagoras/Holder } \\
\text { Pitágoras/Holder }\end{array}$ \\
\hline & Do & 522 & Pitágoras/Holder & 50 & $\mathrm{Si}^{\mathrm{b}}$ & 232 & Pitágoras \\
\hline 17 & $\operatorname{Re}_{\mathrm{h}}$ & 577 & Pitágoras/Holder & 51 & $\mathrm{Si}^{\mathrm{b}}$ & 232 & Pitágoras/Holder \\
\hline & $\mathrm{Mi}^{\mathrm{D}}$ & 620 & Zarlin & & $\mathrm{Mi}^{\mathrm{D}}$ & 313 & Pitágoras/Holder \\
\hline 19 & $\mathrm{D}_{0}$ & 517 & Otros & $53+3$ & Sol & 790 & Otr \\
\hline & $\mathrm{Si}^{\mathrm{i}}$ & 464 & Pitágoras/Holder & 54 & $\mathrm{Fa}$ & 700 & Zarlino \\
\hline & $\begin{array}{l}\text { Do } \\
\text { Re }\end{array}$ & $\begin{array}{l}516 \\
572\end{array}$ & Pitágoras/Holder & $56+2>-1$ & $\mathrm{M} \mathrm{I}_{\mathrm{b}}$ & 621 & Zarlino \\
\hline 2 & $\mathrm{Mi}^{\mathrm{b}}$ & 622 & $\begin{array}{l}\text { Zarlino } \\
\text { Tempers }\end{array}$ & 57 & $\begin{array}{l}\mathrm{INI} \\
\mathrm{Re}\end{array}$ & $\begin{array}{l}625 \\
583\end{array}-2 x$ & $\begin{array}{l}\text { emperado y Zarlino } \\
\text { Zarlino }\end{array}$ \\
\hline & $\mathrm{Fa}$ & 698 & Temperado & & Do & 524 & Temperado \\
\hline & Sol & 790 & Otros & 5 & $\mathrm{Si}$ & 492 & Temperado \\
\hline & $\mathrm{Mi}^{\circ}$ & 622 & Temperado y Zarlino & 60 & Do & 526 & Zarlino \\
\hline & $\mathrm{Re}$ & 582 & Otros & 6 & $\mathrm{Si}$ & 492 & Temperado \\
\hline & $\begin{array}{l}\text { Dog } \\
\text { Cib }\end{array}$ & 518 & Otros & & $\mathrm{D}_{\mathrm{C}}^{\mathrm{D}}$ & 526 & Zarlino \\
\hline & $\mathrm{S}_{\mathrm{C}} 1$ & & Otros & & $\mathrm{Si}$ & & \\
\hline & $\begin{array}{l}\text { Sol } \\
\text { Mib }\end{array}$ & 394 & Otros & 64 & $\mathrm{Di}_{\mathrm{S}}^{\mathrm{D}}$ & $\begin{array}{l}526 \\
404\end{array}$ & $\begin{array}{l}\text { Zarlino } \\
\text { Pitáo/Hold }\end{array}$ \\
\hline & $\mathrm{Re}_{1}$ & 582 & Zarlino & 6 & Do & 527 & $\begin{array}{l}\text { Pitag./Hold } \\
\text { Zarlino }\end{array}$ \\
\hline & $\mathrm{Mi}^{\mathrm{b}}$ & 620 & Zarlino & & $\mathrm{Si}^{\mathrm{b}}$ & 463 & Pitágoras/Holder \\
\hline & Do & 520 & Pitágoras/Holder & & $\mathrm{La}$ & 443 & Todos \\
\hline
\end{tabular}

Porcentajes de los resultados de la grabación 12-02-2003 do

$\begin{array}{lc}\text { Sistema } & N^{0} \text { de notas } \\ \text { Temperado } & 15 \\ \text { Zarlino } & 29 \\ \text { Pitágoras/Hol. } & 26 \\ \text { Otros } & 13\end{array}$

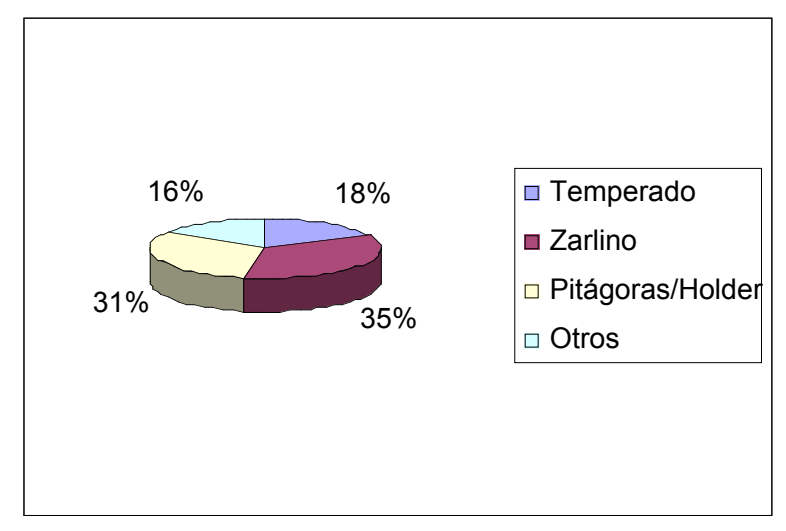




\section{A.2.2 Porcentajes totales concierto de Haydn}

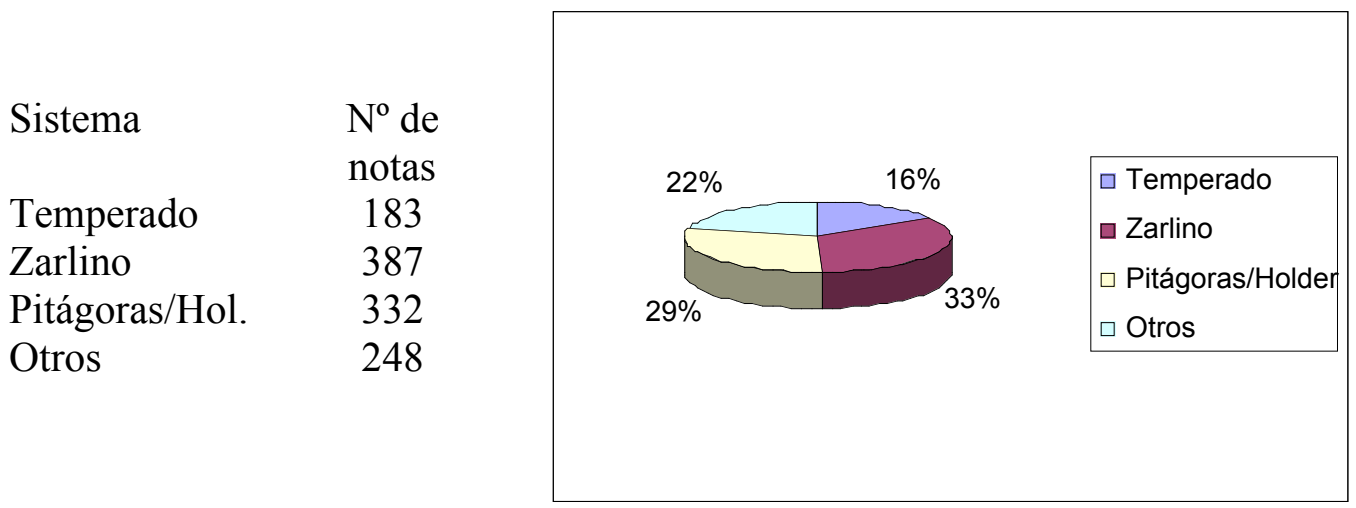

b) Porcentajes según la trompeta utilizada

Se han utilizado cuatro trompetas: Yamaha $\mathrm{si}^{\mathrm{b}}$, $\mathrm{Bach} \mathrm{si}^{\mathrm{b}}$, Bach do y Schilke mi ${ }^{\mathrm{b}}$.

a) Utilizando la trompeta Yamaha $\mathrm{si}^{\mathrm{b}}$ :

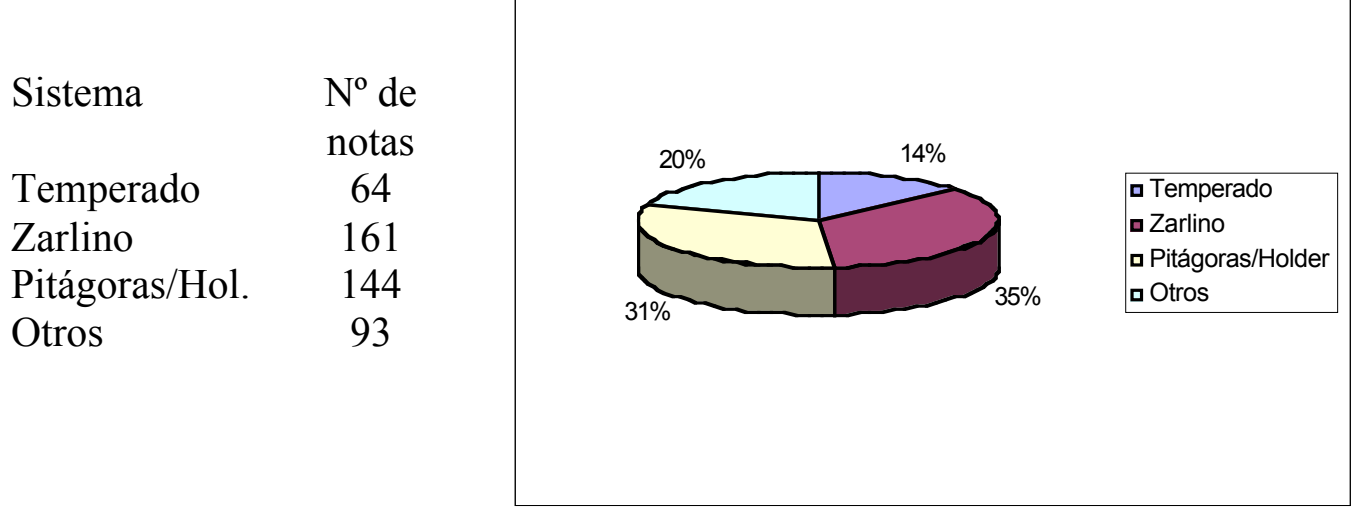




\section{A. 3. Resultados del test de psicoacústica}

A continuación recogemos los resultados de las fichas del test de psicoacústica descrito en el capítulo 5.

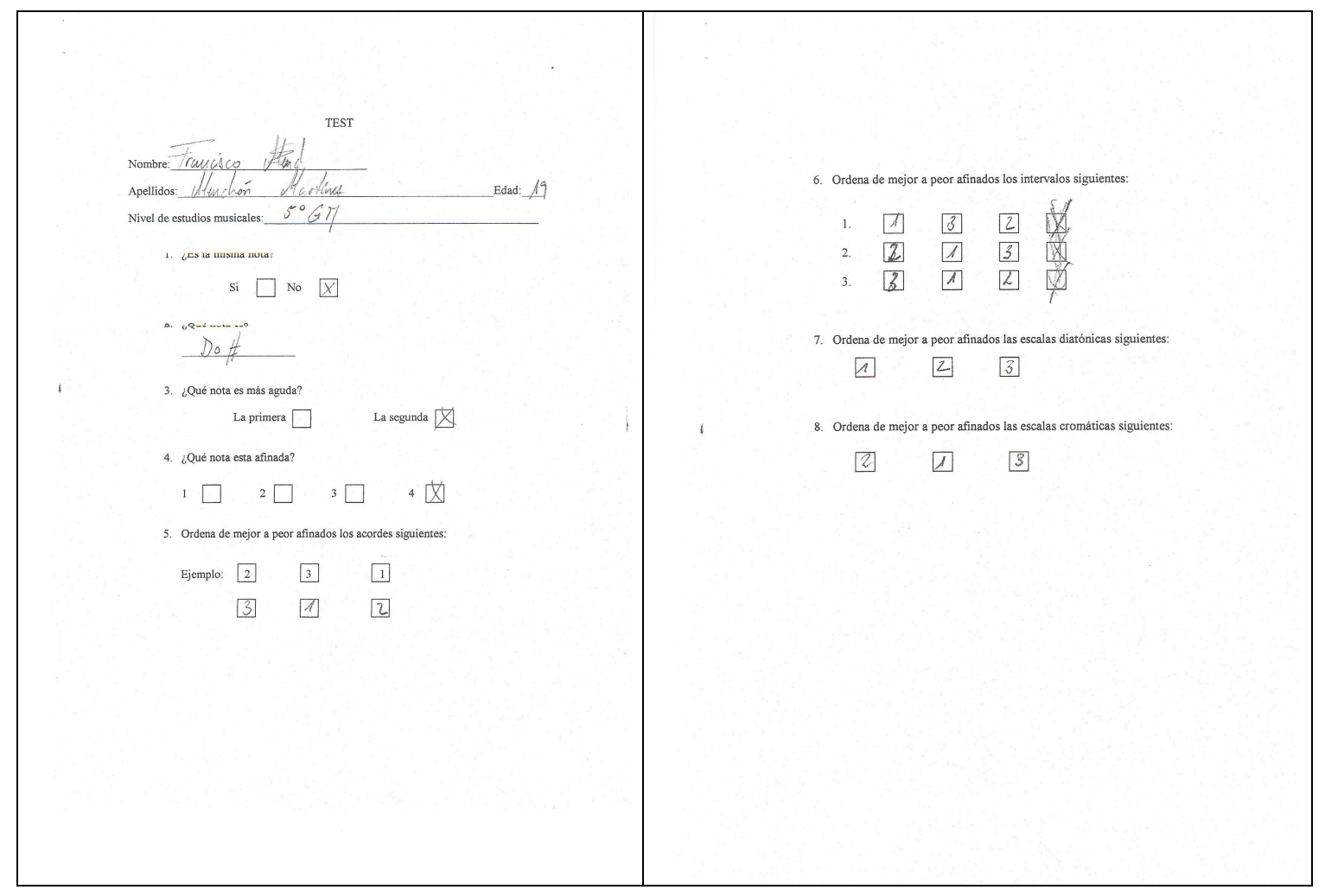

NOTA: Los encuestados, conocían la finalidad del test realizado y dieron su consentimiento a que apareciese una copia de su ficha en la presente tesis doctoral. 

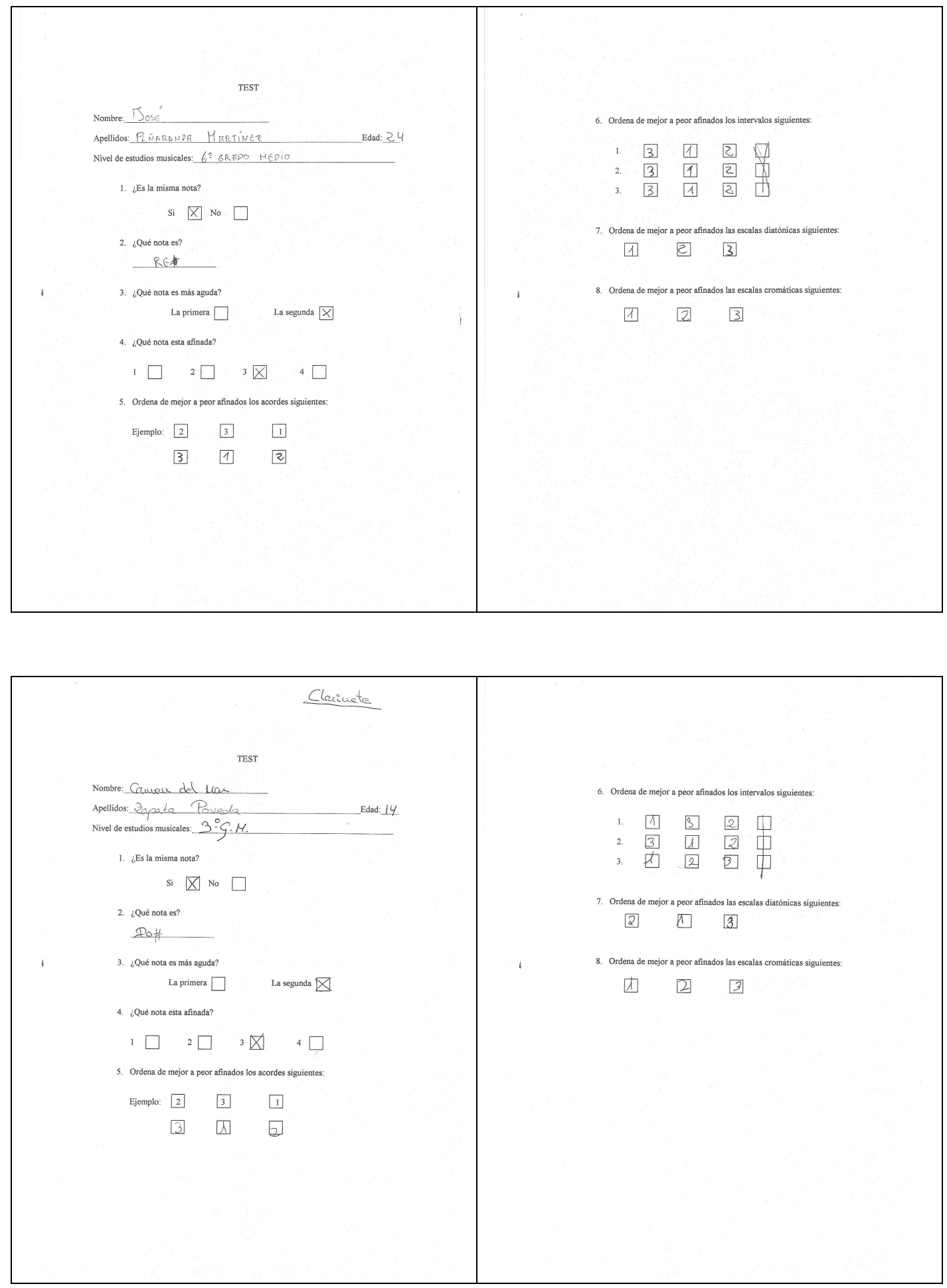

José Ibáñez Barrachina

Universitat Politécnica de València 

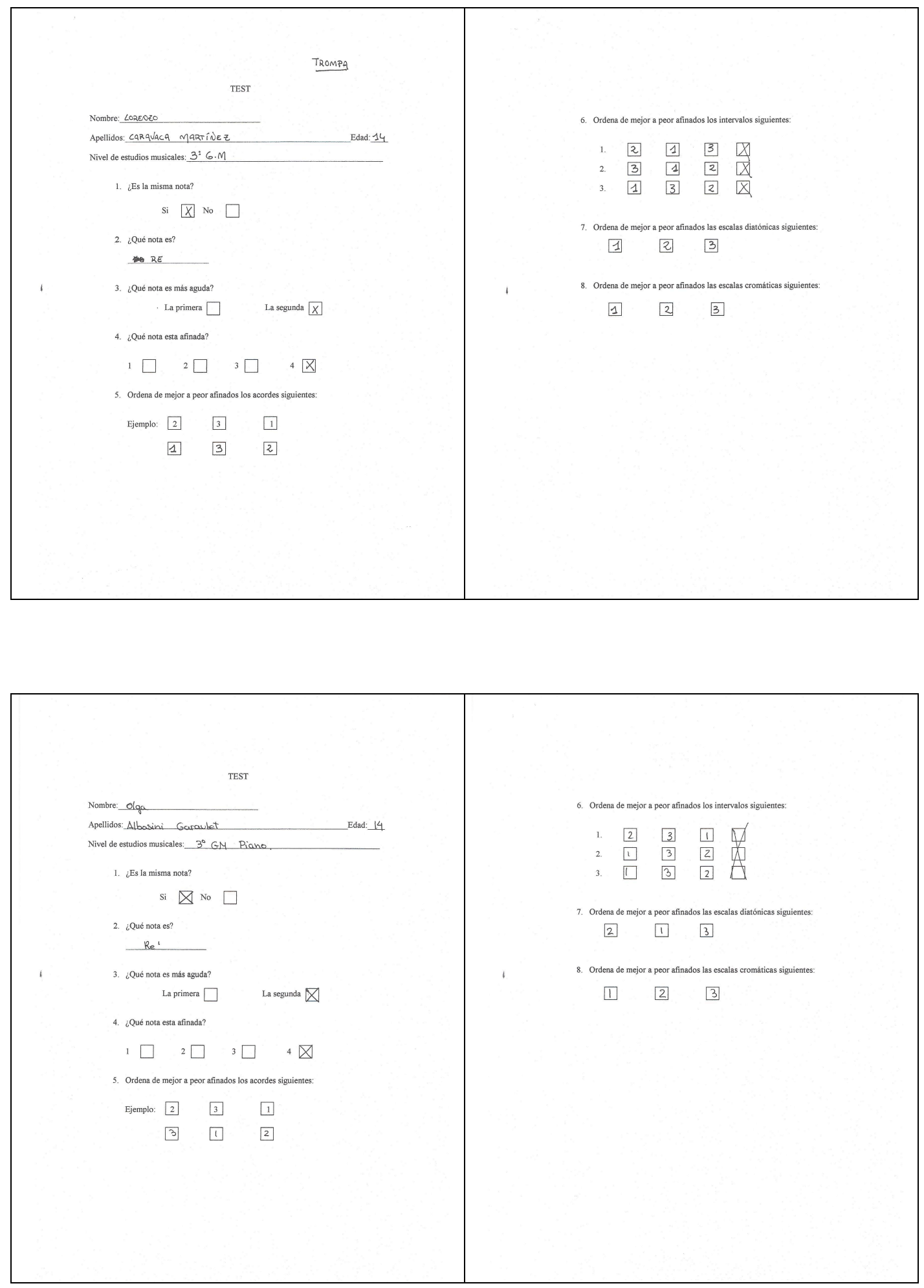

José Ibáñez Barrachina

Universitat Politécnica de València 

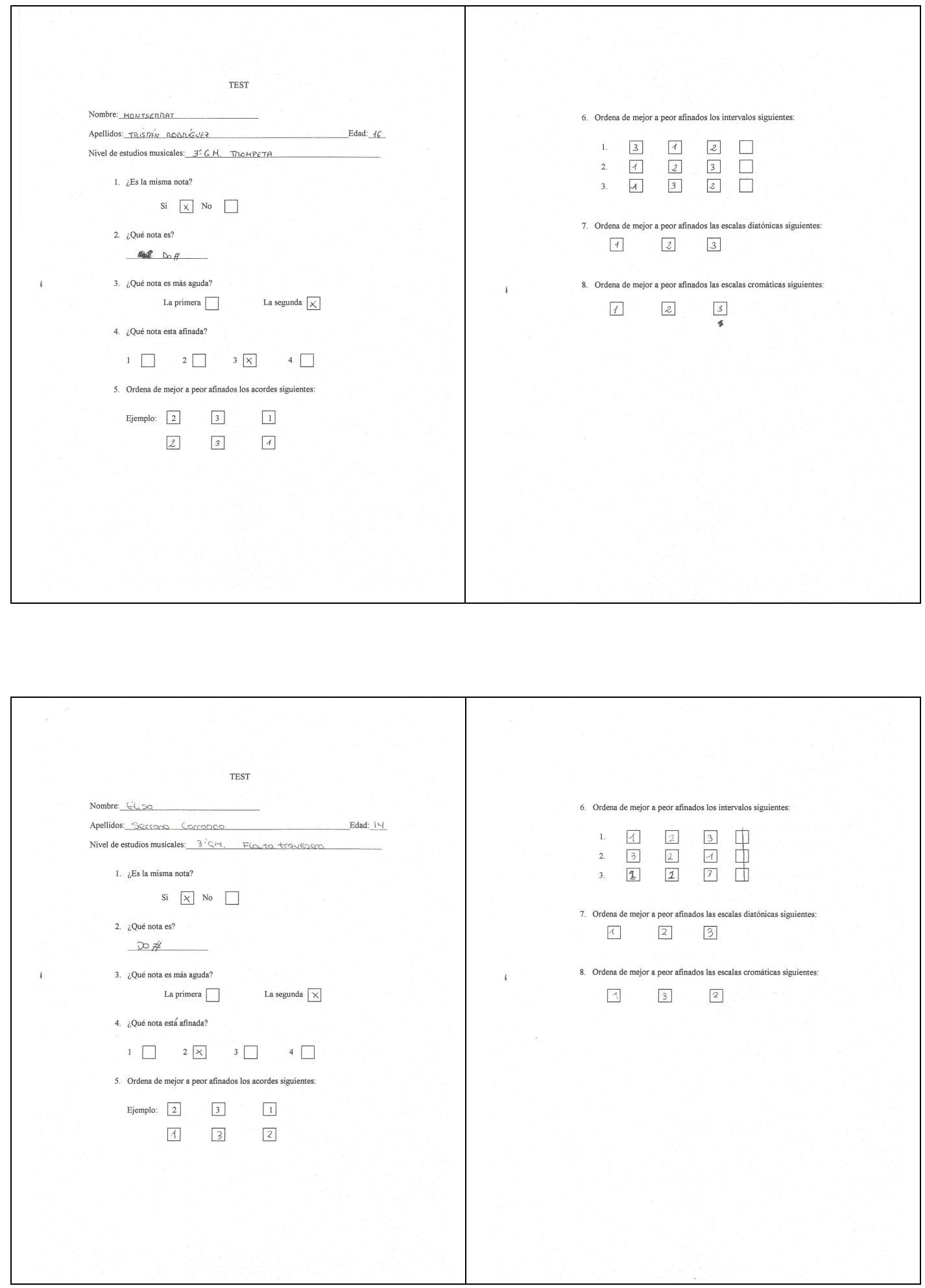

José Ibáñez Barrachina

Universitat Politécnica de València 

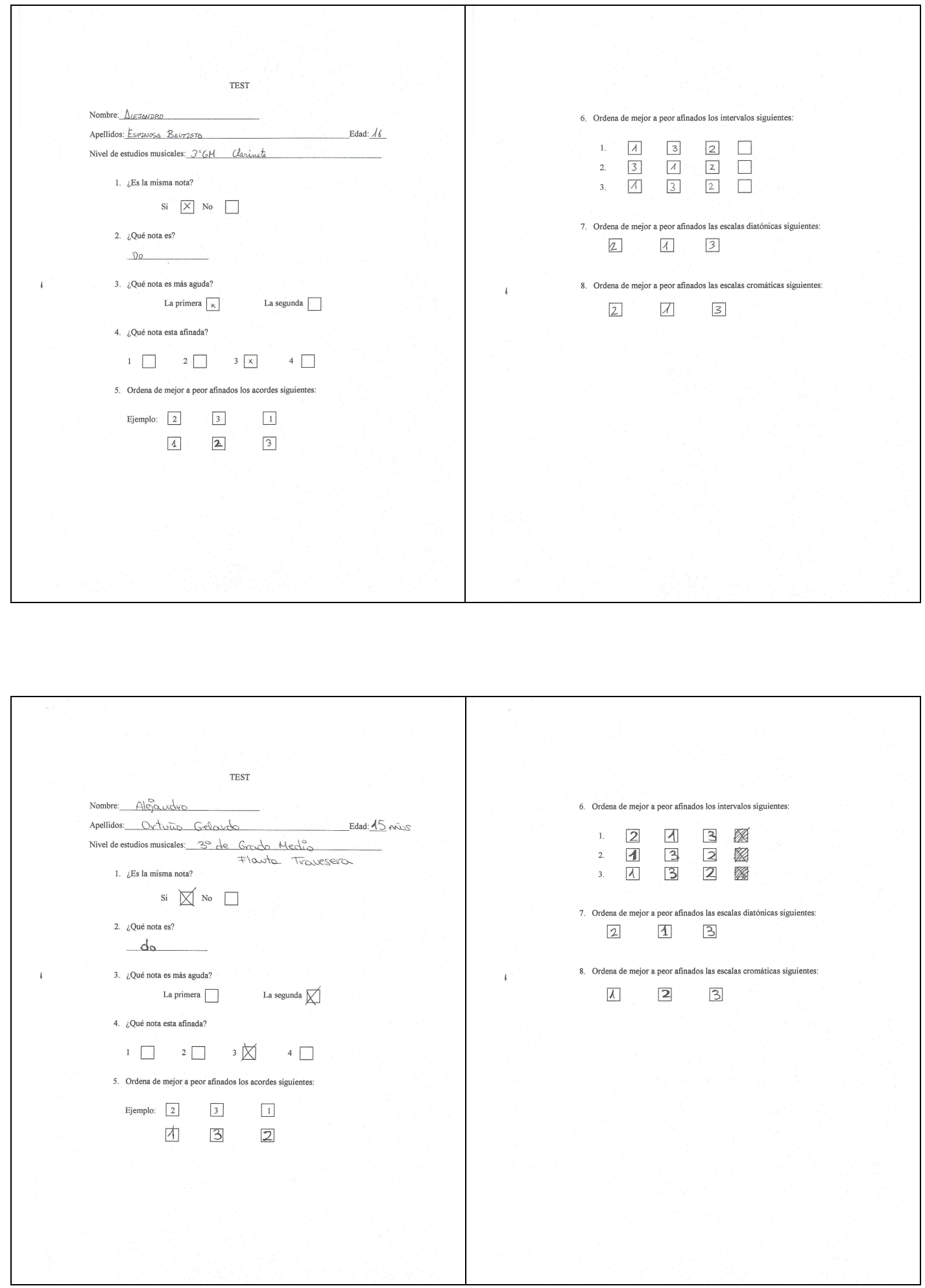

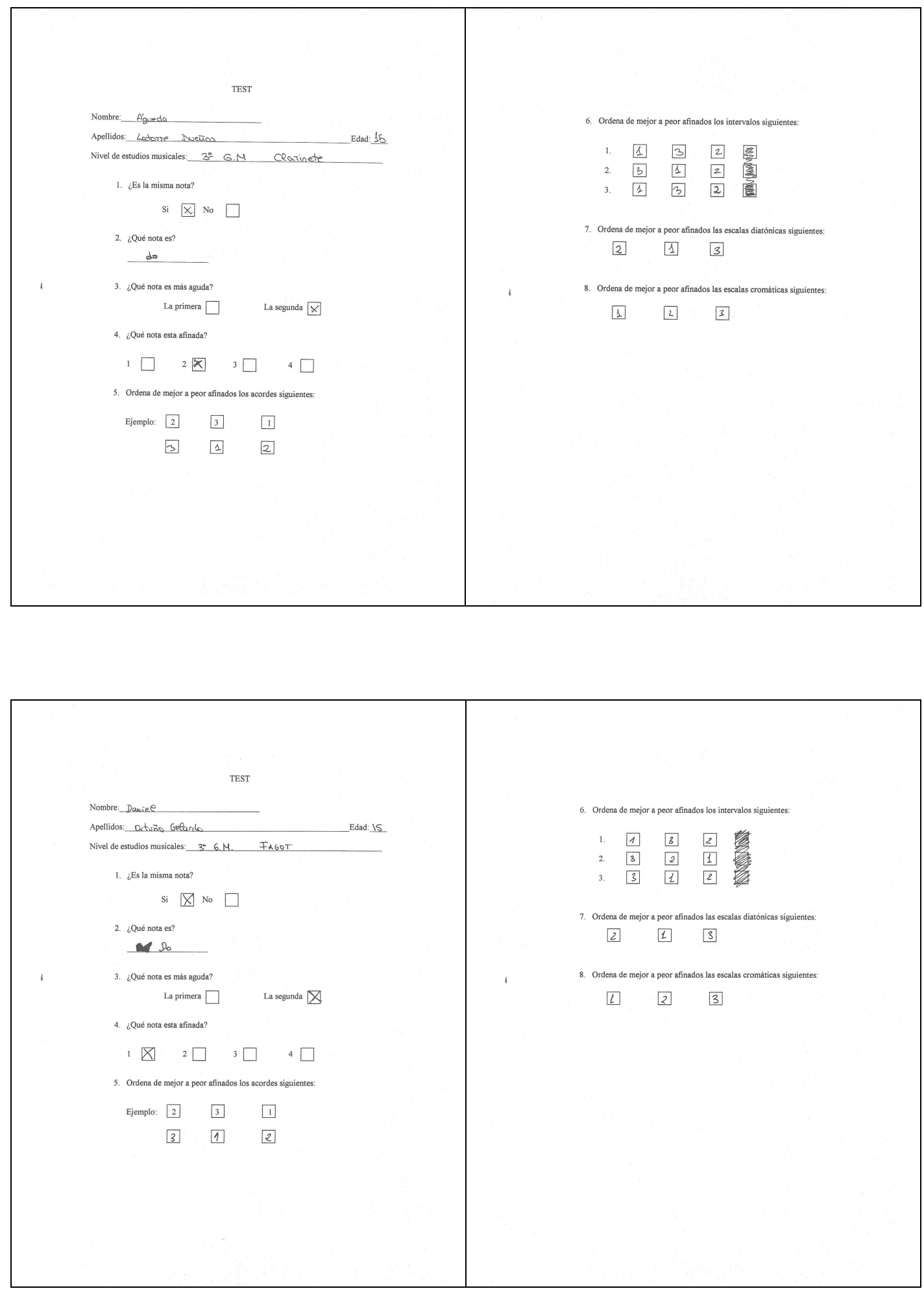

José Ibáñez Barrachina

Universitat Politécnica de València 

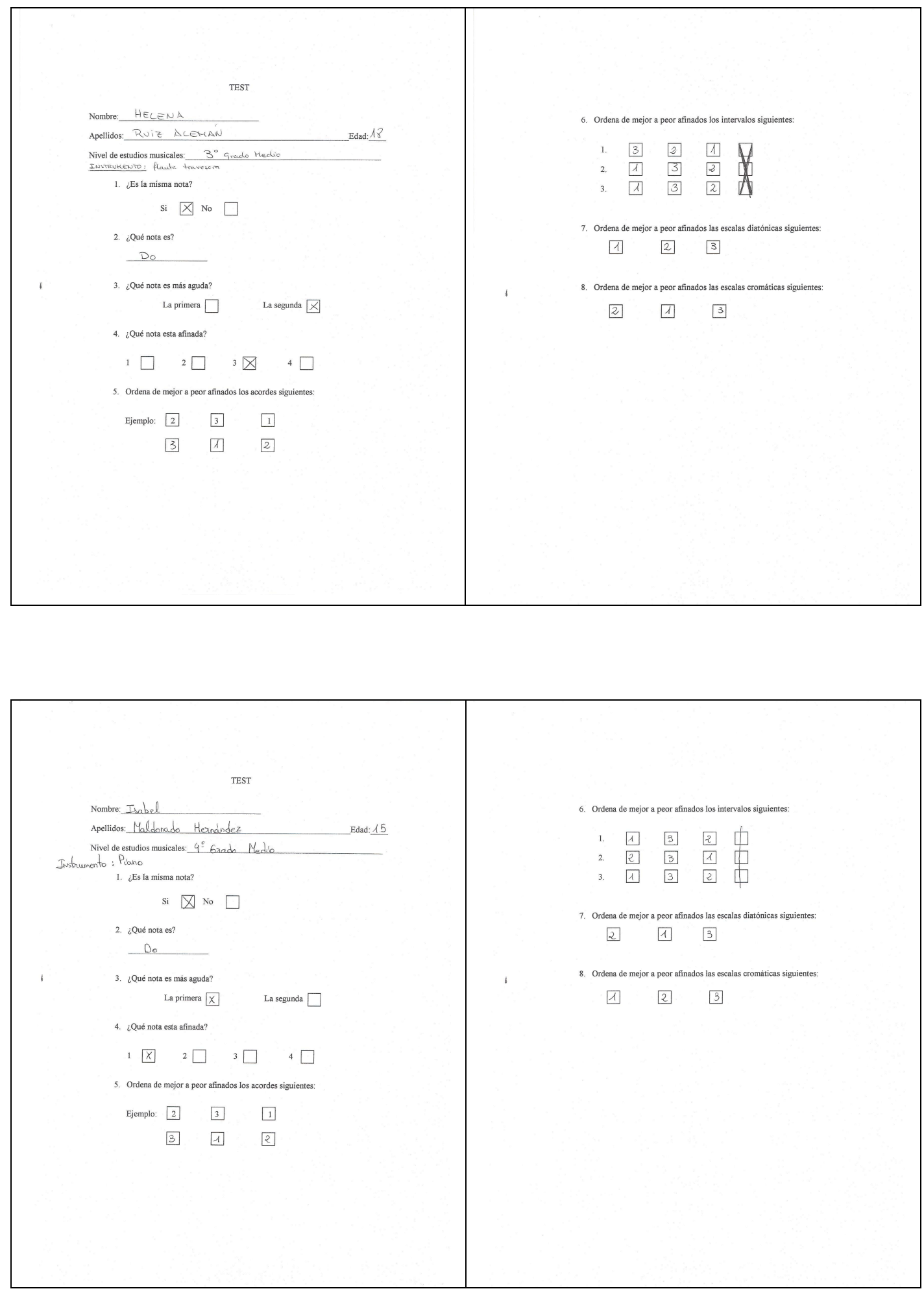

José Ibáñez Barrachina

Universitat Politécnica de València 

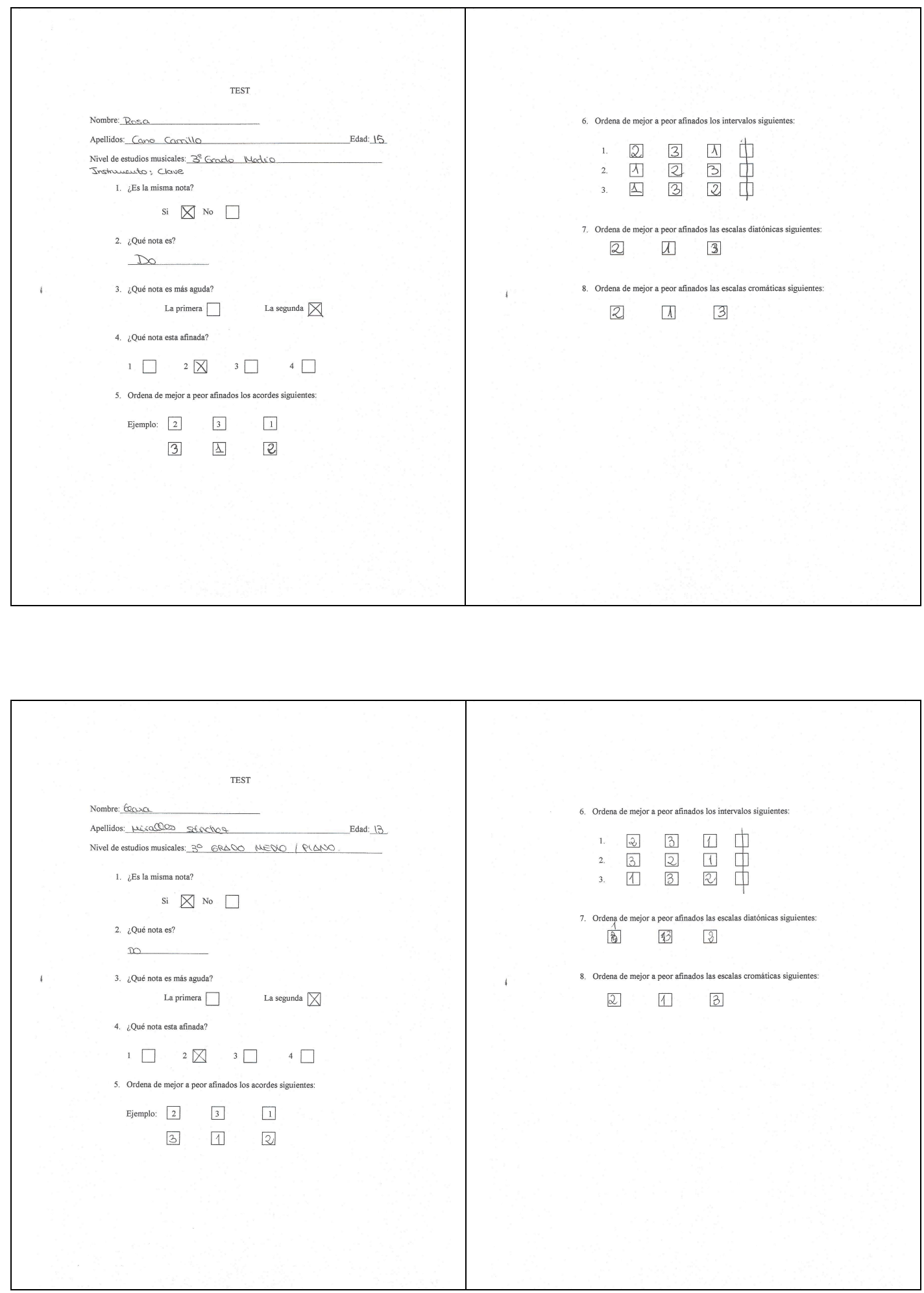

José Ibáñez Barrachina

Universitat Politécnica de València 

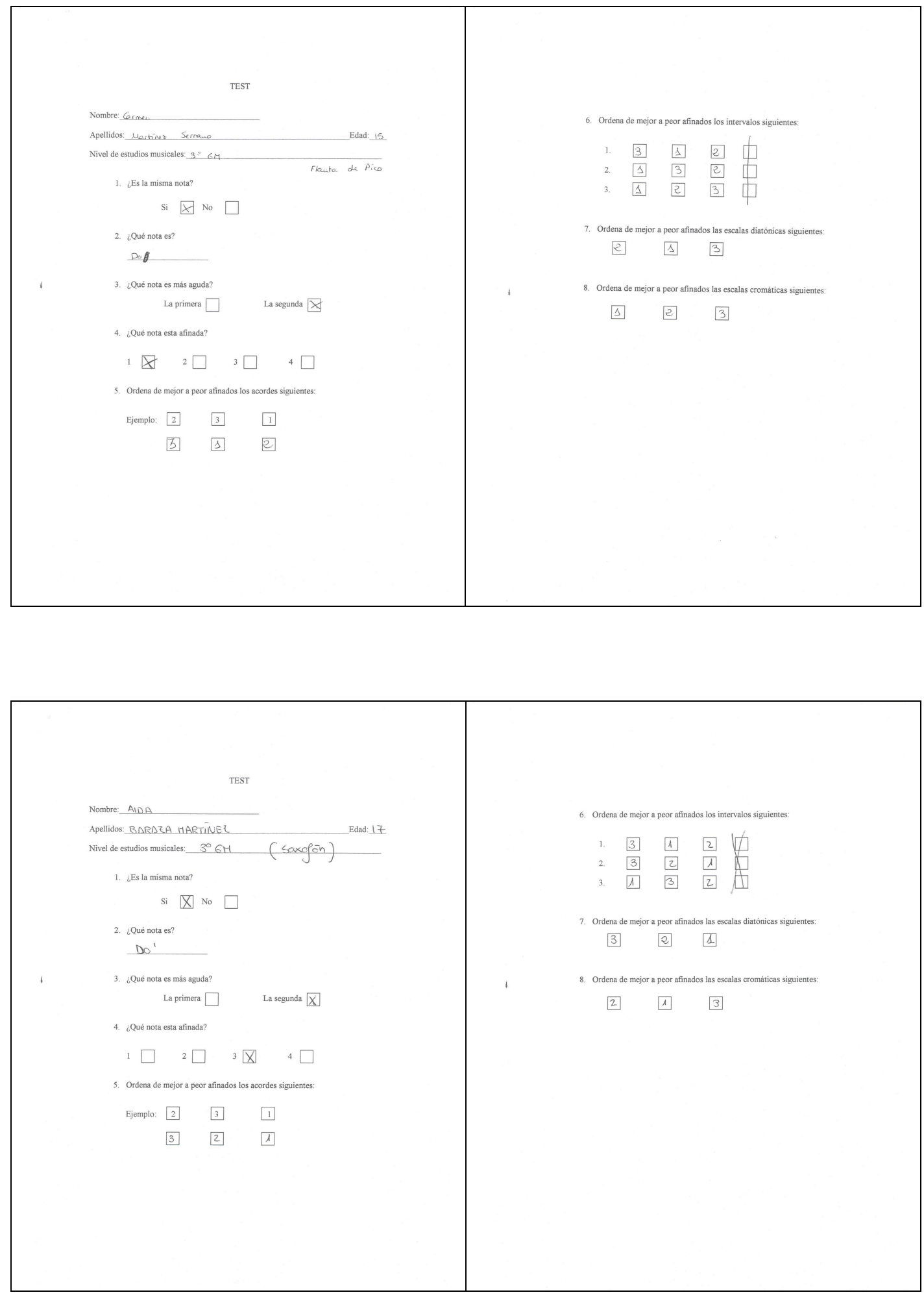

José Ibáñez Barrachina

Universitat Politécnica de València 

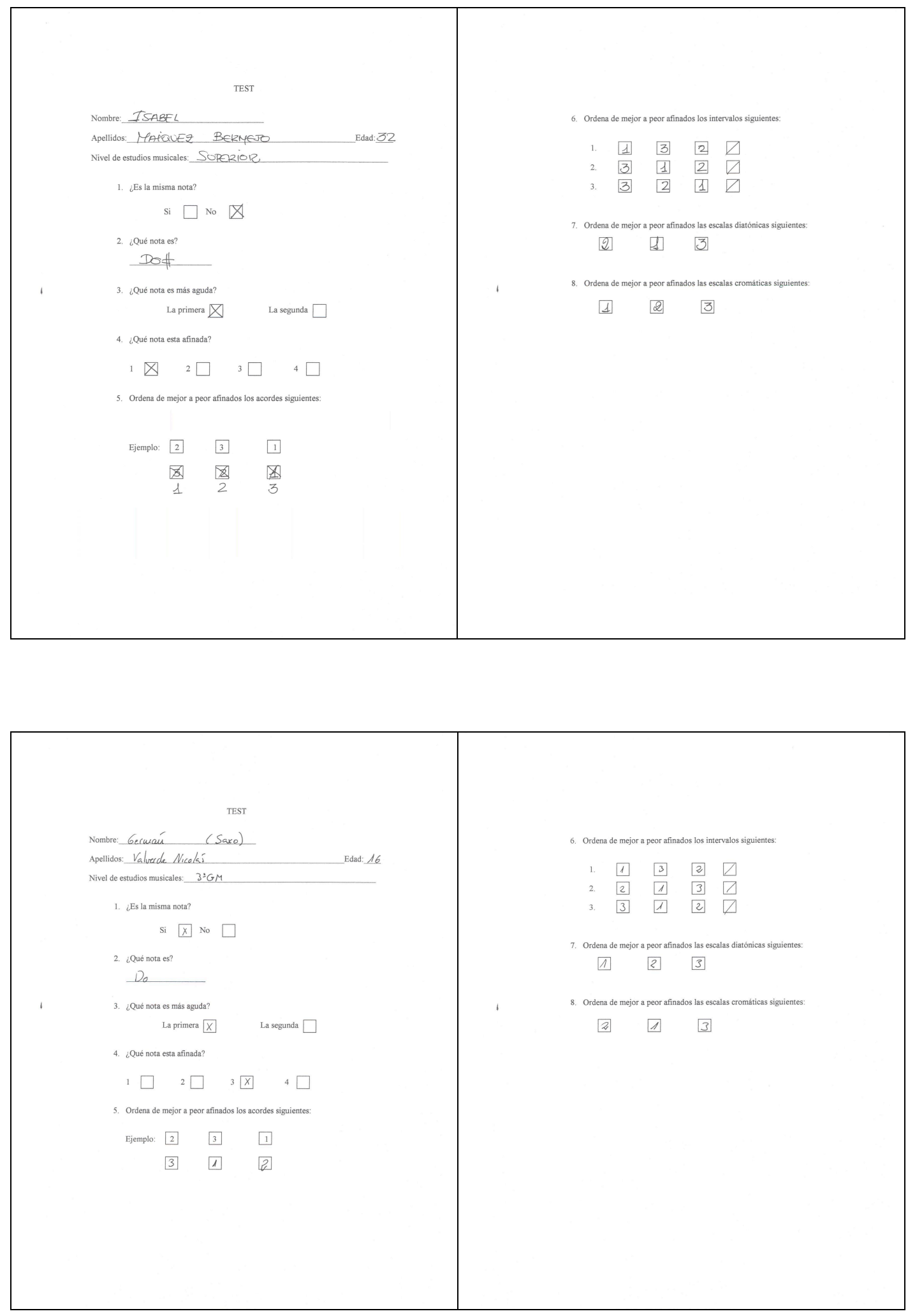

José Ibáñez Barrachina

Universitat Politécnica de València 

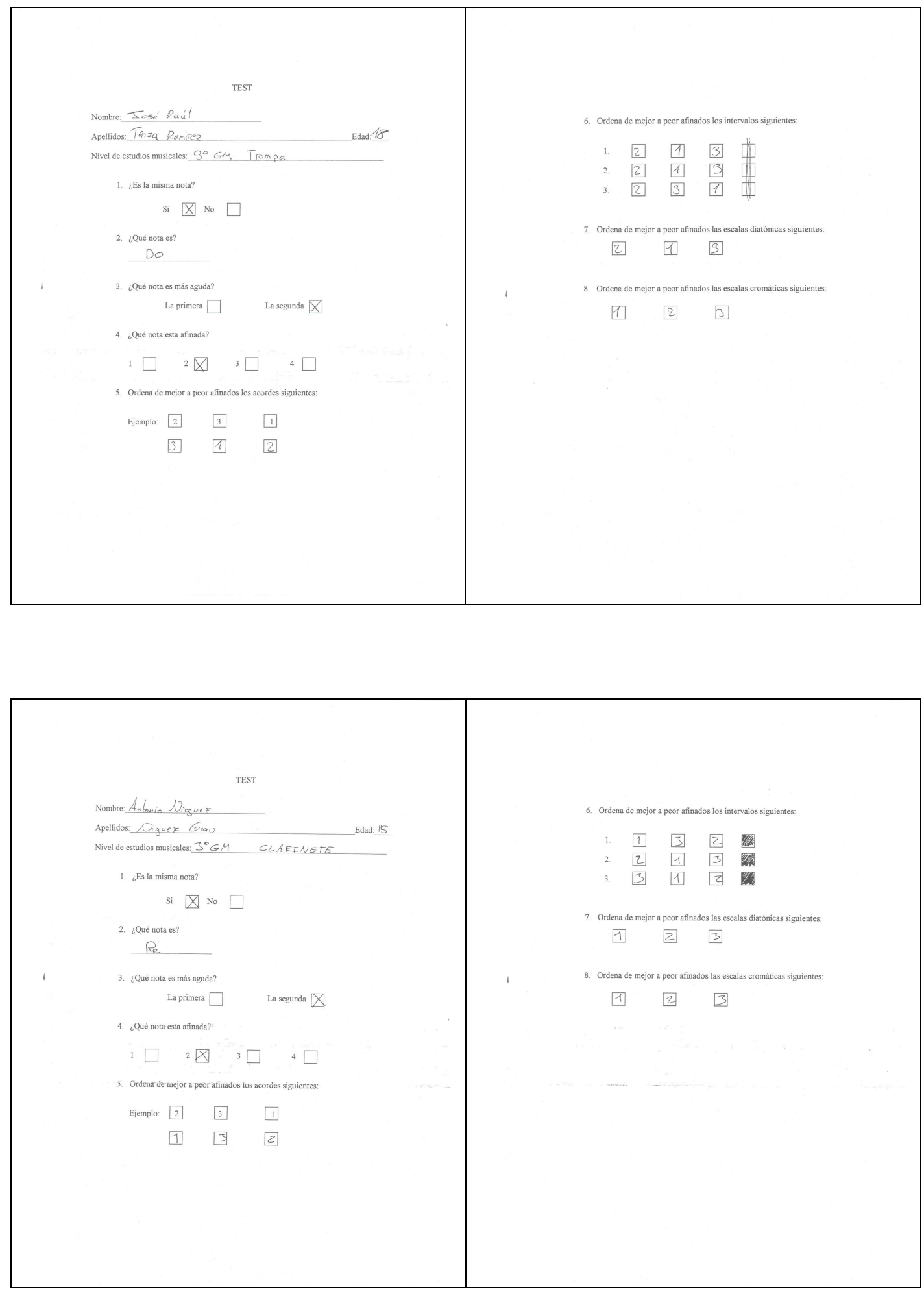

José Ibáñez Barrachina

Universitat Politécnica de València 

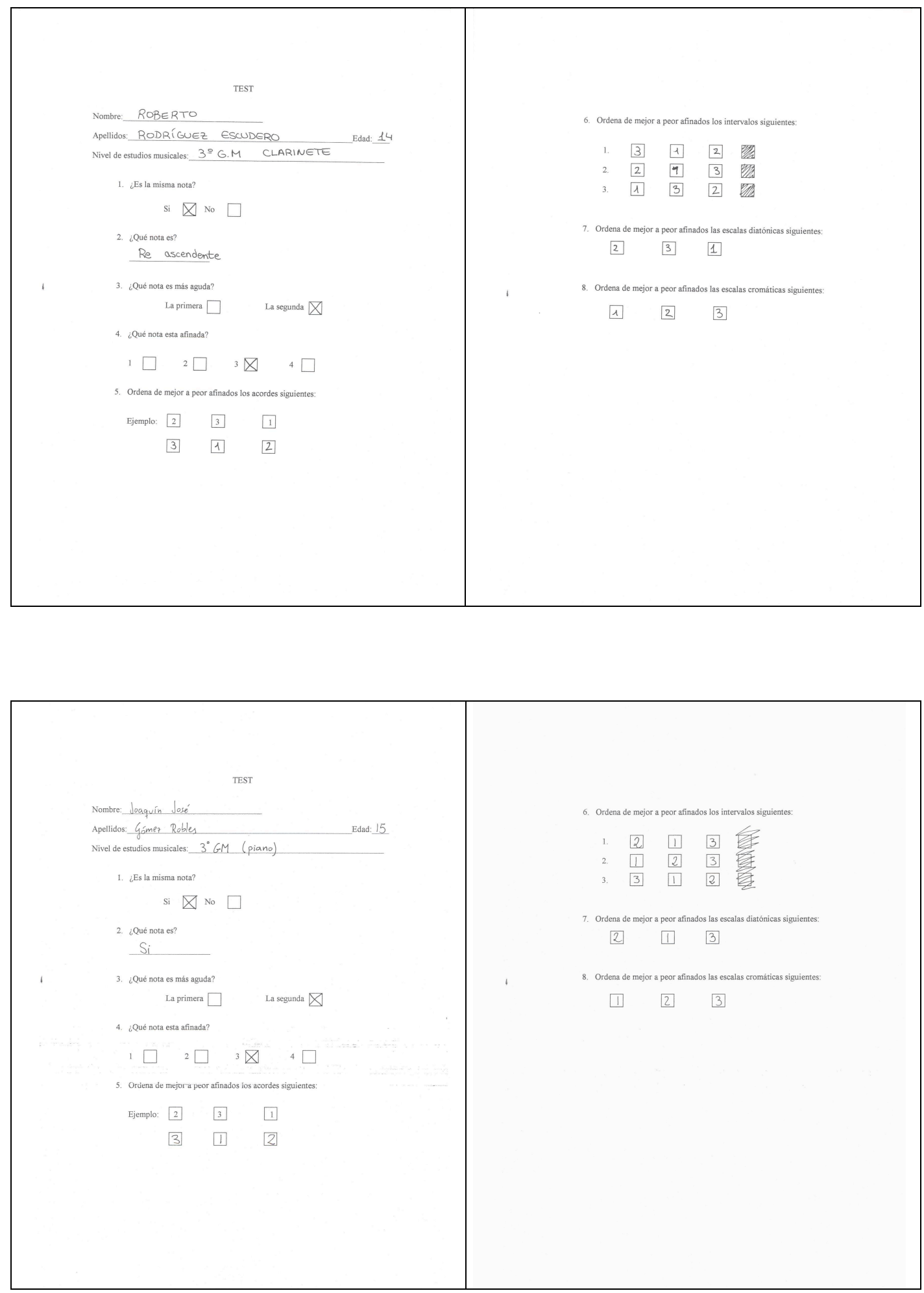

José Ibáñez Barrachina

Universitat Politécnica de València 

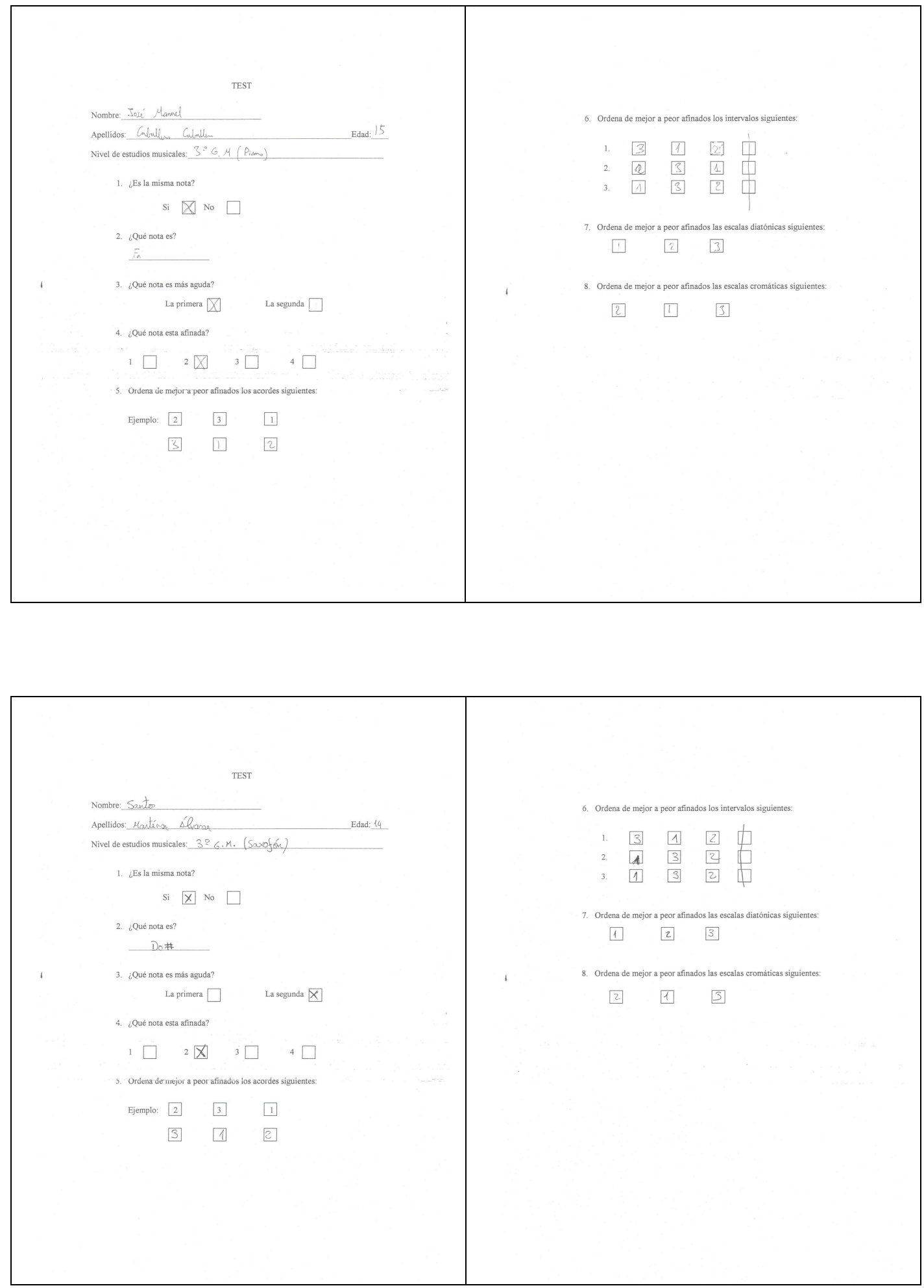

José Ibáñez Barrachina

Universitat Politécnica de València 

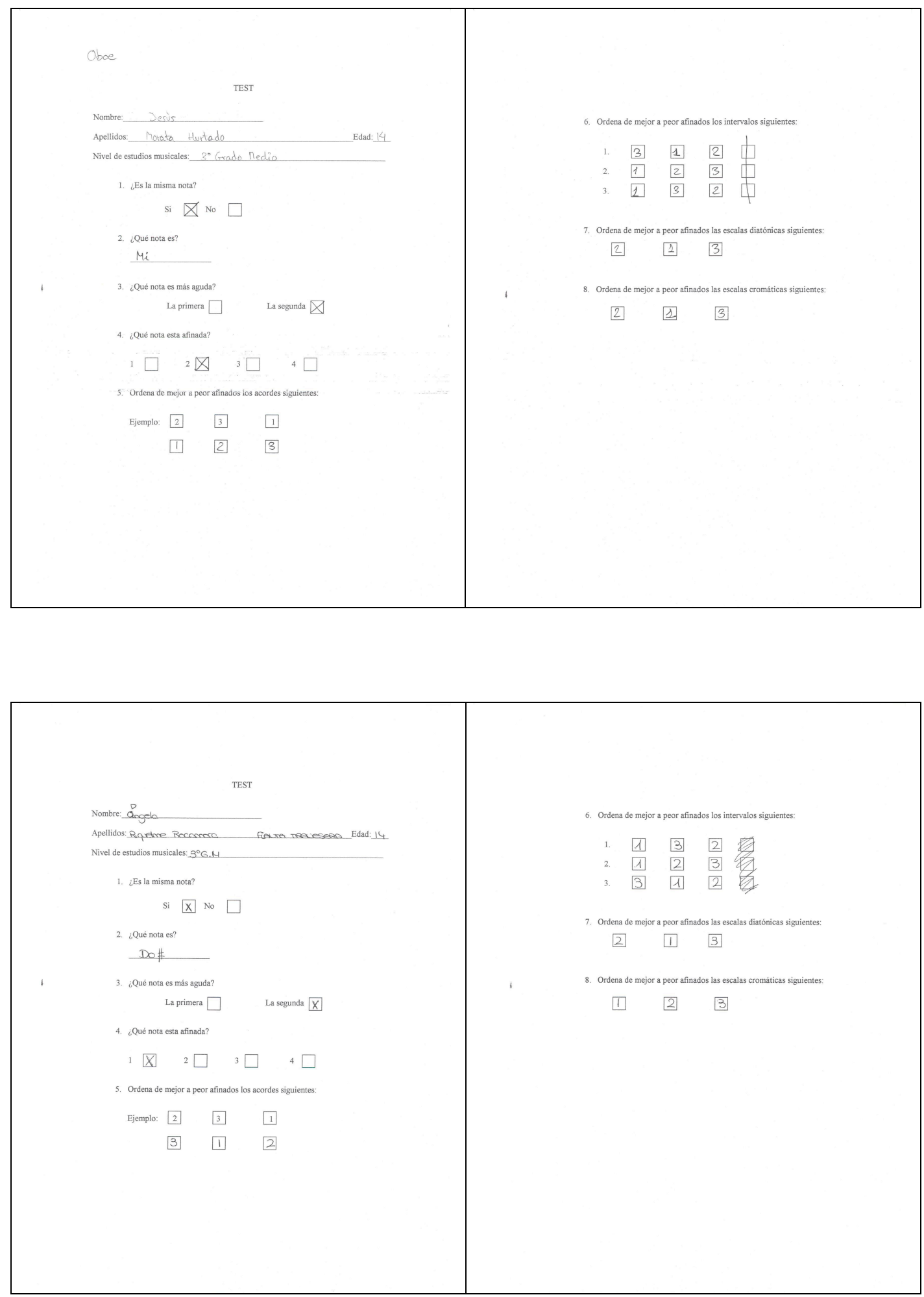

José Ibáñez Barrachina

Universitat Politécnica de València 

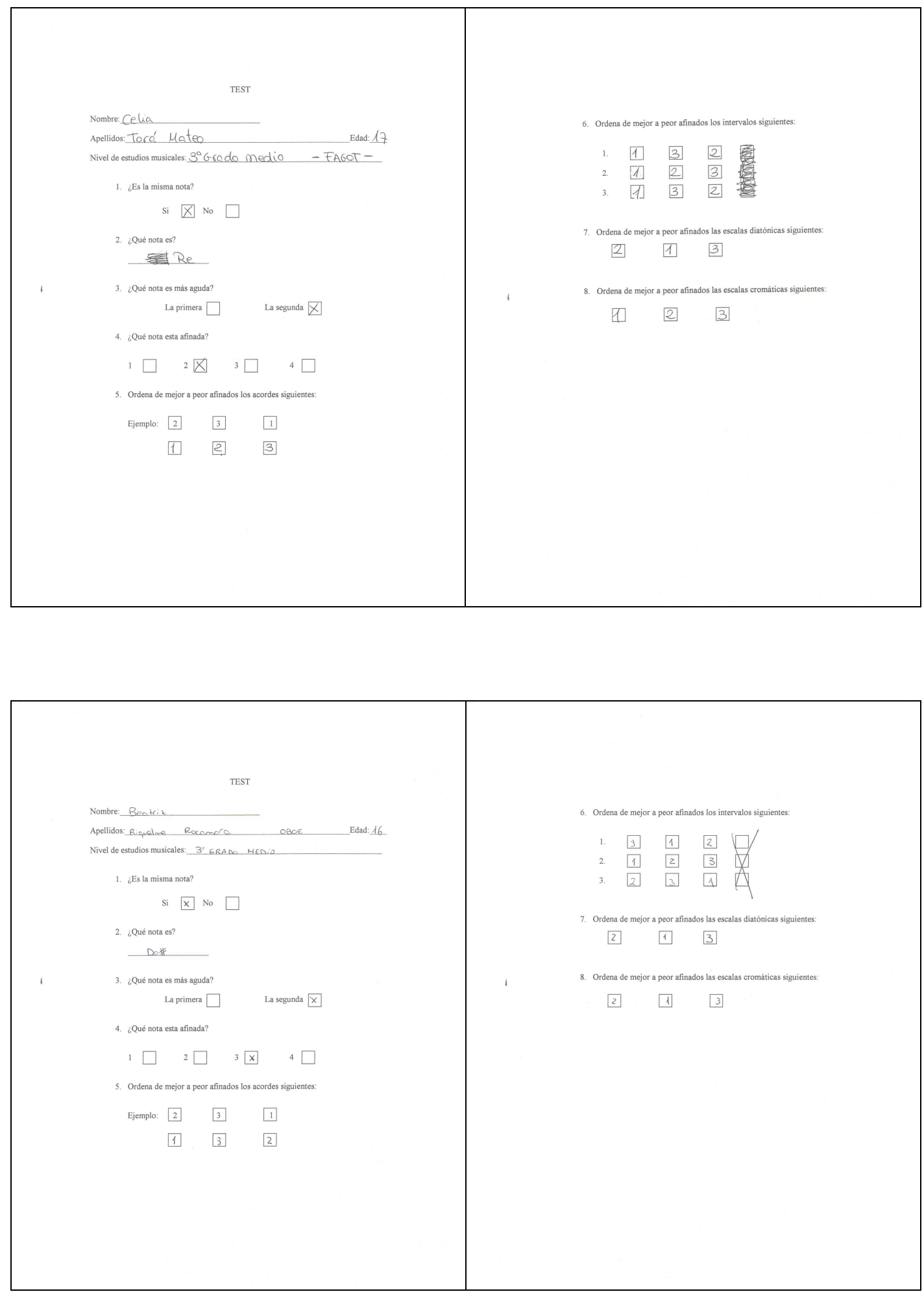

José Ibáñez Barrachina

Universitat Politécnica de València 

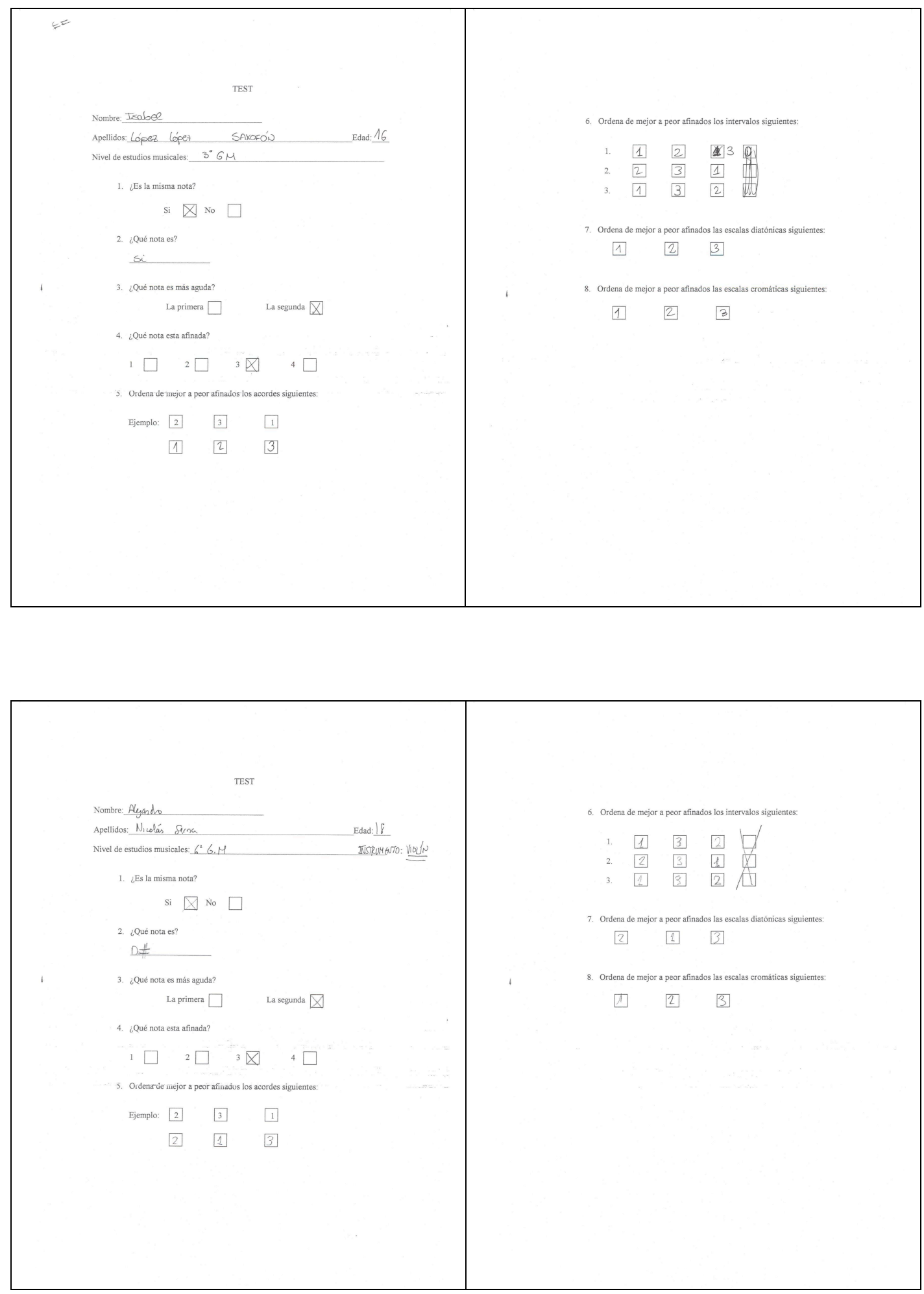

José Ibáñez Barrachina

Universitat Politécnica de València 

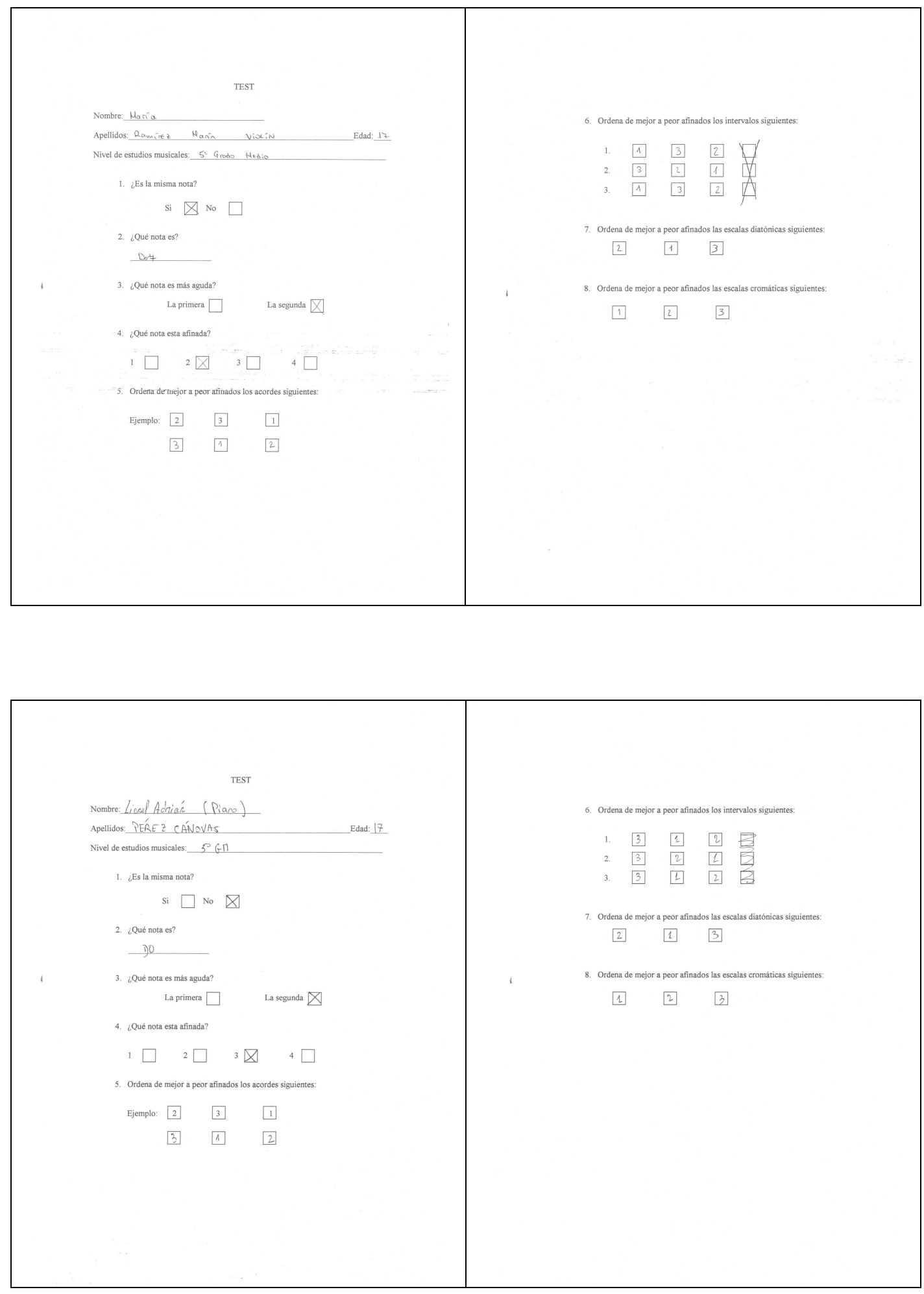

José Ibáñez Barrachina

Universitat Politécnica de València 

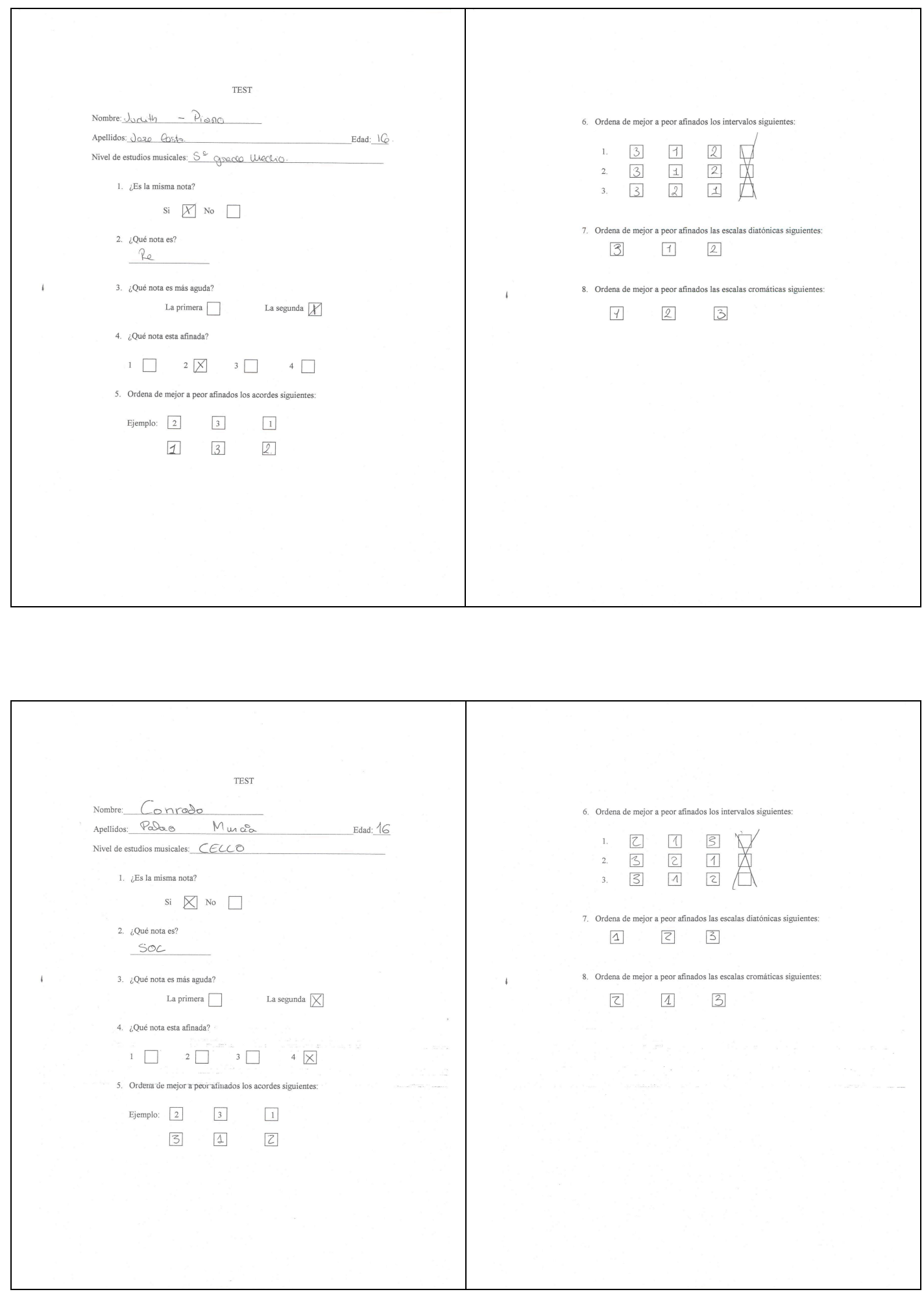

José Ibáñez Barrachina

Universitat Politécnica de València 

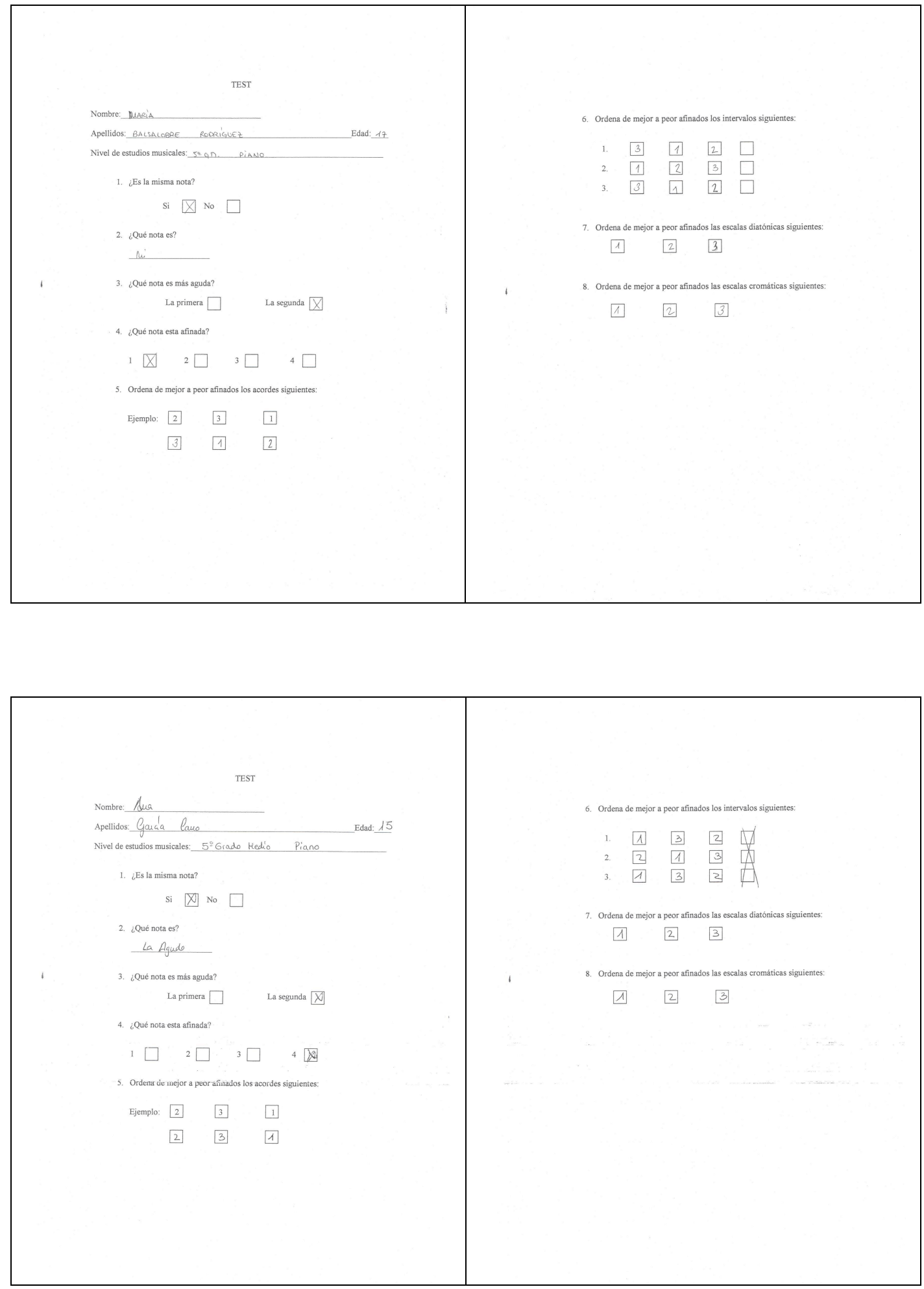

José Ibáñez Barrachina

Universitat Politécnica de València 

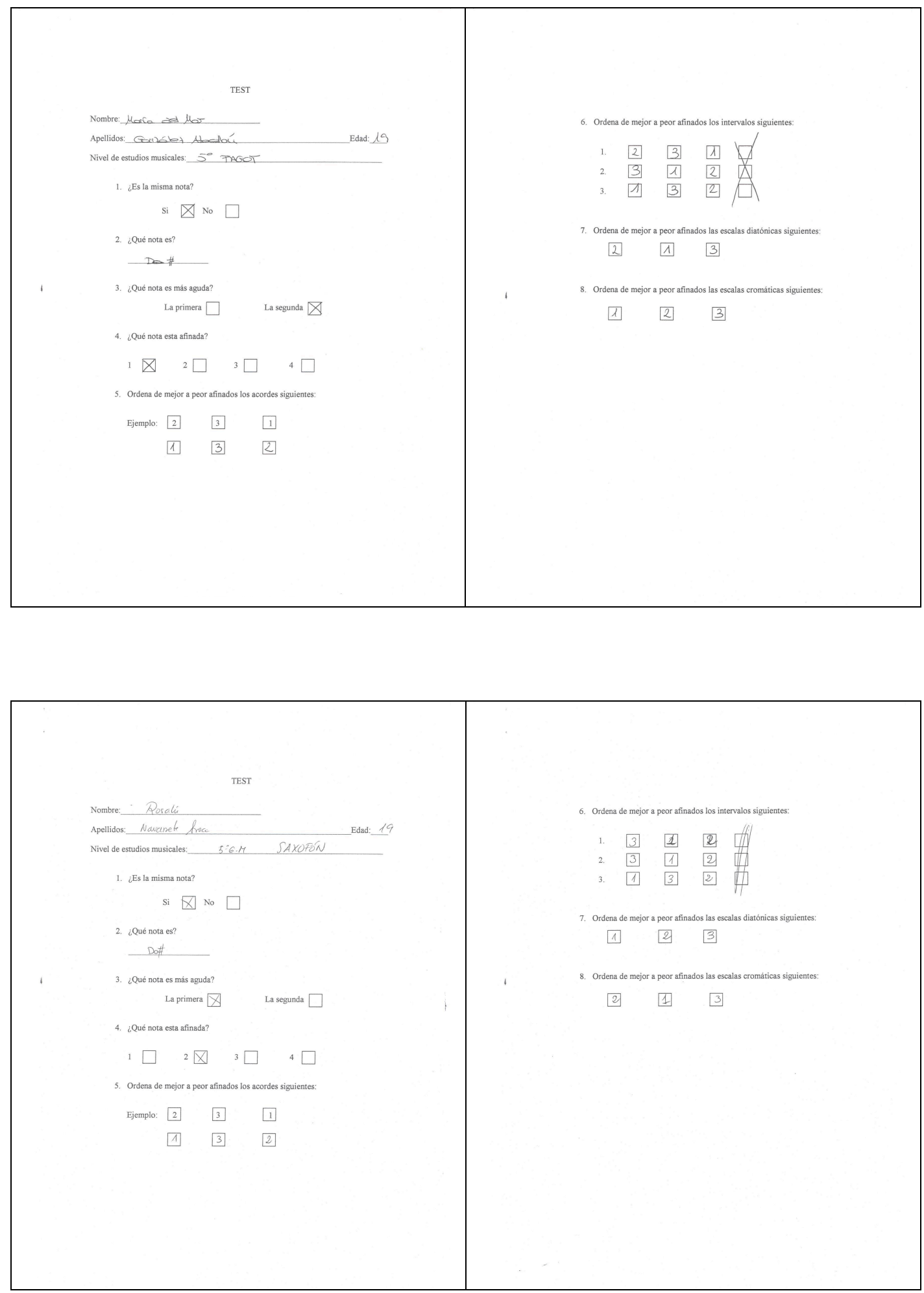

José Ibáñez Barrachina

Universitat Politécnica de València 

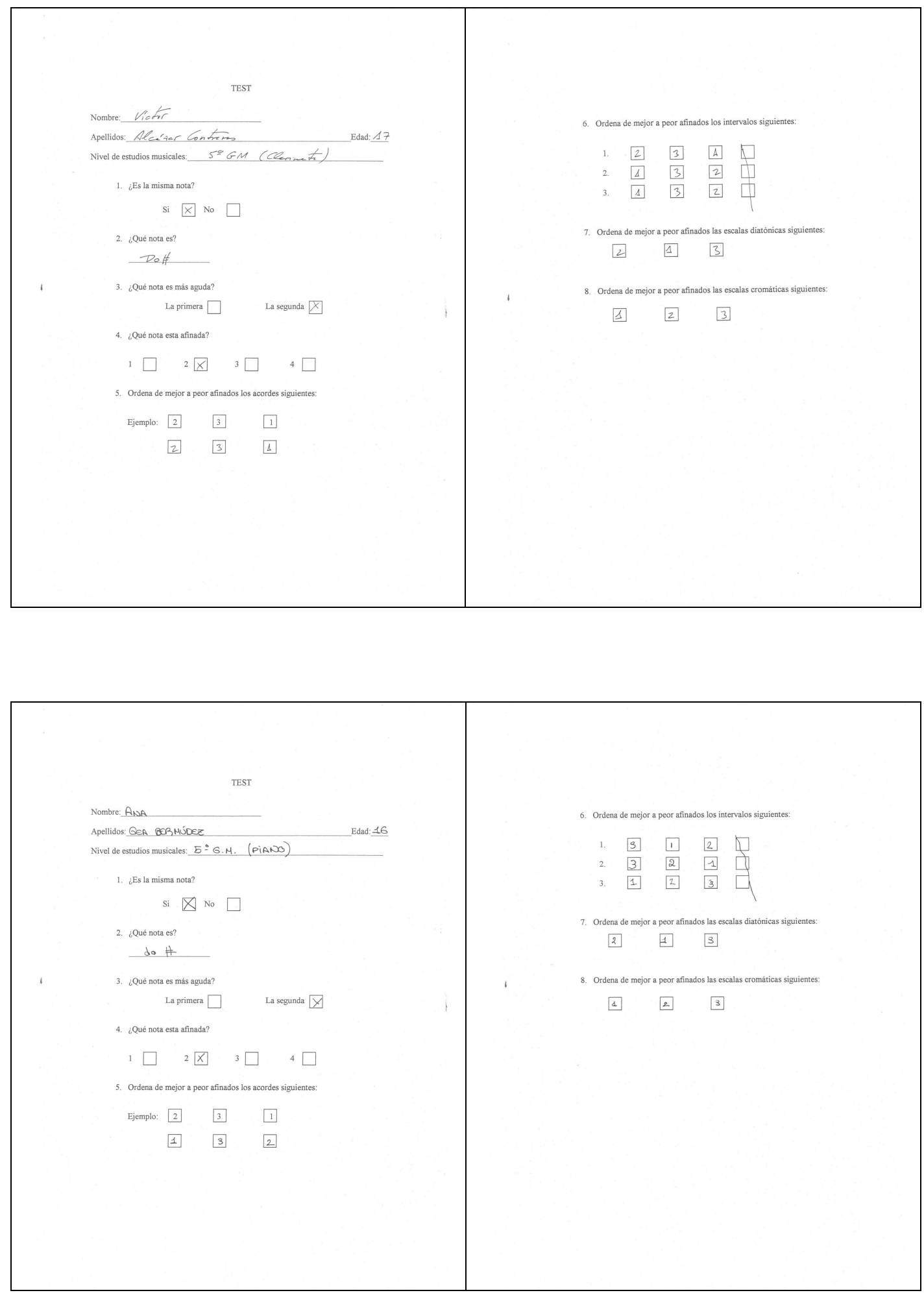

José Ibáñez Barrachina

Universitat Politécnica de València 

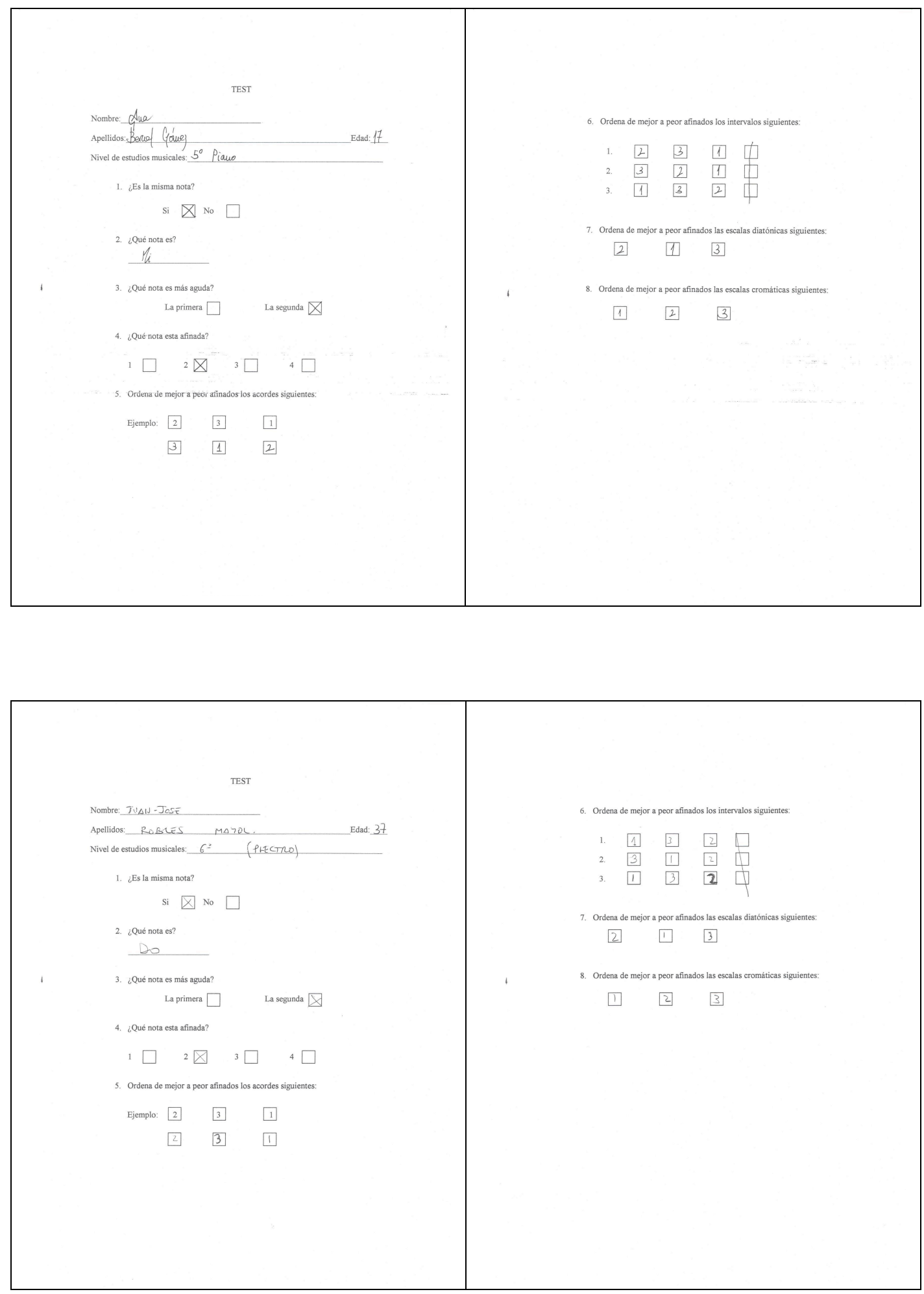

José Ibáñez Barrachina

Universitat Politécnica de València 

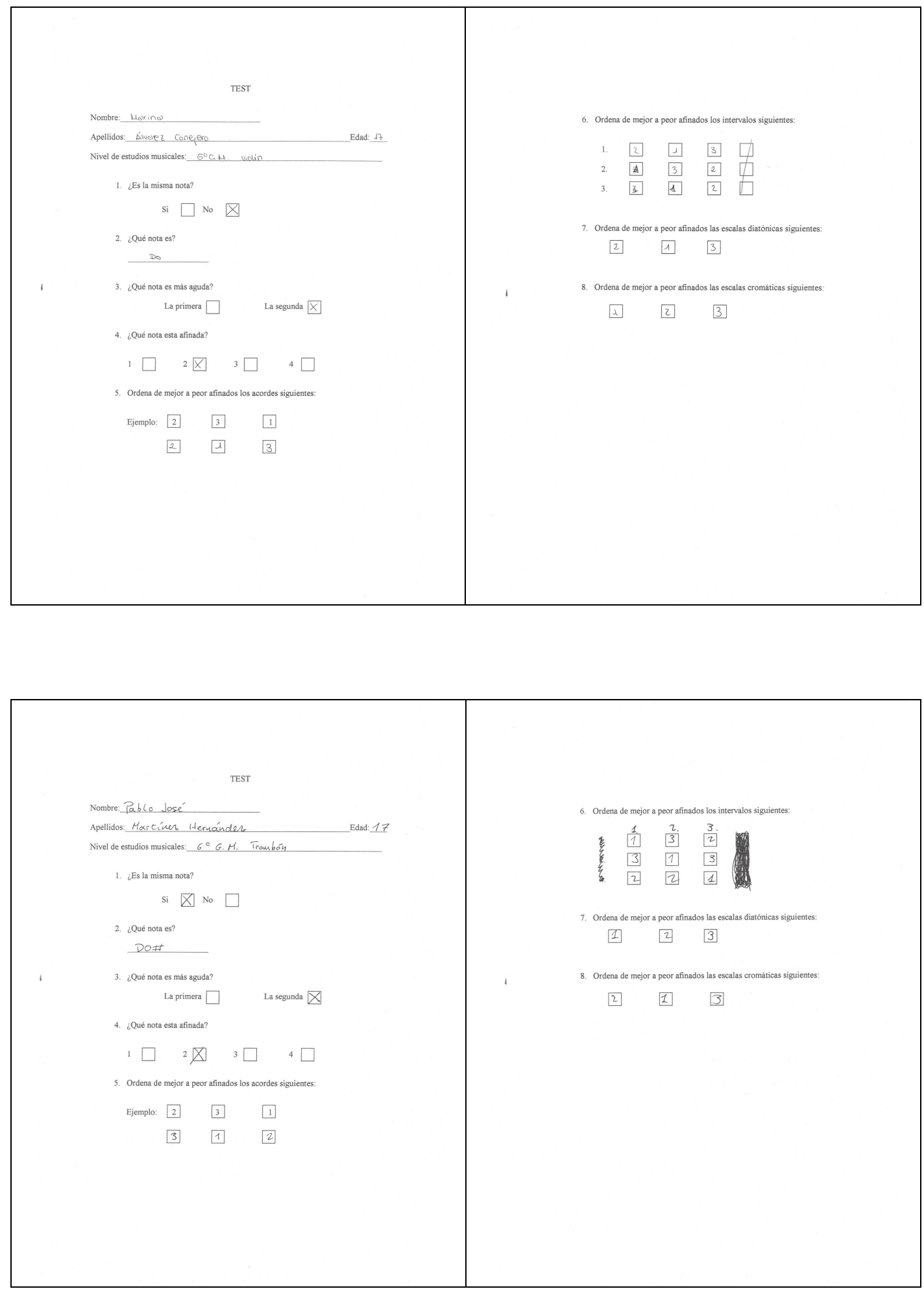

José Ibáñez Barrachina

Universitat Politécnica de València 

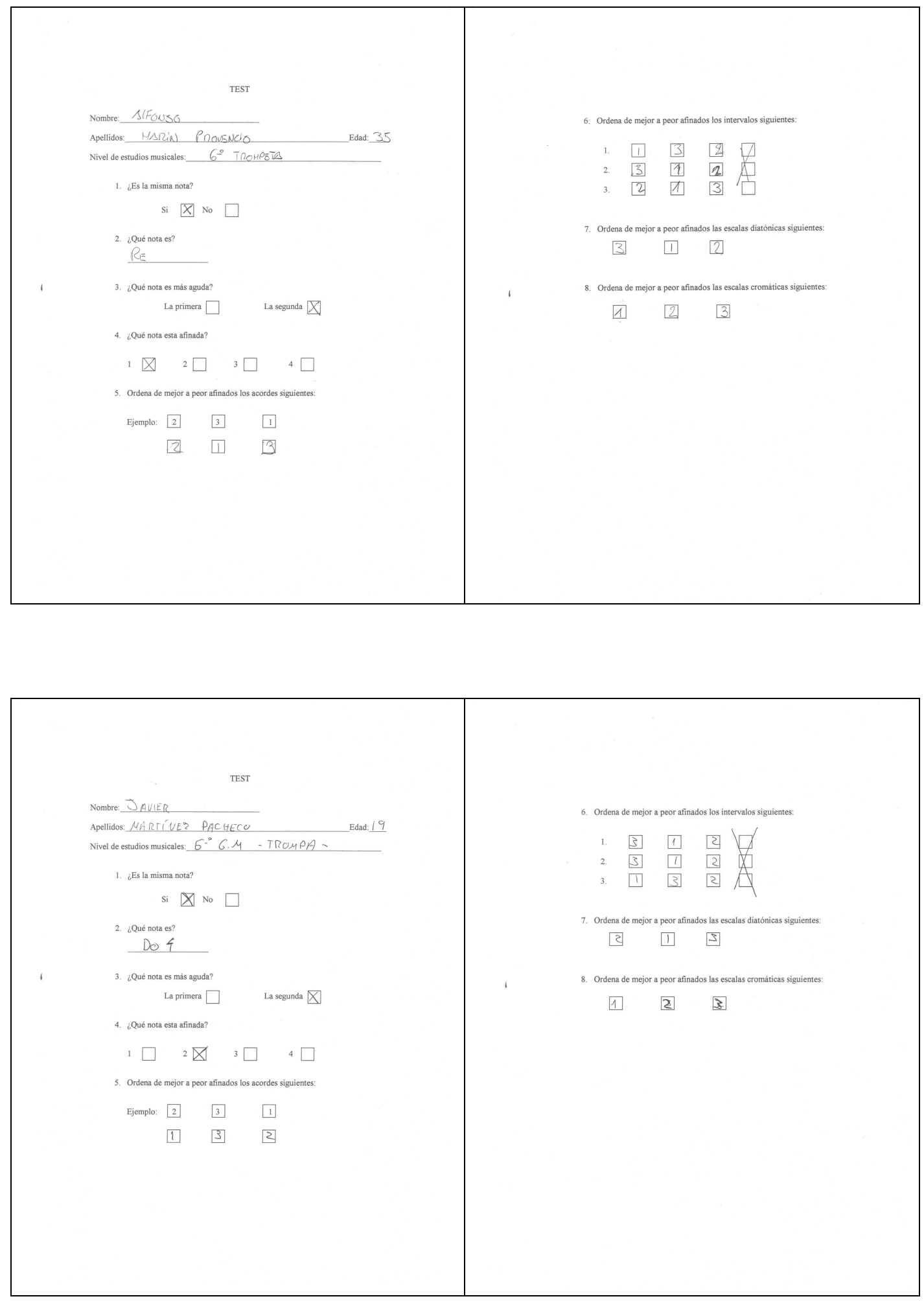

José Ibáñez Barrachina

Universitat Politécnica de València 

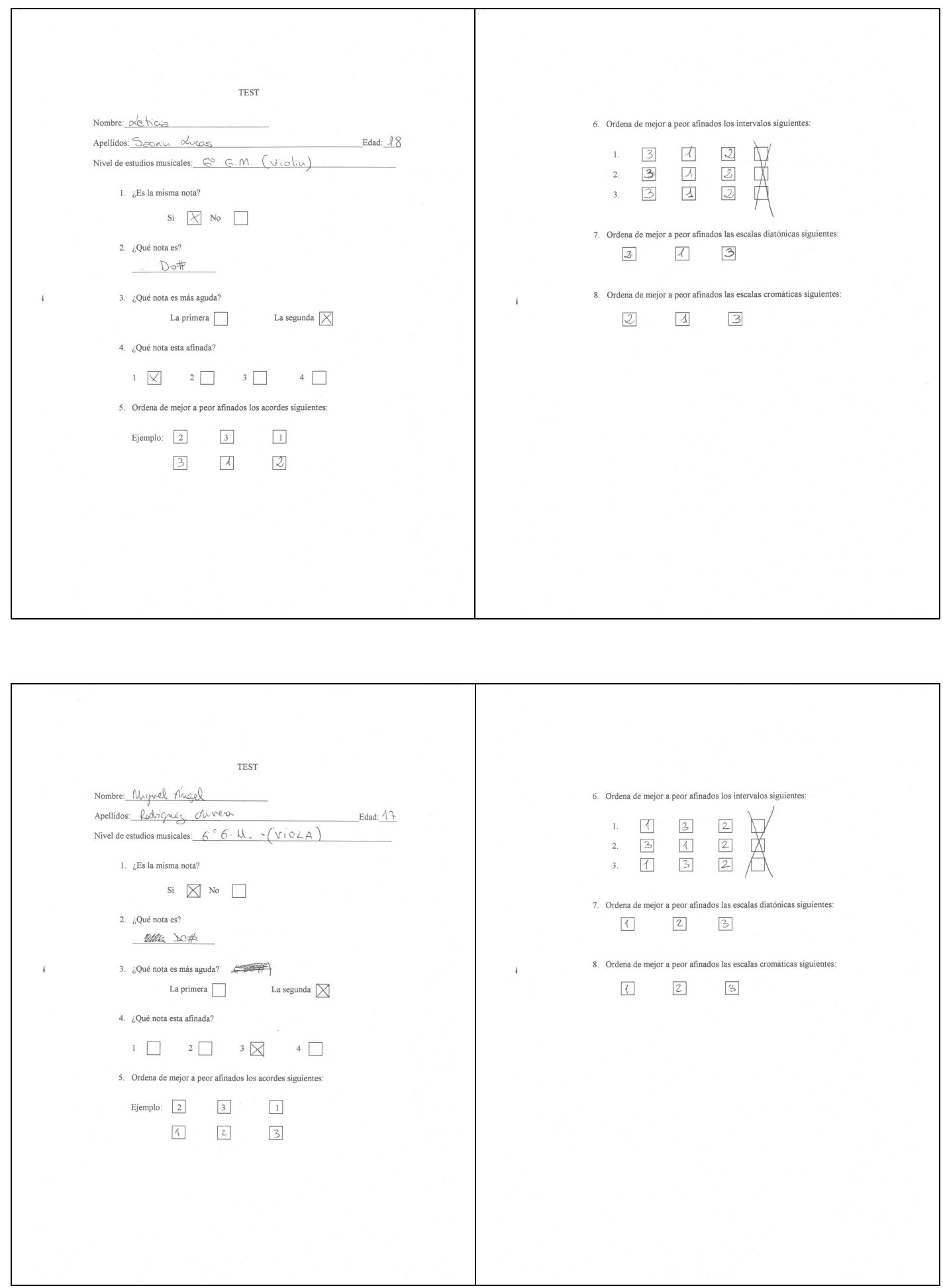

José Ibáñez Barrachina

Universitat Politécnica de València 

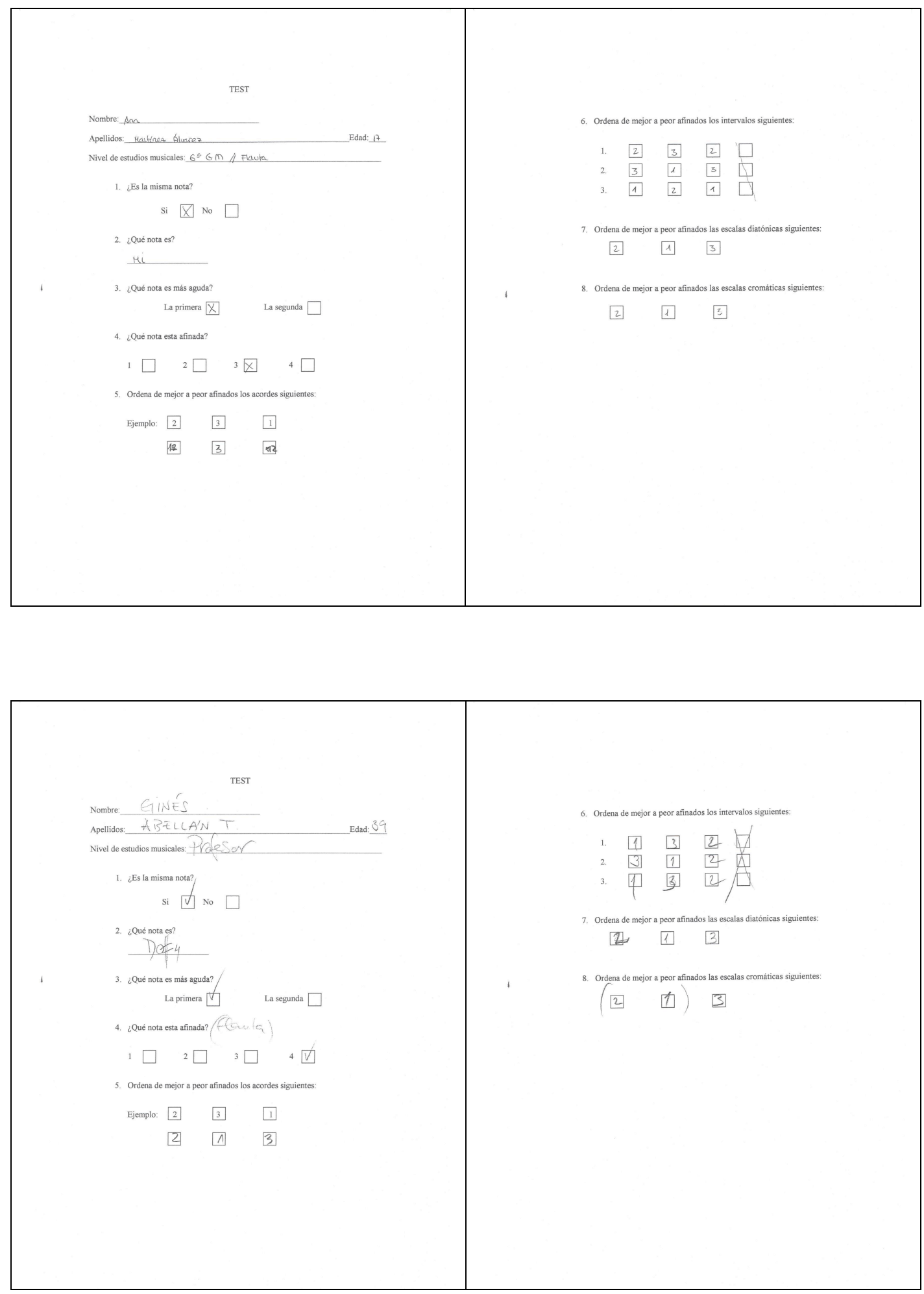

José Ibáñez Barrachina

Universitat Politécnica de València 

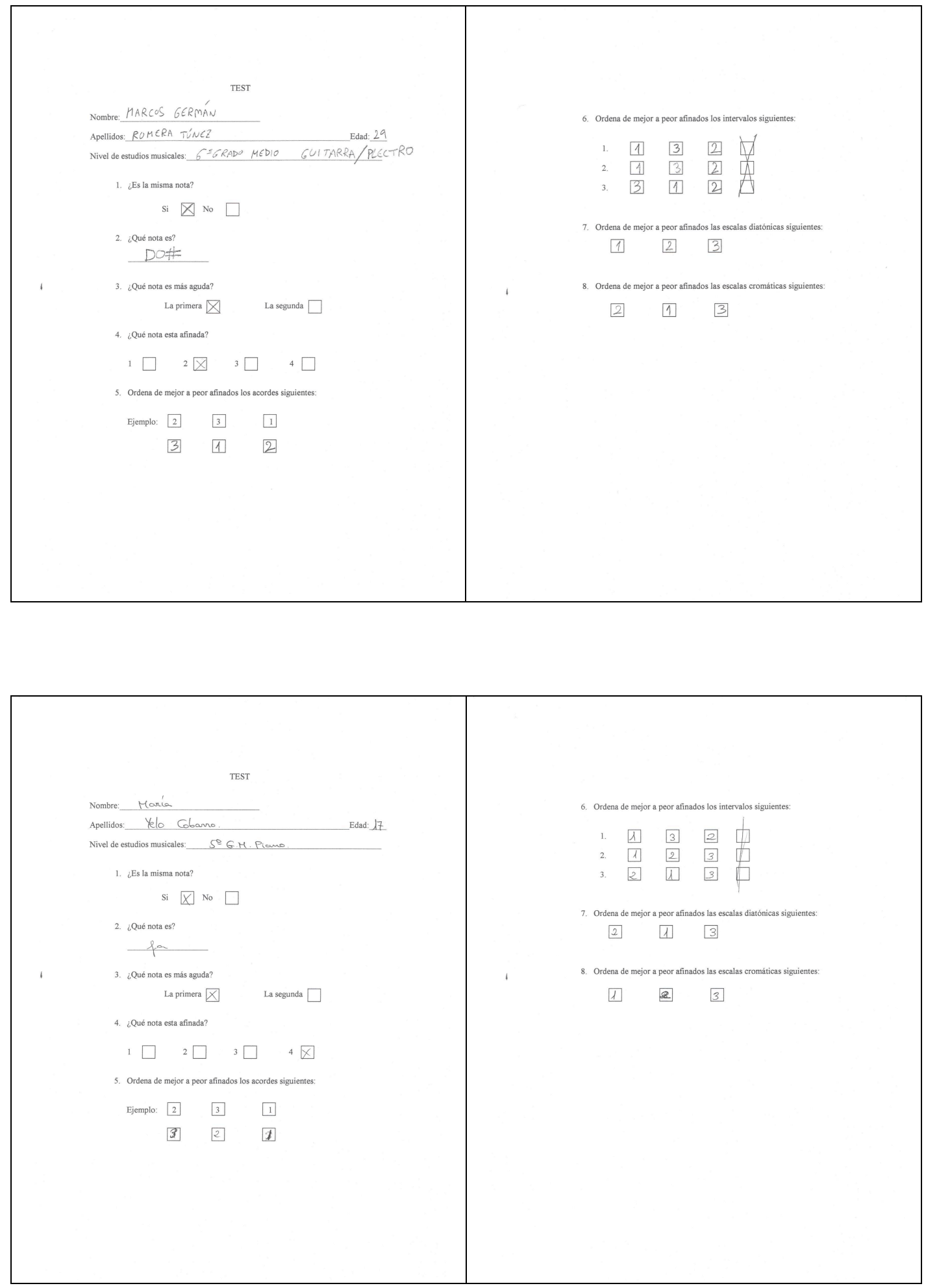

José Ibáñez Barrachina

Universitat Politécnica de València 

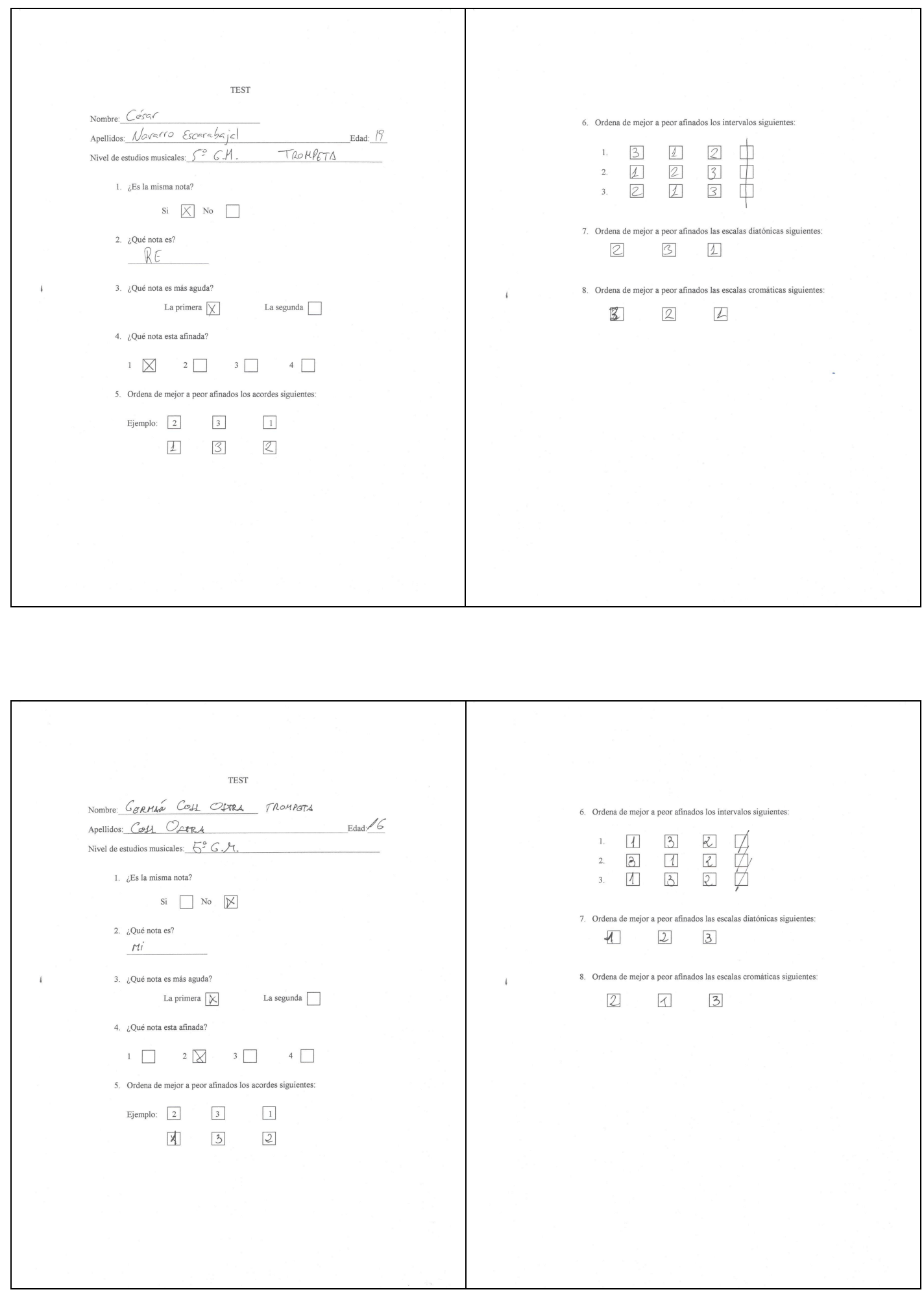

José Ibáñez Barrachina

Universitat Politécnica de València 

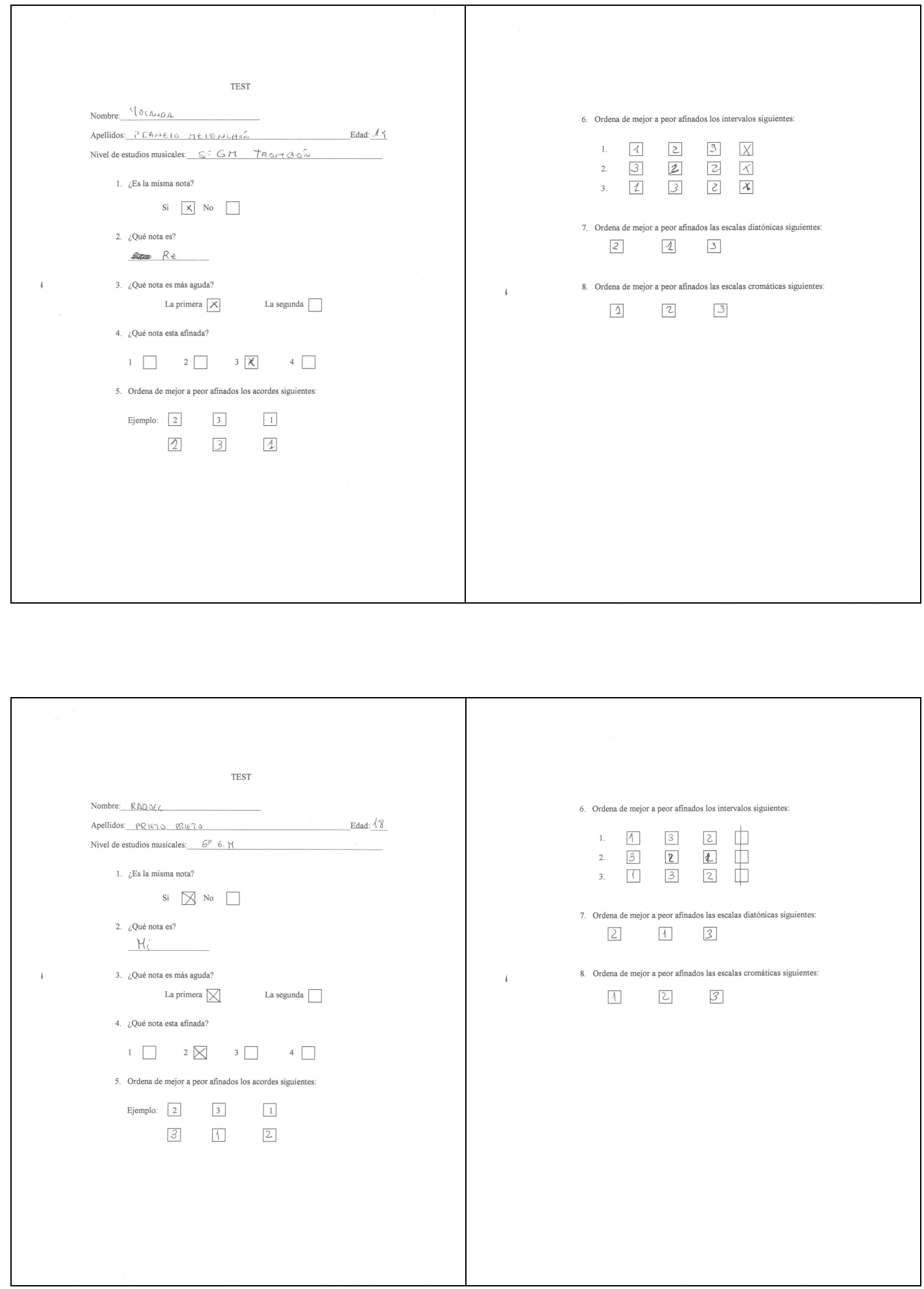

José Ibáñez Barrachina

Universitat Politécnica de València 

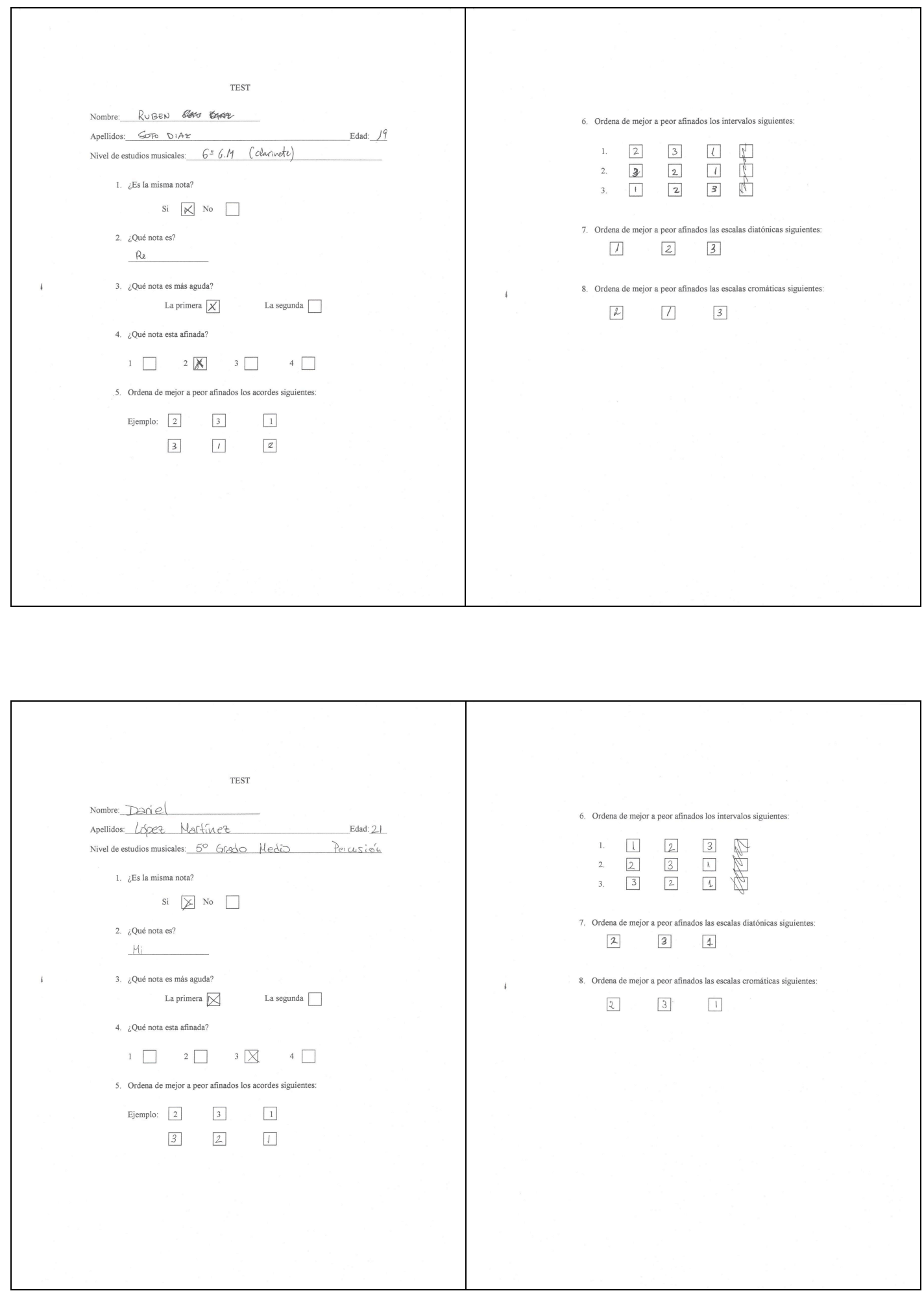

José Ibáñez Barrachina

Universitat Politécnica de València 

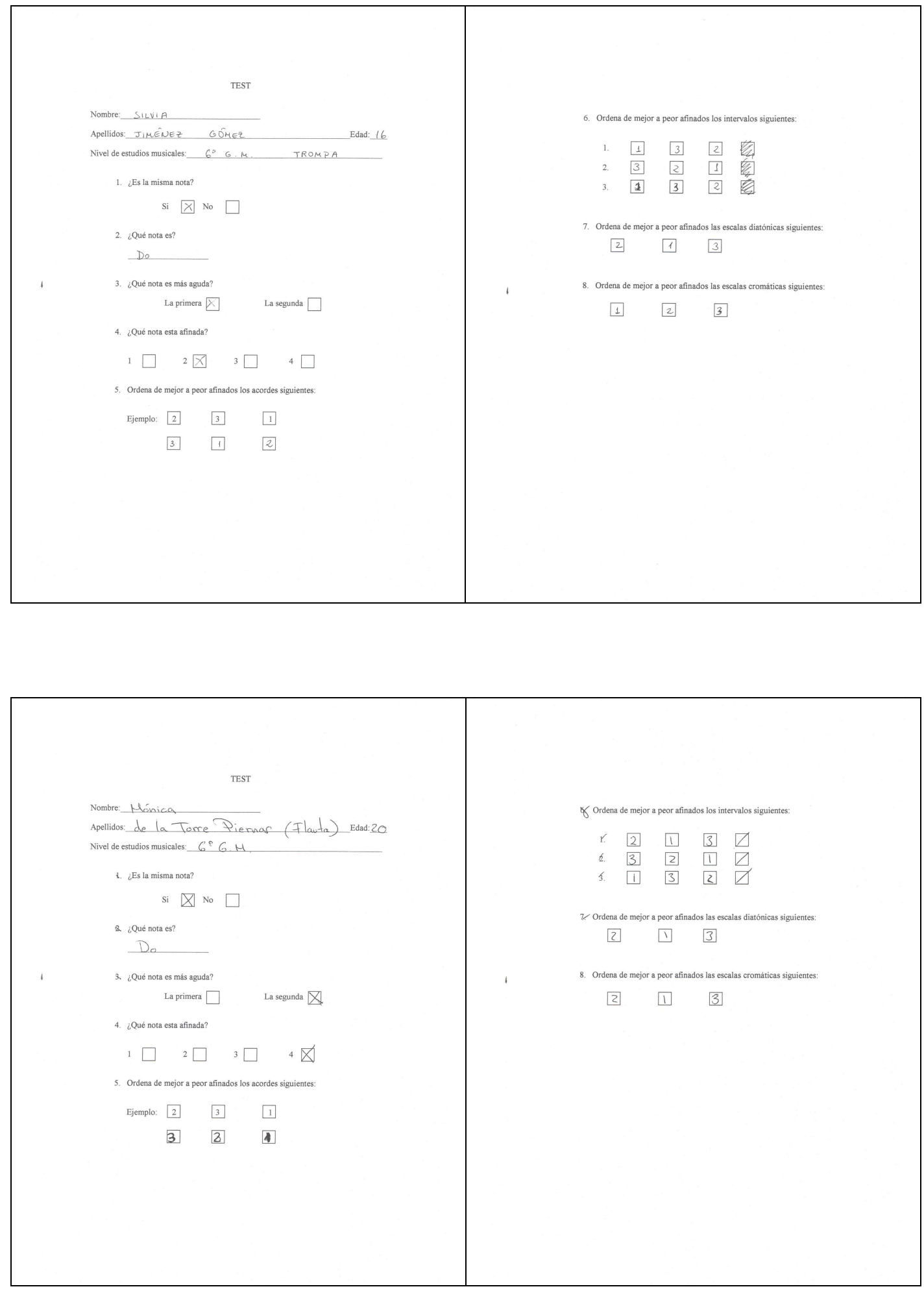

José Ibáñez Barrachina

Universitat Politécnica de València 

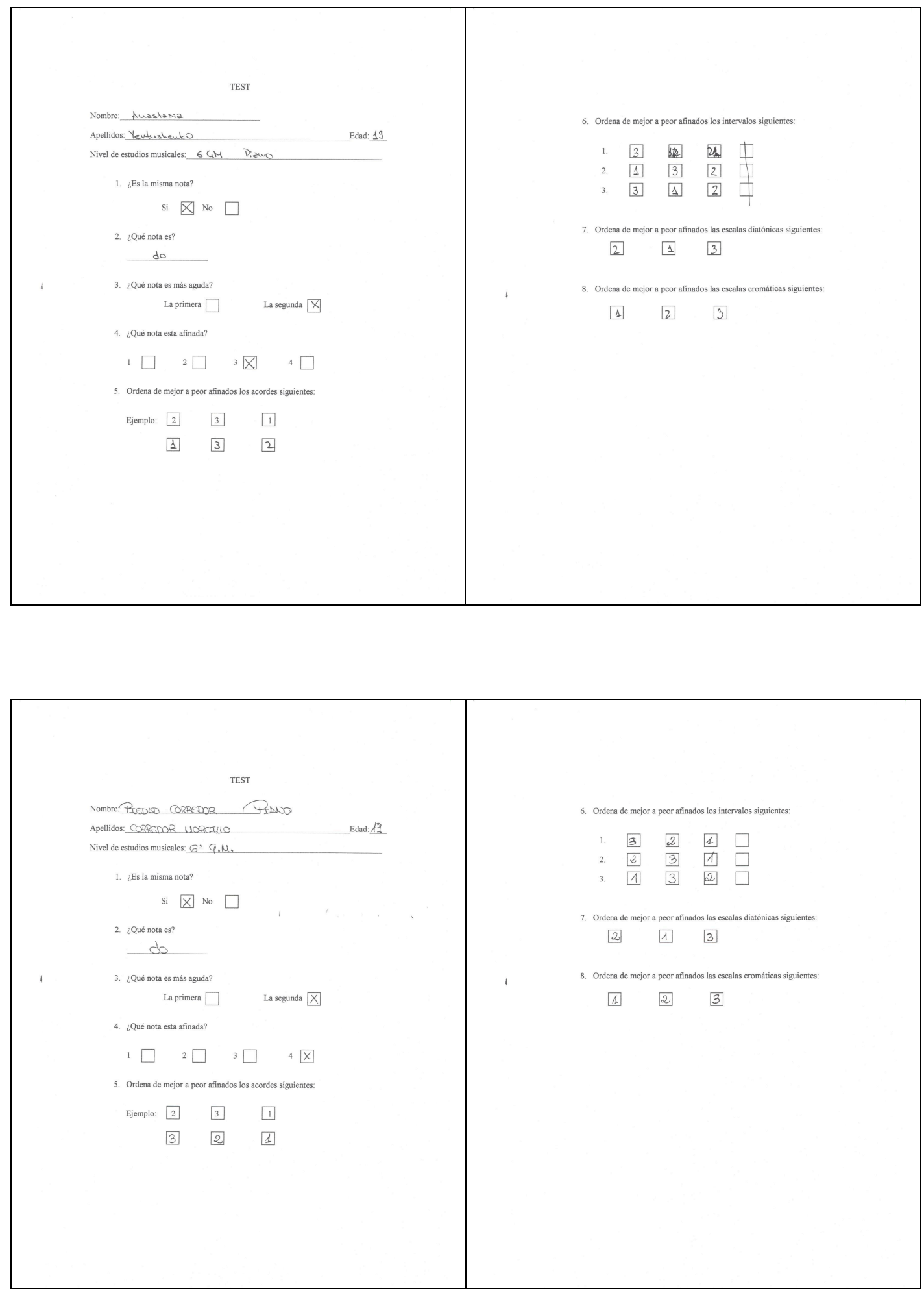

José Ibáñez Barrachina

Universitat Politécnica de València 

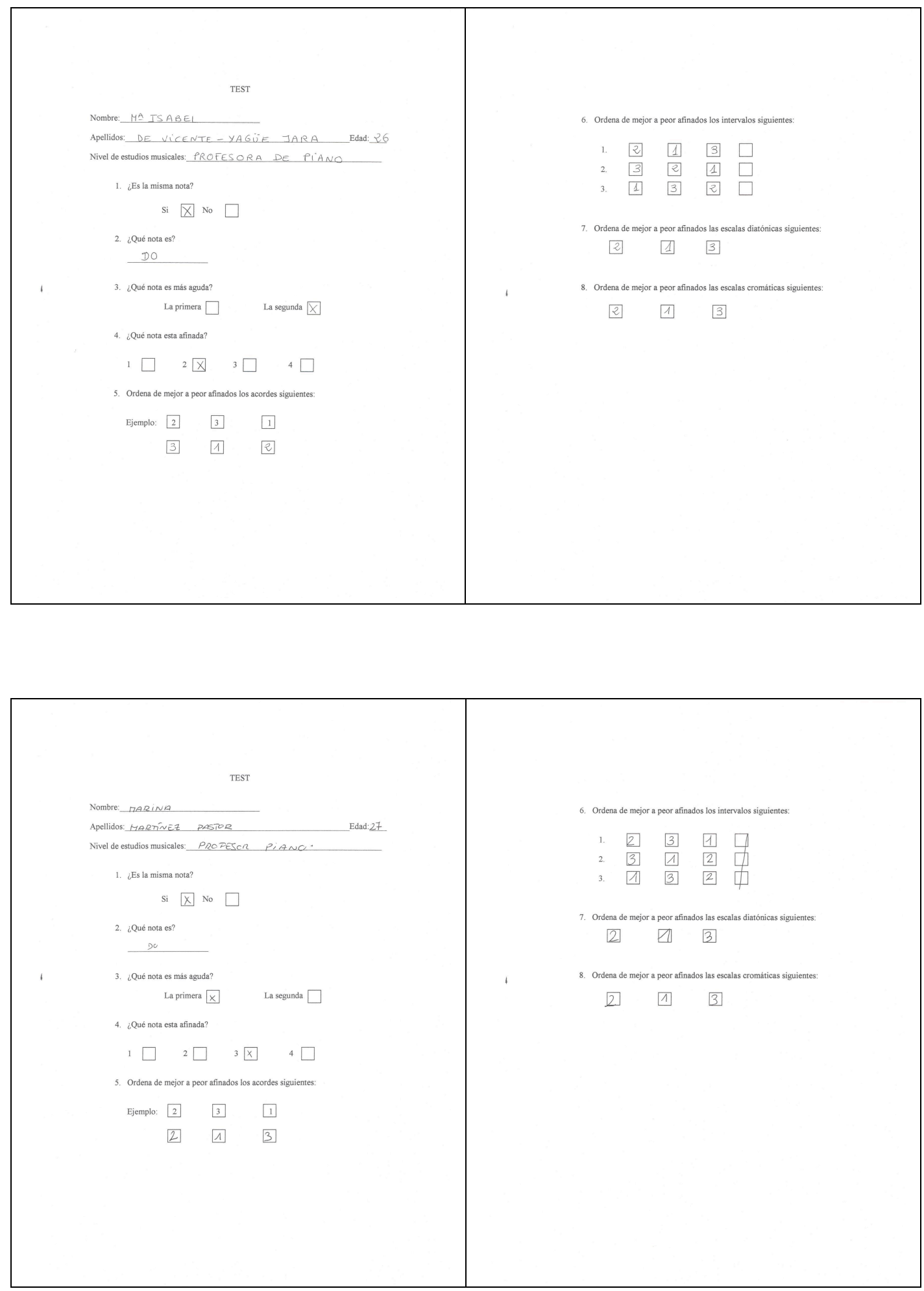

José Ibáñez Barrachina

Universitat Politécnica de València 

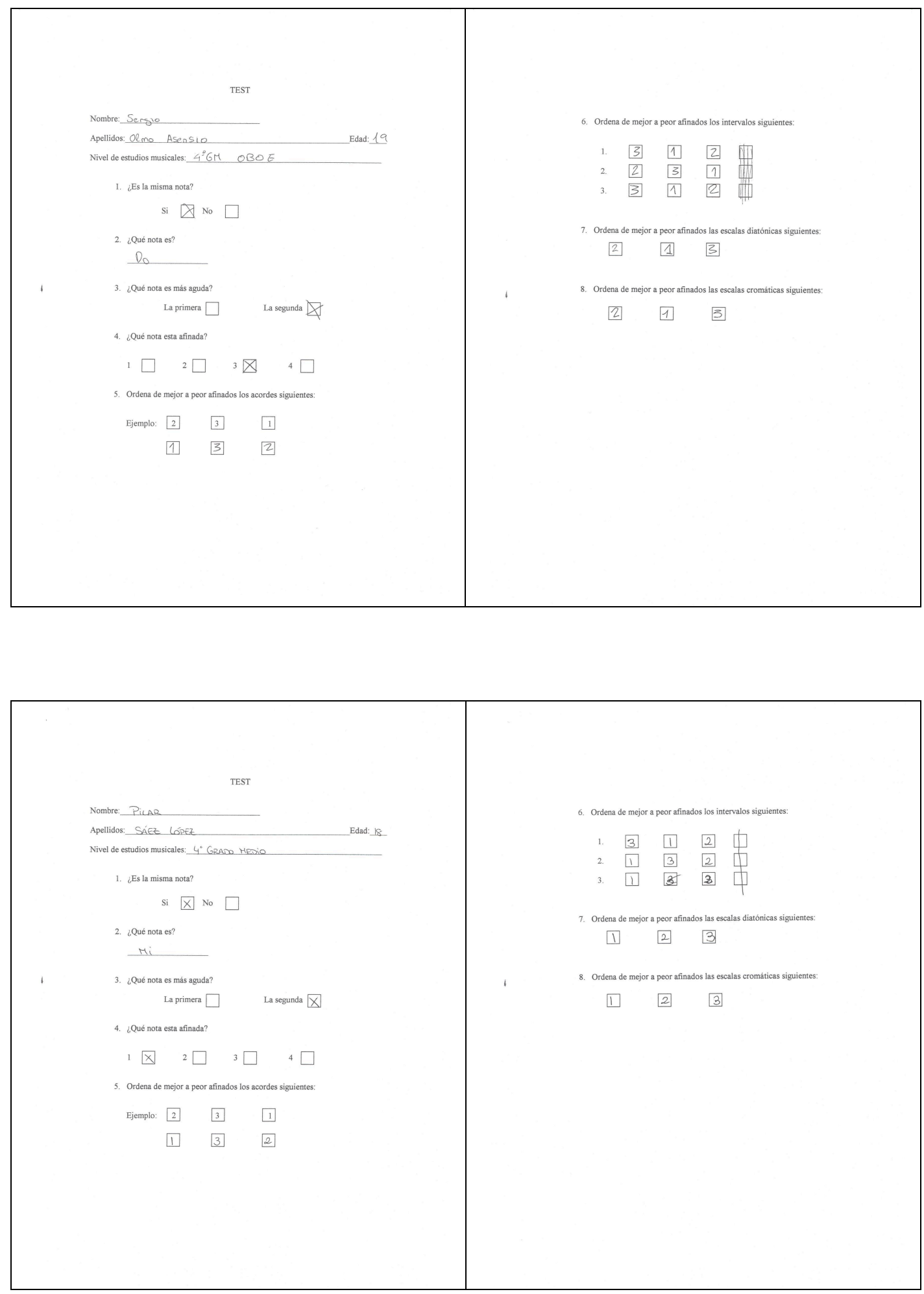

José Ibáñez Barrachina

Universitat Politécnica de València 

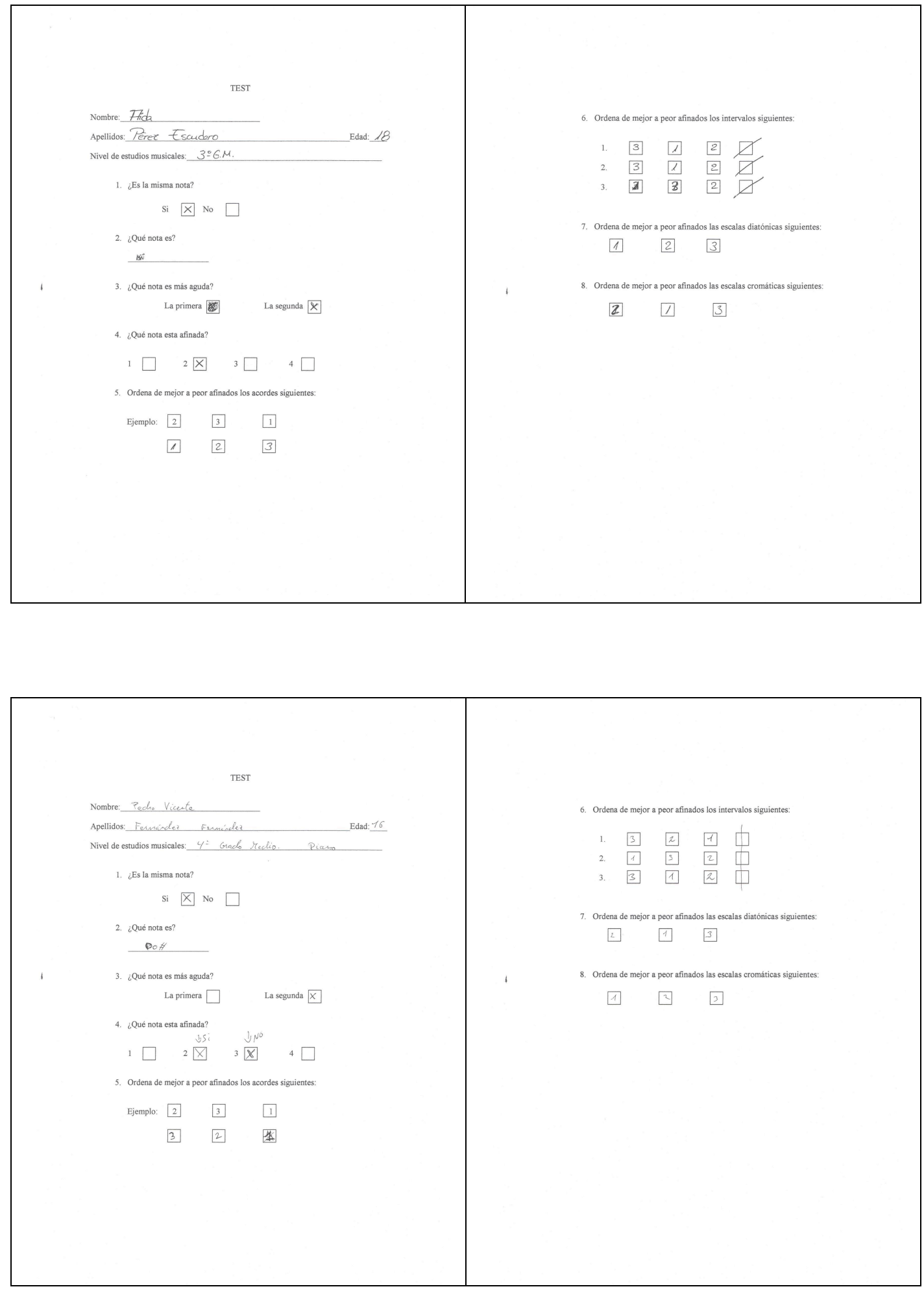

José Ibáñez Barrachina

Universitat Politécnica de València 

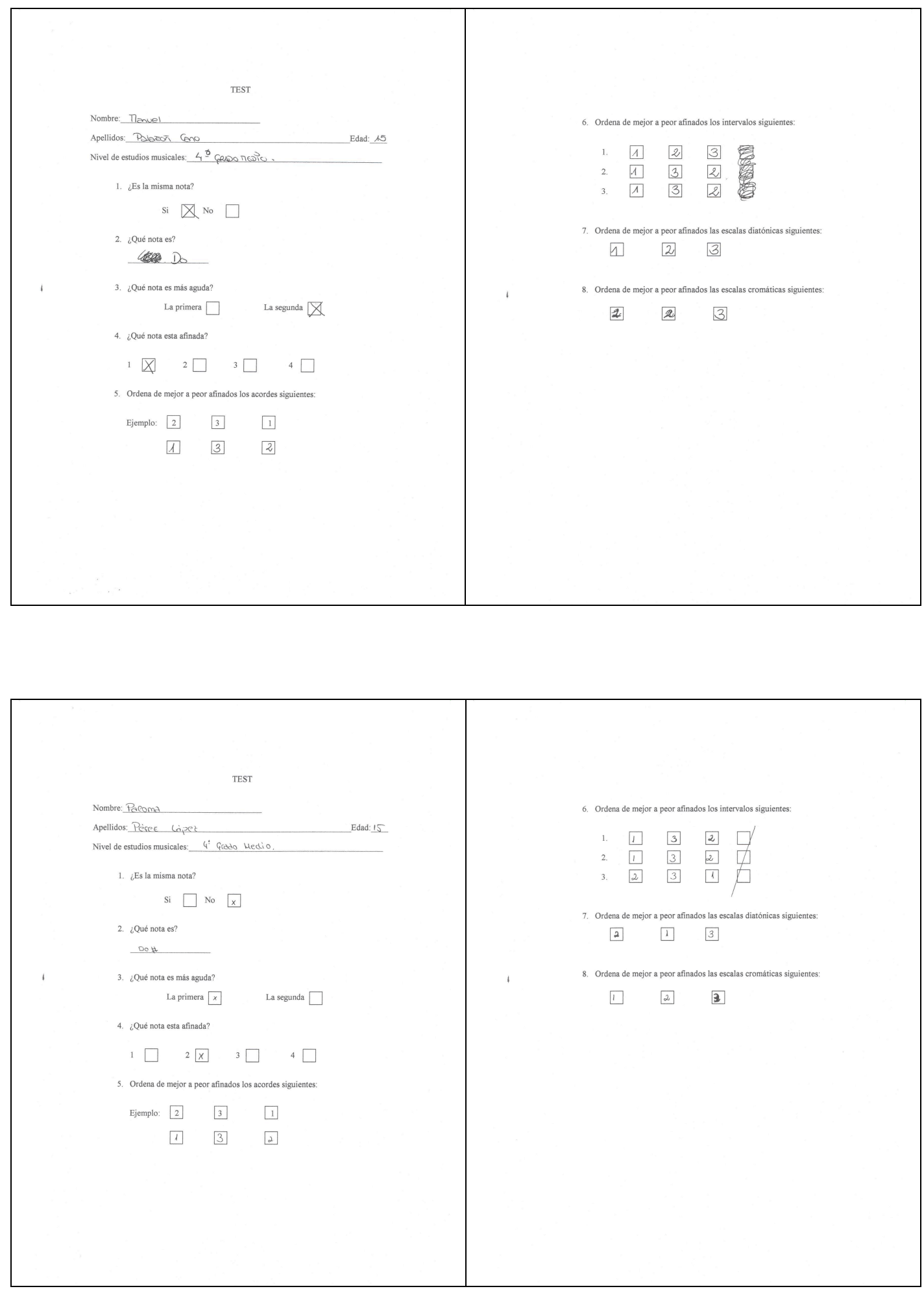

José Ibáñez Barrachina

Universitat Politécnica de València 

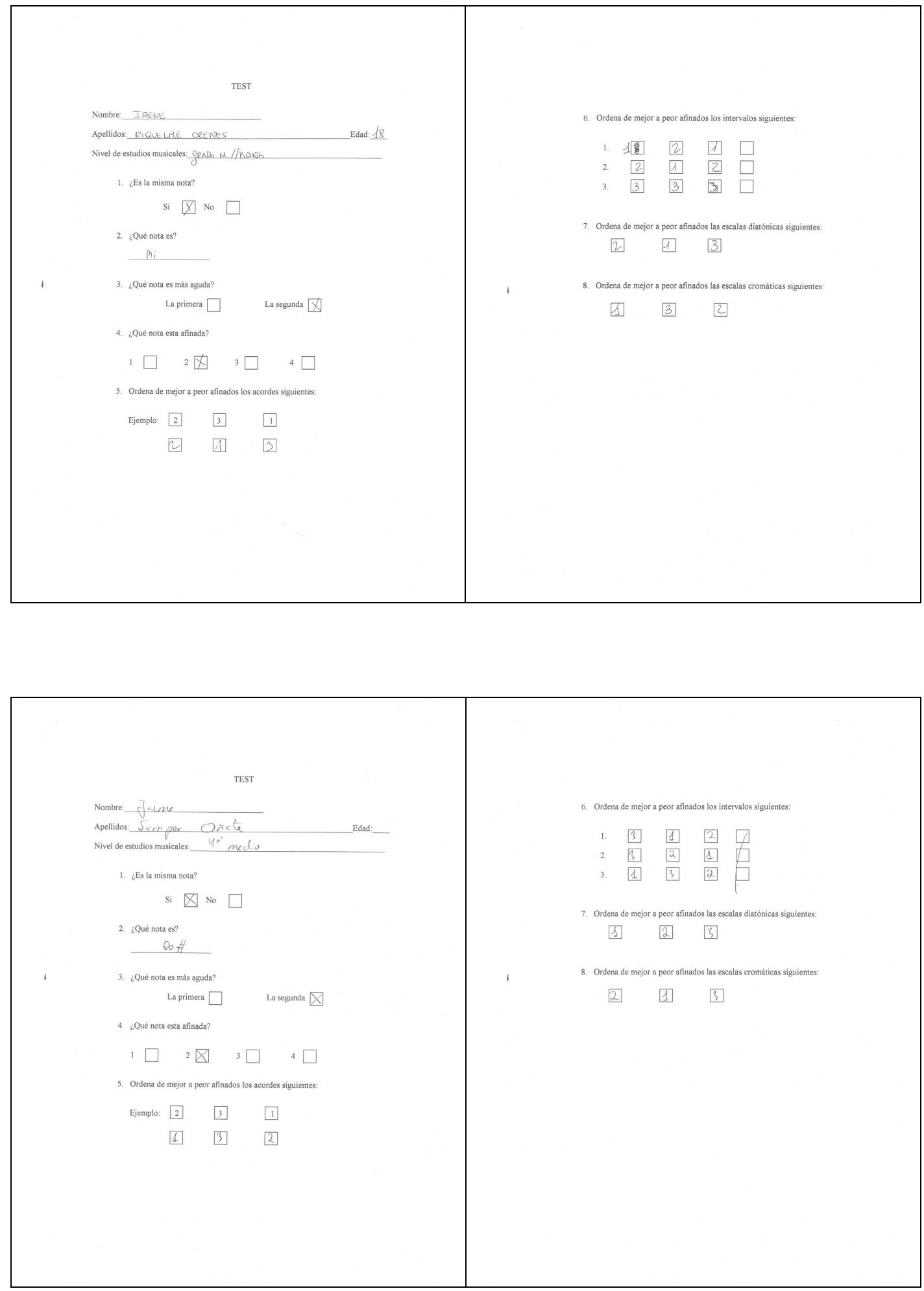

José Ibáñez Barrachina

Universitat Politécnica de València 


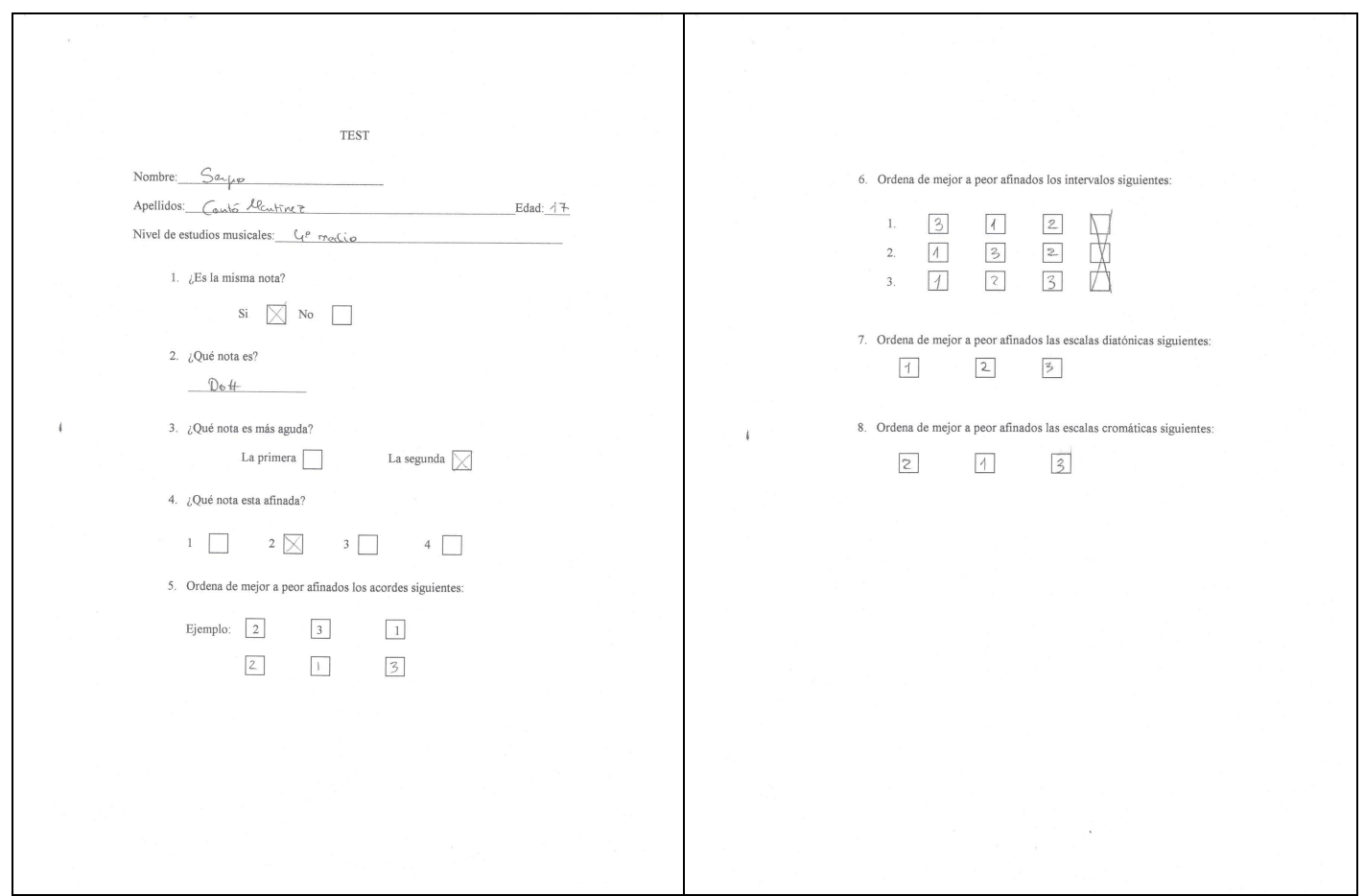

\section{A. 4 Particellas de Esferas}

A continuación presentamos las particellas de la obra Esferas descrita en el capítulo 3 para: Trompeta en do, pícolo, trompa, trompeta y trombón. 
Trompeta Do y piccollo

\section{Esferas}

Kepler en el Siglo XXI
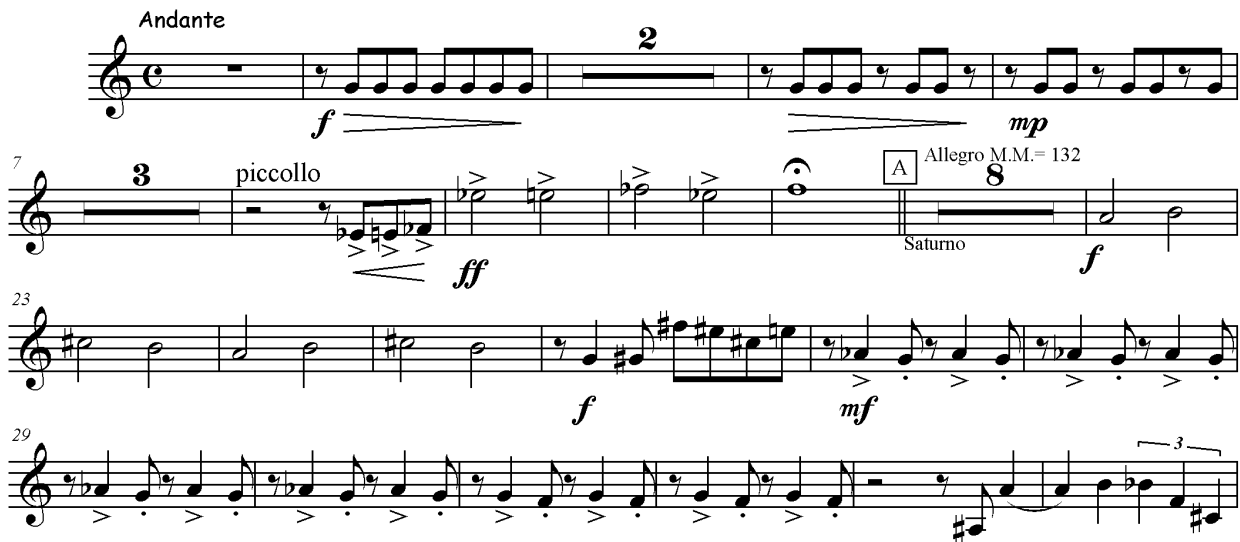

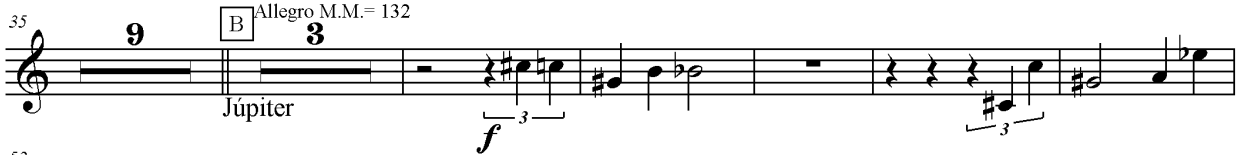
(20) (28) :Tierra $p$ :

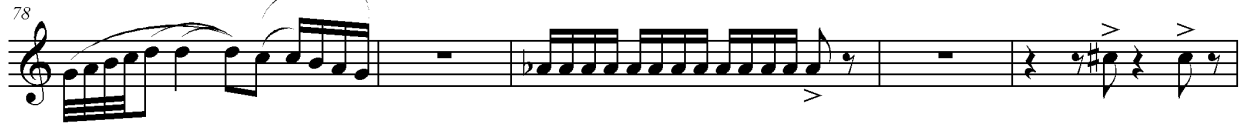

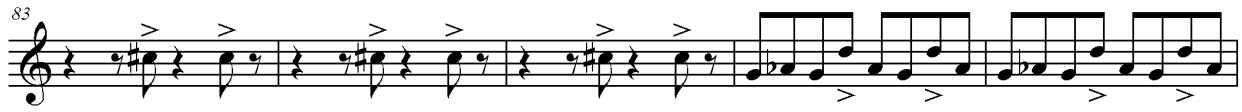

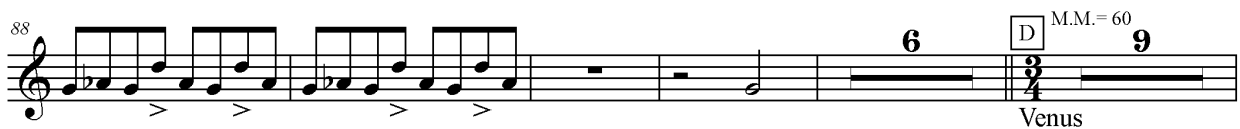



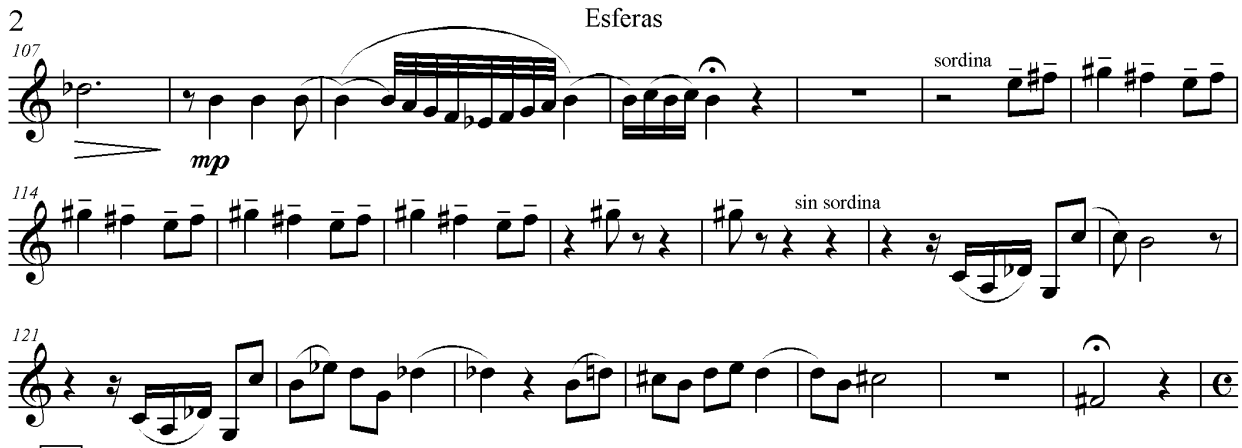

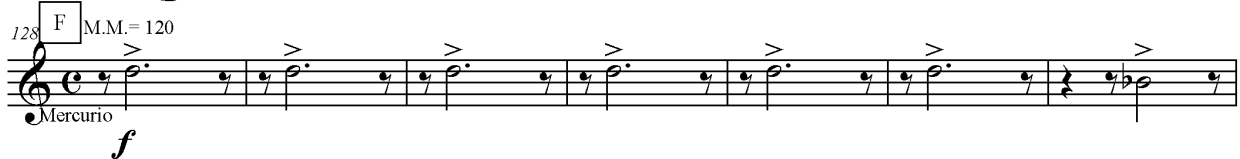

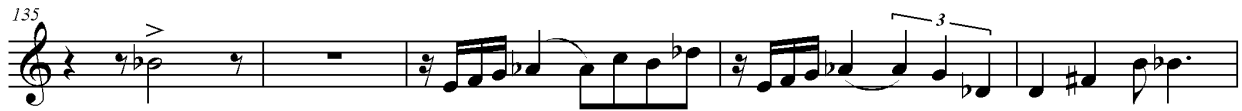
$e_{-3}^{140}$ Marte (a)

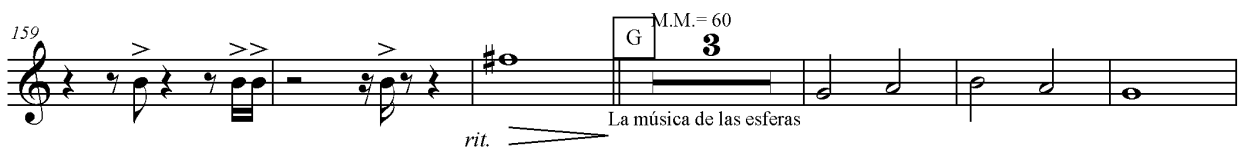

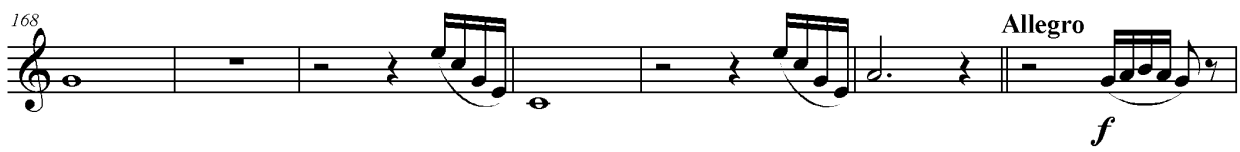
$\frac{7}{20}$ ffe 


\section{Esferas}

Trompeta Do

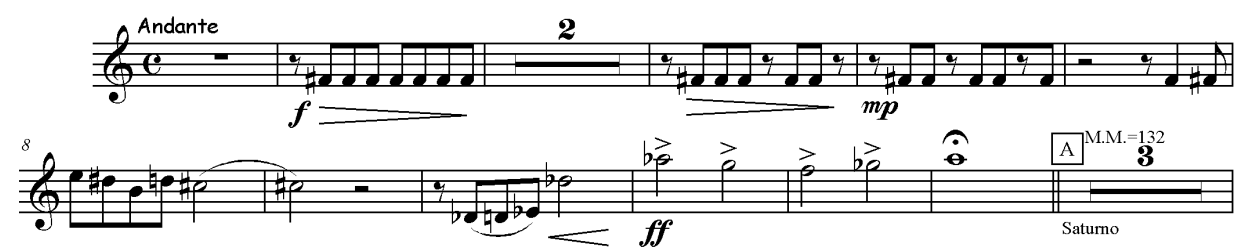

$\frac{17}{17}$

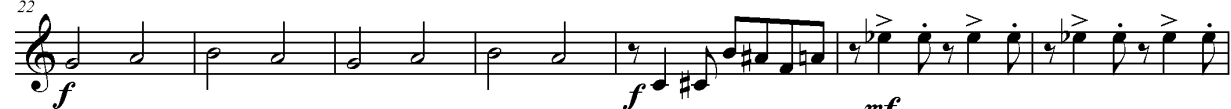

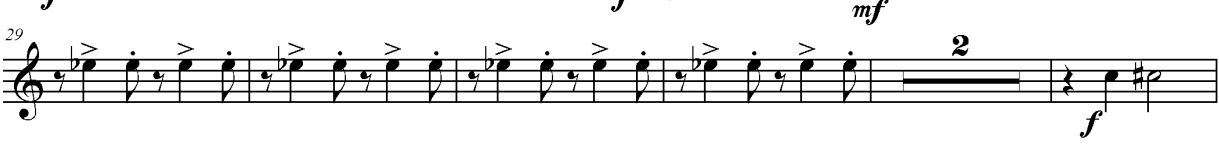

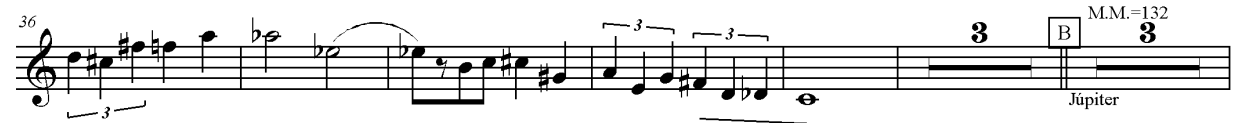

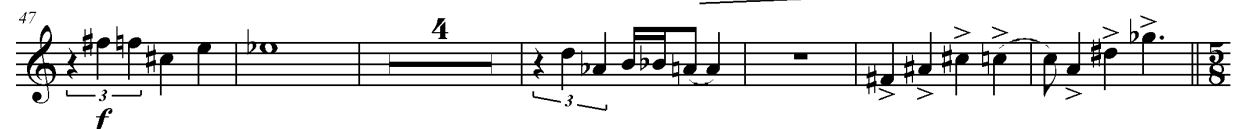

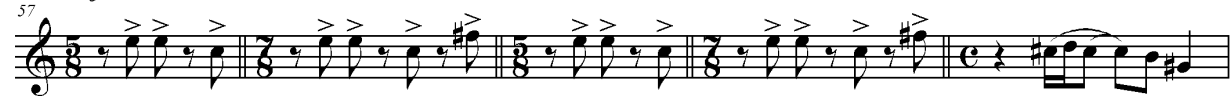
(2) ? ?

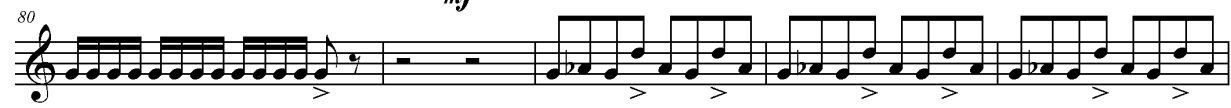

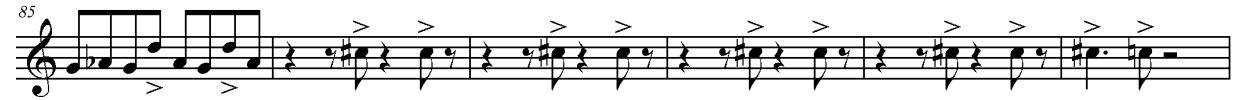



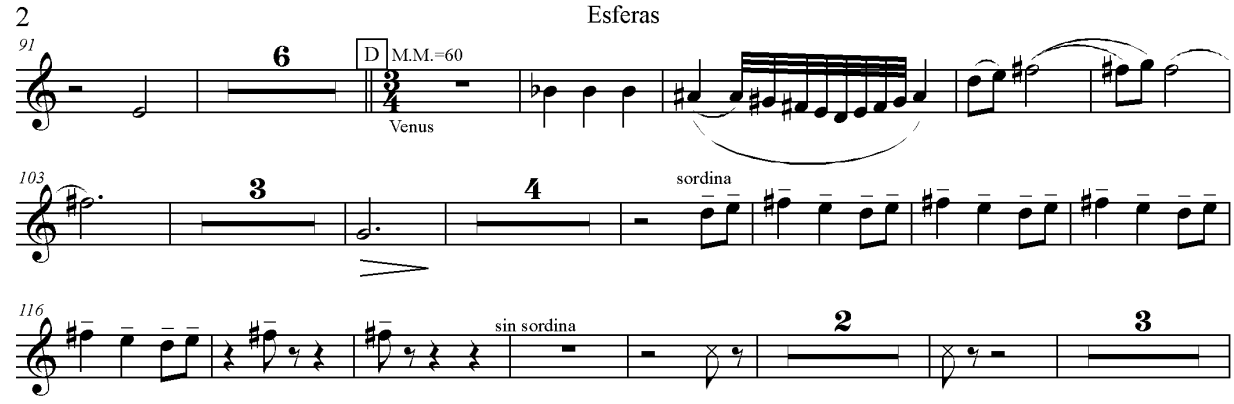

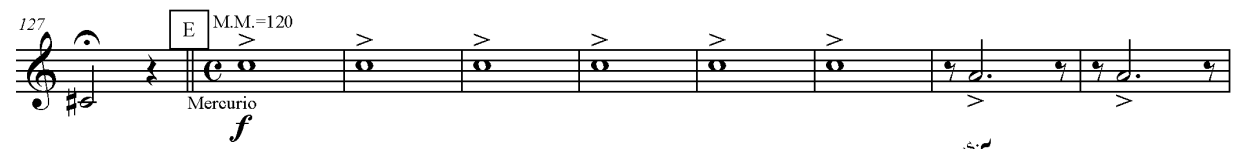

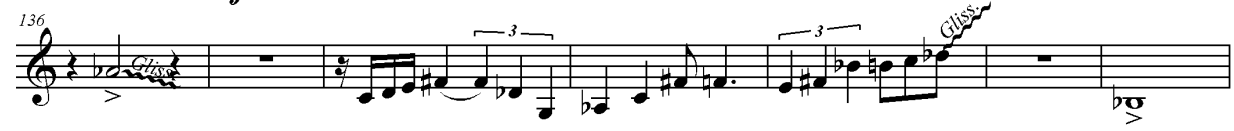
(9) Marte

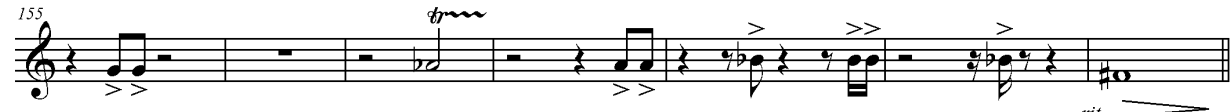

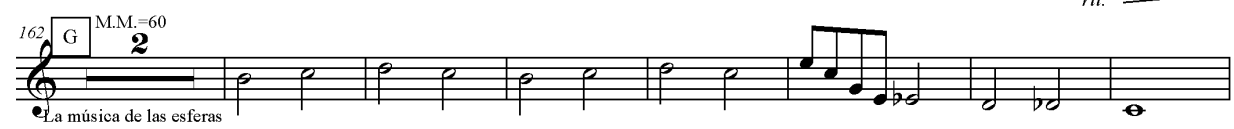
(2)

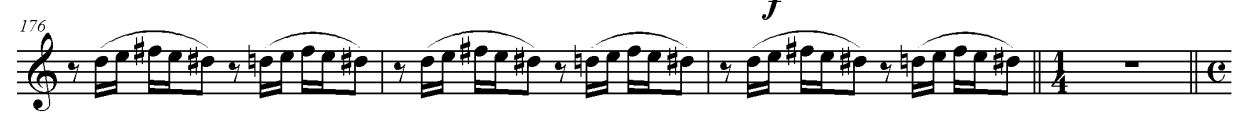

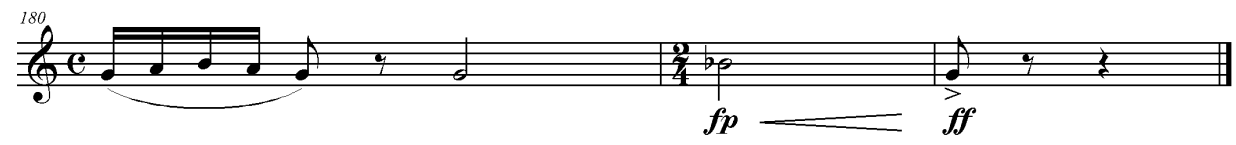




\section{Esferas}

Trompa Fa
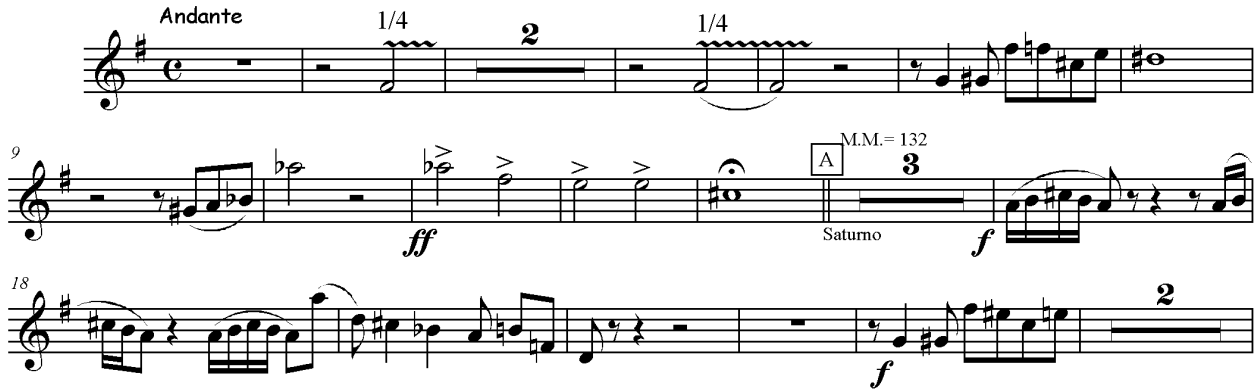

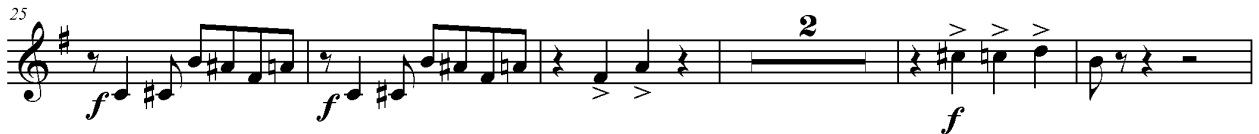
$\frac{a^{32}}{25}$

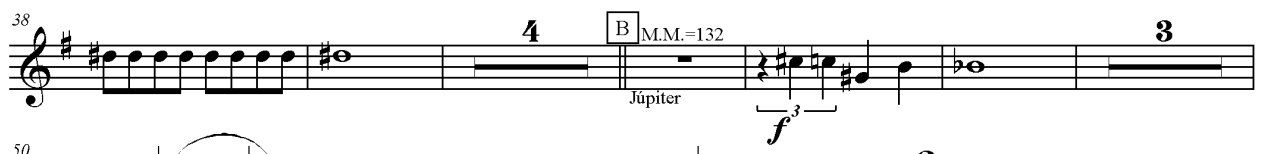

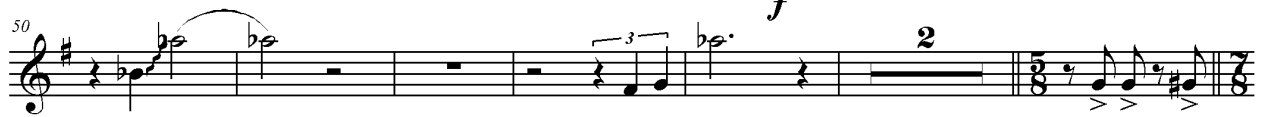

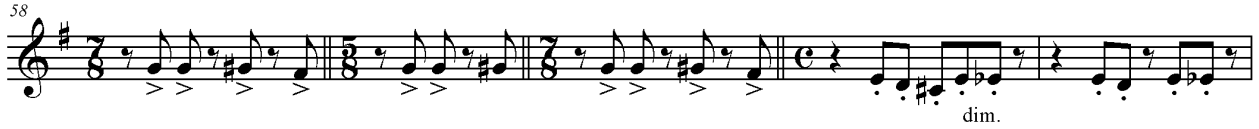
(2) ?:? $\frac{1}{20}$ (a) 28: ${ }^{94}$ 

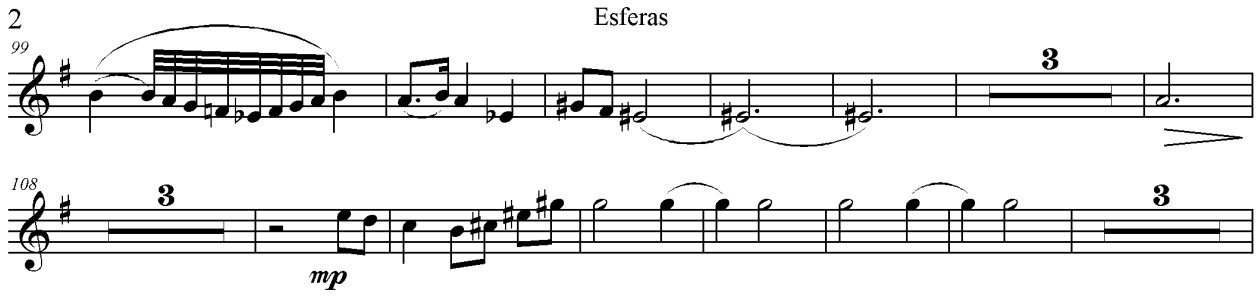

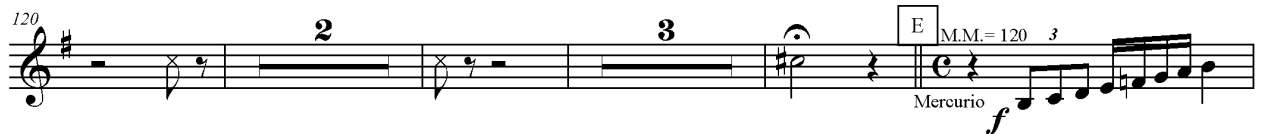

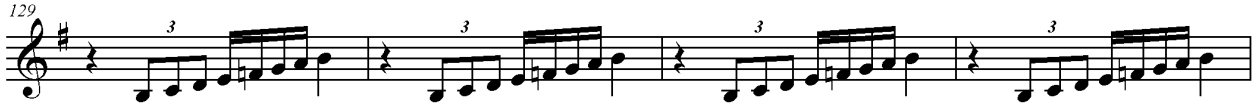

$e^{133}$

(140)

:

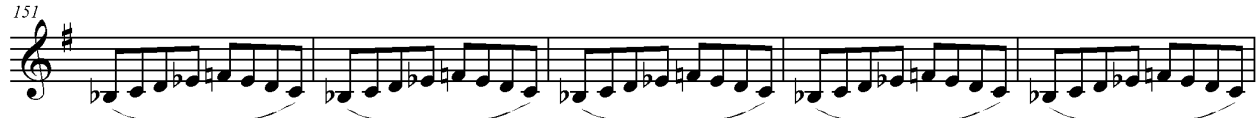

$e_{0}^{1256}$

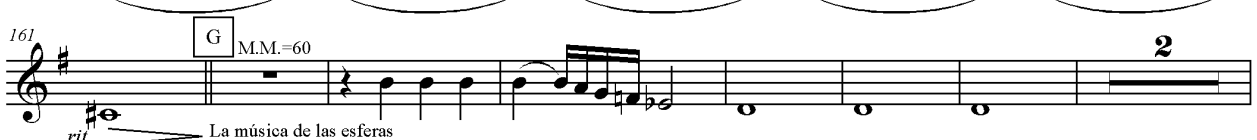

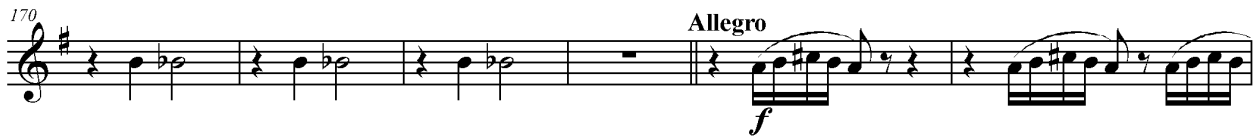

(9)

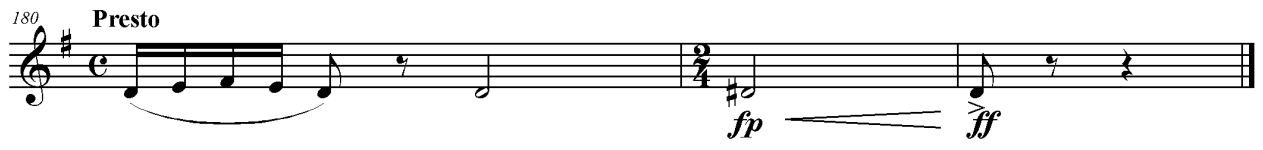


Trombón

\section{Esferas}

Kepler en el Siglo XXI

José Ibáñez Barrachina
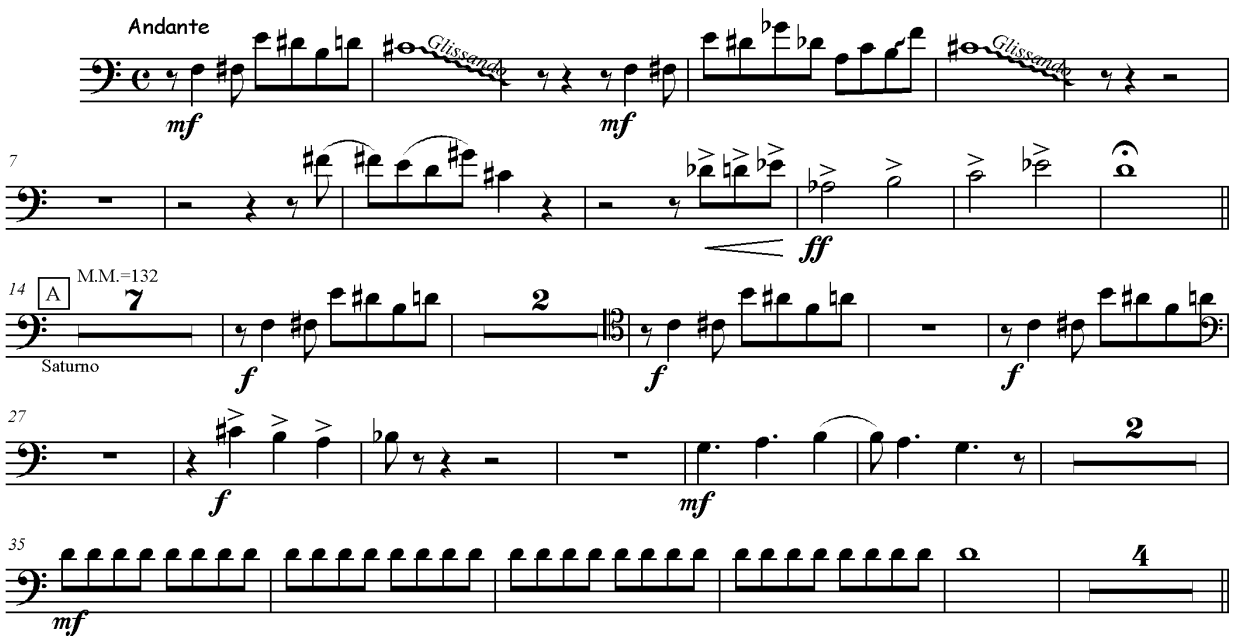

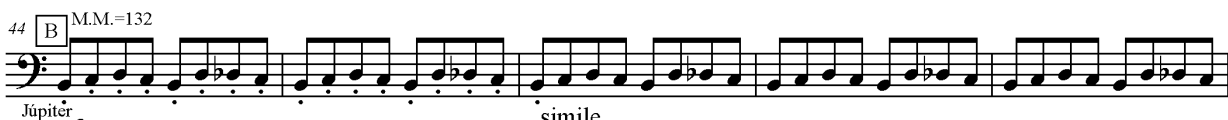
Jupiter simile

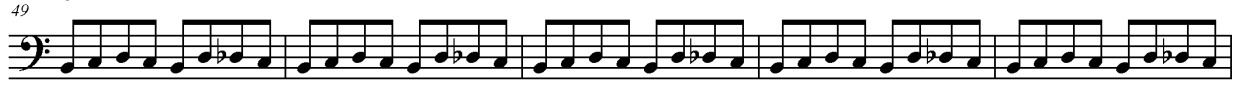

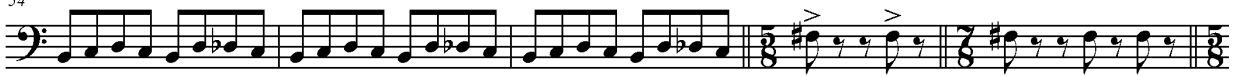
$9: 50+30$ rit.

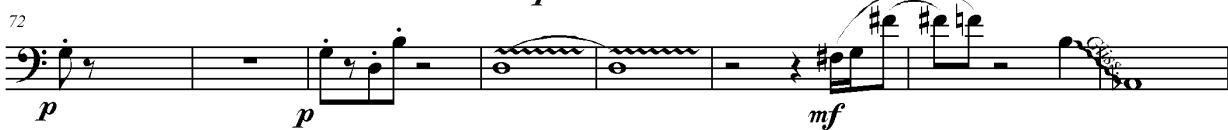
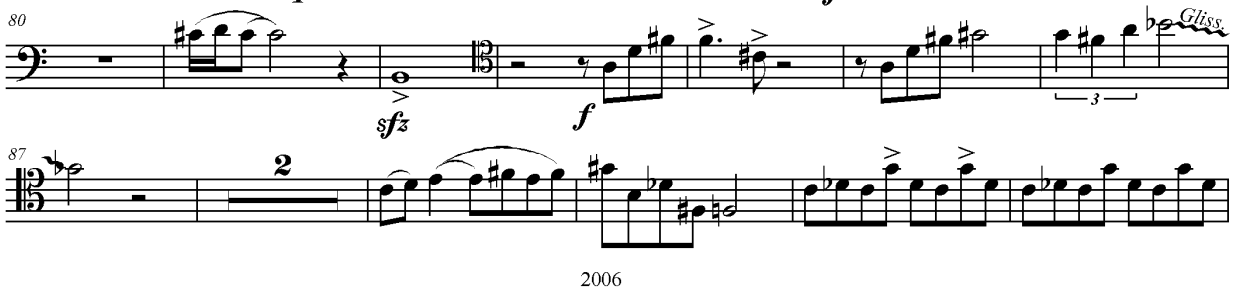

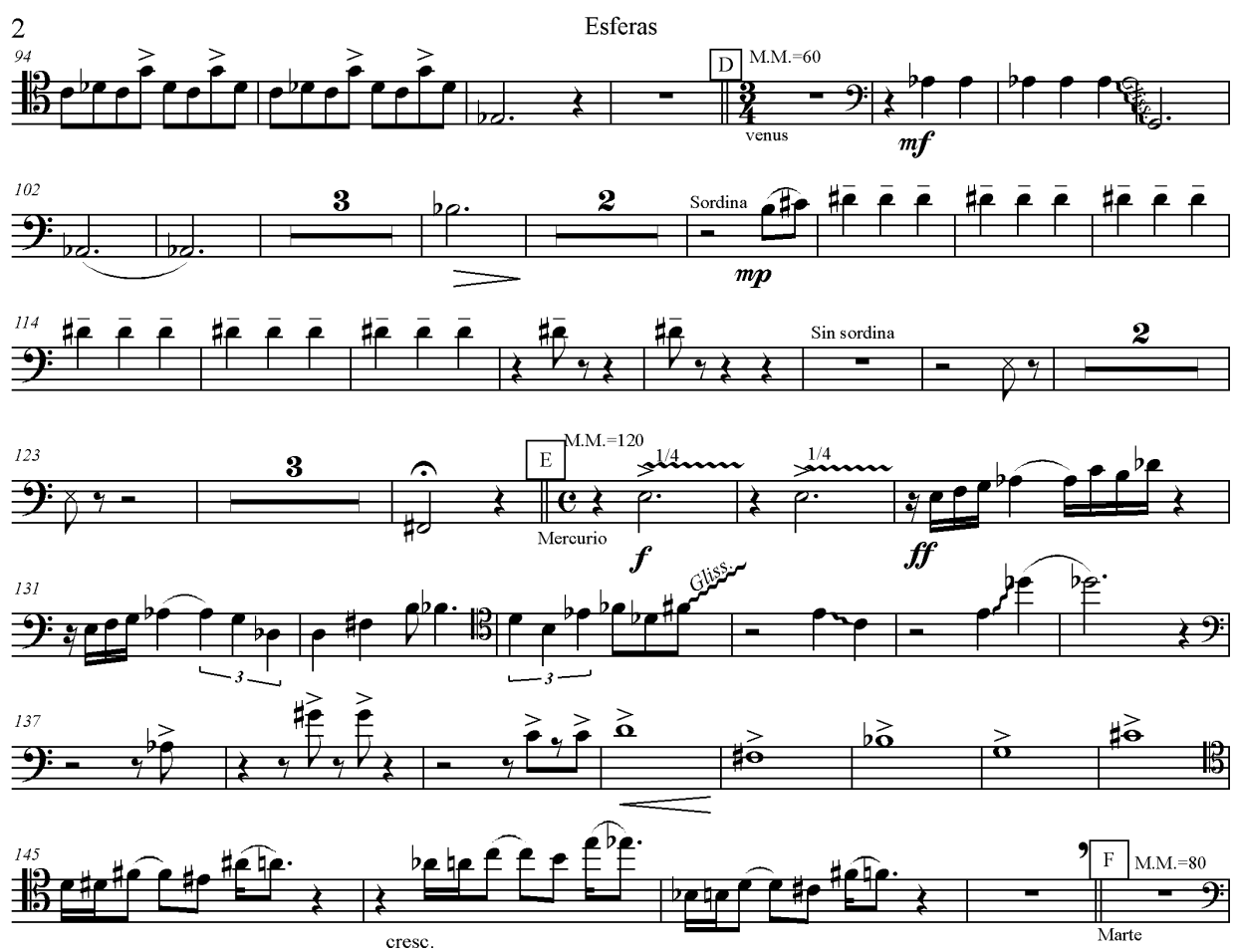

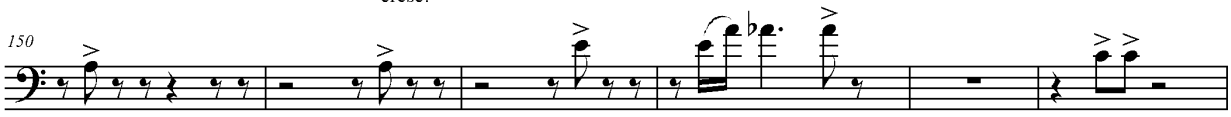
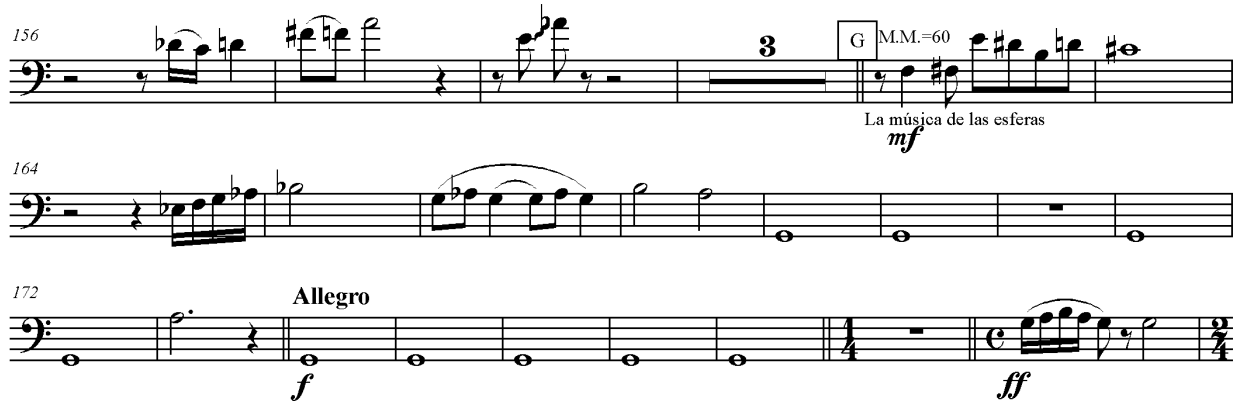

tII

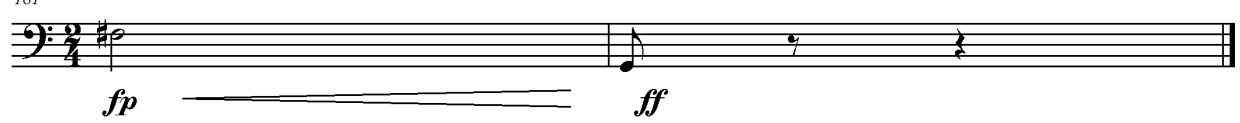


Tuba

\section{Esferas}

Kepler en el Siglo XXI
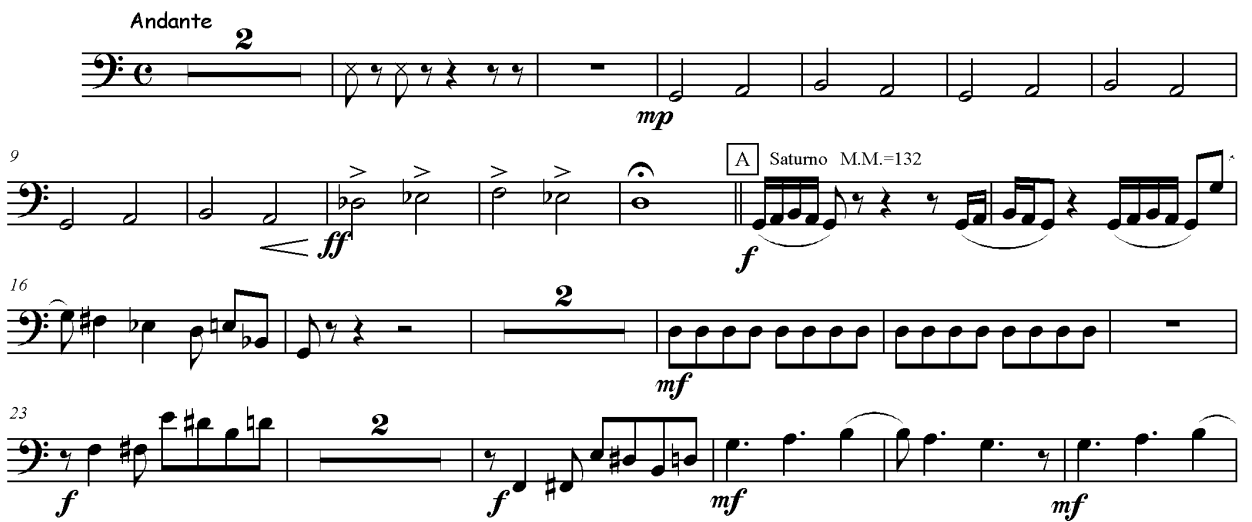

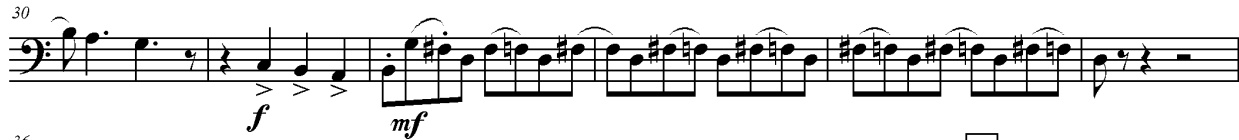

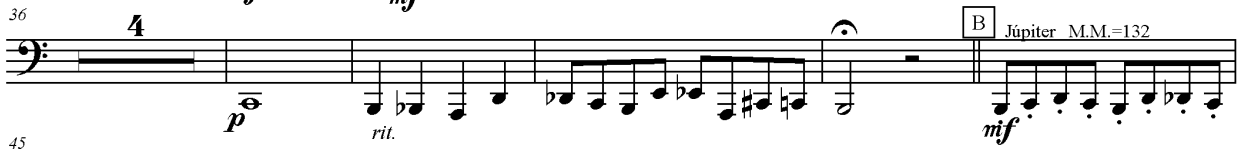

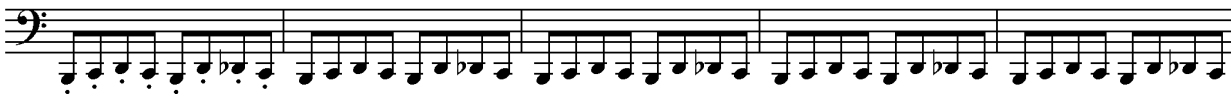

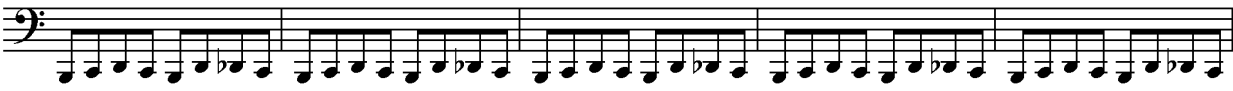

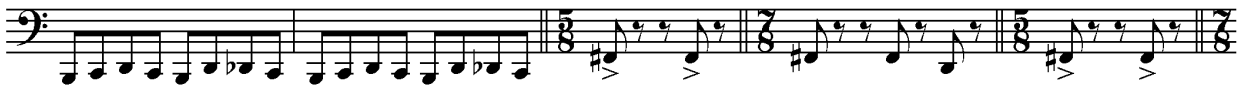
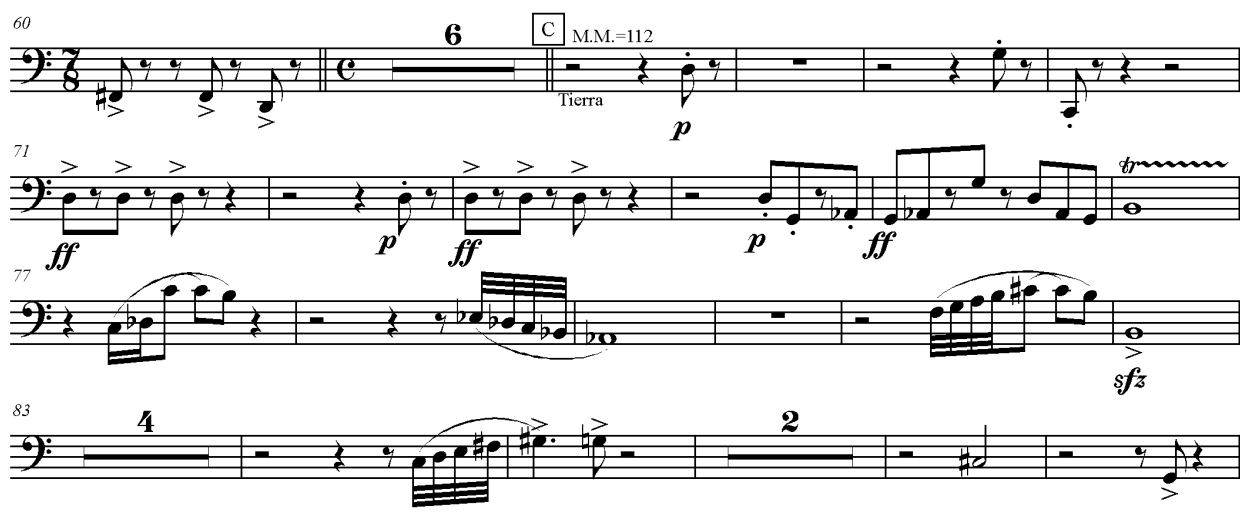


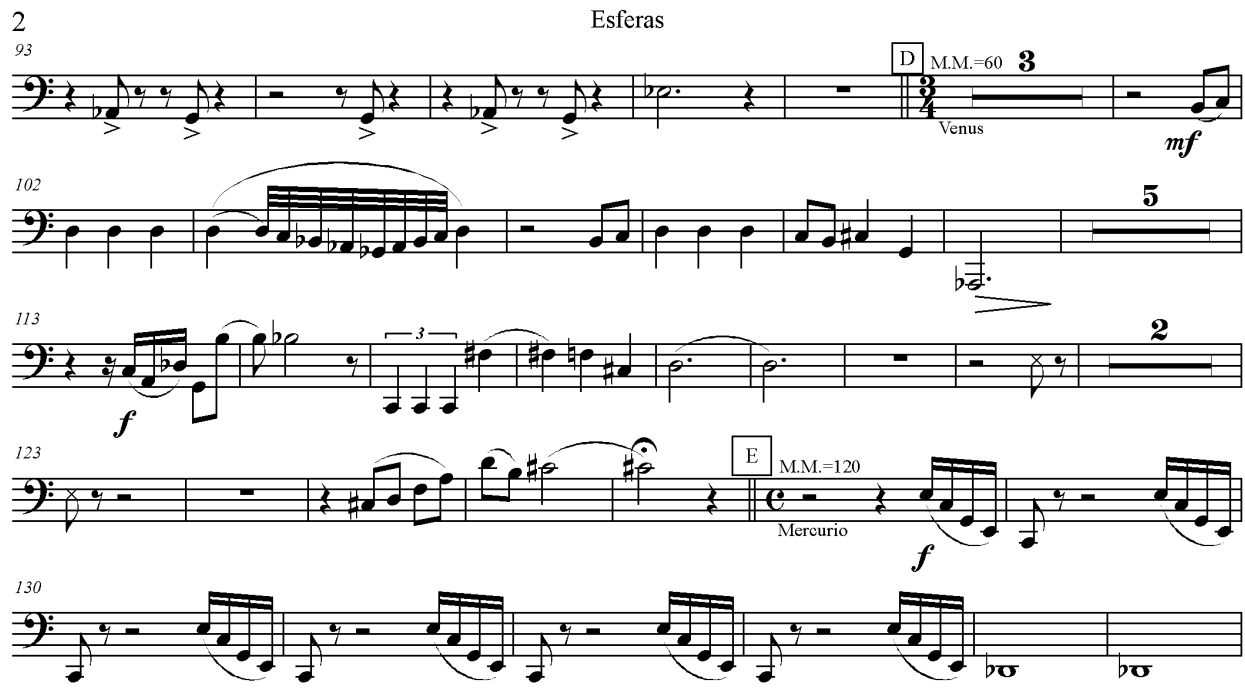

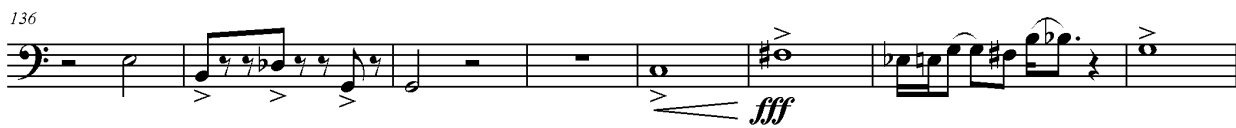
9):0 (50) Lat: 163

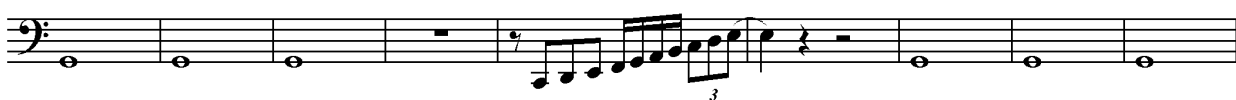
ב: ב्र: 